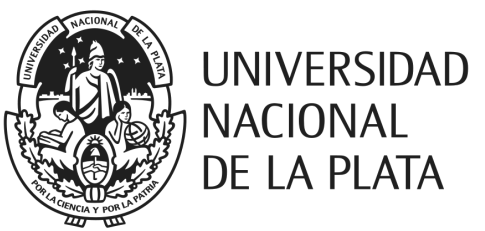

Universidad Nacional de La Plata Facultad de Ciencias Naturales y Museo

\title{
Análisis de concentraciones fósiles en la Formación Monte León (Mioceno inferior), en la costa de la provincia de Santa Cruz
}

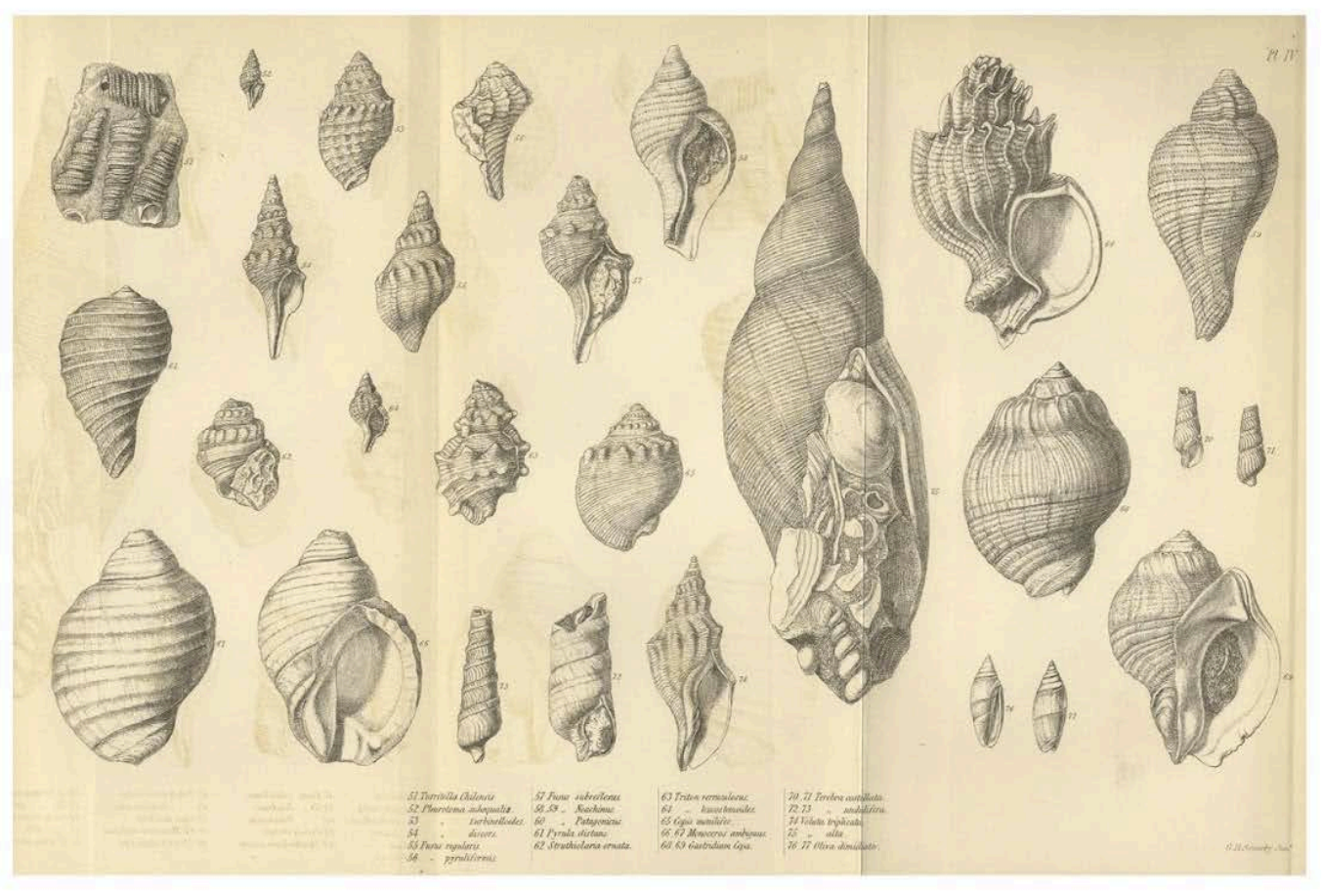

Gabriela Pineda Salgado

Tesis doctoral

Directores: Miguel Griffin, Ana Parras 2020 
A mi mamá, mi abuela y mi abuelichi A Señor Pantufla y Spock-Uhura, los félidos con más estilo 


\section{Agradecimientos}

Al Posgrado de la Facultad de Ciencias Naturales y Museo de la Universidad Nacional de La Plata.

A los doctores Miguel Griffin y Ana Parras por dirigirme, por todas las facilidades brindadas para la realización de este trabajo, así como por su ayuda en las labores de campo y por los apoyos obtenidos para exponer parte de los resultados del mismo en reuniones nacionales e internacionales.

Al jurado conformado por los doctores Claudia del Río, Miguel Manceñido y Sven Nielsen.

A la Agencia Nacional de Promoción Científica y Tecnológica (ANPCyT) por la beca doctoral otorgada a través del Fondo para la Investigación Científica y Tecnológica (FONCyT), en el marco del Proyecto de Investigación Científica y Tecnológica PICT 2012-1726.

Al Consejo Nacional de Investigaciones Científicas y Técnicas (CONICET) por la beca interna de finalización de doctorado otorgada durante el periodo 2017-2019.

Al Instituto de Ciencias de la Tierra y Ambientales de La Pampa (INCITAP, CONICETUNLPam) y a la Facultad de Ciencias Exactas y Naturales de la UNLPam por ceder el espacio institucional para el desarrollo de esta tesis.

A la Administración de Parques Nacionales por autorizar la recolección de muestras en los límites del Parque Nacional Monte León. Al personal del Parque Nacional Monte León por su invaluable ayuda y colaboración.

Al Dr. Guido Pastorino y al Lic. Fabián Tricarico por el apoyo técnico para la obtención de imágenes de microscopía electrónica de barrido.

A la Lic. Analisa Quiroga por su colaboración en el trabajo de campo.

A los doctores Eduardo Mayoral y Sara Quiroz por resolver mis inquietudes, compartir sus conocimientos sobre Tafonomía e Icnología así como por facilitarme material bibliográfico.

A los doctores, Jefrey Robinson, Carlton Brett, David Arpad, Francisco Vega, Ricardo Mariño-Pérez y Leandro Pérez, por su ayuda en la obtención de material bibliográfico de difícil acceso.

A la Society for Sedimentary Geology (SEPM) por la beca otorgada para presentar parte de los resultados de este trabajo en el IV Simposio Latinoamericano de Icnología realizado en Santa Marta Colombia en 2018. 


\section{A título personal}

A Miguel Griffin, por brindarme su confianza y permitirme formar parte de su grupo de trabajo, por compartir su casa, sus recetas de cocina, su humor, sus lugares y sus conocimientos sobre Patagonia y su malacofauna. Mike, you are the best!

A Guido Pastorino, por brindarme la facilidades necesarias durante los primeros años de mis estudios doctorales. Gracias por su oido, por su consejo y por su abrazo en el momento en el que hicieron más falta.

A Sara Quiroz, Francisco Sour, Brian Urbano y Ricardo Mariño por su apoyo, su confianza, gracias por su amistad y por venir a visitarme. Alea iacta est...todo el tiempo.

A Sergio Gonzalez-Mora, por años de amistad, tantos que me alegra ir perdiendo la cuenta del tiempo que llevas a mi lado escuchándome, apoyándome, aconsejándome y cuidándome. Gracias por ser mi persona en el mundo a pesar del paso del tiempo y de la distancia.

A Guillermo Segura, por el cariño inmenso e incondicional, que es recíproco, por su apoyo y sus bellas palabras siempre, gracias por hacerme reír y corregirme todo el tiempo. Ya me puse suéter.

A Analisa Quiroga, por su amistad, que aunque es joven, significa too mucho para mi, gracias por brindarme una amistad llena de espontaneidad y sinceridad, por ayudarme a practicar mi inglés miti-miti y por leerme el horóscopo con regularidad.

A Yolotzin Yescas por sus constantes palabras de aliento, por ser mi soporte, mi familia sin lazos ni ataduras. Gracias también a su familia por el cariño y la hospitalidad constante, mi cariño hacia ustedes es inimaginable e inagotable.

A mi compatriota favorita, Fátima Mendoza, por su amistad y las meriendas acompañadas, también gracias por alegrar mi estómago con su buen sazón mexicano y ayudarme a comenzar mi vida pampeana.

A Eduardo Esquivel, Emmanuel Torrejón, Miguel Esparza, Silvia Hernández, Chantal Baez y Alberto Ayala, por su amistad que sigue superando el tiempo y la distancia, gracias por su apoyo durante estos años. Gracias por ansiar mis esporádicos y fugaces regresos.

A Laura López, Ivan Tiemersma, Dayan Guillén, Renato Canessa, Romina Echagüe, Javier Soreta Encinas y a su familia, por su amistad y aguante, gracias por hacer de mi vida platense una etapa inolvidable. Les quiero.

A Renata Sostillo, Nadia Icasatti, Marina Cock, Eugenia Estanga, Cristina Cardonatto y Viviana Martínez por hacerme sentir en casa desde que llegué, por sus ánimos constantes, por las juntadas que llevamos y las que nos faltan.

A Arturo Heredia por adoptarme en mis visitas a Buenos Aires. 
A Rosana Lodoño González por abrirme las puertas de su casa durante mi visita a Santa Marta, Colombia durante el IV Simposio Latinoamericano de Icnología.

A Rosa Laura Hordoñez, mi Freesia rosada, por recordarme que la vida tiene onditas y nudillos. Gracias por enseñarme a luchar con fortaleza y serenidad las batallas más duras.

A Silvia R. y Federico S., por ayudarme a no ser aquello que «prometí destruir».

A Isela, mi mamá, a mi abuelita Tina y a mi abuelichi Tere, por su amor incondicional, por abrazarme siempre, con todo y mis defectos; por apoyarme en esta gran decisión y en todas las que han seguido. Gracias por alentarme a hacer aquello que me hace feliz y regalarme la libertad de vivir mi vida del modo en el que he elegido. Abuelichi, gracias por enorgullecerte de mi, incluso en mi versión rosa. Las amo.

A De punto De punto por mantener mis pies en la tierra, por darle a todo la importancia justa. Por ser ese momento calmo antes del ojo del huracán y recordarme que no tengo prisa por vivir y mucho menos por llegar a otro sitio diferente, por sacudirme para que me diera cuenta que por primera vez, quiero quedarme en donde estoy.

José Luis San Pedro en una charla dijo que «Uno escribe para descubrirse a sí mismo, para descubrir a otros y para encontrarnos todos, para vivir más, para vivir mejor y para ello puede ser bueno utilizar la propia vida.» Yo me descubrí escribiendo esto entre ustedes. Afortunadamente, me encuentro viviendo entre todos ustedes. ¡Gracias!

Citar esta tesis como:

Pineda-Salgado, G., 2020, Análisis de concentraciones fósiles en la Formación Monte León (Mioceno inferior), en la costa de la provincia de Santa Cruz: La Plata, Argentina, Facultad de Ciencias Naturales y Museo, Universidad Nacional de La Plata, tesis doctoral, $173 \mathrm{p}$.

Portada: Lámina de Geological observations of South America. Moluscos recolectados por Darwin en Argentina y Chile descriptos posteriormente por Sowerby. Tomada de http://darwin-online.org.uk 
Índice 
Resumen .1

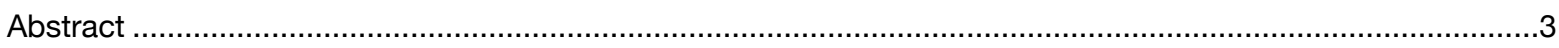

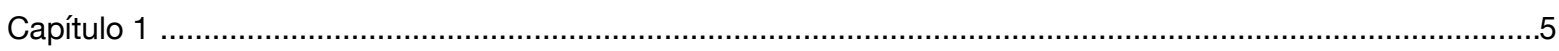

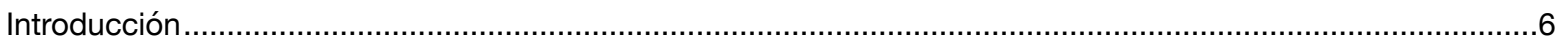

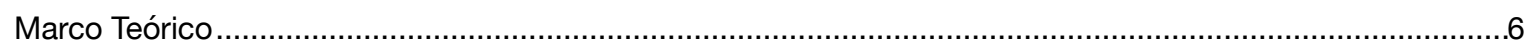

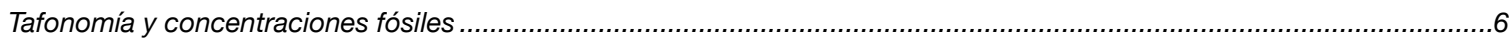

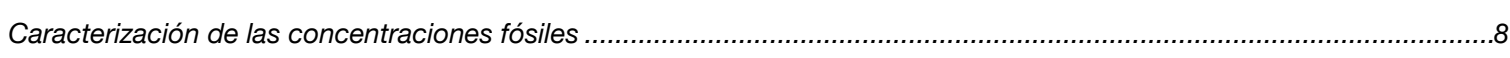

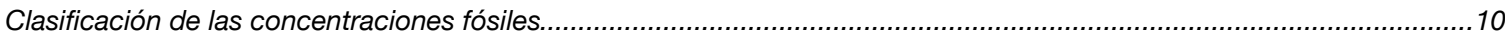

Sedimentación en ambientes clásticos marinos asociada a procesos de tormenta .....................................................14

Estructuras sedimentarias y estratigrafía de los depósitos de tormenta ......................................................................14

Concentraciones fósiles en depósitos de tormenta .......................................................................................16

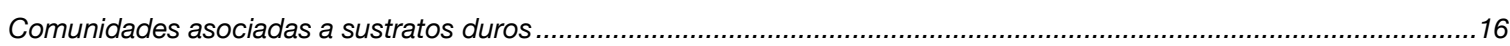

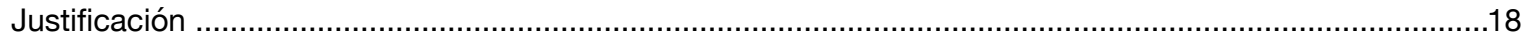

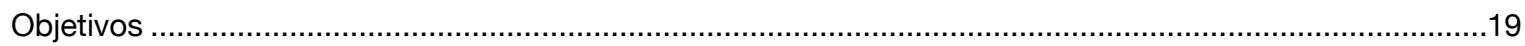

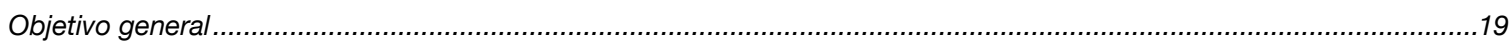

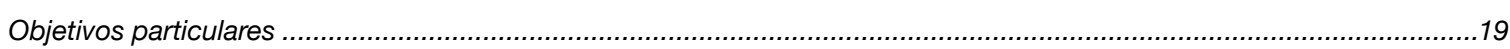

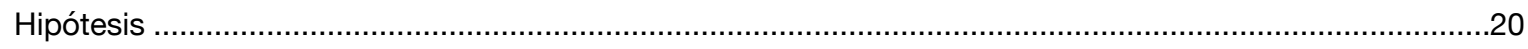

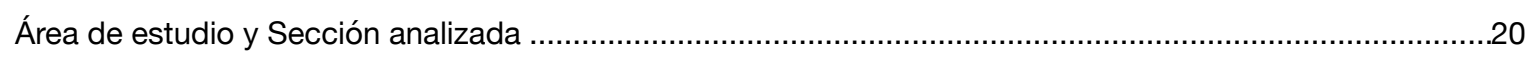

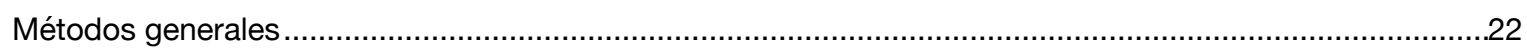

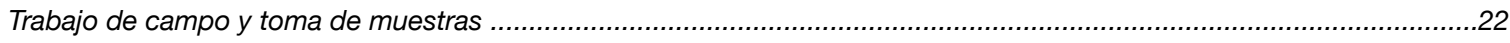

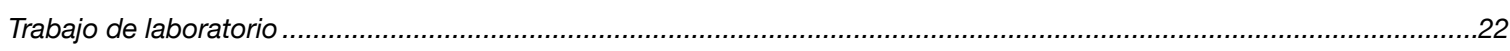

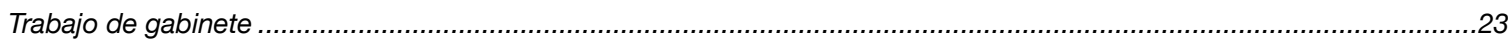

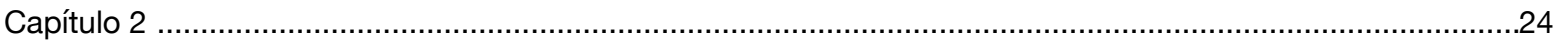

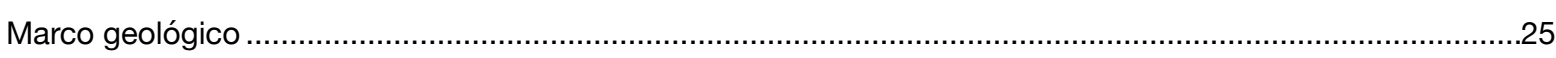

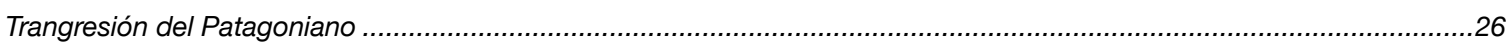

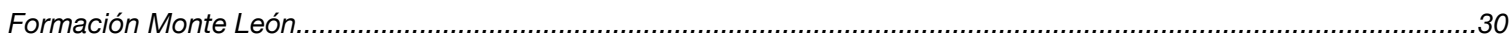

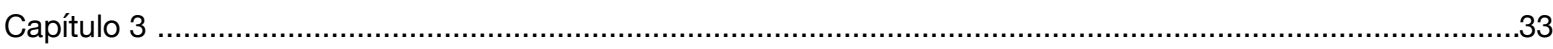

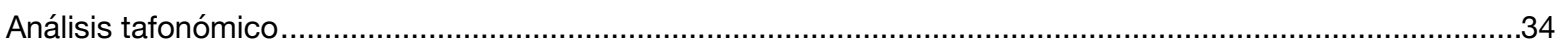

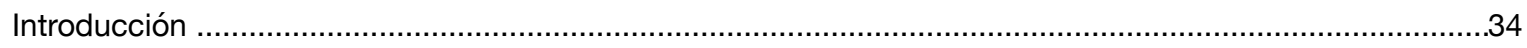

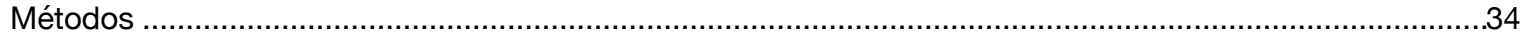

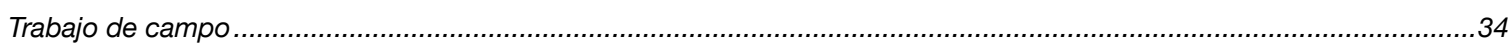

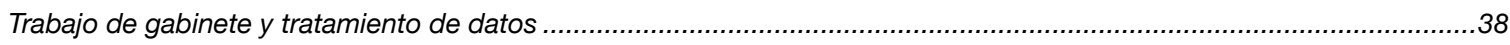

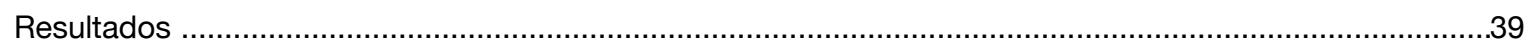

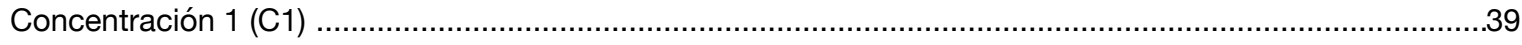

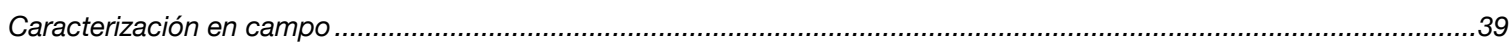

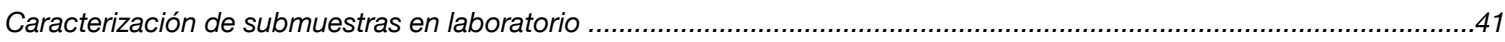

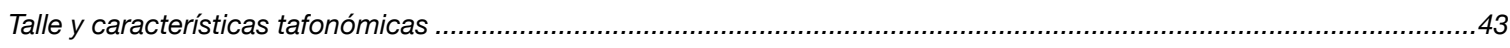

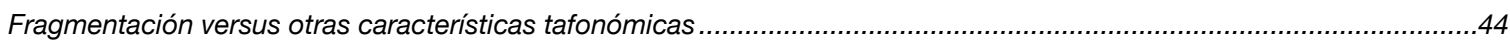

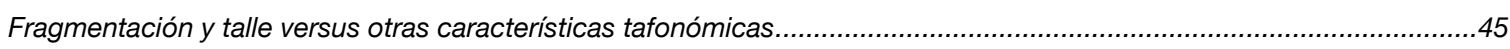

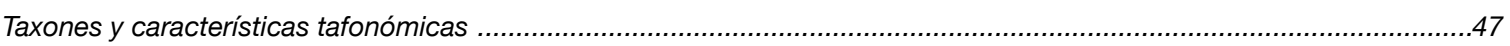

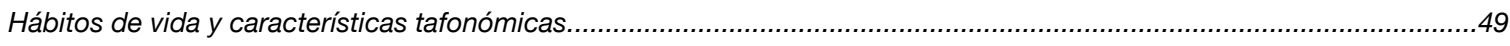

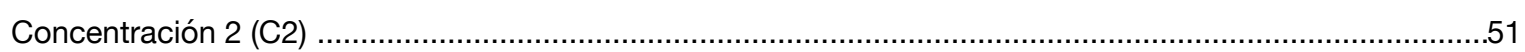




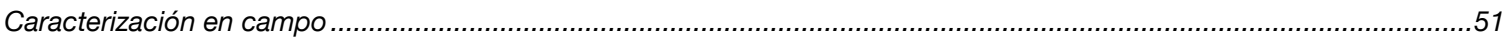

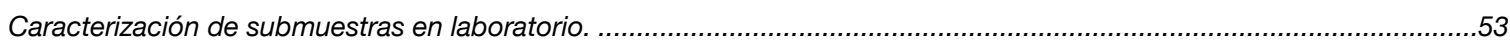

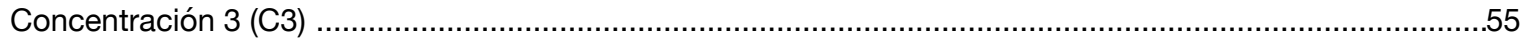

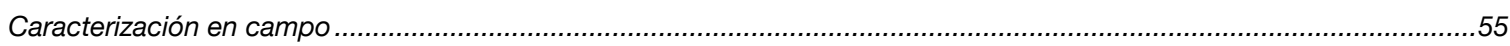

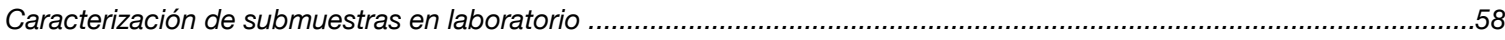

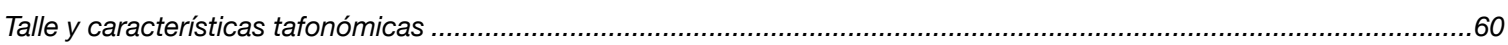

Fragmentación versus otras características tafonómicas .........................................................................................60

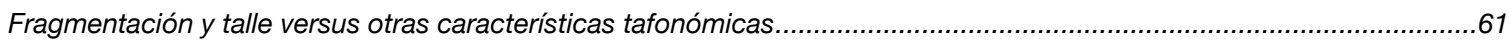

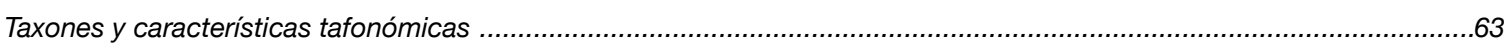

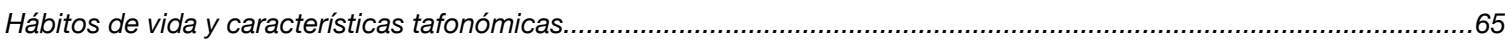

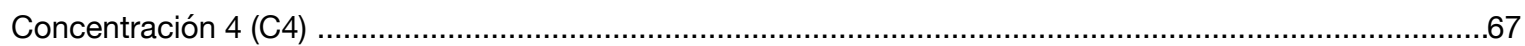

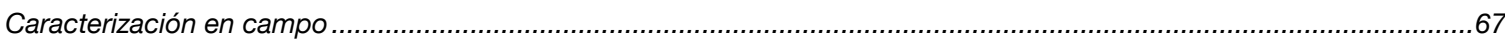

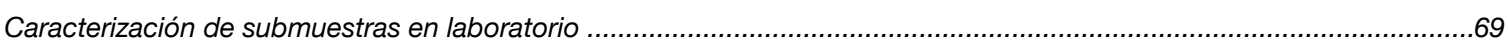

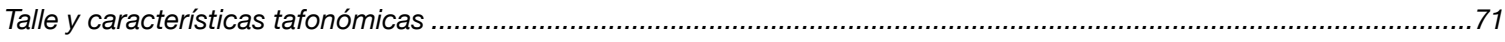

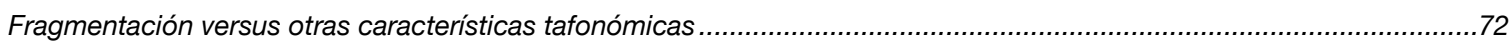

Fragmentación y talle versus otras características tafonómicas......................................................................... 73

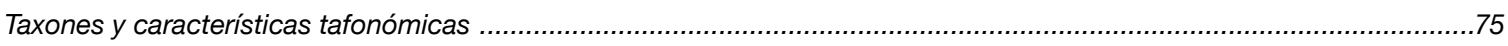

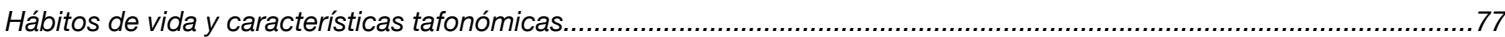

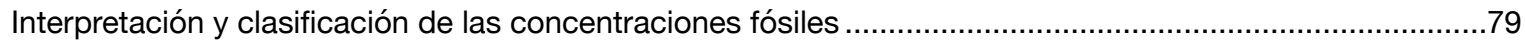

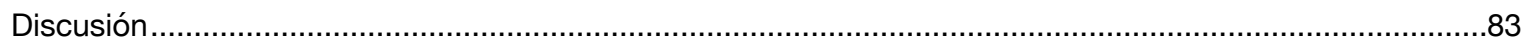

Características paleontológicas: procesos físicos, químicos o biológicos involucrados en la formación de las concentraciones fósiles.... fósiles.

Características tafonómicas: procesos físicos, químicos o biológicos involucrados en la formación de las concentraciones

Relación entre taxones, hábitos de vida y características tafonómicas: su importancia para reconocer las diferentes historias tafonómicas de los bioclastos presentes en las concentraciones .....................................................................94

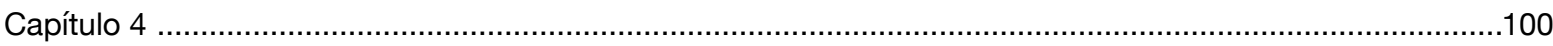

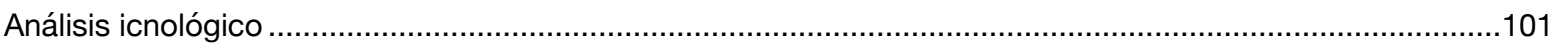

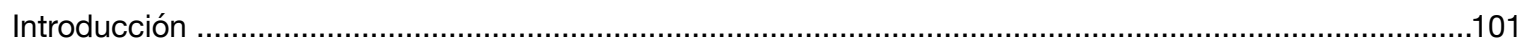

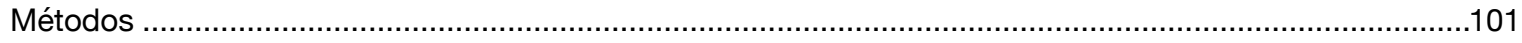

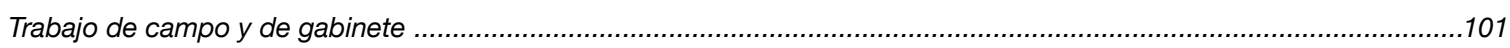

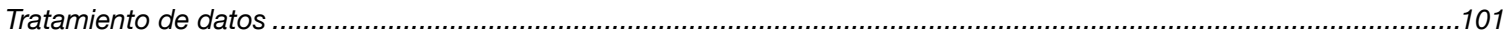

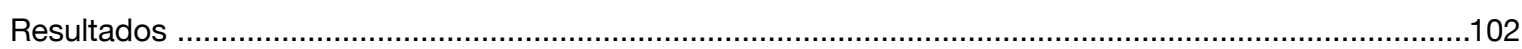

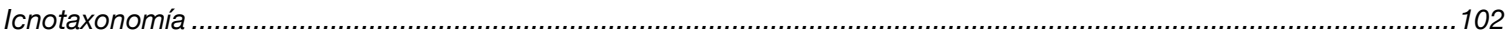

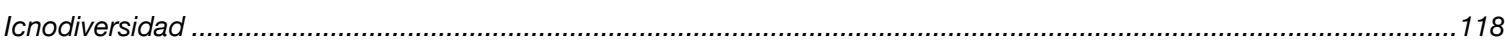

Selectividad de los esclerobiontes en la superficie del sustrato........................................................................124

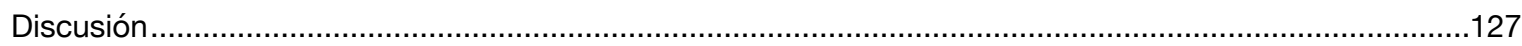

Paleobiología de los productores y selectividad por algunas de las superficies del sustrato .......................................127

Retroalimentación tafonómica y sucesión ecológica..........................................................................................137

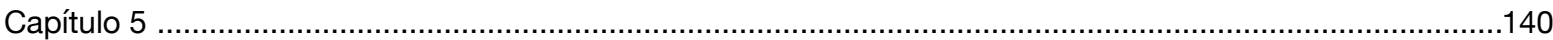

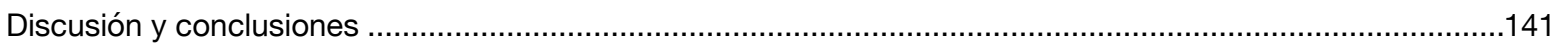

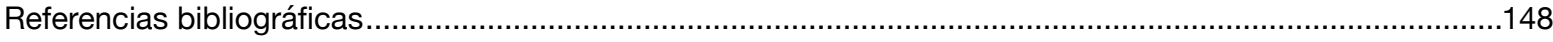

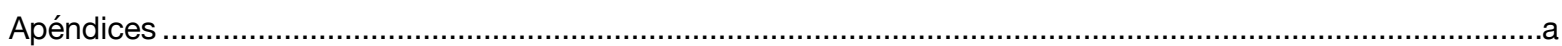




\section{Resumen}

La Formación Monte León (Mioceno inferior) se caracteriza por sus concentraciones fósiles conformadas por invertebrados, en su mayoría moluscos, que han sido objeto de estudios sistemáticos desde el siglo XIX. Las características de preservación de las concentraciones y la presencia de numerosas trazas de bioerosión, brindan una excelente oportunidad para realizar estudios tafonómicos e icnológicos que en conjunto ayuden a reconocer los procesos biológicos, sedimentológicos y diagenéticos que las originaron. En esta Tesis se realizaron análisis tafonómicos e icnológicos en cuatro concentraciones fósiles $(C 1, C 2, C 3$ y C4) de la sección Cabeza de León, localidad ubicada en la costa Atlántica, dentro del Parque Nacional Monte León (Patagonia, Argentina). Las concentraciones fueron caracterizadas en campo de manera descriptiva y semicuantitativa, contemplando sus características estratigráficas, sedimentológicas, paleontológicas y tafonómicas. Adicionalmente, dos muestras por concentración fueron tamizadas en húmedo en laboratorio, con tamices números $25(0,710 \mathrm{~mm}), 16(1,190 \mathrm{~mm})$ y 31/2 $(5,660 \mathrm{~mm})$. En las mismas, se observó el grado de preservación de los bioclastos en cada concentración de manera general y con relación a su talle y fragmentación. Los resultados mostraron que los bioclastos que conforman las concentraciones experimentaron historias tafonómicas diferentes y complejas, las cuales están relacionadas con factores extrínsecos e intrínsecos, permitiendo clasificarlas como concentraciones mixtas biogénicosedimentológicas ( $\mathrm{C} 1, \mathrm{C} 3$ y $\mathrm{C} 4)$ y mixtas sedimentológica-diagenéticas (C2), siendo notable principalmente en C1 y C4 la impronta de la retroalimentación tafonómica. Los atributos tafonómicos, paleoecológicos y la biofábrica, sugieren que las concentraciones se formaron en un ambiente de plataforma interna hasta probablemente el shoreface inferior, cerca del nivel de base de olas de buen tiempo, expuesto a la acción de tormentas; C1 refleja un evento de corta duración mientras que C2 y C4 son el resultado de múltiples eventos. La geometría y estratificación de C3 sugieren que ésta estuvo expuesta a la acción de corrientes de variable duración. Los factores intrínsecos que determinaron la preservación fueron principalmente la mineralogía y los hábitos de vida. En C1, C3 y C4, predominaron las conchillas aragoníticas de moluscos con evidencias de reemplazamiento por calcificación y silicificación, mientras que en C2 fue más notable la acción de diferentes procesos sedimentológicos y diagenéticos involucrados en la preservación. El estudio de muestras en laboratorio permitió realizar una mejor aproximación al conocimiento de la riqueza taxonómica, identificándose 81 taxones, incrementando en más del 50\% el número de taxones presentes en las concentraciones, en relación con lo observado en campo, ya que gran parte del material quedó retenido en los tamices de menor malla. También permitió reconocer que la relación superficie-volumen fue determinante en la calidad de preservación (e.g., fragmentación y alteración superficial). Asimismo, evidenció que la fragmentación es directamente proporcional a la alteración superficial, al redondeamiento y a la modificación de bordes, e inversamente proporcional a la bioerosión.

El análisis icnológico permitió reconocer 24 icnotaxones producidos por briozoos, poliquetos, esponjas, moluscos carnívoros y ramoneadores, y braquiópodos. Se identificaron, además, trazas rosetadas (Dendrinidae) cuyos potenciales productores aún están en debate. Las conchillas retenidas en las mallas de mayor tamaño $(5,660$ y 1,190 $\mathrm{mm}$ ) mostraron una mayor icnodiversidad (entre 6 y 15 icnotaxones, por concentración), mientras que en la malla de menor apertura $(0,710 \mathrm{~mm})$, únicamente se reconocieron 3 
icnotaxones. Las trazas producidas por briozoos incrustantes fueron las más abundantes sugiriendo que los bioclastos de Cabeza de León estuvieron expuestos en un ambiente de plataforma interna o submareal con baja a moderada tasa de sedimentación, en donde el retrabajo por corrientes mareales y olas de tormenta favoreció la presencia de nutrientes. Con relación a su preferencia por el sustrato (superficie externa vs. interna), no se observó en general ningún patrón en las conchillas, sugiriendo que la tendencia a asentarse en una de las superficies, puede estar determinada principalmente por factores extrínsecos. Las trazas producidas por poliquetos fueron menos abundantes, mas mostraron mayor icnodiversidad; la presencia de otros organismos con los mismos requerimientos ecológicos posiblemente limitó los recursos disponibles. Con relación a la selectividad del sustrato, en $\mathrm{C} 1$ se observó una tendencia significativa por colonizar la superficie externa; es posible que esta tendencia se deba a la abundancia de gasterópodos en los que el acceso a la superficie interna de la conchilla es limitado. En C2 las trazas cerca de los márgenes del borde ventral y lateral de la cara interna posiblemente fueron realizadas después de la muerte del molusco. En C3 y C4 no se observó preferencia significativa por una superficie del sustrato por lo que se sugiere que la colonización, en el caso de organismos epifaunales, pudo ocurrir syn vivo o post mortem. La baja abundancia de trazas producidas por esponjas posiblemente esté relacionada a que la abundancia de briozoos limitara el espacio para su colonización; además, habrían influido el tiempo de exposición de los bioclastos, la tasa de sedimentación, su movilidad y la interacción con otros competidores. En C2 se reconocieron trazas producidas por moluscos que corresponden con trazas de alimentación por ramoneo de gasterópodos herbívoros y poliplacóforos; su presencia, principalmente en la cara interna, es evidencia del crecimiento post mortem de algas sobre las conchillas, sugiriendo su depositación en un ambiente de baja turbidez y en la zona fótica. Las trazas de gasterópodos durófagos fueron abundantes en las conchillas retenidas en el tamiz de 1,190 $\mathrm{mm}$, lo que sugiere que este talle de conchillas era fácil de subyugar para los depredadores y aseguraba un ataque exitoso. Las escasas trazas producidas por braquiópodos y su ubicación sugiere que su asentamiento corresponde con sectores de las conchillas que estaban asociados a microhábitas crípticos.

El análisis de concentraciones fósiles es una vasta tarea que puede ser aplicada con diferentes enfoques y a diferentes escalas. Si bien en cualquier caso se aporta información sobre los depósitos estudiados, en esta tesis la inclusión de un enfoque icnológico fue fundamental para reconocer las complejas historias tafonómicas que sufrieron algunos de los bioclastos que conformaban las concentraciones y resultó ser una herramienta útil para el reconocimiento de la promediación temporal y dentro del hábitat. En este sentido, el estudio icnológico en conjunto con la evaluación de otras características tafonómicas, como así también paleontológicas, estratigráficas y sedimentológicas de las concentraciones fósiles de la Formación Monte León, permitieron incrementar el conocimiento acerca de la biota y de las condiciones ambientales existentes durante el Mioceno temprano en la costa de Patagonia. 


\section{Abstract}

The Monte León Formation (lower Miocene) is well-known for its fossil concentrations, which include mainly excellently preserved mollusks that have been studied since the 19th century. The preservation of these concentrations throughout the lithostratigraphic unit, together with the abundant bioerosions, allow taphonomic and ichnologic studies that shed light on the biological, sedimentological and diagenetic processes that originated them.

This thesis deals with four fossil concentrations (C1, C2, C3 y C4) from a stratigraphic section at Cabeza de León, a locality on the coastal cliff along the Atlantic coast within the boundaries of the Monte León National Park (Patagonia, Argentina). The section was carefully measured and the stratigraphic, sedimentologic, paleontologic and taphonomic features were recorded in detail. Two samples were taken from each concentration and sieved with mesh sizes $25(0.710 \mathrm{~mm}), 16(1.190 \mathrm{~mm})$ and 31/2 $(5.660 \mathrm{~mm})$, to recover any biogenic material in which the preservation degree was recorded in a general way and regarding size and fragmentation.

Results show that the bioclast in these concentrations underwent different and complex taphonomic histories related to extrinsic and intrinsic factors. Thus, they can be classified as mixed biogenic-sedimentologic ( $\mathrm{C} 1, \mathrm{C} 3$ and $\mathrm{C} 4)$ and sedimentological-diagenetic (C2); a remarkable feature in $\mathrm{C} 1$ and $\mathrm{C} 4$ is the signature of taphonomic feedback. Taphonomic and paleoecologic attributes and biofabric suggest that the concentrations were deposited in an inner shelf up to probably a lower shoreface environment (near the fair-weather wave base), affected by storms. C1 reflects a short-duration event while C2 and C4 are the result of multiple events. Geometry and stratification of C3 suggest that it was exposed to the action of currents of variable duration. The intrinsic factors that determinate the preservation were the mineralogy of the shells and the life habits. In C1, C3 and C4 the predominant shells were those of mollusks with aragonitc shells with evidence of replacement by calcification and silicification, while in $\mathrm{C} 2$ the action of sedimentologic and diagenetic processes involved in the preservation was evident. Study of the samples in laboratory allowed a clearer understanding of taxonomic richness, 81 taxa were recognized. The number of taxa in the concentrations increased $50 \%$ compared to the total number of taxa observed in the field. A large part of the material was retained in the smaller mesh size sieves. The quality of preservation of the bioclasts regarding fragmentation and surface alteration was established on the basis of the surface/volume ratio of the bioclasts. Assessment of the relation of the other taxonomic indexes with fragmentation of the bioclasts retained in the different mesh sizes revealed that fragmentation is directly proportional to surface alteration, rounding and edge modification. Contrarily, it is inversely proportional to bioerosion.

Ichnologic analysis allowed identification of twenty-four ichnotaxa produced by bryozoans, sponges, carnivorous and grazing mollusks, brachiopods and the ichnofamily Dendrinidae the producers of which remain unidentified. Shells or fragments retained in the $5.660 \mathrm{~mm}$ and $1.190 \mathrm{~mm}$ meshes showed a ichnodiversity of 6 to 15 ichnotaxa per concentration, while in the smallest mesh $(0.710 \mathrm{~mm})$ only three ichnotaxa were identified. Encrusting bryozoan traces were the most abundant in the section, suggesting that the bioclasts from Cabeza de León were exposed to an inner shelf environment with a low to moderate sedimentation rate in which reworking by tidal currents and storm waves favored the 
presence of nutrients. No preference for the substrate (inner vs. outer surface) was observed, suggesting that settlement may have been guided mainly by extrinsic factors. Traces produced by polychaetes were less abundant but showed a higher ichnodiversity. The presence of other organisms with the same ecological requirements possibly limited the amount of available resources. In relation to substrate selectivity, in C1 there was a significant trend to colonize the outer surface; this could be related to the abundance of gastropods, in which access to the inner surface of the shell is limited. In C2 the traces in the inner surface, near to the ventral and lateral edges, probably occurred just after the death of the mollusk. In C3 and C4 there was no preference for a surface of the substrate, in epifaunal molluscs the colonization may occur syn-vivo or post-mortem. Although with low abundances, sponge traces were also identified in the studied concentrations; the abundance of bryozoans possibly limited the available space for sponges. In addition, exposure time of bioclasts and their mobility, sedimentation rate and interaction with other competitors may have also influenced the low abundance they show. Concentration C2 carries grazing gastropod traces and traces of polyplacophorans, chiefly on the inner surface. These traces are evidence of post-mortem growth of algae over the bioclast surface, thus suggesting the settling of the bioclasts in a photic zone with low sedimentation rate. Durophagous gastropod traces were abundant in shells retained in the $1.190 \mathrm{~mm}$ mesh, suggesting that shells this size were easy to subjugate by predators, which were highly successful in their attacks. Traces on brachiopod shells were scarce, suggesting that settlement on them was related to sectors of the shell associated with cryptic microhabitats.

Analysis of fossil concentrations is a vast task that can be undertaken with different approaches and at different scales. In this thesis an ichnologic approach was fundamental to identify the complex taphonomic histories of some of the elements in the concentrations. It was a useful tool to recognize time-averaging and within-habitat averaging. These, together with other taphonomic and sedimentologic features support the idea that the concentrations from Cabeza de León are a good tool to increase the knowledge about the biota of early Miocene rocks exposed along the coast of Patagonia and the environmental conditions under which they were deposited. 


\section{Capítulo 1}

[...] escribo todos los días, poco a poco, sin esperanza ni desesperanza.

-Haruki Murakami

De qué hablo cuando hablo de

escribir 


\title{
Introducción
}

\author{
Marco Teórico
}

\section{Tafonomía y concentraciones fósiles}

Las concentraciones fósiles son cualquier tipo de acumulaciones densas de parte duras de orden biogénico, independientemente de su composición taxonómica, estado de preservación o grado de modificación post mortem (Kidwell et al., 1986). Su estudio aporta información paleoambiental, paleoecológica y estratigráfica. El análisis de las

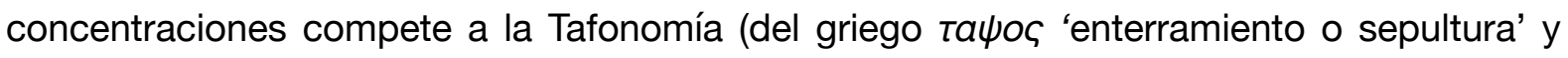
$\eta \sigma \mu \sigma \varsigma$ 'leyes o reglas'), definida originalmente por Efremov (1940) como la ciencia del enterramiento o de las leyes del enterramiento; señalando además que no constituía una ciencia aislada, sino que estaba dentro de la Paleontología, en los límites que la relacionan estrechamente con la Biología y la Geología. El enfoque propuesto por Efremov (1940) resalta los sesgos negativos en la preservación, ya que tenía como fundamento el supuesto de Darwin (1859) de un registro fósil incompleto, orientándose fundamentalmente al entendimiento de los procesos y principios que gobiernan el paso de los restos orgánicos de la biósfera a la litósfera.

Behrensmeyer y Kidwell (1985) argumentaron que la caracterización de Efremov (1940) no muestra de una manera objetiva como las concentraciones fósiles cambian durante la preservación, ya que sólo considera la información que se pierde y no aquella que se incorpora o se altera durante dicho proceso; por esta razón redefinieron a la Tafonomía como la ciencia que estudia los procesos de preservación y como estos afectan la información del registro fósil, con lo que es posible destacar las contribuciones positivas de la tafonomía en el estudio de los organismos y el ambiente a través del tiempo. Por su parte, Fernández-López $(1988,1991,2000)$ definió a la Tafonomía como un subsistema conceptual de la Paleontología que aspira a explicar cómo ha sido producido el registro fósil y qué modificaciones ha sufrido.

A pesar de que la definición y formalización de esta ciencia es reciente, el pensamiento tafonómico ha estado presente desde que se reconoció la naturaleza biológica de los fósiles (Tabla 1.1). El desarrollo del método actualista durante principios del siglo XX fue un antecedente fundamental para la formalización de la Tafonomía, principalmente en Alemania con los trabajos de Walther (1904), Abel (1912, 1922, 1935), Weigelt (1927) y Richter (1928), entre otros (Tabla 1.1). Walther (1904) fue uno de los primeros en interpretar la formación de antiguos depósitos fosilíferos utilizando este enfoque. Richter (1928) por su parte, distinguió el estudio del enterramiento de organismos actuales de aquellos del pasado definiendo a la Actuopalaeontología (Aktuopaläontologie) como una nueva disciplina. Esta propone un enfoque actualista que ayuda al entendimiento del registro fósil a través del estudio de procesos y patrones del presente (Richter, 1928; Efremov, 1940; Kowalewski, 1999). Richter (1928) además consideró que este enfoque debería incluir el 
estudio de las trazas fósiles (Icnología), la destrucción y enterramiento de restos (Tanatología, Necrología y Bioestratinomía) y el estudio de biofacies.

El estudio de las concentraciones fósiles con un enfoque tafonómico creció de manera notable hacia la segunda mitad del siglo XX, especialmente a finales de la década de 1960 y en la década de 1970. Esto pudo deberse en parte a que A. Seilacher, con la fundación en 1970 del proyecto de investigación Sonderforschungsbereich Palökologie, retomó gran parte de las aportaciones de la tafonomía alemana. En esta etapa se destacan también los trabajos de Lawrence (1968) y Behrensmeyer (1975, 1976a, b) (Tabla 1.1). En particular, el trabajo de Lawrence (1968) arrojó importantes contribuciones al estudio y desarrollo de la tafonomía, al considerarla como un prerrequisito para desarrollar trabajos paleoecológicos. Los trabajos de Behrensmeyer (1975, 1976a, b) por su parte, expandieron los conceptos tafonómicos al campo de la Paleoantropología y la Arqueología.

El estudio de la preservación de los fósiles a lo largo de estos años fue incorporando una serie de términos y conceptos, los cuales no siempre fueron utilizados apropiadamente o en el mismo contexto. En las décadas de 1980 y 1990 se publicaron trabajos que mostraron un considerable intento por esclarecer y definir los términos que se venían empleando en el área, además de incorporar aquellos que ayudaran en la descripción e interpretación de los depósitos fosilíferos. Entre estos trabajos se encuentran los de Kidwell $(1985,1986)$ y todos aquellos publicados en el volumen especial de Palaios dedicado a Tafonomía (Thomas, 1986), entre los que pueden destacarse el de Kidwell et al. (1986) sobre la clasificación génetica de las concentraciones fósiles y el de Brett y Baird (1986) sobre tafonomía comparada.

Tabla 1.1. Contribuciones importantes para el desarrollo y la formalización de la Tafonomía.

\begin{tabular}{|l|l|}
\hline Autor y año & Aportaciones \\
\hline $\begin{array}{l}\text { Leonardo Da Vinci } \\
\text { siglos XV-XVI }\end{array}$ & $\begin{array}{l}\text { Desarrolló lo que se considera el primer pensamiento tafonómico, lo } \\
\text { utilizó para probar que las conchillas de bivalvos encontradas en } \\
\text { Monferrato (Italia) no eran restos del diluvio universal. Además, explicó } \\
\text { como el tejido blando de peces que quedaban atrapados en pelitas se } \\
\text { degradaba por actividad orgánica, de modo que solo se preservaban } \\
\text { sus esqueletos. }\end{array}$ \\
\hline $\begin{array}{l}\text { Niels Stensen (Steno) } \\
(1669)\end{array}$ & $\begin{array}{l}\text { Explicó del origen de las glossopterae. } \\
\text { Distinguió el crecimiento de cristales de minerales inorgánicos del de } \\
\text { minerales orgánicos (conchillas). }\end{array}$ \\
\hline Walther (1904) & $\begin{array}{l}\text { Interpretó la formación de depósitos fosilíferos (e.g., las calizas de } \\
\text { Sölnhofen). }\end{array}$ \\
\hline Abel (1912, 1922, 1935) & $\begin{array}{l}\text { Empleó datos tafonómicos para explicar la formación de yacimientos } \\
\text { de preservación excepcional, haciendo comparaciones con ambientes } \\
\text { actuales. }\end{array}$ \\
\hline Weigelt (1927) & $\begin{array}{l}\text { Documentó la muerte, decaimiento e historia post mortem de } \\
\text { vertebrados actuales, determinando la relevancia de estos procesos en } \\
\text { el modo de preservación de los fósiles. Este es considerado como el } \\
\text { primer trabajo propiamente tafonómico y bioestratinómico. }\end{array}$ \\
\hline
\end{tabular}


Tabla 1.1. Contribuciones importantes para el desarrollo y la formalización de la Tafonomía.

\begin{tabular}{|c|c|}
\hline Autor y año & Aportaciones \\
\hline Richter (1928) & $\begin{array}{l}\text { Distinguió el estudio del enterramiento de organismos actuales de } \\
\text { aquellos del pasado, definiendo como una nueva disciplina la } \\
\text { Actuopalaeontología. }\end{array}$ \\
\hline Lawrence (1968) & $\begin{array}{l}\text { Señaló que el estudio de las concentraciones fósiles con un enfoque } \\
\text { tafonómico era un prerequisito para estudios paleoecológicos, ya que } \\
\text { gracias a la tafonomía era posible reconocer sesgos evolutivos y } \\
\text { estratigráficos que de otra manera podrían ser ignorados. }\end{array}$ \\
\hline $\begin{array}{l}\text { Seilacher } \\
\text { Década de } 1970\end{array}$ & $\begin{array}{l}\text { Fundó el proyecto de investigación Sonderforschungsbereich } \\
\text { Palökologieen, retomando gran parte de las aportaciones de la } \\
\text { tafonomía alemana. El objetivo de este proyecto era lograr un desarrollo } \\
\text { sistemático de la Paleoecología (incluyendo a la Tafonomía) que } \\
\text { promoviera la integración de diversas líneas de investigación ayudando } \\
\text { a comprender mejor sus interacciones. }\end{array}$ \\
\hline $\begin{array}{l}\text { Behrensmeyer } \\
(1975,1976 a, b)\end{array}$ & $\begin{array}{l}\text { Enfatizó el contexto paleoecológico de la evolución humana y la } \\
\text { importancia de los agentes humanos versus los no humanos en la } \\
\text { modificación de los restos óseos. }\end{array}$ \\
\hline Kidwell $(1985,1986)$ & $\begin{array}{l}\text { Resaltó la importancia de los cambios en la tasa de sedimentación en } \\
\text { la formación de las concentraciones esqueletales, como así también la } \\
\text { implicancia genética de las características del techo y la base del } \\
\text { estrato portador de las mismas. De esta manera identificó patrones que } \\
\text { pueden relacionarse con el desarrollo de secuencias estratigráficas. }\end{array}$ \\
\hline Kidwell et al. (1986) & $\begin{array}{l}\text { Propusieron una terminología descriptiva estandarizada y una } \\
\text { clasificación genética de las concentraciones fósiles. }\end{array}$ \\
\hline Brett y Baird (1986) & $\begin{array}{l}\text { Propusieron la Tafonomía Comparada, con la finalidad de estudiar la } \\
\text { preservación diferencial de los fósiles en una o a través de varias facies. } \\
\text { Esta subdisciplina de la Tafonomía utiliza como herramienta de estudio } \\
\text { los procesos bioestratinómicos y de fósil-diagénesis para reconocer } \\
\text { tafofacies. }\end{array}$ \\
\hline
\end{tabular}

\section{Caracterización de las concentraciones fósiles}

La dinámica de las concentraciones fósiles puede ser compleja dada la diversidad de partes duras que pueden acumularse y la retroalimentación biológica, física y diagenética previa al enterramiento final (Kidwell, 1991) (Fig. 1.1); a pesar de estas complejas interacciones de factores, es posible reconstruir y reconocer diversos detalles de la historia de las concentraciones al describirlas. La tafonomía comparada se centra en el estudio de la preservación diferencial de los fósiles dentro y entre facies. Esta aproximación, que fue desarrollada por Efremov (1940), fue retomada y definida por Brett y Baird (1986), y es una herramienta útil para analizar cualquier tipo de concentraciones (Kidwell, 1991).

Para diferenciar los procesos tafonómicos involucrados, Brett y Baird (1986) los agruparon siguiendo la subdivisión de los mismos según Müller (1979). En este sentido, la bioestratinomía abarca los procesos de preservación que ocurren desde la muerte del organismo hasta su depósito final (e.g., reorientación, desarticulación, fragmentación y corrasión) y la fósildiagénesis incluye los procesos de fosilización después del enterramiento (e.g., disolución y relleno o reemplazamiento de partes esqueletales por 
sedimento o minerales autigénicos). Mas en ocasiones, las complejas historias tafonómicas de los elementos de las concentraciones no permiten separar estas subdisciplinas.

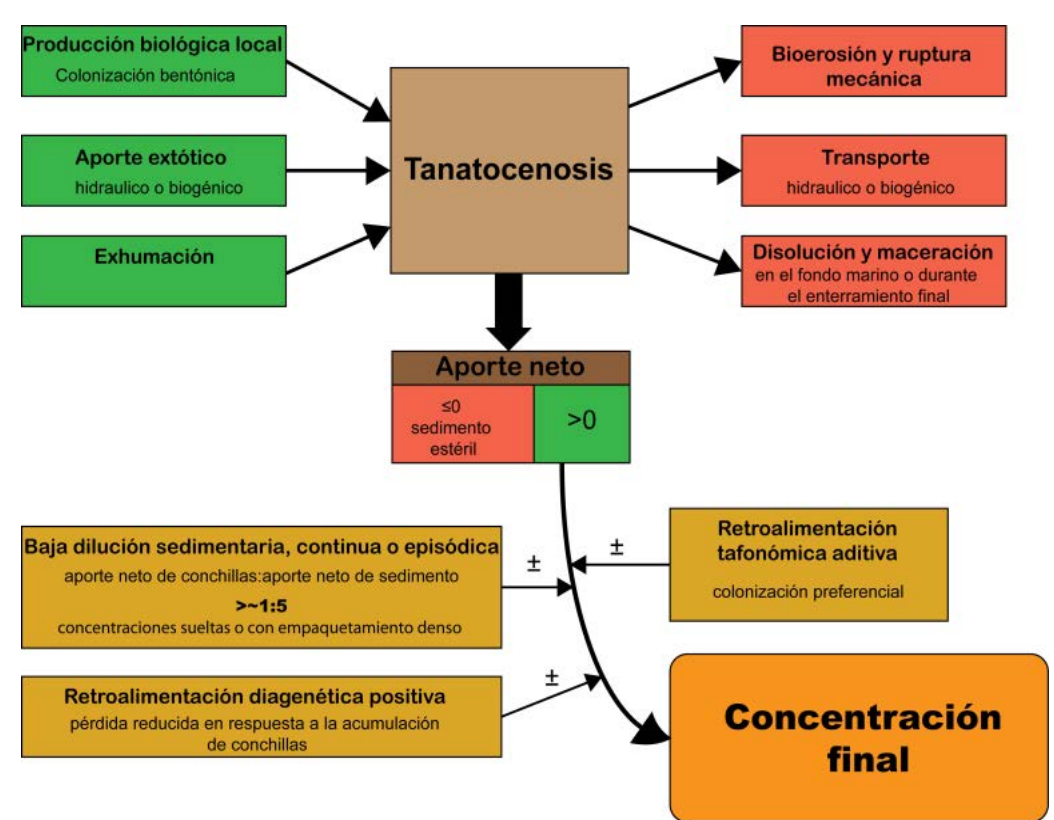

Figura 1.1. Factores que influyen en la formación de concentraciones de conchillas. El requerimiento mínimo para la acumulación es un aporte positivo de conchillas, que puede darse debido a un aporte total alto, una baja tasa de pérdida o alguna combinación favorable de ambos. La concentración final se puede ver influenciada por retroalimentación tafonómica aditiva, retroalimentación diagenética positiva o por baja disolución de sedimento. En verde se señalan aquellos factores que aportan elementos esqueletales y en rojo aquellos intervienen en su pérdida. Modificada Kidwell (1991).

Por otra parte, Kidwell et al. (1986) propusieron una terminología descriptiva estandarizada y una clasificación genética de las concentraciones de fósiles, basada en atributos tales como la composición taxonómica, la biofábrica, la geometría y la estructura interna de las mismas. Los autores introducen el término "concentraciones fósiles o esqueletales» (fossil or skeletal concentrations), diferenciándolo del de «conjuntos o arreglos fósiles» (fossil assemblages) propuesto previamente por Fagerstrom (1964). Además, definen el significado de los términos autóctono, parautóctono y alóctono que ayudan a describir el origen de las concentraciones e incluyen los términos remanié y leaked para referirse a elementos de las concentraciones que fueron retrabajados o incorporados en otros estratos. Respecto a los elementos autóctonos y alóctonos y su significado, FernándezLópez (1990) discutió ampliamente el uso de estos términos y como pueden aplicarse en entidades paleontológicas, sugiriendo que la autoctonía tafonómica debería ser aplicada para los fósiles que son encontrados en el lugar en el que fueron producidos sin tener en cuenta la posición de vida ni el lugar ocupado por las entidades paleobiológicas; la propuesta de Fernandez-López no ha sido utilizada ampliamente en estudios de concentraciones fósiles.

Kidwell (1991) consideró que en el estudio de las concentraciones fósiles, además de la calidad de preservación (abrasión, fragmentación, bioerosión, remineralización) se debían considerar otras características paleontológicas y tafonómicas, como la composición taxonómica, el espectro de edad, la orientación y la selección; sedimentológicas como el 
tamaño de grano de la matriz, el empaquetamiento, el volumen de abundancia de conchillas en sección transversal y la asociación de las conchillas con estructuras sedimentarias; y estratigráficas como el espesor, la geometría, los contactos y la posición en la secuencia. Estas últimas tienden a ser omitidas de las descripciones, sin embargo, son importantes ya que permiten inferir los procesos de concentración.

\section{Clasificación de las concentraciones fósiles}

Debido a la conspicuidad de las concentraciones fósiles en el registro estratigráfico, su estudio ha adquirido interés paleontológico, con la finalidad de reconocer las modificaciones post mortem que reflejan, y geológico, como una herramienta en correlaciones estratigráficas $o$ en el análisis de facies, por ejemplo. Debido a su complejidad, muchas biocenosis, tanatocenosis y tafocenosis pueden estar incluidas en una misma concentración ya que los estratos que las contienen pueden reflejar uno o más eventos de diferente duración (Kidwell, 1991; Patzkowsky y Holland, 2012). Con la finalidad de describir y reconocer los diferentes procesos estratigráficos y depositacionales involucrados en su formación se han propuesto diferentes clasificaciones, en la Tabla 1.2 se resumen algunas de ellas.

Tabla 1.2. Ejemplo de algunas de las clasificaciones de las concentraciones fósiles que se han propuesto sobre la base de diferentes criterios.

\begin{tabular}{|c|c|c|}
\hline Criterio & Clasificación & Referencia \\
\hline \multirow{4}{*}{ 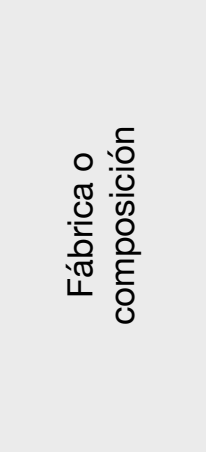 } & $\begin{array}{l}\text { Wackstone, grainstone/packstone (\% de conchillas } \\
>20 \mu \mathrm{m})\end{array}$ & Dunham (1962) \\
\hline & $\begin{array}{l}\text { Bioclasto-soportada, Matriz-soportada } \\
\text { Monotipica, politípica, paucitipica }\end{array}$ & Kidwell et al. (1986) \\
\hline & $\begin{array}{l}\text { Arena de conchilla triturada, arena rica o densa en } \\
\text { conchillas, grava de conchilla }\end{array}$ & Davies et al. (1989) \\
\hline & $\begin{array}{l}\text { Densa, suelta, dispersa } \\
\text { Bien seleccionada, bimodal, mal seleccionada }\end{array}$ & Kidwell y Holland (1991) \\
\hline $\begin{array}{l}\text { Ambiente } \\
\text { de depósito }\end{array}$ & $\begin{array}{l}\text { Astrato vital, lipostrato vital, lipostrato letal, } \\
\text { pantostrato vital y pantostrato letal }\end{array}$ & Schäfer (1972) \\
\hline \multirow{4}{*}{ 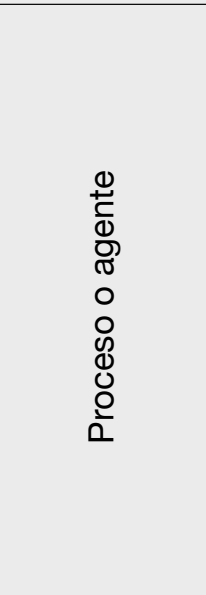 } & $\begin{array}{l}\text { Modelo I Concentración de censo, Modelo II } \\
\text { Acumulación gradual de conchillas autóctonas, } \\
\text { Modelo III Acumulación de conchillas } \\
\text { parautóctonas }\end{array}$ & Johnson (1960) \\
\hline & $\begin{array}{l}\text { Lagerstätten de concentración: depósitos placer, } \\
\text { depósitos de condensación, trampas de } \\
\text { condensación }\end{array}$ & $\begin{array}{l}\text { Seilacher y Westphal } \\
\text { (1971) }\end{array}$ \\
\hline & $\begin{array}{l}\text { Sedimentológica, biogénica, diagenética, de origen } \\
\text { mixto }\end{array}$ & Kidwell et al. (1986) \\
\hline & $\begin{array}{l}\text { Diagrama ternario de factores: Características de } \\
\text { los productores de conchillas, resedimentación } \\
\text { dentro del hábitat o física, aporte de conchillas }\end{array}$ & Kidwell (1991) \\
\hline
\end{tabular}


Tabla 1.2. Ejemplo de algunas de las clasificaciones de las concentraciones fósiles que se han propuesto sobre la base de diferentes criterios.

\begin{tabular}{|c|c|c|}
\hline Criterio & Clasificación & Referencia \\
\hline $\begin{array}{l}\text { Proceso o } \\
\text { agente }\end{array}$ & $\begin{array}{l}\text { Concentración de olas de buen tiempo, } \\
\text { concentración de olas de tormenta, tempestita } \\
\text { proximal, tempestita distal, concentración de } \\
\text { corriente, concentración biogénica primaria, } \\
\text { concentración lavada, lag transgresivo, } \\
\text { concentración condensada. }\end{array}$ & $\begin{array}{l}\text { Fürsich y Oschmann } \\
\text { (1993) }\end{array}$ \\
\hline $\begin{array}{l}\text { Historia de } \\
\text { acumulación } \\
\text { de depósito }\end{array}$ & $\begin{array}{l}\text { Concentración de evento, concentración } \\
\text { compuesta, concentración hiatal o condensada, } \\
\text { concentración lag. }\end{array}$ & Kidwell (1991) \\
\hline
\end{tabular}

La clasificación genética de Kidwell et al. (1986) agrupa las concentraciones de acuerdo a la importancia de los procesos o agentes biológicos, sedimentológicos o diagenéticos involucrados en su formación; en esta clasificación los bioclastos de la concentración pueden ser autóctonos, parautóconos u aloctonos. Las concentraciones biogénicas pueden ser intrínsecas, cuando son producidas por el comportamiento gregario (en vida o post mortem) de los organismos que producen partes duras. Estas concentraciones están constituidas por componentes autóctonos o parautóctonos y reflejan colonización preferencial por larvas de sitios con abundantes adultos, eventos únicos de colonización por especies oportunistas o agregaciones densas y efímeras asociadas a alimentación, ecdisis o desove. Las concentraciones extrínsecas son producidas por otros organismos que interactúan con organismos con esqueleto o sus restos esqueletales; los componentes de estas concentraciones son típicamente parautóctonos o alóctonos.

Las concentraciones sedimentológicas son el resultado de procesos físicos de concentración, usualmente hidráulicos, durante los cuales los componentes esqueletales se comportan como partículas sedimentarias y la matriz no bioclástica también es resedimentada o no se deposita. En este tipo de concentraciones se reconocen tres historias de concentración, que coinciden con los modelos II y III de Johnson (1960) (Fig. 1.2): i) Concentración de elementos esqueletales producidos en el lugar e inicialmente dispersos que fueron concentrados por selección hidráulica o por lavado de la matriz circundante (Modelo II); ii) Acumulación gradual de elementos esqueletales producidos en el lugar durante un periodo con baja tasa de sedimentación (Modelo II); iii) Transporte hidráulico y redepositación selectiva de elementos alóctonos que pueden mezclarse con elementos autóctonos y parautóctonos (Modelo III). Un ejemplo de este último tipo de historia son los depósitos de tormenta.

Las concentraciones diagenéticas son el producto de modificaciones físicas y químicas que actúan sobre los restos esqueletales después del enterramiento. Aunque la mayoría de las concentraciones fósiles han estado sometidas a procesos diagenéticos, únicamente aquellas en las que la densidad de bioclastos es significativamente incrementada se clasifican en esta categoría.

Cuando en el origen de las concentraciones intervienen dos o más tipos de procesos de manera conjunta o cuando uno posterior y diferente se sobrepone a una concentración 
generada por un proceso previo, se considera que su origen es mixto y corresponden con las áreas intermedias (4-6) del diagrama ternario (Fig. 1.2) de Kidwell et al. (1986).

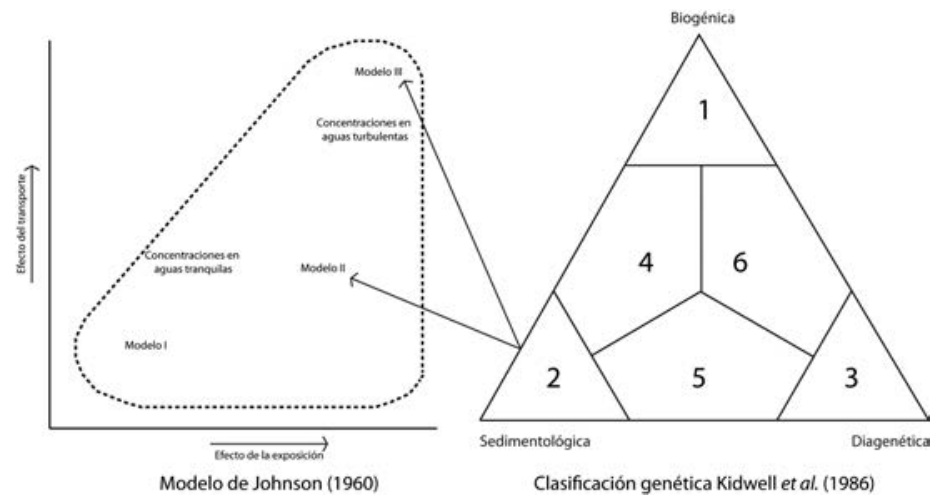

Figura 1.2. Clasificación genética de las concentraciones fósiles sensu Kidwell et al. (1986) (derecha). El origen de las concentraciones sedimentológicas de estos autores se acopla con los modelos II y III de Johnson (1960) (izquierda). Redibujados de las publicaciones originales.

Las concentraciones fósiles también pueden ser clasificadas considerando su estratigrafía y la historia de acumulación. Kidwell (1991) las diferenció en 4 tipos (Fig. 1.3): i) las concentraciones de evento tienen una escala de una sola lámina o capa y representan breves episodios de acumulación; ii) las concentraciones compuestas o multievento pueden ser capas o sets de capas que reflejan la amalgación o acrecimiento de múltiples generaciones o eventos de concentración, se caracterizan por tener mayor espesor que estratos equivalentes; iii) las concentraciones hiatales o condensadas son acumulaciones complejas similares a las anteriores, sin embargo en éstas el espesor de la capa es menor debido a una baja tasa neta de acumulación; iv) las concentraciones lag son concentraciones altamente residuales, de poco espesor, asociadas a superficies con truncamiento estratigráfico; en estas las conchillas son exhumadas y concentradas por selectiva remoción de la matriz por erosión o corrosión.

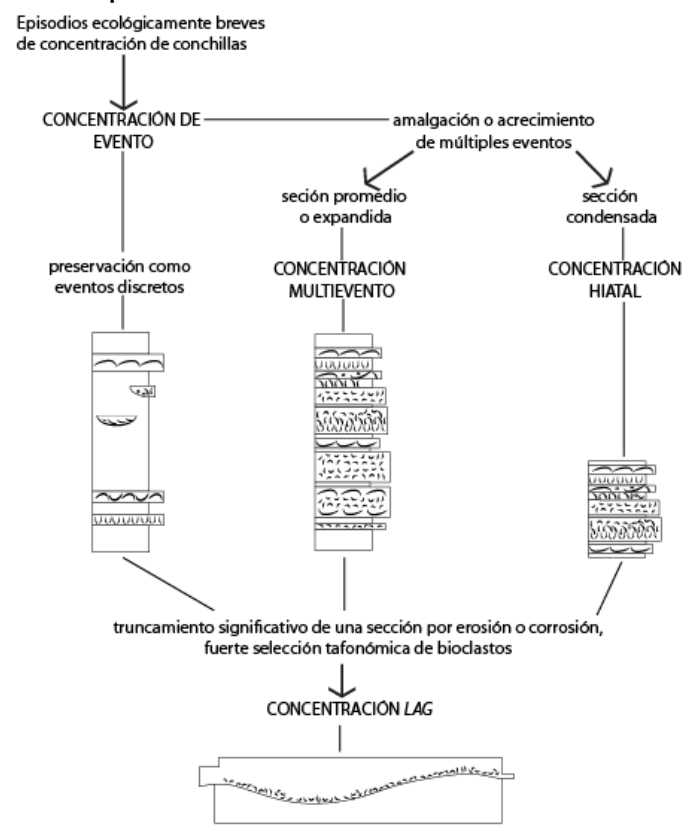

Figura 1.3. Clasificación de las concentraciones fósiles sobre la base de su historia de acumulación en el tiempo (Kidwell, 1991). Redibujado de la publicación original. 
Fürsich y Oschmann (1993), caracterizaron concentraciones jurásicas de las cuencas Kachchh y Rajasthan de la India, considerando la biofábrica de las concentraciones así como las signaturas tafonómicas de sus componentes individuales, con lo cual reconocieron los procesos ocurridos antes y durante el depósito final. Estas observaciones les permitieron agrupar las concentraciones de Kachchh y Rajasthan en nueve tipos (Tabla 1.3, Fig. 1.4), los cuales tienen una distribución característica a lo largo del gradiente onshore-offshore, es decir muestran una tendencia batimétrica.

Tabla 1.3. Tipos de concentraciones fósiles caracterizadas por Fürsich y Oschmann (1993).

\begin{tabular}{|c|c|}
\hline Concentración & Características \\
\hline $\begin{array}{l}\text { 1. de olas de } \\
\text { buen tiempo }\end{array}$ & $\begin{array}{l}\text { Bioclasto soportada con orientación bimodal y mala selección; predomina la alta } \\
\text { abrasión y la fragmentación. Sin bioerosión. La diversidad de especies es baja. }\end{array}$ \\
\hline $\begin{array}{l}\text { 2. de olas de } \\
\text { tormenta }\end{array}$ & $\begin{array}{l}\text { Similar a la concentración anterior, con mejores características de preservación. } \\
\text { Bioclastos con orientación caótica o paralelos al plano, selección bimodal. }\end{array}$ \\
\hline $\begin{array}{l}\text { 3. tempestita } \\
\text { proximal }\end{array}$ & $\begin{array}{l}\text { Similar a la concentración anterior, con mejor preservación. La biofábrica indica } \\
\text { transporte. Empaquetamiento denso. Valvas depositadas con la convexidad hacia } \\
\text { arriba. Con bases erosivas y gradación. }\end{array}$ \\
\hline $\begin{array}{l}\text { 4. tempestita } \\
\text { distal }\end{array}$ & $\begin{array}{l}\text { Concentraciones de menor espesor que las anteriores, con mejor selección, } \\
\text { menor tamaño de bioclastos y gradación. }\end{array}$ \\
\hline $\begin{array}{l}\text { 5. de } \\
\text { corriente }\end{array}$ & $\begin{array}{l}\text { Con estratificación entrecruzada y base erosiva. Bioclasto soportada, con mala } \\
\text { selección y orientación con la convexidad hacia arriba. Alta abrasión y bioerosión } \\
\text { moderada. Diversidad de especies moderada. }\end{array}$ \\
\hline $\begin{array}{l}\text { 6. biogénicas } \\
\text { primarias }\end{array}$ & $\begin{array}{l}\text { Concentraciones esqueletales producto de habitos gregarios de especies que } \\
\text { presentan alta densidad poblacional. Alto grado de preservación. }\end{array}$ \\
\hline 7. lavadas & $\begin{array}{l}\text { Buena preservación. Son el resultado de la remoción de la matriz, por flujos o olas } \\
\text { de tormenta distales o corrientes de poca intensidad. }\end{array}$ \\
\hline $\begin{array}{l}\text { 8. lags } \\
\text { transgresivos }\end{array}$ & $\begin{array}{l}\text { Representan largos intervalos de tiempo por lo que tienen la impronta de varios } \\
\text { procesos tafonómicos. Muestran retrabajo, transporte y alta bioerosión, } \\
\text { evidenciando largos periodos de exposición en la interfase. Concreciones } \\
\text { bioerosionadas e incrustadas pueden evidenciar largos períodos de omisión y } \\
\text { erosión. }\end{array}$ \\
\hline $\begin{array}{l}9 . \\
\text { condensadas }\end{array}$ & $\begin{array}{l}\text { Representan intervalos de tiempo mayores que las de tipo lags. Los bioclastos } \\
\text { muestran diferentes historias tafonómicas, habiendo sido mezclados por } \\
\text { retrabajo. Se observa cementación digenética temprana. }\end{array}$ \\
\hline
\end{tabular}

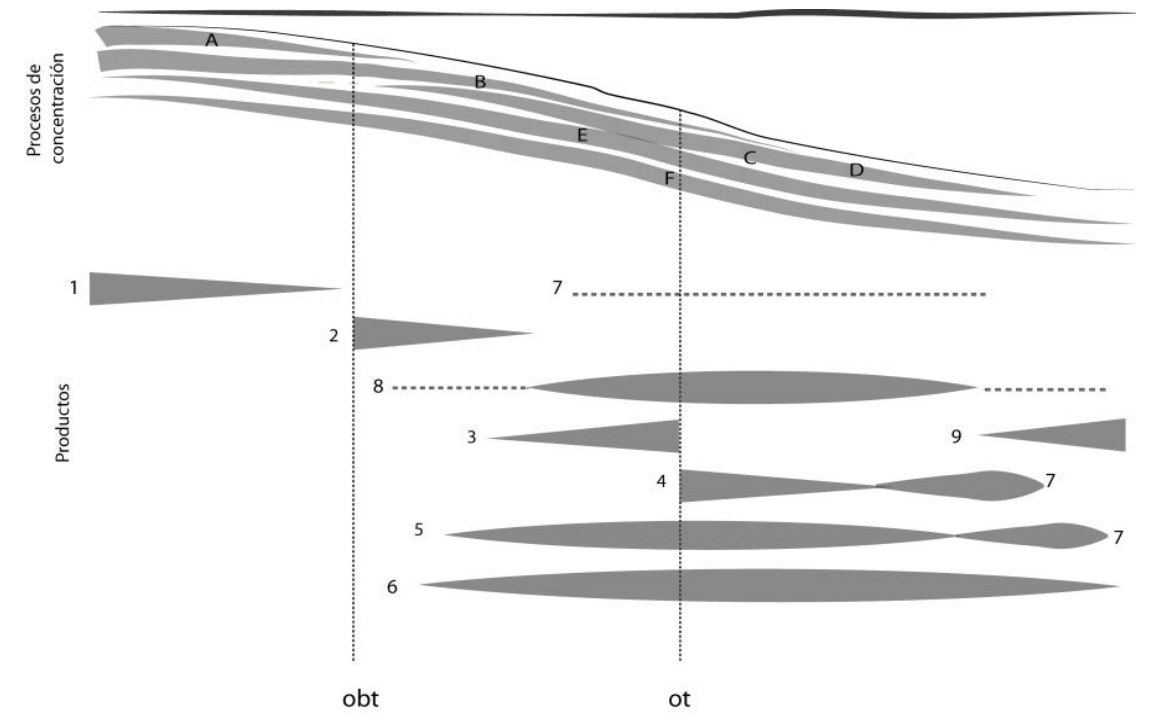


Figura 1.4. Clasificación de las concentraciones fósiles basadas en los pProcesos de acumulación dominantes involucrados en su formación; donde A: olas de buen tiempo, B: olas de tormenta, $\mathrm{C}$ : flujos de tormenta, D: flujos de tormenta distales, E: corrientes de larga duración, F: producción de partes duras biogénicas. obt: nivel de base de olas de buen tiempo y ot: nivel de base de olas de tormenta. Los productos son los nueve tipos de concentraciones descriptas por Fürsich y Oschmann (1993) a lo largo del gradiente onshore-offshore. Adaptado de la publicación original.

\section{Sedimentación en ambientes clásticos marinos asociada a procesos de tormenta}

La sedimentación en ambientes marinos someros mayormente es el resultado de procesos de olas de buen tiempo (corrientes mareales y oceánicas) y procesos asociados a tormentas (corrientes oscilatorias y olas dominadas por viento) (Swift, 1969); es por ello que en depósitos de plataforma se ha distinguido el nivel de base de olas de buen tiempo del nivel de base de olas de tormenta (Aigner, 1985).

Walker (1984) identificó tres ambientes principales en los sistemas dominados por tormentas: la cara de playa (shoreface), la plataforma interna (inner shelf) y la plataforma externa (offshore); la primera zona se caracteriza por un abundante transporte de sedimento sobre el nivel de base de olas de buen tiempo. El límite superior del shoreface es la zona de rompiente (surf zone) y el inferior es la plataforma interna. En la plataforma interna se depositan pelitas que no sufren alteraciones durante los procesos de buen tiempo; se ha considerado que únicamente los procesos dominados por tormentas pueden transportar arena en el offshore (Dyson, 1995).

El nivel de base de olas de tormenta es definido como la mayor profundidad en la que normalmente afectan las olas durante tormentas (Leckie y Krystinik, 1989). Por encima de este se ha reconocido una asociación de facies particular con estratificación tipo hummocky (HCS, hummocky cross stratification) formada por corrientes de densidad (Hamblin y Walker, 1979). Debajo del nivel de base de olas de tormenta, en la plataforma externa, las arenas se depositan mayormente mostrando una secuencia de Bouma por la presencia de corrientes unidireccionales (Aigner, 1985; Dyson, 1995).

\section{Estructuras sedimentarias y estratigrafía de los depósitos de tormenta}

Los depósitos de tormenta están ampliamente representados en el registro geológico. Kelling (en Ager, 1974) empleó el término tempestita para describir los depósitos periódicos producidos por tormentas en ambientes marinos someros; a pesar de que el término fue considerado ambiguo e inapropiado debido a la variabilidad que pueden presentar estos depósitos (Ager, 1974; Walker, 1985), actualmente es ampliamente utilizado. Una de las contribuciones más destacables para el análisis de facies de depósitos de tormenta fue la descripción de HCS; a partir de ello, se ha incrementado el número de estructuras sedimentarias reconocidas como originadas durante tormentas, entre las cuales, además de la HCS, la estratificación entrecruzada tipos swaley (SCS) y la laminación cuasi planar (QPL) son consideradas diagnósticas de este tipo de depósitos (Dyson, 1995).

Estratigráficamente, en el shoreface comúnmente se observan secuencias con bases erosivas con capas de conchillas seguidas de arena laminada, sobre las cuales pueden suprayacer estratos con ondulitas. En la zona de transición shoreface-offshore los depósitos proximales comprenden delgadas (centímetros a decímetros) capas de arena. 
Presentan superficies erosivas y se pueden observar en ocasiones marcas de impacto. En estas secuencias se observan estratos de conchillas que pueden alcanzar varios centímetros de espesor. La laminación que se observa en estas secuencias puede ser de bajo ángulo o formar HCS; hacia el techo de estas secuencias pueden aparecer niveles con laminación ondulítica. Los depósitos de tormenta distales suelen ser de poco espesor y conformados por sedimentos de grano fino. Pueden presentar base erosiva, y laminación. Representan el efecto de tormentas menores (Aigner, 1982).

Varios autores han planteado una secuencia idealizada de las tempestitas proximales ( $V$. Kelling y Mulling, 1975; Aigner, 1982; Walker et al., 1983; Duke, 1985), basándose en observaciones de afloramientos que son similares a la descripción de Goldring y Bridges (1973). Una de las secuencias más utilizadas es la de Walker et al. (1983), que también permite observar relaciones laterales (Fig. 1.5); en esta se sugiere un depósito inicial de sedimento por un flujo unidireccional seguido de estratos producto de flujos oscilatorios.

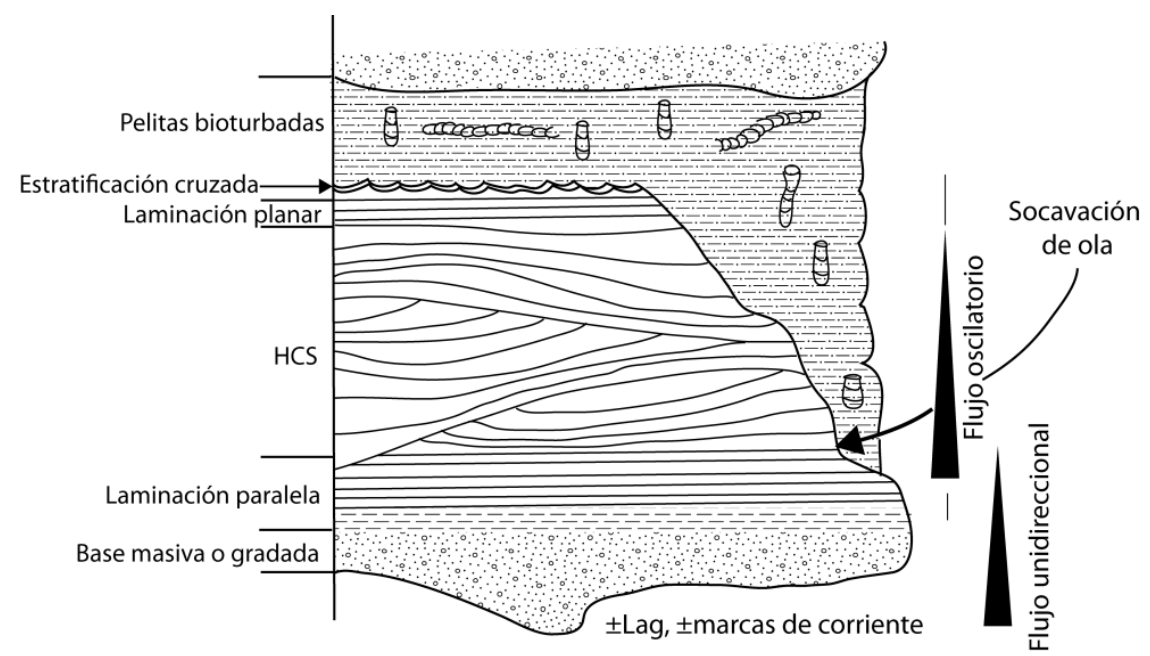

Figura 1.5. Secuencia ideal de tempestitas proximales sensu Walker et al. (1983). Modificada de la publicación original.

En secuencias actuales y fósiles se ha observado que las tendencias de proximidaddistalidad, muestran que el efecto de las tormentas decrece a mayor profundidad y distancia de la costa. Estas tendencias son una herramienta para el análisis vertical de facies, ya que las tempestitas asociadas a secuencias progradantes se caracterizan por ser granocrecientes, y los estratos tienden a ser de mayor espesor hacia el techo, de guisa que las tempestitas distales subyacen a las proximales, las cuales son seguidas por depósitos de tormenta en el shoreface, a los que le suprayacen depósitos mareales. El espesor del depósito de tormenta del shoreface está determinado por la energía del oleaje en la costa y el límite entre éste y la zona de transición marca la profundidad promedio del nivel de base de olas de buen tiempo, mientras que la última ocurrencia de ondulitas denota el nivel máximo alcanzado por las corrientes oscilatorias inducidas por olas mayores (nivel de base de olas de tormenta). Las secuencias transgresivas no son muy comunes en el registro fósil (Aigner, 1985). 
Aigner (1985) señaló que, en algunos casos, las concentraciones de conchillas depositadas por eventos de tormenta a lo largo del gradiente shoreface-offshore podrían ser una herramienta para conocer de dónde proviene el sedimento circundante. Sobre la base de sus observaciones concluyó que los depósitos de tempestitas proximales incluyen una mezcla de taxones lavados parautóctonos y alóctonos, algunos de los cuales provenían de canales mareales o planicies de mareas. Aigner (1985) también observó que a través del nearshore-offshore hay una disminución lateral del porcentaje de aloctonía. En tormentas distales, las conchillas tienden a ser parautóctonas o lavadas. De esta manera, las concentraciones hidráulicas decrecen desde el shoreface hacia el offshore, al igual que el sedimento transportado (Aigner, 1985; Kidwell, 1991).

En estudios de acumulaciones de conchillas en ambientes actuales se ha observado que los procesos tafonómicos son altamente selectivos, y que, en concentraciones asociadas a tormentas, el proceso de depositación produce efectos mínimos en la preservación. También se ha observado que un sólo evento de alta energía no produce daños significativos en las signaturas tafonómicas en concentraciones depositadas con anterioridad; estos eventos únicamente lavan el sedimento, reorientan y reseleccionan los bioclastos sesgando la distribución de las conchillas por talle (Davies et al., 1989). Sin embargo, en el registro fósil los procesos involucrados en la preservación, resedimentación y desplazamiento de las conchillas tienden a ser más complejos ya que la concentración representa un evento breve pero el registro fósil es más antiguo y muchos bioclastos pueden estar expuestos a más de un evento de resedimentación y exposición en la interfase agua sedimento; en estos casos las características tafonómicas producidas por un evento de tormenta pueden ser difíciles de reconocer (Fürsich y Oschmann, 1993).

\section{Comunidades asociadas a sustratos duros}

La Icnología es una ciencia multidisciplinaria que estudia las trazas producidas por organismos en o dentro del sustrato y aborda todos los procesos relacionados con la bioturbación, bioerosión y biodepositación (Mángano y Buatois, 2016). Al igual que la Tafonomía, la Icnología es una ciencia que se encuentra entre los límites de la Geología (ya que las trazas tienen un componente sedimentológico) y de la Biología (por el origen de las mismas).

Del mismo modo que ocurrió con el pensamiento Tafonómico, fue Da Vinci el primero en entender la naturaleza de las trazas de bioerosión fósiles y demostró el origen biológico de las conchillas fósiles de Parma y Piacenza (Italia) recurriendo a los icnofósiles (Tabla 1.5). A pesar de que estas trazas de sustratos duros fueron las primeras en ser apreciadas y reconocidas, el estudio de las de sustratos no consolidados predominó durante el desarrollo de la Icnología. Muchos conceptos fundamentales fueron desarrollados a partir del estudio de estas últimas, por ejemplo, el de icnofacies propuesto por Seilacher (1967). Estas icnofacies no consideraban estrictamente las trazas de bioerosión, siendo la icnofacies Entobia la primera para sustratos duros, definida mucho tiempo después por Bromley y Asgaard (1993). En la Tabla 1.5, se resumen los principales hitos en el desarrollo y formalización de la Icnología. 
El estudio de trazas de bioerosión fue retomado después de que Neumann (1966) estudió los arrecifes en las costas de Bermuda y acuñó el término «bioerosión» para designar la alteración de sustratos consolidados por acción directa de organismos y diferenciarla de la destrucción física que causa el oleaje en estos ecosistemas. En este trabajo, Neumann (1966) reconoce la importancia del estudio de la bioerosión para evaluar su efecto acumulado y compararlo con los procesos erosivos físicos y químicos. A partir de estos estudios, paleontólogos y neontólogos han reconocido la importancia de la información evolutiva y ecológica que brindan las comunidades marinas que habitan sustratos duros (e.g., Bingham, 1992; Taylor y Wilson, 2003; Wisshak, 2006; Wilson, 2007; Buatois et al., 2016; Zatón et al., 2016; Bassi et al., 2017).

Tabla 1.5 Contribuciones importantes para de desarrollo y la formalización de la Icnología (Baucon 2010; Baucon et al., 2012)

\begin{tabular}{|c|c|}
\hline Autor y año & Aportaciones \\
\hline $\begin{array}{l}\text { Leonardo Da Vinci } \\
1508-1510\end{array}$ & $\begin{array}{l}\text { Utilizó las trazas de invertebrados para demostrar el origen } \\
\text { sedimentario de los estratos portadores de fósiles y la naturaleza } \\
\text { orgánica de los fósiles. } \\
\text { Describió trazas de bioerosión, siendo el primero en entender su } \\
\text { naturaleza. } \\
\text { Aplicó un enfoque neoicnológico al comparar algunos icnofósiles de } \\
\text { Parma y Piacenza, Italia, con trazas actuales en madera. }\end{array}$ \\
\hline Brongniart (1823) & $\begin{array}{l}\text { Asoció diversas trazas ramificadas a feofitas del género Fucus, por lo } \\
\text { que empleó el término «fucoide» para referirse a estas formas. Además } \\
\text { de describir estas formas y otras plantas fósiles, resaltó su importancia } \\
\text { biostratigráfica. La importancia de la hipótesis de Brongiart aún es } \\
\text { evidente en la descripción de icnogéneros de sustratos no } \\
\text { consolidados como Rhizocorallium, Scolicia, Daedalus, Palaeodictyon, } \\
\text { Zoophycos y Cruziana. }\end{array}$ \\
\hline Lyell (1837) & $\begin{array}{l}\text { Explicó como los moluscos producen sus trazas al enterrarse en el } \\
\text { sustrato. } \\
\text { Las trazas de bioerosión desempeñaron un papel central en el } \\
\text { desarrollo de Uniformitarismo, cuando reconoció las fluctuaciones en el } \\
\text { nivel del mar a través de sus observaciones en columnas romanas } \\
\text { bioerodadas. }\end{array}$ \\
\hline de la Beche (1846) & $\begin{array}{l}\text { Realizó reconstrucciones paleontológicas basadas en estudio de } \\
\text { coprolitos. }\end{array}$ \\
\hline Nathorst (1881) & $\begin{array}{l}\text { Aceptó el origen biológico de varios icnofósiles que durante muchos } \\
\text { años habían sido considerados restos de plantas o animales. } \\
\text { Realizó experimentos neoicnológicos, en los cuales colocaba a varios } \\
\text { animales en contenedores con yeso y observaba las trazas que } \\
\text { producían, de modo que pudo señalar la correspondencia entre trazas } \\
\text { de invertebrados actuales y fucoides. } \\
\text { Las aportaciones de Nathorst desafiaron las ideas tradicionales } \\
\text { relacionadas a la formación de los icnofósiles y promovieron el } \\
\text { desarrollo de la paleoicnología. }\end{array}$ \\
\hline
\end{tabular}


Tabla 1.5 Contribuciones importantes para de desarrollo y la formalización de la Icnología (Baucon 2010; Baucon et al., 2012)

\begin{tabular}{|c|c|}
\hline Autor y año & Aportaciones \\
\hline Richter (1928) & $\begin{array}{l}\text { La fundación del Laboratorio Senckenberg permitió que la Icnología } \\
\text { ocupara un lugar central, y pronto se convirtió en un renombrado centro } \\
\text { dedicado a su estudio. } \\
\text { Sus trabajos propiciaron que se acuñaran los términos de } \\
\text { Actuopaläontologie y «texturas bioturbadas» (relat. icnofábrica, V. Frey, } \\
\text { 1973; Bromley y Ekdale, 1986), que fueron muy importantes para } \\
\text { promover el resurgimiento de esta disciplina. }\end{array}$ \\
\hline Rosselli (1938) & $\begin{array}{l}\text { Sus trabajos en paleosuelos paleógenos de Uruguay representan las } \\
\text { bases de la paleoicnología de insectos en Argentina y Uruguay. }\end{array}$ \\
\hline $\begin{array}{l}\text { Seilacher, Schäfer y } \\
\text { Häntzchel } \\
\text { 1947- década de } 1950\end{array}$ & $\begin{array}{l}\text { Sentaron las bases que permitieron fundar una "Era Moderna de la } \\
\text { Icnología", ya que sus innovadores métodos y alcances de la disciplina, } \\
\text { permitieron que resurgiera el interés por el estudio de los icnofósiles en } \\
\text { el resto de Europa y Norteamérica. }\end{array}$ \\
\hline $\begin{array}{l}\text { Casamiquela y } \\
\text { Frenguelli } \\
1950-1965\end{array}$ & $\begin{array}{l}\text { Iniciaron el desarrollo de la Icnología moderna en Sudamérica, al } \\
\text { dedicar contribuciones únicamente al estudio de las trazas. }\end{array}$ \\
\hline
\end{tabular}

La ausencia de una nomenclatura propia para este tipo de estudios ocasionó que algunos términos fueran empleados de forma poco consistente. Taylor y Wilson (2002) propusieron una nueva terminología que hace referencia a la relación entre los organismos marinos y el sustrato duro que ellos habitan; de esta contribución destaca el término esclerobionte, que define a cualquier organismo que ocupe cualquier tipo de sustrato duro; además, este término se acompañó de un colectivo de palabras que permite especificar qué tipo de organismo interactúa con el sustrato (e.g., esclerofita y esclerozoo).

El estudio de estas comunidades ha resultado de gran importancia más allá de los señalamientos de Neumman (1966), ya que brinda información paleoecológica importante, como la posición de vida de los colonizadores y su distribución y orientación espacial sobre el sustrato; por otra parte, brinda evidencia de la interacción que podrían tener diferentes colonizadores, ya sea a modo de sucesión ecológica o por competencia (e.g., Wilson, 1985, 1987; Taylor y Wilson, 2003; Parras y Casadío, 2006; Brezina et al., 2014; Luci y Lazo, 2015; Färber et al., 2016; Liow et al., 2016; Taylor, 2016). En un contexto evolutivo, el estudio de comunidades de sustratos duros es también de interés debido a que diferentes linajes de animales y plantas han desarrollado esta estrategia evolutiva a lo largo de todo el Fanerozoico (Taylor y Wilson, 2003). Finalmente, en un contexto tafonómico y paleoambiental, el estudio de estas comunidades permite incrementar la información acerca de las condiciones del ambiente de depositación y de la historia tafonómica del sustrato colonizado previo al enterramiento final (e.g., Siggereud et al., 2000; Domènech et al., 2001; Johnson et al., 2011; Pineda-Salgado et al., 2015).

\section{Justificación}

La Formación Monte León (Mioceno inferior) posee numerosas concentraciones de invertebrados fósiles, que se caracterizan por la abundancia de macromoluscos y 
micromoluscos bien preservados, lo cual ha favorecido su estudio, principalmente sistemático, desde finales del siglo XIX, con pocas referencias a la naturaleza de dichas concentraciones (e.g. Olivera, 1990) considerado algunas sus características tafonómicas, paleontológicas, estratigráficas y sedimentológicas, así como su variación vertical. Adicionalmente, la abundancia de conchillas es un recurso que favorece el desarrollo de comunidades de sustratos duros, que no han sido estudiadas previamente en esta unidad.

En este sentido, las concentraciones fósiles presentes en la Formación Monte León brindan una valiosa oportunidad para realizar estudios tafonómicos e icnológicos combinados. Estos incluyen la identificación taxonómica de los esclerobiontes y el análisis cualitativo y cuantitativo de su riqueza, abundancia y distribución espacial, en conjunto con el análisis de los atributos tafonómicos, paleontológicos, estratigráficos y sedimentológicos de las concentraciones.

Los estudios planteados en esta Tesis permiten el reconocimiento de los procesos biológicos y sedimentarios responsables de la formación de concentraciones fósiles presentes en la Formación Monte León. El análisis de los esclerobiontes, contribuye a incrementar el conocimiento sistemático y paleoecológico de las comunidades marinas de sustratos duros presentes en la unidad y durante el Mioceno. Adicionalmente, constituye el primer trabajo sobre los mismos en la formación, incrementando así el conocimiento de las comunidades de sustratos duros en las latitudes medias a altas del hemisferio sur. En este sentido, los estudios sobre bioerosión marina han sido ampliamente desarrollados en el Caribe y el Mediterráneo; siendo escasos y restringidos, principalmente al hemisferio norte ,los trabajos en latitudes altas. Finalmente, el análisis cuantitativo de estas comunidades en conjunto con otros datos tafonómicos, paleontológicos, estratigráficos y sedimentológicos permiten reconstruir la historia tafonómica de las concentraciones fósiles y refinar las interpretaciones paleoambientales.

\section{Objetivos}

\section{Objetivo general}

Contribuir al conocimiento paleontológico, tafonómico, icnológico, estratigráfico y sedimentológico de las concentraciones fósiles del Cenozoico marino de Patagonia.

\section{Objetivos particulares}

1. Describir y analizar diversas concentraciones fósiles presentes en la Formación Monte León sobre la base de sus características paleontológicas, tafonómicas, estratigráficas y sedimentológicas. Reconstruir su historia tafonómica y determinar las condiciones ambientales y los procesos de depósito responsables de su formación.

2. Evaluar los diferentes atributos tafonómicos de los macro y micro moluscos en las concentraciones fósiles de la Formación Monte León, con relación al tamaño de las conchillas y su vulnerabilidad a diferentes procesos de alteración, desgaste y depósito.

3. Reconocer y describir las trazas de bioerosión presentes en el sustrato biogénico de las concentraciones fosilíferas de la Formación Monte León e identificar la información que 
aportan su riqueza, abundancia y distribución, en el reconocimiento de procesos tafonómicos y sedimentarios.

\section{Hipótesis}

Las concentraciones fósiles presentes en la Formación Monte León están formadas por bioclastos que experimentaron historias tafonómicas diferentes y complejas, las cuales podrían estar relacionadas con variaciones locales en las condiciones ambientales (o de depósito).

La calidad de preservación de macro y micro moluscos en las concentraciones fósiles de la Formación Monte León está influenciada por el tamaño de las conchillas y su vulnerabilidad a diferentes procesos de alteración, desgaste y depósito.

El desarrollo de comunidades de sustratos duros sobre conchillas de moluscos presentes en las concentraciones fósiles de la Formación Monte León está relacionado con la colonización del sustrato en diferentes etapas de resedimentación y exhumación, previas al enterramiento final.

\section{Área de estudio y Sección analizada}

El área de estudio de esta Tesis se encuentra en la costa de la provincia de Santa Cruz (Fig. 1.6), dentro del ámbito de la Hoja Geológica 5169-I y II, Puerto Coig y Puerto Santa Cruz (Sacomani y Panza, 2011). La región del sector costanero comprende los principales afloramientos de la Formación Monte León; en ésta se encuentra el área tipo y la sección tipo de la formación que fue descripta a partir del perfil Monte Entrada. Asimismo, se encuentran los principales afloramientos de la formación entre ellos, además de Monte Entrada, la sección de Darwin, Restinga Norte, Las Cuevas, Yegua Quemada y Cabeza de León. Las concentraciones fósiles estudiadas se encuentran en el sector medio de la sección Cabeza de León, ubicada dentro del Parque Nacional Monte León (S 50²1' 25,4"; O 68 53' 05,9") (Fig. 1.6). El acceso a la misma se realiza por la Ruta Nacional $\mathrm{N}^{\circ} 3$, recorriendo $7 \mathrm{~km}$ en dirección sur desde la entrada al centro de interpretación del Parque Nacional Monte León. Se continúa luego hacia la costa unos $18 \mathrm{~km}$ por la Ruta Provincial $N^{\circ} 63$.

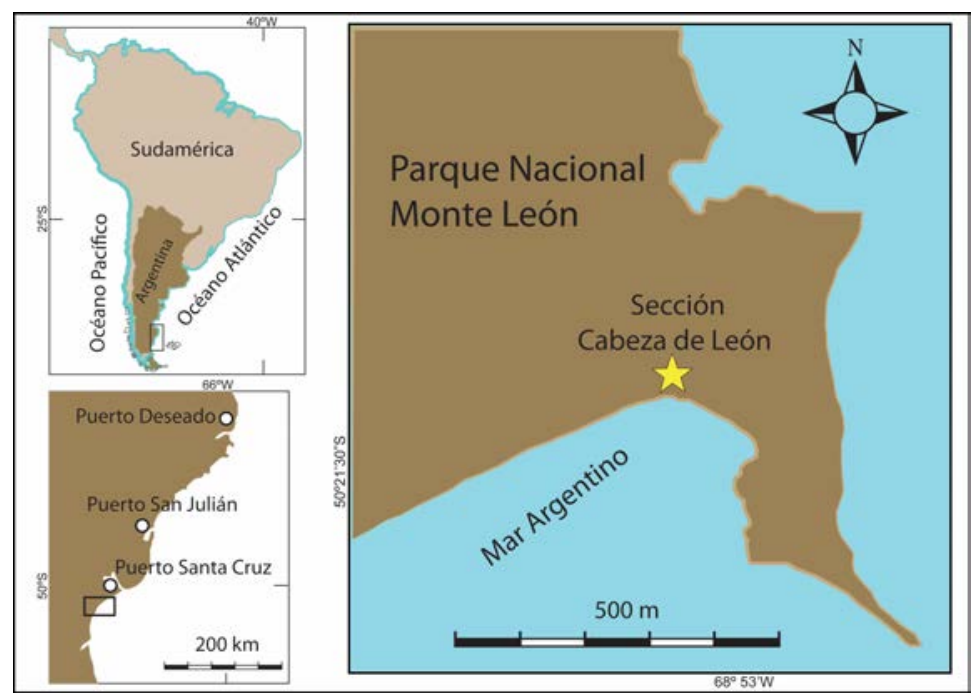


Figura 1.6 Ubicación del área de estudio en donde la estrella amarilla señala la ubicación de la sección Cabeza de León.

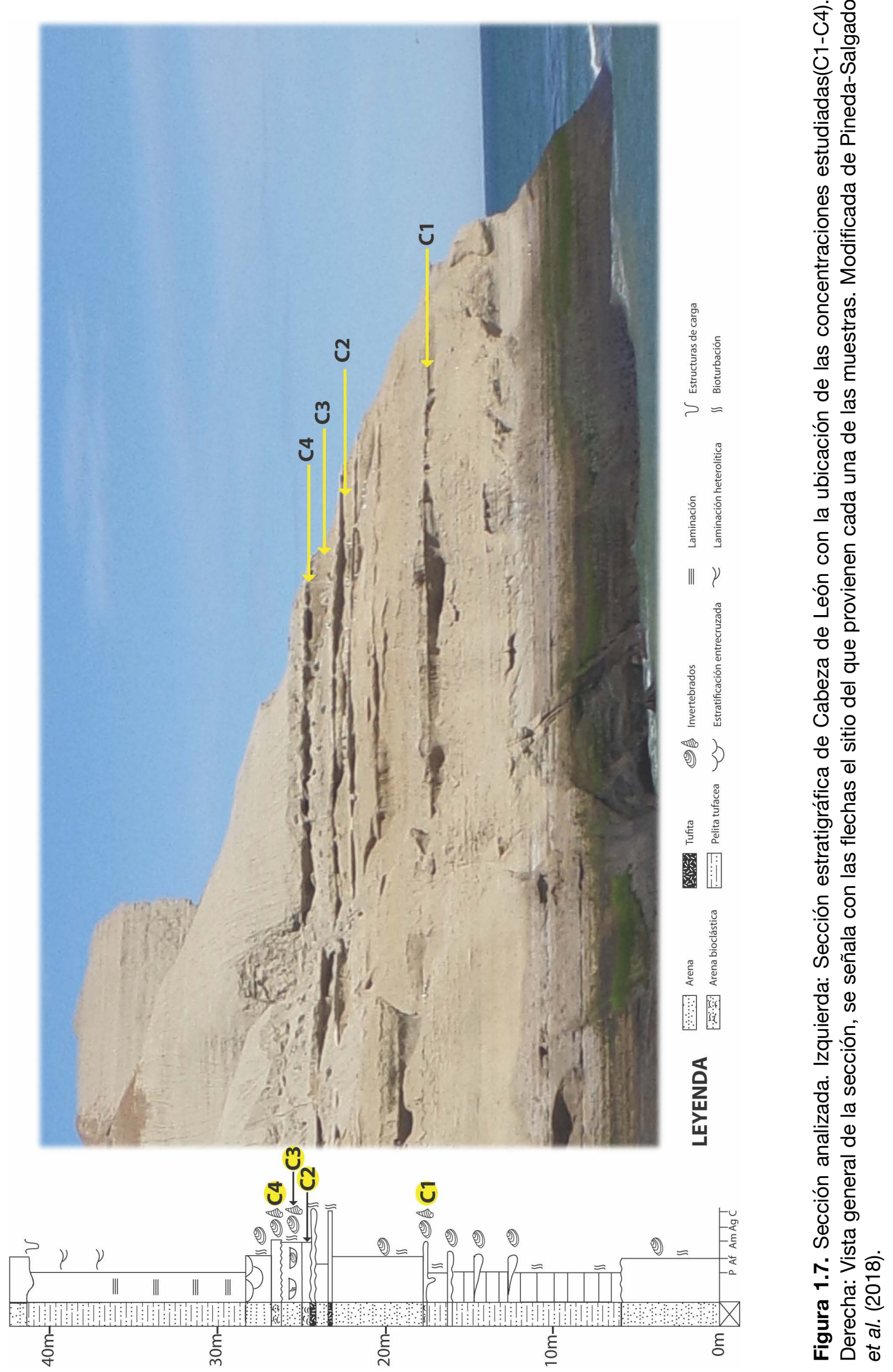


El tramo inferior de la sección comprende alrededor de 17 metros de areniscas finas y limolitas bioturbadas, con estructura maciza o con estratificación horizontal. Presenta escasos fósiles de invertebrados representados por decápodos articulados y especímenes de "Ostrea" hatcheri Ortmann, 1897 en posición de vida. El sector medio tiene un espesor aproximado de 10 metros y está conformado por areniscas finas muy bioturbadas, presentando cuatro concentraciones fósiles constituidas principalmente por gasterópodos, bivalvos, escafópodos, braquiópodos, equinodermos, balanos y briozoos; cada una de estas concentraciones fósiles fueron analizas en esta Tesis (Fig. 1.7). El último tramo de la sección comprende unos 14 metros de limolitas y areniscas muy finas, tufáceas, laminadas y con estructuras heterolíticas.

\section{Métodos generales}

\section{Trabajo de campo y toma de muestras}

El material estudiado fue colectado durante campañas realizadas en 2005 y 2013 por los directores de esta Tesis, en las cuales se levantaron perfiles estratigráficos y sedimentológicos verticales y laterales de detalle de varias secciones de la Formación Monte León. Las diversas características preservacionales a lo largo de las concentraciones fósiles presentes en la sección Cabeza de León, así como la diversidad y abundancia de trazas de bioerosión en algunas de estas concentraciones, fueron factores determinantes para elegir a la sección Cabeza de León como sección de estudio para esta Tesis. De cada una de las concentraciones presentes en esta sección se tomaron dos muestras con un volumen aproximado de $3000 \mathrm{~cm}^{3}$.

Durante 2017 y 2018 se realizaron campañas específicas a la sección Cabeza de León, donde se realizaron observaciones estratigráficas, sedimentológicas, paleontológicas y tafonómicas de detalle en cada una de las concentraciones fósiles, utilizando cuadros de 50 por $50 \mathrm{~cm}$. Asimismo, se colectaron especímenes adicionales de cada una de las concentraciones, para refinar las determinaciones taxonómicas e icnotaxonómicas.

\section{Trabajo de laboratorio}

De cada una de las muestras procedentes de las cuatro concentraciones se tomó por cuarteo una submuestra estandarizada (1a y b, 2a y b, 3a y b, 4a y b) con un volumen equivalente a $1000 \mathrm{~cm} 3$ que fue disgregada y lavada con peróxido de hidrógeno al $30 \%$, agua tibia y detergente; posteriormente cada submuestra fue tamizada en húmedo con tamices marca ZonyTest, números $25(0,710 \mathrm{~mm}), 16(1,190 \mathrm{~mm})$ y 31/2 $(5,660 \mathrm{~mm})$. El material retenido en cada tamiz fue separado y secado en una estufa a $40{ }^{\circ} \mathrm{C}$ entre 45 y 180 minutos, posteriormente se midió el volumen de material retenido en cada tamiz.

Las conchillas retenidas en cada fracción fueron limpiadas en un equipo de lavado ultrasónico VEVOR; en este proceso las fracciones se colocaron en el limpiador con agua y peróxido de hidrógeno al $30 \%$ durante 1 minuto para el material retenido en el tamiz 25 , y de 2 a 25 minutos para el retenido en los tamices 16 y 31/2; en este último caso adicionalmente se aumentó la temperatura entre 1 y $3^{\circ} \mathrm{C}$. Las conchillas fueron separadas y observadas en lupas binoculares Leica M80, ubicada en el Anexo del Museo de La Plata en la Facultad de Ciencias Naturales y Museo de la Universidad Nacional de La Plata (FCEyM, UNLP), y Leica S6D, ubicada en Facultad de Ciencias Exactas y Naturales de la 
Universidad Nacional de La Pampa (FCEyN, UNLPam), para realizar los análisis tafonómicos e icnológicos (V. Capítulo 3, 4 §. Métodos). Finalmente, el material fue fotografiado con cámara Leica EC3 (adaptada a lupa binocular Leica S6D), con cámara semireflex Kodak Az421 y con el microscopio electrónico de barrido del Museo Argentino de Ciencias Naturales "Bernardino Rivadavia" (MACN).

Trabajo de gabinete

Para la elaboración del marco teórico se realizó una búsqueda y revisión bibliográfica de trabajos relacionados con ambientes sedimentarios, Tafonomía e Icnología, principalmente de trazas de sustratos duros. Para la elaboración del marco geológico y los antecedentes se revisaron trabajos geológicos y paleontológicos sobre la cuenca Austral en general y sobre la ingresión marina del "Patagoniense" y la Formación Monte León, en particular.

La sección estratigráfica y las figuras incluidas en esta tesis fueron realizadas en Adobe Illustrator CS5. Las fotografías del material paleontológico fueron editadas en Adobe Photoshop CS5 para posteriormente elaborar las figuras con ambas suites de Adobe. 


\section{Capítulo 2}

[...] un tiempo sin tiempo, tan infinito y tan intenso.

-Mario Vargas Llosa

Cinco esquinas 


\section{Marco geológico}

La comarca Patagónica, ubicada en el extremo sur de América del Sur, se divide en dos grandes regiones, la Plataforma Patagónica al este y la Cordillera Patagónica al oeste. La Plataforma Patagónica comprende dos macizos cristalinos, el macizo de Somun Curá al norte y el macizo del Deseado en el sur; este último constituye el límite septentrional de la cuenca Austral (Fig. 2.1). La Cordillera Patagónica comprende las provincias geológicas de la Cordillera Patagónica Septentrional y la Cordillera Patagónica Austral. Esta última unidad está compuesta principalmente por depósitos marinos y continentales del Mesozoico y Cenozoico depositados en el ámbito de la cuenca Austral.

La cuenca Austral cubre un área de $230.000 \mathrm{~km}^{2}$ abarcando las provincias de Santa Cruz y Tierra del Fuego, parte de Chile y la plataforma submarina sudatlántica (Fig. 2.1). Su límite septentrional y oriental lo constituye el Macizo del Deseado, que se extiende con una forma alargada de norte a sur, formando el alto estructural denominado Dorsal de Río ChicoDungeness que la separa de la cuenca de Malvinas. El límite occidental está constituido por los Andes Patagónicos Australes y los Andes Fueguinos. El relleno de la cuenca consiste en una sucesión sedimentaria de hasta $8.000 \mathrm{~m}$ de espesor, constituida casi exclusivamente por rocas silicoclásticas (Varela et al., 2012). En su evolución se han reconocido cuatro etapas tectónicas principales (Ghiglione et al., 2010). La primera, que marca su inicio, se corresponde con un periodo de extensión regional acaecido durante el Triásico-Jurásico, que está asociado a la disgregación de Gondwana. Desde finales del Jurásico y durante el Cretácico Temprano, la cuenca experimentó un período de subsidencia térmica evidenciada en el desarrollo de típicas secuencias transgresivasregresivas. A partir del Cretácico Tardío se instauró un régimen compresivo; esta etapa se relaciona con el levantamiento de la Cordillera Patagónica Austral y el desarrollo de una faja plegada y corrida, con la consecuente generación de espacio de acomodación debido a subsidencia por carga en el antepaís. Finalmente, durante el Neógeno se registra una etapa de deformación asociada a transcurrencia, ocasionada por reorganización de las placas en el margen occidental.

Las concentraciones fosilíferas estudiadas en esta Tesis se encuentran dentro de sedimentitas cenozoicas depositadas en el sector oriental de la provincia de Santa Cruz durante la etapa de antepaís de la cuenca. Malumián (2002) dividió a los depósitos cenozoicos del sur de la provincia en cuatro ciclos de sedimentación y reconoció dos áreas de sedimentación, un sector oriental de plataforma afectado por varias transgresiones y un sector occidental cordillerano con espesas secuencias de antepaís. Las principales transgresiones, procedentes del océano Atlántico, que inundaron la Plataforma Patagónica ocurrieron durante el Maastrichtiano-Daniano, Eoceno Medio tardío, Oligoceno tardíoMioceno temprano y Mioceno medio (Malumián y Náñez, 2011). La transgresión del Oligoceno tardío-Mioceno temprano, se conoce con el nombre informal de transgresión «Patagoniense» o «Patagoniana»y, en la región costera del sur de la provincia de Santa Cruz, incluye los afloramientos que aparecen en los acantilados de la costa atlántica desde Puerto San Julián en el norte hasta la desembocadura del río Coyle en el sur. En la región occidental se reconocen afloramientos desde el Lago Posadas hasta Río Turbio (Fig. 2.1). 
En toda la región a partir del Mioceno temprano alto se instala el ciclo regresivo más importante de la cuenca, representado por las sedimentitas continentales de la Formación Santa Cruz que sobreyacen a los depósitos de marinos del Patagoniano.

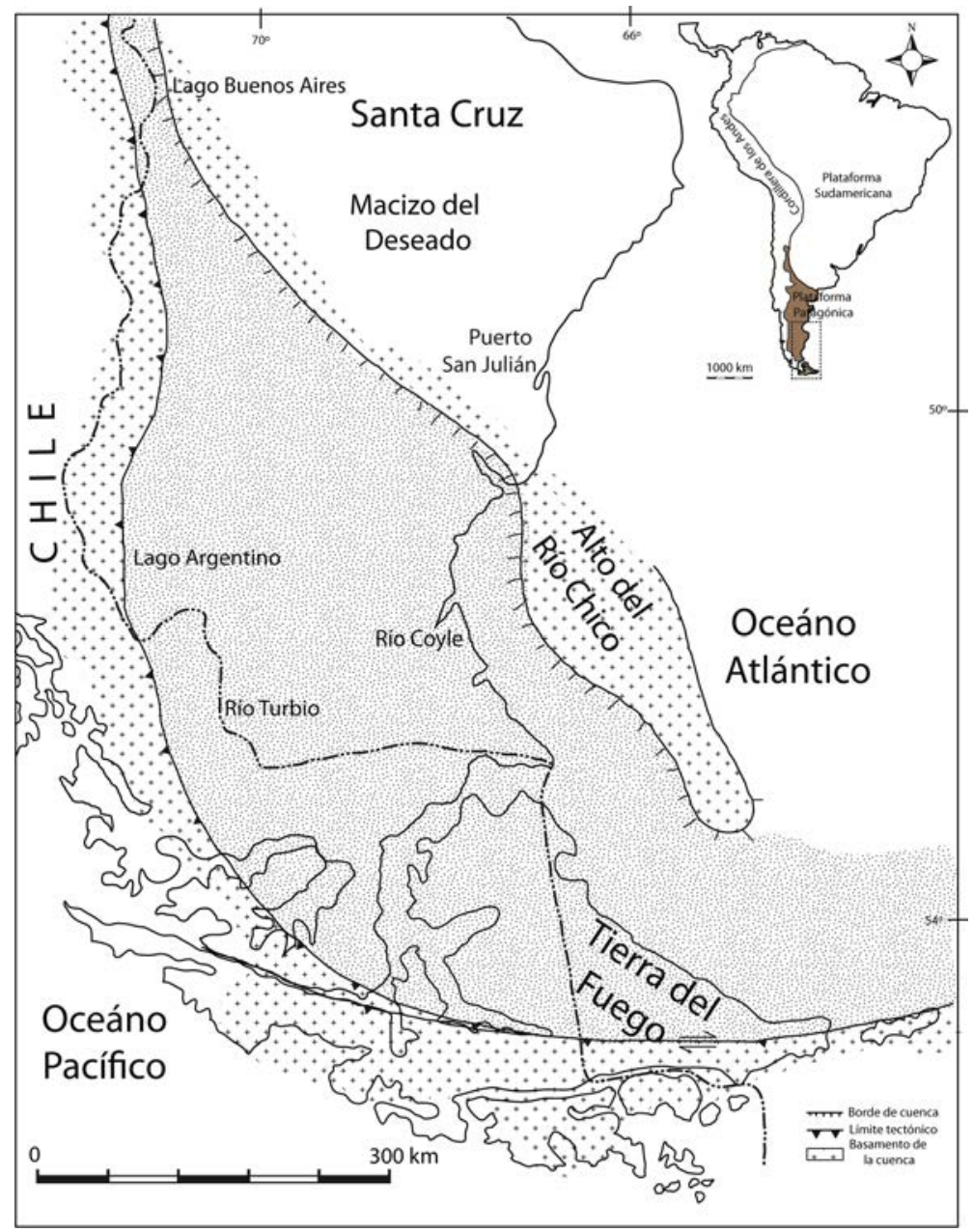

Figura 2.1. Localización la Cuenca Austral. Modificado de Pérez-Panera (2012).

\section{Trangresión del Patagoniano}

El Patagoniano o Patagoniense incluye al conjunto de sedimentitas que afloran en Patagonia, desde la provincia de Río Negro en el norte, hasta las provincias de Santa Cruz y Tierra del Fuego en el sur de Argentina, y también en el sur de Chile. Estas son el resultado de las transgresiones atlánticas acaecidas durante el Oligoceno tardío-Mioceno temprano (Malumián y Náñez, 2011; Cuitiño et al., 2012; Parras et al., 2012) (Fig. 2.2).

Malumián y Náñez (2011), a partir de asociaciones de foraminíferos, reconocen dos ambientes contrastantes en la mayoría de las transgresiones ocurridas durante el Cenozoico en Patagonia, incluyendo a la del Patagoniano: uno marino somero a marginal y otro turbidítico o marino profundo; este último reconocido particularmente en los Andes Fueguinos. La primera transgresión que se incluye en el Patagoniano es la del Oligoceno tardío, que fue somera y de extensión limitada. Durante este evento, la presencia de escasos foraminíferos miliólidos en la cuenca Austral sugiere condiciones hiposalinas (Malumián y Náñez, 2011). En la segunda transgresión, acaecida durante el Mioceno 
temprano, la asociación de foraminíferos refleja la entrada de aguas corrosivas antárticas, estando la etapa regresiva caracterizada por la presencia de rotálidos (Malumián y Náñez, 2011).

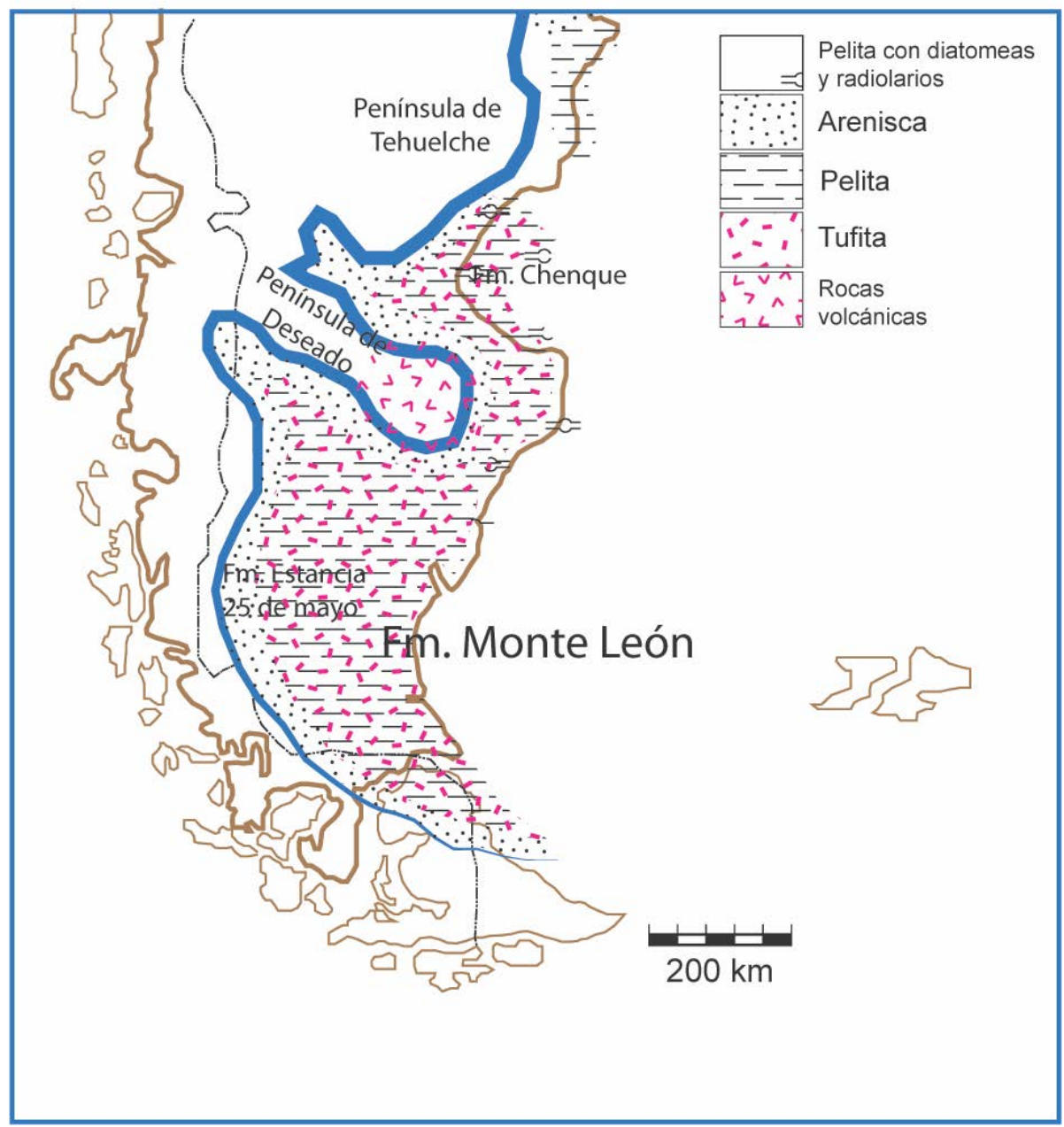

Figura 2.2. Área cubierta durante la mayor extensión de la transgresión del Patagoniense acaecida durante el Mioceno temprano. En azul se señala la línea de costa. En el registro sedimentario, esta transgresión está representada principalmente por depósitos tufáceos marino someross. Modificado de Malumián y Náñez (2011).

El significado de los términos Patagoniense y Patagoniano, así como la edad y la subdivisión estratigráfica de los depósitos involucrados, ha sido ampliamente debatido desde los estudios pioneros de d'Orbigny (1842) y Darwin (1846). Ameghino (1898) propuso el nombre de Formación Patagónica para los depósitos marinos cenozoicos más antiguos expuestos en la costa de Patagonia, subdividiendo a estos en los pisos Juliense y Leonese. Si bien el término "formación" de Ameghino tenía una significancia cronoestratigráfica, el mismo fue empleado como una unidad litoestratigráfica por varios autores en el siglo pasado. Esta mala interpretación del término empleado por Ameghino dio como resultado una compleja y confusa variedad de nombres en la literatura, que continúan siendo debatidos en la actualidad (Figs. 2.3, 2.4).

Las primeras descripciones de las rocas marinas del Cenozoico de Patagonia fueron publicadas por Alcide d'Orbigny, quien exploró el sur de Sudamérica entre 1826 y 1833. Sobre la base de sus observaciones, d'Orbigny (1842) denominó Tertiaire Patagonien a los 
depósitos de los acantilados costeros expuestos desde Carmen Patagones (Río Negro) hasta el estrecho de Magallanes. Posteriormente, Darwin (1846) realizó una descripción geológica de las rocas marinas cenozoicas expuestas en el sector costanero de Puerto San Julián y Puerto Santa Cruz y discutió las posibles condiciones paleoambientales en las que fueron depositadas, incluyendo a estos depósitos en su Great Patagonian Tertiary Formation o Patagonian Tertiary Formation.

Años más tarde, Carlos Ameghino recorrió el área de las rías de Coig y Santa Cruz (Ameghino, 1890) y recolectó fósiles de vertebrados e invertebrados que fueron estudiados posteriormente por su hermano Florentino y otros paleontólogos y malacólogos reconocidos. Sobre la base de las observaciones realizadas por Carlos Ameghino y el estudio de la fauna, Florentino Ameghino (1889) definió dos unidades: la "Formación Santacruzeña" y la "Formción Patagónica". A la primera la dividió en dos pisos: uno inferior, el piso Sub-Patagónico (=Superpatagónico, Ameghino, 1898), que reflejaba condiciones marinas; y uno superior, Santacruzeño, que reflejaba condiciones fluviales subaéreas. Por encima reconoció a la "Formación Patagónica", formada por depósitos marinos expuestos en la región costera. Mercerat (1893a, b, 1896) llamó a los depósitos marinos que afloraban en la costa desde Monte León a Coig y en los valles de los ríos Santa Cruz, Coyle y Gallegos Système Patagonique (=Formación Patagónica de Ameghino, 1889) y señaló que estos eran anteriores a su Système Santacruzien (=Formación Santacruzeña de Ameghino, 1889). Posteriormente, Ameghino (1898) ubicó correctamente a la Formación Santacruzeña por encima de la Formación Patagónica, a la cual a partir de ese año dividió en dos pisos: el "Juliense" aflorante en el Gran Bajo de San Julián, y el "Leonense" expuesto en Monte León y Puerto Santa Cruz.

La división efectuada por Ameghino $(1889,1898)$ fue muy criticada por Hatcher (1897, 1900), quien nombró Patagonian beds a los depósitos de origen marino que se extendían a lo largo de la costa atlántica, caracterizados por un contenido abundante de restos de invertebrados, considerándolos como una serie indivisible e indicando que los mismos no podían ser más antiguos que el Eoceno. Por encima de estos depósitos Hatcher (1897) identificó las Supra-Patagonian Beds y las Santa Cruz Beds, separadas por una discordancia que representaba un periodo de erosión entre ambas unidades. Hatcher (1900) revisó y enmendó su trabajo anterior y consideró que los pisos Juliense y Leonense de Ameghino (1898) no eran válidos, y que Patagonian Beds y Superpatagonian Beds no pertenecían a unidades distintas, sino que representan diferentes fases de una misma formación.

Después del extenso debate sobre la división estratigráfica del Patagoniano a través de las diferentes ideas de Ameghino $(1889,1898)$ y Hatcher $(1897,1900)$, Wilckens (1905) buscó unificar la terminología para referirse a estos sedimentos marinos y propuso la denominación "Molasa Patagónica" por la similitud litológica y de depositación que estos afloramientos tenían con la Molasa del Norte de los Alpes. Por su parte, Ihering (1907) agrupó a la Formación Patagónica y el piso Superpatagónico en su Superformation Panpatagonienne, considerando que estas unidades estaban relacionadas y que tenían cierto número de especies de moluscos en común. 


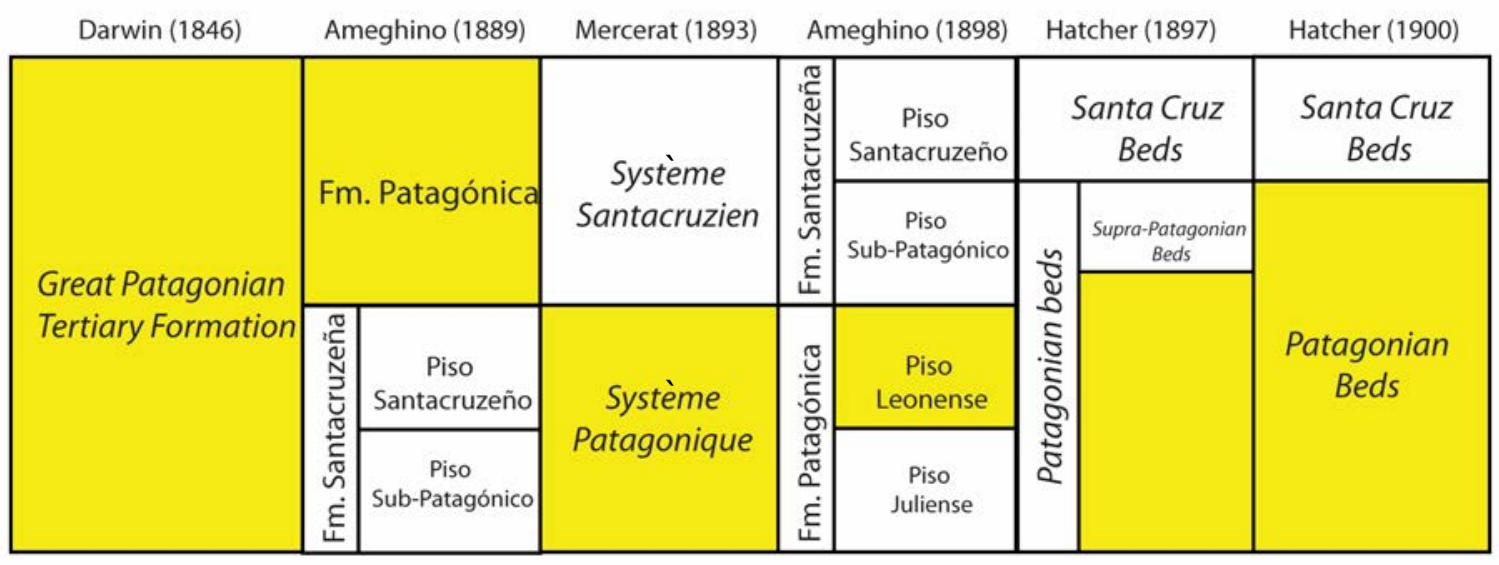

Figura 2.3. Nomenclatura empleada para referirse a los afloramientos patagonianos del sector oriental de la provincia de Santa Cruz, durante la segunda mitad del siglo XIX y hasta 1900. Las áreas en amarillo indican las unidades que incluyen sedimentitas de la actual Formación Monte León (Miembro Punta Entrada).

El término Patagoniense fue empleado por primera vez por Rovereto (1921) para referirse a las pelitas margosas de "edad leonense" que afloraban en Puerto Madryn y contenían Ostrea hatcheri. Feruglio (1949), quien sentó las bases de la estratigrafía de Patagonia, denominó Patagoniense a las capas marinas del Golfo de San Jorge y a las que se ubican entre la región del río Chico de Santa Cruz y el estrecho de Magallanes. A las capas marinas suprayacentes al Patagoniense, en el noreste de Patagonia, las denominó Entrerriense, y a las capas continentales suprayacentes al Patagoniense en Santa Cruz, Santacrucense. Incluyó en el Patagoniense a las sedimentitas aflorantes en el Golfo de San Jorge, el valle inferior del Río Chubut y Golfo Nuevo, la región de Nahuel Huapi y Río Foyel y en gran parte de la provincia de Santa Cruz. Asimismo, incluyó en esta unidad los pisos Juliense y Leonense de Ameghino (1898), agregando además el piso Superpatagoniense.

Bertels (1970) realizó un estudio detallado del Patagoniano en la provincia de Santa Cruz, dentro del cual definió formalmente dos unidades litoestratigráficas: la Formación San Julián y la Formación Monte León. Contemporáneamente, otros autores (e.g., Zambrano y Urien, 1970; Russo y Flores, 1972; Di Paola y Marchese, 1973; Riggi, 1978, 1979) se refirieron al Patagoniano en su conjunto como Formación Patagonia. Di Paola y Marchese (1973) dividieron a esta última unidad en tres miembros denominados de base a techo Miembro San Julián, Miembro Monte León y Miembro Monte Observación (=Superpatagoniense). Bertels (1977) dividió a la Formación San Julián en dos miembros, denominando al inferior Miembro Gran Bajo y al superior Miembro Meseta Chica. Para la Formación Monte León Bertels (1980) redefinió en la desembocadura del río Santa Cruz el Miembro Punta Entrada, incorporando también en la unidad formacional al Miembro Monte Observación definido previamente por Di Paola y Marchese (1973). 


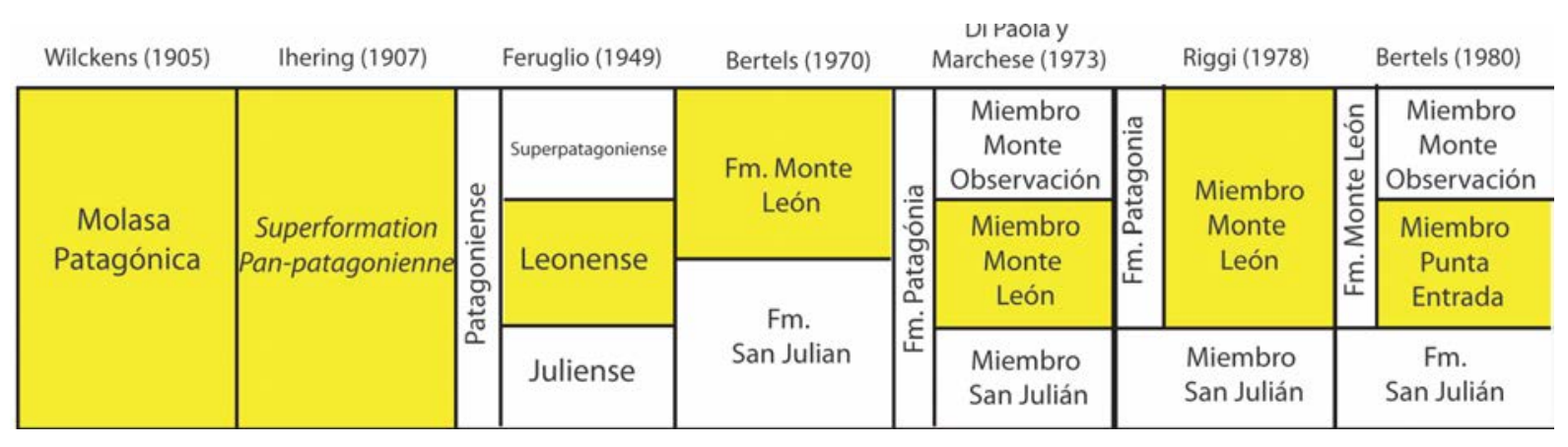

Figura 2.4. Nomenclatura empleada por algunos autores para referirse a los afloramientos Patagonianos del sector oriental de la provincia de Santa Cruz, durante el siglo XX. Las áreas en amarillo indican las unidades que incluyen sedimentitas de la actual Formación Monte León (Miembro Punta Entrada).

\section{Formación Monte León}

Bertels (1970) definió a la Formación Monte León en el área de la desembocadura del río Santa Cruz. La unidad se caracteriza por ser una sucesión de limolitas y areniscas amarillogrisáceo, con alto contenido de material piroclástico producto de la actividad volcánica que se presentó durante el desarrollo del Arco Andino. Entre estos sedimentos se intercalan estratos que contienen abundantes invertebrados fósiles, principalmente conchillas de moluscos con un excelente estado de preservación. El área tipo de la unidad la constituye la región costanera atlántica, entre la desembocadura del Río Santa Cruz y la Isla Monte León. Los mejores afloramientos se encuentran expuestos en el Gran Bajo de San Julián y en el área de Puerto San Julián y desde Monte Entrada hasta Rincón del Buque, en donde forman la restinga, para posteriormente desaparecer en el subsuelo en la ría de Coig.

Se han referido diversos espesores para la Formación Monte León. En el área de Puerto San Julián-Gran Bajo de San Julián, Panza et al. (1995) citaron un valor superior a los 200 m. En el área del Parque Nacional Monte León, Sacomani y Panza (2011) indicaron que los perfiles Cabeza de León y Cerro Monte León integrados tienen un espesor de aproximadamente $100 \mathrm{~m}$, aunque en los mismos no aflora la base de la unidad. En el pozo SC-1, en los alrededores de Puerto Coig, Malumián et al. (1971) atribuyeron a la formación $440 \mathrm{~m}$ de espesor.

La Formación Monte León yace en disconformidad sobre la Formación San Julián (Parras et al., 2012; Dix y Parras, 2014); esta última unidad está conformada litológicamente por sedimentos silicoclásticos y calcáreos de ambientes marino-marginales a marino someros de plataforma. Sobre la base de dataciones mediante isótopos de estroncio $\left({ }^{87} \mathrm{Sr} /{ }^{86} \mathrm{Sr}\right.$ ) sobre conchillas de moluscos, Parras et al. (2008) indicaron que su depositación se habría producido durante el Oligoceno tardío. Sobre la Formación Monte León se encuentra la Formación Santa Cruz con depósitos continentales, principalmente lacustres y fluviales. A partir de dataciones radiométricas y tefrocronología Perkins et al. (2012) determinaron una edad entre 17,7 y $16 \mathrm{Ma}$ (Mioceno temprano tardío). La Formación Monte León se correlaciona lateralmente con sedimentitas expuestas en el sector cordillerano de la cuenca Austral, contenidas en la Formación Estancia 25 de Mayo (Cuitiño y Scasso, 2010) en la zona de Lago Argentino, en la Formación El Chacay (Chiesa y Camacho, 1995) en el área de Lago Posadas y en la Formación Guadal (Niemeyer et al., 1984) en el área de Lago General Carreras en Chile. La Formación Monte León también se correlaciona en parte con 
la Formación Chenque (Bellosi, 1990) localizada al norte, en la cuenca del Golfo San Jorge (Fig. 2.5).

Respecto a la edad de la Formación Monte León, se realizaron diferentes propuestas a través de diferentes indicadores bioestratigráficos, así como dataciones mediante estratigrafía isotópica de Sr y edades absolutas (Fig. 2.5). Becker (1964), a partir de muestras de foraminíferos y ostrácodos recolectados en Las Cuevas y Monte Entrada, ubicó a las sedimentitas de la unidad en el Mioceno medio. Posteriormente Bertels (1970), al proponer los nombres litoestratigráficos formales de Formación San Julián y Formación Monte León, reconoció tres zonas de foraminíferos planctónicos, dos de las cuales, Globigerina ciperoensis-Globorotalia opima y Globigerina angulisuturalis, caracterizaban a la Formación Monte León y permitían correlacionarla con el piso Chattiano del Oligoceno tardío. Posteriormente, la misma autora (Bertels, 1980) reconoció tres zonas de foraminíferos planctónicos en el miembro Punta Entrada (Globigerina anguliofficinalis, G. ciperoensis y $G$. angulisuturalis) y sugirió que la edad de la formación podía correlacionarse con la parte superior del Piso Rupeliano y con el Piso Chattiano. Por su parte, diversos autores, también sobre la base de foraminíferos (Malumián y Náñez 1989, 1998, 2002, 2011; Caramés et al., 2004; Náñez et al., 2009), sugirieron que la unidad se habría depositado durante el Oligoceno tardío-Mioceno temprano o exclusivamente en el Mioceno temprano.

Los estudios de Barreda y Palamarczuk (2000a, b) realizados con granos de polen de angiospermas y quistes de dinoflagelados permitieron reconocer dos asociaciones informales en Monte León: C-T (Cyperaceapollis neogenicus y Tricolpites trioblatus) y G (Glencopollis ornatus), atribuidas al Mioceno temprano. Del Río (2004), en un análisis bioestratigráfico reconoció cinco conjuntos de moluscos a partir de la malacofauna recolectada en la costa de Patagonia, desde el río Santa Cruz, en la provincia de Santa Cruz, hasta Comodoro Rivadavia, en la provincia de Chubut. En los horizontes fosilíferos medios y superiores de la Formación Monte León identificó dos asociaciones: Reticulochlamys zinsmeisteri-Struthiolarella patagoniensis-Pleuromeris cruzensis (RSP) y Pseudoportlandia glabra-Antimelatoma quemadensis (PA) que restringirían la edad de la unidad al Mioceno temprano.

Las dataciones con argón $\left({ }^{40} \mathrm{Ar} /{ }^{39} \mathrm{Ar}\right)$ de tobas de la parte superior de la Formación Monte León y parte inferior de la Formación Santa Cruz realizadas por Bown y Fleagle (1993) y Fleagle et al. (1995) determinaron para una toba ubicada en el techo de la Formación Monte León una edad de 19,3 Ma. Recientemente, esta edad fue cuestionada por Perkins et al. (2012) quienes, basados en la tasa de acumulación sedimentaria y la correlación con otros niveles de toba datados mediante tefrocronología, consideraron una edad de aproximadamente 17,7 Ma para la toba anteriormente mencionada. Por su parte, Parras et al. (2012) realizaron una serie de mediciones de ${ }^{87} \mathrm{Sr} / 86 \mathrm{Sr}$ sobre macrofósiles calcíticos ("Ostrea" hatcheri, Reticulochlamys proxima (Ihering, 1897), Jorgechlamys centralis (Sowerby, 1846), Nodipecten sp. y Pachymagas sp.) recolectados en la Formación Monte León, obteniendo una edad de entre 22 y 18 millones de años (=Mioceno temprano, pisos Aquitaniano y Burdigaliano) para la unidad. De modo que la edad para el techo de la Formación Monte León estimada por Perkins et al. (2012) quedó confirmada, restringiendo la edad de esta unidad al Mioceno temprano. 


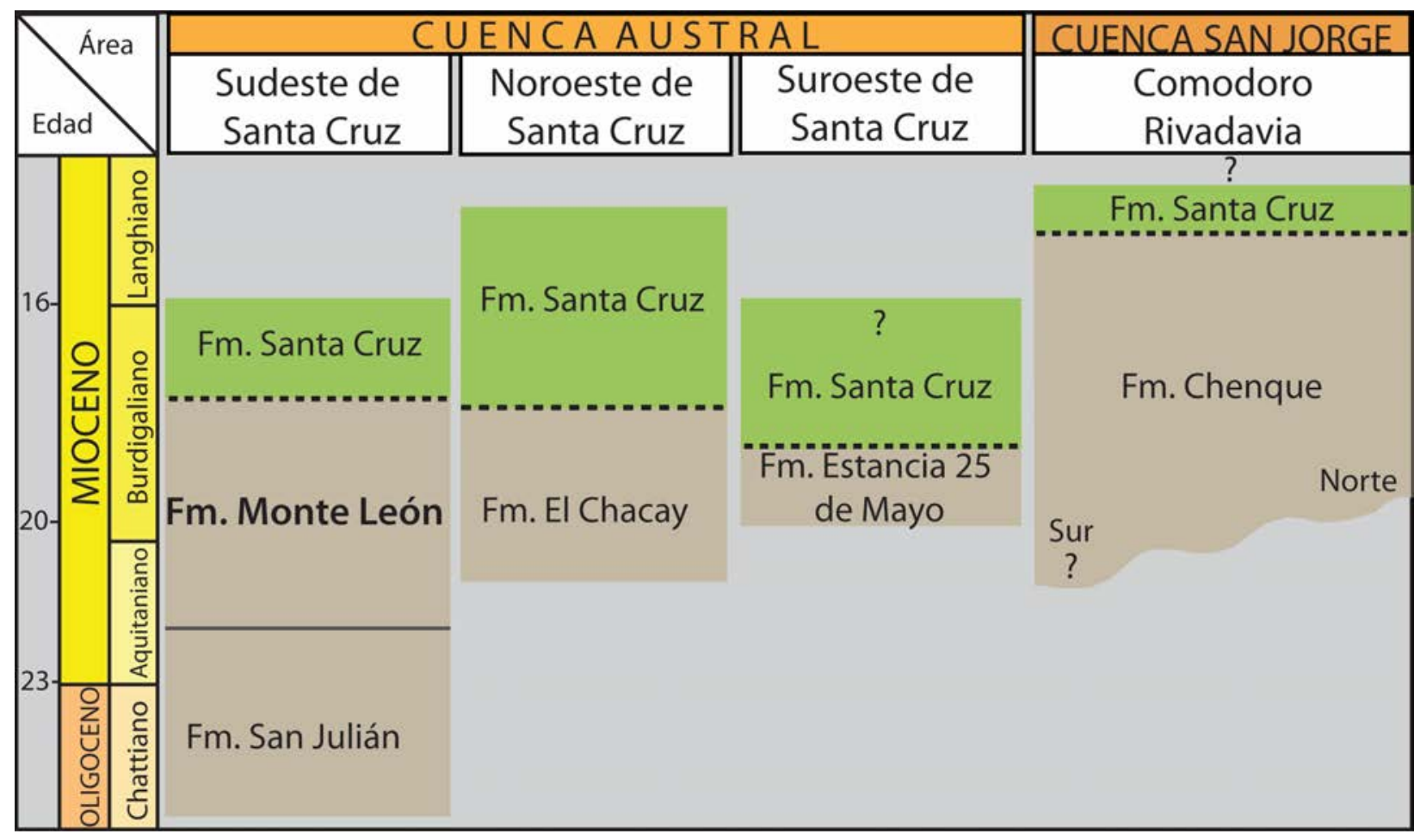

Figura 2.5. Cuadro Cronoestratigráfico para el Oligoceno tardío-Mioceno temprano en el sur de Patagonia. Las áreas en color marrón corresponden a unidades de ambientes marinos y marinomarginales, mientras que las verdes a continentales. Las áreas en color gris representan hiatos. Modificado de Cuitiño et al. (2015).

Con relación al ambiente de depósito de la unidad, Bertels (1980) consideró que la Formación Monte León se depositó en un ambiente de plataforma externa. Hacia el techo se presentan condiciones de depósito más someras que terminan en un ambiente pantanoso y de marismas costeras (Barreda y Palamarczuck, 2000a; Panza et al., 1995). Parras y Griffin (2009) mediante un análisis sedimentológico y paleontológico de los afloramientos de la Formación Monte León cerca de la boca del Río Santa Cruz, en la Sección de Darwin, sugieren un ambiente de depósito de plataforma interna a submareal e incluso intermareal hacia el sector cuspidal de la unidad.

En cuanto al contenido paleontológico de la Formación Monte León, esta se caracteriza por la abundancia de moluscos bien preservados; sin embargo, también destaca la presencia de braquiópodos, briozoos, crustáceos, balánidos y restos de equinodermos. La malacofauna de la Formación Monte León ha sido ampliamente estudiada desde que Sowerby (1846) describió el material recolectado por Chales Darwin. Los horizontes con mayor contenido paleontológico se encuentran en los tramos medio y superior de la unidad, en la boca del Río Santa Cruz (Monte Entrada, Punta Quilla, Cañadón de los Misioneros y Estancia los Manantiales) y al sur de la misma en las localidades Cabeza de León, Las Cuevas y Yegua Quemada (Olivera, 1990, del Río, 2002, 2004; Griffin y Nielsen, 2008; Parras y Griffin, 2009, Urteaga et al., 2011; Griffin y Pastorino, 2012, entre otros). Los grupos de bivalvos más comunes son árcidos, nucúlidos, ostreídos y venéridos; los gasterópodos registran una mayor diversidad con respecto a la Formación San Julián (del Río, 2002). 


\section{Capítulo 3}

La realidad trabaja con mucha rapidez

-Haruki Murakami

Crónica del pájaro que da cuerda al mundo 


\section{Análisis tafonómico}

\section{Introducción}

En este capítulo se presentan los resultados del análisis realizado para cada una de las concentraciones reconocidas en la Sección Cabeza de León. En métodos se detallan las características y los criterios considerados para describir las concentraciones en campo y las muestras volumétricas de las mismas en laboratorio. Los resultados se presentan de manera separada para cada concentración y, a su vez, se separan en caracterización en campo y caracterización en laboratorio. A continuación se muestran los resultados resumidos en tablas y gráficos necesarios para cumplir los objetivos de la tesis ( $\mathrm{V}$. Capítulo 1); en el Apéndice I se incluyen gráficos adicionales que soportan la información aquí presentada; en el Apéndice II se incluyen un listado de los taxones reconocidos. Los datos y tablas originales pueden consultarse en línea de manera permanente. Enseguida se presenta una interpretación general y clasificación de las concentraciones realizadas a partir de las características sedimentológicas, estratigráficas paleontológicas y tafonómicas predominantes en cada concentración. Este capítulo cierra con una discusión sobre el origen de las concentraciones estudiadas.

\section{Métodos}

\section{Trabajo de campo}

Las concentraciones fósiles de Cabeza de León fueron caracterizadas en campo de manera descriptiva y semicuantitativa, siguiendo los criterios propuestos por Kidwell et al. (1986), Kidwell y Holland (1991) y Kidwell (1991), que contemplan diversas características sedimentológicas, estratigráficas paleontológicas y tafonómicas. Estas características se observaron en cuadros de 50 × $50 \mathrm{~cm}$. Las características semicuantitativas fueron tomadas de los bioclastos que estaban incluidos en estos cuadros $(n \leqq 30)$, las cualitativas fueron tomadas en estos cuadros pero, adicionalmente fueron complementadas con observaciones realizadas a lo largo de cada concentración.

Las características sedimentológicas consideradas fueron el tipo de matriz, el empaquetamiento, la selección, la presencia de estructuras sedimentarias y la orientación. En el tipo de matriz se consideró el tamaño de grano del sedimento siendo caracterizado como arcilla, limo, arena (fina, mediana y gruesa) y grava. El empaquetamiento se evaluó de manera semicuantitativa siguiendo el criterio de Kidwell y Holland (1991), siendo (1) denso, cuando es bioclasto sostenido con cemento o partículas finas en los espacios intersticiales; (2) suelto, cuando es matriz sostenido pero los bioclastos están cercanos entre si; y (3) dispersos, cuando es matriz sostenido y la distancia entre los bioclastos es mayor que la longitud o el diámetro de éstos (Fig. 3.1).

Los criterios de selección de tamaño considerados, también de Kidwell y Holland (1991), fueron: (1) bien seleccionado, cuando los depósitos exhiben poca variación en el talle de los bioclastos y el $80 \%$ de éstos están incluidos en una o dos categorías de tamaño 
adyacentes; (2) bimodal, cuando los depósitos están bien seleccionados pero tienen una segunda moda distintiva; y (3) mal seleccionado, cuando se observa gran variación en el talle de los bioclastos, y el $80 \%$ de estos están incluidos en tres o más clases adyacentes.

Como presencia de estructuras sedimentarias se consideraron las inorgánicas y las orgánicas (trazas). Se prestó particular atención a la gradación, es decir el acomodamiento de las conchillas en la concentración, v.g. si era grano-creciente (gradación directa) o grano-decreciente (gradación inversa) a lo largo de la misma o si las conchillas se concentraban de manera particular en sus contactos.

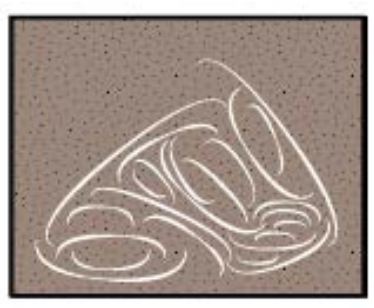

Denso

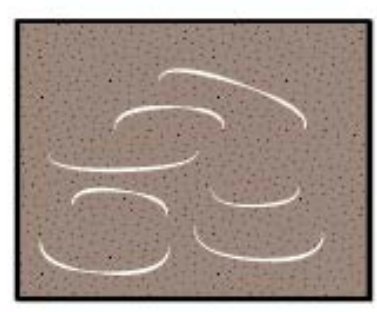

Suelto

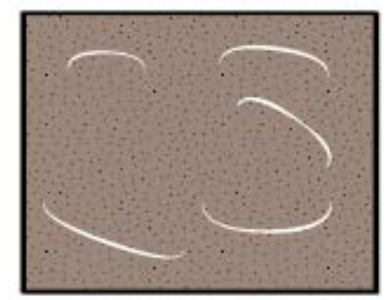

Disperso

Figura 3.1. Ilustración sistemática de las categorías de empaquetamiento consideradas. Modificada de Kidwell y Holland (1991).

La orientación (Fig. 3.2) se determinó cualitativa y cuantitativamente, siguiendo el criterio de Kidwell et al. (1986), en aquellas concentraciones en las que se exponía la vista en planta y fue referida como unimodal o bimodal; de manera cuantitativa se midió la orientación de los bioclastos, considerando como referencia el ápice en los gasterópodos de espira alta y el umbo en los bivalvos. La orientación en vista transversal fue definida como concordante, perpendicular u oblicua, especificando además el tipo de agrupamiento como imbricado, de canto, apilado, anidado o telescopado.

Las características estratigráficas que se consideraron fueron espesor, geometría, complejidad interna y tipo de contactos. La geometría se describió considerando el plano en el cual era posible observar cada concentración; en planta fueron referidas como pavimento o planchas. Cuando el espesor de la concentración fue mayor a la longitud (o diámetro) de uno o dos bioclastos la geometría fue referida como capa, cuña, lente, masiva, vaina y relleno de fisura (Fig. 3.3). Los tipos de contacto se observaron a lo largo de la concentración y se definieron en la base, en el techo y lateralmente. Finalmente, la complejidad de la concentración se definió como simple o compleja.

Las características paleontológicas consideradas fueron: composición taxonómica, número de taxones, hábitos de vida, espectro de edad, mineralogía original y mineralogía preservada de la conchilla. La composición taxonómica fue caracterizada como (1) monotípica o (2) politípica. El número de taxones fue cuantificado a partir de los que se reconocieron a nivel de familia o género.

Para el hábito de vida de los taxones reconocidos se consideraron las categorías (1) infaunal y (2) epifaunal, siguiendo el criterio de Best y Kidwell (2000a). De guisa que, los 
hábitos infaunales sifonados y asifonados son referidos como 1 (infaunales) y los hábitos anidados en sustratos no consolidados, cavadores de sustratos arenosos y seminfaunales son referidos en las bases de datos como 2 (epifaunales) (V. Apéndice II). El espectro de edad se determinó de manera cualitativa considerando la dominancia de (1) juveniles y (2) adultos. La mineralogía original fue registrada como (1) calcítica, (2) aragonítica y (3) otra; la mineralogía preservada como (1) original y (2) reemplazada o recristalizada.

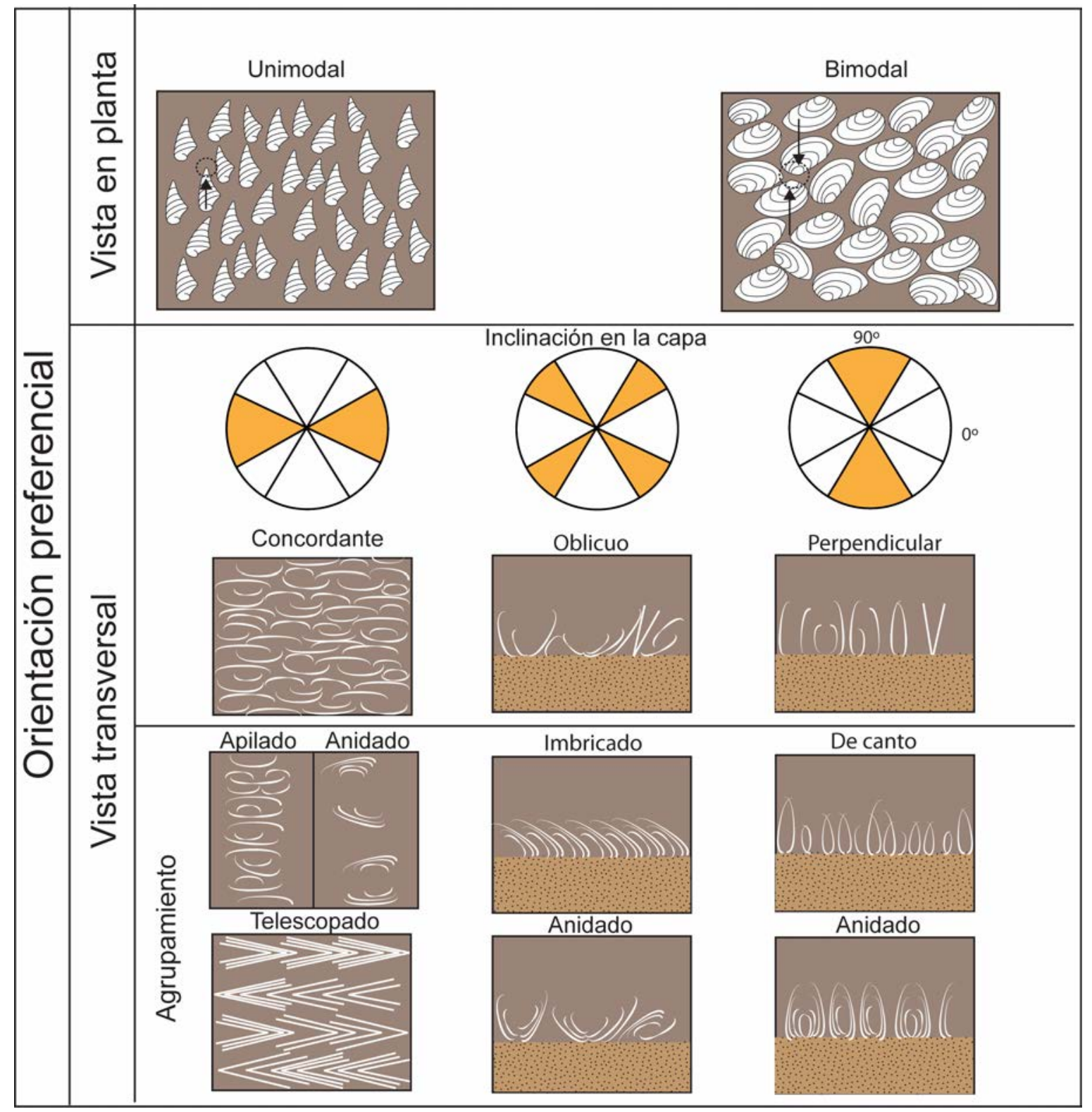

Figura 3.2. Conjunto de términos empleados para describir la orientación de los bioclastos; en la vista en planta se midió la orientación del ápice y del umbo (círculo discontinuo y flecha) para determinar la orientación preferencial de los bioclastos. Modificado de Kidwell et al. (1986).

Los características tafonómicas considerados fueron: fragmentación (F), alteración superficial (AS), modificación de bordes (MB), redondeamiento (R), bioerosión (B) y articulación (A). Primero se realizó una caracterización cualitativa y posteriormente una cuantitativa de los bioclastos incluidos en cada cuadro. La fragmentación se estableció considerando la proporción de la conchilla preservada, siendo (1) completa, cuando se 
preserva más del $70 \%$ de la conchilla; (2) incompleta, cuando se preserva una proporción entre el 69 y el $40 \%$; y (3) fragmentos, cuando se preserva menos del $40 \%$ de la conchilla.

El término alteración superficial se utiliza en esta tesis para referirse a la modificación producida por abrasión y disolución, caracterizándola como (1) baja, para especímenes con ornamentación bien preservada o apariencia lustrosa; (2) moderada, para aquellos especímenes cuya ornamentación muestra desgaste o apariencia porcelanosa y; (3) alta, para especímenes que presentan orificios por disolución, apariencia cretosa o tipo chalky o cuya ornamentación se ha perdido completamente. Este atributo sólo fue observado en la superficie externa de las conchillas. El redondeamiento, que considera los márgenes producto de fragmentación, se caracterizó como (1) ausente, cuando no hay evidencias de fragmentación; (2) aguzado y; (3) redondeado. Adicionalmente, en bivalvos se observó la modificación de bordes considerando la preservación del margen ventral siendo (1) continuo; (2) discontinuo y; (3) ausente, cuando este no se preservaba.

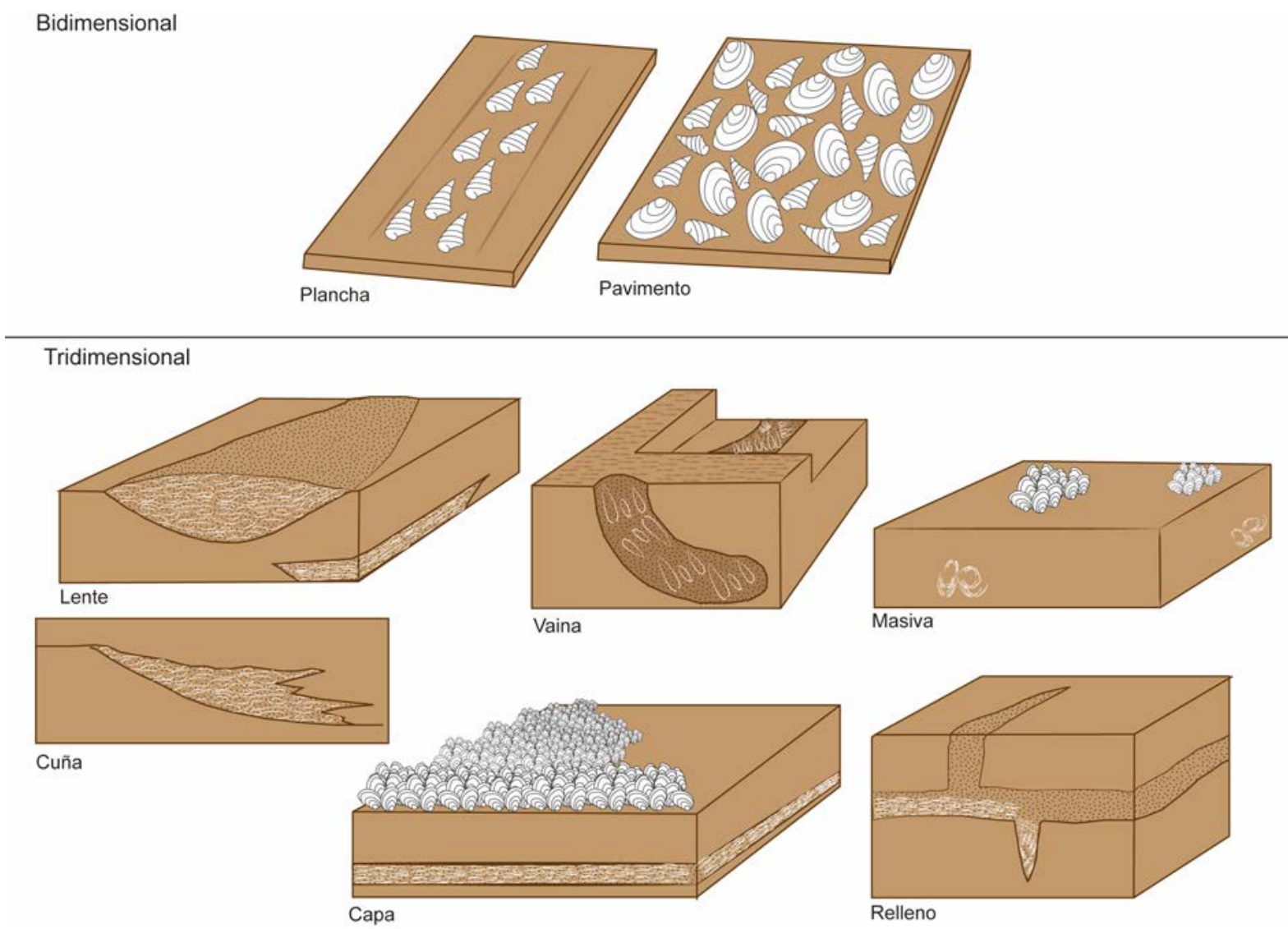

Figura 3.3. Conjunto de términos empleados para describir la geometría de las concentraciones fósiles. Modificado de Kidwell et al. (1986).

La bioerosión fue cuantificada como baja, moderada y alta según el porcentaje de la superficie interna y externa de la conchilla que fue afectado siendo (1) baja, cuando la superficie bioerodada es menor al 30\%; (2) moderada, cuando la superficie bioerodada es de entre el $31 \%$ y el $60 \%$ y; (3) alta, cuando más del $61 \%$ de la superficie presenta bioerosión. Finalmente, para la articulación se siguió el criterio de Davies et al. (1989): (1) articuladas, cuando las valvas están unidas en la región del umbo; (2) separadas, cuando 
las valvas están juntas pero ya no están unidas en el umbo y (3) desarticuladas, cuando solo se conserva una de las valvas.

Las observaciones de campo se consignaron en grillas y posteriormente los datos se vaciaron en hojas de cálculo del procesador Numbers para ser graficados (V. siguiente apartado).Cuando algún atributo no pudo ser observado en la concentración se señaló en la grilla con el acrónimo NV «no visible».

\section{Trabajo de gabinete y tratamiento de datos}

En cada submuestra estandarizada (V. Capítulo 1 §Métodos generales §Trabajo de laboratorio) se reconocieron nuevamente las características paleontológicas y tafonómicas de los bioclastos siguiendo los mismos criterios definidos en el apartado anterior. En las características paleontológicas, el número de taxones se obtuvo a partir de la determinación de los bioclastos a nivel de género o familia, aquellos que no pudieron determinarse fueron registrados como indeterminados (Indet.). En las características tafonómicas la articulación no fue considerada, ya que gran parte de los bivalvos mostraron desarticulación después de haber sido procesados; en las observaciones de las bases de datos se señalan los especímenes articulados.

Se elaboró una base de datos para cada submuestra y para cada una de las concentraciones estudiadas; los atributos tafonómicos fueron graficados con la finalidad de conocer el porcentaje relativo de los diferentes índices en cada submuestra y en cada uno de los tamices utilizados ( $\underline{V}$. Apéndice $\mathrm{I})$. Asimismo, a fin de resumir la información, se confeccionaron tablas donde se indica cual es el índice predominante para cada caso; considerándose como predominante cuando la diferencia con el segundo índice más abundante es mayor al $10 \%$. Lo anterior se realizó también para los taxones más abundantes y para los hábitos de vida en cada concentración y en cada submuestra. Además, se graficaron los atributos tafonómicos en relación con la fragmentación $(\mathrm{V}$. Apéndice I) de manera que se graficó de manera separada alteración superficial, modificación de bordes, redondeamiento y bioerosión para las conchillas (1) completas, (2) incompletas y (3) fragmentos. En todos los gráficos y tablas de este capítulo así como en el Apéndice I, los índices tafonómicos se representaron con los siguientes colores: 1.-azul, 2.verde, 3.-amarillo y para el acrónimo NV se utilizó violeta. 


\section{Resultados}

\section{Concentración 1 (C1)}

\section{Caracterización en campo}

a) Características sedimentológicas y estratigráficas: Concentración de aproximadamente $40 \mathrm{~cm}$ de espesor con geometría de capa, con vainas en la base que miden $20-24 \mathrm{~cm}$ de largo, $10-15 \mathrm{~cm}$ de ancho en la parte distal y $16-22 \mathrm{~cm}$ de ancho en la proximal (Fig. 3.4a, b); matriz de arena fina; empaquetamiento denso y selección bimodal (Fig 3.4c, d, e). Los contactos fueron del tipo ondulado/bioturbado en la base y ondulado en el techo. Los bioclastos mostraban una orientación preferencial concordante (Fig. 3.4c), con agrupamiento apilado (Fig. 3.4c, d). Sobre la base de las observaciones a lo largo de la concentración y el estudio semicuantitativo en ocho cuadros se considera la estructura interna de C1 como simple (sensu Kidwell et al., 1986).

b) Características paleontológicas: En esta concentración predominaban moluscos, gasterópodos y bivalvos. Se reconocieron 19 taxones, 14 géneros y 5 familias, algunos bioclastos fueron reconocidos únicamente a nivel de clase y tres no pudieron ser reconocidos (Tabla 3.1, V. Apéndice II). Predominaron las conchillas de Turritella, seguida de Xymenella y Solariella, de guisa que se consideró una concentración de composición taxonómica pauciespecífica. Con respecto al hábito de vida de los elementos que conforman la concentración, predominaban aquellos de hábitos epifaunales (V. Métodos y Apéndice II) y el espectro de edad que se observó fue mixto, mas predominaron adultos. Los elementos de la concentración fueron en su mayoría de composición aragonítica y la proporción de bioclastos con mineralogía original y con reemplazo fue similar.

Tabla 3.1. Riqueza de C1 en campo.

\begin{tabular}{|c|c|c|c|c|c|}
\hline Taxón & $\mathbf{n}$ & Taxón & $\mathbf{n}$ & Taxón & $\mathbf{n}$ \\
\hline Turritella & 74 & Panopea & 3 & Naticidae & 9 \\
\hline Xymenella & 11 & Maorimactra & 2 & Mactridae & 5 \\
\hline Solariella & 10 & Cardita & 1 & Eulimidae & 4 \\
\hline Kaitoa & 6 & Fusiguraleus & 1 & Pectinidae & 1 \\
\hline Pleuromeris & 5 & Phorcus & 1 & Trochidae & 1 \\
\hline Dosinia & 4 & Seila & 1 & Indet. & 21 \\
\hline Cylichnania & 3 & Tenuiacteon & 1 & $\mathbf{n}$ & 164 \\
\hline
\end{tabular}

c) Características tafonómicas: La preservación de los bioclastos fue moderada (Tabla. 3.2, Apéndice I §Fig. 1). Predominaron conchillas incompletas (2, 58\%) con alteración superficial de moderada a alta (2, 40\%; 3, 44\%); los márgenes fragmentados mostraron redondeamiento $(3,61 \%)$ y la bioerosión fue baja $(1,63 \%)$. Predominaron trazas producidas por briozoos (Pennatichnus, Finichnus y Pinaceocladichnus), poliquetos 
(Maeandropolydora) y gasterópodos (Oichnus). En bivalvos, entre los preservados, predominaron márgenes ventrales continuos $(1,36 \%)$ y valvas desarticuladas $(3,58 \%)$.

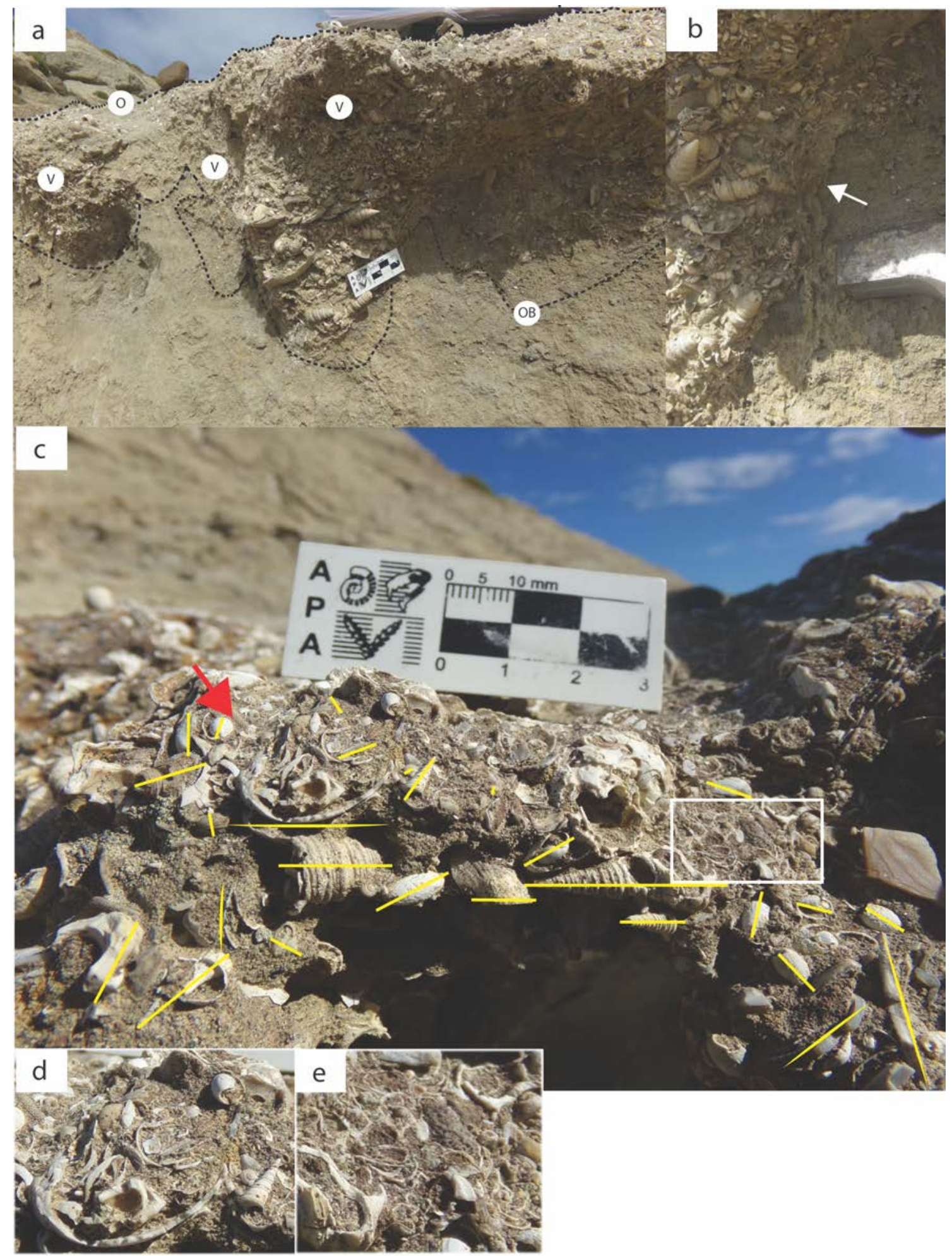

Figura 3.4. Características sedimentológicas y estratigráficas de C1. a) Geometría de capa con contacto ondulado bioturbado $(\mathrm{OB})$ en la base y vainas (V); en el techo el contacto es ondulado (O). b) Detalle del contacto ondulado bioturbado de la base. c) Empaquetamiento denso (rectángulo blanco, acercamiento en e), orientación predominante concordante al plano de estratificación (líneas amarillas) y agrupamiento apilado (flecha roja, acercamiento en d). d) Detalle del la orientación y el agrupamiento. e) Detalle del empaquetamiento. 
Las características tafonómicas observadas en cada uno los ocho cuadros muestran índices de fragmentación, alteración superficial, modificación bordes y bioerosión similares. La modificación de bordes y la articulación varían a lo largo de los cuadros 1-6, en los cuadros 7 y 8 no se tiene registro de estos atributos debido a la escasa presencia de bivalvos (Tabla 3.2, Apéndice I §Fig. 1).

Tabla 3.2. Características Tafonómicas de C1 en campo en donde se señala la categoría predominante de cada atributo. Fragmentación (F): (1) completo, (2) incompleto, (3) fragmento. Alteración superficial (AS): (1) baja, (2) moderada, (3) alta. Modificación de bordes (MB): (1) continuo, (2) discontinuo, (3) ausente. Redondeamiento (R): (1) ausente, (2) aguzado, (3) redondeado. Bioerosión (B): (1) baja, (2) moderada, (3) alta. Articulación (A): (1) articulado, (2) separado, (3) desarticulado. 1, azul; 2, verde; 3, amarillo; NV (no visible), violeta. Los gráficos de cada cuadrante se encuentran en el Apéndice I, Fig. 1.

\begin{tabular}{|r|r|r|r|r|r|r|}
\hline Cuadro & Fragmentación & \multicolumn{1}{|c|}{ AS } & MB & Redondeamiento & Bioerosión & Articulación \\
\hline 1 & 1 & 3 & 1 & 3 & 1 & 3 \\
\hline 2 & 2 & $2-3$ & 1 & 3 & 1 & 3 \\
\hline 3 & 2 & $2-3$ & $1-3$ & 3 & 1 & 1 \\
\hline 4 & 2 & 3 & 2 & 3 & 1 & 3 \\
\hline 5 & 2 & $2-3$ & $N V$ & 3 & 1 & $1-3$ \\
\hline 6 & 2 & $2-3$ & $3-N V$ & 3 & 1 & 3 \\
\hline 7 & $1-2$ & 2 & 3 & 1 & \\
\hline 8 & 2 & 2 & 3 & 3 & $\mathbf{3}$ \\
\hline C1 & 2 & $\mathbf{2 - 3}$ & $\mathbf{1 - 2}$ & $\mathbf{3}$ & $\mathbf{1}$ & \\
\hline
\end{tabular}

\section{Caracterización de submuestras en laboratorio}

a) Características paleontológicas: En la submuestra 1a predominaron moluscos. Se obtuvieron 778 ejemplares designados en 41 géneros. Los más abundantes fueron Turritella y Solariella con $n>100$, seguidos de Maorimactra, Kaitoa y Cylichnania; para el resto de los géneros su $\mathrm{n}$ fue menor a 20. Dieciséis especímenes fueron determinados en tres familias y 93 no pudieron ser determinados (Tabla 3.3). En relación con los hábitos de vida, más del $80,2 \%$ de los especímenes se asocian a hábitos de vida epifaunales, el resto a infaunales (V. Apéndice II).

Tabla 3.3. Riqueza en C1 submuestra 1a.

\begin{tabular}{|c|c|c|c|c|c|c|c|}
\hline Taxón & $\mathbf{n}$ & Taxón & $\mathbf{n}$ & Taxón & $\mathbf{n}$ & Taxón & $\mathbf{n}$ \\
\hline Turritella & 164 & Scalpomactra & 7 & Neoguraleus & 2 & Serratina & 1 \\
\hline Solariella & 121 & Fusiguraleus & 5 & Phorcus & 2 & Splendrillia & 1 \\
\hline Maorimactra & 95 & Odostomia & 5 & Capulus & 4 & Tenuiacteon & 1 \\
\hline Kaitoa & 87 & Pyramidella & 4 & Cirsonella & 1 & Trichotropis & 1 \\
\hline Cylichnania & 58 & Retizafra & 4 & Cosa & 1 & Urosalpinx & 1 \\
\hline
\end{tabular}




\begin{tabular}{|c|c|c|c|c|c|c|c|}
\hline Taxón & $\mathbf{n}$ & Taxón & $\mathbf{n}$ & Taxón & $\mathbf{n}$ & Taxón & $\mathbf{n}$ \\
\hline Polinices & 16 & Acteon & 3 & Dosinia & 1 & Naticidae & 11 \\
\hline Xymenella & 15 & Brocchia & 3 & Ennuncula & 1 & Galommatidae & 2 \\
\hline Pleuromeris & 14 & Calyptraea & 3 & Epitonium & 1 & Columbellidae & 3 \\
\hline Cardita & 11 & Oamaruia & 3 & Marinula & 1 & Indet. & 93 \\
\hline Hima & 9 & Seila & 3 & Perissodonta & 1 & $\mathbf{n}$ & 781 \\
\hline Anachis & 8 & Caryocorbula & 2 & Pteromyrtea & 1 & & \\
\hline Diplodonta & 8 & Mysella & 2 & Saxicava & 1 & & \\
\hline
\end{tabular}

Al igual que en la submuestra anterior, en $1 \mathrm{~b}$ predominaron fósiles de moluscos, se obtuvieron 981 especímenes que fueron asignados a 41 géneros. Los más abundantes fueron Turritella y Solariella con $n>100$ seguidos de Kaitoa, Maorimactra y Cylichnania; el resto de los taxones tuvieron un $n<30$. Veintinueve especímenes fueron designados en seis familias, Naticidae fue más abundante $(n=20)$, y 164 no pudieron ser determinados (Tabla 3.4). Más del $70 \%$ de los taxones reconocidos son epifaunales (V. Apéndice II).

Tabla 3.4. Riqueza en C1 submuestra $1 \mathrm{~b}$.

\begin{tabular}{|c|c|c|c|c|c|c|c|}
\hline Taxón & $\mathbf{n}$ & Taxón & $\mathbf{n}$ & Taxón & $\mathbf{n}$ & Taxón & $\mathbf{n}$ \\
\hline Turritella & 250 & Diplodonta & 6 & Cirsonella & 2 & Pododesmus & 1 \\
\hline Solariella & 129 & Fusiguraleus & 6 & Hima & 2 & Serratina & 1 \\
\hline Kaitoa & 92 & Phorcus & 6 & Kellia? & 2 & Splendrillia & 1 \\
\hline Maorimactra & 87 & Oamaruia & 4 & Neoguraleus & 2 & Tornatellaea & 1 \\
\hline Cylichnania & 75 & Urosalpinx & 4 & Pyramidella & 2 & Triploca & 1 \\
\hline Pleuromeris & 23 & Acteon & 3 & Tenuiacteon & 2 & Naticidae & 20 \\
\hline Xymenella & 23 & Brocchia & 3 & Trichotropis & 2 & Ellobiidae & 4 \\
\hline Scalpomactra & 13 & Montacutinae & 3 & Anachis & 1 & Lucinidae & 2 \\
\hline Odostomia & 8 & Seila & 3 & Cyanium & 1 & Columbellidae & 1 \\
\hline Retizafra & 7 & Zeadmate & 3 & Dosinia & 1 & Trochidae & 1 \\
\hline Cardita & 6 & Ataxocerithium & 2 & Epitonium & 1 & Veneridae & 1 \\
\hline \multirow[t]{2}{*}{ Aligena } & 6 & Calyptraea & 2 & Mysella & 1 & Indet. & 164 \\
\hline & & & & & & $\mathbf{n}$ & 981 \\
\hline
\end{tabular}

Como fauna acompañante, en las dos submuestras se reconocieron fragmentos de briozoos y placas desarticuladas de balanos, las cuales se encuentran completas en la mayoría de los casos, con evidencias de disolución. La bioerosión que se observó en éstas fue baja y está representada en su mayoría por trazas de depredación. En menor proporción se encontraron restos de equinoideos, representados por espinas de aspecto pulido, algunas de las cuales aún poseían el pedicelario; sin embargo también se encontraron pedicelarios sueltos, con aspecto porcelanoso y redondeados. Finalmente, se encontraron tubérculos primarios con superficie alterada y bordes redondeados. 
b) Características tafonómicas: Las conchillas de C1 muestran una preservación general moderada (Fig. 3.5). El $49 \%$ de las conchillas se preservaron incompletas (2) y la alteración superficial fue de moderada a alta (2, 50\%; 3, 43\%); predominaron los bioclastos redondeados $(3,56 \%)$ y la bioerosión fue considerablemente baja $(1,91 \%)$. En bivalvos, entre los preservados predominaron bordes continuos $(1,34 \%)$. Las características tafonómicas de las submuestras 1a y $1 \mathrm{~b}$ fueron similares (Fig. 3.5); en ambas predominaron conchillas incompletas (2) con la alteración superficial de moderada a alta (2-3) y redondeamiento (3); la bioerosión fue baja (1) en el $90 \%$ de los bioclastos de ambas muestras. En los bivalvos, entre los preservados, predominaron valvas con bordes continuos $(1,39 \%)$ mientras que en $1 \mathrm{~b}$ la proporción de continuos y discontinuos fue similar $(1-2, \approx 30 \%)$. Al determinar los atributos tafonómicos de las conchillas retenidas en cada uno los tamices utilizados ( $\mathrm{V}$. Métodos) se observaron algunas variaciones en su

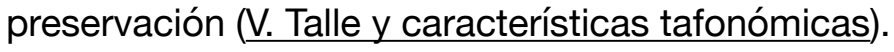
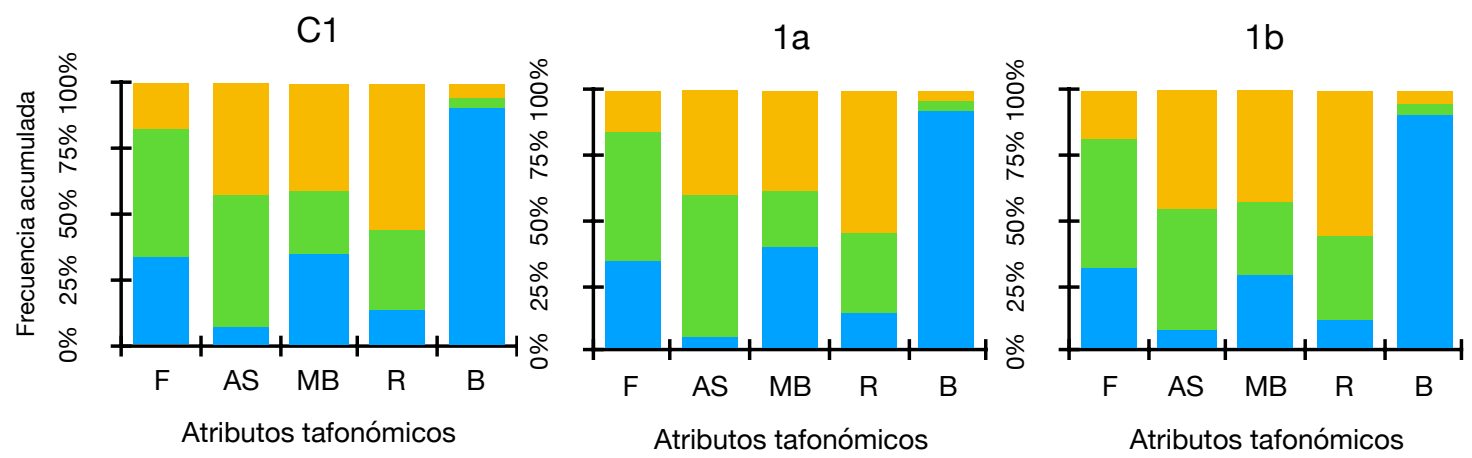

Figura 3.5. Frecuencia acumulada de los atributos tafonómicos observados en $\mathrm{C} 1$, y en las submuestras 1a y 1b. Fragmentación (F): (1) completo, (2) incompleto, (3) fragmento. Alteración superficial (AS): (1) baja, (2) moderada, (3) alta. Modificación de bordes (MB): (1) continuo, (2) discontinuo, (3) ausente. Redondeamiento (R): (1) ausente, (2) aguzado, (3) redondeado. Bioerosión (B): (1) baja, (2) moderada, (3) alta. Articulación (A): (1) articulado, (2) separado, (3) desarticulado. 1, azul; 2, verde; 3 , amarillo.

\section{Talle y características tafonómicas}

En el tamiz 5,660 mm, el grado de preservación de conchillas fue moderado (Tabla 3.5., Apéndice I §Fig. 2). En 1a predominaron conchillas incompletas y fragmentos (2, 40\%; 3, $44 \%$ ) y en $1 \mathrm{~b}$ fragmentos $(3,57 \%)$; ambas muestras mostraron alteración superficial de moderada a alta $(2-3,44-53 \% 1 \mathrm{a} ; 46-43 \% 1 \mathrm{~b})$ y redondeamiento ( $3,>50 \%$ en ambas). La bioerosión fue baja en el $\approx 52 \%$ de las conchillas retenidas en este tamiz; sin embargo se reconocieron 14 icnotaxones entre los que predominan Pennatichnus isp., P. moguerenica y Maeandropolydora sulcans (V. Capítulo 4). En las conchillas de bivalvos, entre los preservados, predominaron los bordes discontinuos (2, 42\% 1a; 32\% 1b).

La mayor parte del $\mathrm{n}$ de $\mathrm{C} 1$ proviene del tamiz 1,190 mm. Los restos esqueletales de esta malla se caracterizan por presentar diversos grados de preservación (Tabla 3.5. Apéndice I §Fig. 2). Las conchillas principalmente se preservan incompletas (2, 49\% 1a; 51\% 1b), con alteración superficial moderada $(2,60 \% 1 \mathrm{a} ; 51 \% 1 \mathrm{~b})$ y redondeamiento $(3,>50 \%$ en ambas); en los bivalvos, los bordes preservados fueron principalmente discontinuos (2, $\approx 45 \%)$. Si bien la bioerosión en este tamiz fue baja (1, 94\% 1a; 93\% 1b), se reconocieron trazas de Oichnus paraboloides, O. simplex, Finichnus peristroma, F. dromeus, 

4).

Las de conchillas retenidas en la malla $0,710 \mathrm{~mm}$, presentaron en general mala preservación (Tabla 3.5, Apéndice I §Fig. 2). Predominaron conchillas incompletas $(2, \approx 54 \%$ en ambas), con alteración superficial alta $(3,51 \% 1 \mathrm{a} ; 59 \% 1 \mathrm{~b})$ y redondeamiento $(3,>50 \%$ en ambas). La bioerosión fue baja (1, 99\% en ambas) y estuvo representada exclusivamente por trazas de depredación (V. Capítulo 4). En cuanto a la preservación del margen ventral de los bivalvos, entre los preservados, en 1a predominaron los continuos (1, $26 \%)$ mientras que en $1 \mathrm{~b}$ los discontinuos $(2,52 \%)$.

\begin{tabular}{|c|c|c|c|c|c|}
\hline Malla (mm) & Fragmentación & AS & MB & Redondeamiento & Bioerosión \\
\hline \multicolumn{6}{|c|}{$1 a$} \\
\hline 5,660 & $2-3$ & $2-3$ & 2 & 3 & 1 \\
\hline 1,190 & 2 & 2 & 2 & 3 & 1 \\
\hline 710 & 2 & 3 & 1 & 3 & 1 \\
\hline \multicolumn{6}{|c|}{$1 b$} \\
\hline 5,660 & 3 & $2-3$ & 2 & 3 & 1 \\
\hline 1,190 & 2 & 2 & 2 & 3 & 1 \\
\hline 710 & 2 & 3 & 2 & 3 & 1 \\
\hline
\end{tabular}

\section{Fragmentación versus otras características tafonómicas}

Al analizar los atributos tafonómicos con relación al grado de fragmentación (Tabla 3.6, Apéndice I §Fig. 3) se observó que en las conchillas completas, la alteración superficial predominante fue alta en $1 \mathrm{a}(3,56 \%)$ y moderada en $1 \mathrm{~b}(2,49 \%)$; en ambas submuestras predominaron las conchillas sin redondeamiento $(1,41 \% 1 \mathrm{a} ; 36 \% 1 \mathrm{~b})$ y con bordes redondeados (3, 38\% 1a; $43 \%$ en 1b). En las dos submuestras la bioerosión fue baja (1, $\geq 96 \%$ ); en aproximadamente el $65 \%$ los bivalvos de ambas submuestras predominaron los márgenes discontinuos (2).

En las conchillas incompletas los índices tafonómicos fueron similares entre 1a y 1b (Tabla 3.6, Apéndice I §Fig. 3). Predominó la alteración superficial moderada $(2, \pm 50 \%)$ y el redondeamiento $(3, \geq 60 \%)$. La bioerosión fue baja $(1,>90 \%)$. En ambas submuestras predominaron las valvas de bivalvos con bordes discontinuos $(2,38 \% 1 \mathrm{a} ; 36 \%, 1 \mathrm{~b}) \mathrm{o}$ ausentes (3, 39\% 1a; 40\% 1b).

Finalmente, los fragmentos (Tabla 3.6, Apéndice I §Fig. 3) en 1a mostraron mayormente alteración superficial moderada $(2,50 \%)$ y en $1 \mathrm{~b}$ alta $(3,58 \%)$. Ambas submuestras mostraron redondeamiento $(3, \geq 80 \%)$ y bioerosión baja $(1,77 \% 1 \mathrm{a} ; 83 \% 1 \mathrm{~b})$. En las conchillas de bivalvos, predominaron aquellas en las que el margen ventral no se 
preservaba $(3,74 \% 1 \mathrm{a} ; 52 \% 1 \mathrm{~b})$; de los preservados, predominaron los discontinuos (2, $\pm 25 \%)$.

Tabla 3.6. Características Tafonómicas predominantes en 1a y 1b en relación a la fragmentación (conchillas completas, incompletas y fragmentos). Referencias como en tabla 3.2. Los gráficos se encuentran en el Apéndice I, Fig. 3.

\begin{tabular}{|c|c|c|c|c|}
\hline Fragmentación & AS & MB & Redondeamiento & Bioerosión \\
\hline Completas & 3 & $\mathbf{1 a}$ & & \\
\hline Incompletas & 2 & 2 & 1 y 3 & 1 \\
\hline Fragmentos & 2 & $2-3$ & 3 & 1 \\
\hline Completas & 2 & 3 & 3 & 1 \\
\hline Incompletas & 2 & $\mathbf{1 b}$ & & 1 \\
\hline Fragmentos & 3 & $2-3$ & 3 & 1 \\
\hline
\end{tabular}

\section{Fragmentación y talle versus otras características tafonómicas}

Al considerar en conjunto el grado de fragmentación y la apertura del tamiz (Tabla 3.7, Apéndice I §Fig. 4), los bioclastos completos del tamiz 5,660 mm tuvieron una preservación moderada. En ambas submuestras predominaron aquellos con alteración superficial moderada $(2,67 \%$ 1a; $63 \% 1 b)$, sin redondeamiento $(1,>60 \%)$ y con bioerosión baja $(1$, $83 \%$ 1a; $69 \%$ 1b). En bivalvos, en 1a la proporción de bordes es continuos y discontinuos fue similar (50\%) y en $1 \mathrm{~b}$ predominaron discontinuos (2, 67\%). En los completos del tamiz $1,190 \mathrm{~mm}$ la preservación también fue moderada (Tabla 3.7, Apéndice I §Fig. 4). La alteración superficial fue alta en $1 \mathrm{a}(3,59 \%)$ y moderada $(2,51 \%)$ en $1 \mathrm{~b}$; en 1a la proporción de conchillas sin redondeamiento y redondeadas fue similar ( 1 y $3,40 \%$ ) y en $1 \mathrm{~b}$ predominaron las redondeadas $(3,45 \%)$. En la modificación de bordes entre los preservados en 1a predominaron discontinuos $(2,67 \%)$ mientras que en $1 \mathrm{~b}$ la proporción entre continuo y discontinuo fue similar $(1,48 \% ; 2,52 \%)$. Finalmente, la bioerosión fue baja en ambas submuestras (1,>96\%). En el tamiz de 0,710 mm la preservación fue de moderada a mala (Tabla 3.7, Apéndice I §Fig. 4). En ambas submuestras se observó alteración superficial alta $(3, \approx 55 \%)$, un porcentaje similar de conchillas sin redondeamiento $(1,34 \% 1 \mathrm{a} ; 43 \% 1 \mathrm{~b})$ y redondeadas $(3,39 \%)$ y bioerosión baja $(1,>90)$. En las valvas de $1 a$ los bordes se preservaron continuos en el $55 \%$ de los bivalvos, mientras que en $1 \mathrm{~b}$ se preservaron discontinuos en el $87 \%$.

De las conchillas incompletas (Tabla 3.7, Apéndice I §Fig. 5), en la malla 5,660 mm la alteración superficial fue de moderada $(2,50 \%)$ a alta $(3,46 \%)$ en 1a y moderada $(2,58 \%)$ en 1b. En ambas submuestras predominaron bioclastos redondeados $(3,>50 \%)$, con baja bioerosión (1, 46\% 1a; 65\% 1b). En cada submuestra, solo un bivalvo presevó el margen ventral; en 1a fue continuo (1) y en 1b discontinuo (2). En la malla de 1,190 mm se observó una preservación similar entre 1a y 1b (Tabla 3.7, Apéndice I §Fig. 5); la alteración superficial fue moderada (2, $61 \% 1 \mathrm{a} ; 53 \% 1 \mathrm{~b})$; los bioclastos mostraron redondeamiento 
$(3, \cong 54 \%)$ y baja bioerosión $(1,92 \%)$. Cerca del $45 \%$ de los bivalvos retenidos en este tamiz tenían bordes discontinuos (2). Finalmente, en la malla $0,710 \mathrm{~mm}$ en ambas submuestras se observaron altos índices de alteración superficial (3, 52\% 1a; $60 \% 1 b)$, redondeamiento $(3,56 \% 1 \mathrm{a} ; 66 \% 1 \mathrm{~b})$ y baja bioerosión $(1,99 \%)$. En la mayoría de los bivalvos los bordes no se preservaron (3, 50\% 1a, 53\% 1b); de los preservados predominaron los discontinuos $(2, \geq 27 \%)$.

En los fragmentos de la malla $5,660 \mathrm{~mm}$ se observó en ambas submuestras alteración superficial alta $(3,>60 \%)$ y redondeamiento $(3,>65 \%$ ) (Tabla 3.7, Apéndice 1 §Fig. 6). En 1a la proporción de conchillas con bioerosión baja $(1,43 \%)$ y alta $(3,47 \%)$ fue similar; en $1 \mathrm{~b}$ predominó la bioerosión baja (1,43\%). En 1a el $50 \%$ de los bivalvos se preservaron con bordes discontinuos (2) y en $1 \mathrm{~b}$ el porcentaje de bordes discontinuos y de no preservados fue igual $(2-3,36 \%)$. En los retenidos en la malla $1,190 \mathrm{~mm}$, la alteración superficial predominante fue moderada en $1 \mathrm{a}(2,58 \%)$ y alta en $1 \mathrm{~b}(3,54 \%)$ (Tabla 3.7, Apéndice 1 §Fig. 6). En ambas submuestras más del $70 \%$ de los bioclastos mostraron redondeamiento, baja bioerosión y bordes no preservados; de los preservados predominaron los discontinuos $(2,18 \% 1 \mathrm{a} ; 27 \% 1 \mathrm{~b})$. La preservación de los fragmentos en la malla 0,710 mm fue similar a la de la malla anterior (Tabla 3.7, Apéndice 1 §Fig. 6), con alteración superficial moderada en 1a (2, 54\%) y alta en 1b (3,61\%). En ambas submuestras entre el 80 y $90 \%$ de los fragmentos mostraban redondeamiento y baja bioerosión $(1, \approx 100 \%)$. Entre el 80 y $90 \%$ de los bivalvos no preservaron sus márgenes ventrales;

d e

Ios

preser

Tabla 3.7. Características Tafonómicas predominantes en 1a y $1 \mathrm{~b}$ en conchillas completas, incompletas y fragmentos con relación a su talle. Referencias como en tabla 3.2. Los gráficos se encuentran en el Apéndice I, Figs. 4, 5 y 6.

\begin{tabular}{|c|c|c|c|c|c|}
\hline $\mathbf{F}$ & Malla & AS & MB & Redondeamiento & Bioerosión \\
\hline & \multicolumn{5}{|c|}{$1 a$} \\
\hline \multirow{7}{*}{ C } & 5,660 & 2 & $1-2$ & 1 & 1 \\
\hline & 1,190 & 3 & 2 & 1 y 3 & 1 \\
\hline & 710 & 3 & 1 & 1 y 3 & 1 \\
\hline & \multicolumn{5}{|c|}{$1 b$} \\
\hline & 5,660 & 2 & 2 & $1-2$ & 1 \\
\hline & 1,190 & 2 & $1-2$ & 3 & 1 \\
\hline & 710 & 3 & 2 & $1-3$ & 1 \\
\hline & \multicolumn{5}{|c|}{$1 a$} \\
\hline & 5,660 & $2-3$ & 1 & 3 & 1 \\
\hline & 1,190 & 2 & 2 & 3 & 1 \\
\hline & 710 & 3 & 3 & 3 & 1 \\
\hline 1 & \multicolumn{5}{|c|}{$1 b$} \\
\hline & 5,660 & 2 & 2 & 3 & 1 \\
\hline & 1,190 & 2 & 2 & 3 & 1 \\
\hline & 710 & 3 & 3 & 3 & 1 \\
\hline
\end{tabular}




\begin{tabular}{|c|c|c|c|c|c|}
\hline $\mathbf{5}$ & \multicolumn{5}{|c|}{$\mathbf{1 a}$} \\
\hline $\mathbf{F}$ & Malla & AS & MB & Redondeamiento & Bioerosión \\
\hline $\mathbf{5 , 6 6 0}$ & 3 & 2 & 3 & 1 y 3 \\
\hline $\mathbf{1 , 1 9 0}$ & 2 & 3 & 3 & 1 \\
\hline $\mathbf{7 1 0}$ & 2 & 3 & 3 & 1 \\
\hline & & & $\mathbf{1 b}$ & & 1 \\
\hline $\mathbf{5 , 6 6 0}$ & 3 & $2-3$ & 3 & 1 \\
\hline $\mathbf{1 , 1 9 0}$ & 3 & 3 & 3 & 1 \\
\hline $\mathbf{7 1 0}$ & 3 & 3 & 3 & \\
\hline
\end{tabular}

vados, predominaron los discontinuos $(2,6 \% 1 \mathrm{a}, 14 \% 1 \mathrm{~b})$.

\section{Taxones y características tafonómicas}

Con la finalidad de saber si había alguna diferencia en la calidad de preservación de los diferentes taxones reconocidos, se observaron de manera separada y semicuantitativa las características tafonómicas de los taxones más abundantes (Tablas 3.1, 3.3 y 3.4). De los reconocidos en campo se consideraron Turritella, Xymenella y Solariella (Tabla 3.8, Apéndice 1 §Fig. 7). Las turritellas mostraron una preservación moderada, el $66 \%$ de las conchillas se preservaron incompletas, la alteración superficial fue moderada en el $55 \%$ y se observó redondeamiento en más del $90 \%$. Predominó la bioerosión alta $(3,50 \%)$ con trazas producidas por briozoos, poliquetos, esponjas, y gasterópodos (V. Capítulo 4). El $55 \%$ de las conchillas de Xymenella se preservaron incompletas, la alteración superficial fue moderada en el $82 \%$ y el redondeamiento se observó en un $75 \%$ de las mimas. Predominó la bioerosión baja $(1,55 \%)$, principalmente se observaron trazas producidas por briozoos (Finichnus peristroma) ( $\mathrm{V}$. Capítulo 4). Finalmente, las conchillas del género Solariella mostraron una buena preservación con el $60 \%$ de las conchillas completas, con alteración superficial moderada $(2,70 \%)$, redondeamiento $(3,67 \%)$ y baja bioerosión $(1$, $100 \%)$.

Tabla 3.8. Características Tafonómicas predominantes en los taxones más abundantes en los cuadros de C1. Referencias como en tabla 3.2. Los gráficos se encuentran en el Apéndice I, Fig. 7.

\begin{tabular}{|c|c|c|c|c|}
\hline Taxón & Fragmentación & AS & Redondeamiento & Bioerosión \\
\hline Turritella & 2 & 2 & 3 & 3 \\
\hline Xymenella & 2 & 2 & 3 & 1 \\
\hline Sollariella & 1 & 2 & 3 & 1 \\
\hline
\end{tabular}

En las submuestras procesadas en laboratorio, para 1a se consideraron los géneros Turritella, Kaitoa, Cylichnania y Solariella y las familias Mactridae y Carditidae (bivalvos), Muricidae y Naticidae (gasterópodos). En 1b se consideraron los mismos géneros que en 1a, pero se incluyó también Maorimactra y a nivel de familia sólo Naticidae fue contemplada (Tabla 3.9, Apéndice I §Fig. 8). En 1a, las conchillas de Kaitoa son las mejor preservadas con un $57 \%$ de conchillas completas, mientras que en Solariella la proporción de completas e incompletas fue similar $(1-2, \pm 45 \%)$ y en Turritella y Cylichnania 
predominaron incompletas $(\geq 58 \%)$. La alteración superficial fue moderada en todos los géneros considerados (>50\%) y más del $50 \%$ de los especímenes mostraron redondeamiento. La bioerosión fue baja en aproximadamente el 100\% de los especímenes en Solariella, Kaitoa y Cylichnania, y en el $80 \%$ en Turritella.

A nivel de familia se observó una mayor variación en la calidad de preservación (Tabla 3.9, Apéndice I §Fig. 8). La Familia Carditidae incluyó a los géneros "Cardita" y Pleuromeris, cuyas conchillas se preservaron mayormente completas $(1,52 \%)$ con alteración superficial moderada en el $72 \%$ de los especímenes y bioerosión baja (1, 80\%); la modificación de bordes mostró que cerca del $50 \%$ de los cardítidos preservaban márgenes continuos. En la Familia Mactridae se incluyeron los géneros Maorimactra y Scalpomactra, la proporción de conchillas completas, incompletas y fragmentadas fue similar $(1,31 \% ; 2,37 \% ; 3,32 \%)$, mientras que la alteración superficial fue alta en más del $50 \%$ de los especímenes; predominaron los bordes discontinuos y el redondeamiento en más $70 \%$ de los mismos. La bioerosión fue baja (1, $\approx 100 \%)$. En la Familia Naticidae se incluyeron especímenes determinados como Naticidae indet. y aquellos del género Polinices. Los bioclastos de esta familia se preservaron completos e incompletos en igual proporción $(1-2,37 \%)$, predominaron la alteración superficial alta $(3,76 \%)$, el redondeamiento $(3,>50 \%)$ y la bioerosión baja (1, 46\%). Finalmente, la Familia Muricidae incluyó a los géneros Urosalpinx y Xymenell. En esta familia predominaron conchillas incompletas (2, 47\%) con alteración superficial moderada $(2,71 \%)$ y redondeamiento $(3,77 \%)$. La bioerosión fue baja en el $59 \%$ de los bioclastos; sin embargo, fue común encontrar, en el género Xymenella, trazas producidas por briozoos (V. Capítulo 4).

Tabla 3.9. Características Tafonómicas predominantes en los taxones más abundantes en 1a. Referencias como en tabla 3.2. Los gráficos se encuentran en el Apéndice I, Fig. 8.

\begin{tabular}{|c|c|c|c|c|c|}
\hline Taxón & Fragmentación & AS & Redondeamiento & Bioerosión & MB \\
\hline Turritella & 2 & 2 & 3 & 1 & \\
\hline Solariella & $1-2$ & 2 & 3 & 1 & \\
\hline Kaitoa & 1 & 2 & 3 & 1 & \\
\hline Cylichnania & 2 & 2 & 3 & 1 & \\
\hline Carditidae & 1 & 2 & 3 & 1 & 2 \\
\hline Mactridae & $1-3$ & 3 & 3 & 1 & \\
\hline Naticidae & $1-2$ & 3 & 3 & 1 & \\
\hline Muricidae & 2 & 2 & 3 & 1 & \\
\hline
\end{tabular}

En 1b la preservación de las turritelas fue moderada (Tabla 3.10, Apéndice I §Fig. 9); predominaron conchillas incompletas (2,44\%), alteración superficial moderada (2, 54\%) y redondeamiento $(3,65 \%)$. La bioerosión fue baja $(1,76 \%)$ mas la icnodiversidad fue alta. El segundo género más abundante, Solariella, mostró una preservación moderada, predominando conchillas incompletas $(2,59 \%)$, con moderada alteración superficial (2, $65 \%)$ y redondeamiento $(3,54 \%)$. La bioerosión fue baja en cerca del $100 \%$ de los especímenes. Los bivalvos del género Maorimactra tienen una preservación moderada; predominaron conchillas incompletas $(2,59 \%)$, con alta alteración superficial $(3,66 \%)$, redondeamiento $(3,70 \%)$ y baja bioerosión $(1,98 \%)$. El $68 \%$ los márgenes ventrales 
preservados son discontinuos. Las conchillas del género Kaitoa, mostraron una buena preservación, con más del $50 \%$ de las conchillas completas y una proporción igual de conchillas con alteración superficial moderada y alta (2-3, 46\%). Se observó redondeamiento en el $65 \%$, la bioerosión baja en el cerca del $100 \%$. Finalmente, en la Familia Naticidae (Naticidae indet. y Polinices) la preservación fue moderada, con $57 \%$ de las conchillas incompletas, alteración superficial alta $(3,71 \%)$, redondeamiento $(3,54 \%)$ y baja bioerosión $(1,100 \%)$

Tabla 3.10. Características Tafonómicas predominantes en los taxones más abundantes en 1b. Referencias como en tabla 3.2. Los gráficos se encuentran en el Apéndice I, Fig. 9.

\begin{tabular}{|c|c|c|c|c|c|}
\hline Taxón & Fragmentación & AS & Redondeamiento & Bioerosión & MB \\
\hline Turritella & 2 & 2 & 3 & 1 & \\
\hline Solariella & 2 & 2 & 3 & 1 & \\
\hline Kaitoa & 1 & $2-3$ & 3 & 1 & \\
\hline Maorimactra & 2 & 3 & 3 & 1 & 2 \\
\hline Cylichnania & 2 & $2-3$ & 3 & 1 & \\
\hline Naticidae & 2 & 3 & 3 & 1 & \\
\hline
\end{tabular}

\section{Hábitos de vida y características tafonómicas}

Con la finalidad de saber si existen diferencias en la calidad de preservación de organismos infaunales y epifaunales, se reconocieron de manera separada y semicuantitativa las características tafonómicas en ambos grupos y analizando separadamente los datos de campo y laboratorio (Tabla 3.11, Apéndice 1 §Fig. 10). En campo, las conchillas de organismos con hábitos infaunales $(n=36)$ se preservaron completas e incompletas en proporción similar $(2-3, \approx 45 \%)$, con alta alteración superficial $(3,74 \%)$ y bioerosión baja ( 1 , $97 \%$; más del $50 \%$ mostraron márgenes ventrales dicontinuos y redondeamiento. Las conchillas de organismos epifaunales fueron más abundantes $(n=142)$, se preservaron mayormente incompletas $(2,61 \%)$, con alteración superficial moderada $(2,47 \%)$, márgenes ventrales continuos $(1,60 \%)$, redondeamiento $(3,86 \%)$ y bioerosión baja $(1,57 \%)$.

En 1a predominaron epifaunales $(n=561)$ sobre los infaunales $(n=126)$. Las conchillas de infaunales de la submuestra se preservaron principalmente incompletas $(2,60 \%)$, con alteración superficial alta $(3,60 \%)$, márgenes ventrales discontinuos $(2,62 \%)$, redondeamiento $(3,80 \%)$ y bioerosión baja (1, 98\%) (Tabla 3.11, Apéndice I §Fig. 10). Por otra parte, las conchillas de epifaunales se preservaron completas e incompletas en proporción similar (1-2, $\approx 45 \%)$, con alteración superficial moderada (2, 59\%), redondeamiento $(3,60 \%)$ y baja bioerosión $(1,90 \%)$. La proporción de bordes continuos y discontinuos fue similar (1-2, $\approx 45 \%)$.

En $1 b$ también predominaron los epifaunales $(n=712)$ sobre los infaunales $(n=119)$ (Tabla 3.11, Apéndice I §Fig. 10). La preservación de los infaunales fue moderada con más del $50 \%$ de las conchillas incompletas, la alteración superficial fue alta $(3,61 \%)$; predominaron los bordes discontinuos $(2,68 \%)$ y el redondeamiento $(3,>65 \%)$ de los individuos, la bioerosión fue baja en cerca del $100 \%$. En los epifaunales, predominaron también 
conchillas incompletas $(2,49 \%)$ con alteración superficial de moderada a alta $(2-3,>40 \%)$, bordes discontinuos $(2,55 \%)$, redondeamiento $(3,64 \%)$ y baja bioerosión $(1, \approx 90 \%)$.

Tabla 3.11. Características Tafonómicas predominantes en C1 con relación al hábito de vida. Referencias como en tabla 3.2. Los gráficos se encuentran en el Apéndice I, Fig. 10.

\begin{tabular}{|c|c|c|c|c|c|c|}
\hline Hábito & Submuestra & Fragmentación & AS & Redondeamiento & Bioerosión & MB \\
\hline \multirow{3}{*}{ 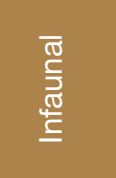 } & Cuadro & $1-2$ & 3 & 3 & 1 & 2 \\
\hline & $1 a$ & 2 & 3 & 3 & 1 & 2 \\
\hline & $1 b$ & 2 & 3 & 3 & 1 & 2 \\
\hline \multirow{3}{*}{ 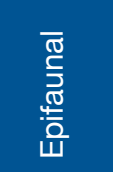 } & Cuadro & 2 & 2 & 3 & 1 & 1 \\
\hline & $1 a$ & $1-2$ & 2 & 3 & 1 & $1-2$ \\
\hline & $1 b$ & 2 & $2-3$ & 3 & 2 & 2 \\
\hline
\end{tabular}




\section{Concentración 2 (C2)}

\section{Caracterización en campo}

a) Características sedimentológicas y estratigráficas: Concentración de aproximadamente $44 \mathrm{~cm}$ de espesor con geometría de capa, matriz de arena fina con ceniza; empaquetamiento de suelto a denso, selección bimodal y contactos ondulados bioturbados (Fig. 3.6a). La orientación de los bioclastos mostró variaciones laterales, siendo concordante principalmente -predominando bivalvos con la convexidad hacia abajo-, con sectores con orientación oblicua y perpendicular (V. información en línea); el agrupamiento es apilado, pero en algunas orientaciones perpendiculares es anidado (Fig. $3.6 b, c)$.

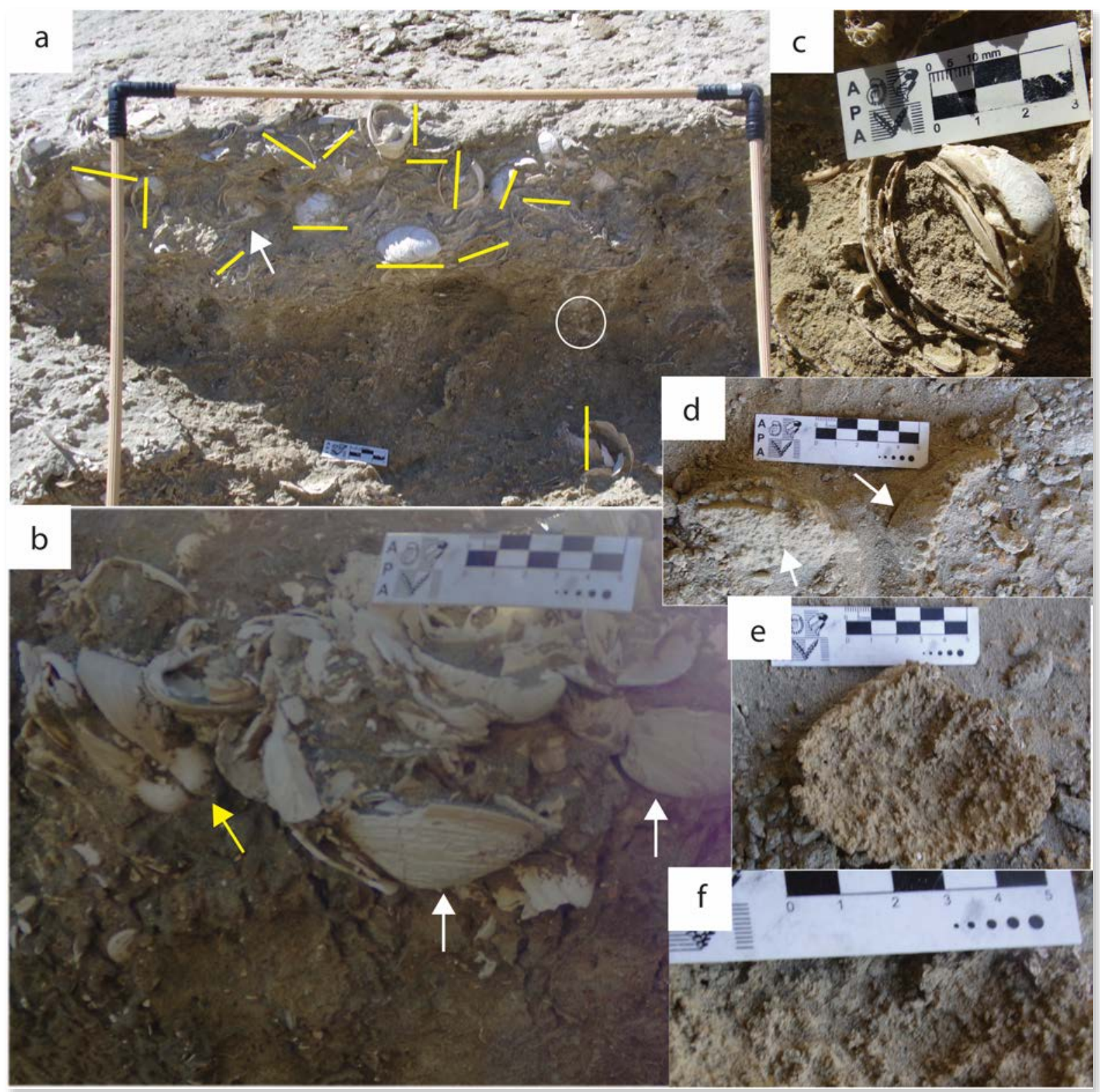

Figura 3.6. Características sedimentológicas y estratigráficas de C2. a) geometría de capa con contactos bioturbados (círculo blanco). Las líneas amarillas señalan las variaciones en orientación que se observan a lo largo de la misma. El empaquetamiento denso se señala con una flecha 
blanca. b) Detalle de la orientación concordante y el agrupamiento apilado. Las flechas blancas señalan valvas de Dosinia con la convexidad hacia abajo y la amarilla un espécimen de $P$. quemadensis Ihering, 1897 articulado y desplazado de su posición original. c) Detalles de orientación perpendicular y agrupamiento anidado. d) Moldes internos de Dosinia? en posición de vida (flechas blancas). e) Parte interna de un molde de Dosinia?, en el que se observa bioturbación. f) Biortubación en moldes de Dosinia?, acercamiento de e.

En la base de la concentración se observaron moldes internos de Dosinia? en posición de vida, formadas por una matriz de arena fina y bioturbada (Fig. $3.6 \mathrm{~d}$, e, f). A lo largo de la concentración se observaron pequeños bolsones con placas desarticuladas de balanos. Considerando las variaciones de las características paleontológicas, la orientación y el agrupamiento de los bioclastos, se considera que la estructura interna de C2 es compleja (sensu Kidwell et al., 1986).

b) Características paleontológicas: Esta concentración destaca la presencia de bivalvos aragoníticos, especialmente del género Dosinia $(n=72)$, pero también destaca la presencia de elementos calcíticos, principalmente placas de balanos; en los 10 cuadros que se realizó el scoring, se evaluó la preservación de 39 placas, aunque su abundancia fue mayor. Con respecto a los moluscos, se reconocieron 10 taxones más pero su abundancia fue muy baja (Tabla 3.12), por lo cual esta concentración se considera como pauciespecífica. Con respecto al hábito de los elementos que conforman la concentración, predominaron aquellos infaunales ( $\underline{V}$. Métodos y Apéndice II); en el espectro de edad, predominaron adultos. Debido a que la abundancia de bioclastos en los cuadros fue baja, el scoring se realizó con un n de entre 15 y 20 (V. datos en línea).

Tabla 3.12. Riqueza de C2 en campo.

\begin{tabular}{|c|c|c|c|c|c|c|c|}
\hline Taxón & $\mathbf{n}$ & Taxón & $\mathbf{n}$ & Taxón & $\mathbf{n}$ & Taxón & $\mathbf{n}$ \\
\hline Dosinia & 72 & Maorimactra & 1 & Arcidae & 1 & Indet. & 45 \\
\hline Balanus & 39 & Pleuromeris & 1 & Naticidae & 1 & $\mathrm{n}$ & 174 \\
\hline Panopea & 4 & Tenuiacteon & 1 & Nuculidae & 1 & & \\
\hline Turritella & 3 & Veneridae & 4 & Trochidae & 1 & & \\
\hline
\end{tabular}

c) Características tafonómicas: La preservación de los bioclastos de esta concentración es moderada. Predominaron los completos $(1,51 \%)$ con alteración superficial alta (3, 55\%); en la modificación de bordes predominaron los discontinuos (2, 41\%), los márgenes fragmentados mostraron redondeamiento $(3,41 \%)$ y la bioerosión fue baja $(1,70 \%)$. El $67 \%$ de los bivalvos y balanos se preservaron desarticulados (Tabla 3.13, Apéndice I §Fig. 11).

Tabla 3.13. Características Tafonómicas de $\mathrm{C} 2$, en campo en donde se señala la categoría predominante de cada atributo. Fragmentación (F): (1) completo, (2) incompleto, (3) fragmento. Alteración superficial (AS): (1) baja, (2) moderada, (3) alta. Modificación de bordes (MB): (1) continuo, (2) discontinuo, (3) ausente. Redondeamiento (R): (1) ausente, (2) aguzado, (3) redondeado. Bioerosión (B): (1) baja, (2) moderada, (3) alta. Articulación (A): (1) articulado, (2) separado, (3) desarticulado. 1, azul; 2, verde; 3, amarillo; NV (no visible), violeta. Los gráficos de cada cuadrante se encuentran en el Apéndice I, Fig. 1.Los gráficos de cada cuadrante se encuentran en el Apéndice I Fig. 11.

\begin{tabular}{|r|r|r|r|r|r|r|}
\hline Cuadro & Fragmentación & AS & MB & Redondeamiento & Bioerosión & Articulación \\
\hline 1 & 1 & 3 & $3-\mathrm{NV}$ & 2 & 1 \\
\hline 2 & 1 & 3 & 2 & 3 & 1 & 3 \\
\hline
\end{tabular}




\begin{tabular}{|r|r|r|r|r|r|r|}
\hline 3 & $2-3$ & 2 & 3 & 1 & 3 \\
\hline Cuadro & Fragmentación & AS & MB & Redondeamiento & Bioerosión & Articulación \\
\hline 4 & 1 & 3 & NV & 3 & 1 & 3 \\
\hline 5 & 2 & 3 & 3 & 3 & 1 & 3 \\
\hline 6 & $1-2$ & 2 & 3 & 2 & 1 & $2-3$ \\
\hline 7 & 2 & 3 & 3 & 2 & 1 & 3 \\
\hline 8 & 1 & 3 & 3 & 3 & 1 & 3 \\
\hline 9 & 1 & 3 & 3 & 2 & 1 & 3 \\
\hline 10 & 1 & 3 & $3-N V$ & 3 & 1 & 3 \\
\hline C2 & 1 & $\mathbf{3}$ & $\mathbf{2}$ & $\mathbf{3}$ & $\mathbf{1}$ & $\mathbf{3}$ \\
\hline
\end{tabular}

Caracterización de submuestras en laboratorio.

a) Características paleontológicas: En esta concentración se encontró una abundante cantidad de placas de balanos desarticuladas $(n=166)$, predominando en orden de mención, carinas rostrum, carina y rostro-laterales y, en menor proporción, placas operculares. En la submuestra 2a se obtuvieron 162 especímenes de moluscos que fueron reconocidos en 15 taxones (Tabla 3.14). Los bivalvos Dosinia y Pteromyrtea tuvieron un mayor número de especímenes ( $n=87$ y $n=10$, respectivamente); el resto de los taxones estuvieron representados por un ene menor a 10; 37 bioclastos no pudieron ser determinados. En relación al hábito de vida, la mayoría de los especímenes se asocian a hábitos de vida infaunales. ( $\underline{\text {. Apéndice II). }}$

Tabla 3.14. Riqueza en C2, submuestra 2a.

\begin{tabular}{|c|c|c|c|c|c|c|c|}
\hline Taxón & $n$ & Taxón & $\mathbf{n}$ & Taxón & $\mathbf{n}$ & Taxón & n \\
\hline Dosinia & 87 & Trochita & 2 & Fusiguraleus & 1 & Indet. & 37 \\
\hline Pteromyrtea & 10 & Turritella & 2 & Serratina & 1 & Total & 162 \\
\hline Odostomia & 4 & Xymenella & 2 & Tellina & 1 & & \\
\hline Retrotapes & 4 & Eliptotellina & 1 & Muricidae & 1 & & \\
\hline Tenuiacteon & 2 & Ellobia & 1 & Verenidae & 6 & & \\
\hline
\end{tabular}

En la submuestra 2b, la presencia de balanos también fue considerable junto con restos de briozoos de formas coloniales, robustas y articuladas; los restos de equinodermos fueron escasos. La presencia de moluscos es notable; sin embargo, gran parte del material retenido en los tamices estaba muy fragmentado, lo cual dificultaba su reconocimiento; de estos únicamente fue posible separar 100 especímenes correspondientes a 15 taxones del filo. Dosinia fue el más abundante con $n=26$; el resto de los taxones tuvo un $n \leqq 10$ (Tabla 3.15). 
Tabla 3.15. Riqueza en C2 submuestra 2b.

\begin{tabular}{|c|c|c|c|c|c|c|c|}
\hline Taxón & $\mathbf{n}$ & Taxón & $\mathbf{n}$ & Taxón & $\mathbf{n}$ & Taxón & $\mathbf{n}$ \\
\hline Dosinia & 26 & Calliostoma & 2 & Neilo & 1 & Veneridae & 11 \\
\hline Ataxocerithium & 6 & Odostomia & 2 & Pectinidae & 1 & Lucinidae & 2 \\
\hline Pteromyrtea & 6 & Urosalpinx & 2 & Pyramidella & 1 & Indet. & 34 \\
\hline Calyptraea & 4 & Kaitoa & 1 & Xymenella & 1 & Total & 100 \\
\hline
\end{tabular}

b) Características tafonómicas: Las conchillas de C2 muestran en general una mala preservación (Fig. 3.7); la proporción de bioclastos incompletos y fragmentos fue similar $(1-2, \approx 44 \%)$, predominó la alteración superficial alta $(3,57 \%)$, el redondeamiento $(3,58 \%)$ y la baja bioerosión $(1,68 \%)$. El $64 \%$ de los bivalvos no preservaban el borde; de los preservados predominaron los discontinuos $(2,27 \%)$

En la submuestra 2a, la preservación fue moderada (Figura 3.7) y predominaron bioclastos incompletos y fragmentos $(2-3, \approx 44 \%)$; con moderada alteración superficial $(2,60 \%)$ y redondeamiento $(3,51 \%)$. La bioerosión fue baja $(1,69 \%)$ y el $63 \%$ de las conchillas de bivalvos no preservaban el borde; de los preservados predominaron los discontinuos (2, $30 \%$ ). En $2 \mathrm{~b}$ la preservación fue mala (Fig. 3.7); predominaron fragmentos de conchillas (3, $55 \%)$ con alteración superficial moderada (2, 52\%), redondeamiento $(3,69 \%)$ y baja bioerosión $(1,67 \%)$. El $65 \%$ de las conchillas de bivalvos no preservó el borde; de los preservados predominaron los discontinuos $(2,19 \%)$.

$\mathrm{C} 2$

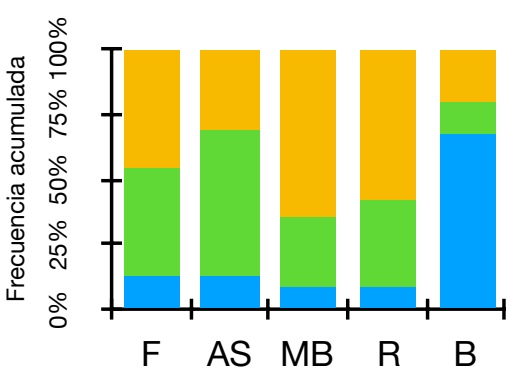

Atributos tafonómicos

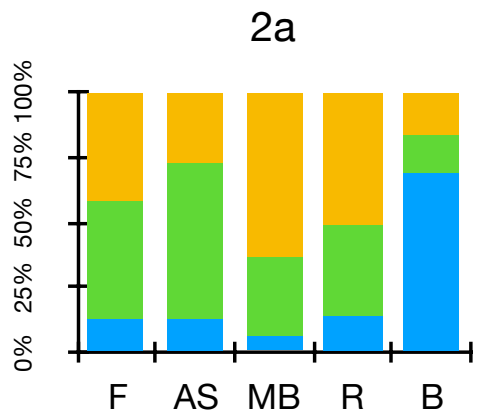

Atributos tafonómicos

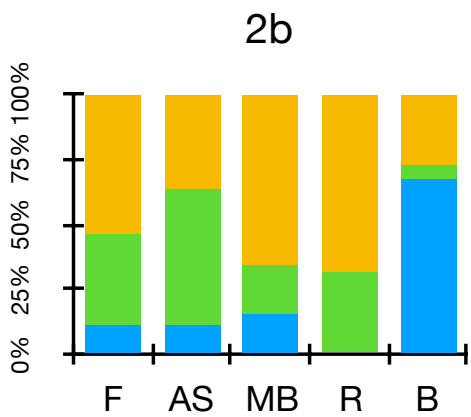

Atributos tafonómicos

Figura 3.7. Frecuencia acumulada de los atributos tafonómicos observados en $\mathrm{C} 2$, y en las submuestras $2 \mathrm{a}$ y $2 \mathrm{~b}$. Fragmentación (F): (1) completo, (2) incompleto, (3) fragmento. Alteración superficial (AS): (1) baja, (2) moderada, (3) alta. Modificación de bordes (MB): (1) continuo, (2) discontinuo, (3) ausente. Redondeamiento (R): (1) ausente, (2) aguzado, (3) redondeado. Bioerosión (B): (1) baja, (2) moderada, (3) alta. Articulación (A): (1) articulado, (2) separado, (3) desarticulado. 1, azul; 2, verde; 3 , amarillo.

Debido al bajo número de especímenes observados en los cuadros de campo y en las submuestras procesadas, "Talle y características tafonómicas», "Fragmentación versus otras características tafonómicas», «Fragmentación y talle versus otras características tafonómicas», «Taxones y características tafonómicas» y «Hábitos de vida y características tafonómicas» no fueron cuantificados para esta concentración. 


\section{Concentración 3 (C3)}

\section{Caracterización en campo}

a) Características sedimentológicas y estratigráficas: Concentración con espesor variable, con geometría lenticular; lentes finos y alargados (largo entre 45 y $320 \mathrm{~cm}$, espesor entre 20 y $60 \mathrm{~cm}$, matriz de arena fina (Fig. 3.8a y b), empaquetamiento de suelto a disperso y selección buena a bimodal en algunos sectores. En algunos lentes se observó estratificación entrecruzada difusa (Fig. 3.8c). El contacto fue neto en la base y en el techo. Los bioclastos mostraron una orientación preferencial concordante al plano de estratificación, sin embargo en algunos sectores podía ser oblicua o perpendicular, en el caso de algunos bivalvos (Fig. 3.8d), el agrupamiento fue apilado (Fig. 3.8e).

Sobre la base de las variaciones estratigráficas y sedimentológicas observadas dentro de cada lente y entre ellos, v. gr. estructuras sedimentarias, empaquetamiento y orientación preferencial; se sugiere que la estructura interna de C3 es compleja (sensu Kidwell et al., 1986). Respecto de la geometría de esta concentración, el scoring se realizó considerando los bioclastos incluidos en cada lente (6) teniendo un número de bioclastos variable, entre 6 y 30 por cuadro.

b) Características paleontológicas: En C3 predominaron moluscos, gasterópodos y bivalvos $(n=102)$. Se reconocieron 16 taxones, 11 géneros y cinco familias; 13 bioclastos sólo pudieron ser determinados a nivel de clase (Tabla 3.16, V. Apéndice II). Pteromyrtea y Turritella tuvieron el mayor número de individuos ( $n=55$ y 10 respectivamente), el número de individuos del resto de los taxones fue menor o igual a 5 . De esta manera se considera a C3 como una concentración pauciespecífica. Con respecto al hábito de vida de los elementos que conforman la concentración, predominaron aquellos de hábitos infaunales (V. Métodos y Apéndice II), en el espectro de edad predominaron adultos. La mayoría de los elementos de la concentración fueron de composición aragonítica y la proporción de bioclastos con mineralogía original y reemplazo fue similar.

Tabla 3.16. Riqueza de C3 en campo.

\begin{tabular}{|c|c|c|c|c|c|}
\hline Taxon & $\mathbf{n}$ & Taxon & $\mathbf{n}$ & Taxon & $\mathbf{n}$ \\
\hline Pteromyrtea & 55 & Arca & 1 & Naticidae & 1 \\
\hline Turritella & 10 & Glycymeris & 1 & Phylobridae & 1 \\
\hline Pleuromeris & 5 & Solariella & 1 & Indet. & 15 \\
\hline Kaitoa & 2 & Xymenella & 1 & Total & 104 \\
\hline Ostrea & 2 & Lucinidae & 3 & & \\
\hline Panopea & 2 & Trochidae & 2 & & \\
\hline "Cardita" & 1 & Eulimidae & 1 & & \\
\hline
\end{tabular}




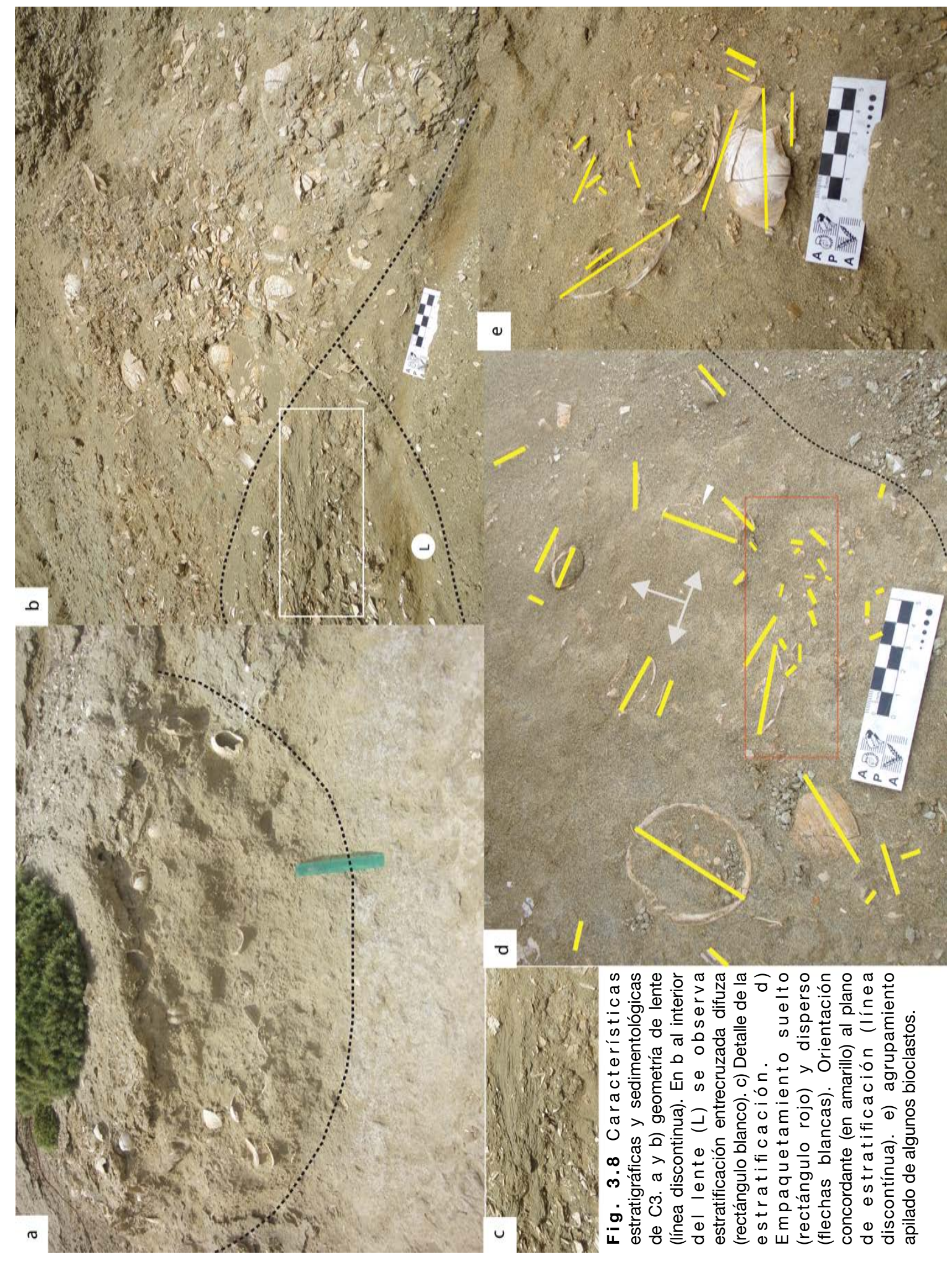


Además de los moluscos, se encontraron placas desarticuladas de balanos, con preservación de buena a moderada. En el lente 1 se observó una pequeña acumulación de equinoideos irregulares en orientación concordante y agrupamiento apilado y en el lente 5 restos de briozoos cementados y con reemplazamiento (Fig. 3.9a,b).

c) Características tafonómicas: Los bioclastos cuantificados en los lentes de esta concentración mostraron una preservación de buena a moderada (Tabla 3.17, Apéndice I $\S$ Fig. 12); el $43 \%$ de estos se preservaron completos (1), la alteración superficial fue de moderada a alta con un porcentaje igual para estos dos índices (2-3, 46\%). La proporción de bioclastos sin redondeamiento (1), aguzados (2) y redondeados (3) fue similar (entre 29 y $35 \%$ ) y la bioerosión fue baja (1) en el $67 \%$. El $82 \%$ de los bivalvos cualificados estaban desarticulados (3) y los bordes de las valvas se preservaron continuos y discontinuos en proporción similar (1-2, $\approx 35 \%)$. En algunos lentes se observaron acumulaciones de Pteromyrtea con preservación de buena a moderada y algunas valvas articuladas; estas concentraciones fueron clasto soportadas, con empaquetamiento denso y orientación perpendicular o concordante, convexas hacia abajo y con agrupamiento apilado o anidado (Fig 3.9c).

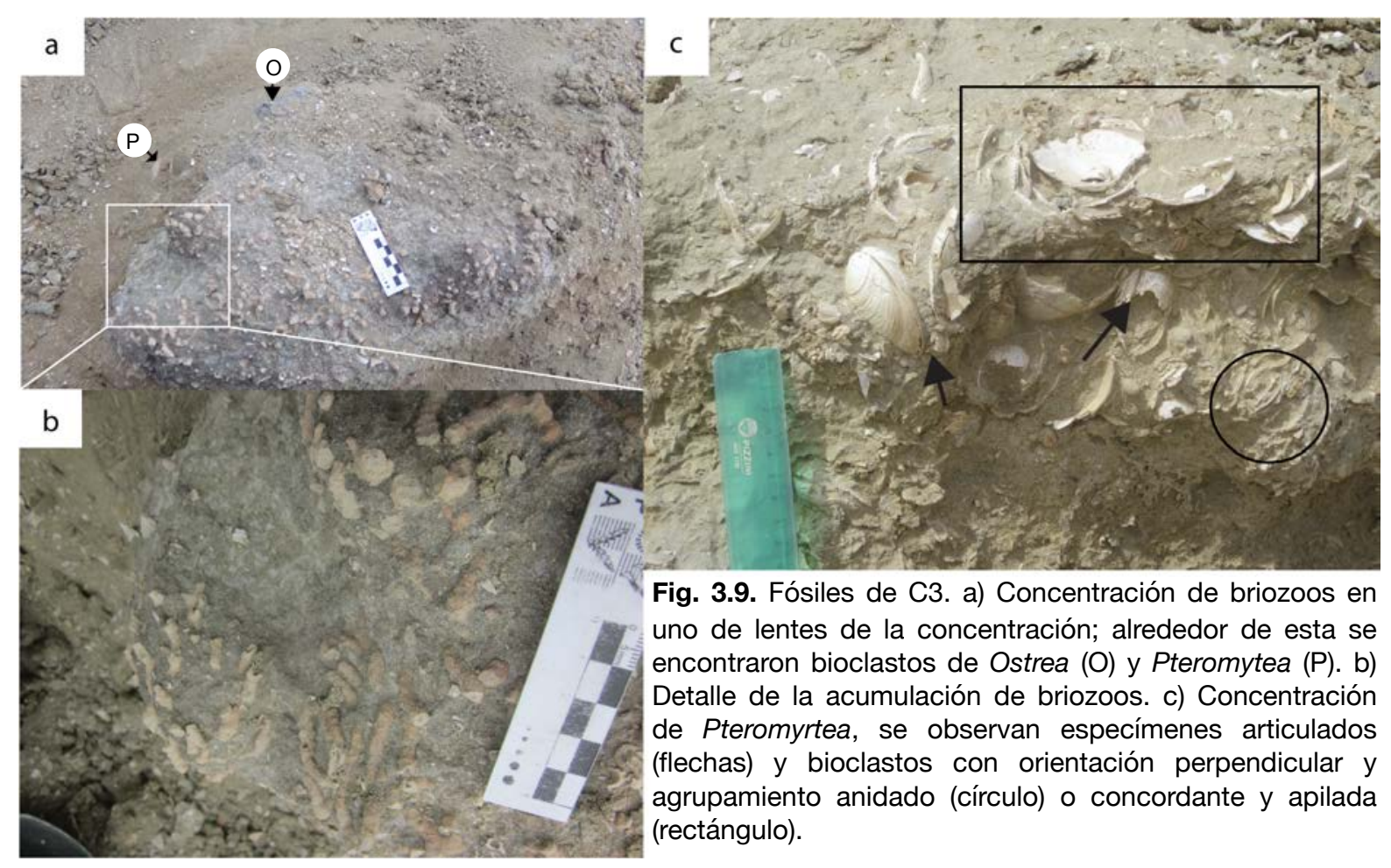

Tabla 3.17. Características Tafonómicas de C3 en campo en donde se señala la categoría predominante de cada atributo.. Fragmentación (F): (1) completo, (2) incompleto, (3) fragmento. Alteración superficial (AS): (1) baja, (2) moderada, (3) alta. Modificación de bordes (MB): (1) continuo, (2) discontinuo, (3) ausente. Redondeamiento (R): (1) ausente, (2) aguzado, (3) redondeado. Bioerosión (B): (1) baja, (2) moderada, (3) alta. Articulación (A): (1) articulado, (2) separado, (3) desarticulado. 1, azul; 2, verde; 3, amarillo; NV (no visible), violeta. Los gráficos de cada cuadrante se encuentran en el Apéndice I, Fig. 1 Los gráficos de cada cuadrante se encuentran en el Apéndice I, Fig. 12.

\begin{tabular}{|r|r|r|r|r|r|r|}
\hline Lente & Fragmentación & AS & MB & Redondeamiento & Bioerosión & Articulación \\
\hline 1 & $1-3$ & 3 & 1 & 1 & 1 \\
\hline 2 & 3 & 3 & 1 & 3 & 1 & 3 \\
\hline
\end{tabular}




\begin{tabular}{|r|r|r|r|r|r|r|}
\hline 3 & 1 & 2 & $1-2$ & 1 & 1 \\
\hline 4 \\
\hline 5
\end{tabular}

Caracterización de submuestras en laboratorio

a) Características paleontológicas: En ambas submuestras predominaron los moluscos. En 3a se separaron 198 bioclastos de moluscos que corresponden a 23 taxones del filo, los más abundantes fueron Retrotapes $(n=48)$ y Pteromyrtea $(n=22)$; el resto de los taxones tuvieron un número de individuos bajo (entre 1 y 3 ). Noventa y dos bioclastos no pudieron ser determinados (Tabla 3.18). Con relación al hábito de vida, en $3 a$ el $85 \%$ de los especímenes se asocian a hábitos de vida infaunales (V. Apéndice II).

Tabla 3.18. Riqueza en C3, submuestra 3a.

\begin{tabular}{|c|c|c|c|c|c|}
\hline Taxon & $\mathbf{n}$ & Taxon & $\mathbf{n}$ & Taxon & $\mathbf{n}$ \\
\hline Retrotapes & 48 & Pododesmus & 2 & Naticidae & 2 \\
\hline Pteromyrtea & 22 & Trochita & 2 & Tellinidae & 2 \\
\hline "Pleuromeris" & 3 & Dosinia & 1 & Crasatellidae & 1 \\
\hline Laubrieria & 3 & Ennuncula & 1 & Pectinidae & 1 \\
\hline Nuculana & 3 & Maorimactra & 1 & Turbinidae & 1 \\
\hline Cosa & 2 & Perissondonta & 1 & Indet. & 92 \\
\hline Eulima & 2 & Serratina & 1 & Total & 198 \\
\hline Odostomia & 2 & Turritella & 1 & & \\
\hline Pleuromeris & 2 & Muricidae & 2 & & \\
\hline
\end{tabular}

Por otra parte, en 3b se separó un mayor número de individuos $(n=388)$ y la riqueza fue mayor, en cerca del 50\%, ya que se reconocieron 45 taxones, los más abundantes fueron Turritella $(\mathrm{n}=119)$, Pleuromeris $(\mathrm{n}=41)$ y Trochita $(\mathrm{n}=21)$; Nuculana, Cosa, "Pleuromeris" y Dosinia tuvieron un $n$ entre 10 y 20 , en el resto de los taxones $n<10$. Sesenta y seis bioclastos no pudieron ser determinados (Tabla 3.19). El $66 \%$ de los especímenes se asocian a hábitos epifaunales (V. Apéndice II).

Tabla 3.19. Riqueza en C3, submuestra 3b.

\begin{tabular}{|c|c|c|c|c|c|}
\hline Taxon & $\mathbf{n}$ & Taxon & $\mathbf{n}$ & Taxon & $\mathbf{n}$ \\
\hline Turritella & 119 & Anachis & 2 & Fusiguraleus & 1 \\
\hline Pleuromeris & 41 & Cerithioderma & 2 & Glycymeris & 1 \\
\hline Trochita & 21 & Ennuncula & 2 & Notolimea & 1 \\
\hline Nuculana & 19 & Homalopoma & 2 & Phylobria & 1 \\
\hline
\end{tabular}




\begin{tabular}{|c|c|c|c|c|c|}
\hline Taxon & $\mathbf{n}$ & Taxon & $\mathbf{n}$ & Taxon & $\mathbf{n}$ \\
\hline Cosa & 14 & Kaitoa & 2 & Retizafra & 1 \\
\hline "Pleuromeris" & 10 & Marcia & 2 & Seila & 1 \\
\hline Dosinia & 10 & Neoguraleus & 2 & Terebra & 1 \\
\hline Maorimactra & 8 & Retrotapes & 2 & Zeadmete & 1 \\
\hline Arca & 7 & Solariella & 2 & Naticidae & 5 \\
\hline Pteromyrtea & 6 & Spirogalerus & 2 & Tellinidae & 2 \\
\hline Calliostoma & 5 & Xymenella & 2 & Columbellidae & 1 \\
\hline Pododesmus & 5 & "Cidarina" & 1 & Turbinidae & 1 \\
\hline Serratina & 5 & Austroimbricaria & 1 & Indet. & 66 \\
\hline Ataxocerithium & 3 & Austromarginella & 1 & Total & 389 \\
\hline Eliptotellina & 3 & Cylichnania & 1 & & \\
\hline Scalpomactra & 3 & Cirsonella & 1 & & \\
\hline
\end{tabular}

b) Características tafonómicas. La preservación de los bioclastos de C3 fue de moderada a mala (Fig. 3.10). El $51 \%$ de las conchillas se preservaron incompletas (2) mientras que predominó la alteración superficial de moderada a alta $(2-3, \approx 45 \%)$. Más del $60 \%$ de los bioclastos mostraron redondeamiento (3) y el $90 \%$ baja bioerosión (1). En los bivalvos, el $54 \%$ de las valvas no preservó sus bordes (3). No se observaron diferencias de preservación entre $3 a$ y $3 b$ (Fig. 3.10), en ambas predominaron las conchillas incompletas (2, 55\% 3a; $49 \% 3 \mathrm{~b})$, con alteración superficial de moderada (2, 50\% 3a; $48 \% 3 \mathrm{~b})$ a alta (3, $46 \% 3 a, 40 \% 3 b)$ y redondeamiento $(3,>50 \%$ 3a y $3 b)$. La bioerosión fue baja en más del $90 \%$ de los bioclastos las dos submuestras. En 3a, predominaron las conchillas de bivalvos en las que el borde no se preservaba $(3,70 \%)$, de los preservados predominaron los discontinuos $(2,23 \%)$. En $3 \mathrm{~b}$ la proporción entre conchillas con bordes discontinuos y no preservados fue similar $(2-3, \geq 35 \%)$.

C3

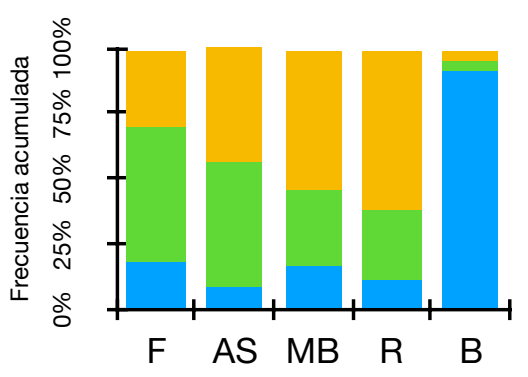

Atributos tafonómicos 3a

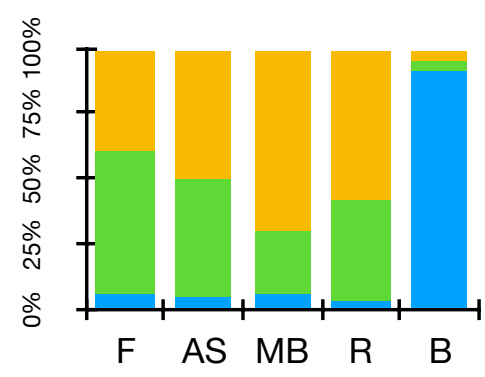

Atributos tafonómicos
$3 b$

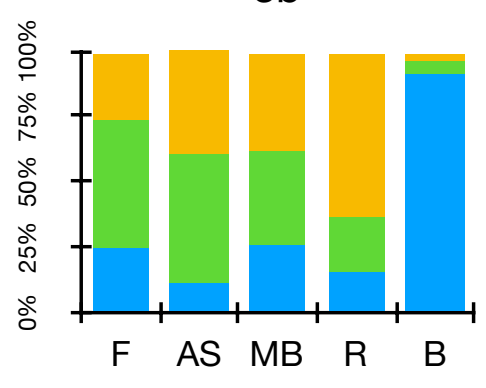

Atributos tafonómicos

Figura 3.10. Frecuencia acumulada de los atributos tafonómicos observados en $C 3$, y en las submuestras 3a y 3b. Fragmentación (F): (1) completo, (2) incompleto, (3) fragmento. Alteración superficial (AS): (1) baja, (2) moderada, (3) alta. Modificación de bordes (MB): (1) continuo, (2) discontinuo, (3) ausente. Redondeamiento (R): (1) ausente, (2) aguzado, (3) redondeado. Bioerosión (B): (1) baja, (2) moderada, (3) alta. Articulación (A): (1) articulado, (2) separado, (3) desarticulado. 1, azul; 2, verde; 3 , amarillo. 
En el tamiz de mayor apertura $(5,660 \mathrm{~mm})$, la preservación fue mala (Tabla 3.20, Apéndice I $\S$ Fig. 13). En 3a y en 3b predominaron bioclastos fragmentados (70\% 3a; $55 \% 3 b)$, con alta alteración superficial $(3,>65 \%$; 3a y 3b)y redondeamiento $(3,63 \% 3 a ; 87 \% 3 b)$. La proporción de bioeorosión baja y alta fue similar en ambas muestras ( 1 y $3, \approx 35 \%$ ). Las trazas más abundantes fueron las de los icnogéneros Entobia, Pennatichnus y Pyrodendrina? (V. Capítulo 4). En ambas submuestras el $50 \%$ de los bivalvos no preservaron el borde; de los preservados predominaron los discontinuos (2, >35\%).

En la malla de 1,190 mm la preservación fue de mala a moderada (Tabla 3.20, Apéndice I $\S$ Fig. 13). En las dos submuestras más del $50 \%$ de las conchillas estaban incompletas (2), en $3 a$ la alteración superficial fue alta $(3,51 \%)$, mientras que en $3 b$ moderada $(2,52 \%)$; en las dos submuestras predominaron las conchillas redondeadas (3, 59\% 3a; $64 \% 3 \mathrm{~b})$ y la bioerosión baja $(1,>90 \%)$.Se reconocieron trazas de Oichnus, Finichnus, y Pennatichnus. (V. Capítulo 4). En $3 a$, el $74 \%$ de los bivalvos no preservaron el margen ventral; de los preservados predominaron los discontinuos $(2,20 \%)$, mientras que en $3 \mathrm{~b}$ la proporción de valvas con borde discontinuo y no preservado fue similar $(2-3, \approx 35 \%)$.

Finalmente, los bioclastos de la malla de $0,710 \mathrm{~mm}$ mostraron una preservación moderada a mala (Tabla 3.20, Apéndice I §Fig. 13). En ambas submuestras predominaron las conchillas incompletas (2, 50\% 3a; $44 \% 3 \mathrm{~b})$, con alteración superficial moderada $(2,54 \%$ $3 a ; 45 \% 3 b)$, redondeamiento $(3,>50 \%)$ y baja bioerosión $(1, \approx 100 \%)$. En el $73 \%$ de los bivalvos de $3 \mathrm{a}$, las conchillas no preservaron el borde; de los preservados predominaron los discontinuos $(2,20 \%)$; en $3 b$, la proporción de conchillas con bordes continuos (1), discontinuos (2) y no preservados (3) fue similar ( $\approx 35 \%)$.

Tabla 3.20. Características Tafonómicas predominantes en 3a y 3b con relación al talle. Como en tabla 3.17. Los gráficos se encuentran en el Apéndice I, Fig. 13.

\begin{tabular}{|c|c|c|c|c|c|}
\hline Malla & Fragmentación & AS & MB & Redondeamiento & Bioerosión \\
\hline \multicolumn{6}{|c|}{$3 a$} \\
\hline 5,660 & 3 & 3 & 3 & 3 & 1 y 3 \\
\hline 1,190 & 2 & 3 & 3 & 3 & 1 \\
\hline 710 & 2 & 2 & 2 & $2-3$ & 1 \\
\hline \multicolumn{6}{|c|}{$3 b$} \\
\hline 5,660 & 3 & 3 & 3 & 3 & 1 y 3 \\
\hline 1,190 & 2 & 2 & $2-3$ & 3 & 1 \\
\hline 710 & 2 & 2 & $1-3$ & 3 & 1 \\
\hline
\end{tabular}

Fragmentación versus otras características tafonómicas

Al analizar los atributos tafonómicos en relación al grado de fragmentación, se observó que la preservación de las conchillas completas fue buena; en 3a el número de bioclastos 
completos fue bajo $(n=12)$ en comparación con $3 b$; sin embargo, se aprecian índices tafonómicos similares (Tabla 3.21, Apéndice I §Fig. 14). En ambas muestras predominaron los bioclastos con alteración superficial moderada $(2, \approx 60 \%)$ y baja bioerosión $(\approx 100 \%)$; no mostraron redondeamiento (1) más del $50 \%$ de los bioclastos de cada submuestra. En el caso de los bivalvos, más del $60 \%$ mostraron bordes continuos (1).

Los bioclastos incompletos de ambas submuestras tuvieron una preservación de moderada a mala (Tabla 3.21, Apéndice I §Fig.14). En ambas submuestras, la alteración superficial fue de moderada a alta $(2-3, \approx 45 \%)$ y la bioerosión baja $(1,>90 \%)$. En 3a la proporción de bioclastos aguzados y redondeados fue similar $(2-3, \approx 50 \%)$; en $3 b$ predominaron los redondeados $(3,73 \%)$. En $3 a$ predominaron las valvas sin bordes $(3$, $68 \%)$, mientras que en $3 \mathrm{~b}$ lo hicieron aquellas de borde discontinuo $(2,53 \%)$.

La preservación de los fragmentos fue mala (Tabla 3.21, Apéndice I §Fig. 14); en ambas muestras se observó alteración superficial alta $(3,>50 \%)$, redondeamiento $(3,>65 \%)$ y baja bioerosión (1,>80\%). Aproximadamente el $80 \%$ de los bivalvos no preservaron el borde (3); de los preservados predominaron los discontinuos (2, 10-11\%).

Tabla 3.21. Características Tafonómicas predominantes en $3 a$ y $3 b$ en relación a la fragmentación (conchillas completas, incompletas y fragmentos). Referencias como en tabla 3.17. Los gráficos se encuentran en el Apéndice I, Fig. 14.

\begin{tabular}{|c|c|c|c|c|}
\hline Fragmentación & AS & MB & Redondeamiento & Bioerosión \\
\hline \multicolumn{5}{|c|}{$3 a$} \\
\hline Completas & 2 & 1 & 1 & 1 \\
\hline Incompletas & $2-3$ & 3 & $2-3$ & 1 \\
\hline Fragmentos & 3 & 3 & 3 & 1 \\
\hline \multicolumn{5}{|c|}{$3 b$} \\
\hline Completas & 2 & 1 & 1 & 1 \\
\hline Incompletas & $2-3$ & 2 & 3 & 1 \\
\hline Fragmentos & 3 & 3 & 3 & 1 \\
\hline
\end{tabular}

\section{Fragmentación y talle versus otras características tafonómicas}

Al evaluar la preservación de los bioclastos con relación a su fragmentación y talle, se observó que su preservación fue principalmente moderada y mala (Tabla 3.22, Apéndice I § Figs. 15-17). En la malla de mayor apertura, 5,660 mm, el número de bioclastos completos fue menor a 5 en las dos submuestras, de guisa que no fueron considerados para ser graficados, sin embargo se observó una preservación moderada, con similar proporción de bioclastos con alteración superficial baja, moderada y alta, redondeamiento y baja bioerosión. En las conchillas de bivalvos predominaron los bordes discontinuos. Por otra parte, los bioclastos completos de la malla 1,190 mm mostraron una buena preservación (Tabla 3.22, Apéndice I §Fig. 15). En 3a el número de bioclastos fue bajo $(n=10)$ sin embargo la preservación de estos fue similar a la de 3b (Tabla 3.22), en donde predominó la alteración superficial moderada $(2,63 \%)$, sin redondeamiento $(1,61 \%)$ y baja bioerosión (1, $97 \%$ ). En los bivalvos, predominaron las conchillas con bordes continuos (1,69\%). En los 
bioclastos completos en la malla de menor apertura, $0,710 \mathrm{~mm}$, también se observó buena preservación (Tabla 3.22, Apéndice I §Fig. 15); en 3a $(n=3)$, todos los bioclastos tuvieron una alteración superficial moderada (2), sin redondeamiento (1) y baja bioerosión (1). Las valvas de bivalvos tenían borde continuo (1). En 3b, con un número de especímenes mayor, se observó una preservación similar; el $46 \%$ de ellos mostró alteración superficial moderada (2), el $74 \%$ no mostró redondeamiento (1) y la bioerosión fue baja en el $100 \%$. Más del $70 \%$ de los bivalvos preservaron bordes continuos.

Los bioclastos incompletos mostraron una preservación entre moderada y mala (Tabla 3.22, Apéndice I §Fig.16). En la malla 5,660 mm, nuevamente el número de individuos en las dos submuestras fue bajo, ( $3 a n=6 ; 3 b n=5)$; estos mostraron alteración superficial de moderada a alta (2-3) y bioerosión de moderada a alta (2-3). Se observaron principalmente trazas de Pennatichnus, Finichnus y Entobia. La proporción de individuos sin redondeamiento, aguzados y redondeados fue similar. En los bivalvos predominaron en proporción similar las conchillas con bordes discontinuos y no preservados. En la malla $1,190 \mathrm{~mm}$, se observó diferente preservación entre 3a y 3b (Tabla 3.22, Apéndice I § Fig. 16); en $3 a$ fue mala, predominaron la alteración superficial alta $(3,53 \%)$, el redondeamiento $(3,54 \%)$ y la baja bioerosión (1, 100\%); el $72 \%$ de las conchillas de bivalvos no preservaba bordes (3), en el $24 \%$ restante se preservaron bordes discontinuos. En 3b, la preservación fue moderada; la proporción de conchillas con alteración superficial moderada y alta fue similar $(2-3, \approx 47 \%)$, mientras que predominó el redondeamiento $(3,74 \%)$ y la baja bioerosión (1,91\%). El 55\% de los bivalvos mostraron borde discontinuo. En la malla 0,710 $\mathrm{mm}$ la preservación de los bioclastos fue de moderada a mala en ambas muestras (Tabla 3.22, Apéndice I § Fig. 16). En las dos submuestras predominó la alteración superficial moderada $(2,56 \% 3 a ; 45 \% 3 b)$ y la bioerosión baja $(1, \approx 100 \%)$. En 3a la proporción de conchillas aguzadas y redondeadas fue similar $(2-3, \approx 50 \%)$ y en $3 b$ predominaron las redondeadas $(3,70 \%)$. En 3a predominaron las conchillas de bivalvos sin borde $(3,68 \%)$ y en $3 \mathrm{~b}$ las de borde discontinuo $(2,47 \%)$.

Finalmente, en los fragmentos la preservación de los bioclastos fue mala (Tabla 3.22, Apéndice I \$Fig. 17). En la malla $5,660 \mathrm{~mm}$, en $3 \mathrm{~b}$ el número de bioclastos fue apenas mayor a $10(n=12)$, en los que predominaron los índices altos para todos los atributos tafonómicos. En $3 a$, el $76 \%$ de los bioclastos mostró alta alteración superficial (3), el $71 \%$ redondeamiento (3) y el $41 \%$ alta bioerosión (3); principalmente se observaron trazas de Pennatichnus, Finichnus y Entobia (V. Capítulo 4). En los bivalvos, el $65 \%$ no preservó el borde. En la malla de 1,190 mm en las dos submuestras predominó la alteración superficial de moderada a alta $(2-3, \approx 50 \%)$, el redondeamiento $(3,71 \% 3 \mathrm{a} ; 80 \% 3 \mathrm{~b})$ y la baja bioerosión $(1,>90 \%)$. Más del $80 \%$ de las conchillas de bivalvos no preservaron el borde (3) (Tabla 3.22, Apéndice I §Fig. 17). En la malla 0,710 en 3a la alteración superficial fue alta $(3,55 \%)$, en $3 \mathrm{~b}$ la proporción entre moderada y alta fue similar $(2-3, \approx 45 \%)$. En ambas predominaron los bioclastos redondeados $(3,64 \% 3 \mathrm{a} ; 81 \% 3 \mathrm{~b})$ y bioerosión baja $(1,91 \%$ $3 a, 100 \% 3 b$ ); más del $80 \%$ de los bivalvos no preservaban el borde (3) (Tabla 3.22 . Apéndice I §Fig. 17). 
Tabla 3.22. Características Tafonómicas predominantes en conchillas completas, incompletas y fragmentos de $3 a$ y $3 b$. Referencias igual que para tabla 3.17. Los gráficos se encuentran en el Apéndice I, Figs. 15, $16,17$.

\begin{tabular}{|c|c|c|c|c|c|}
\hline $\mathbf{F}$ & Malla & AS & MB & Redondeamiento & Bioerosión \\
\hline \multicolumn{6}{|c|}{$3 a$} \\
\hline \multirow{7}{*}{$\mathrm{C}$} & 5,660 & & & & \\
\hline & 1,190 & 2 & 1 & 1 y 3 & 1 \\
\hline & 710 & 2 & 2 & 1 & 1 \\
\hline & \multicolumn{5}{|c|}{$3 b$} \\
\hline & \multicolumn{5}{|l|}{5,660} \\
\hline & 1,190 & 2 & 1 & 1 & 1 \\
\hline & 710 & 2 & 1 & 1 & 1 \\
\hline \multirow{8}{*}{ I } & \multicolumn{5}{|c|}{$3 a$} \\
\hline & 5,660 & & & & \\
\hline & 1,190 & 3 & 3 & 3 & 1 \\
\hline & 710 & 2 & 3 & $2-3$ & 1 \\
\hline & \multicolumn{5}{|c|}{$3 b$} \\
\hline & \multicolumn{5}{|l|}{5,660} \\
\hline & 1,190 & $2-3$ & 2 & 3 & 1 \\
\hline & 710 & 2 & 2 & 3 & 1 \\
\hline \multirow{8}{*}{ F } & \multicolumn{5}{|c|}{$3 a$} \\
\hline & 5,660 & 3 & 3 & 3 & 3 \\
\hline & 1,190 & $2-3$ & 3 & 3 & 1 \\
\hline & 710 & 3 & 3 & 3 & 1 \\
\hline & \multicolumn{5}{|c|}{$3 b$} \\
\hline & 5,660 & 3 & 3 & 3 & 3 \\
\hline & 1,190 & $2-3$ & 3 & 3 & 1 \\
\hline & 710 & $2-3$ & 3 & 3 & 1 \\
\hline
\end{tabular}

Taxones y características tafonómicas

Con la finalidad de saber si había alguna diferencia en la calidad de preservación de los diferentes taxones reconocidos, se observaron de manera separada y semicuantitativa las características tafonómicas de los taxones más abundantes (Tablas 3.23, 3.24 y 3.25). De las muestras en campo se observó la preservación de los géneros Pteromyrtea y Turritella (Tabla 3.23, Apéndice I §Fig. 18). La preservación de las conchillas de Pteromyrtea fue buena, el $48 \%$ de las valvas se preservaron completas (1), predominó la alteración superficial moderada $(2,55 \%)$ y la bioerosión baja $(1,66 \%)$. La proporción de valvas sin redondeamiento y aguzadas fue similar $(1-2, \approx 35 \%)$ al igual que la de bordes continuos y 
discontinuos $(1-2, \approx 35 \%)$. Turritella tuvo una preservación moderada, el $56 \%$ de las conchillas se preservaron incompletas (2), con alteración superficial moderada (2, 44\%), bordes aguzados $(2,88 \%)$ y baja bioerosión $(1,44 \%)$.

Tabla 3.23. Características Tafonómicas predominantes en los taxones más abundantes en los cuadros de C3. Referencias
como en tabla 3.17. Los gráficos se encuentran en el Apéndice I, Fig. 18.
\begin{tabular}{|c|c|c|c|c|c|c|}
\hline Taxón & Fragmentación & AS & Redondeamiento & Bioerosión & MB & Articulación \\
\hline Pteromyrtea & 1 & 2 & $1-2$ & 1 & $1-2$ & 3 \\
\hline Turritella & 2 & 2 & 2 & 1 & & \\
\hline
\end{tabular}

Para las submuestras procesadas en laboratorio, en 3a se consideraron los géneros Retrotapes y Pteromyrtea y en 3b, Turritella, Pleuromeris y Trochita (Tablas 3.24, 3.25, V. Apéndice I $\S$ Figs. 19 y 20). Las conchillas de Retrotapes tuvieron una preservación moderada, el $75 \%$ se conservaron incompletas (2), con alteración superficial de moderada a alta $(2-3, \approx 50 \%)$; La proporción de valvas aguzadas y redondeadas fue igual $(2-3,50 \%)$; entre los margenes ventrales preservados, predominaron los discontinuos $(2, \approx 50 \%)$. La bioerosión fue baja (1, 98\%). De la misma submuestra, Pteromyrtea mostró una preservación moderada, el $55 \%$ de las conchillas se preservaron incompletas (2), la alteración superficial fue moderada $(2,64 \%)$ y predominaron las valvas aguzadas $(2,55 \%)$. La proporción de valvas con borde discontinuo y ausente fue igual (2-3,50\%). La bioerosión fue baja (1,73\%).

Tabla 3.24. Características Tafonómicas predominantes en los taxones más abundantes en 3a. Referencias como en tabla 3.17. Los gráficos se encuentran en el Apéndice I, Fig. 19.

\begin{tabular}{|c|c|c|c|c|c|}
\hline Taxón & Fragmentación & AS & Redondeamiento & Bioerosión & MB \\
\hline Retrotapes & 2 & $2-3$ & $2-3$ & 1 & 2 \\
\hline Pteromyrtea & 2 & 2 & 2 & 1 & $2-3$ \\
\hline
\end{tabular}

En 3b, se consideraron Turritella, Pleuromeris y Trochita (Tabla 3.25, Apéndice I § Fig. 20). La preservación de Turritella fue moderada; el 53\% de las conchillas se preservaron incompletas (2), la alteración superficial fue moderada $(2,51 \%)$ y más del $70 \%$ estaban redondeadas (3). La bioerosión fue baja (1) en casi el 90\%. Pleuromeris tuvo una buena preservación, predominaron las valvas completas (1,46\%), con alteración superficial moderada $(2,61 \%)$, redondeamiento $(3,61 \%)$ y baja bioerosión $(1,95 \%)$. La proporción de valvas con bordes continuos y discontinuos fue similar $(1-2, \approx 37 \%)$. Finalmente el género Trochita tuvo una preservación de moderada a mala. Predominaron las conchillas incompletas $(2,76 \%)$, la alteración superficial alta $(3,70 \%)$ y el redondeamiento $(3,45 \%)$. La bioerosión fue baja (1, 81\%). 
Tabla 3.25. Características Tafonómicas predominantes en los taxones más abundantes en 3b. Referencias como en tabla 3.17. Los gráficos se encuentran en el Apéndice I, Fig. 20.

\begin{tabular}{|c|c|c|c|c|c|}
\hline Taxón & Fragmentación & AS & Redondeamiento & Bioerosión & MB \\
\hline Turritella & 2 & 2 & 3 & 1 & \\
\hline Pleuromeris & 1 & 2 & 3 & 1 & $1-2$ \\
\hline Trochita & 2 & 3 & 3 & 1 \\
\hline
\end{tabular}

Hábitos de vida y características tafonómicas.

Con la finalidad de saber si existen diferencias en la calidad de preservación de organismos infaunales y epifaunales, se reconocieron de manera separada y semicuantitativa las características tafonómicas en ambos grupos y analizando separadamente los datos de campo y laboratorio (Tabla 3.26, Apéndice I § Fig. 21). Del scoring de los cuadros en campo, los bioclastos correspondientes a organismos infaunales mostraron una preservación moderada (Tabla 3.26, Apéndice I § Fig. 21). Predominaron los bioclastos completos $(1,43 \%)$, con alteración superficial de moderada a alta $(2-3, \geq 45 \%)$; la proporción de aquellos aguzados y redondeados fue similar $(2-3, \approx 35 \%)$ y la bioerosión predominate fue baja $(1,65 \%)$. En los bivalvos, la proporción de conchillas con bordes continuos y discontinuos fue similar $(1-2, \approx 35 \%)$ y predominaron las desarticuladas (3, $82 \%)$. Los bioclastos correspondientes a hábitos epifaunales también mostraron una preservación moderada (Tabla 3.26, Apéndice I § Fig. 21). Predominaron conchillas completas $(1,44 \%)$, con alteración superficial entre moderada y alta $(2-3, \geq 44 \%)$, sin redondeamiento $(2,50 \%)$ y baja bioerosión $(1,75 \%)$. En bivalvos predominaron las valvas con márgenes continuos $(1,60 \%)$ y desarticuladas $(3,100 \%)$.

De la submuestra 3a, los bioclastos de organismos infaunales mostraron una preservación de moderada a mala (Tabla 3.26, Apéndice I § Fig. 21). El 58\% estaban incompletos (2), con alteración superficial de moderada a alta $(2,46 \% ; 3,51 \%)$, redondeamiento $(3,56 \%)$ y baja bioerosión (1,90\%). El 73\% de las conchillas de bivalvos no preservaban el borde (3). Los bioclastos de epifaunales tuvieron una preservación moderada (Tabla 3.26, Apéndice I §Fig. 21); la proporción de completos, incompletos y fragmentos fue similar (1-3, $35 \%)$; con alteración superficial de moderada a alta $(2-3, \geq 41 \%)$, aguzados $(2,72 \%)$ y baja bioerosión (1,97\%). El 50\% de las valvas preservaron el margen ventral continuo (1).

En la submuestra 3b, los bioclastos de organismos infaunales tuvieron una preservación de moderada a mala (Tabla 3.26, Apéndice I §Fig. 21); predominaron las conchillas incompletas $(2,46 \%)$ con alteración superficial de moderada a alta $(2-3, \geq 48 \%)$, redondeamiento $(3,53 \%)$ y baja bioerosión $(1,91 \%)$. En los bivalvos, predominaron las conchillas cuyo borde no se preservaba (3,46\%); de los bordes preservados, predominaron los discontinuos (2,34\%). Los bioclastos de organismos epifaunales tuvieron una preservación moderada (Tabla 3.26, Apéndice I §Fig. 21). El 52\% de los bioclastos estaban incompletos (2, 52\%), la alteración superficial fue moderada $(2,52 \%)$; el $68 \%$ mostró redondeamiento (3) y el $92 \%$ baja bioerosión (1). La proporción de valvas con márgenes continuos y discontinuos fue similar $(1-2, \geq 37 \%)$. 
Tabla 3.26. Características Tafonómicas predominantes en C3 con relación al hábito de vida. Referencias como en tabla 3.17. Los gráficos se encuentran en el Apéndice I, Fig. 21.

\begin{tabular}{|c|c|c|c|c|c|c|}
\hline Hábito & Submuestra & Fragmentación & AS & Redondeamiento & Bioerosión & MB \\
\hline \multirow{3}{*}{ 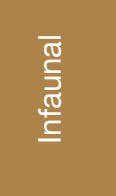 } & Cuadros & 1 & $2-3$ & $2-3$ & 1 & $1-2$ \\
\hline & $3 a$ & 2 & $2-3$ & 3 & 1 & 3 \\
\hline & $3 b$ & 2 & $2-3$ & 3 & 1 & 3 \\
\hline \multirow{3}{*}{ 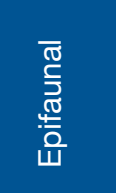 } & Cuadros & 1 & $2-3$ & 1 & 1 & 1 \\
\hline & $3 a$ & $1-3$ & 2 & 2 & 1 & 1 \\
\hline & $3 b$ & 2 & 2 & 3 & 1 & $1-2$ \\
\hline
\end{tabular}




\section{Concentración $4(\mathrm{C} 4)$}

\section{Caracterización en campo}

a) Características sedimentológicas y estratigráficas: Concentración de espesor variable, entre 35 y $60 \mathrm{~cm}$, con geometría de capa (Fig. 3.11a), matriz de arena fina a media de color amarillo pálido-grisáceo. Empaquetamiento clasto soportado, denso en la base y suelto hacia el techo, selección bimodal (Fig. 3.11b). Contacto basal ondulado, en algunos sectores se observan vainas con contactos bioturbados (Fig. 3.11a, c). Los bioclastos en la base mostraron una orientación concordante con agrupamiento apilado, en el techo la orientación es oblicua con agrupamiento apilado (Fig. 3.11d). Las variaciones estratigráficas y sedimentológicas observadas tanto lateral como verticalmente a lo largo de la concentración permiten sugerir que es una concentración compleja (sensu Kidwell et al., 1985). En esta concentración se realizó el scoring de 9 cuadros, separados entre sí por una distancia de $1 \mathrm{~m}$, excepto los cuadros 7 y 8 cuya distancia de separación fue de 1,5 m. En cada uno se evaluaron las características tafonómicas y paleontológicas de un máximo de 30 bioclastos elegidos de manera aleatoria.

b) Características paleontológicas: En esta concentración predominaron los moluscos, se reconocieron 25 taxones del filo (Tabla 3.27, V. Apéndice II), siendo más abundantes los géneros Turritella y Dosinia ( $\mathrm{n}=30$ y 27 respectivamente); 70 bioclastos no pudieron ser designados a una categoría taxonómica inferior a clase y 3 fragmentos no pudieron ser asignados a nivel de clase. La riqueza taxonómica sugiere que esta concentración es poliespecífica. Con relación al hábito de vida, predominaron ligeramente aquellos de hábitos epifaunales (V. Métodos y Apéndice II), el espectro de edad observado fue mixto. Predominaron los elementos aragoníticos, también se encontraron calcíticos, pero en menor proporción.

Como fauna acompañante se encontraron restos de briozoos, placas de equinodermos con alta fragmentación y alteración superficial y braquiópodos desarticulados con preservación de buena a moderada.

Tabla 3.27 Riqueza de C4 en campo.

\begin{tabular}{|c|c|c|c|c|c|}
\hline Taxón & $\mathbf{n}$ & Taxón & $\mathbf{n}$ & Taxón & $\mathbf{n}$ \\
\hline Turritella & 30 & Arca & 1 & Trochidae & 5 \\
\hline Dosinia & 27 & Epitonium & 1 & Pectinidae & 3 \\
\hline Pleuromeris & 22 & Glycymeris & 1 & Acteonideae & 1 \\
\hline Calyptraea & 9 & Mactra & 1 & Muricidae & 1 \\
\hline Xymenella & 9 & Maorimactra & 1 & Phylobridae & 1 \\
\hline Solariella & 8 & Trophon & 1 & Indet. & 76 \\
\hline Lucinidae & 7 & Naticidae & 16 & Total & 255 \\
\hline Ostrea & 7 & Lucinidae & 7 & Braquiópodo & 1 \\
\hline Panopea & 7 & Veneridae & 6 & & \\
\hline Zygochlamys & 2 & Carditidae & 5 & & \\
\hline
\end{tabular}




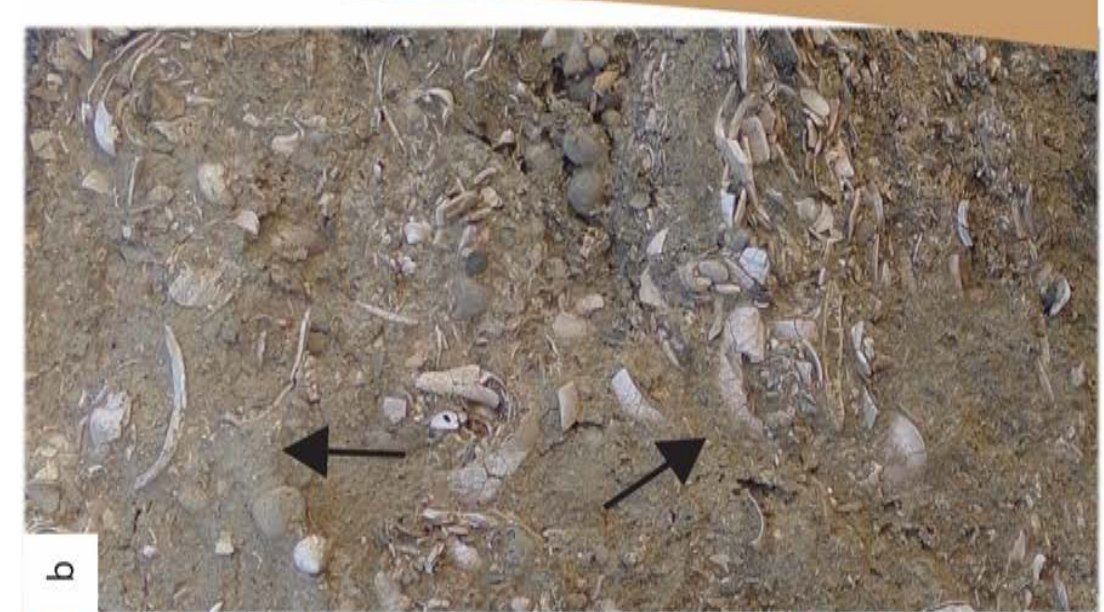

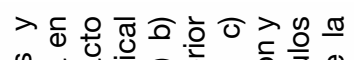

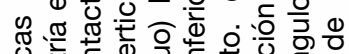

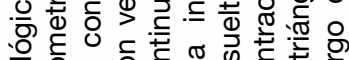

응 o 0 :

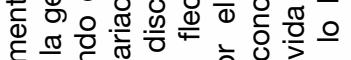

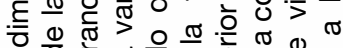

0
0

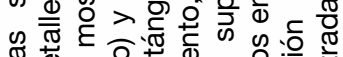

它 卷

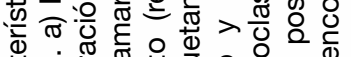

苋过芒

ऽ̄ ⿺辶寸

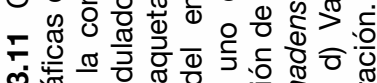

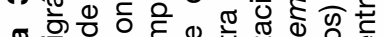

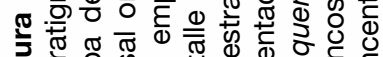

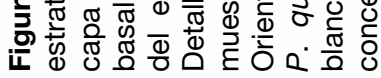
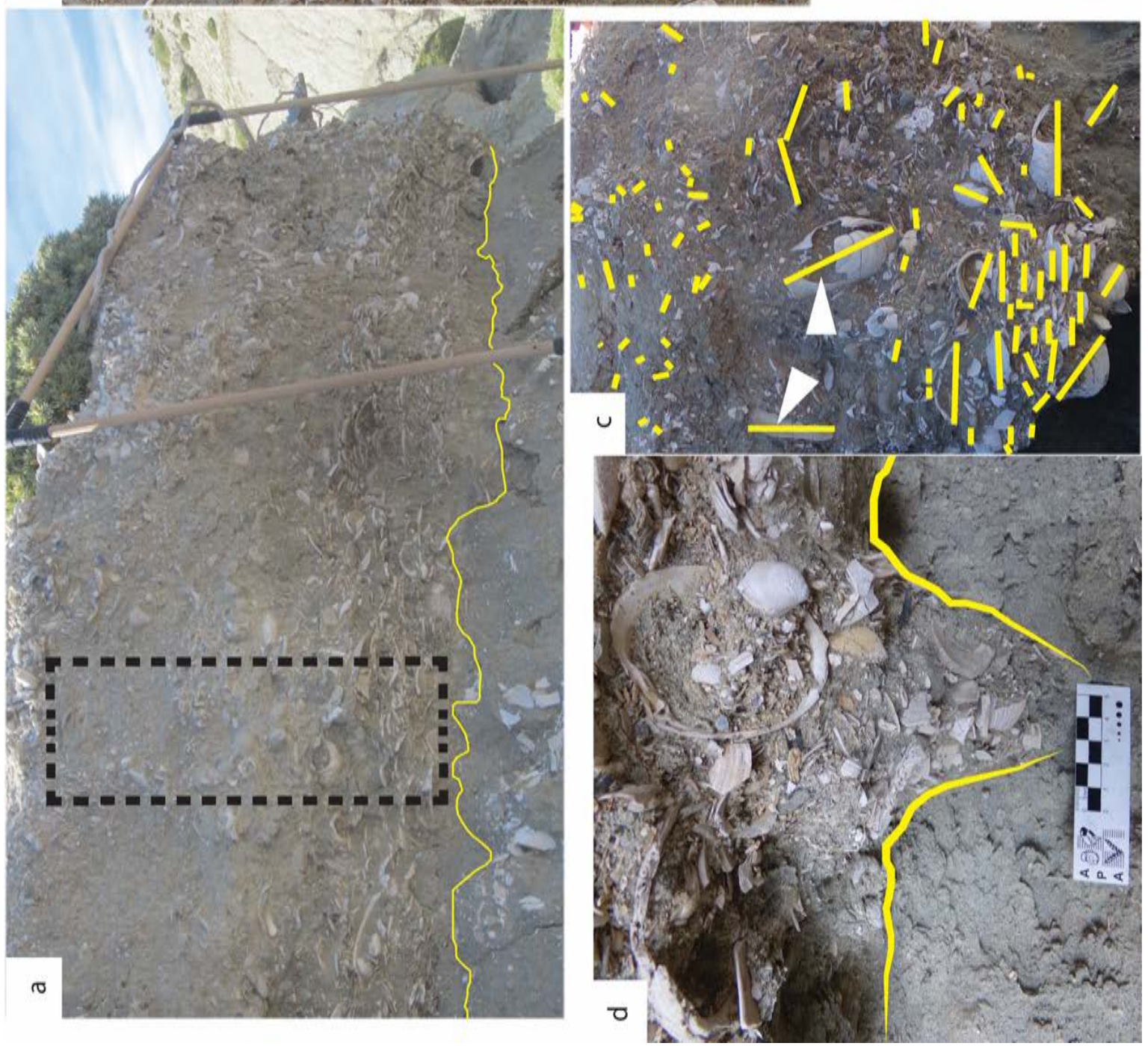
c) Características tafonómicas: La preservación promedio de la concentración es moderada (Tabla 3.28, Apéndice I §Fig. 22). Predominaron conchillas incompletas (2, 40\%), con alta alteración superficial $(3,50 \%)$, más de $50 \%$ de los bioclastos mostraron redondeamiento (3) y en el $61 \%$ de los especímenes la bioerosión fue baja (1), sin embargo en gran parte de los bioclastos se observó la presencia de al menos un icnotaxón. En cuanto a los bivalvos, la proporción entre márgenes continuos, discontinuos y ausentes fue similar $(1-3, \approx 30 \%)$ y la mayoría de las valvas estaban desarticuladas (3, 90\%).

Tabla 3.28:Frecuencia acumulada de los atributos tafonómicos observados en C4, y en las submuestras 4a y 4b. Fragmentación (F): (1) completo, (2) incompleto, (3) fragmento. Alteración superficial (AS): (1) baja, (2) moderada, (3) alta. Modificación de bordes (MB): (1) continuo, (2) discontinuo, (3) ausente. Redondeamiento (R): (1) ausente, (2) aguzado, (3) redondeado. Bioerosión (B): (1) baja, (2) moderada, (3) alta. Articulación (A): (1) articulado, (2) separado, (3) desarticulado. 1, azul; 2, verde; 3, amarillo; NV (no visible), violeta. Los gráficos de cada cuadrante se encuentran en el Apéndice I, Fig. 1.Los gráficos de cada cuadrante se encuentran en el Apéndice I Fig. 11. Los gráficos de cada cuadrante se encuentran en el Apéndice I, Fig. 22.

\begin{tabular}{|r|r|r|r|r|r|r|}
\hline Cuadro & Fragmentación & \multicolumn{1}{|c|}{ AS } & MB & Redondeamiento & Bioerosión & Articulación \\
\hline 1 & 3 & 3 & 1 & 2 & 1 & 3 \\
\hline 2 & 3 & 3 & 1 & 2 & 1 \\
\hline 3 & $1-2$ & 3 & 2 & 2 & 1 & 3 \\
\hline 4 & 2 & $2-3$ & $1-2$ & 2 & 1 & 3 \\
\hline 5 & 1 & $2-3$ & $1-3$ & 3 & 1 & 3 \\
\hline 6 & 2 & $2-3$ & 3 & 3 & 1 & 3 \\
\hline 7 & 2 & 3 & 2 & 2 & 1 & 3 \\
\hline 8 & 2 & $2-3$ & 3 & 2 & 1 & 3 \\
\hline 9 & 1 & 3 & 3 & 3 & 1 y 3 & 3 \\
\hline $\mathbf{C 4}$ & $\mathbf{1 - 2}$ & $\mathbf{2 - 3}$ & $\mathbf{1 - 3}$ & $\mathbf{3}$ & $\mathbf{1}$ & $\mathbf{3}$ \\
\hline
\end{tabular}

Caracterización de submuestras en laboratorio

a) Características paleontológicas: En la muestra 4a predominaron conchillas de moluscos, se separaron 671 especímenes de moluscos que corresponden a 68 taxones (Tabla 3.29); siendo más abundantes los géneros Turritella $(n=203)$, Cosa $(n=53)$, Pleuromeris $(n=40)$ y Nuculana ( $n=37$ ), para el resto de los taxones la ocurrencia mostró un $n$ menor a 20 . Con relación al hábito de vida, el $53,9 \%$ de los taxones se relacionan con hábitos epifaunales $(\underline{V}$. Métodos y Apéndice II).

Tabla 3.29 Riqueza taxonómica en C4 muestra 4a

\begin{tabular}{|c|c|c|c|c|c|c|c|}
\hline Taxón & $\mathbf{n}$ & Taxón & $\mathbf{n}$ & Taxón & $\mathbf{n}$ & Taxón & $\mathbf{n}$ \\
\hline Turritella & 203 & Trochita & 5 & Ennuncula & 2 & Mathilda & 1 \\
\hline Cosa & 53 & Xymenella & 5 & Epitonium & 2 & Miomelon & 1 \\
\hline Pleuromeris & 40 & Anachis & 4 & Eulima & 2 & Neilo & 1 \\
\hline Nuculana & 37 & Caliptraea & 4 & Homalopoma & 2 & Notolimea & 1 \\
\hline Maorimactra & 20 & Fusiguraleus & 4 & Kaitoa & 2 & Pitar & 1 \\
\hline Retrotapes & 17 & Serratina & 4 & Laubrieria & 2 & Saxicava & 1 \\
\hline
\end{tabular}




\begin{tabular}{|c|c|c|c|c|c|c|c|}
\hline Taxón & $\mathbf{n}$ & Taxón & $\mathbf{n}$ & Taxón & $\mathbf{n}$ & Taxón & $\mathbf{n}$ \\
\hline "Pleuromeris" & 16 & Capulus & 3 & Nucula & 2 & Tenuiacteon & 1 \\
\hline Arca & 14 & Lissarca & 3 & Panopea & 2 & Crassatellidae & 1 \\
\hline Phorcus & 8 & Marcia & 3 & Retizafra & 2 & Lucinidae & 4 \\
\hline Condylocuna & 7 & Pododesmus & 3 & Scaeoleda & 2 & Mathildidae & 1 \\
\hline Odostomia & 7 & Polinices & 3 & Seila & 2 & Montacutinae & 15 \\
\hline Philobrya & 7 & Sigapatella & 3 & Varinucula & 2 & Naticidae & 1 \\
\hline Eliptotellina & 6 & Austromarginella & 2 & Zeadmete & 2 & Pholadidae & 1 \\
\hline Ataxocerithium & 5 & Cerithium & 2 & Acteon & 1 & Veneridae & 1 \\
\hline Calliostoma & 5 & Cyclocardia & 2 & Cerithioderma & 1 & Indet. & 92 \\
\hline Kellia & 5 & Cyamiomactra & 2 & Cerithiopsis & 1 & Total & 670 \\
\hline Mysella & 5 & Dendropoma & 2 & Diplodonta & 1 & & \\
\hline Solariella & 5 & Eatoniella & 2 & Ellobia & 1 & & \\
\hline
\end{tabular}

En la muestra 4b, también predominaron los fósiles de moluscos ( $n=668$ ); se reconocieron 68 taxones, siendo los más abundantes Turritella $(n=144)$, Maorimactra $(n=41)$, Pleuromeris $(n=41)$, Cosa $(n=38)$ y Dosinia $(n=21)$; la ocurrencia del resto de los taxones fue menor o igual a 20 (Tabla 3.30). El 48.8\% de los taxones reconocidos se asocia a hábitos de vida epifaunales (V. Métodos y Apéndice II).

En ambas submuestras como fauna acompañante, se observaron valvas desarticuladas de braquiópodos, placas desarticuladas de balanos, fragmentos de briozoos y equinodermos.

Tabla 3.30. Riqueza en C4 submuestra 4b.

\begin{tabular}{|c|c|c|c|c|c|c|c|}
\hline Taxón & $n$ & Taxón & n & Taxón & n & Taxón & n \\
\hline Turritella & 144 & Neilo & 4 & Eurhomalea & 2 & “Ostrea” & 1 \\
\hline Maorimactra & 41 & Serratina & 4 & Muricidae & 2 & Ostrea & 1 \\
\hline Pleuromeris & 41 & Trochita & 4 & Naticidae & 2 & Penion & 1 \\
\hline Cosa & 38 & Xymenella & 4 & Ocenebra & 2 & Ficus & 1 \\
\hline Dosinia & 21 & Anachis & 3 & Phorcus & 2 & Polinices & 1 \\
\hline "Pleuromeris" & 20 & Asaphis & 3 & Pyramidellidae & 2 & Seila & 1 \\
\hline Nuculana & 15 & Calliostoma & 3 & Scalpomactra & 2 & Trophon & 1 \\
\hline Solariella & 14 & Calyptraea & 3 & Tenuiacteon & 2 & Valdesia & 1 \\
\hline Arca & 12 & Cirsonella & 3 & Acteon & 1 & Zeadmete & 1 \\
\hline Odostomia & 11 & Corbula & 3 & Brocchia & 1 & Buccinidae & 1 \\
\hline Brookula & 8 & Homalopoma & 3 & Cardites & 1 & Galeommatidae & 1 \\
\hline Diplodonta & 8 & Kaitoa & 3 & Caryocorbula & 1 & Newtonellidae & 1 \\
\hline
\end{tabular}




\begin{tabular}{|c|c|c|c|c|c|c|c|}
\hline Taxón & $\mathbf{n}$ & Taxón & $\mathbf{n}$ & Taxón & $\mathbf{n}$ & Taxón & $\mathbf{n}$ \\
\hline Sigapatella & 7 & Mysella & 3 & Eatoniella & 1 & Pholadidae & 1 \\
\hline Perissodonta & 6 & Philobrya & 3 & Fuegotrophon & 1 & Rissoinidae & 1 \\
\hline Ataxocerithium & 4 & Pyramidella & 3 & Fusiguraleus & 1 & Tornidae & 1 \\
\hline Condylocuna & 4 & Austroginella & 2 & Glycymeris & 1 & Indet. & 167 \\
\hline Cyamiomactra & 4 & Cardita & 2 & Mathilda & 1 & Total & 665 \\
\hline Limea & 4 & Eulima & 2 & Neoguraleus & 1 & & \\
\hline
\end{tabular}

b) Características tafonómicas: La preservación de los bioclastos de esta concentración fue moderada (Fig. 3.12). El 38\% de las conchillas están incompletas (2), con alteración superficial de moderada a alta $(2-3, \approx 43 \%)$ y redondeamiento $(3,>50 \%)$; la bioerosión fue baja $(1,87 \%)$ a pesar de que la icnodiversidad fue elevada (V. Capítulo 4). En el $34 \%$ de las conchillas de bivalvos preservadas, el margen ventral es discontinuo (2) y en el $38 \%$ este no se preservó (3).

En la submuestra 4a la preservación fue moderada (Fig. 3.12), los bioclastos se preservaron completos e incompletos en proporción similar (1-2, $\approx 38 \%)$; se observó alteración superficial moderada a alta $(2,46 \% ; 3,40 \%)$ y redondeamiento $(3,60 \%)$, la bioerosión fue baja $(1,93 \%)$ y en el $42 \%$ las valvas de bivalvos el margen ventral no se preservó. Por otra parte, en la submuestra $4 \mathrm{~b}$, los bioclastos mostraron proporciones de fragmentación similares entre completas (1), incompletas (2) y fragmentos (3); con alteración superficial moderada a alta $(2,40-3,44 \%)$ y redondeamiento $(3,63 \%)$. a bioerosión fue baja (1, 81\%). Al igual que en la fragmentación en los bivalvos, en la modificación de bordes se observaron valores similares entre continuos (1,30\%), discontinuos (2,36\%) y no preservados (3, 34\%) (Fig. 3.12).

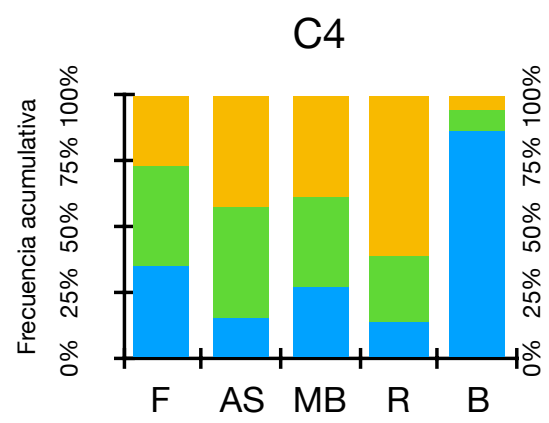

Atributos tafonómicos

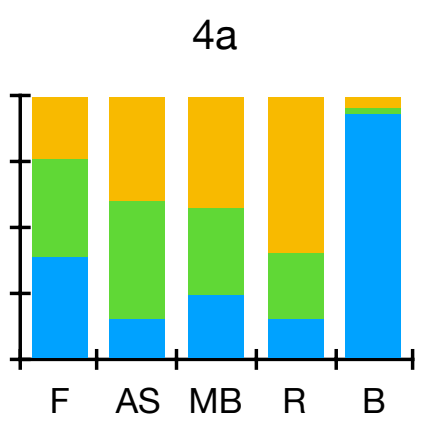

Atributos tafonómicos

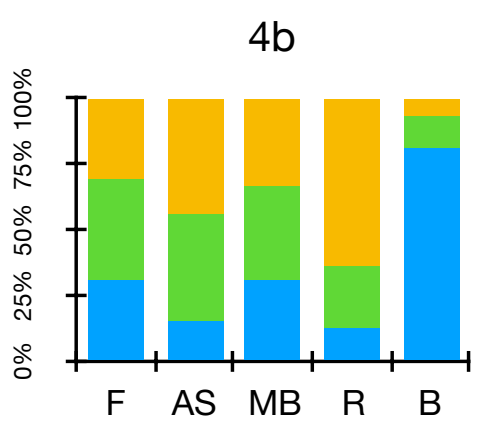

Atributos tafonómicos

Figura 3.12.Frecuencia acumulada de los atributos tafonómicos observados en C4, y en las submuestras 4a y 4b.Fragmentación (F): (1) completo, (2) incompleto, (3) fragmento. Alteración superficial (AS): (1) baja, (2) moderada, (3) alta. Modificación de bordes (MB): (1) continuo, (2) discontinuo, (3) ausente. Redondeamiento (R): (1) ausente, (2) aguzado, (3) redondeado. Bioerosión (B): (1) baja, (2) moderada, (3) alta. Articulación (A): (1) articulado, (2) separado, (3) desarticulado. 1, azul; 2, verde; 3 , amarillo.

\section{Talle y características tafonómicas}


En el tamiz de mayor apertura, 5,660 mm, la preservación de los bioclastos fue mala (Tabla 3.31, Apéndice I §Fig. 23). En $4 a$ y 4 b predominaron conchillas fragmentadas $(3,>50 \%)$ con alta alteración superficial $(3,53 \%)$, en $4 a$ predominaron cuchillas redondeadas $(3,60 \%)$ y en $4 \mathrm{~b}$ aguzadas $(2,70 \%)$. En más del $50 \%$ de las conchillas de bivalvos de las dos submuestras los bordes no se preservaron (3) y de los preservados, predominaron los discontinuos $(2,>30 \%)$. En $4 a$ la bioerosión fue alta (3,60\%) mientras que en $4 \mathrm{~b}$ fue baja (1, 40\%). Por otra parte, en el tamiz 1,190 mm, la preservación de los bioclastos varió entre 4a y 4b (Tabla 3.31. Apéndice I §Fig. 23); en 4a, más del $40 \%$ de las conchillas se preservaron completas (1) mientras que en $4 \mathrm{~b}$ la proporción de conchillas completas, incompletas y fragmentos fue similar $(1-3, \approx 35 \%)$; la alteración superficial fue moderada (2, $43 \%)$ en $4 \mathrm{a}$ y de moderada a alta $(2,42 \% ; 3,41 \%)$ en $4 \mathrm{~b}$. En las dos submuestras predominaron las conchillas con redondeamiento $(3,>50 \%)$, bioerosión baja $(1,>80 \%)$. Los bordes en las conchillas de bivalvos no se preservaron $(3,40 \%)$, de los preservados predominaron los discontinuos $(2, \approx 30 \%)$.

Finalmente, en el tamiz de menor apertura, $0,710 \mathrm{~mm}$, la preservación de los bioclastos retenidos fue moderada (Tabla 3.31, Apéndice I §Fig. 23). En ambas submuestras, las conchillas se preservaron incompletas $(2, \geqq 40 \%)$, con bioclastos redondeados $(3,>60 \%)$ y bioerosión baja ( $1, \leqq 100 \%)$; en 4 a la alteración superficial fue moderada $(2,48 \%)$ y en $4 \mathrm{~b}$ alta $(3,46 \%)$; en 4 a predominaron las valvas de bivalvos que no preservaron los bordes ( 3 , $44 \%)$, mientras que en $4 \mathrm{~b}$ las de bordes discontinuos $(2,44 \%)$.

Tabla 3.31. Características Tafonómicas predominantes en 4a y 4b con relación al talle. Referencias como en la tabla 3.28. Los gráficos se encuentran en el Apéndice I, Fig. 23.

\begin{tabular}{|c|c|c|c|c|c|}
\hline Malla & Fragmentación & AS & MB & Redondeamiento & Bioerosión \\
\hline \multicolumn{6}{|c|}{$4 a$} \\
\hline 5,660 & 3 & 3 & 3 & 3 & 3 \\
\hline 1,190 & 1 & 2 & 3 & 3 & 1 \\
\hline 710 & 2 & 2 & 3 & 3 & 1 \\
\hline \multicolumn{6}{|c|}{$4 b$} \\
\hline 5,660 & 3 & 3 & 3 & 2 & 1 \\
\hline 1,190 & $1-3$ & $2-3$ & 3 & 3 & 1 \\
\hline 710 & 2 & 3 & 2 & 3 & 1 \\
\hline
\end{tabular}

Fragmentación versus otras características tafonómicas

Al considerar la preservación de los bioclastos con relación a su grado de fragmentación, se observó que en las conchillas completas el grado de preservación fue bueno a moderado (Tabla 3.32, Apéndice I §Fig. 24). Tanto en 4a como en 4b, los bioclastos completos presentaron una alteración superficial moderada $(2,>40 \%)$; la proporción de bioclastos $\sin (1)$ y con (3) redondeamiento fue similar (1 y 3, 38\% 4a; 1, 41\% y 3, 44\% 4b) y la bioerosión fue baja $(1,>80 \%)$. El borde de las conchillas de bivalvos se preservó continuo $(1,>60 \%)$ en las dos submuestras. 
En los bioclastos incompletos la preservación es moderada (Tabla 3. 32, Apéndice I §Fig. $24)$; en ambas submuestras la alteración superficial fue de moderada a alta $(2-3,>40 \%)$, con redondeamiento $(3, \geq 65 \%)$ y baja bioerosión $(1, \leq 96 \%)$. En $4 a$ las valvas con bordes discontinuos y ausentes predominaron en igual proporción (2-3, 45\%). En 4b predominaron las valvas con borde discontinuo $(2,51 \%)$.

Finalmente, en los fragmentos de conchillas la preservación fue de moderada a mala (Tabla 3.32, Apéndice I §Fig. 24). En las dos submuestras predominó la alteración superficial alta (3, 49\% 4a, $57 \% 4 \mathrm{~b})$, el redondeamiento $(3, \geqq 78 \%$ ) y la bioerosión baja (1, 85\% 4a; $77 \%$ 4b) .Predominaron los bivalvos que no preservaron el borde $(3,>70 \%)$.

Tabla 3.32. Características Tafonómicas predominantes en $4 \mathrm{a}$ y $4 \mathrm{~b}$ en relación a la fragmentación (conchillas completas, incompletas y fragmentos). Referencias como en tabla 3.28. Los gráficos se encuentran en el Apéndice I, Fig. 24.

\begin{tabular}{|c|c|c|c|c|}
\hline Fragmentación & AS & MB & Redondeamiento & Bioerosión \\
\hline \multicolumn{5}{|c|}{$4 a$} \\
\hline Completas & 2 & 1 & 1 y 3 & 1 \\
\hline Incompletas & $2-3$ & $2-3$ & 3 & 1 \\
\hline Fragmentos & 3 & 3 & 3 & 1 \\
\hline \multicolumn{5}{|c|}{$4 b$} \\
\hline Completas & 2 & 1 & 1 y 3 & 1 \\
\hline Incompletas & $2-3$ & 2 & 3 & 1 \\
\hline Fragmentos & 3 & 3 & 3 & 1 \\
\hline
\end{tabular}

\section{Fragmentación y talle versus otras características tafonómicas}

Las conchillas completas de la fracción $5,660 \mathrm{~mm}$ no fueron consideradas para la evaluación en conjunto del grado de fragmentación y la apertura del tamiz, debido a que en 4a solo tres bioclastos se preservaron completos, mientras que en $4 \mathrm{~b}$ ninguno. La preservación de las conchillas completas de la fracción 1,190 mm fue de buena a moderada (Tabla 3.33, Apéndice I §Fig. 25); en ambas submuestras, predominaron las conchillas con alteración superficial moderada (2, 43\% 4a; $53 \% 4 b)$, sin redondeamiento (1, $44 \% 4 a ; 55 \% 4 b)$ y con baja bioerosión $(1,>80 \%)$. Los bivalvos retenidos en esta fracción mostraron bordes discontinuos en $4 a(1,55 \%)$ y continuos en $4 b(1,78 \%)$. La fracción $0,710 \mathrm{~mm}$ también muestra una preservación similar a la fracción anterior (Tabla 3.33, Apéndice I §Fig. 25). En 4a la alteración superficial fue moderada (2, 48\%), en 4b fue moderada a alta $(\geq 38 \%)$. Las dos submuestras mostraron una mayor proporción de bioclastos con redondeamiento $(3,42 \% 4 a ; 55 \% 4 b)$ y baja bioerosión (1, >80\%); en más del $50 \%$ de los bivalvos el borde se preservó continuo (1).

Del mismo modo que en las conchillas completas, las incompletas de la fracción 5,660 mm no fueron consideradas cuantitativamente debido a que el número de especímenes con este grado de fragmentación era bajo, siete en $4 a$ y 17 en $4 b$; cualitativamente, la preservación de esta fracción se consideró moderada (V. Bases de datos). Las conchillas incompletas de la fracción 1,190 mm mostraron una preservación moderada (Tabla 3.33, Apéndice I §Fig. 26). La alteración superficial fue moderada; en 4a (2, 42\%) y de moderada 
a alta en $4 b(2,38 ; 3,43 \%)$. En las dos submuestras se observó redondeamiento (3) en más del $60 \%$ de los bioclastos y baja bioerosión (1) en más del $80 \%$. En 4a la proporción de bivalvos con borde discontinuo (2) y no preservado fue similar $(2-3, \approx 40 \%)$, mientras que en $4 \mathrm{~b}$ predominaron los discontinuos (2, 49\%). En la fracción más pequeña, 0,710 $\mathrm{mm}$, la preservación fue moderada (Tabla 3.33, Apéndice I §Fig. 26). Los bioclastos de 4a y 4b mostraron alteración superficial alta $(3,>45 \%)$, redondeamiento $(3,>65 \%)$ y bioerosión baja $(1,>80 \%)$; la proporción de valvas con bordes discontinuos fue similar en ambas submuestras $(2,>52 \%)$.

Tabla 3.33. Características tafonómicas predominantes en $4 a$ y $4 \mathrm{~b}$ en conchillas completas, incompletas y fragmentos. Referencias como en la tabla 3.28. Los gráficos se encuentran en el Apéndice I, Figs. 25, 26 y 27.

\begin{tabular}{|c|c|c|c|c|c|}
\hline $\mathbf{F}$ & Malla & AS & MB & Redondeamiento & Bioerosión \\
\hline \multicolumn{6}{|c|}{$4 a$} \\
\hline \multirow{7}{*}{$\mathrm{C}$} & 5,660 & & & & \\
\hline & 1,190 & 2 & 2 & 1 & 1 \\
\hline & 710 & 2 & 1 & 3 & 1 \\
\hline & \multicolumn{5}{|c|}{$4 b$} \\
\hline & \multicolumn{5}{|l|}{5,660} \\
\hline & 1,190 & 2 & 1 & 1 & 1 \\
\hline & 710 & $2-3$ & 1 & 3 & 1 \\
\hline \multicolumn{6}{|c|}{$4 a$} \\
\hline \multirow{7}{*}{ I } & 5,660 & & & & \\
\hline & 1,190 & 2 & $2-3$ & 3 & 1 \\
\hline & 710 & 3 & $2-3$ & 3 & 1 \\
\hline & \multicolumn{5}{|c|}{$4 b$} \\
\hline & \multicolumn{5}{|l|}{5,660} \\
\hline & 1,190 & $2-3$ & 2 & 3 & 1 \\
\hline & 710 & 3 & 2 & 3 & 1 \\
\hline \multirow{8}{*}{ F } & \multicolumn{5}{|c|}{$4 a$} \\
\hline & 5,660 & 3 & 3 & 3 & 3 \\
\hline & 1,190 & 3 & 3 & 3 & 1 \\
\hline & 710 & 2 & 3 & 3 & 1 \\
\hline & \multicolumn{5}{|c|}{$4 b$} \\
\hline & 5,660 & 3 & 3 & 3 & $1-3$ \\
\hline & 1,190 & 3 & 3 & 3 & 1 \\
\hline & 710 & 3 & 3 & 3 & 1 \\
\hline
\end{tabular}

Los fragmentos de conchillas de la fracción 5,660 mm mostraron una mala preservación (Tabla 3.33, Apéndice I §Fig. 27). En 4a y 4b la alteración superficial fue alta (3) en más del 
$50 \%$ de los bioclastos, estos mostraron redondeamiento en $4 a(3,50 \%)$, pero en fueron aguzados en $4 \mathrm{~b}(2,65 \%)$. En los bivalvos de ambas muestras no se preservaron los bordes $(3,58 \%)$. La bioerosión fue alta en $4 a(3,60 \%)$, mientras que en $4 b$ la proporción entre baja, moderada y alta fue similar (1-3, 30-35\%). La fracción 1,190 mm también mostró una mala preservación (Tabla 3.33, Apéndice I §Fig. 27), en las dos submuestras la alteración superficial fue alta $(3,>55 \%)$, en 4 a se observó redondeamiento $(3,>75 \%)$ mientas que en $4 \mathrm{~b}$ predominaron bordes aguzados $(2,>75 \%)$. En ambas muestras la bioerosión fue baja (1, $>80 \%$ ); más del $80 \%$ de los bivalvos no preservaron el borde (3). Finalmente, en los fragmentos de la fracción $0,710 \mathrm{~mm}$, la preservación también fue mala (Tabla 3.33, Apéndice I §Fig. 27); en 4a la alteración superficial fue moderada (2) en el 54\% de los bioclastos mientras que en $4 \mathrm{~b}$ fue alta $(3,53 \%)$. En las dos submuestras predominaron bioclastos aguzados $(2,>75 \%)$ y baja bioerosión (1, 83\% 4a; $100 \% 4$ b); más del $60 \%$ de los bivalvos de esta fracción no preservaban el borde (3).

\section{Taxones y características tafonómicas}

Con la finalidad de saber si había alguna diferencia en la calidad de preservación de los diferentes taxones reconocidos, se observaron de manera separada y semicuantitativa las características tafonómicas de los taxones más abundantes (Tablas 3.28, 3.29, 3.30). De las muestras en campo se observó la preservación de los géneros Turritella, Dosinia y Pleuromeris y la Familia Naticidae (Tabla 3.34, Apéndice I §Fig. 28). Las turritellas en campo mostraron una preservación moderada, predominaron las conchillas incompletas $(2,62 \%)$, con alteración superficial de moderada a alta $(2,48 \% ; 3,44 \%)$ y redondeamiento $(3,78 \%)$.

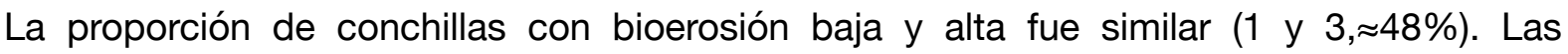
conchillas del género Dosinia también mostraron una preservación moderada. La proporción de conchillas completas, incompletas y fragmentos fue similar (1-3, $\pm 35 \%)$; la proporción de las valvas con borde continuo, discontinuo y no preservado fue similar (1-3, $\pm 35 \%)$; los márgenes aguzados y con redondeamiento también se mantuvieron en proporciones similares (2, 40\%; 3, 48\%). La bioerosión fue alta $(3,>50 \%)$ y predominaron trazas del icnogénero Entobia y de la Icnofamilia Dendrinidae (V. Capítulo 4). Las conchillas del género Pleuromeris mostraron una presevación buena; predominaron conchillass con baja fragmentación $(1,95 \%)$ y bioerosión (1,91\%); los bordes continuos $(1,63 \%)$ y sin redondeamiento $(1,73 \%)$. La proporción de conchillas con alteración superficial baja, moderada y alta fue similar (1-3, 32-36\%). Todas las valvas se encontraron desarticuladas $(3,100 \%)$. Finalmente, las conchillas de la Familia Naticidae mostraron una preservación de moderada a mala con fragmentación moderada $(2,50 \%)$, alteración superficial alta $(3,75 \%)$ y redondeamiento $(3,67 \%)$. La bioerosión fue baja $(1,88 \%)$.

Tabla 3.34. Características Tafonómicas predominantes en los taxones más abundantes en los cuadros de C4. Referencias como en tabla 3.28. Los gráficos se encuentran en el Apéndice I, Fig. 28.

\begin{tabular}{|c|c|c|c|c|c|}
\hline Malla & Fragmentación & AS & Redondeamiento & Bioerosión & MB \\
\hline Turritella & 2 & $2-3$ & 3 & 1 y 3 & 3 \\
\hline Dosinia & $1-3$ & 3 & $2-3$ & 1 & 1 \\
\hline Pleuromeris & 1 & 2 & 1 & 1 & \\
\hline Naticidae & 2 & 3 & 3 & \\
\hline
\end{tabular}


En 4a se consideraron los géneros Turritella, Cosa, Pleuromeris, Nuculana y Maorimactra (Tabla 3.35, Apéndice I §Fig. 29). Los especímenes más abundantes (Turritella) tuvieron una preservación de buena a moderada. El $48 \%$ de las conchillas se preservaron completas (1); predominó la alteración superficial moderada (2, 45\%), redondeamiento (3,67\%) y la bioerosión baja (1,94\%). El segundo género más abundante, Cosa, tuvo una preservación moderada; el porcentaje de conchillas completas e incompletas fue igual (1-2, 47\%), la alteración superficial fue alta $(3,60 \%)$ y predominaron las valvas redondeadas $(3,47 \%)$ y con baja bioerosión (1,98\%). Se observó un porcentaje similar entre valvas con bordes continuos, discontinuos y no preservados (1-3, $\approx 30 \%)$. Pleuromeris mostró una buena preservación (Tabla 3.35, Apéndice I §Fig. 29). El 60\% de las conchillas se preservaron completas (1) con alteración superficial moderada $(2,60 \%)$ y baja bioerosión $(1,100 \%)$ La proporción de valvas sin redondeamiento y redondeadas fue similar (1, 40\%; 3, 48\%), así como la proporción de bordes continuos y discontinuos $(1-2, \approx 45 \%)$. La preservación de Nuculana fue de buena a moderada. Predominaron las conchillas completas (1,71\%), la alteración superficial moderada $(2,58 \%)$, la baja bioerosión $(1,100 \%)$ y los bordes discontinuos $(2,56 \%)$. El porcentaje de conchillas sin y con redondeamiento fue similar (1 y 3 , $\geq 42 \%$ ) (Tabla 3.35, Apéndice I §Fig. 29). Finalmente, Maorimactra tuvo una mala preservación. Predominaron conchillas incompletas y fragmentos en igual proporción (2-3, $50 \%)$, con alteración superficial alta $(3,65 \%)$ y redondeamiento $(3,75 \%)$; en el $80 \%$ de las valvas no se preservó el borde (3). La bioerosión fue baja (1, 100\%).

Tabla 3.35. Características Tafonómicas predominantes en los taxones más abundantes en 4a. Referencias como en tabla 3.28. Los gráficos se encuentran en el Apéndice I, Fig. 29.

\begin{tabular}{|c|c|c|c|c|c|}
\hline Malla & Fragmentación & AS & Redondeamiento & Bioerosión & MB \\
\hline Turritella & 1 & 2 & 3 & 1 & $1-3$ \\
\hline Cosa & $1-2$ & 3 & 3 & 1 & $1-2$ \\
\hline Pleuromeris & 1 & 2 & $2-3$ & 1 & 2 \\
\hline Nuculana & 1 & 2 & $2-3$ & 1 & 3 \\
\hline Maorimactra & $2-3$ & 3 & 3 & & 1 \\
\hline
\end{tabular}

En 4b se consideró la preservación de los géneros Turritella, Maorimactra, Pleuromeris, Cosa, Dosinia y "Pleuromeris" (Tabla 3.36, Apéndice I §Fig. 30). La preservación de Turritella fue moderada. Predominaron las conchillas incompletas $(2,58 \%)$, con alteración superficial de moderada a alta $(2-3, \approx 40 \%)$ y redondeamiento $(3,66 \%)$; la bioerosión fue baja (1, $76 \%)$. Maorimactra tuvo una preservación moderada. Predominaron valvas incompletas (2, $49 \%)$ con alteración superficial alta $(3,68 \%)$, redondeamiento $(3,80 \%)$ y baja bioerosión $(1$, $90 \%)$. La proporción de valvas con bordes discontinuos y ausentes fue similar $(2-3, \approx 45 \%)$. Las valvas de Pleuromeris tuvieron una buena preservación, más del $59 \%$ de estas se conservaron completas (1), con alteración superficial moderada (2,66\%), sin evidencias de redondeamiento $(1,56 \%)$ y con baja bioerosión (98\%); $54 \%$ de las valvas preservaron con el borde continuo (1).

Tabla 3.36 Características Tafonómicas predominantes en los taxones más abundantes en 4b. Referencias igual que para tabla 3.28. Los gráficos se encuentran en el Apéndice I, Fig. 30.

\begin{tabular}{|l|l|l|l|l|l|}
\hline Malla & Fragmentación & AS & Redondeamiento & Bioerosión & MB \\
\hline
\end{tabular}




\begin{tabular}{|c|c|c|c|c|c|}
\hline Turritella & 2 & $2-3$ & 3 & 1 & \\
\hline Maorimactra & 2 & 3 & 3 & 1 & $2-3$ \\
\hline Pleuromeris & 1 & 2 & 1 & 1 & 1 \\
\hline Cosa & 1 & 3 & 3 & 1 & 2 \\
\hline Dosinia & 3 & 3 & 3 & 1 & 3 \\
\hline "Pleuromeris" & 1 & 1 & $1-2$ & 1 & $1-2$ \\
\hline
\end{tabular}

Por otra parte, las conchillas del bivalvo Cosa mostraron una preservación moderada, predominaron conchillas completas $(1,47 \%)$, con alta alteración superficial $(3,58 \%)$ y redondeamiento $(3,58 \%)$. La bioerosión fue baja $(1,87 \%)$ y predominaron valvas con bordes discontinuos $(2,44 \%)$. La preservación de las valvas de Dosinia fue mala ya que más del $50 \%$ eran fragmentos (3), con alta alteración superficial $(3,52 \%)$ y redondeamiento (3, 57\%). La bioerosión fue baja $(1,67 \%)$ y más del $60 \%$ de los especímenes no preservaban el borde (3). Finalmente, "Pleuromeris" al igual que Pleuromeris tuvo una buena preservación, el $85 \%$ de las valvas se preservaron completas (1) con baja alteración superficial $(1,45 \%)$ y baja bioerosión $(1,85 \%)$. La proporción de valvas sin y con redondeamiento fue similar $(1-3 \approx 45 \%)$. El porcentaje de bordes continuos y discontinuos fue el mismo (1-2, 40\%).

Hábitos de vida y características tafonómicas.

Se observaron las características tafonómicas en campo y en las submuestras con relación al hábito de vida (Tabla 3.37, Apéndice I \$Fig. 31). La preservación de los taxones infaunales de los cuadros fue de moderada a mala. Predominaron fragmentos de conchillas $(3,42 \%)$ con alta alteración superficial $(3,62 \%)$ y redondeamiento $(3,54 \%)$. La bioerosión fue baja $(1,47 \%)$ y en las conchillas de bivalvos la proporción de bordes discontinuos y ausentes fue igual $(2-3,39 \%)$. Los taxones epifaunales tuvieron una preservación moderada; el $48 \%$ de las conchillas se preservaron incompletas (2) con alteración superficial moderada a alta $(2-3, \approx 44 \%)$, redondeamiento $(3,63 \%)$ y baja bioerosión $(1$, $71 \%)$. Las valvas conservaban el borde discontinuo (2, 47\%).

En 4a las conchillas de taxones infaunales tuvieron una preservación moderada. El 40\% de estas se conservaron incompletas (2), con alteración superficial alta (3, 48\%) y redondeamiento $(3,55 \%)$. La bioerosión en estas conchillas fue baja $(1,92 \%)$ y más, del $46 \%$ de los bivalvos no preservaban el borde (3). La preservación de los organismos epifaunales fue de buena a moderada. Predominaron conchillas completas (1, 46\%), con alteración superficial moderada $(2,49 \%)$ y redondeamiento $(3,55 \%)$. La bioerosión fue baja $(1,93 \%)$ y en bivalvos predominaron conchillas con borde continuo $(1,45 \%)$.

En 4b la preservación de las conchillas de organismos infaunales y epifaunales fue moderada. En los primeros, el porcentaje de conchillas completas, incompletas y fragmentos fue similar (1-3, $\pm 33 \%)$, al igual que la modificación de bordes en bivalvos (1-3, $\pm 35 \%)$; la alteración superficial fue alta $(3,58 \%)$ y el $60 \%$ de las conchillas mostraron redondeamiento (3). La bioerosión fue baja (1,86\%). En las conchillas de organismos epifaunales predominaron aquellas con fragmentación moderada $(2,42 \%)$, alteración 
superficial moderadas $(2,45 \%)$, redondeamiento $(3,65 \%)$ y baja bioerosión $(1,79 \%)$. La proporción de los bordes continuos, discontinuos fue similar (1-2, $\pm 35 \%)$.

Tabla 3.37 Características Tafonómicas predominantes en C4 con relación al hábito de vida. Referencias como en tabla 3.28. Los gráficos se encuentran en el Apéndice I, Fig. 31.

\begin{tabular}{|c|c|c|c|c|c|c|}
\hline Hábito & Submuestra & Fragmentación & AS & Redondeamiento & Bioerosión & MB \\
\hline \multirow{3}{*}{ 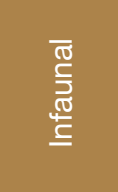 } & Cuadros & 3 & 3 & 3 & 1 & $2-3$ \\
\hline & $4 a$ & 2 & 3 & 3 & 1 & 3 \\
\hline & $4 b$ & $1-3$ & 3 & 3 & 1 & $1-3$ \\
\hline \multirow{3}{*}{ 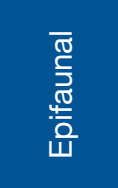 } & Cuadros & 2 & $2-3$ & 3 & 1 & 1 \\
\hline & $4 a$ & 1 & 2 & 3 & 1 & 1 \\
\hline & $4 b$ & 2 & 2 & 3 & 1 & $1-2$ \\
\hline
\end{tabular}




\section{Interpretación y clasificación de las concentraciones fósiles}

Las concentraciones fósiles de Cabeza de León mostraron diferentes características paleontológicas y tafonómicas, las cuales en conjunto con el análisis de sus características sedimentológicas y estratigráficas (Tabla 3.38), permiten interpretarlas genéticamente y clasificarlas según el esquema de diferentes autores.

Tabla 3.38. Características sedimentológicas y estratigráficas de las concentraciones de Cabeza de León

\begin{tabular}{|c|c|c|c|c|c|c|c|c|}
\hline Concentración & Espesor $(\mathrm{cm})$ & Geometría & Litología & Contacto & Selección & Empaquetamiento & Orientación & Agrupamiento \\
\hline C1 & \pm 40 & capa con vainas & arena fina & $\begin{array}{c}\text { ondulado } \\
\text { bioturbado en la } \\
\text { base }\end{array}$ & Bimodal & Denso & Concordante & Apilado \\
\hline C2 & \pm 44 & сара & $\begin{array}{l}\text { arena fina con } \\
\text { ceniza }\end{array}$ & $\begin{array}{l}\text { bioturbado en la } \\
\text { base }\end{array}$ & Bimodal & Suelto a denso & $\begin{array}{l}\text { Concordante, } \\
\text { perpendiculary } \\
\text { oblicua. }\end{array}$ & Apilado, anidado \\
\hline C3 & $20-60$ & $\begin{array}{l}\text { lenticular con } \\
\text { estratificación } \\
\text { entrecruzada } \\
\quad \text { difusa }\end{array}$ & arena fina & neto en la base & Buena, bimodal & Suelto a disperso & $\begin{array}{l}\text { Concordante, } \\
\text { oblicua y } \\
\text { perpendicular }\end{array}$ & Apilado \\
\hline C4 & $35-60$ & capa con vainas & arena fina a media & $\begin{array}{l}\text { bioturbado en la } \\
\text { base }\end{array}$ & Bimodal & $\begin{array}{l}\text { Denso en la base, } \\
\text { suelto en el techo }\end{array}$ & $\begin{array}{l}\text { Concordante en la } \\
\text { base, oblicua en } \\
\text { el techo }\end{array}$ & Apilado \\
\hline
\end{tabular}

La concentración $\mathrm{C} 1$ es politípica, rica de turritelas. La mayoría de los especímenes de la concentración muestran orientación concordante y se agrupan apilados, no están en posición de vida. La dominancia de un grado moderado de fragmentación, alteración superficial, modificación de bordes en bivalvos y redondeamiento, sugiere que no hubo un transporte lateral significativo, siendo elementos parautóctonos. La baja bioerosión y el tipo de bioerodantes ( $\mathrm{V}$. Capítulo 4) también sugieren que las conchillas no estuvieron expuestas en la interfase por un tiempo prolongado. Panopea quemadensis, se considera como el único elemento autóctono de la concentración, ya que se encuentra articulado y en posición de vida. La mezcla de elementos correspondientes a diferentes comunidades sugiere promediación dentro del hábitat, y las características de preservación , así como las sedimentológicas y estratigráficas, sugieren que esta concentración constituye un depósito de evento; las características tafonómicas y la biofábrica de las conchillas sugieren una tafocenosis producida por un evento de corta duración, como los flujos de tormenta, dentro de la plataforma interna o transición offshore.

La concentración C2 es pauciespecífica, con dominancia de balanos. La baja cantidad de moluscos en esta concentración con relación a la presencia de balanos, sugiere un sesgo preservacional, ya que posiblemente los organismos aragoníticos de talle pequeño fueron disueltos, mientras que aquellos restos calcíticos se preservaron. Adicionalmente, la preservación moderada de las placas de balanos puede estar asociada a su talle pequeño, peso ligero y porosidad. La presencia de los moldes de Dosinia en posición de vida en la base soporta la notable influencia de los procesos diagéneticos en la preservación de esta concentración. En los otros moluscos, la alta alteración superficial, en conjunto con la predominancia de conchillas sin bordes preservados, puede estar también asociada a procesos de disolución. La alta fragmentación y el redondeamiento de estos bioclastos sugiere además que el transporte lateral que presentaron pudo ser significativo y su baja bioeorosión sugiere que la exposición en la interfase agua sedimento no fue prolongada. La orientación las conchillas en algunas posiciones hidrodinámicamente inestables puede asociarse a un enterramiento final rápido. Los elementos de esta concentración son principalmente parautóctonos y alóctonos, a excepción de los moldes de Dosinia en la 
base, que son autóctonos. Las características de preservación y taxonómicas de la concentración sugieren que fue depositada en la plataforma interna o zona de transición del offshore, en donde los depósitos de tormenta pueden ser comunes.

La concentración C3 se considera pauciespecífica por su baja riqueza taxonómica con predominancia de Pteromyrtea y Turritella. La dominancia de bioclastos de organismos con hábitos de vida infaunales con preservación moderada a mala sugieren exhumación y resedimentación. Los fragmentos de estas comunidades mostraron una mala preservación que sugiere historias tafonómicas complejas en las que el transporte lateral y la retroalimentación tafonómica pudieron ser significativos. La orientación de algunos de los bivalvos infaunales desarticulados no es hidrodinámicamente estable, (v. gr. oblicua apilada, con la convexidad hacia abajo o perpendicular anidada), sugiriendo un enterramiento rápido. Por su parte, los elementos epifaunales mostraron una preservación moderada que puede también sugerir un rápido enterramiento; aunque en estos el transporte lateral posiblemente no fue significativo. La mezcla de bioclastos con historias tafonómicas complejas (v.g. fragmentos) y de diferentes comunidades (moluscos infaunales y epifaunales; briozoos cementados y reemplazados), sugieren promediación en el tiempo y dentro del hábitat. La geometría de lentes de la concentración con estratificación entrecruzada difusa, el empaquetamiento suelto a disperso predominante y la selección buena a bimodal por tamaño sugieren que C3 se formó por olas o flujos de tormenta, dentro de la parte más proximal de la plataforma interna a shoreface.

La concentración C4 es politípica rica en turritellas; la preservación varía entre buena y moderada según los taxones, sugiriendo que el transporte y la energía a la que éstos fueron sometidos no fueron significativos. Por otra parte, los elementos esqueletales retenidos en el tamiz de mayor apertura de malla $(5,660 \mathrm{~mm})$, tienen una mala preservación, de guisa que, su alta fragmentación y alteración superficial sugieren un transporte lateral significativo. Asimismo, presentan mayor grado de bioerosión con relación a los bioclastos retenidos en las mallas menores, sugiriendo un mayor tiempo de exposición en la interfase agua-sedimento. La presencia de trazas de bioerosión en bordes fragmentados y redondeados en estos bioclastos podría estar asociada a procesos de retroalimentación y resedimentación tafonómica (sensu Fernández-López, 2000). Las diferencias preservacionales entre conchillas de organismos infaunales y epifaunales, sugiere que los elementos infaunales fueron exhumados y resedimentados tafonómicamente, mientras que los epifaunales sufrieron un rápido enterramiento, explicando así su mejor preservación. Un tercer grupo característico de la concentración está dado por especímenes de Panopea quemadensis en posición de vida. De esta manera, la concentración muestra una mezcla de elementos autóctonos, parautóctonos e incluso alóctonos que podría estar asociada, en conjunto con las características tafonómicas, a una concentración promediada dentro del hábitat; la elevada riqueza taxonómica de bioclastos con diferente preservación, que reflejan diferentes historias tafonómicas, sugiere que estos fueron mezclados y resedimentados. La mezcla de elementos parautóctonos y autóctonos, y su diversidad taxonómica, en conjunto con la litología de la matriz (arena fina a media), el empaquetamiento clasto-soportado y la presencia de trazas de bioerosión y bioturbación abundantes, sugieren que el depósito de esta concentración ocurrió por flujos u olas de tormenta en un ambiente de plataforma interna proximal a shoreface. 
Existen diferentes modelos descriptivos y genéticos para clasificar las concentraciones fosilíferas, siendo los últimos los más ampliamente usados. En esta tesis se consideraron tres clasificaciones genéticas que tienen en cuenta los procesos o agentes de formación y/ o la historia de acumulación (Kidwell et al., 1986; Kidwell, 1991; Fürsich y Oschmann, 1993).

Kidwell et al. (1986) agruparon las concentraciones de acuerdo con la predominancia de procesos biológicos, sedimentológicos (físicos) y diagenéticos que las formaron. Considerando este criterio, las concentraciones de Cabeza de León se habrían originado principalmente por procesos sedimentológicos. En este sentido, aunque los bioclastos que las conforman pudieron tener historias tafonómicas complejas, la selección, el empaquetamiento, la orientación y el agrupamiento (i.e., la biofábrica) reflejan la concentración de partes dispersas, principalmente, por selección hidraúlica y resedimentación.

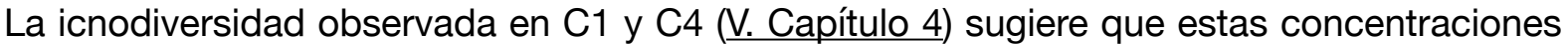
de conchillas actuaron como sustratos duros en un ambiente con sustrato no consolidado, promoviendo así el asentamiento de comunidades de esclerobiontes que modificaron la concentración inicial; por ello, las mismas serían concentraciones mixtas biogénicosedimentológicas (Fig. 3.13). Por otra parte aquellos lentes de C3 dominados por briozoos (e.g., lente 6), podrían corresponder a concentraciones mixtas biogénico-sedimentológicas con elementos de la comunidad original (autóctonos) que luego son enriquecidos con elementos parautóctonos (Fig. 3.13).

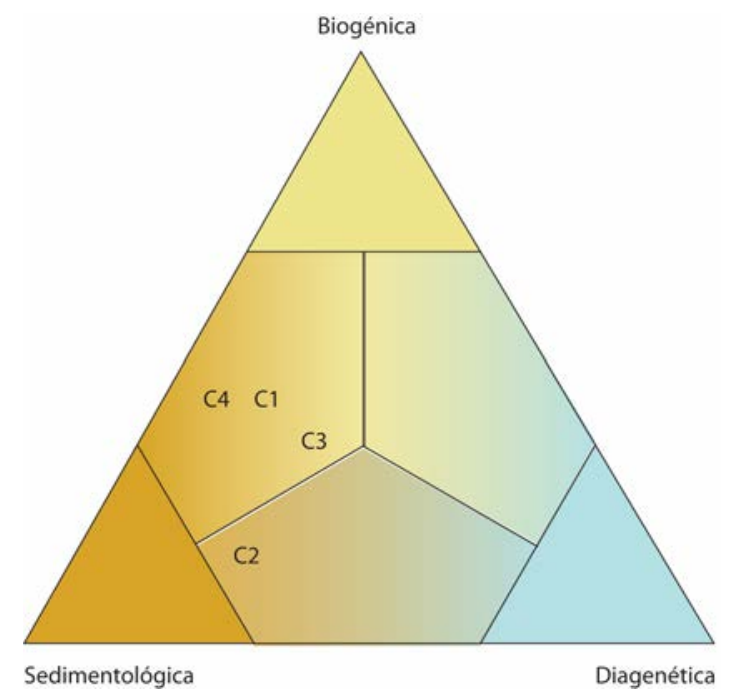

Figura 3.13. Clasificación de las concentraciones fósiles de Cabeza de León sensu Kidwell et al. (1986), en donde C2 es una concentración mixta sedimentológico-diagenética mientras que C1, C3 y C4 son concentraciones mixtas biogénico-sedimentológicas.

La concentración C2 se ve altamente influenciada por procesos sedimentológicos y diagenéticos. La presencia de vaciados de Dosinia bioturbados y las trazas de bioturbación a lo largo de la misma se asocian a una modificación de la biofábrica original, además esta pudo tener una influencia considerable en la preservación de organismos de comunidades infaunales ( $\underline{V}$. Discusión § Características paleontológicas). Kidwell et al. (1986) describieron las concentraciones sedimentológicas como conjuntos producidos por procesos físicos de 
concentración que pueden incluir elementos autóctonos, parautóctonos y alóctonos. La concentración C2 cuenta con elementos autóctonos (vaciados y Panopea quemadensis y Dosinia en posición de vida), parautóctonos y alóctonos (balánidos); la acumulación de los últimos puede asociarse a flujos de tormenta ( $\underline{\mathrm{V}}$. Discusión § Características tafonómicas) y su preservación ha estado determinada principalmente por repetidos procesos de exhumación y transporte. La baja bioerosión, así como la ausencia de incrustantes, sugiere que estos bioclastos no actuaron como sustrato para otras comunidades. Por lo tanto, C2 se considera como una concentración mixta sedimentológico-diagenética, con una tasa neta de aporte de sedimentos mayor a la de conchillas, en donde la presencia de vaciados bioturbados de Dosinia evidencian un enriquecimiento diagenético de la concentración original (Fig. 3.13).

Fürsich y Oschmann (1993) describieron nueve tipos de concentraciones sobre la base de la importancia de los principales procesos responsables de la concentración final (registrados por la biofábrica) y aquellos que tuvieron lugar con anterioridad a la formación de la misma (registrados por los atributos tafonómicos). Si bien este modelo, que muestra una tendencia batimétrica, fue desarrollado originalmente para describir las concentraciones de la Cuenca Kachchh en la India, puede aplicarse a cualquier mar epicontinental, siendo una herramienta útil en el análisis de cuencas (Fürsich y Oschmann, 1993; Fürsich, 1995).

Considerando la batimetría y el posible ambiente de depósito de las concentraciones se considera que C1 corresponde a una tempestita proximal (Fig. 3.14), debido a la biofábrica con empaquetamiento denso, selección bimodal y el grado de preservación moderado de las conchillas (Tabla 3.38); estas posiblemente fueron depositadas por flujos de tormenta de corta duración que resedimentaron y depositaron los bioclastos en la plataforma interna. Asimismo, las características de preservación de esta concentración sugieren correspondencia con una concentración de evento (sensu Kidwell, 1991) formada principalmente por retrabajo durante un solo evento de tormenta dentro del hábitat representando así un evento breve en el registro. C2 también se considera que corresponde a de una tempestita proximal formada por flujos de tormenta de corta duración en la plataforma interna (Fig. 3.14). La litología y el empaquetamiento (Tabla 3.38); así como la fragmentación y alteración superficial de las conchillas además de la acumulación de balanos sugieren una historia tafonómica compleja. Sobre la base de la clasificación de Kidwell (1991) esta concentración puede considerarse como multievento, ya que en la base es posible reconocer la muerte de una comunidad infaunal, su hábito de vida en conjunto con el posterior establecimiento de una nueva comunidad infaunal, promovió la diagénesis de algunos de los elementos de la primera (v.g. los moldes de Dosinia); adicionalmente, estos depósitos se vieron influenciados principalmente por el aporte de placas de balanos y el retrabajo dentro del hábitat de las comunidades infaunales que se asentaron a posteriori.

La presencia de estratificación entrecruzada difusa y la geometría de lente de C3 sugieren que el ambiente de depositación corresponde también a la parte más proximal de la plataforma interna o al shoreface inferior; las estructuras sedimentarias, la diversidad moderada y la alta bioerosión (observada en bioclastos de la malla 5,660 $\mathrm{mm}$ y en el scoring de campo) guarda similitud con la concentración tipo 5, de corriente, de Fürsich y Oschmann (1993) siendo una concentración física depositada en un lapso largo de tiempo, 
por lo que además de estar sujeta a corrientes de larga duración pudo estar afectada por flujos de tormenta que influyeron en la acumulación de briozoos autóctonos. La heterogeneidad en la preservación observada dentro de algunos lentes y entre ellos, permite considerar la presencia de múltiples eventos de diferente duración que crearon una sobreimpronta, de guisa que dentro del esquema de clasificación de Kidwell (1991) es posible que esta concentración también sea multievento. Finalmente, C4 se considera que fue depositada en un ambiente de plataforma interna a shoreface inferior, cerca del nivel de base de olas de buen tiempo y es similar a la concentración tipo 2 (olas de tormenta) de Fürsich y Oschmann (1993), en la que corrientes de corta duración resedimentaron y enterraron los bioclastos preservados; la gradación observada puede sugerir que la concentración sea el producto de la acumulación de diferentes eventos de tormenta (multivento sensu Kidwell), y la presencia de bioclastos con diferente impronta tafonómica sugiere historias previas (Fig. 3.14).

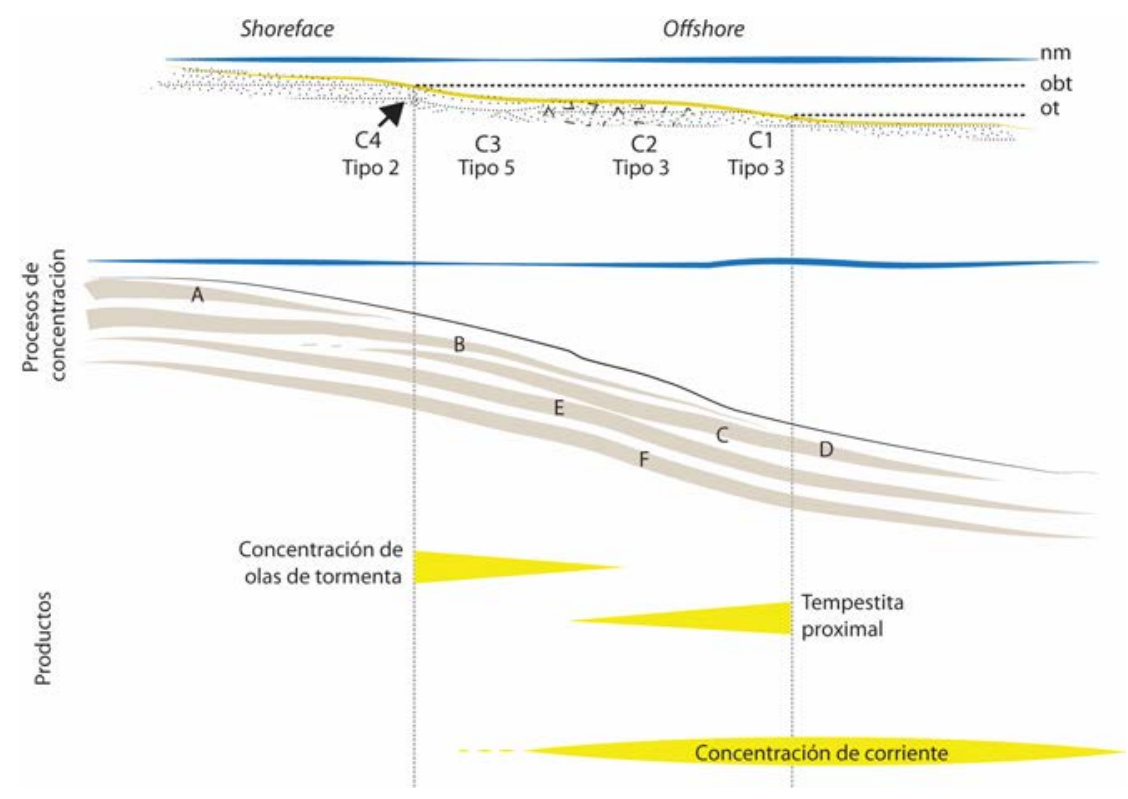

Figura 3.14. Clasificación de las concentraciones de Cabeza de León sensu Fürsich y Oschmann (1993). Arriba se muestran los ambientes de depósito considerados para cada una de las concentraciones de Cabeza de León con su litologías. Al centro se observan los procesos de concentración que influyen en cada ambiente de depósito y la ubicación más probable de los tipos de concentraciones reconocidos a lo largo del gradiente onshore-offshore, donde A: olas de buen tiempo, B: olas de tormenta, C: flujos de tormenta, D: flujos de tormenta distales, E: corrientes de larga duración, F: producción de partes biogénicas. Adaptado de Fürsich y Oschmann (1993).

\section{Discusión}

Características paleontológicas: procesos físicos, químicos o biológicos involucrados en la formación de las concentraciones fósiles

El análisis de las características paleontológicas de las concentraciones fósiles de Cabeza de León permitió mejorar el conocimiento acerca de los principales procesos físicos, químicos y biológicos involucrados en su formación. Se discuten aquí las principales 
inferencias realizadas en cada una de las concentraciones mediante la evaluación de espectro de edad, mineralogía, composición taxonómica y hábito de vida.

i) Espectro de edad: En campo los bioclastos analizados tuvieron un talle $>2 \mathrm{~mm}$, debido a su facilidad de ser reconocidos y de analizar sus características de preservación. Solo algunos individuos de talle menor $(\approx 1,190 \mathrm{~mm})$ fueron incluidos en este análisis, debido a que su presencia en campo no resultaba tan evidente, excepto cuando eran parte del relleno de un bioclasto de mayor talle. Esta limitante en las observaciones macroscópicas en campo implicó un sesgo en la interpretación del espectro de edad, ya que mayormente los especímenes analizados resultaron adultos.

Por otra parte, en las muestras procesadas de C1, C3 y C4, el número total de individuos estuvo determinado de forma importante por los bioclastos retenidos en la malla de 1,190 $\mathrm{mm}$ (V. Apéndice). En estas muestras los bioclastos completos en su mayoría correspondieron a estadios juveniles de taxones también representados en las concentraciones en la malla de mayor apertura $(5,660 \mathrm{~mm})$. Los bioclastos incompletos o fragmentos correspondieron a restos de especímenes de estadio adulto. Si bien en la malla $0,710 \mathrm{~mm}$ se encontraron protoconchas, prodisoconchas y especímenes juveniles, gran parte de los bioclastos correspondían a fragmentos de especímenes de talle mayor (juveniles posiblemente). De esta manera, se considera que el espectro de edad de C1, C3 y C4 es mixto; lo que posiblemente refuerza la evidencia de un transporte lateral no significativo para algunos de los bioclastos de estas concentraciones. En C2 por otra parte el número de especímenes en las mallas $1,190 \mathrm{~mm}$ y 0,710 $\mathrm{mm}$ fue bajo (V. Apéndice I), de guisa que predominaron adultos. Esta baja fidelidad ontogénica puede estar asociada a procesos de disolución y diagenéticos, más que a procesos físicos, ya que en esta concentración las placas de balanos (calcíticas), más resistentes a la disolución, fueron abundantes.

ii) Mineralogía original y preservada: En las concentraciones estudiadas destacó la presencia de moluscos con mineralogía original aragonítica. Dada la inestabilidad de este mineral, el reemplazamiento por calcita ocurre en la mayoría de los fósiles. Sin embargo, mediante este proceso, denominado calcitización, se preserva en diferente grado la mineralogía original de la conchilla (Wardlaw et al., 1978; Saller, 1992). En C1, C3 y C4 algunos de los bioclastos de mayor talle $(>1,190 \mathrm{~mm})$, evidenciaron reemplazamiento por calcitización, como así también por silicificación. Estos bioclastos, posiblemente de mayor antigüedad, pudieron tener un enterramiento previo en sedimentos con alto contenido de materia orgánica o pudieron estar sometidos a fluidos porales que favorecieron su reemplazamiento; posteriormente fueron exhumados e incorporados en la concentración final. Su presencia en conjunto con otras características tafonómicas y sedimentológicas sugieren una promediación dentro del hábitat en estas concentraciones ( $\mathrm{V}$. Discusión $\S$ Características tafonómicas). Las conchillas de talles medianos y pequeños $(1,190$ y 0,710 $\mathrm{mm}$ ) no mostraron evidencias considerables de reemplazamiento mas en algunas se observaron nódulos de manganeso y hierro que pudieron ser incorporados durante la diagénesis mediante intercambio con los fluidos porales (Tucker, 1991). La preservación de bioclastos con mineralogía original aragonítica dominante en estas concentraciones sugiere un rápido enterramiento, que reduce el tiempo de permanencia en la zona tafonómicamente activa (TAZ, por sus siglas en inglés) y el decaimiento de la materia orgánica en la zona de reducción de sulfatos asociado al incremento de la alcalinidad 
favoreciendo su preservación (Canfield y Rasiwell, 1991). Asimismo, eventos tales como las tormentas pueden remover la materia orgánica por transporte y lavado reduciendo así la presencia de disolución mediada por bacterias (Cherns et al., 2011).

En C2 por otra parte, la preservación de bioclastos aragoníticos fue considerablemente menor a diferencia de la presencia de exoesqueletos de mineralogía calcítica. El bajo número de bioclastos aragoníticos en las mallas de menor talle puede estar asociado a procesos de lavado o disolución, ya que las conchillas juveniles delgadas y débilmente calcificadas son propensas a ser diluidas (Cherns et al., 2011). En la base de esta concentración se observaron abundantes trazas y moldes internos bioturbados de Dosinia?. Considerando que la profundidad de enterramiento que tienen los venéridos es de entre 0 y $15 \mathrm{~cm}$ (Ansell, 1962; Kondo, 1987), la formación de estos moldes puede asociarse a la disolución del carbonato de calcio en la zona tafonómicamente activa (TAZ). En esta zona la disolución puede deberse a cambios en la saturación de aguas porales a través de la oxidación de materia orgánica. La bioturbación también desempeña un papel importante en la disolución ya que disuelve componentes a través de procesos redox y permite el paso de agua a través de las trazas, facilitando la oxidación del sedimento, lo que ocasiona un decaimiento aeróbico de la materia orgánica y permite el reflujo de carbonato disuelto de las aguas porales hacia el agua marina (Cherns et al., 2011).

Otros invertebrados presentes en las concentraciones fueron los balanos, cuyo exoesqueleto está compuesto por el rostrum, la carina y las placas rostro y carino laterales, y las placas operculares: la escuta y la terga. La composición mineralógica de sus placas es principalmente calcita policristalina alta en magnesio con un bajo contenido de materia orgánica (Tucker, 1991; Khalifa et al., 2011). Sin embargo, se han observado algunas variaciones mineralógicas entre especies; por ejemplo, algunas contienen aragonita en la base de su exoesqueleto, mientras que en el género lbla se ha observado el contenido de hidroxilapatita en las placas operculares (Khalifa et al., 2011). A lo largo de la sección estudiada, pero particularmente en $\mathrm{C} 2$, es notable la presencia de placas de balanos, principalmente de aquellas que forman la pared corporal; las placas operculares se preservan en menor proporción, lo cual puede deberse a que después de la muerte del organismo son las primeras en desarticularse. En esta concentración predominaron concentraciones de balanos en pequeños pods, siendo otros taxones de composición calcítica (v. g. pectínidos, ostras, briozoos y equinoideos) menos abundantes. Las características tafonómicas de las placas de balanos ( $\mathrm{V}$. Discusión § Características tafonómicas) sugieren que su acumulación pudo estar asociada a procesos diagenéticos que impidieron la preservación de organismos aragoníticos, como así también a selección durante la depositación o lavado de fósiles más livianos y de menor talle después de la misma.

Los equinoideos regulares e irregulares también se encontraron en el material procesado, sin embargo, su presencia fue poco representativa y caracterizada por un alto índice de desarticulación y fragmentación. A pesar de que la composición mineralógica de su endoesqueleto es de calcita alta en magnesio (Killian y Wilt, 2008), es posible que su subrepresentación en las concentraciones estudiadas hubiera estado influenciada principalmente por aspectos tafonómicos (físicos) más que mineralógicos. 
El registro de briozoos en las concentraciones fue abundante (especialmente en C4), tanto por la diversidad de restos de colonias (incrustantes, con forma de domo, robustas ramificadas, articuladas y de vida libre) como por sus trazas (V. Capítulo 4). Aquellos del orden Cheilostomata fueron los que predominaron; estos invertebrados pueden construir sus esqueletos con calcita, aragonita o con una combinación de ambas (Smith et al., 2006; Taylor et al., 2009; Di Martino et al., 2016). En representantes actuales, predomina la composición aragonítica mas en faunas tropicales abundan también aquellos de composición bimineral (Di Martino et al., 2016). Hacia latitudes polares el contenido de aragonita disminuye (Taylor et al., 2009). A pesar de que en el registro fósil existe evidencia de esqueletos de briozoos queilostomados calcíticos para el Cenozoico, también hay registros de aragoníticos, como los del Mioceno de Malasia que han sido preservados por calcitización (Di Martino et al., 2016). La presencia de estos invertebrados en las concentraciones de Cabeza de León puede estar asociada al hecho de que la preservación de organismos con aragonita se vio favorecida por un enterramiento rápido tal como habría ocurrido con los moluscos de esta mineralogía (V. arriba) o a que dentro de su composición calcítica, como parte de los queilostomados actuales, tuvieran un bajo contenido de magnesio (Taylor et al., 2009), uno de los polimorfos más estables del carbonato de calcio.

iii) Composición taxonómica y hábitos de vida: Al igual que para la estimación del espectro de edades, la recolección de muestras volumétricas de conchillas y sedimento de las concentraciones de Cabeza de León y su posterior procesamiento y análisis en laboratorio, permitió una mejor aproximación al conocimiento de la riqueza taxonómica de las mismas, evitando su subestimación. Esto a su vez, permitió caracterizar y clasificar adecuadamente a las concentraciones según la abundancia relativa de los taxones. En este sentido, el estudio de la malacofauna en laboratorio incrementó en más del $50 \%$ el número de taxones presentes en las concentraciones con respecto al estimado mediante observaciones directas en los cuadros de campo (Fig. 3.15), ya que gran parte del tamaño de muestra estuvo conformado por conchillas retenidas en las mallas de 1,190 y $0,710 \mathrm{~mm}$ ( . Apéndice I).

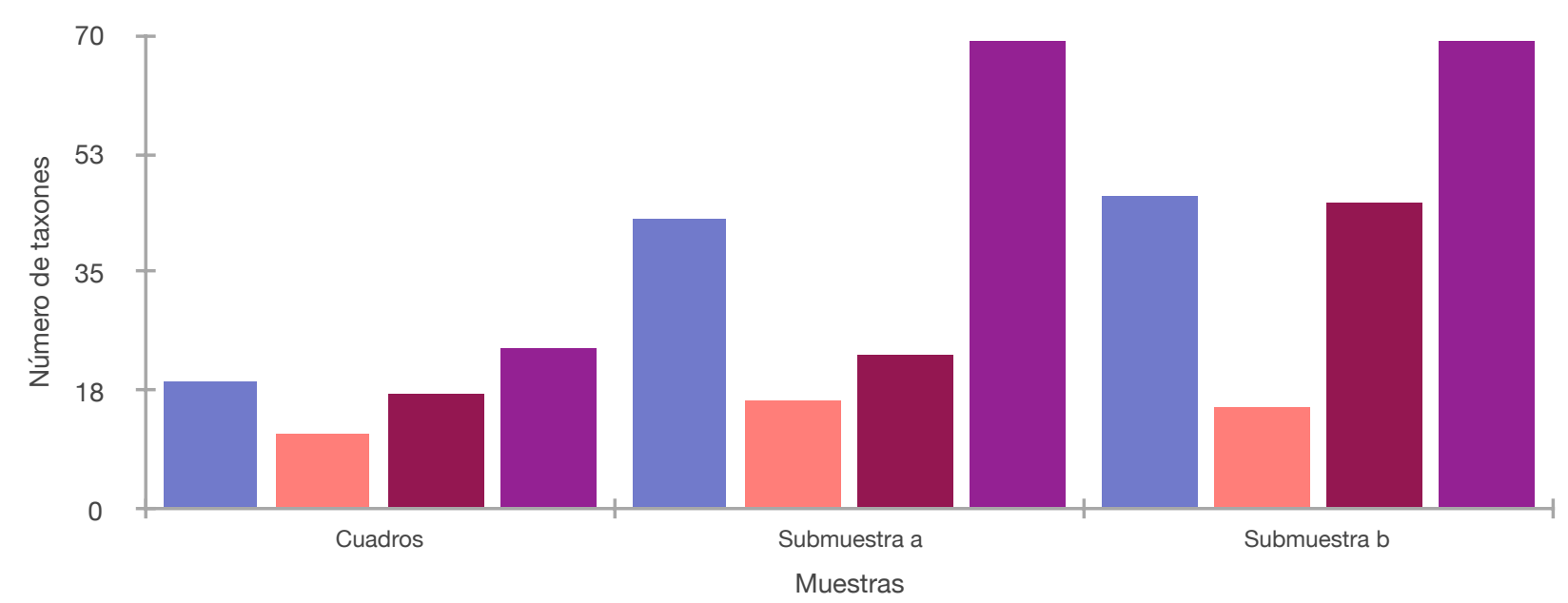

Figura 3.15. Riqueza taxonómica observada en las concentraciones $\mathrm{C} 1-\mathrm{C} 4$, en el scoring de los cuadros en campo y en las submuestras a y b de cada una de ellas. $\mathrm{C} 1=$ azul, $\mathrm{C} 2=$ rosa, $\mathrm{C} 3=$ bordó, $\mathrm{C} 4=$ violeta. 
Las concentraciones de Cabeza de León pueden considerarse como politípicas siguiendo el criterio de Kidwell et al. (1986), sin embargo, en algunas de ellas uno o más taxones son más abundantes que el resto. Particularmente, $\mathrm{C} 1$ y $\mathrm{C} 4$ tienen un número de individuos considerable de turritelas. Allmon (2007) definió los «conjuntos dominados por turritelas», Turritelline-dominated assemblages en inglés, como cualquier conjunto macrofósil en el que las turritelas comprendan al menos el $20 \%$ del total de la biomasa estimada o al menos el $20 \%$ de los individuos y, sean al menos $20 \%$ más abundantes que la siguiente especie más común en el conjunto; adicionalmente el autor sugirió que el término "conjunto rico en turritelas», en inglés Turritelline rich assemblage, se emplee cuando, aunque no se cumplan los requerimientos cuantitativos, las turritelas sean abundantes. En ambas concentraciones las turritelas comprenden el $25 \%$ de las muestras, sin embargo, en ninguno de los casos son $20 \%$ más abundantes que el siguiente taxón más abundante; en C1 sólo son $11,87 \%$ más abundantes que Solariella y en C4, 18,26\% más abundantes que Pleuromeris de modo que ambas concentraciones pueden considerarse como conjuntos ricos en turritelas (Fig. 3.16).
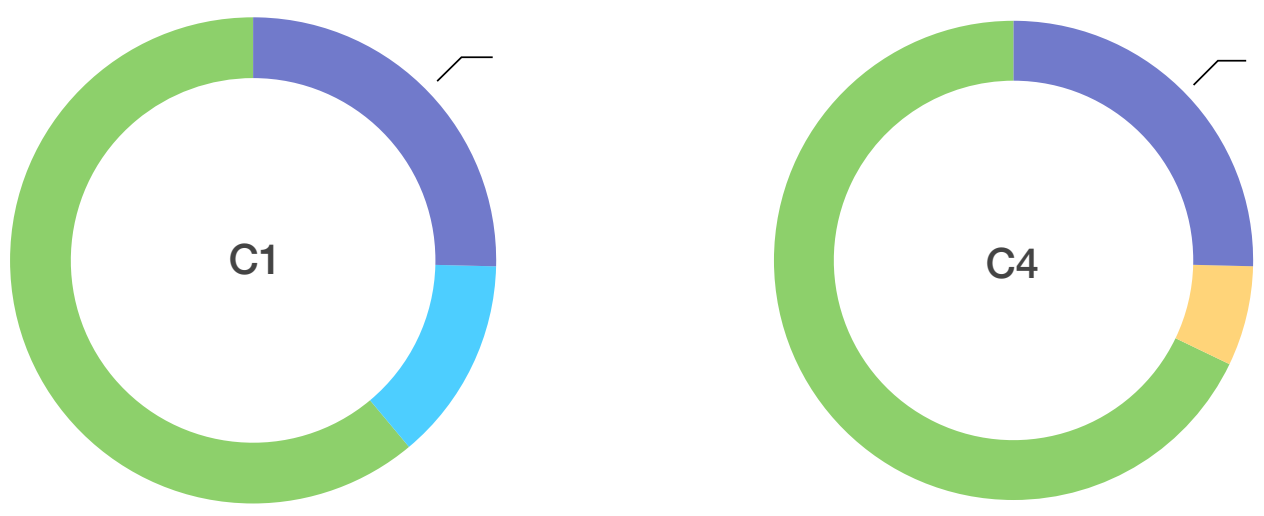

Figura 3.16. Abundancia relativa de Turritella (violeta) en $\mathrm{C} 1$ y $\mathrm{C} 4$, en comparación con la del segundo taxón más abundante en cada una de las concentraciones, Solariella (azul) en C1 y Pleuromeris (amarillo) en C4. La abundancia relativa de los otros taxones se representa en color verde.

Actualmente, los turritélidos tienen una amplia distribución y tienden a ser los más abundantes en las comunidades que habitan; sus requerimientos abióticos incluyen mayormente aguas de $15^{\circ}-20^{\circ} \mathrm{C}$, una profundidad de entre 10 y 100 metros (aunque se han reportado especies más someras, y otras que también habitan a más de 200 metros), salinidad normal con poca tolerancia a ambientes salobres o estuarinos y un ambiente con gran cantidad de nutrientes y productividad primaria (Allmon, 2007, 2011). En cuanto al tipo de sustrato, Merriam (1941) señaló que Turritella no muestra preferencia por un tipo de sustrato, mientras que otros autores han señalado algún tipo de selectividad (V. Allmon, 1988). La abundancia de turritelas en el tiempo geológico ha mostrado variaciones en las facies en las que se encuentran, ya que conjuntos dominados por y ricos en turritelas son comunes en rocas carbonáticas del Cretácico al Paleógeno, pero posteriormente y hasta la actualidad estos conjuntos son comunes en ambientes silicoclásticos. En un contexto paleobiológico, estas variaciones de facies sugieren un cambio en el rango ambiental, de templado a cálido y de carbonático a clástico, durante el Paleógeno y el Neógeno (Allmon, 2007, 2011). Biológicamente, se ha sugerido que la abundancia de las turritelas es un 
ejemplo del Efecto Alle o densidad inversa de dependencia (Kennedy, 1995) o que depende directamente de la productividad primaria (Allmon, 1992, 2001). En el contexto de la Tafonomía, la información que brindan los turritélidos actuales, cuyas poblaciones tienden a ser densas con un gran número de conchillas (tanatofacies de Turritella sensu Giacobbe y Mondelo, 1994), tiende a ser confusa. Por ejemplo, en el suroeste de Australia se ha observado que la densidad de conchillas muertas de Maoricolpus roseus Quoy y Gaimand, 1834 no incrementa con el tiempo (Nicastro et al., 2009), sino que los enterramientos periódicos son suficientes para prevenir la acumulación de conchillas en las superficies biológicamente activas; por otro lado en canales de mareas de Auckland, Nueva Zelanda, las conchillas de esta especie son más comunes que los individuos vivos, mostrando evidencias de pagurización y colonización por epibiontes (Allmon, 2011), sugiriendo promediación temporal y condensación.

La posición de vida es un criterio ampliamente utilizado para reconocer parte de la historia tafonómica de los elementos de una concentración, pero en el caso de estos moluscos tiende a resultar problemática, ya que las turritelas de vida libre en estadio adulto pueden tener dos orientaciones en sustratos pelíticos o arenosos. La primera, cuando el organismo descansa y se alimenta, el eje más largo se orienta de manera subparalela a la superficie del sedimento de modo que la apertura es perpendicular al mismo; en la segunda orientación, el eje de mayor tamaño también está paralelo al sedimento, pero la apertura se encuentra en contacto con el sustrato, esta posición se asocia a etologías de desplazamiento y enterramiento (Allmon, 2011). En C1 y C4, las características estratigráficas como el empaquetamiento denso y el agrupamiento apilado de las conchillas indican que los turritélidos no están en posición de vida. La presencia de algunos especímenes orientados de manera perpendicular al sustrato (una posición hidrodinámica inestable), sugiere para su formación un evento episódico y un enterramiento rápido.

En C1 otros géneros de gasterópodos abundantes fueron Solariella, Kaitoa y Cylichnania (Tablas 3.1, 3.3, 3.4), que son moluscos epifaunales que actualmente habitan en sustratos arenosos (Hayward, 1976; Dornellas y Simone, 2015). Además, fue notable la abundancia de los bivalvos de la Familia Mactridae, especialmente del género Maorimactra, la presencia de este género ha sido referida en comunidades de sustratos arenosos entre $7 \mathrm{y}$ $40 \mathrm{~m}$ de profundidad; actualmente estas comunidades con comunes en la plataforma de Nueva Zelanda en diferentes tipos de sustratos (McKnight, 1969). La presencia de taxones que en comunidades actuales tienen requerimientos ecológicos similares sugiere que los elementos de esta concentración habitaron el mismo hábitat y experimentaron poco transporte lateral, soportando la parautoctonía representada en la concentración. En C4, las turritelas son el único gasterópodo abundante, los siguientes taxones con mayor número de individuos fueron Pleuromeris, Cosa y Maorimactra (Tablas 3.27, 3.29, 3.30). Pleuromeris es un bivalvo que en la base de datos fue considerado epifaunal (V. Métodos), mas en sentido estricto se considera seminfaunal o infaunal asifonado (V. Apéndice II) que habita sustratos arenosos; Cosa por otra parte es bisado, se ha referido que estos bivalvos son epibiontes de algas feofitas (Griffin y Pastorino, 2012), las cuales habitan en zonas intermareales. La presencia de especímenes de diferentes comunidades soportaría la promediación temporal y dentro del hábitat para C4. 
Por otra parte, en C2 y C3, los taxones más abundantes corresponden a bivalvos sifonados, los venéridos Dosina y Retrotapes y el lucínido Pteromyrtea (Tablas 3.12, 3.14, $3.15,3.17,3.19,3.20)$. Se ha referido en la literatura que Dosinia indica depósitos de aguas someras, y en algunas ocasiones se ha asociado a incremento en la temperatura del agua, pero este bivalvo que ha tenido una amplia distribución en el mundo también ha habitado en aguas templadas desde Neógeno hasta la actualidad (Addicott, 1976; del Río, 1997). El género Retrotapes es antártico, siendo referido su registro más antiguo en las formaciones San Julián (Oligoceno tardío), El Chacay (Mioceno temprano) y en otras secciones de la Formación Monte León (del Río, 1997; Parras y Griffin, 2009) sugiriendo que la fauna Neoaustral se adaptaba a un rango de temperatura que fluctuó entre cálido y templado; con relación al sustrato, se ha referido que habita sustratos blandos (Gordillo, 2006).

En C2 la presencia de moldes de Dosinia? en sustratos arenosos, sugiere un ambiente somero y estos especímenes podrían considerarse una asociación de censo; sin embargo, su presencia sólo se restringe a un sector de la concentración lo que evidencia además variaciones laterales a lo largo de la misma. Por su parte, las conchillas preservadas y su grado de preservación (V. Discusión $\S$ Características tafonómicas) son los elementos parautóctonos de estas concentraciones que evidencian promediación temporal y dentro del hábitat. En C3, la composición taxonómica observada en campo (de todos los lentes y en las submuestras, que corresponden a diferentes lentes) también evidencia variación lateral (Tablas 3.16, 3.18, 3.18; Figura 3.9). La presencia de elementos epi- e infaunales sugiere promediación dentro del hábitat y soporta la influencia de procesos mecánicos en la acumulación de los bioclastos (V. Discusión § Características tafonómicas).

En campo, a lo largo de toda la sección, fue notable la presencia de bivalvos de la especie Panopea quemadensis en posición de vida; de modo que $P$. quemadensis constituye un elemento autóctono de las concentraciones C1, C2 y C4. Los bivalvos de este género son dióicos y presentan siete estadios de vida que incluyen tres de larva, trocófora, veliger I y veliger II; uno postlarval, el juvenil y el adulto; las postlarvas permanecen algunas semanas en la superficie del sedimento y se alimentan de depósitos superficiales, posteriormente cuando se desarrollan los sifones, en el estadio juvenil, los organismos comienzan a enterrarse en el sustrato (Orensans et al., 2000). Habitan sustratos pelíticos y arenosos, enterrados entre 0,6 y $1 \mathrm{~m}$ de profundidad; batimétricamente se distribuyen desde la zona intermareal a profundidades de hasta $110 \mathrm{~m}$ (Straus et al., 2008). Las valvas de los adultos alcanzan talles desde $75 \mathrm{~mm}$ hasta más de $200 \mathrm{~mm}$ de longitud (Cortez-Lucero, 2013).

En la actualidad se han descripto seis especies de Panopea, tres de las cuales habitan en el Hemisferio Sur: $P$. abbreviata (Valenciennes, 1839) se distribuye desde Río de Janeiro a Puerto Deseado, su valva mide unos $150 \mathrm{~mm}$ de longitud; P. zelandica (Quoy y Gaimand, 1835) habita en aguas poco profundas $(5-25 \mathrm{~m})$ de la Isla Stewart (Nueva Zelanda), en sustratos pelíticos y arenosos; mide entre 65 y $121 \mathrm{~mm}$ de longitud y puede extender su sifón hasta $45 \mathrm{~cm}$ sobre el sustrato; $P$. smithae Powell, 1950, también es endémica de Nueva Zelanda, tiene una conchilla de menor tamaño que $P$. zelandica $(90-110 \mathrm{~mm}$ de longitud) y habita a mayor profundidad en sustratos gruesos y finos (Beu y Maxwell, 1990; Gribben, 2003). Estudios sobre ecología y reproducción de Panopea globosa (Dall 1898) han mostrado que se distribuye formando agregados y que su densidad poblacional está determinada biológicamente por su condición gonocórica y su hábito infaunal y 
ambientalmente por disponibilidad de nutrientes, turbidez, temperatura y principalmente por el tipo de sustrato, en este sentido se ha observado una mayor densidad de individuos en sustratos limo-arcillosos (Gómez-García, 2005; Sánchez et. al., 2009; Cortez-Lucero, 2013) y limo-arenosos (Godwin y Pease, 1991); esta diferencia de sustratos observada, se considera que puede estar determinada además por la presencia de otras especies.

Las valvas de Panopea quemadensis presentes en Cabeza de León tienen una longitud entre 93 y $125 \mathrm{~mm}$ (Tabla 3.39) y el tamaño de las vainas descriptas oscila entre 200 y 240 $\mathrm{mm}$ de largo; posiblemente estas vainas corresponden a galerías habitadas por estos bivalvos. Debido a su preservación y a que su relleno corresponde con la matriz circundante, es posible que eventos de alta energía y corta duración que depositaron el resto de los bioclastos causaran el sepultamiento y la muerte de estos organismos excavadores. En los especímenes encontrados en la sección no se observaron trazas de escape, sin embargo existe el registro de las mismas en la Formación Monte León (Carmona et al., 2007).

La recurrente aparición de Panopea quemadensis a lo largo de la sección estudiada puede estar influenciada por el sedimento, arena fina limosa en $\mathrm{C} 1-\mathrm{C} 3$ y arena fina a media limosa en C4. Por otra parte, resulta importante señalar que los especímenes que se encontraron son de talles $>70 \mathrm{~mm}$, indicando que los estadios preservados pudieron corresponder a juveniles y adultos (Tabla 3.39); la ausencia de un espectro de edad más amplio puede deberse a la labilidad de la conchilla en los primeros estadios y a que esta habita en la superficie del sustrato durante los mismos, disminuyendo su potencial de preservación. En el procesamiento de muestras no se observaron conchillas de $P$. quemadensis que pudieran pertenecer a estadios de vida más jóvenes. En panopeas actuales con talles similares, se ha observado que las gónadas no están completamente maduras o son pocos los especímenes que entran en etapa reproductiva (Cortez-Lucero, 2013). Esto, sumado a lo anterior podría influir en la ausencia de conchillas de los primeros estadios de vida. Estudios paleoecológicos detallados de esta especie a lo largo de la sección podrían brindar características más detalladas sobre la impronta tafonómica que muestran y contribuirían al conocimiento de los eventos relacionados con la depositación de las sedimentitas de la Formación Monte León y sus concentraciones fósiles.

Tabla 3.39. Medidas en milímetros de Panopea quemadensis de la Formación Monte León. Las filas señaladas con asterisco $\left(^{*}\right)$ corresponden a especimenes colectados en campañas anteriores.

\begin{tabular}{|l|c|c|c|c|c|}
\hline \multicolumn{1}{|c|}{ Localidad } & Largo & Ancho & \multicolumn{1}{c|}{ Localidad } & Largo & Ancho \\
\hline Cabeza de León & 94 & 70 & Cabeza de León & 98 & 66 \\
\hline Cabeza de León & 108 & $\approx 67$ & Cabeza de León & 125 & 82 \\
\hline Punta Índice & 102 & 94 & Cabeza de León & 105 & 73 \\
\hline
\end{tabular}

Características tafonómicas: procesos físicos, químicos o biológicos involucrados en la formación de las concentraciones fósiles

El análisis de las características tafonómicas de las concentraciones fósiles de Cabeza de León permitió mejorar el conocimiento acerca de los principales procesos involucrados en su formación. Se discuten aquí las principales inferencias realizadas en cada una de las 
concentraciones mediante la evaluación de la fragmentación, la alteración superficial, el redondeamiento y la bioerosión.

i) Fragmentación: La fragmentación es un atributo ampliamente asociado a la energía del ambiente y a la resedimentación; cuando sus índices son elevados se asocian a ambientes de alta energía por encima del nivel de base de olas de buen tiempo, como playas y canales de mareas, y a una prolongada resedimentación (Brett y Baird, 1986; Parsons y Brett, 1991). Brett y Baird (1986) han señalado que este atributo, puede estar asociado también a la depredación; en este contexto se han descripto los patrones de fragmentación o fracturas en conchillas de braquiópodos (Alexander, 1981) y moluscos (Boucot, 1981). Adicionalmente, trabajos de tafonomía experimental (Oji et al., 2003) han evaluado las diferencias entre los patrones de fragmentación producidos por agentes bióticos de los abióticos y, trabajos enfocados en las trazas de depredación en el registro fósil señalan que el comportamiento hidrodinámico de las conchillas depredadas es diferente al de aquellas que no lo han sido, ya que la fragmentación por crustáceos, asteroideos y aves, así como las perforaciones producidas por moluscos y otros invertebrados aumentan la probabilidad de fragmentación.

En C1, C3 y C4 la fragmentación predominante fue moderada (Tablas 3.2, 3.17, 3.28; Figs. $\underline{3.5}, \underline{3.10}, \underline{3.12}$, mostrando mayores índices en la fracción retenida en la malla de mayor apertura (5,660 mm, Tablas 3.5, 3.20, 3.31); en este rango de talle es posible que factores abióticos fueran los responsables de la fragmentación ya que los patrones que se observan coinciden con puntos frágiles de las conchillas como los cambios en la estructura determinados por líneas de crecimiento y ornamentación. Parsons y Brett (1991) señalaron que las conchillas de gasterópodos tienden a romperse en la apertura, y que en conchillas de espira alta la última vuelta tiende a separarse del resto de la conchilla. Este patrón de fragmentación fue notorio en las conchillas turriteliformes, especialmente en $\mathrm{C} 1$ y C4, las cuales fueron consideradas como incompletas. Al evaluar la relación de los otros índices tafonómicos con respecto a la fragmentación en los bioclastos retenidos en los diferentes tamaños de malla empleados (Tablas 3.7, 3.22, 3.33), se observó que ésta es directamente proporcional a la alteración superficial, al redondeamiento y a la modificación de bordes e inversamente proporcional a la bioerosión. Estas características preservaciones coinciden con las observaciones de Driscoll (1967) relacionadas con la proporción superficievolumen, en la que las conchillas de menor talle tienden a mostrar mayor alteración superficial. Tanto el redondeamiento como la modificación de bordes son atributos que además de estar asociados a la fragmentación pueden estar determinados por la alteración superficial. La baja bioerosión por otra parte, puede corresponder al hecho de que cuanto más fragmentada esté una conchilla, es menor la superficie disponible para colonizar $(\underline{V}$. Capítulo 4).

En las conchillas retenidas en el tamiz de apertura 1,190 $\mathrm{mm}$ la fragmentación predominante fue de baja a moderada (Tablas 3.5, 3.20, 3.31), lo cual permite considerar que estos especímenes, por su menor talle, experimentaron menor fragmentación. Sin embargo, en esta fracción a pesar de que la bioerosión fue baja, predominaron trazas de depredación por lo que, si bien la fragmentación pudo estar asociada a factores abióticos, los factores bióticos pudieron influir en su fragmentación posterior. 
Finalmente, las conchillas retenidas en la malla $0,710 \mathrm{~mm}$ mostraron principalmente fragmentación moderada (Tablas 3.5, 3.20, 3.31); parte de los fragmentos retenidos en esta fracción posiblemente correspondieran a fragmentos de conchillas de mayor tamaño.

El grado de fragmentación moderado observado en las concentraciones estudiadas, sugiere un transporte poco significativo, pero es posible que en estas concentraciones la energía del evento de depositación final no fuera el único elemento determinante, ya que la preservación de los fragmentos de la malla $5,660 \mathrm{~mm}$ sugiere previos eventos de exhumación y resedimentación.

ii) Alteración superficial: El término corrasión fue propuesto por Brett y Baird (1986) para referirse la alteración de la superficie de los elementos esqueletales por bioerosión, disolución -corrosión en conjunto- y abrasión. En este trabajo la bioerosión fue reconocida y estudiada en detalle (V. Capítulo 4) por lo que se empleó el concepto alteración superficial que únicamente incluye la alteración producida por abrasión y disolución que en algunos especímenes fue difícil reconocer de manera separada.

La abrasión ocurre cuando los elementos esqueletales son expuestos a partículas en movimiento o estos son movidos junto con otras; el movimiento de los elementos esqueletales y el sedimento requiere de alta energía, de modo que altos índices de este atributo se asocian a ambientes costeros expuestos a la acción del oleaje y de mareas (Parsons y Brett, 1991); otros autores además señalan que altos índices de abrasión están relacionados con la distancia y el proceso de transporte (Kuenen, 1964; Driscoll 1967; Davies et al.,1989). Driscoll (1967) señaló que, en moluscos, la rapidez e intensidad de la abrasión depende también de la relación superficie-volumen, por lo que las conchillas con una baja relación superficie-volumen tienden a sufrir menos abrasión que aquellas con una mayor relación superficie-volumen. El tamaño de grano y la selección también influyen en la durabilidad de las conchillas con respecto a la abrasión ya que se ha observado que cuando los elementos son expuestos a granos gruesos o a una pobre selección, la intensidad de abrasión es mayor (Driscoll y Weltin, 1973). En algunas ocasiones, para evaluar el índice de abrasión es necesario examinar los especímenes mediante microscopía electrónica de barrido, para diferenciar la abrasión mecánica de la disolución y microbioerosión; macroscópicamente puede reconocerse por la preservación atenuada de la ornamentación y el facetamiento localizado (Parsons y Brett, 1991).

Por otra parte, la disolución puede ocurrir antes o después de enterramiento y es evidenciada por la presencia de pozos o el adelgazamiento de las conchillas. La disolución sugiere altas condiciones de salinidad, baja temperatura, bioturbación activa 0 fluctuaciones de $\mathrm{pH}$ y $\mathrm{pCO}_{2}$; se ha debatido si estas condiciones ocurren en microhabitats que rodean a los elementos esqueletales (Alexandersson, 1978; Parsons y Brett, 1986). La solubilidad de los minerales está determinada por su mineralogía; algunos autores (Flessa y Brown, 1983; Peterson, 1976; Tucker, 1991) han señalado que esqueletos calcíticos con alto contenido en magnesio (balanos y equinodermos) presentan mayor solubilidad, seguido de aquellos aragoníticos, como la mayoría de los moluscos, y de organismos calcíticos con bajo contenido en magnesio (ostras y braquiópodos).

En C1 la alteración superficial predominante fue moderada y en C3 y C4 de moderada a alta (Tablas 3.2, 3.17, 3.28; Figs. 3.5, 3.10, 3.12), predominando así especímenes con 
ornamentación desgastada o ausente y apariencia porcelanosa o cretosa. Esto sugiere la exposición de la mayoría de las conchillas de estas concentraciones a corrientes de energía moderada o alta junto con otros elementos esqueletales, lo cual promovió el desgaste de su ornamentación y el pulido de su superficie. En los especímenes de estas concentraciones no se reconoció facetamiento; es posible que esta característica fuera obnubilada por posteriores procesos biostratinómicos. Las evidencias de disolución en los especímenes son reconocidas como descamaciones en la superficie de la conchilla y la presencia de pozos con bordes aguzados o con apariencia astillada o aserrada y textura cretosa; en algunos casos, la disolución se observó como pequeños parches en la superficie de la conchilla. Si bien esta alteración también puede deberse a la bioturbación y la bioerosión, en C1, C3 y C4 ésta no se considera como un agente principal, sino que se atribuye así a las condiciones ambientales a las que fueron sometidos durante la exposición en la interfase agua-sedimento.

Al evaluar la presencia de este atributo en las conchillas considerando su talle y su fragmentación (Tablas 3.7, 3.22, 3.33), en C1, C3 y C4 se observó que en los especímenes completos la alteración superficial fue mayor en las conchillas de los tamices 1,190 mm y $0,710 \mathrm{~mm}$; en las conchillas incompletas la alteración superficial fue de moderada a alta, siendo mayor en los elementos del tamiz 0,710; finalmente, en los fragmentos se observó una mayor alteración superficial en las conchillas del tamiz 5,660 mm. La selectividad tafonómica observada en las conchillas completas e incompletas responde a la elevada relación superficie-volumen observada por algunos autores (v.g. Driscoll, 1967; Powell et al., 1986; Davies et al., 1989); sin embargo en los fragmentos de mayor tamaño (5,660 mm) el alto índice de alteración superficial podría estar asociado además a diferentes episodios de exposición y resedimentación previos a la acumulación y enterramiento final. Esto sugeriría que los elementos esqueletales con mayor fragmentación y alteración superficial pueden corresponder a cohortes más antiguas con respecto de aquellos elementos que presentan menor fragmentación y alteración superficial, soportando la promediación temporal y la condensación ambiental.

En C2, la alteración superficial predominante fue alta (Tabla 3.13, Fig. 3.7), la mayoría de las valvas mostraron en su cara externa una apariencia cretosa y una ornamentación resaltada; al tratarse principalmente de especies infaunales se considera que este ocurrió post mortem. Adicionalmente, la mala preservación en general de estos bioclastos sugiere que su tiempo de permanencia en la TAZ fue prolongado; también la alta alteración superficial puede estar relacionada con el contacto entre bioclastos durante el transporte. En esta concentración, las placas desarticuladas de balanos fueron abundantes, su preservación fue moderada, con descamación de la superficie y en algunos casos ornamentación exagerada; cuando la alteración superficial era mayor, fue posible observar la estructura porosa que presentan estas placas. Parsons y Brett (1991) mencionaron que la porosidad de los esqueletos también afecta la tasa de disolución y que en el caso de los balánidos, a pesar de poseer placas calcíticas y una baja relación superficie-volumen, su porosidad incrementa la disolución; adicionalmente las placas de balanos mostraron redoneamiento y superficies pulidas. De guisa que, la desarticulación en conjunto con las características de abrasión de las placas, sugiere un transporte significativo de las mismas; las rubricas de abrasión pudieron ocurrir durante el transporte, pero también durante el enterramiento, ya que en esta concentración hay evidencias de bioturbación. 
iii) Redondeamiento: Este atributo es un proxy que sugiere abrasión y disolución (Chave, 1964; Cutler, 1987; Davies et al., 1989). La presencia del redondeamiento predominó en todas las concentraciones y en las tres aperturas de tamices (Tablas 3.2, 3.13, 3.17, 3.28; Figs. $3.5,3.7,3.10,3.12$ ), mostrando que no hay ninguna relación entre este atributo y el tamaño de las conchillas. Sin embargo, se observó una mayor proporción de redondeamiento en fragmentos que en conchillas completas e incompletas. El redondeamiento se considera como un atributo asociado a la fragmentación y a la alteración superficial que soporta la resedimentación de las conchillas.

Best y Kidwell (2000b) sugirieron que el redondeamiento puede también estar asociado a microbioerosión, de manera que este atributo no queda restringido a la exposición y a la resedimentación en ambientes de alta energía. En el material estudiado se observaron algunas trazas de macrobioerosión asociadas a márgenes redondeados; sin embargo, estas se consideran como evidencia de exposición posterior a la fragmentación ( $\underline{V}$. Capítulo 4), mientras que el estudio de trazas de microbioerosión no forma parte de los alcances de este trabajo.

iv) Bioerosión: En todas las concentraciones la bioerosión fue baja (Tablas 3.2, 3.13, 3.17, 3.28; Figs. 3.5, 3.7, 3.10, 3.12), sugiriendo una corta exposición en la interfase agua sedimento, sin embargo al considerar este atributo con relación a la apertura de los tamices, se observó una mayor cobertura de la superficie en el de 5,660 mm (Tablas 3.5, $3.20,3.31)$. El tipo de trazas que predominan corresponden a la categoría etológica Domichnia sugiriendo que el asentamiento en conchillas de este talle corresponde con un requerimiento espacial por parte de los bioerodantes ( $\underline{\text {. Capítulo } 4})$.

Al considerar la presencia de la bioerosión en relación con la fragmentación (Tablas 3.7, $3.22,3.33)$, ésta fue más notoria en los fragmentos de elementos esqueletales retenidos en el tamiz de mayor apertura de malla $(5,660 \mathrm{~mm})$, sugiriendo un mayor tiempo de exposición de los fragmentos en la interfase agua-sedimento. La evidencia de una mayor cobertura superficial de las trazas de bioerosión en fragmentos soporta la presencia de elementos que sufrieron diferentes episodios de colonización y resedimentación previos al enterramiento final, evidenciando, además de promediación en el tiempo, retroalimentación tafonómica. Asimismo, a pesar de que la bioerosión fue baja, considerando como criterio la proporción de la conchilla cubierta por la traza, la icnodiversidad observada es considerable, de modo que este atributo tafonómico resulta importante pues más allá de sugerir el tiempo de permanencia de los bioclastos en la zona tafonómicamente activa, evidencia las condiciones ambientales bajo las cuales estos estuvieron expuestos ( $V$. Capítulo 4).

Relación entre taxones, hábitos de vida y características tafonómicas: su importancia para reconocer las diferentes historias tafonómicas de los bioclastos presentes en las concentraciones

Al considerar si había diferencias de preservación entre los taxones más abundantes de la concentración, en C1 y C3 (Tablas 3.8, 3.9, 3.10, 3.23, 3.24, 3.25) no se observaron diferencias significativas. Solamente algunos taxones mostraron una ligera variación en el grado de fragmentación, el resto de los atributos muestran el predominio de índices tafonómicos similares. En C4 se observaron diferencias de preservación entre los taxones 
más abundantes observándose mejores índices tafonómicos en Pleuromeris y "Pleuromeris" (Tablas 3.34, 3.35, 3.36). En una de las submuestras de esta concentración (Tabla 3.36) las conchillas de Dosinia muestran mayor alteración tafonómica que el resto de los taxones considerados. Este bivalvo infaunal al presentar mayor alteración tafonómica que algunos taxones epifaunales o seminfaunales (v.g. Pleuromeris), evidencia la presencia de bioclastos que fueron exhumados y resedimentados antes del enterramiento final, soportando la promediación temporal y dentro del hábitat que presentan esta concentración, además de reflejar una baja fidelidad temporal (Fig. 3.17).

Al evaluar si existían diferencias en la preservación de las conchillas pertenecientes a organismos infaunales y epifaunales, en C1, C3 y C4 tampoco se observaron diferencias significativas (Tabla 3.11, 3.26, 3.37). En C1 únicamente se observaron diferencias en la bioerosión, que fue moderada en los taxones epifaunales, pero en este modo de vida es difícil discriminar entre la bioerosión que fue realizada syn vivo y aquella post mortem. En C3, los resultados fueron similares; en el scoring de campo, las conchillas asociadas a hábitos infaunales mostraron mayor bieorosión, que posiblemente se realizó después de la muerte del organismo; en la submuestra $3 a$ se observó una ligera diferencia en la preservación predominante de infaunales (moderada) y epifaunales (buena a moderada). En el scoring de C4 los organismos infaunales mostraron mayor alteración superficial, pero en las submuestras analizadas no se observaron diferencias significativas entre los dos hábitos de vida.

Best y Kidwell (2000a) evaluaron en concentraciones actuales el efecto del hábito de vida y la mineralogía de las conchillas en la preservación de bivalvos. Las autoras únicamente observaron diferencias significativas en concentraciones asociadas a sustratos duros, siendo no significativo el daño observado en conchillas epifaunales en sustratos no consolidados. La preservación de los moluscos epifaunales de Cabeza de León fue similar a la de los infaunales, hecho posiblemente relacionado con el carácter areno-limoso del sedimento del hábitat de los mismos. Best y Kidwell (2000a) también observaron que la frecuencia de incrustación y perforación (no por depredación) fue elevada en organismos epifaunales. Aunque este tipo de daño puede ocurrir en vida, cuando los organismos mueren la conchilla queda expuesta en la interfase agua-sedimento y la colonización por esclerobiontes tiende a ser el primer tipo de daño que sufre la conchilla (Fig. 3.17). En el scoring de C1, C4 el índice de bioerosión fue mayor en epifaunales (Tabla 3.11, 3.26, 3.37), el incremento de este atributo puede ser consecuencia de que es el primer daño al que están expuestas las conchillas después de la muerte.

La presencia de los balanos en las concentraciones de Cabeza de León, especialmente en $\mathrm{C} 2$, es destacable. La mayoría del material encontrado corresponde a placas desarticuladas, redondeadas y con abrasión. Los balanomorfos son principalmente sublitorales ya que el $73 \%$ de las especies conocidas habitan entre 0 y $100 \mathrm{~m}$ de profundidad y únicamente el $26 \%$ habitan en zonas intermareales. En el registro fósil, el principal objeto de estudio sobre este clado comprende su asentamiento en sustratos duros y sus implicaciones ecológicas o de zonación de ambientes litorales; sin embargo, los estudios tafonómicos aún son escasos o se orientan a fósiles completos que aún están incrustados o excepcionalmente preservados (Donovan, 1988; Doyle et al., 1997, Nielsen y Funder, 2003; Bianucci et al., 2006; Aguirre et al., 2008; Buckeridge et al., 2014). 


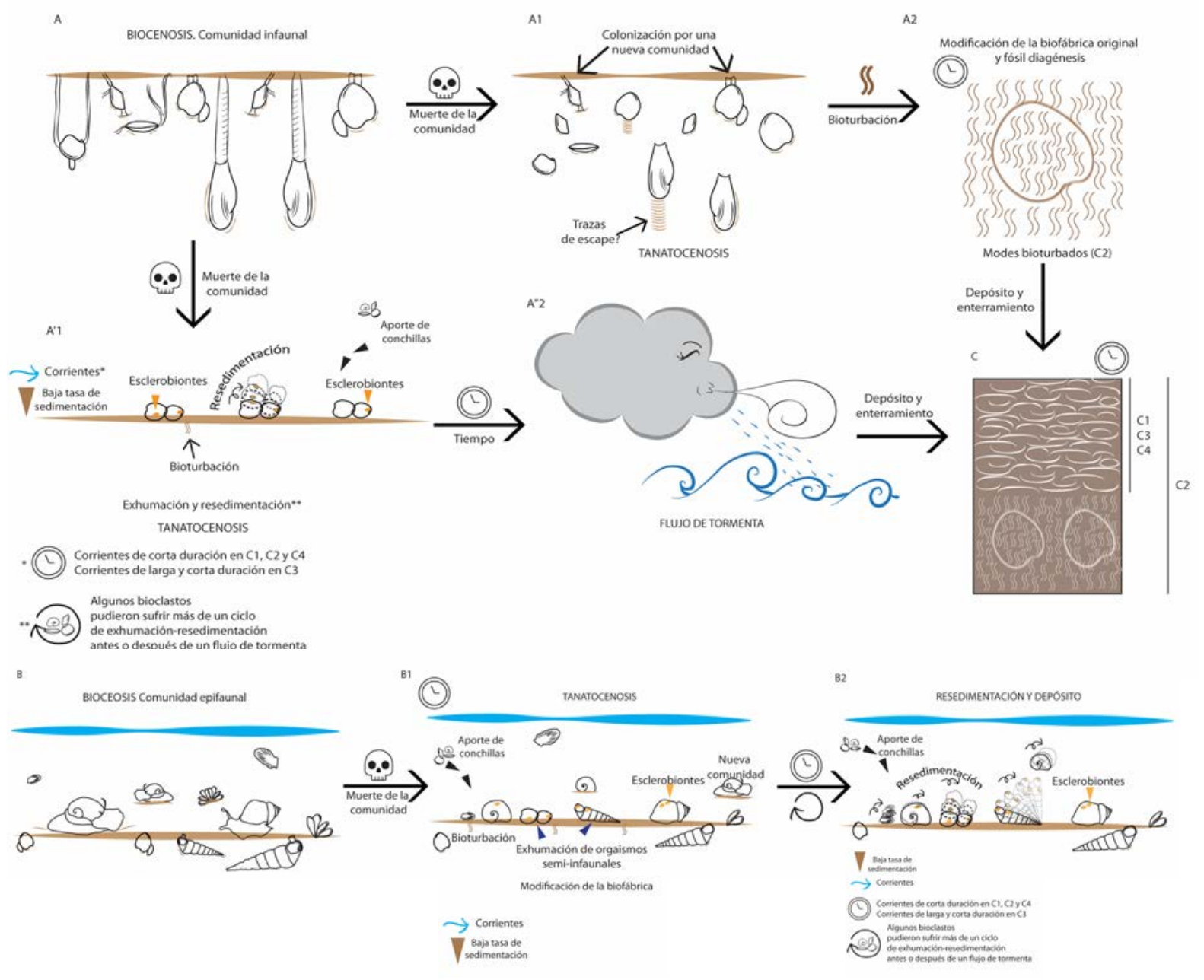

Figura 3.17. Posibles historias tafonómicas de las conchillas de moluscos de las concentraciones fósiles (C1-C4) en la sección Cabeza de León. A) Biocenosis de la comunidad infaunal que después de la muerte, dio lugar a una asociación de muerte (A1) en donde la baja tasa de sedimentación favoreció el establecimiento de una nueva comunidad infaunal que a través de la bioturbación modificó la biofábrica original y en C2 promovió la formación de moldes bioturbados a través de fosil diagénesis (A2). Por otra parte, la bioturbación también modifico la posición de los bioclastos y favoreció su exhumación y exposición en la interfase agua-sedimento (A'1). La exposición favoreció la retroalimentación tafonómica (esclerobiontes) y la presencia de corrientes de larga o corta duración favoreció la resedimentación y el aporte de conchillas (promediación temporal y dentro del hábitat). Finalmente, la presencia de flujos de tormenta (A'2) resedimentó los bioclastos depositándolos en la plataforma interna. Estos eventos representan episodios de breve duración en el registro geológico. B) Biocenosis de la comunidad epifaunal, después de la muerte, las conchillas quedan expuestas en el fondo marino (B1), lo que permite la colonización post mortem de comunidades de sustratos (retroalomentación tafonómica), la bioturbación del sedimento además de modificar la biofábrica, favorece la exhumación de restos de organismos seminfauales. La presencia de corrientes de diferente duración promueve el aporte de conchillas y la resedimentación de los bioclastos (B2). La presencia de flujos de tormenta (A'2) resedimenta y re deposita los bioclastos en la plataforma interna. C) Depósito y enterramiento final.

Donovan (1988) estudió la paleoecología y la tafonomía de balanos del Plio-Pleistoceno de Anglia Oriental enfocándose principalmente a aquellos organismos incrustados en conchillas de moluscos. También mencionó la presencia de placas desarticuladas en la concentración estudiada señalando su alto grado de abrasión, el cual atribuyó a la abrasión mecánica; mas no realizó ninguna interpretación sobre su origen y depósito. Doyle et al. 
(1997) reconocieron siete tafofacies de concentraciones de balanos, las de tipo 5 y 6 , que se componen únicamente restos desarticulados y fragmentados de balanos, presentan características similares a las observadas en C2. Bianucci et al. (2006) analizaron el conjunto de Coronula diadema (Linnaeus, 1767), una especie que habita en la región dorsal de la ballena Megaptera novaeangliae (Borowski, 1781) en diferentes concentraciones biogénicas y sedimentológicas del Pleistoceno de Ecuador. Los resultados de este estudio indicaron que las concentraciones biogénicas no sufrían alteraciones físicas significativas, pero sí alteraciones biológicas (bioerosión e incrustación), mas aquellas depositadas en concentraciones sedimentológicas mostraron elevada alteración superficial y baja o nula alteración biológica.

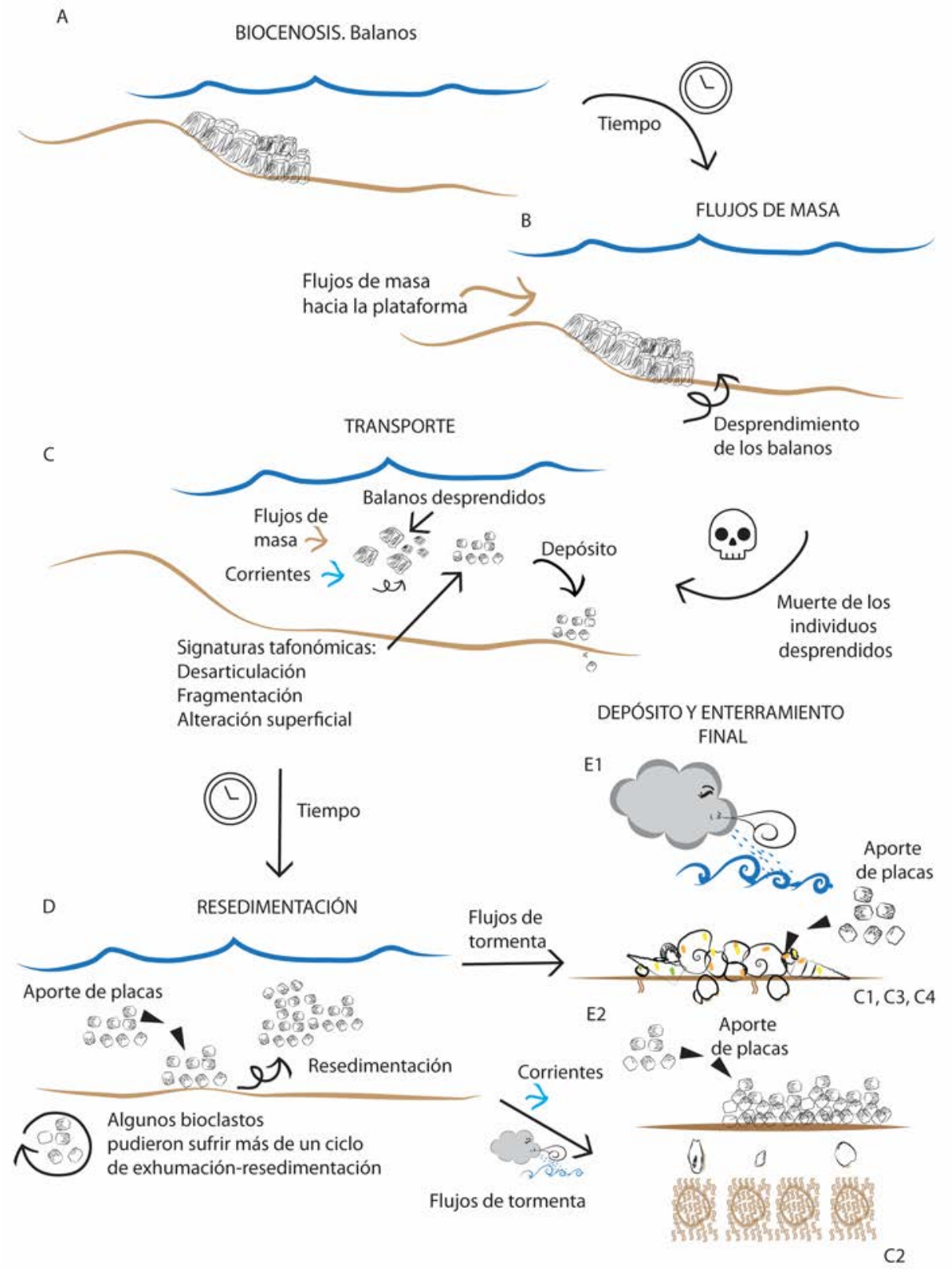

Figura 3.18. Posibles historias tafonómicas de las placas de balanos de las concentraciones fósiles de Cabeza de León. A) Biocenosis de balanos en la zona intermareal. B) Presencia de un flujo de masa que desprende a los balanos. C) Balanos transportados y desarticulados hacia la 
plataforma .D) Acumulación y resedimentación de balanos por depósitos de flujo (Promediación temporal). E1) Depósito y enterramiento final de los balanos en conjuntos de conchillas (C1, C3 y C4). E2) Depósito y enterramiento final de los balanos en C2.

El redondeamiento de las placas de balanos de la concentración C2 sugiere transporte (Fig. 3.18). La alteración superficial observada, también pudo ocurrir durante el mismo cuando las placas chocaban con el sedimento y con otros bioclastos transportados. El diferente grado de alteración observado puede reflejar promediación temporal en la que algunos bioclastos pudieron estar sometidos a diferentes ciclos de resedimentación (Fig. 3.18c, d). Debido a la baja bioerosión o incrustación de las conchillas observadas, se sugiere una corta exposición en la interfase agua-sedimento y un enterramiento rápido. Además, la ausencia de registros de trazas de bioerosión atribuidas a estos artrópodos (V. Capítulo 4) sugiere que dentro de la concentración son elementos alóctonos. Doyle et al. (1997) asocian este tipo de tafofacies a depósito de flujo involucrados en cambios en el nivel del mar de poca magnitud.

La preservación de los briozoos en las concentraciones de Cabeza de León es de moderada a mala, ya que presentan un alto grado de fragmentación y alteración superficial. Predominaron las formas coloniales robustas, articuladas y delicadas. En C2 y C4 se registraron escasos fragmentos de colonias fenestradas, y en $\mathrm{C} 4$ se encontraron varias colonias con forma de domo. En C3 la presencia de estos invertebrados destaca en el lente 6 (Fig. 3.9). Las colonias de briozoos incrustantes no fueron abundantes en las concentraciones, pero su registro icnológico fue extenso (V. Capítulo 4).

Taylor y James (2013) señalaron que después de la muerte los briozoos pueden producir partículas sedimentarias de tres maneras: por desprendimiento (detachment), ruptura, y desarticulación (Fig. 3.19). En colonias incrustantes, el desprendimiento puede ocurrir cuando la bioadhesión al sustrato se debilita después de la muerte del organismo (Wilson et al., 1999) (Fig. 3.19a) y cuando se adhieren a las partes blandas de un organismo (v. gr. algas) las colonias se desprenden y liberan cuando el huésped muere y el tejido es degradado (Taylor y James, 2013). En formas erectas ocurre cuando su anclaje orgánico o sistema radicular se rompe, liberando así todo el esqueleto (Fig. 3.19b, c). La ruptura puede ser física, debido a la interacción de las partículas y su intensidad de colisión con relación a la energía hidrodinámica, o biológica por depredación de peces, decápodos o equinodermos. La desarticulación ocurre cuando los nodos orgánicos entre los zooides o ramas se degradan y los elementos calcáreos son liberados. Las colonias con forma de domo no sufren modificaciones considerables y se integran a depósitos como partículas con talle equivalente a grava. Posteriormente, el depósito de sus restos depende de la energía del ambiente; en ambientes de baja energía, los fragmentos de briozoos pueden permanecer casi intactos; sin embargo, los esqueletos pueden ser degradados rápidamente por bioerosión o bioturbación reduciendo así su tamaño. La abrasión y la fragmentación se intensifican de manera proporcional a la energía del medio (Taylor y James, 2013).

Los briozoos presentes en las concentraciones de Cabeza de León sufrieron fragmentación y alteración superficial durante el transporte. La energía de este provocó que los restos de ramas delgadas se fragmentaran sucesivamente hasta tener talles equivalentes a los de la 
arena (Fig. 3.19c), mientras que en colonias robustas el talle fue equivalente a arena o grava (Fig. 319d). Su abundancia en el registro paleontológico, permite sugerir que son elementos parautóctonos; su alto grado de alteración puede ser un indicador de la energía de la corriente. En C3, posiblemente la acumulación de briozoos en el lente 6 puede indicar un elemento autóctono que fue fragmentado y desarticulado por una corriente de alta energía pero que sufrió un enterramiento rápido ya que los fragmentos acumulados son de un tamaño equivalente a grava y con las mismas características, sugiriendo que pertenecían a un solo organismo o varios organismos de la misma especie (Fig. 3.19d).

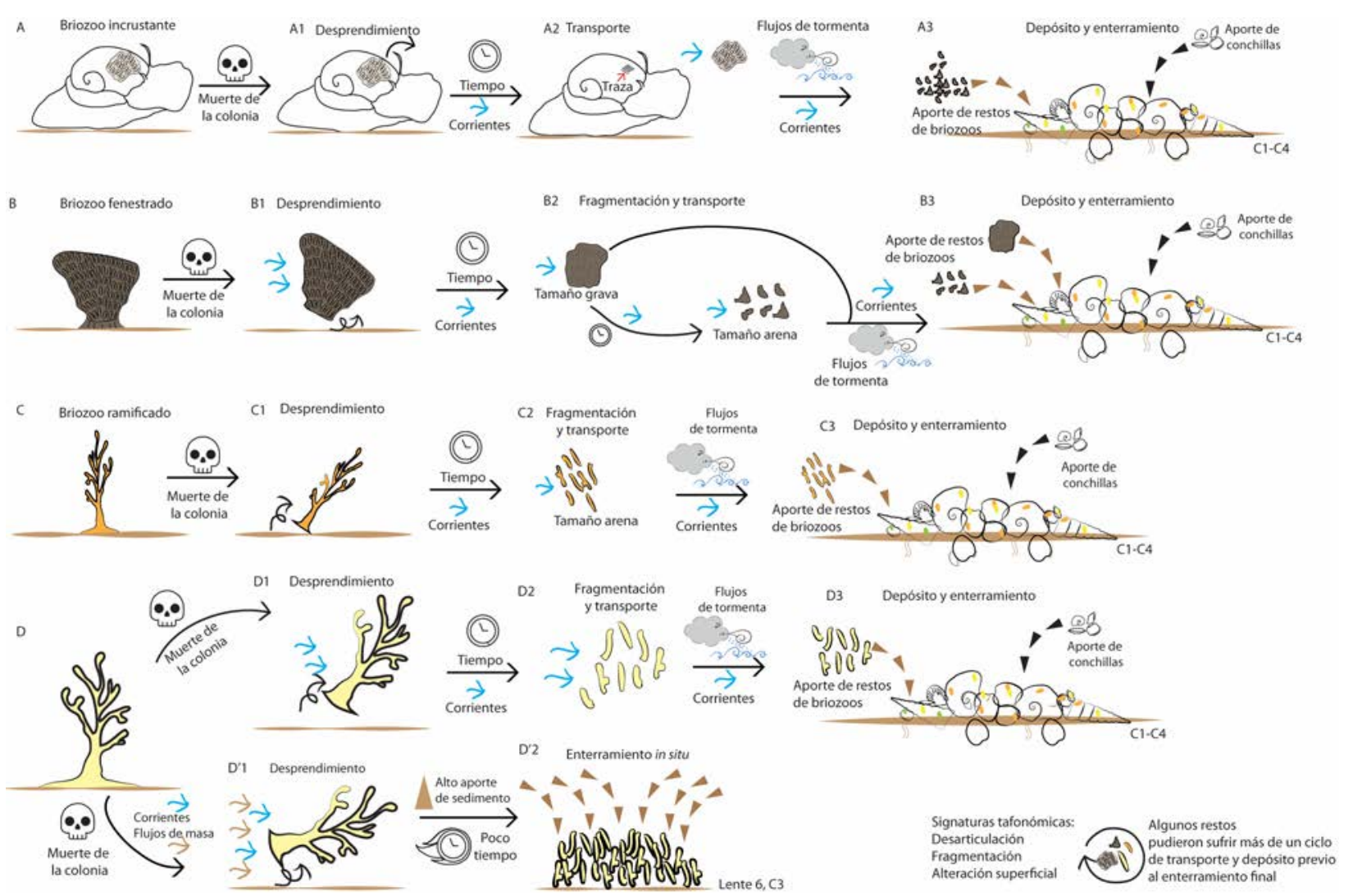

Figura 3.19. Posibles historias tafonómicas de las colonias de briozoos más comunes en las concentraciones fósiles de la sección Cabeza de León. A) Historia de colonias incrustantes que después de la muerte se desprenden del huésped (A1) y al ser sometidas a corrientes de diferente energía se fragmentan en talles equivalentes a arena (A2), la flecha roja señala la posibilidad de que parte de la colonia quede adherida en el huésped o permanezca el registro de una traza. Flujos de tormenta o corrientes de carga o corta duración favorecen el transporte y el depósito final de la colonia o sus restos. B) Historia de colonias fenestradas., C) Historia de colonias ramificadas delicadas. D)Historia de colonias ramificadas gruesas. Las colonias de $B, C$ y $D$ después de la muerte se desprenden del sustrato (B1, C1 D1 y D'1); antes del desprendimiento pueden comenzar a fragmentarse, los restos sufren alteración tafonómica durante el transporte y pueden adquirir talles equivalentes a grava o arena según la energía a la que son sometidos (B2, C2, D2) y finalmente se depositan con partículas sedimentarias (B3, C3, D3). En la colonia ramificada gruesa del lente 6 de la Concentración 3 , corrientes y flujos de masa provocaron la muerte y desprendimiento de la colonia (D'1), la energía de las corrientes además provocó la desarticulación y un bajo grado de fragmentación que acompañados de un alto aporte de sedimento en un intervalo corto de tiempo permitieron un rápido enterramiento in situ (D’2). Adaptado de Taylor y James (2013). 


\section{Capítulo 4}

...dejando en la hoja en blanco cicatrices que el tiempo imprime.

-Jorge Drexler

Quimera 


\section{Análisis icnológico}

\section{Introducción}

En este capítulo se presenta el análisis icnológico de las trazas de bioerosión presentes en los bioclastos de las concentraciones de Cabeza de León. En métodos se señalan las observaciones en campo y de gabinete que fueron consideras para este análisis, así como el tratamiento que recibieron los datos tomados. En los resultados, en primer lugar se presenta la icnotaxonomía de las trazas de bioerosión reconocidas en todas las concentraciones estudiadas $(\mathrm{C} 1-\mathrm{C} 4)$, las mismas se describen en orden alfabético. Posteriormente se presenta la icnodiversidad observada en las concentraciones, tanto en campo como en las muestras estandarizadas, y la preferencia de las trazas de bioerosión por alguna de las caras de los bioclastos. En este caso, a diferencia del capítulo anterior, los resultados son presentados de manera separada por productor para poder discutir las implicaciones paleobiológicas de los mismos al final de este capítulo.

\section{Métodos}

\section{Trabajo de campo y de gabinete}

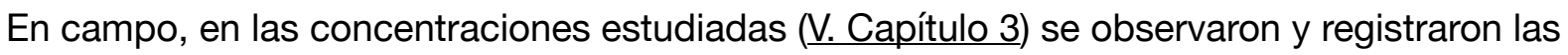
trazas de bioerosión presentes en los bioclastos incluidos en cuadros de $50 \mathrm{~cm} \times 50 \mathrm{~cm}$. En las submuestras estandarizadas (V. Capítulo 1 §Métodos generales §Trabajo de laboratorio), además de determinar el índice de bioerosión (1, bajo; 2 , medio; 3 , alto V. Capítulo 3 §Métodos generales §Trabajo de campo), se reconocieron las trazas a la menor categoría icnotaxonómica posible. Posteriormente se determinó la icnodiversidad y la abundancia relativa de cada icnotaxón en cada concentración y para cada uno de los tamices empleados $(5,660 \mathrm{~mm}, 1,190 \mathrm{~mm}$ y $0,710 \mathrm{~mm})$.

Los icnotaxones reconocidos fueron agrupados sobre la base de su posible productor. El material fue fotografiado con cámara Leica EC3 (adaptada a lupa binocular Leica S6D) en la Facultad de Ciencias Exactas y Naturales (FCEyN) de la Universidad Nacional de La Pampa y con el microscopio electrónico de barrido del Museo Argentino de Ciencias Naturales "Bernardino Rivadavia" (MACN).

\section{Tratamiento de datos}

Para cada concentración, se registraron los icnotaxones y su presencia en cada bioclasto. Para los bioclastos de la malla 5,660 mm además se señaló si el icnotaxón se encontraba en ambas o en una cara del bioclasto, en el último caso, se especificó si era la interna o la externa. Los icnotaxones reconocidos fueron asociados a sus posibles productores. Considerando a los productores como observaciones independientes, para cada uno de ellos se realizó una prueba de bondad de ajuste de dos colas con un intervalo de confianza 
de 0,95 para conocer si había alguna tendencia por parte de los productores a asentarse en una o ambas caras del bioclasto. Para esta prueba se consideró como una "observación exitosa» la presencia de la traza en una de las caras del bioclasto; este calificativo no tiene ninguna connotación paleobiológica. La hipótesis nula en esta prueba sugiere que los productores pueden asentarse de igual manera en una o en ambas caras de un bioclasto.

Adicionalmente, se realizó la misma prueba para evaluar la tendencia de los posibles productores a colonizar la cara interna o externa del bioclasto. En este caso, se consideró como «observación exitosa» la presencia de las trazas en la cara interna. La hipótesis nula sugiere que los productores colonizan el sustrato de manera azarosa.

\section{Resultados}

Icnotaxonomía

Icnogénero Caulostrepsis Clarke, 1908

Icnoespecie tipo. Caulostrepsis taeniola Clarke, 1908

Icnoespecie. Caulostrepsis biforans (Gripp, 1967)

Figura 4.1A

Material. Traza con forma de U sin veleta, el largo de la galería oscila entre 3 y $4 \mathrm{~mm}$, el ancho promedio es de $1 \mathrm{~mm}$. Los miembros (limbs sensu Bromley y D'Alessandro, 1983) se encuentran unidos por una pared intermedia a lo largo de toda la traza, presentando estos un ancho de entre 0,34 y 0,42 mm cerca de la apertura y de entre 0,40 y 0,55 $\mathrm{mm}$ hacia la base de la traza. La sección transversal es circular a ovalada. La preservación de las trazas varía; en algunos casos no se preserva la galería completa debido a fragmentación o alteración superficial, lo cual también puede afectar en la preservación de la pared intermedia. No se observan surcos aperturales.

Procedencia. C1, C2, C4.

Observaciones. Estas trazas se asignan al icnogénero por la galería en forma de $U$, en tanto que la ausencia de la veleta y la forma de la sección transversal, permite la asignación icnoespecífica. Los especímenes se diferencian de C. avipies Bromley y D'Alessandro, 1983, icnoespecie que también puede carecer de una veleta, por presentar ésta una sección transversal en forma ovalada-aplanada o de pesa y surcos aperturales similares a la impresión dejada por las extremidades posteriores de las aves. Mayores diferencias existen con $C$. taeniola Clarke, 1908 ya que en esta icnoespecie hay una veleta separando los miembros, mientras que en C. cretacea (Voigt, 1971) los miembros se encuentran fusionados sin una pared intermedia o los remanentes de esta quedan como una ligera depresión axial.

Icnoespecie. Caulostrepsis contorta Bromley y D'Alessandro, 1983

Figura 4.1B, C

Material. Traza que en vista en planta presenta secciones aperturales con forma de pesa o de coma. El ancho de los miembros es variable (mínimo 0,011 mm, máximo 0,030 mm, promedio $0,020 \mathrm{~mm}$ ) al igual que la amplitud de la veleta (mínimo $0,05 \mathrm{~mm}$, máximo 0,14 $\mathrm{mm}$, promedio $0,10 \mathrm{~mm})$; la veleta es estrecha y con diámetro constante $(0,009 \mathrm{~mm})$. 
Algunos especímenes presentan pequeños surcos aperturales (ancho 0,009 mm) que se ensanchan en la región distal. Únicamente en un ejemplar se observa el interior de la galería que presenta forma de $U$ asimétrica, más ancha que larga. En este ejemplar se observa, hacia la apertura, una veleta que separa a los limbos; mientras que en la región distal se observa un pequeño lóbulo desarrollado en el mismo eje.

Procedencia. C2.

Observaciones. Este material se designa al icnogénero por la forma de $U$ de la galería y por la forma de pesa que presentan las aperturas vistas en planta de algunas icnoespecies, similares a las variaciones morfológicas referidas por Mayoral (1991). Estos ejemplares difieren de C. taeniola, por la forma de la galería que en esta icnoespecie es alargada. También difieren de $C$. biforans y $C$. cretacea por la presencia de la veleta. No se designan además a $C$. avipies, icnoespecie en la cual la veleta puede o no desarrollarse, por la ausencia se surcos aperturales.

Icnoespecie. Caulostrepsis taeniola Clarke, 1908

Figura 4.1D

Material. Traza con forma de $\mathrm{U}$ alargada (largo promedio $5,75 \mathrm{~mm}$, ancho promedio 1,4 $\mathrm{mm}$ ), con limbos (ancho entre 0,5 y $0,9 \mathrm{~mm}$, promedio $0,7 \mathrm{~mm}$ ) unidos por una pared intermedia hacia la apertura. Hacia el extremo distal ambos limbos están interconectados por una veleta pequeña (ancho promedio 0,25 mm), en algunos casos desgastada por alteración superficial. Las trazas están mal preservadas, y en la mayoría de los especímenes no se puede apreciar la apertura; sin embargo, en algunos se puede reconocer la forma de 8 de la misma, característica de esta icnoespecie.

Procedencia. C1, C2, C4.

Observaciones. Los ejemplares poseen la característica forma de $U$ alargada de la icnoespecie. Los limbos están bien definidos, no fusionados como los de Caulostrepsis cretacea. La presencia de la veleta la distingue de $C$. biforans. La vista en planta en algunos ejemplares es similar a las variaciones morfológicas de $C$. contorta referidas para el Plioceno del Bajo Guadalquivir, España (Mayoral, 1991). Debido a que es difícil distinguir en planta $C$. taeniola de C. contorta por la morfología similar que presentan sus aperturas (Hanken et al., 2012), no se descarta que algunos de los especímenes considerados aquí como C. taeniola puedan corresponder a C. contorta. Debido a esto la abundancia de $C$. taeniola podría estar sobrestimada.

Icnofamilia Dendrinidae Bromley, Wisshak, Glaub y Botquelen, 2007

Icnogénero tipo Dendrina Quenstedt, 1849

Trazas con forma de roseta o de rosetas incompletas que se caracterizan por tener un nodo (central o lateral) del cual emergen galerías de longitud variable, las cuales pueden ramificarse y unirse entre sí para formar patrones reticulados 0 anastomosados. La profundidad de penetración en el sustrato de estas trazas puede ser somera o profunda.

Si bien en el material analizado estas trazas presentan gran variabilidad, su morfología general en forma de roseta permite incluirlas en la icnofamilia Dendrinidae propuesta por Bromley et al. (2007) y posteriormente revisada sistemática e históricamente por Wisshak (2017). Tomando este último trabajo como referencia, algunas de las trazas rosetiformes observadas en el material de Cabeza de León pudieron ser determinadas a una menor categoría icnotaxonómica. Sin embargo, dada la gran abundancia y las variaciones 
morfológicas observadas, estas determinaciones quedan a reserva de ser soportadas o modificadas posteriormente.
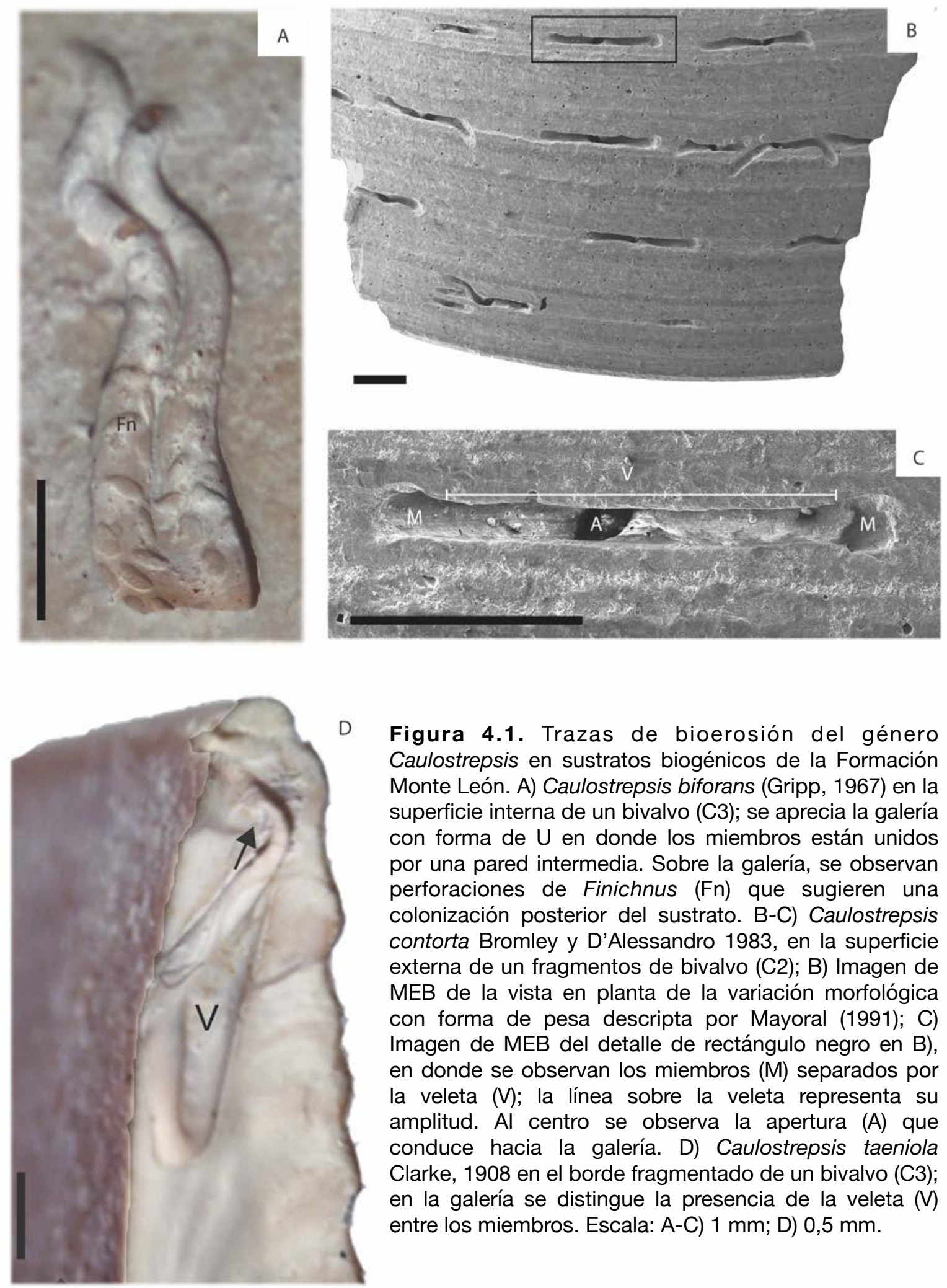

Figura 4.1. Trazas de bioerosión del género Caulostrepsis en sustratos biogénicos de la Formación Monte León. A) Caulostrepsis biforans (Gripp, 1967) en la superficie interna de un bivalvo (C3); se aprecia la galería con forma de $U$ en donde los miembros están unidos por una pared intermedia. Sobre la galería, se observan perforaciones de Finichnus (Fn) que sugieren una colonización posterior del sustrato. B-C) Caulostrepsis contorta Bromley y D'Alessandro 1983, en la superficie externa de un fragmentos de bivalvo (C2); B) Imagen de MEB de la vista en planta de la variación morfológica con forma de pesa descripta por Mayoral (1991); C) Imagen de MEB del detalle de rectángulo negro en $\mathrm{B}$ ), en donde se observan los miembros (M) separados por la veleta (V); la línea sobre la veleta representa su amplitud. Al centro se observa la apertura (A) que conduce hacia la galería. D) Caulostrepsis taeniola Clarke, 1908 en el borde fragmentado de un bivalvo (C3); en la galería se distingue la presencia de la veleta (V) entre los miembros. Escala: A-C) $1 \mathrm{~mm}$; D) 0,5 mm. 
Icnogénero Antodendrina Wisshak, 2017

Icnoespecie tipo. Antodendrina ligula Wisshak, 2017

Icnoespecie. Antodendrina cf. A. ligula Wisshak, 2017

Figura $4.2 \mathrm{~A}$

Material. Cámara o lóbulo poco profundo de forma triangular (largo 0,014 mm, ancho $0,011 \mathrm{~mm}$ ) del cuál emergen finas ramas (largo mínimo $0,019 \mathrm{~mm}$, máximo 0,045 mm, promedio $0,030 \mathrm{~mm}$ ) y forman pequeñas aperturas arqueadas que conectan el lóbulo con la superficie del sustrato.

Procedencia. C2.

Observaciones. Esta traza presenta afinidades con Antodendrina ligula descripta por Whisshak (2017) ya que la forma triangular es similar a los lóbulos que surgen de un punto de origen con forma alargada o de lágrima, el cual no siempre es visible. La presencia de esta traza en el margen interno de una valva con un alto grado de alteración superficial no permite seguir su continuidad con la finalidad de observar otros lóbulos. Debido a que este es el único ejemplar observado, su determinación queda a reserva de la observación de material completo o en un sustrato mejor preservado.

Icnogénero Clionolithes Clarke, 1908

Icnoespecie tipo. Clionolithes radicans Clarke, 1908

Icnoespecie. Clionolithes isp.

Figura 4.2B

Material. Trazas rosetadas con apertura tipo techo abierto (open roof sensu Whisshak, 2017); presentan un nodo vertical irregular o alargado (largo $0,15 \mathrm{~mm}$ ), de este emergen galerías rectas o curveadas de longitud variable (largo mínimo 0,06 mm, máximo 0,08 mm, promedio $0,07 \mathrm{~mm}$ ), las cuales en el algunos casos se bifurcan y tienen forma palmeada 0 de abanico. En todas las ramificaciones disminuye el diámetro hacia la región distal.

Procedencia. C1, C2, C4.

Observaciones. Se sugiere que las trazas de Cabeza de León presentan afinidad con el icnogénero Clionolithes, por la expansión palmeada y en abanico de las galerías que surgen del centro. En esta tesis se describen las trazas únicamente a nivel icnogénerico debido a que el estrado de preservación del sustrato en ocasiones dificulta reconocer algunos caracteres taxonómicos de las mismas. Sin embargo, considerando la forma del centro de la traza y como las galerías de distribuyen y ramifican alrededor de este, es posible que las trazas observadas correspondan a más de una icnoespecie.

Icnogénero Dictyoporus Mägdefrau, 1937

Icnoespecie tipo. Dictyoporus nodosus Mägdefrau, 1937

Icnoespecie. Dictyoporus cf. D. nodosus Mägdefrau, 1937

Figura 4.2C

Material. Pequeña traza formada por canales (diámetro mínimo 0,005mm, máximo 0,017 $\mathrm{mm}$, promedio $0,013 \mathrm{~mm}$ ) que se unen entre sí creando un patrón reticulado del cual se desprenden ramificaciones con terminaciones de menor diámetro

Procedencia. C2. 
Observaciones. Esta traza se asigna a Dictyoporus, por el sistema de galerías que tienen un arreglo reticulado. Presenta características comunes a $D$. nodosus, icnoespecie que presenta una gran variabilidad morfológica que depende del estadio ontogenético que represente y el tipo de sustrato en el que se encuentre. También es importante la preservación de la traza, que puede consistir en pequeñas impresiones abiertas, o puede presentarse como verdaderos túneles endolíticos (Wisshak, 2017). El único espécimen observado se encuentra en la cara interna de una valva con alta alteración superficial que posiblemente influye en las impresiones abiertas que se observan. El patrón reticulado de esta traza también es similar al de Abeliella riccioides Mägdefrau, 1937; sin embargo, esta traza se restringe a sustratos óseos.

Icnogénero Neodendrina Wisshak y Neumman, 2018

Icnoespecie tipo. Neodendrina carnelia Wisshak y Neumman, 2018

Icnoespecie. Neodendrina isp.

Figura 4.2D

Material. Traza en forma de roseta radial con canales pequeños, de diámetro constante (entre $0,088 \mathrm{~mm}$ y $0,1 \mathrm{~mm}$ ), ramificados con patrón dicotómico y terminación redondeada. El nodo del que surgen las ramificaciones es alargado y de tamaño similar a estas $(0,094$ $\mathrm{mm})$.

Procedencia. C1, C4.

Observaciones. El material de Cabeza de León guarda similitud con Neodendrina carnelia, por la presencia de ramificaciones dicotómicas con terminación redondeada. El tamaño de la traza y la longitud de los canales sugiere que refleja estadios ontogenéticos tempranos. No se observaron estadios ontogenéticos adultos en el material estudiado, por lo que la determinación icnoespecífica de estas trazas queda a reserva.

Icnogénero Nododendrina Vogel, Golubic y Brett, 1987

Icnoespecie tipo. Nododendrina nodosa Vogel, Golubic y Brett, 1987

Icnoespecie. Nododendrina cf. N. europaea (Fischer, 1875)

Figura 4.2E, F

Material. Traza con forma de media roseta, presenta un nodo vertical alargado que tiene un punto de origen subcircular (largo $0,44 \mathrm{~mm}$ ). Del nodo surge un plexus lateral con forma de abanico (largo 0,18 mm, ancho 0,15 $\mathrm{mm}$ ), ramificado y anastomosado. El diámetro de las ramas es constante (largo 0,04 mm; diámetro 0,01 mm): no se ensancha en la región distal.

Procedencia. C2, C4.

Observaciones. Esta traza se designa al icnogénero Nododendrina, por la posición lateral del nodo que lo caracteriza; por su parte, la presencia de un plexus que se extiende sólo hacia un extremo con forma de abanico permite compararla con $N$. europaea. Los ejemplares estudiados también presentan similitud con $N$. paleodendrica (Elias, 1957), icnoespecie en la que el plexus también puede estar orientado sólo hacia un extremo; sin embargo, en esta icnoespecie las ramas se ensanchan en la región distal. Una de las características que podría ayudar a confirmar la icnoespecie es la textura de traza, para lo cual se requeriría la observación de varios vaciados de silicona en MEB. 


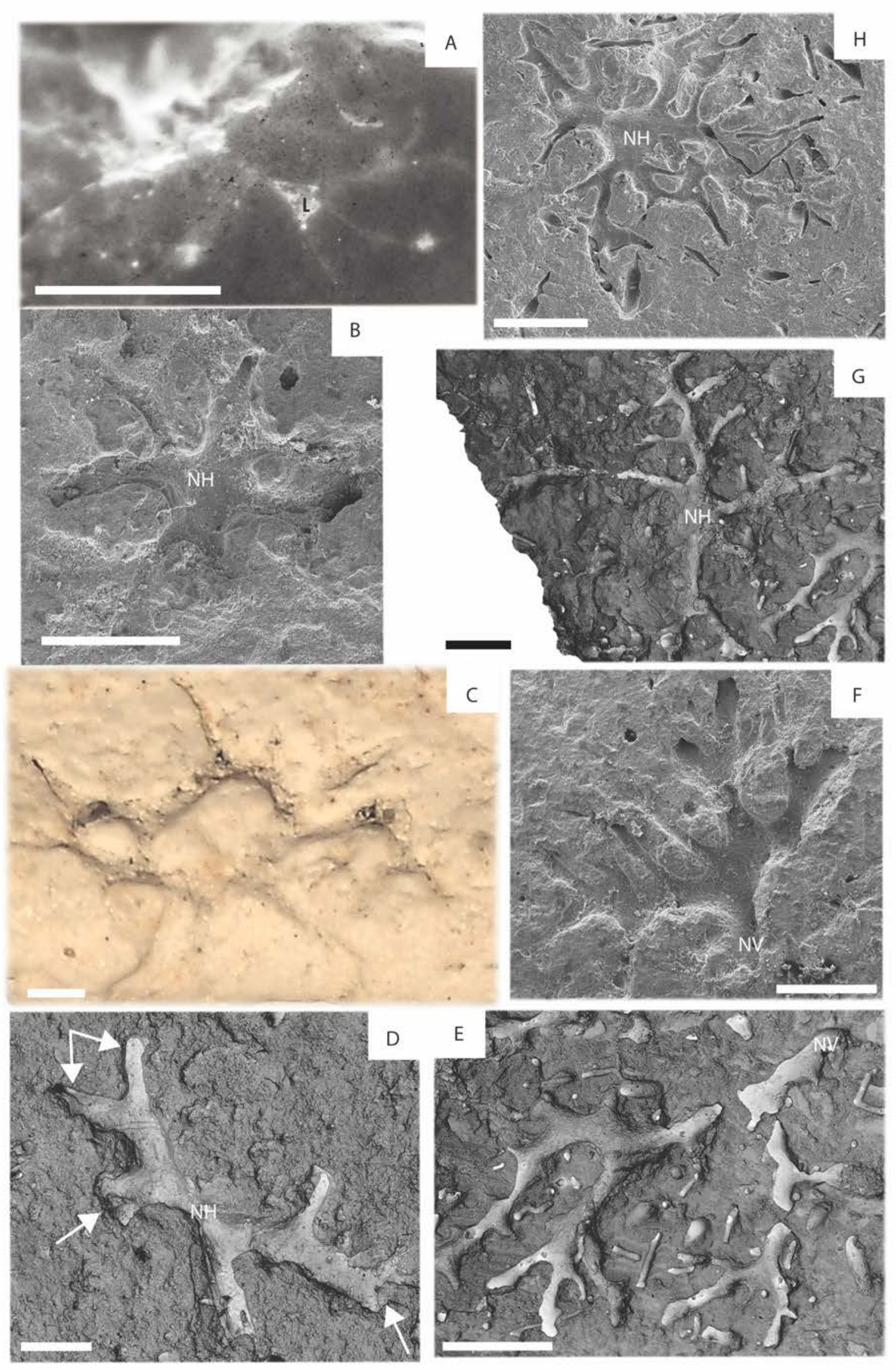


Figura 4.2. Trazas de bioerosión de la Icnofamilia Dendrinidae en sustratos biogénicos de la Formación Monte León. A) Antodendrina cf. A. ligula Wisshak, 2017 en la cara interna de un bivalvo (C2), imagen invertida en Photoshop, en donde se observa el lóbulo triangular (L) del que se desprenden finas ramificaciones. B) Imagen de MEB de Clionolithes isp. en la cara externa de un bivalvo (C2), nótese el nodo horizontal $(\mathrm{NH})$ al centro de la traza, del cual se desprenden las ramificaciones. C) Dictyoporus cf. D. nodosus Mägdefrau, 1937 en la cara interna de un bivalvo (C2). D) Imagen de MEB de Neodendrina isp., estadio temprano, en la cara interna de un bivalvo (C4), al centro de la traza se observa el nodo horizontal $(\mathrm{NH})$ del que surgen canales con ramificación dicotómica (flechas blancas). E-F) Nododendrina cf. N. europaea (Fischer, 1875); E) Imagen de MEB invertida en Photoshop de esta traza en la cara externa de un fragmento de bivalvo (C2), nótese el nodo desplazado hacia un costado (nodo vertical, NV) del cual surge el plexus con los canales ramificados; F) Imagen de MEB Nododendrina. cf. N. europaea en la cara externa de un fragmento de bivalvo (C2), nótese el nodo vertical (NV) en la parte inferior de la traza. G-H) Pyrodendrina villosa Whisshak, 2017; G) Imagen de MEB invertida en Photoshop de $P$. villosa en la cara externa de un fragmento de bivalvo (C2); nótese el nodo horizontal con forma alargada; $H$ ) Imagen de MEB de $P$. villosa en la cara interna de un bivalvo (C4); nótese la forma rosetada del nodo horizontal (NH). Escala: A) 0,05 mm; B-H) 0,5 mm.

Icnogénero Pyrodendrina Tapanila, 2008

Icnoespecie tipo. Pyrodendrina cupra Tapanila, 2008

Icnoespecie. Pyrodendrina villosa Whisshak, 2017

Figura 4.2G, $\mathrm{H}$

Material. Dendrínidas con forma irregular que muestran una penetración de somera a profunda en el sustrato y una apertura tipo techo abierto (open roof sensu Whisshak, 2017). El nodo horizontal de la traza puede ser alargado (largo $0,2 \mathrm{~mm}$ ) o rosetado (diámetro 0,25 $\mathrm{mm}$ ); de este emergen galerías (largo mínimo $0,04 \mathrm{~mm}$, largo máximo $0,08 \mathrm{~mm}$, largo promedio $0,06 \mathrm{~mm}$ ) de diámetro constante o que se ensanchan hacia la región distal, las galerías se ramifican en bi- o trifurcaciones que no se unen para formar un patrón anastomosado.

Procedencia. C1, C2, C3, C4.

Observaciones. El material estudiado se designa al icnogénero Pyrodendrina, 2008, debido a la forma irregular de las galerías conformadas por canales que emergen de un nodo central . Estas trazas corresponderían a $P$. villosa debido al desarrollo de canales abiertos y ramificados que son aguzados hacia la región distal. A pesar de que el material estudiado presenta afinidades con $P$. belua Wisshak, 2017, las galerías observadas terminan de manera aguzada y no ensanchada como es característico en esta icnoespecie.

Icnogénero Entobia Bronn, 1837

Icnoespecie tipo. Entobia cretacea Portlock, 1843

Icnoespecie. Entobia isp.

Figuras 4.3A, B

Material. Traza formada por un sistema reticulado (boxwork) de galerías medianamente entrelazadas. Las galerías son subcilíndricas e irregulares con pocas ramificaciones. En la vista en planta las aperturas son circulares (diámetro entre 0,15 y $0,77 \mathrm{~mm}$, promedio 0,47 $\mathrm{mm}$ ) y se disponen alineadas o de manera irregular. En vaciados de silicona se observan galerías irregulares de las que se desprenden finas apófisis. En algunas partes de las galerías se observan protuberancias irregulares unidas entre sí por pequeñas 
constricciones, las cuales podrían interpretarse como pequeñas cámaras unidas por canales intercamerales.

Procedencia. C1, C2, C3, C4.

Observaciones. Se estudiaron especímenes y vaciados de silicona, en los que se no se observan cámaras definidas como las que caracterizan a icnoespecies como Entobia geometrica Bromley y D'Alessandro, 1984, E. ovula Bromley y D'Alessandro, 1984 y E. laquea Bromley y D'Alessandro, 1984. Esto podría remitir a E. megastoma (Fischer, 1868) en fase C o D sensu Bromley y D'Alessandro (1984) o a las trazas de la forma geronte de $E$. paradoxa (Fischer, 1868), icnoespecie que presenta cámaras irregulares de forma ameboidal que en estadios avanzados llegan a fusionarse para desarrollar galerías sin cámaras. La variabilidad observada en la disposición de las aperturas sugiere que en el material estudiado podría encontrarse representada más de una icnoespecie.
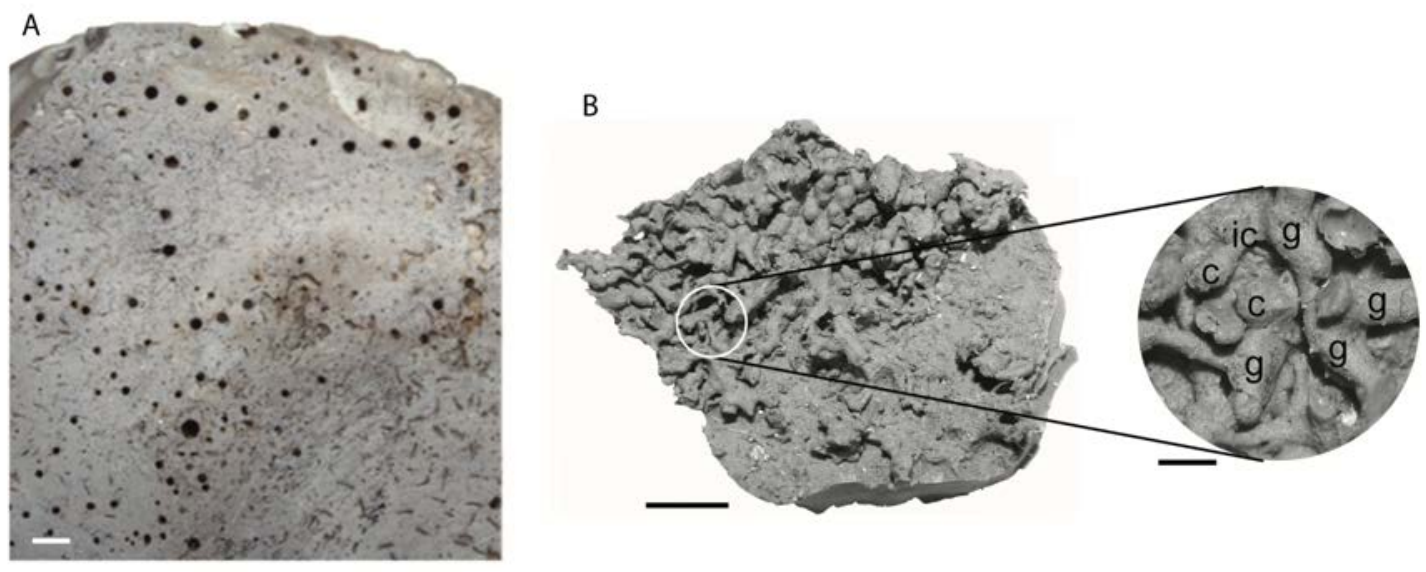

Figura 4.3. Trazas de bioerosión del icnogénero Entobia en sustratos biogénicos de la Formación Monte León. A) Entobia isp. en la superficie interna de un bivalvo (C3); nótese un arreglo alineado de las aperturas en la periferia, el cual hacia el centro tiende a ser irregular; B) Vaciado de silicona de Entobia isp., se observan galerías irregulares (g), cámaras y canales intercamerales (ic). Escala: 0,5 $\mathrm{mm}$.

Icnogénero Finichnus Taylor, Wilson y Bromley, 2013

Icnoespecie tipo. Leptichnus peristroma Taylor, Wilson y Bromley, 1999

Icnoespecie. Finichnus dromeus (Taylor, Wilson y Bromley, 1999)

Figuras 4.4A, B

Material. Pozos poco profundos de forma elíptica (eje mayor entre 0,16 y 0,33 mm, promedio $0,20 \mathrm{~mm}$; eje menor entre 0,09 y $0,14 \mathrm{~mm}$, promedio $0,11 \mathrm{~mm}$ ), excavados en forma perpendicular al sustrato. Se disponen cercanos entre sí, con un arreglo uniserial. En algunas conchillas las trazas se preservan como impresiones producto de la alteración superficial.

Procedencia. C1, C2, C3, C4.

Observaciones. Las trazas descriptas se asignan a Fininchnus dromeus (por su disposición uniserial. Esta característica permite diferenciarlas de F. tortus (Rosso, 2008) y F. peristroma, en las cuales las impresiones de disponen radialmente. Esta traza también difiere de los icnogéneros Iramena Boekschoten, 1970, Pennatichnus Mayoral, 1988 y 
Pinaceocladichnus Mayoral, 1988, ya que no se observa la construcción de túneles interconectados.

Icnoespecie. Finichnus peristroma (Taylor, Wilson y Bromley, 1999)

Figuras 4.4C, D

Material. Sistema de pequeños pozos poco profundos (eje mayor entre 0,24 y $0,40 \mathrm{~mm}$, promedio $0,34 \mathrm{~mm}$; eje menor entre 0,14 y $0,22 \mathrm{~mm}$, promedio $0,18 \mathrm{~mm}$ ) y cercanos entre sí, que presentan un arreglo radial. Los pozos del centro son elípticos y pequeños; hacia la periferia su tamaño aumenta ligeramente.

Procedencia. C1, C2, C3, C4.

Observaciones. Las trazas se asignan a Finichnus peristroma por la disposición radial de las impresiones, las cuales son más pequeñas en el centro y aumentan de tamaño al alejarse del mismo. Los ejemplares difieren de $F$. tortus, que también presenta estructura radial, pues esta icnoespecie presenta en la región distal un arreglo espiral de los pozos; además, el pozo central se caracteriza por ser de mayor tamaño que los de la periferia. Las trazas estudiadas no se asignan al icnogénero Podichnus Bromley y Surlyk, 1973, que también posee un arreglo radial, pues las perforaciones en este icnogénero son más profundas y oblicuas a la superficie del sustrato hacia la periferia.

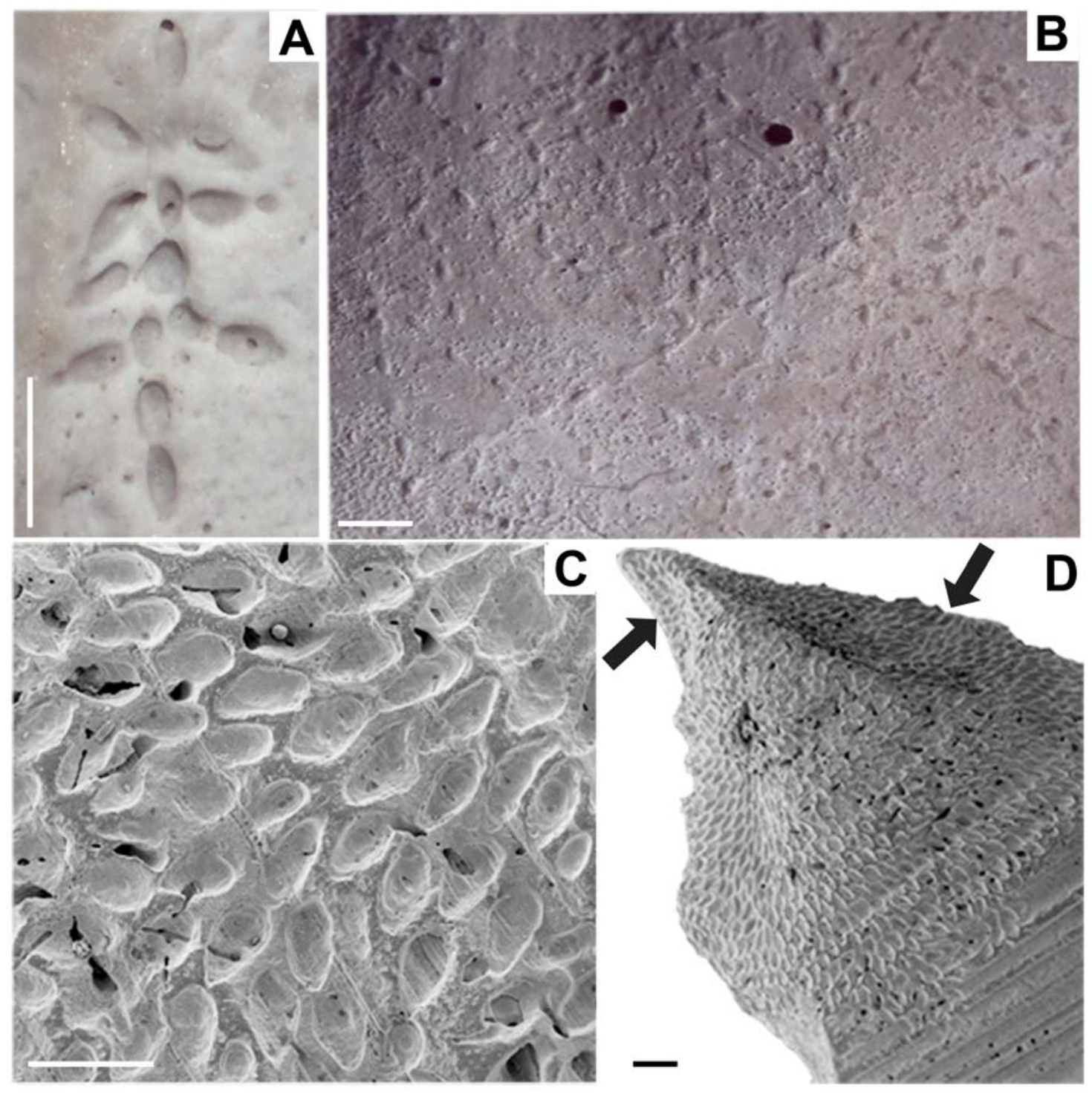


Figura 4.4. Trazas de bioerosión del icnogénero Finichnus en sustratos biogénicos de la Formción Monte León. A-B) F. dromeus (Taylor, Wilson y Bromley, 1999); A) en la superficie externa de un bivalvo (C3); B) en la superficie interna de un bivalvo (C4); C-D) F. peristroma (Taylor, Wilson y Broley, 1999) imágenes de MEB, C) en la superficie externa de un bivalvo (C3); D) misma traza; nótese como la traza colonizó los márgenes que evidencían fragmentación y alteración superficial previa (flechas negras) Escala: A-C) 0,5 mm; D) $1 \mathrm{~mm}$.

Icnogénero Maeandropolydora Voigt, 1965

Icnoespecie tipo. Maeandropolydora decipiens Voigt, 1965

Icnoespecie. Maeandropolydora decipiens Voigt, 1965

Figura 4.5A

Material. Galería cilíndrica con más de una apertura, irregular, mal preservada, miembros (limbs) no fusionados. En un sector, los miembros están interconectados por una veleta, formando una especie de bolsa (pouch) (longitud 7,0 mm, ancho 1,0 mm).

Procedencia. C1, C4.

Observaciones. Estas trazas se asignan al icnogénero por ser galerías cilíndricas que se desplazan en el sustrato de manera sinuosa con dos o más aperturas. Corresponden a Maeandropolydora decipiens, ya que esta icnoespecie se caracteriza por la presencia de bolsas que forman los miembros al girar y quedar unidos por una veleta de forma similar a lo que se observa en el icnogénero Caulostrepsis. El material de Cabeza de León difiere de M. elegans Bromley y D'Alessandro, 1983, ya que en esta icnoespecie a pesar de que los miembros también pueden desplazarse de forma pareada, lo hacen sin fusionarse; además, esta icnoespecie se caracteriza por la presencia de numerosas aperturas.

Icnoespecie. Maeandropolydora sulcans Voigt, 1965

Figura 4.5B,C

Material. Galerías cilíndricas, contorsionadas, con dos aperturas (largo $4 \mathrm{~mm}$, diámetro $0,35 \mathrm{~mm}$ ). Se observan algunas variaciones morfológicas representadas por depresiones dispuestas en forma irregular (sensu Santos et al., 2003) que vistas en planta pueden tener forma de riñón, ovalada o subcircular (largo de 1 a 1,5 mm, promedio 1,3 mm).

Procedencia. C1, C2, C4.

Observaciones. Estas trazas difieren de Maeandropolydora elegans por no presentar galerías con miembros que se desplazan de forma pareada. Las depresiones observadas se considera que corresponden a $M$. sulcans de acuerdo con las variedades morfológicas propuestas por Santos et al. (2003), basadas en la erosión del sustrato y el nivel de profundización de la traza. Estas depresiones difieren del icnogénero Renichnus Mayoral, 1987 ya que no están dispuestas en hilera.

Icnoespecie. Maeandropolydora isp.

Figura 4.5D

Material. Galerías cilíndricas con dos aperturas, paralelas a la superficie del sustrato con trayectoria sinuosa. En algunos especímenes se observa que los miembros que siguen la misma trayectoria están unidos por una pared intermedia; en otros especímenes la trayectoria de los miembros se interrumpe por el incipiente desarrollo de una veleta.

Procedencia. C1, C2, C3, C4. 
Observaciones. Estas trazas se asignan a Maeandropolydora por ser galerías sinuosas que presentan más de una apertura. Posiblemente las mismas correspondan a algunas de las icnoespecies mencionadas anteriormente; sin embargo, debido al estado de preservación del bioclasto y de la traza, la asignación icnoespecífica queda a reserva.

Icnogénero Oichnus Bromley, 1981

Icnoespecie tipo. Oichnus simplex Bromley 1981

Icnoespecie. Oichnus paraboloides Bromley, 1981.

Figura 4.5E

Material. Perforaciones circulares y subcirculares (diámetro externo $2 \mathrm{~mm}$ ) que atraviesan las conchillas de gasterópodos y bivalvos, rodeadas por un borde biselado (bevelled edge) y de sección transversal paraboloide. En conchillas bien preservadas, el borde interior de la perforación se distingue por ser de diámetro menor que el borde exterior, mientras que en conchillas gruesas y con alto grado de alteración superficial se dificulta su reconocimiento.

Procedencia. C1, C2, C3, C4.

Observaciones. Este material se asigna a Oichnus paraboloides, por el borde liso y biselado que rodea a la perforación y su forma paraboloide. En algunos especímenes esta asignación se trata de forma dudosa debido al estado de preservación de la conchilla. Las trazas estudiadas difieren de $O$. simplex en la pared de la perforación, que en esta icnoespecie es recta; tampoco presentan similitud con $O$. coronatus Nielsen y Nielsen, 2001, ya que en el material de Cabeza de León las perforaciones presentan un mayor diámetro y no están rodeadas por un halo con textura granular.

Icnoespecie. Oichnus simplex Bromley, 1981

Figura 4.5F

Material. Perforaciones circulares (diámetro $2 \mathrm{~mm}$ ) con paredes lisas y perpendiculares a la superficie de la conchilla. Estas perforacionese pueden o no penetrar en su totalidad el sustrato, cuando no lo hacen presentan un fondo liso y poco profundo.

Procedencia. C1, C2, C3, C4.

Observaciones. Las trazas observadas se atribuyen a Oichnus simplex por sus bordes rectos y perpendiculares a la superficie del sustrato. Las mismas difieren de $O$. paraboloides y O. ovalis Bromley, 1993, por no presentar un borde biselado. Se considera su origen biológico porque los bordes son regulares y redondeados, no observándose adelgazamiento en los mismos que pueda indicar su origen por disolución. En especímenes completos o con poca fragmentación, la ubicación de la traza puede relacionarse con un acceso facilitado a las partes blandas del organismo.

Icnoespecie. Oichnus isp.

Material. Perforación circular con evidencias de disolución y pared perpendicular a la superficie de la conchilla.

Procedencia. C1, C4.

Observaciones. Las trazas observadas se atribuyen a Oichnus, por ser una perforación circular o subcircular con bordes perpendiculares. En las trazas designadas en este 
icnotaxón, la disolución de la perforación impide reconocer si la traza corresponde a $O$. simplex o a O. parabolides.
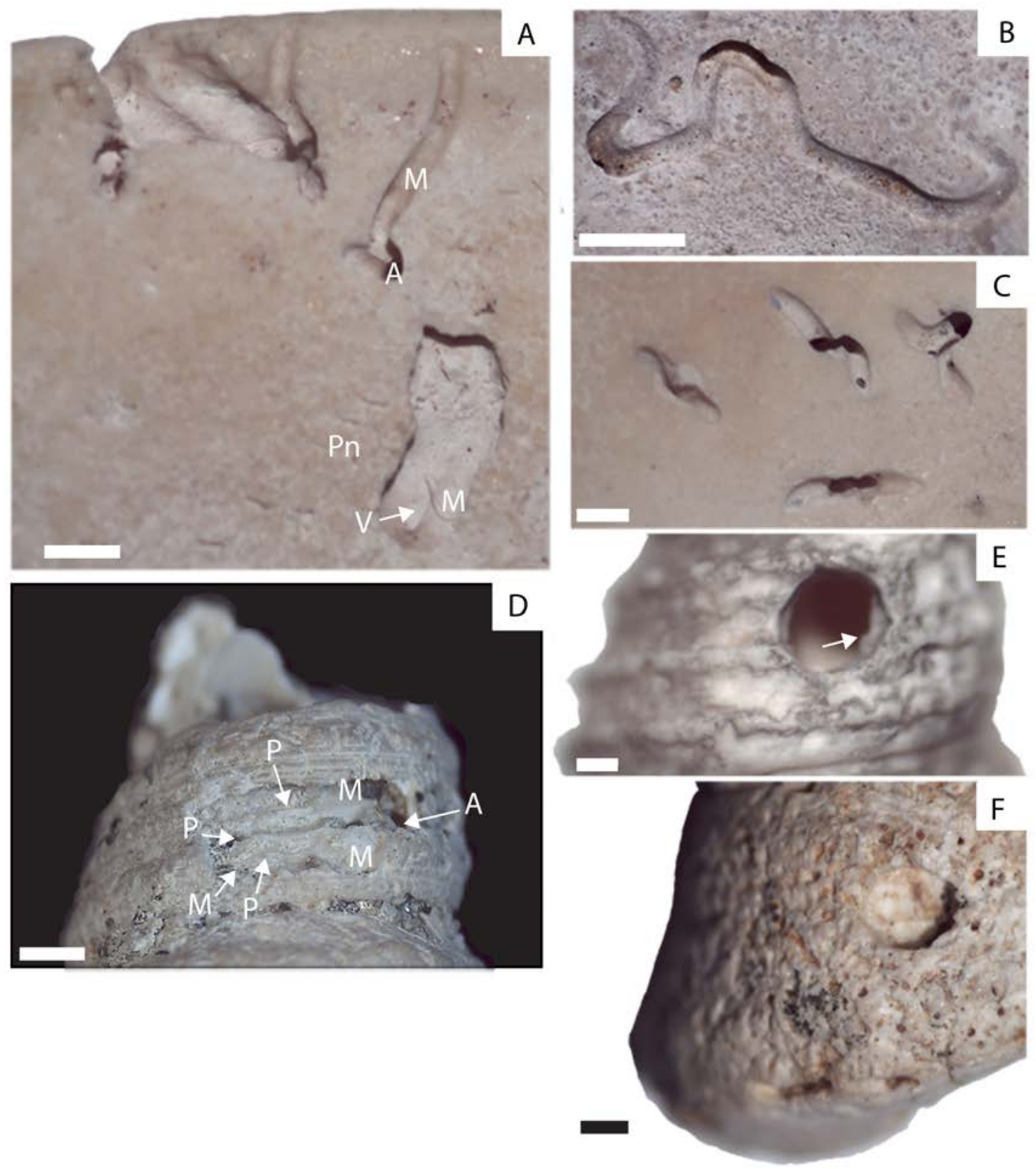

Figura 4.5. Trazas de bioerosión en sustratos biogénicos de la Formación Monte León. A) Maeandropolydora decipiens Voigt, 1965 en la superficie interna de un bivalvo (C4); nótese la posterior colonización de la traza por Pennatichnus isp. (Pn) sobre los miembros (M) y el comienzo de la veleta (V); B-C) Maeandropolydora sulcans Voigt, 1965; B) en la superficie interna de un bivalvo (C4); nótese la galería meandriforme con dos aperturas; C) posible variación morfológica de la traza (sensu Santos et al., 2003); D) Maeandropolydora isp. en la superficie externa de una turritela (C1); al costado se observa parte de la apertura (A) seguida de la trayectoria de los miembros (M) que se une por una posible pared intermedia (P); E) Oichnus paraboloides Bromley, 1981 en un turritélido (C3); en el interior de la perforación se observa el borde biselado (flecha blanca). F) Oichnus simplex Bromley, 1981 sobre un gasterópodo (C4); nótese la base plana de la perforación asociada con un ataque fallido. Escala: $1 \mathrm{~mm}$. 
Icnogénero Pennatichnus Mayoral, 1988

Icnoespecie tipo. Pennatichnus moguerenica Mayoral, 1988

Icnoespecie. Pennatichnus luceni Mayoral, 1988

Figura 4.6A, B

Material. Traza paralela a la superficie del sustrato, con un túnel principal mal preservado (ancho 0,026 mm) y conductos subordinados alternados y curvados (largo entre 0,12 mm y $0,28 \mathrm{~mm}$, promedio $0,18 \mathrm{~mm}$; ancho entre 0,05 y $0,10 \mathrm{~mm}$, promedio $0,07 \mathrm{~mm}$ ) que finalizan con aperturas primarias subcirculares (largo entre 0,18 y $0,28 \mathrm{~mm}$, promedio 0,21 $\mathrm{mm}$; ancho entre 0,10 y $0,24 \mathrm{~mm}$, promedio $0,16 \mathrm{~mm}$ ). Las aperturas primarias en conjunto con el conducto subordinado presentan una forma virguliforme (largo entre 0,34 y 0,47 mm, promedio 0,40 $\mathrm{mm}$; ancho entre 0,12 $\mathrm{mm}$ y 0,21 $\mathrm{mm}$, promedio 0,16 $\mathrm{mm}$ ).

Procedencia. C3.

Observaciones. Esta traza fue asignada al icnogénero por consistir de un conjunto de finos túneles y por la presencia de aberturas primarias unidas a este por conductos subordinados dispuestos de forma alternada. La designación icnoespecífica se realizó considerando la forma curvada de los conductos, que difiere de los de Pennatichnus moguerenica, que son rectos. El material de Cabeza de León es escaso y mal preservado debido a la alta alteración superficial de los bioclastos.

\section{Icnoespecie. Pennatichnus moguerenica Mayoral, 1988}

Figura 4.6C

Material. Traza paralela a la superficie del sustrato, formada por un túnel principal fino y elongado (longitud entre 4,2 y 5,5 mm), del cual surgen de manera alternada conductos subordinados de primer orden rectos o ligeramente curvados (longitud entre 0,09 y 0,29 $\mathrm{mm}$, promedio $0,19 \mathrm{~mm}$ ) conectados con aperturas primarias de forma circular a subcircular (eje mayor entre 0,06 y $0,12 \mathrm{~mm}$, promedio $0,08 \mathrm{~mm}$; eje menor entre 0,03 y $0,09 \mathrm{~mm}$, promedio $0,061 \mathrm{~mm}$ ). La distancia entre las aperturas primarias varía entre 0,09 y $0,41 \mathrm{~mm}$, con un promedio de 0,26 $\mathrm{mm}$. La distancia entre las aperturas primarias y el túnel principal varía entre 0,19 y $0,54 \mathrm{~mm}$, con un promedio de $0,34 \mathrm{~mm}$.

Procedencia. C1, C2, C3, C4.

Observaciones. Esta traza se designa como Pennatichnus moguerenica, por la presencia de un túnel principal con conductos subordinados alternados rectos y aperturas circulares a sub-circulares. Se diferencia de $P$. luceni, pues esta icnoespecie presenta aperturas primarias con forma de gota y canales subordinados ligeramente curvados que en conjunto tienen aspecto virguliforme. El material de Monte León no presenta afinidades con el icnogénero Iramena, ya que este se caracteriza por tener túneles con un entramado irregular y aperturas primarias con forma de riñón ubicadas muy cerca de los túneles. Asimismo, los especímenes de Cabeza de León difieren del icnogénero Pinaceocladichnus Mayoral, 1988, en la longitud de los túneles y en la ausencia de cámaras alargadas.

Icnoespecie. Pennatichnus isp.

Figura 4.6D

Material. Traza paralela a la superficie del sustrato, formada por un túnel principal fino y alargado alrededor del cual se disponen de manera alternada cámaras ovaladas (eje mayor entre 0,136 y $0,351 \mathrm{~mm}$, promedio $0,225 \mathrm{~mm}$; eje menor entre 0,045 y $0,109 \mathrm{~mm}$, promedio 
$0,071 \mathrm{~mm}$ ). El ángulo de las cámaras con respecto al estolón oscila entre $30^{\circ}$ y $72^{\circ}$, con un promedio de $52^{\circ}$.

Procedencia. C1, C2, C3, C4.

Observaciones. Estas trazas se asignan al icnogénero Pennatichnus debido a presencia de cámaras que se disponen en forma alternada a ambos lados del túnel principal; sin embargo difieren de las icnoespecies $P$. luceni y $P$. moguerenica Mayoral, 1988, en la ausencia de conductos subordinados de primer orden que unen a las aberturas primarias con el túnel principal.
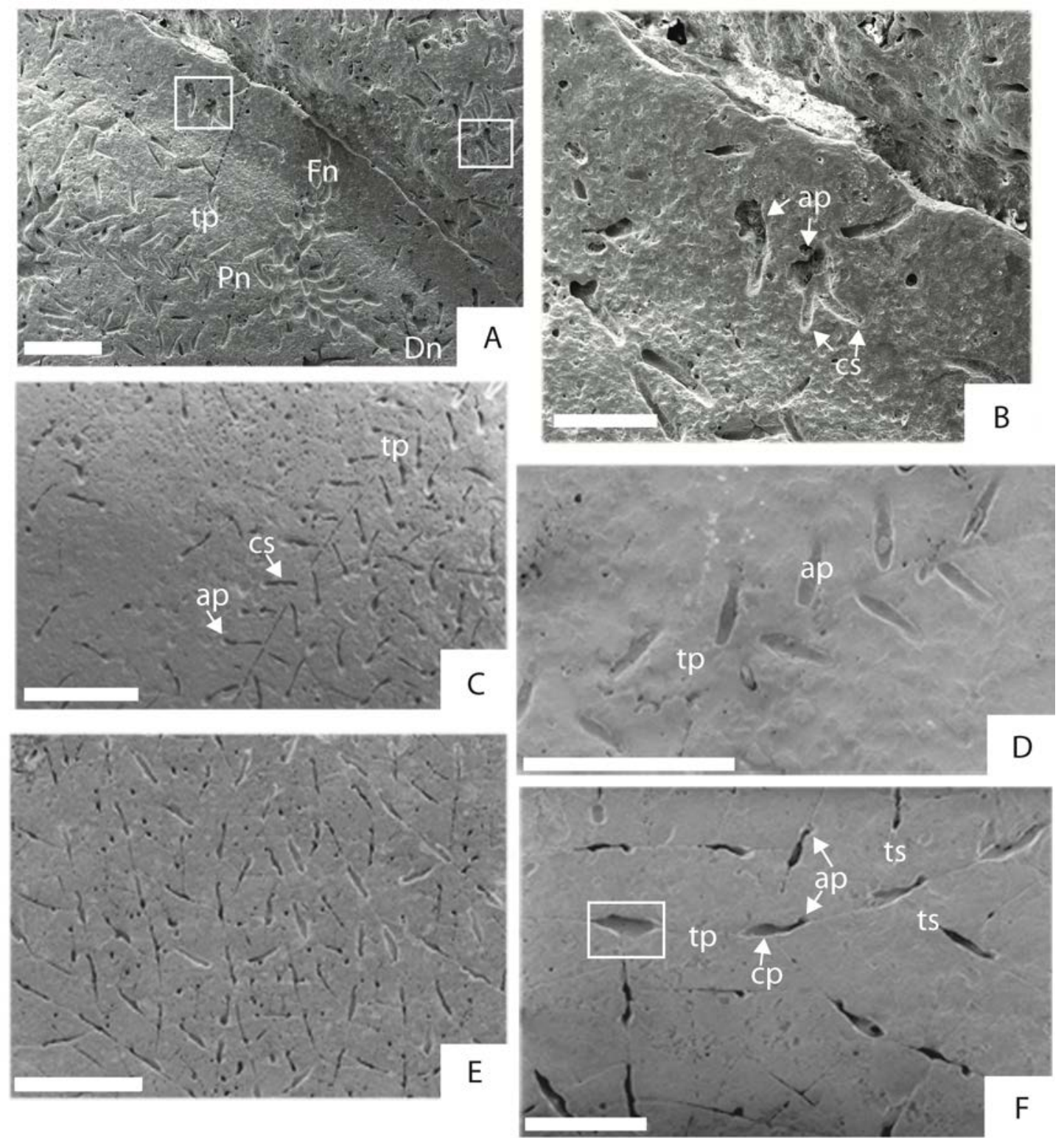

Figura 4.6. Trazas de bioerosión en sustratos biogénicos de la Formación Monte León, imágenes de MEB. A-B) Pennatichnus luceni Mayoral, 1988, en la cara externa de un bivalvo (C3); A) se observa el túnel principal (tp) con gran alteración superficial, la línea discontinua sugiere su posible trayectoria. Hacia la parte superior de la figura (rectángulos blancos) se observan algunas aperturas y conductos que en conjunto muestran forma de coma; B) Acercamiento de A) en donde se observan en detalle las aperturas principales (ap) unidas a los conductos subordinados (cs); C) Pennatichnus moguerenica Mayoral, 1988 en la superficie interna de una valva (C3), nótese el delgado túnel principal (tp) y la ramificación alternada de los conductos subordinados (cs) que culminan con una 
pequeña apertura (ap). D) Pennatichnus isp. en la superficie interna de una valva (C4), nótese el túnel principal (tp) del que surgen alargadas aperturas (ap) de manera alternada. E-F) Pinaceocladichnus onubensis Mayoral, 1988; E) en la superficie interna de una valva (C3); se observa la ramificación de túneles primarios en secundarios y las cavidades principales estrechas y alongadas; F) acercamiento de E) en donde se observa en detalle el túnel principal (tp) y los túneles secundarios (ts), nótense a lo largo de los túneles las pequeñas aperturas subcirculares (ap) seguidas de la cavidad principal (cp). En algunos casos, cuando la alteración superficial es notable, la apertura y la cavidad se fusionan (rectángulo blanco). Escala: A, C-E) $1 \mathrm{~mm}$; B), F) 0,5mm.

Icnogénero Pinaceocladichnus Mayoral, 1988

Icnoespecie tipo. Pinaceocladichnus onubensis Mayoral, 1988

Icnoespecie. Pinaceocladichnus onubensis Mayoral, 1998.

Figura 4.6E, $\mathrm{F}$

Material. Sistema de túneles finos y poco profundos (diámetro entre 0,006 y 0,02 mm, promedio 0,014 $\mathrm{mm}$ ), paralelos al sustrato; presentan una bifurcación simétrica que da lugar a túneles secundarios (diámetro $0,013 \mathrm{~mm}$ ). Tanto los túneles primarios como los secundarios presentan aperturas primarias circulares o subcirculares (diámetro entre 0,014 y $0,044 \mathrm{~mm}$, promedio $0,030 \mathrm{~mm}$ ) que se conectan con cámaras alargadas y estrechas (largo entre 0,20 y 0,23 mm, promedio 0,26; ancho entre 0,03 y 0,09 mm, promedio 0,06 $\mathrm{mm}$ ). La distancia entre las cámaras varía entre 0,03 y $0,09 \mathrm{~mm}$, con un promedio de 0.06 $\mathrm{mm}$. En ocasiones, la cámara principal y la apertura se encuentran fusionadas debido a la alteración superficial del sustrato.

Procedencia. C1, C2, C3, C4.

Observaciones. Esta traza se incluye en Pinaceocladichnus onubensis por la bifurcación regular de los túneles y la presencia de cámaras alargadas. A pesar de que esta traza presenta túneles similares a los del icnogénero Iramena, éste presenta un patrón de entramado irregular y aperturas primarias reniformes ubicadas muy cercanas a los túneles. En el material estudiado los túneles pueden estar ligeramente resaltados por la alteración superficial del sustrato; por otra parte, en algunos sectores se dificulta su reconocimiento ya que las trazas se traslapan con las de otras icnoespecies.

Icnogénero Podichnus Bromley y Surlyk, 1973

Icnoespecie tipo. Podichnus centrifugalis Bromley y Surlyk, 1973

Icnoespecie. Podichnus centrifugalis Bromley y Surlyk, 1973.

Figura 4.7A, B

Material. Conjunto de pequeñas perforaciones circulares o subcirculares (diámetro entre 0,02 y $0.03 \mathrm{~mm}$, promedio $0,022 \mathrm{~mm}$ ), que penetran en forma oblicua al sustrato y están dispuestas en arreglo radial.

Procedencia. C4.

Observaciones. El material de Cabeza de León corresponde al Icnogénero Podichnus ya que la traza está formada por un conjunto de orificios circulares o subcirculares cercanos entre sí; la forma circular de los orificios y su arreglo radial permite asignar las trazas a $P$. centrifugalis. Estas trazas difieren de $P$. perpendicularis Robinson y Lee, 2008, en la forma de los orificios que en esta icnoespecie pueden extenderse lateralmente para formar surcos curvados. En cuanto a la disposición de los orificios difiere de $P$. conicus Santos y 
Mayoral, 2014 (en Santos et al., 2014), cuyo arreglo es también radial pero asimétrico. Si bien $P$. donovani Breton, 2011, también muestra orificios con un arreglo radial y simétrico, estos están acompañados de un patrón estriado que modifica la superficie del sustrato. Esta traza tampoco coincide con $P$. obliquus Robinson y Lee, 2008, ya que en esta icnoespecie los orificios de la periferia tienden a estar muy separados entre ellos.

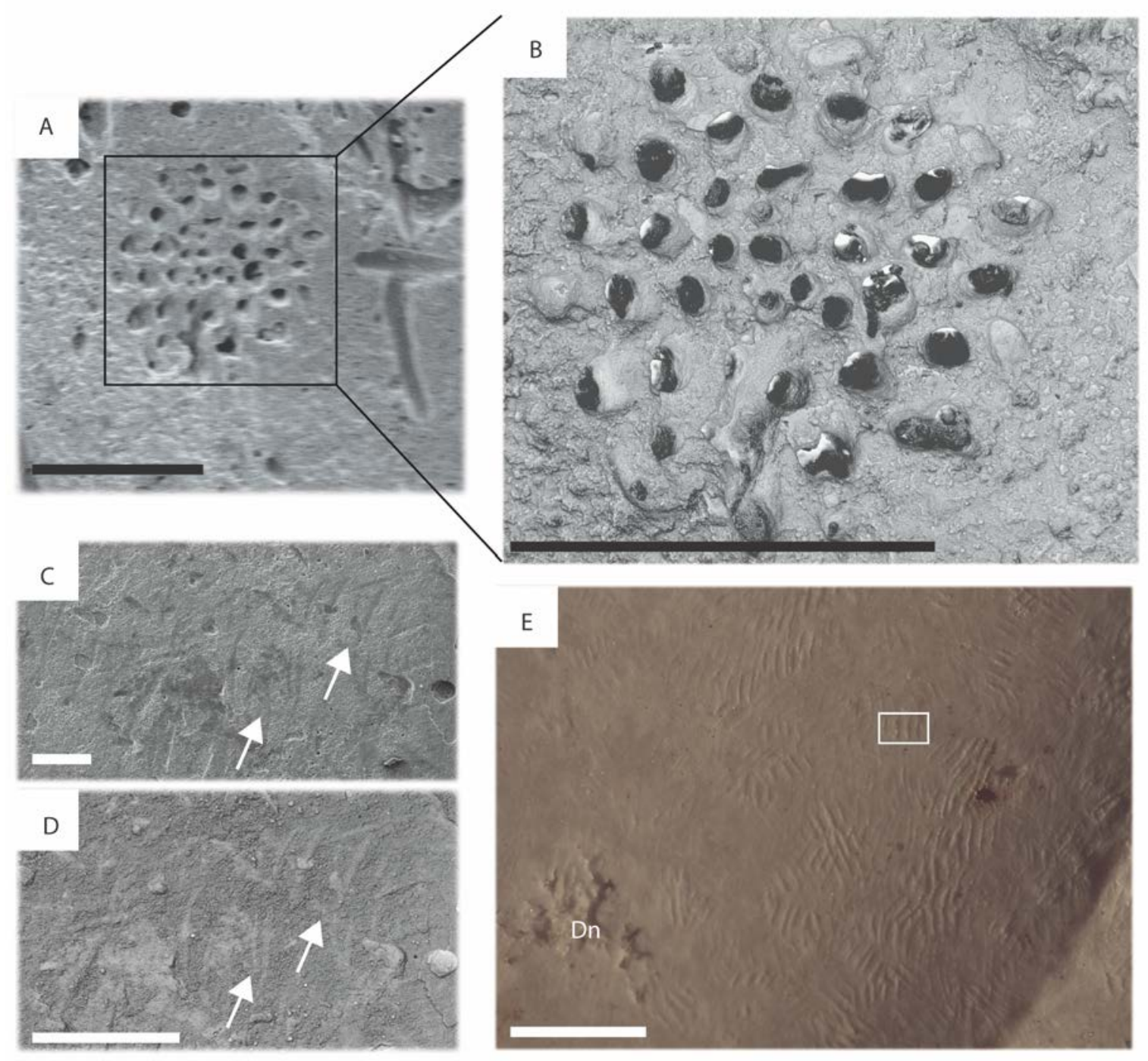

Figura 4.7. Trazas de bioerosión en sustratos biogénicos de la Formación Monte León. A-B) Podichnus centrifugalis Bromley y Surlyk, 1973; A) Imagen de MEB de la superficie externa de una conchilla de bivalvo (C4); B) acercamiento de A) invertido en Photoshop en donde se aprecia como las perforaciones están oblicuas al sustrato; C-E) Radulichnus inopinatus Voigt, 1977, en la cara interna de bivalvos (C2); C) imagen de MEB de grupo de tres arañazos alargados y curveados (flechas blancas); D) figura C) invertida en Photoshop; E) conjunto de cuatro arañazos cortos y rectos (rectángulo blanco) que cubren toda la cara interna de un bioclasto (C2); traza de la Icnofamilia Dendrinidae (Dn) en la parte inferior. Escala: A-D) 0,5 mm; E) 0,1 mm.

Icnogénero Radulichnus Voigt, 1977

Icnoespecie tipo. Radulichnus inopinatus Voigt, 1977

Icnoespecie. Radulichnus inopinatus Voigt, 1977 


\section{Figura 4.7C-E}

Material. Grupo de entre tres y cinco arañazos individuales rectos o ligeramente curvados (largo de los arañazos individuales, mínimo 0,011 mm, máximo, 0,020 mm, promedio 0,015 $\mathrm{mm}$; ancho del grupo de arañazos, mínimo 0,021 mm, máximo 0,030 $\mathrm{mm}$, promedio 0,026 $\mathrm{mm}$ ). Este patrón de arañazos se repite en gran parte de la superficie del sustrato, y aunque en algunos casos es posible apreciar el trayecto que siguen estos grupos, generalmente se observa un patrón caótico en el que los grupos de arañazos se sobrelapan siguiendo diferentes direcciones.

Procedencia. C2.

Observaciones. Estas trazas se asignaron a este icnogénero e icnoespecie por el arreglo estriado que forman y por su distribución irregular. Esta traza es similar a la referida por Parras y Casadío (2006) en ostras de la Formación San Julián, aunque en éstas las trazas son de mayor longitud y las estrías son más arqueadas.

\section{Icnodiversidad}

Sobre la base de criterios morfológicos, se reconocieron 24 icnotaxones (Tabla 4.1), 18 de ellos fueron asignados a nivel icnoespecífico mientras que los seis restantes a nivel icnogenérico. De los icnotaxa reconocidos, seis son incluidos en la Icnofamilia Dendrinidae; sin embargo, estas determinaciones quedan a reserva de ser confirmadas o modificadas a posteriori. En la tabla 4.1 se muestran los icnotaxones determinados y su presencia en cada una de las concentraciones estudiadas.

Tabla 4.1. Icnotaxones determinados en las concentraciones fosilíferas de la sección Cabeza de León (Formación Monte León). Se señala el posible productor de cada traza, la categoría etológica en la que se la incluye y su presencia en cada una de las concentraciones (C1-C4).

\begin{tabular}{|c|c|c|c|c|c|c|}
\hline Icnotaxa & Productor & Etología & C1 & C2 & C3 & C4 \\
\hline Caulostrepsis biforans & Poliquetos & Domichnia & $x$ & $x$ & & $x$ \\
\hline Caulostrepsis contorta & Poliquetos & Domichnia & & $x$ & & \\
\hline Caulostrepsis taeniola & Poliquetos & Domichnia & $x$ & $x$ & & $x$ \\
\hline $\begin{array}{l}\text { Antodenrina cf. A. ligula } \\
\text { (Dendrinidae) }\end{array}$ & Desconocido & ?Domichnia & & $\mathrm{x}$ & & \\
\hline $\begin{array}{l}\text { Clionolithes isp. } \\
\text { (Dendrinidae) }\end{array}$ & Esponjas & Domichnia & $x$ & $\mathrm{x}$ & & $x$ \\
\hline $\begin{array}{l}\text { Dictyoporus cf. } D . \\
\text { nodosus } \\
\text { (Dendrinidae) }\end{array}$ & Desconocido & ?Domichnia & & $x$ & & \\
\hline $\begin{array}{l}\text { Neodendrina isp. } \\
\text { (Dendrinidae) }\end{array}$ & Desconocido & Domichnia & $x$ & & & $x$ \\
\hline $\begin{array}{l}\text { Nododendrina cf. } N \text {. } \\
\text { europaea } \\
\text { (Dendrinidae) }\end{array}$ & Foraminíferos & Domichnia & & $\mathrm{x}$ & & $x$ \\
\hline $\begin{array}{l}\text { Pyrodendrina villosa } \\
\text { (Dendrinidae) }\end{array}$ & Desconocido & ?Domichnia & $x$ & $\mathrm{x}$ & $\mathrm{X}$ & $x$ \\
\hline Entobia isp. & Esponjas & Domichnia & $x$ & $x$ & $x$ & $x$ \\
\hline
\end{tabular}




\begin{tabular}{|c|c|c|c|c|c|c|}
\hline Icnotaxa & Productor & Etología & C1 & C2 & C3 & C4 \\
\hline Finichnus dromeus & Briozoos & Domichnia & $x$ & $x$ & $x$ & $x$ \\
\hline Finichnus peristroma & Briozoos & Domichnia & $x$ & $x$ & $x$ & $x$ \\
\hline $\begin{array}{l}\text { Maeandropolydora } \\
\text { decipiens }\end{array}$ & Poliquetos & Domichnia & $x$ & & & $x$ \\
\hline $\begin{array}{l}\text { Maeandropolydora } \\
\text { sulcans }\end{array}$ & Poliquetos & Domichnia & $x$ & $x$ & & $x$ \\
\hline Maeandropolydora isp. & Poliquetos & Domichnia & $x$ & $x$ & $x$ & $x$ \\
\hline Oichnus paraboloides & Gastrópodos & Praedichnia & $x$ & $x$ & $x$ & $x$ \\
\hline Oichnus simplex & Gastrópodos & Praedichnia & $x$ & $x$ & $x$ & $x$ \\
\hline Oichnus isp. & Gastrópodos & Praedichnia & $x$ & & & $x$ \\
\hline Pennatichnus Iuceni & Briozoos & Domichnia & & & $x$ & \\
\hline $\begin{array}{l}\text { Pennatichnus } \\
\text { moguerenica }\end{array}$ & Briozoos & Domichnia & $x$ & $x$ & $x$ & $x$ \\
\hline Pennatichnus isp. & Briozoos & Domichnia & $x$ & $x$ & $x$ & $x$ \\
\hline $\begin{array}{l}\text { Pinaceocladichnus } \\
\text { onubensis }\end{array}$ & Briozoos & Domichnia & $x$ & $x$ & $x$ & $x$ \\
\hline Podichnus centrifugalis & Braquiópodos & Fixichnia & & & & $x$ \\
\hline Radulichnus inopinatus & Gastrópodos & Pascichnia & & $x$ & & \\
\hline
\end{tabular}

a) Icnodiversidad observada en campo: En los bioclastos observados en campo se reconocieron 18 icnotaxones (Fig. 4.8). En C4 se observó la mayor icnodiversidad con 16 icnotaxones, mientras que en C3 se observó la menor icnodiversidad con 8 icnotaxones. Las trazas producidas por briozoos fueron las más abundantes, mientras que las producidas por poliquetos fueron las más icnodiversas con siete icnotaxones. En C2 se reconoció una traza similar a Rogerella Saint-Seine, 1951, atribuida a balanos, sin embargo por su baja abundancia y su preservación su asignación se realiza con duda.

De las trazas producidas por briozoos se reconocieron cinco icnotaxones. El icnotaxón que mostró mayor abundancia fue Pennatichnus isp., especialmente en $\mathrm{C} 1$ y C4, en donde su abundancia relativa fue de $29 \%$ y $21 \%$, respectivamente. La abundancia de $P$. moguerenica también fue notable, especialmente en C1 (16\%). Por otra parte el icnotaxón que mostró menor abundancia en las concentraciones fue Finichnus dromeus, que en C3 fue ausente (Fig.4.8).

Las trazas de la icnofamilia Dendrinidae mostraron similitudes con la icnoespecie Pyrodendrina villosa. Fueron más abundantes en C4 (19\%), mientras que en C1 su abundancia relativa fue de apenas $0,8 \%$ (Fig. 4.8 ).

Las trazas producidas por esponjas fueron reconocidas a nivel icnogenérico como Entobia por sus características aperturas. Algunas trazas guardaban similitud con E. megastoma en 
el agrupamiento lineal de las aperturas. Este icnotaxón fue más abundante en C3 (21\%) y C2 (17\%) (Fig.4.8).

Las trazas producidas por gasterópodos corresponden a la categoría etológica praedichnia, las más abundantes fueron las de la icnoespecie Oichnus simplex, que mostró una mayor abundancia relativa en C1 (11\%) (Fig. 4.8). En algunos bioclastos la traza únicamente se reconoció nivel icnogenérico, debido al grado de preservación, que impedía reconocer la presencia o ausencia de un borde biselado.

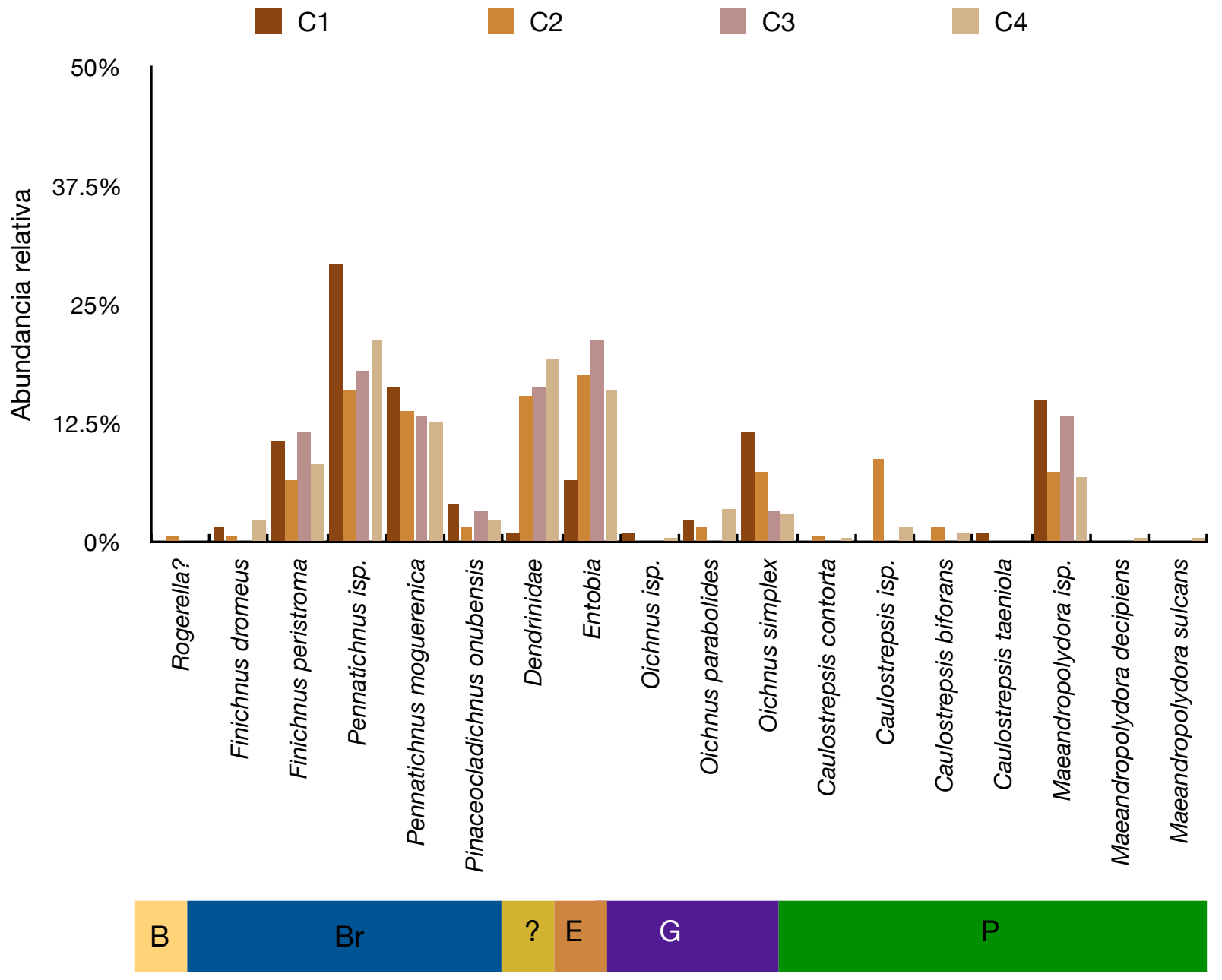

Figura 4.8 Abundancia relativa de los icnotaxones reconocidos en bioclastos observados en los cuadros de campo. La barra inferior señala los posibles productores de las trazas, donde: B: balanos, Br: briozoos, ?: No conocido, E: esponjas, G: gasterópodos, P: poliquetos.

Finalmente, las trazas producidas por poliquetos fueron preferentemente determinadas hasta nivel icnogenérico, debido a que en algunas ocasiones solo se observaba la apertura de la traza o la galería estaba incompleta. El icnogénero más abundante fue Maeandropolydora, que alcanzó mayor abundancia relativa en C1 (14\%) y C3 (13\%). Caulostrepsis fue más abundante en C2 (0,8\%) (Fig. 4.8).

b) Icnodiversidad en muestras procesadas en laboratorio: En las submuestras procesadas se reconocieron 21 icnotaxones (Fig. 4.9). C4 fue la más icnodiversa con 16 icnotaxones, en $\mathrm{C} 1$ y $\mathrm{C} 2$ se reconocieron 15 icnotaxones respectivamente; mientras que en C3 se 
reconocieron 11 icnotaxones. Las trazas más abundantes corresponden a las producidas por gaterópodos, mientras que las más icnodiversas fueron producidas por briozoos y poliquetos, con 7 y 8 icnotaxones, respectivamente.

De las trazas producidas por briozoos se reconocieron siete icnotaxones (Fig.4.9). El más abundante fue Finichnus peristroma, que en $\mathrm{C} 3$ y $\mathrm{C} 4$ tuvo una abundancia de entre 8 y $10 \%$. En C2 fue mayor la abundancia de Pennatichnus isp. con $11 \%$. El resto de los icnotaxones reconocidos tuvo una abundancia relativa menor a $10 \%$. P. Iuceni fue escaso (2\%) y únicamente fue reconocido en C3.

Las trazas de la Icnofamilia Dendrinidae guardan similitud principalmente con Pyrodendrina villosa y Neodendrina isp.; estas trazas fueron más abundantes en C3 y C4, con una proporción similar ( $\approx 13 \%)$, mientras que en $\mathrm{C} 1$ su abundancia fue baja $(1,5 \%)$. Por otra parte las trazas producidas por esponjas, determinadas a nivel icnogenérico (Entobia), fueron más abundantes en C2 y C4, con una proporción mayor al 10\%, mientras que en C1 fueron escasas con una proporción menor a 0,5\% (Fig. 4.9).
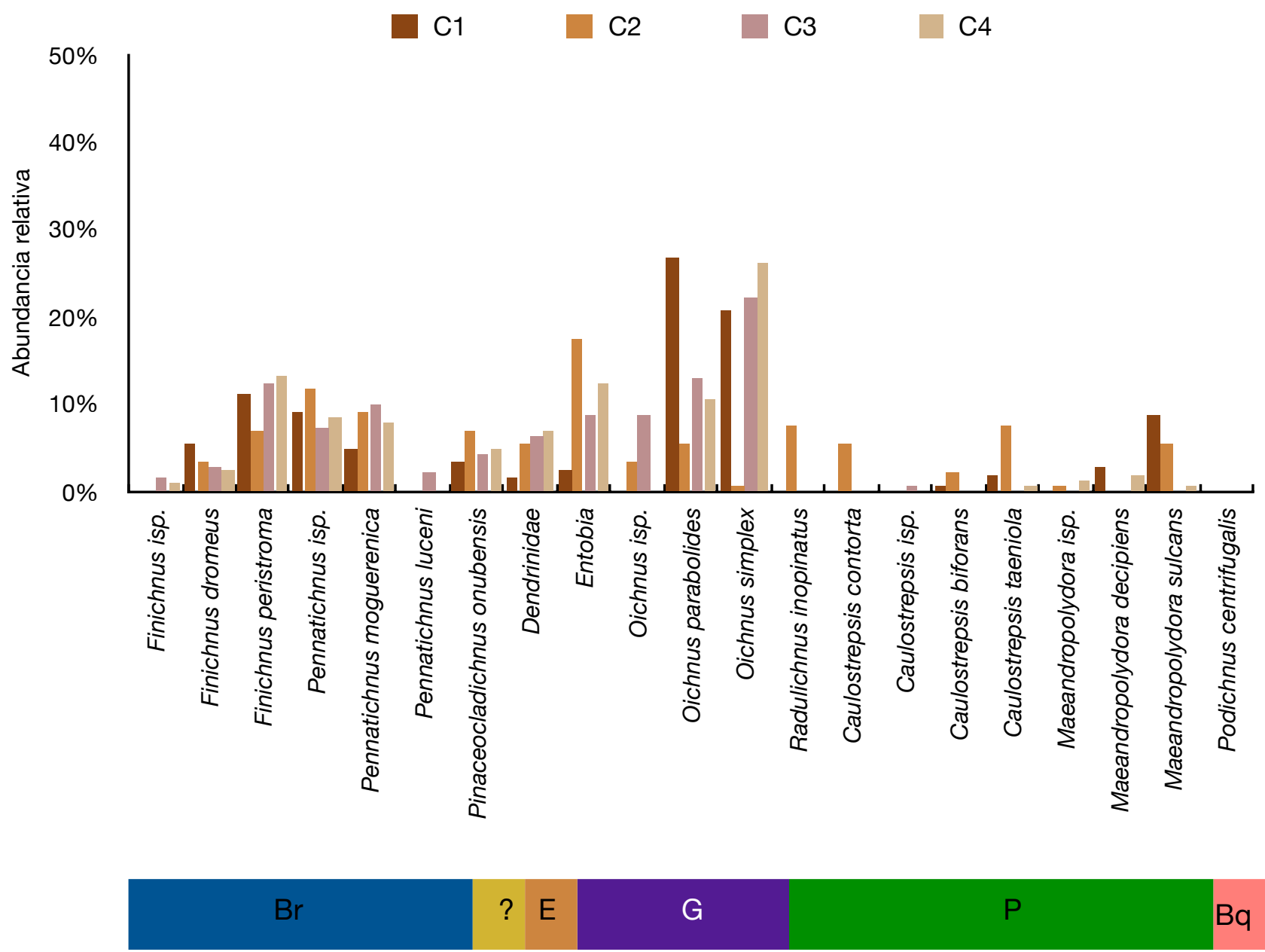

Figura 4.9 Abundancia relativa de los icnotaxones reconocidos en bioclastos observados en las muestras procesadas en laboratorio. La barra inferior señala los posibles productores de las trazas, donde: Br: briozoos, ?: No conocido, E: esponjas, G: gasterópodos, P: poliquetos, Bq: braquiópodos. 
Las trazas producidas por gasterópodos fueron abundantes (Fig.4.9), predominando las producidas por carnívoros. En C1, C3 y C4 la abundancia sumada de Oichnus simplex y $\mathrm{O}$. paraboloides fue mayor o igual a 10\%. En C2 se reconocieron trazas de Radulichnus (7\%), producidas por gasterópodos ramoneadores. Si bien en las trazas producidas por poliquetos se observó una mayor icnodiversidad con ocho icnotaxones, la abundancia relativa de estos fue menor a 0,10 (Fig. 4.9). En C4 se observó una mayor icnodiversidad, ya que se reconocieron siete de los ocho icnotaxones totales, mientras que en C3 únicamente se reconocieron trazas del icnogénero Caulostrepsis. Escasas trazas de Podichnus centrifugalis, atribuidas a braquiópodos, fueron reconocidas en C4.

Considerando los tamices empleados, en el de malla de mayor apertura, 5,660 mm (Fig. 4.10), se observó una icnodiversidad similar en todas las concentraciones. En C1, C2 y C4 se reconocieron entre 14 y 15 icnotaxones, mientras que en C3, 10. Las trazas de briozoos en conjunto mostraron mayor icnodiversidad en $\mathrm{C} 4$, C3 y C1. En C1, Pennatichnus isp. fue la icnoespecie más abundante, mientras que en C2 y C3 fue $P$. moguerenica; por otra parte, en C4 la abundancia de $P$. moguerenica y Finichnus peristroma fue similar. Finichnus dromeus fue la icnoespecie menos abundante en $\mathrm{C} 2, \mathrm{C} 3$ y $\mathrm{C} 4$, mientras que $P$. luceni solo fue observada en C3. Las trazas de la Icnofamilia Dendrinidae fueron más abundantes en C4 y C2 (Fig. 4.10), mientras que las producidas por esponjas lo fueron en C2 y C3.

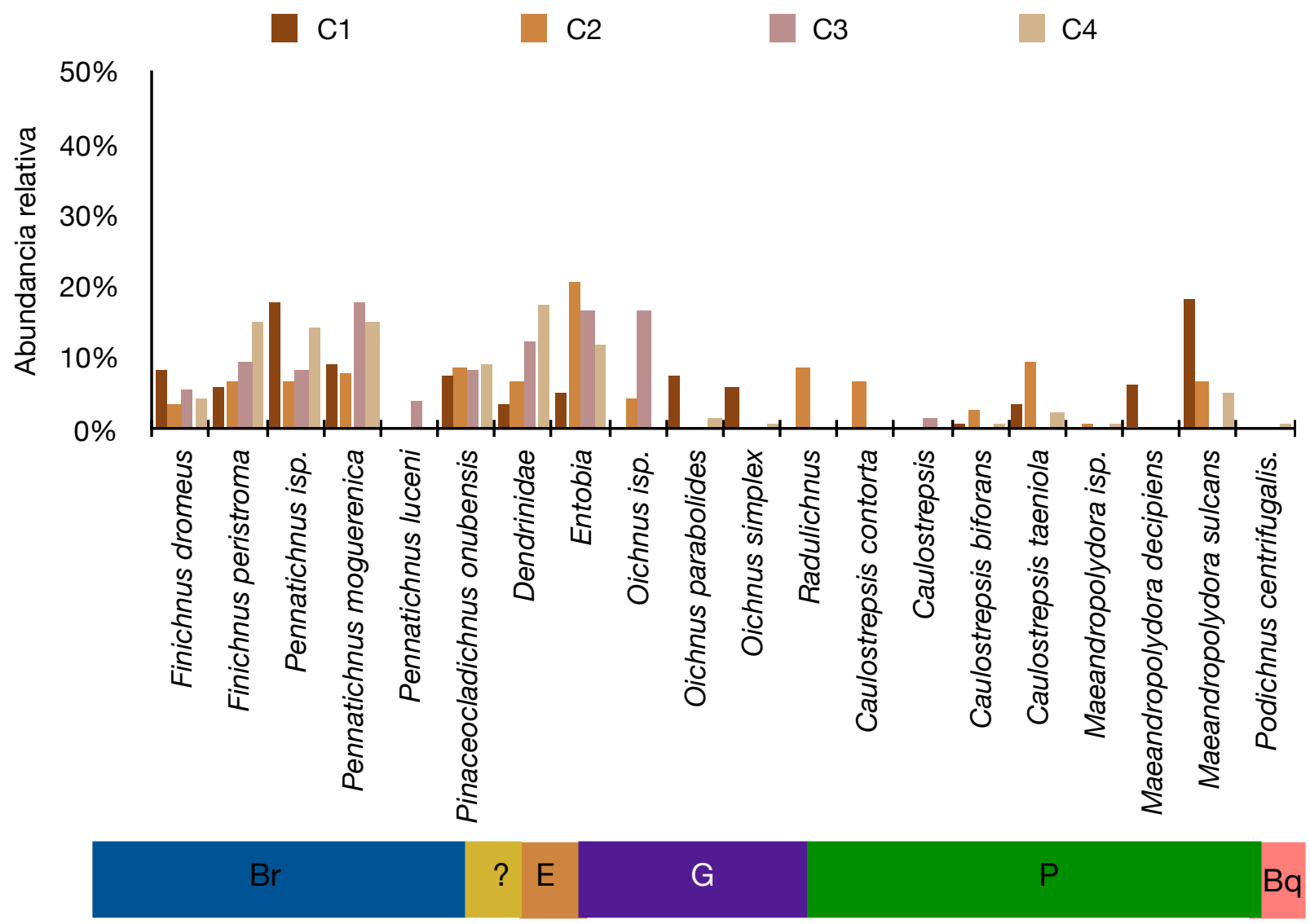

Figura 4.10 Abundancias relativas de icnotaxones reconocidos en $\mathrm{C} 1-\mathrm{C} 4$ en los bioclastos de la malla $5,660 \mathrm{~mm}$. La barra inferior señala los posibles productores de las trazas, donde: $\mathrm{Br}$ : briozoos, ?: No conocido, E: esponjas, G: gasterópodos, P: poliquetos, Bq: braquiópodos. 
De las trazas producidas por gasterópodos, las del icnogénero Oichnus fueron muy abundantes en C4 y C2 (Fig. 4.10), las de las icnoespecies O. simplex y O. paraboloides mostraron mayor abundancia en $\mathrm{C} 1$, mientras que Radulichnus solo fue observada en C2. Finalmente las trazas producidas por poliquetos mostraron bajas abundancias relativas (Fig. 4.10). Maeandropolydora sulcans fue la más abundante en C1 y C4, mientras que en C2 lo fue Caulostrepsis contorta.

En la malla de 1,190 mm, en C1 y C4 la icnodiversidad fue similar a la de la malla 5,660 mm (Fig. 4.11), con 15 icnotaxones. En C2 y C3 la icnodiversidad fue de 7 y 6 icnotaxones, respectivamente. De las trazas de briozoos, Finichnus peristroma fue el icnotaxón más abundante en $\mathrm{C} 1$, C3 y C4, mientras que en $\mathrm{C} 2$ lo fue Pennatichnus isp. Las trazas producidas por gasterópodos fueron las más abundantes en todas las concentraciones, Oichnus paraboloides fue muy abundante en $\mathrm{C} 1$ y C2, mientras que $\mathrm{O}$. simplex fue muy abundante en C3 y C4. Las trazas de la Icnofamilia Dendrinidae, como así también las producidas por esponjas y poliquetos, fueron escasas.

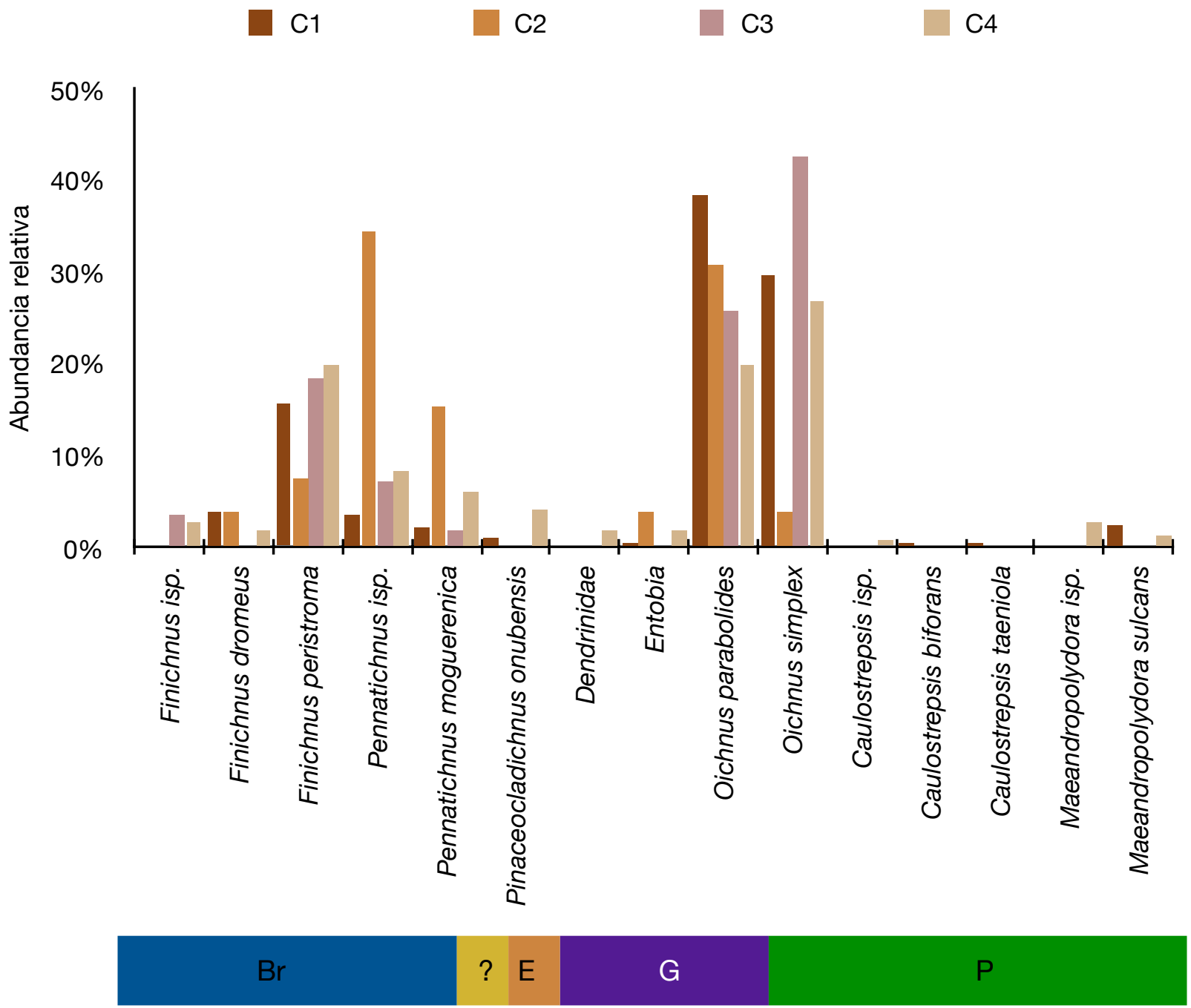

Figura 4.11 Abundancias relativas de icnotaxones reconocidos en $\mathrm{C} 1-\mathrm{C} 4$ en los bioclastos de la malla $1,190 \mathrm{~mm}$. La barra inferior señala los posibles productores de las trazas, donde: Br: briozoos, ?: No conocido, E: esponjas, G: gasterópodos, P: poliquetos. 
Finalmente, en la malla de menor apertura, $0,710 \mathrm{~mm}$, sólo se consideraron las concentraciones $\mathrm{C} 1, \mathrm{C} 3$ y C4 ( $\mathrm{V}$. Capítulo 3); en éstas la icnodiversidad fue baja ya que se reconocieron 3 icnotaxones (Fig. 4.12). Las trazas de Oichnus simplex fueron abundantes en $\mathrm{C} 3$ y $\mathrm{C} 4$, mientras que $\mathrm{O}$. paraboloides lo fue en $\mathrm{C} 1$. Finichnus peristroma solo se observó en $\mathrm{C} 1$ con baja abundancia.

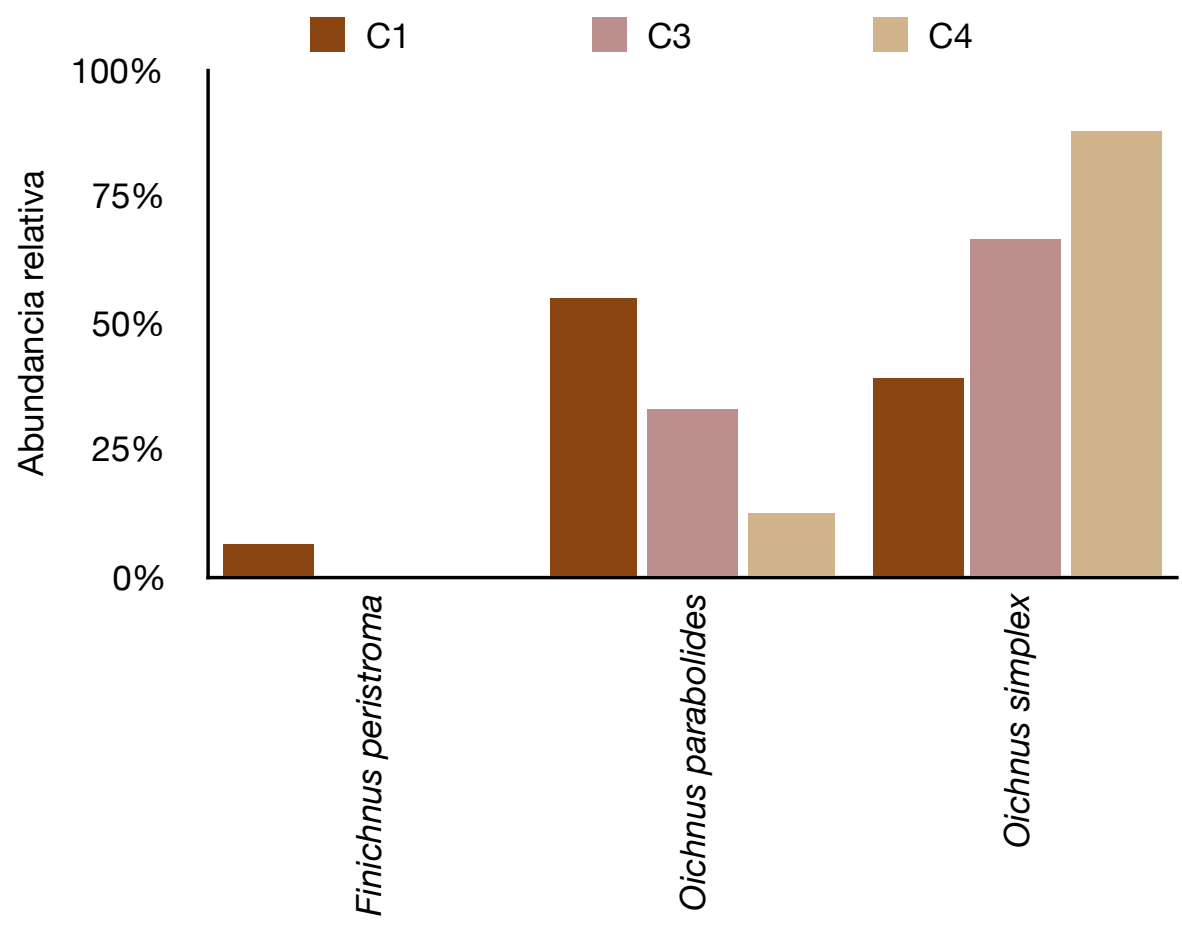

Figura 4.12. Abundancias relativas de icnotaxones reconocidos en $\mathrm{C} 1, \mathrm{C} 3$ y $\mathrm{C} 4$ en los bioclastos de la malla $0,710 \mathrm{~mm}$. La barra inferior señala los posibles productores de las trazas, donde: Br: briozoos, G: gasterópodos.

Selectividad de los esclerobiontes en la superficie del sustrato

a) Selectividad por una o ambas superficies del sustrato: Por medio de una prueba de Bondad de Ajuste, se evaluó de forma independiente en las cuatro concentraciones si los productores mostraban una preferencia por colonizar una o ambas superficies del sustrato. Las trazas fueron agrupadas de acuerdo a sus productores: briozoos, esponjas y poliquetos. En C2 se consideraron también los gasterópodos para el caso de Radulichnus. Las trazas de la Icnofamilia Dendrinidae se evaluaron en conjunto y no fueron atribuidas a ningún productor. Las trazas producidas por braquiópodos (Podichnus) no fueron contempladas debido a su baja abundancia relativa. Las trazas correspondientes a la categoría etológica Praedichnia (Oichnus) tampoco han sido incluidas ya que se asume que estas ocurren en la cara externa del sustrato para poder acceder al tejido del molusco. 
Los briozoos mostraron valores de $p$ altamente significativos $(p<0,001)$ en $C 1, C 2$ y C3 (Tabla 4.2), sugiriendo así una alta tendencia a encontrar estas trazas únicamente en una de las caras del bioclasto. Los valores de $p$ fueron ajustados en cada muestra para detectar falsos positivos o negativos; después del ajuste todos los valores de $p$ continuaron siendo altamente significativos (Tabla 4.2). En C4, el valor de $\mathrm{p}$ para las trazas de briozoos fue $>0,05$, por lo que, en este caso, la hipótesis nula (la probabilidad de que las trazas se encuentren en una o ambas caras del sustrato es igual) no se rechaza.

Las trazas incluidas en la categoría dendrínidos, mostraron valores de $\mathrm{p}$ significativos $(p<0,05)$ en $\mathrm{C} 1$ y $\mathrm{C} 2$; no se reconocieron falsos negativos después del ajuste en los valores de $\mathrm{p}$ (Tabla 4.2). Por otra parte, las trazas producidas por esponjas solo mostraron valores significativos en C3 $(p<0,05)$. Las traza atribuidas a moluscos (gasterópodos herbívoros) en $\mathrm{C} 2$ mostraron un valor de $\mathrm{p}$ significativo $\mathrm{y}$, finalmente, las producidas por poliquetos mostraron valores de $p$ altamente significativos $(p<0,001)$ en $C 1$ y $C 2$.

Tabla 4.2. Test de bondad de ajuste que evaluó de manera independiente si las trazas atribuidas a cada productor mostraban tendencia a ser encontradas en una o ambas caras de los bioclastos.

\begin{tabular}{|c|c|c|c|c|c|}
\hline Concentración & Productor & $p$-value & Intervalo de confianza & $\begin{array}{l}\text { Probabilida } \\
\text { d }\end{array}$ & p-value Bonferroni \\
\hline \multirow{4}{*}{1} & Briozoos & $<2.2 \mathrm{E}-16$ & $0.8870403-0.9800891$ & 0.9464286 & $8.8000 \mathrm{E}-16$ \\
\hline & Dendrínidos & 0.007812 & $0.6305834-1.0000000$ & 1 & $3.1248 \mathrm{E}-02$ \\
\hline & Esponjas & 0.7744 & $0.1516522-0.7233303$ & 0.4166667 & 1 \\
\hline & Poliquetos & $\begin{array}{r}6.209 \mathrm{E}-0 \\
8\end{array}$ & 0.71202720 .9053500 & 0.8235294 & 2.4836E-07 \\
\hline \multirow{5}{*}{2} & Briozoos & $\begin{array}{r}3.609 E-0 \\
8\end{array}$ & $0.7912981-0.9838467$ & 0.9230769 & $1.8045 \mathrm{E}-07$ \\
\hline & Dendrínidos & 0.02246 & $0.5455289-0.9807933$ & 0.8461538 & 1.123E-01 \\
\hline & Esponjas & 0.1338 & $0.4512756-0.8613535$ & 0.6818182 & $6.6900 \mathrm{E}-01$ \\
\hline & Moluscos & 0.001953 & 0.69150291 .0000000 & 1 & $9.7650 \mathrm{E}-03$ \\
\hline & Poliquetos & $2.98 \mathrm{E}-08$ & 0.83297890 .9991836 & 0.9677419 & $1.4900 \mathrm{E}-07$ \\
\hline \multirow{4}{*}{3} & Briozoos & $1.51 \mathrm{E}-05$ & $0.6863591-0.9302593$ & 0.8333333 & 0.0000604 \\
\hline & Dendrínidos & 0.7744 & $0.1516522-0.7233303$ & 0.4166667 & 1 \\
\hline & Esponjas & 0.003906 & $0.6637329-1.0000000$ & 1 & 0.01562400 \\
\hline & Poliquetos & 1 & $0.025-1.000$ & 1 & 1 \\
\hline \multirow{4}{*}{4} & Briozoos & 0.3428 & $0.4469960-0.6603558$ & 0.5652174 & 1 \\
\hline & Dendrínidos & 0.07681 & $\begin{array}{r}0.07266204-0.5237708 \\
2\end{array}$ & 0.25 & 0.30724 \\
\hline & Esponjas & 0.21 & $0.4273440-0.8362364$ & 0.6521739 & 0.84000 \\
\hline & Poliquetos & 0.2668 & $0.3857383-0.9090796$ & 0.6923077 & 1 \\
\hline
\end{tabular}

b) Selectividad por la superficie interna o externa: Siguiendo los criterios expuestos en el apartado anterior, se evaluó si las trazas se encontraban preferencialmente en la superficie 
interna o externa de los bioclastos (Tabla 4.3). En este caso se consideró como "éxito" la cara interna. Los briozoos mostraron valores de $p$ altamente significativos $p<0,001$ en $C 1$, C3 y C4; en C1 y C4 la preferencia fue por la superficie externa, mientras que en C3 lo fue por la interna. No se detectaron falsos positivos. Las trazas de la Icnofamilia Dendrinidae no mostraron valores de $p$ significativos. Las trazas producidas por esponjas no mostraron valores de $\mathrm{p}$ significativos en ninguna concentración, en $\mathrm{C} 4$ el valor de $\mathrm{p}$ obtenido fue significativo, sin embargo al ajustar los valores de $p$, se sugiere como falso positivo.

En C2, las trazas de moluscos mostraron un valor de $p<0,05$, sugiriendo una preferencia significativa por la superficie interna de los bioclastos. Finalmente, las trazas producidas por poliquetos mostraron valores de $\mathrm{p}<0,001$ en $\mathrm{C} 1$ y C2, encontrándose principalmente en la superficie externa (Tabla 4.3).

Tabla 4.3.Test de bondad de ajuste que evaluó de manera independiente si las trazas atribuidas a cada productor mostraban tendencia a ser encontradas en la cara interna o externa de los bioclastos.

\begin{tabular}{|c|c|c|c|c|c|}
\hline Concentración & Productor & p-value & Intervalo de confianza & $\begin{array}{l}\text { Probabilida } \\
\text { d }\end{array}$ & p-value Bonferroni \\
\hline \multirow{4}{*}{1} & Briozoos & $1.399 \mathrm{E}-11$ & $0.1115059-0.2656755$ & 0.1792453 & $5.5960 \mathrm{E}-11$ \\
\hline & Dendrínidos & 0.2891 & $\begin{array}{r}0.03185403-0.6508557 \\
9\end{array}$ & 0.25 & 1 \\
\hline & Esponjas & 0.7539 & $0.2623781-0.8784477$ & 0.6 & 1 \\
\hline & Poliquetos & $8.137 E-13$ & $\begin{array}{l}0.01118697 \\
0.14867445\end{array}$ & 0.05357143 & $3.2548 \mathrm{E}-12$ \\
\hline \multirow[t]{5}{*}{2} & Briozoos & 0.1325 & $0.4622090-0.7917771$ & 0.6388889 & $6.625 \mathrm{E}-01$ \\
\hline & Dendrínidos & 0.4531 & $0.2904209-0.9633074$ & 0.7142857 & 1 \\
\hline & Esponjas & 0.7539 & $0.2623781-0.8784477$ & 0.6 & 1 \\
\hline & Moluscos & 0.001953 & $0.6915029-1.0000000$ & 1 & $9.765 \mathrm{E}-03$ \\
\hline & Poliquetos & 8.43E-06 & $\begin{array}{l}0.02111714 \\
0.26528845\end{array}$ & 0.1 & 4.215E-05 \\
\hline \multirow[t]{4}{*}{3} & Briozoos & 0.001878 & $0.5986367-0.8957896$ & 0.7714286 & 0.007512 \\
\hline & Dendrínidos & 1 & $0.1466328-0.9472550$ & 0.6 & 1 \\
\hline & Esponjas & 1 & $0.2120085-0.8630043$ & 0.5555556 & 1 \\
\hline & Poliquetos & 1 & $0.000-0.975$ & 0 & 1 \\
\hline \multirow[t]{4}{*}{4} & Briozoos & 0.002602 & $0.1623106-0.4249054$ & 0.28 & 0.010408 \\
\hline & Dendrínidos & 0.625 & $0.1941204-0.9936905$ & 0.75 & 1 \\
\hline & Esponjas & 0.03516 & $0.5191089-0.9566880$ & 0.8 & 0.140640 \\
\hline & Poliquetos & 0.1797 & $0.3999064-0.9718550$ & 0.7777778 & 0.718800 \\
\hline
\end{tabular}




\section{Discusión}

Paleobiología de los productores y selectividad por algunas de las superficies del sustrato

\section{Briozoos}

a) Posibles productores: De las trazas atribuidas a estos invertebrados, destaca la abundancia relativa del icnogénero Pennatichnus; se considera que estas trazas han sido producidas por briozoos ctenostomados. Los briozoos ctenostomados no desarrollan un exoesqueleto calcáreo, lo cual implica una ventaja ecológica al penetrar y habitar otros sustratos calcáreos. Pohowsky (1978) realizó una extensa investigación sobre briozoos como agentes bioerosivos, en la cual reconoció alrededor de 48 formas endolíticas; sin embargo, hasta ese momento una de las disputas más importantes era acerca del estado nomenclatural de algunos taxones que eran considerados como biotaxones, a pesar de ser descriptos sobre la base de la morfología de sus perforaciones. Posteriormente, la descripción formal de los icnogéneros Iramena, Pennatichnus y Pinaceocladichnus resolvió, en parte, estos conflictos nomenclaturales. Cuando Mayoral (1988) describió el icnogénero Pennatichnus, sugirió que el modelo de perforación de $P$. moguerenica se corresponde con el que produce actualmente el briozoo Spathipora occidentalis Pohowsky, 1978, en donde las cavidades elongadas corresponden con los zooides individuales, los cuales se conectan a una red de estolones a través de un pequeño pedúnculo. Wisshak (2006) señaló que, en esta traza el zooide inicial (ancéstrula), los estolones se desarrollan interconectando a los autozooides o heterozooides a través de pequeños túneles (los conductos subordinados primarios o de primer orden sensu Mayoral, 1988). Con respecto a $P$. luceni, Mayoral (1988) señaló que el modelo de perforación de esta traza corresponde con el de Spathipora comma Soulé, 1950. Se ha observado que en la formación de estas trazas, la penetración mecánica es facilitada por la penetración química con ácido fosfórico (Borg, 1940; Silén, 1946).

Por su parte, las trazas del icnogénero Finichnus también fueron abundantes en las concentraciones estudiadas, en particular F. peristroma en bioclastos de la malla 1,190 $\mathrm{mm}$. A diferencia de las anteriores, estas son consideradas como cicatrices de fijación someras en el sustrato (Wisshak, 2006), pero incluidas en la categoría etológica Domichnia por Taylor et al. (2009). Se atribuyen a diversas especies de briozoos queilostomados de las familias Membraniporidae, Electridae, Cribrilinidae, Hippothoidae, Microporellidae y Romancheinidae (Taylor et al., 1999). En este caso se considera que la acción química es el principal agente de bioerosión ya que facilita la adherencia de los briozoos (Taylor et al., 1999; Whisshak, 2006). En la Formación Monte León, las trazas de F. dromeus guardan similitud con las colonias de la especie Neothoa reptans Pérez, López-Gappa y Griffin, 2015; esta especie, se caracteriza por ser uniserial incrustante, con auto zooides piriformes que construyen un zooide distal y uno o dos disto-laterales (Pérez et al., 2015).

Finalmente, el icnogénero Pinaceocladichnus se mantuvo presente en todas las muestras, pero en una proporción menor a los dos anteriores. Mayoral (1988), al describir este icnogénero discutió la similitud que presenta esta traza con el modelo de perforación producido por Immergentia spp. Por su parte, Casadío et al. (2007) describieron trazas de 
este icnogénero sobre conchillas de Antarctodarwinella ellioti Zinsmeister, 1976, del Eoceno de Antártida, sugiriendo que estas presentan similitud con las perforaciones del género Terebripora d'Orbigny, 1847.

b) Implicaciones palebiológicas y paleoambientales: El conjunto de briozoos a los que se atribuyen las trazas de Cabeza de León son intersticiales. Se ha observado que organismos adaptados a este hábito de vida comparten adaptaciones como talle pequeño, forma elongada, bauplan simple (con relación al de otros taxones del mismo clado y con otros hábitos de vida), desarrollo de órganos de fijación o adhesión, neotenia y desarrollo no planctónico. Winston y Håkansson (1986), observaron en las costas del Atlántico de Florida que la diversidad de briozoos intersticiales con relación al tamaño de grano tiende a ser bimodal, mostrando una alta diversidad en las fracciones de tamaño arena y grava fina; declina de manera considerable en conchillas completas de entre 6 y $10 \mathrm{~mm}$, y en conchillas de talle mayor la diversidad aumenta nuevamente. A diferencia de lo anterior, en Monte León las trazas producidas por estos invertebrados mostraron mayor icnodiversidad y abundancia en conchillas con tamaño equivalente a grava $(5,660 \mathrm{~mm})$, mientras que en aquellas de talles equivalentes a arena media $(0,710 \mathrm{~mm})$ y gruesa $(1,190 \mathrm{~mm})$ tanto su icnodiversidad como asímismo su abundancia, fueron menores; estos resultados pueden estar relacionados con las condiciones ambientales bajo las cuales se encontraban estas fracciones de bioclastos, incluyendo su susceptibilidad a disturbios. Adicionalmente, como algunos bioclastos de la fracción de $0,710 \mathrm{~mm}$ correspondían a fragmentos de conchillas de mayor talle con mala preservación, es posible que los restos de briozoos así como sus trazas se perdieran durante el proceso tafonómico.

En un contexto paleoambiental, la abundancia y diversidad de trazas producidas por briozoos en las concentraciones estudiadas es destacable (Figs. 4.4, 4.6, 4.8, 4.9). Debido a su distribución actual y a la diversidad de formas que pueden adquirir las colonias, se ha sugerido a los mismos como indicadores de condiciones paleoambientales (Smith, 1995). En este sentido, se ha observado que la presencia y abundancia de briozoos es buen indicador de bajas condiciones de estrés; además, factores tales como la temperatura y la presencia de fitoplancton son cruciales para determinar la distribución de estos organismos. La dominancia de algunas formas coloniales estaría relacionada también con la profundidad, la energía, el sustrato y la tasa de sedimentación. Las formas incrustantes dominan en ambientes someros, posiblemente debido al grado de perturbación física y biológica que predomina en estos ambientes (McKinney y Jackson, 1989); las colonias erectas y flexibles pueden soportar la acción del oleaje en ambientes mareales y submareales (Annoscia y Fierro, 1973), sin embargo, en sedimentos actuales de Nueva Zelanda, este tipo de formas son dominantes en la plataforma interna y media (Smith, 1992).

Considerando sus requerimientos, la naturaleza del sustrato y la dominancia de formas incrustantes, es posible que las conchillas de las concentraciones de la sección Cabeza de León, especialmente $\mathrm{C} 1$ y $\mathrm{C} 4$, estuvieran expuestas en un ambiente de plataforma interna, en los que la tasa de sedimentación es baja, aunque se registra retrabajo por corrientes mareales y olas de tormenta favoreciendo la presencia de nutrientes; o incluso en un ambiente submareal con influencia del oleaje y una tasa de sedimentación moderada. 
c) Selectividad en el sustrato: Al evaluar si había alguna tendencia significativa en la distribución de las trazas de briozoos en una o en ambas caras del sustrato, se observó que en C1, C2 y C3 había preferencia significativa por una de las caras del bioclasto, mientras que en C4 la distribución fue azarosa (Tabla 4.2). La distribución de las trazas en la superficie del biosustrato tiende a estar relacionada con el momento de colonización del mismo (Santos y Mayoral, 2008); las trazas producidas por briozoos no muestran ningún patrón en las conchillas ni de gasterópodos ni de bivalvos, ya que comúnmente se encuentran distribuidos a lo largo de toda la superficie disponible. Al evaluar si había preferencia por una de las caras del bioclasto, se observaron diferentes tendencias en las concentraciones estudiadas (Tabla 4.3), lo que sugiere que la tendencia a asentarse en un sector de la conchilla puede estar determinada principalmente por factores extrínsecos y no por intrínsecos.

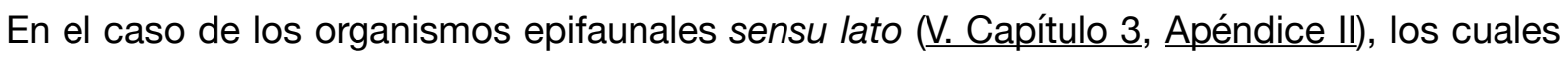
predominaron en $\mathrm{C} 1$ y $\mathrm{C} 4$ (que muestran preferencia por la superficie externa), es difícil determinar si la colonización ocurrió syn vivo o post mortem. En C2 y C3 predominaron bivalvos infaunales; en C2 se observó una distribución azarosa, mientras que en C3 una preferencia por la cara interna. Considerado el hábito de vida de estos organismos, los bioclastos de estas concentraciones posiblemente fueron colonizados post mortem, después de la desarticulación y en algunos casos después de la fragmentación.

\section{Dendrinidae}

a) Posibles productores: Estas trazas se consideran estructuras de habitación, sin embargo la identidad de los organismos productores aún es especulativa y ampliamente debatida, habiéndose considerado como productores potenciales principalmente a las esponjas y a los foraminíferos endolíticos (Bromley et al., 2007; Buatois et al., 2017). Wisshak (2017) realizó una revisión histórica y sistemática de esta icnofamilia a partir de la cual fue posible homogeneizar el registro de trazas fósiles y actuales que se han descripto o mencionado de manera informal para esta familia, logrando reducir de 85 a 22 el número de icnoespecies nominales, incluyéndolas en siete icnogéneros. Mas los productores de la mayoría de estas trazas aún se desconocen, ya que existen pocas evidencias directas que permitan atribuir estas trazas a uno o varios productores; por otro lado, también destaca que estas trazas son más diversas en el registro fósil, mientras que en ambientes marinos actuales se tienen muy pocos registros de formas dendrínidas e inclusive en estos casos no ha sido posible reconocer a los posibles productores.

El productor de Antodendrina ligula no se conoce, pero se considera como potenciales productores a organismos organotróficos (Wisshak, 2017). El icnogénero Clionolithes fue interpretado originalmente por Clarke (1908) como una traza producida por esponjas del género Cliona Grant, 1826. Esta interpretación fue apoyada en contribuciones posteriores (e.g., Clarke, 1921; Fenton y Fenton, 1932; Solle, 1938), a pesar de que no había evidencia directa del productor. Posteriormente, Plewes (1996) reforzó esta interpretación al encontrar micro-ornamentación con forma de punta (cuspate micro-sculptures) llamada pseudo-chip sculpture en especímenes bien preservados de Clionolithes alcicornis (Vogel, Golubic y Brett, 1987). En esponjas actuales, una pequeña ornamentación con forma de punta -más larga que la descripta por Plewes- es formada por células de anclaje al liberar 
las sponge chips; sin embargo, esta textura es característica de Entobia. Se han referido reminiscencias de una micro ornamentación de las dimensiones de C. alcicornis, que corresponde a $E$. mikra Wisshak, 2008, de manera que una relación inequívoca con trazas de esponjas podría ser confirmada posteriormente, especialmente por la similitud morfológica que el icnogénero guarda con E. megastoma y E. dendritica Pleydell y Jones, 1988 (Wisshak, 2017).

En cuanto a las trazas del icnogénero Dictyoporus, el productor se desconoce. Elias (1957) consideró que $D$. nodosus correspondía a una traza producida por una esponja, basándose en su similitud morfológica con pequeñas especies de Cliona referidas por Hancock (1849). Palmer y Palmer (1977) también sugirieron que $D$. nodosus pudo ser producida por esponjas perforantes y posteriormente Lindström (1979) apoyó esta idea. Por otra parte, Elias (1980) explicó detalladamente que estas trazas podrían haber sido producidas por algas parcialmente endolíticas y parcialmente epilíticas. Otra hipótesis para el posible productor de estas trazas es propuesta por Wisshak (2017), quien notó similitudes del patrón anastomosado de Dictyoporus con las redes de estolones desarrolladas por ciertos hidroides, particularmente con los de los géneros Podocoryne Sars, 1846 e Hydractinia Van Beneden, 1844. A pesar de que Goette (1916) reportó que la red de estolones de estos hidroides también puede crecer en o por debajo del periostraco de las conchillas, no se han referido hasta el momento trazas de bioerosión verdaderas producidas por estos organismos, por lo que aún se requieren trabajos que permitan evaluar si algunos hidroides pueden realizar trazas de este tipo.

Por otra parte, Nododendrina europaea ha recibido mayor atención debido a su amplia distribución en el registro fósil y en ambientes marinos actuales; además esta icnoespecie es la única de la icnofamilia que ha sido encontrada con restos de su productor, una chimenea aglutinada que rodea el orificio, el cual fue descripto como parte de un foraminífero aglutinado y designado como biotaxón, i.e. Globodendrina monile Plewes, Palmer y Haynes, 1993. A pesar de que en trazas actuales no se ha observado esta estructura aglutinada, Bromley et al. (2007) concluyeron que el productor de esta traza ha sido reducido parcialmente a esta característica desde el Jurásico o que es un reflejo de la diversidad taxonómica.

Se ha reportado que los foraminíferos endolíticos pueden colonizar una gran variedad de sustratos orgánicos tal como conchillas de moluscos, briozoos, crustáceos, otros foraminíferos, corales y algas calcáreas; con distintos fines como parasitismo, protección, alimentación (superficie pasiva de alimentación) o como fuente de carbonato para la construcción de su testa (Vénec-Peyré, 1996). Posiblemente, los foraminíferos endolíticos poseen una testa que queda embebida y crece dentro de la cavidad bioerodada o que puedan ser formas completamente desnudas, como se ha sugerido para Globodendrina monile; estos protistas podrían producir el nodo principal de la traza y expandir sus pseudopodios a través del plexus ramificado y anastomosado que conecta con la superficie del sustrato para facilitar la alimentación (Bromley et al., 2007). Con estos conocimientos es posible que las trazas incluidas en este icnogénero en general sean producidas por foraminíferos (Wisshak, 2017). Actualmente se conocen cerca de 20 especies de foraminíferos bioerodantes. Si bien los primeros estudios sobre estos protistas estaban orientados hacia el parasitismo y la relación huésped-endobionte, recientemente 
comienza a reconocerse el impacto que la actividad de estos organismos tiene en la destrucción de sustratos duros, ya que a pesar de que sus trazas son muy pequeñas debilitan el sustrato haciéndolo vulnerable a otros procesos erosivos. Por otra parte, la creación de cavidades microscópicas en la superficie de sustratos biogénicos desocupados facilita el reclutamiento de otros bioerodantes, de modo que los foraminíferos bioerodantes podrían favorecer significativamente el desarrollo de comunidades de sustratos duros (Hutchings, 1986; Vénec-Peyré, 1996).

El productor de Pyrodendrina no se conoce. Tapanila (2008) descartó a los foraminíferos como productores potenciales de la icnoespecie tipo y sugirió que el productor podría ser auto o heterotrófico ya que esta icnpespecie ha sido referida para ambientes afóticos. En cuanto a las icnoespecies descriptas por Wisshak (2017), el autor sugiere que los productores potenciales podrían ser micro esponjas o foraminíferos endolíticos, debido a su ocurrencia en ambientes fóticos; además excluye a organismos fototróficos como productores potenciales.

Finalmente, a partir de los canales abiertos y parcialmente discontinuos de Neodendrina carnelia, Wisshak y Neumman (2018) infierieron que el potencial productor de esta traza tuviera partes blandas alternadas con partes epilíticas. La presencia de un patrón bifurcado estrictamente dicotómico y la ausencia de un patrón anastomosado son caracteres desarrollados por algas, hongos y cianobacterias; sin embargo el tamaño de la traza hace que esta suite de microbioerodantes no sea considerada como parte de los productores potenciales. De esta manera, Wisshak y Neumman (2018), han planteado la posibilidad de que esta icnoespecie sea una compleja traza de anclaje considerando así como potenciales productores a foraminíferos bentónicos o macrofitas. Varios representantes de clorofitas del género Acetabularia Lamouroux, 1812, forman trazas de bioerosión con sus rizoides. También algunas rodofitas se anclan en sustratos duros por medio de hapterios y zarcillos (holdfast); algunos autores (e.g., Emery, 1963; Warme, 1975; Radwanski, 1977) han sugerido que algunos de estos protistas se fijan en sustratos carbonáticos; sin embargo, se requiere realizar trabajos icnotaxonómicos más detallados en este tipo de trazas.

b) Implicaciones paleobiológicas y paleoambientales: Desafortunadamente, el desconocimiento de los productores de este grupo de trazas limita el reconocimiento de los factores ambientales que promueven su asentamiento, por lo que la información tafonómica y paleoambiental que brindan es limitada.

c) Selectividad en el sustrato: Al evaluar la presencia de estas trazas en una o en ambas caras del sustrato, en $\mathrm{C} 1$ y $\mathrm{C} 2$ se observó una preferencia significativa por una de las caras (Tabla 4.2), pero al evaluar su preferencia por la interna o la externa se observó una distribución azarosa (Tabla 4.3), sugiriendo una colonización post mortem, especialmente en conchillas de bivalvos; sin embargo, el asentamiento en el sustrato puede estar relacionado con los factores extrínsecos y no con la naturaleza de la conchilla.

\section{Esponjas}

a) Posibles productores: Las trazas asignadas a Entobia se consideran producidas principalmente por esponjas cliónidas, que penetran sustratos calcáreos para construir 
complejos sistemas de cámaras o galerías interconectadas, con múltiples conexiones a la superficie del sustrato, que permiten la filtración del agua (Wilson, 2007).

b) Implicaciones paleobiológicas y paleoambientales: Al igual que los briozoos, las esponjas requieren de condiciones ambientales particulares para desarrollarse de manera óptima. En este sentido, se ha observado que su diversidad y abundancia están influenciadas principalmente por la naturaleza, homogeneidad y disponibilidad de sustratos duros. Por otra parte factores físicos tales como la tasa de sedimentación, la luminosidad y la energía, como así también factores ecológicos, tal como la presencia de otros incrustantes y depredadores, influyen de forma importante sobre la proporción de larvas, su patrón de crecimiento y colonización (Bromley y D’Alessandro, 1984).

Al tener requerimientos ambientales similares a los de los briozoos, es posible que algunas de estas trazas fueran contemporáneas y mantuvieran una interacción de competencia. Considerando la riqueza y abundancia de trazas de briozoos, especialmente en C1 y C4, es posible que estos dominaran, limitando la colonización de las esponjas. Sin embargo, aspectos paleoecológicos relacionados con el tiempo de exposición al sustrato y la sucesión de comunidades de sustratos duros también podrían ser considerados, ya que experimentos en ambientes marinos actuales sobre sucesión ecológica en regiones tropicales y mediterráneas sugieren que las esponjas requieren de poco tiempo (biológico) para colonizar nuevos sustratos disponibles; no obstante, el tiempo en el cual se llega a una diversidad y una mayor tasa de bioerosión, es mayor.

Algunos trabajos muestran que las trazas de poliquetos y algunos moluscos llegan a establecerse en un par de meses, a diferencia de las esponjas, que requieren periodos de tiempo anuales para mostrar una mayor tasa de bioerosión y una mayor diversidad. En este sentido, Fäber et al. (2016) reconocieron al menos dos fases de desarrollo de las comunidades de poríferos en un estudio experimental en el Mediterráneo que tuvo una duración de 14 años; durante los primeros 5 años, se observó una comunidad temprana que mostraba bajas tasas de macrobioerosión que incluía bioerosión inicial por esponjas. Durante el resto del experimento se observó el establecimiento de las esponjas y un incremento de la variabilidad hacia el final del mismo. En este sentido la naturaleza del sustrato (inestable y efímero) también pudo desempeñar un papel determinante en el asentamiento y desarrollo de poríferos en el sustrato biogénico de las concentraciones de Cabeza de León. Sin embargo, para confirmar esto es necesario caracterizar detalladamente las trazas de Entobia, determinándolas hasta nivel icnoespecífico, así como reconocer el estadio ontogénetico que las mismas representan.

c) Selectividad en el sustrato: Las trazas correspondientes al icnogénero Entobia, en la mayoría de las concentraciones no mostraron ningún tipo de preferencia significativa en las concentraciones estudiadas (Tablas 4.2, 4.3), lo cual tafonómicamente podría sugerir una colonización post mortem.

\section{Moluscos}

a) Posibles productores: Las trazas producidas por moluscos corresponden a dos categorías etológicas: praedichnia (Oichnus) y pascichnia (Radulichnus). Voigt (1977) describió formalmente al icnogénero Radulichnus con la finalidad de caracterizar las trazas 
producidas por gasterópodos herviboros y poliplacóforos al alimentarse. Una de las primeras referencias sobre estas trazas es de Ankel (1938), quien observó que gasterópodos de los géneros Littorina Férussac, 1822, y Helcion Montfort, 1810, dejaban pequeños patrones meandriformes cuando se alimentaban de la fina película de algas que cubría las paredes de un acuario. Esta traza se produce cuando la rádula raspa el sustrato para obtener el alimento, algas, produciendo parches con estrías regulares; los diminutos surcos de estos parches corresponden con la cúspide de los dientes de la rádula; de esta manera se ha sugerido que el número y la forma de las estriaciones varíe entre los diferentes grupos de gasterópodos. Märkel (1966) observó que el mismo tipo de rádula puede producir diferentes trazas de ramoneo, relacionándolas con la dirección y velocidad de la rádula al raspar el sustrato. A pesar de estas variaciones en los patrones de estriación entre diversos gasterópodos y de que en el mismo trabajo en el que describe al icnogénero, Voigt (1977) describe las diferencias en las estriaciones producidas por quitones, únicamente designó una icnoespecie.

Teniendo presente la diversidad de estas trazas recopiladas por Gibert et al. (2007), es posible que las trazas presentes en la Formación Monte León fueran producidas por gasterópodos con rádula tipo ripidoglosa o por poliplacóforos. Las trazas producidas por los primeros son delgadas, ligeramente arqueadas y perpendiculares al eje de la traza (Gibert et al., 2007), mientras que las producidas por los segundos son ligeramente más arqueadas, ya que son perpendiculares al eje de las agrupaciones de la rádula del molusco (Voigt, 1977). Esta inferencia podría ser apoyada por el registro paleontológico de la Formación Monte León, ya que se ha referido la presencia de gasterópodos de las familias Calliostomatidae, Trochidae y algunos del orden Littorinimorpha, los cuales pueden poseer

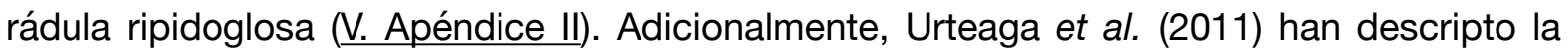
presencia de restos de poliplacofóros en la formación. Esta traza es similar a la referida por Parras y Casadío (2006) en la Formación San Julián, aunque en esta unidad las trazas son de mayor longitud y posiblemente producidas por gasterópodos con rádula docoglosa (e.g., patellas).

Las trazas del icnogénero Oichnus son producidas por durofagia. En la durofagia existen diversos mecanismos de subyugación, siendo las perforaciones el más especializado (Vermeij, 1987). A pesar de que actualmente estas trazas son producidas principalmente por gasterópodos de las familias Muricidae y Naticidae; en el registro fósil no es posible ni aconsejable asumir que todas ellas fueron realizadas por el mismo organismo o que representan una misma etología (Bromley, 1981; Kowaleski, 2002), ya que estas pueden ser realizadas por un amplio espectro de organismos, incluyendo alrededor de 14 grupos de invertebrados (nemátodos, gasterópodos y octópodos) parásitos o depredadores.

En la Formación Monte León es común la presencia de gasterópodos de las familias Naticidae, Muricidae y Buccinidae (V. Apéndice II); se considera que estos organismos sean los posibles productores de las trazas estudiadas, a reserva del bajo potencial de preservación que pueden tener otros depredadores y parásitos perforantes. La determinación de las perforaciones en conchillas observadas en esta tesis se realizaron sobre la base de la diagnosis enmendada por Wisshak et al. (2015), en la que se incluyen en el icnogénero aquellas perforaciones que penetran el sustrato en su totalidad y aquellas que muestran una penetración incompleta, considerada paleoecológicamente como un ataque no exitoso. 
b) Implicaciones paleobiológicas y paleoambientales: Las trazas de Radulichnus en la Formación Monte León fueron muy escasas y restringidas solamente a la concentración C2. Estas trazas son evidencia indirecta del crecimiento de algas sobre las conchillas, lo que sugiere una depositación de las mismas en un ambiente fótico con baja turbidez. Por otra parte, la presencia de organismos ramoneadores en comunidades de sustratos duros es un importante agente de disturbio que las modifica al remover especies y al mismo tiempo favorecer el asentamiento de otras. En comunidades intermareales de California se observó que la remoción de algas por moluscos herbívoros era importante para favorecer el reclutamiento de balanos (Taylor y Wilson, 2003). Por lo que la presencia de estas trazas, además de indicar la presencia de fitobiontes refleja parte de la dinámica de las comunidades que habitan estos sustratos.

Por otra parte, las trazas del icnogénero Oichnus fueron abundantes, especialmente en conchillas retenidas en el tamiz de $1,190 \mathrm{~mm}$, sugiriendo que este talle de conchillas es fácil de subyugar para los depredadores. Trabajos en los que se estudian este tipo de interacciones muestran que cuando la presa es muy grande para ser manipulada por el depredador, la depredación tiende a no ser exitosa (Kitchell et al., 1981; Kelley, 1988), además de que se ha observado que existe una correlación entre el tamaño de la presa y el del depredador, inferido a partir del diámetro de la perforación (Kelley y Hansen, 1996). En las conchillas retenidas en el tamiz $0,710 \mathrm{~mm}$ la presencia de trazas de depredación fue baja, ya que a pesar de que las conchillas pequeñas son fáciles de manipular, no se adecuan al modelo de preferencia de natícidos propuesto por Kitchell et al. (1981), que sugiere que los depredadores maximizan el retorno de energía por tiempo de forrajeo.

c) Selectividad en el sustrato: De este grupo de productores únicamente se consideraron las trazas de Radulichnus, las cuales sólo fueron observadas en C2. Estas trazas mostraron una presencia altamente significativa en la cara interna de los bioclastos (Tabla 4.3), sugiriendo colonización post mortem. Santos y Mayoral (2008) observaron Radulichnus en la cara interna de Megacardita Sacco, 1899, Glycymeris da Costa, 1778, Circomphalus Mörch, 1853, Ostrea Linnaeus, 1758 y Gigantopecten Rovereto, 1899, sugiriendo que la colonización habría ocurrido en un estadio post mortem avanzado (III), cuando las valvas están separadas o desarticuladas con evidencias de exposición prolongada.

\section{Poliquetos}

a) Posibles productores: Las trazas producidas por poliquetos corresponden a los icnogéneros Caulostrepsis y Maeandropolydora. Estas trazas de habitación reflejan dos tipos de penetración del sustrato (Bromley y D'Alessandro, 1983) y se caracterizan por tener al menos una apertura en dirección a la columna de agua, lo que les permite alimentarse (Wilson, 2007). Actualmente Caulostrepsis es producida principalmente por el género Polydora Bosc, 1802 (Bromley, 2004); durante el proceso de perforación el poliqueto disuelve la conchilla de forma química y mecánica con las espinas notoquetas, para formar la galería típica con forma de $U$ cuyo centro es rellenado con detrito (Botelho de Souza et al., 2017). Bromley (1978) sugirió que la especie Lysidice ninetta Audouin y Edwards, 1833, también produce esta traza. Por su parte Maeandropolydora también se ha atribuido a la actividad perforante de poliquetos, principalmente de la Familia Spionidae, 
que se desplazan irregularmente en diferentes niveles por debajo de la superficie del sustrato, lo que promueve la diversidad morfológica de las traza (Santos et al., 2003).

b) Implicaciones paleobiológicas y paleoambientales: Actualmente, los poliquetos perforantes del género Polydora, tienen una distribución cosmopolita y se ha observado que pueden habitar diversos sustratos duros, calcáreos y no calcáreos; la interacción de estos organismos con moluscos ha sido estudiada ampliamente en los últimos años, debido a que la infestación por estos invertebrados afecta a especies de importancia comercial. Cuando la infestación de poliquetos es baja, se considera una interacción de comensalismo ya que no daña al molusco; sin embargo, cuando la intensidad de infestación se incrementa se considera parasitismo, ya que en respuesta a la actividad perforante, el molusco secreta mayor cantidad de conquiolina. El gasto energético involucrado en esta acción retarda y reduce el crecimiento de la conchilla, así como su capacidad para acumular reservas nutricionales, aumentando su mortalidad (Wargo y Ford, 1993; Almeida et al., 1996; Silina, 2006). Los sitios de mayor colonización de poliquetos están asociados con ambientes ricos en fitoplancton y materia orgánica (González-Ortíz et al., 2017).

Algunas especies de este género son oportunistas, inclusive pueden habitar sustratos no consolidados; sus poblaciones colonizan parches con abundantes recursos y pocos competidores (Zajac, 1991). A pesar de que las trazas producidas por poliquetos mostraron mayor icnodiversidad, su abundancia relativa fue baja en todas las concentraciones. Posiblemente, la presencia de otros organismos con los mismos requerimientos ecológicos limitaron los recursos disponibles para estos anélidos. Adicionalmente, la plasticidad de estos organismos para asentarse en diferentes tipos de sustratos sugiere que en la mayoría de las observaciones las trazas ocurrieron después de la muerte de los moluscos, por lo que no reflejan una interacción ecológica directa con los mismos.

c) Selectividad en el sustrato: En C1 y C2 las trazas de poliquetos mostraron una tendencia estadísticamente significativa a colonizar la superficie externa de los bioclastos (Tabla 4.3). En C3 y C4 se observó una distribución azarosa (Tablas 4.2, 4.3). En C1 no se observa un patrón de distribución particular a lo largo de la superficie externa de la conchilla (Tabla 4.2); esta concentración se considera rica en turritelas (V. Capítulo 3), de guisa que la tendencia a encontrar las conchillas en la superficie externa posiblemente sea producto de la abundancia de este taxón, en el que el acceso a la cara interna de su conchilla está limitado a la parte interna de la última vuelta.

Por otra parte en C2 algunas de las trazas preservadas en la cara interna se encuentran con la apertura cerca de los márgenes de la conchilla; sin embargo, no en todos los casos es posible reconocer si corresponde con la parte anterior o posterior de esta. Santos y Mayoral (2008) sugirieron que las trazas encontradas en la superficie interna de las conchillas son post mortem; sin embargo, aquellas que se encuentran cerca de los márgenes en el borde ventral y los bordes laterales posiblemente fueron realizadas al poco tiempo de la muerte del molusco (estadío II sensu Santos y Mayoral, 2008), ya que en esos momentos esta área comienza a ser accesible para colonizar. Por otra parte, las trazas que llegaban a encontrarse en la superficie interna de la conchilla distantes a los márgenes, posiblemente ocurrieron después de la desarticulación y resedimentación de las conchillas (estadío III sensu Santos y Mayoral, 2008). En C2 destaca la presencia de las variaciones 
morfotípicas de Caulostrepsis contorta. Mayoral (1991) sugirió que estas variaciones se presentan como una restricción física impuesta por la ubicación de las galerías, que podría estar relacionado con el momento de la colonización. Para el caso de venéridos sugirió que la colonización post mortem ocurre en zonas externas de mayor espesor o en el lado interno mostrando una vista superior con forma de 8 o de coma. En el material estudiado, las trazas de esta icnoespecie se observaron en bioclastos gruesos de bivalvos infaunales entre la ornamentación resaltada por alteración superficial, por lo que es posible que estas trazas fueran producidas post mortem. En C3 y en C4, posiblemente la colonización por estos organismos ocurrió syn vivo, en el caso de organismos epifaunales o post motem, ya que no se observó alguna preferencia estadísticamente significativa por una de las superficies en particular.

\section{Braquiópodos}

a) Posibles productores: La trazas de Podichnus centrifugalis fueron escasas. Esta traza es producida por el pedicelo de los braquiópodos al fijarse en el sustrato. Su estudio se ha hecho a partir de la observación del proceso de fijación en braquiópodos actuales y su posterior comparación con el registro fósil. Robinson y Lee (2008) describieron tres tipos de trazas que las raicillas (rootles) y las papilas del pedicelo realizan al fijarse al sustrato; además las han atribuido a diferentes órdenes y subórdenes de braquiópodos. Los orificios hemisféricos e irregulares que son realizadas por las papilas del pedicelo se sugiere que son producidos por nueve especies actuales y una fósil de terebratelidinos y una especie de rinconélido. Los grupos de perforaciones circulares o subcirculares producidos por las raicillas se atribuyen a dos especies actuales y cinco fósiles de terebratulidinos. Finalmente, los surcos curvados más o menos paralelos a la superficie del sustrato, se atribuyen a una especie actual y tres fósiles de rinconélidos (Robinson y Lee, 2008). En la formación se ha referido la presencia de braquiópodos (Parras et al., 2012); además, en las concentraciones estudiadas se han encontrado valvas de estos invertebrados retenidas en la malla de $1,190 \mathrm{~mm}$.

b) Implicaciones palebiológicas y paleoambientales: A excepción de los géneros infaunales Lingula Bruguiére, 1791 y Glottidia Dall, 1870, la mayoría de los braquiópodos actuales habitan sustratos duros, al menos durante gran parte de su vida; una vez que los braquiópodos se fijan en el sustrato permanecen fijados en él durante el resto de su vida,. Sin embargo, especies como Neothyris lenticularis (Deshayes, 1839) pueden separarse del sustrato y quedar libres en el suelo marino. En otros taxones, cuando el pedúnculo se desprende del sustrato, este no puede volver a fijarse (Thayer, 1977).

En algunos braquiópodos, principalmente articulados, se ha observado que sus larvas muestran fototaxis negativa, por lo que tienden a asentarse en hábitats crípticos (Thayer, 1977); por otra parte, algunos autores (Doherty, 1979; Assgard y Bromley, 1991) consideraron que su presencia en ambientes crípticos se relaciona con que son los últimos organismos en colonizar un sustrato. Algunas larvas han mostrado preferencia por sustratos rugosos. La rugofilia en conjunto con la fototaxis negativa podrían asociarse con la distribución de braquiópodos en ambientes submareales, en donde comúnmente se encuentran en grietas y áreas irregulares (James et al., 1992). Por el contrario, en ambientes marinos someros, en donde la competencia es mayor, los braquiópodos tienden 
a ser gregarios. Estas trazas fueron escasas y únicamente ocurrieron en $\mathrm{C} 4$, por lo que es posible que el productor tuviera un hábito solitario y su asentamiento ocurriera en un ambiente críptico.

A pesar de la intensa competencia ecológica en ambientes submareales, Doherty (1979) señaló que los braquiópodos son competidores espaciales pasivos; adicionalmente señaló que los braquiópodos pequeños son vulnerables al sofocamiento por incrustantes, v.g. briozoos y esponjas. Debido a la considerable icnodiversidad y a la abundancia de briozoos incrustantes en $\mathrm{C} 4$, posiblemente las larvas de braquiópodos no contaron con espacio suficiente para poder asentarse en estas comunidades, lo que también explicaría su baja abundancia. En este sentido, en campo, en esta concentración se observaron algunas valvas sueltas y desarticuladas de braquiópodos juveniles; sin embargo, no se observaron hábitos gregarios, de guisa que su escasez en Cabeza de León puede reflejar condiciones hostiles para su asentamiento y crecimiento. En otras secciones de la Formación Monte León (e.g., Restinga Norte), pero en niveles infrayacentes, se observaron acumulaciones masivas tipo cluster de estos lofoforados en posición de vida.

\section{Retroalimentación tafonómica y sucesión ecológica}

Se considera como retroalimentación tafonómica (taphonomic feedback) todas aquellas interacciones entre los restos muertos de los organismos (tanatocenosis o tafocenosis) y los organismos vivos (biocenosis), en las que los primeros ejercen efectos facilitativos o inhibitorios sobre los segundos. Kidwell y Jablonski (1983) clasifican estas interacciones como facilitación tafonómica e inhibición tafonómica. En Cabeza de León, los bioclastos acumulados por depósitos de tormenta son un ejemplo de facilitación tafonómica ya que promovieron el asentamiento de comunidades de sustratos duros en un ambiente que originalmente se caracterizaba por la presencia de sustratos blandos.

Driscoll (1967) observó que el aporte de conchillas tiende a ser directamente proporcional a la diversidad de epibiontes. Kidwell y Jablonski (1983) señalaron que las conchillas pequeñas que actúan como sustratos duros ejercen un impacto desproporcionado en la riqueza de especies de los esclerobiontes, ya que sólo una pequeña muestra de la biota puede asentarse en sustratos pequeños, por lo que comúnmente actúan como refugios para especies oportunistas y competidores «inferiores», ya que en estos sustratos es menor la probabilidad de que se instalen competidores mayores, especialmente cuando hay un sobrecrecimiento de algunos colonizadores. En Monte León, la abundancia de trazas de briozoos con respecto a las de otros esclerobiontes puede ser evidencia de una sobrerrepresentación de las comunidades de sustratos duros por su facilidad a asentarse en sustratos pequeños que difícilmente pueden ser ocupados por otros competidores (e.g., Entobia). Por otra parte, a pesar de que los bioclastos bioerodados, por sus características tafonómicas sugieren complejas historias con ciclos de exhumación y resedimentación, la abundancia de briozoos y la icnodiversidad de poliquetos sugiere que el grado de disturbio fue bajo en algunas etapas, ya que cuando se producen altos disturbios físicos, los oportunistas se encuentran en menor densidad en las comunidades.

Con respecto al momento de colonización, si bien en el registro fósil se ha referido que las comunidades de epibiontes se desarrollan syn vivo, la acción de organismos perforantes con frecuencia ocurre post mortem. En este sentido, considerando la distribución de los 
esclerobiontes en relación a la superficie interna o externa de los bioclastos, en las concentraciones estudiadas se considera que esta distribución refleja una colonización post mortem por organismos perforantes. La supervivencia de los esclerobiontes depende del sustrato disponible y del tiempo que este permanece en la interfase agua-sedimento; durante largos periodos de exposición puede ocurrir una colonización con alta riqueza taxonómica en poco tiempo. La contraparte de estos procesos es que una riqueza o abundancia considerable reducen el espacio disponible para colonizar y lo degradan, causando la destrucción del hábitat. Si bien los bioclastos son constantemente girados causando la destrucción de las secuencias de crecimiento previas y exponiendo espacios nuevos para ser colonizados, la bioerosión constante sobre la conchilla continúa limitando el desarrollo de otros colonizadores.

Considerando que en Cabeza de León la mayoría de productores de las trazas se asentaron en las conchillas después de la muerte de los moluscos, es posible que la presencia de sus trazas en una o ambas caras del sustrato responda a diferentes periodos de exposición, de igual forma que su presencia en la cara interna o externa de la conchilla responde al espacio expuesto disponible para colonizar. Los patrones de sucesión ecológica en sustratos duros están principalmente determinados por la relación entre el reclutamiento, la competencia y los disturbios (Wilson, 1987, 1988; Taylor y Wilson, 2003). Desde la década de 1970, el estudio de estas comunidades se ha enfocado en conocer si el proceso de sucesión es predecible y si la comunidad alcanza un clímax como en las comunidades vegetales. El desarrollo de diversos trabajos en comunidades actuales y fósiles (V. Taylor y Wilson, 2003) sugiere que la sucesión en comunidades de sustratos duros es impredecible, ya que el reclutamiento de larvas es muy variable, y en algunas ocasiones los primeros colonizadores no facilitan la colonización posterior, sino que la inhiben. Adicionalmente, si bien la diversidad de especies puede estar determinada principalmente por los disturbios en el sustrato (Osman, 1977; Wilson, 1987), también responde a la disponibilidad de larvas a lo largo de variaciones estacionales (Turner y Todd, 1993).

Un ejemplo de estudio de sucesión ecológica sobre conchillas de moluscos lo constituye el realizado por Mayoral y Reguant (1995) en concentraciones fósiles del Plioceno inferior del suroeste de España. Mayoral y Reguant (1995) analizaron las interacciones de comensalismo y la secuencia de colonización en Glycymerys insubrica (Brocchi, 1814), concluyendo que la mayoría de las trazas observadas ocurrieron después de la muerte y desarticulación de la conchillas, aunque destacaron que algunas trazas producidas por poliquetos (Caulostrepsis y Maeandropolydora) ocurrieron en vida, ya que reconocieron crecimiento anómalo de las conchillas en respuesta a la infestación. Después de la muerte, sugieren la colonización inicial por talofitas asociadas a Caulostrepsis y Maeandropolydora, Entobia y algunos briozoos en áreas expuestas a la interfase o justo por debajo de esta. Posterior a la desarticulación y a la resedimentación, sugieren la colonización por organismos coloniales (briozoos principalmente) y en un tercer estadio sugieren a colonización de balánidos, serpúlidos, briozoos y forónidos.

En los bioclastos analizados en Cabeza de León, posiblemente la colonización de briozoos ocurrió en etapas iniciales, después de la muerte de los moluscos y fue constante en etapas posteriores; las condiciones ambientales permitieron un reclutamiento abundante de sus larvas, favoreciendo su dominancia. Es posible que el tiempo de exposición de la 
superficie colonizada fuera el suficiente para que estos organismos se desarrollaran, pero la rotación de los bioclastos inhibió la dominancia de otros competidores (como esponjas, poliquetos, braquiópodos), por lo que no se observa un cambio notorio en la dominancia de organismos coloniales a solitarios. En regiones templadas este cambio de hábito en la comunidad ocurre cuando las especies coloniales (con menor tiempo de vida) mueren y las de hábitos solitarios forman densas agregaciones a través del reclutamiento de larvas (Taylor y Wilson, 2003). 


\section{Capítulo 5}

One of the beautiful things about science is that it allows us to bumble along, getting it wrong time after time, and feel perfectly fine as long as we learn something each time.

-Martin A. Schwartz

The importance of stupidity in scientific research 


\section{Discusión y conclusiones}

El análisis tafonómico e icnológico combinado de las concentraciones fósiles presentes en la Formación Monte León permitió reconocer que están formadas por bioclastos que experimentaron historias tafonómicas diferentes y complejas, las cuales están relacionadas con factores extrínsecos e intrínsecos (sensu Fernández-López, 2000). Los factores extrínsecos están determinados por procesos físicos químicos y sedimentológicos reconocidos a través de las características tafonómicas, sedimentológicas y estratigráficas que presentaban las concentraciones. Los factores intrínsecos están determinados por procesos biológicos reconocidos a través de sus características paleontológicas. La identificación de las características dejadas por los procesos físicos, químicos y biológicos, tanto en los bioclastos individuales como en cada concentración en su conjunto; permitió clasificar a éstas considerando los criterios de Kidwell et al. (1986), Kidwell (1991) y Fürsich y Oschmann (1993), identificando los procesos dominantes antes del depósito, como así también las variaciones locales en las condiciones de depósito final.

Teniendo en cuenta la predominancia de procesos biológicos, sedimentológicos y diagenéticos, C1, C3 y C4 se consideran como concentraciones mixtas biogénicosedimentológicas (sensu Kidwell et al., 1986); en C1 y C4 es notable la impronta de la retroalimentación tafonómica que modificó la concentración original, mientras que en C3 se observa también como la presencia de elementos autóctonos se ve enriquecida por elementos parautóctonos. Por otra parte, C2 se considera una concentración mixta sedimentológica-diagenética (sensu Kidwell et al., 1986), con mezcla de elementos autóctonos, parautóctonos y alóctonos, cuya preservación ha estado determinada por procesos de exhumación y resedimentación, mientras que la presencia de los moldes de Dosinia?, que evidencian la acción de la diagénesis, enriquecieron la concentración. La presencia recurrente de Panopea quemadensis en posición de vida a lo largo de las concentraciones estudiadas, evidencia repetidos episodios de colonización del sustrato. así como el alto potencial de preservación de los organismos infaunales con relación a los epifaunales en estas condiciones de depósito.

Al considerar los atributos tafonómicos y la biofábrica de las concentraciones en C1 y en C2 se observó que su empaquetamiento denso a suelto y su preservación de moderada (C1) a mala (C2) sugieren similitudes con una tempestita proximal (sensu Fürsich y Oschmann, 1993), en donde C1 refleja un evento de corta duración (=concentración de evento, sensu Kidwell, 1991), mientras que la diversidad de procesos de preservación observados en C2 sugiere que esta concentración refleja diferentes eventos (=concentración multievento, Kidwell, 1991) entre los que destacan el asentamiento de dos comunidades infaunales diferentes, así como el aporte de placas de balanos. Por su parte, la geometría de lente de C3 y su estratificación entrecruzada difusa sugieren un depósito 
en la parte proximal de la plataforma; la alta bioerosión observada en los bioclastos así como la heterogeneidad de la preservación entre los lentes muestran similitud con una concentración de corriente (sensu Fürsich y Oschmann, 1993) que pudo estar sujeta a corrientes de variable duración; por ello, esta concentración también puede considerarse como una concentración multievento (sensu Kidwell, 1991). Por otra parte, las características tafonómicas y de biofábrica de C4 guardaron similitudes con la concentración de olas de tormenta de Fürsich y Oschmann (1993) en la que eventos de corta duración resedimentaron y enterraron los bioclastos; la gradación observada sugiere que esta concentración es el producto de múltiples eventos de tormenta (=concentración multievento, sensu Kidwell, 1991).

Los factores intrínsecos están determinados por las características de los invertebrados preservados, principalmente su mineralogía y sus hábitos de vida. En C1, C3 y C4, predominaron las conchillas aragoníticas de moluscos con escasas evidencias de reemplazo por calcificación y silicificación; su preservación puede asociarse al poco tiempo de permanencia en la TAZ o la remoción de materia orgánica por transporte y lavado durante eventos de tormenta. En C2 se observó la acción de diferentes procesos sedimentológicos y diagenéticos involucrados en la preservación. En esta concentración la presencia de conchillas aragoníticas fue menor con relación a exoesqueletos calcíticos de otros invertebrados; además la escasez de conchillas de talles menores a 5,660 mm sugiere la acción procesos de lavado y disolución durante su depositación. La presencia de moldes de Dosinia bioturbados en la base de esta concentración puede estar asociada a la permanencia de estas conchillas en la TAZ durante un tiempo prolongado.

Si bien los balanos se encontraron como fauna acompañante en $\mathrm{C} 1, \mathrm{C} 3$ y $\mathrm{C} 4$, en $\mathrm{C} 2$ su abundancia fue considerable, por lo que además de asociarse a procesos de selección y lavado, como en el resto las concentraciones, su preservación se atribuye también a procesos diagenéticos. La presencia de briozoos en las concentraciones fue destacable, tanto por la preservación de restos de sus colonias como de sus trazas sobre las conchillas de moluscos, el esqueleto de estos organismos está conformado principalmente de calcita, aunque en algunos clados se ha reconocido una composición bimineral. La abundancia de sus exoesqueletos en $\mathrm{C} 1, \mathrm{C} 3$ y C4 puede estar relacionada con su composición mineralógica (calcita con bajo contenido de magnesio) o con el lavado durante eventos de tormenta.

Con relación al hábito de vida, en C1, C3 y C4 la preservación de las conchillas de moluscos con hábitos infaunales, fue de buena a moderada. Esta preservación sugiere que después de la muerte los restos de estos organismos habrían permanecido enterrados. Sin embargo la alteración tafonómica evidenciada por parte de los bioclastos, indica que los mismos son el producto de uno o varios eventos de exhumación y resedimentación, que pudieron ser causados por la acción de bioturbadores o procesos hidrodinámicos tales como flujos $\mathrm{u}$ olas de tormenta. En $\mathrm{C} 2$, predominaron los bioclastos de organismos infaunales mas su preservación fue mala. Posiblemente algunos de estos elementos pasaron por más de un ciclo de exhumación y resedimentación y estuvieron expuestos a una constante modificación de la biofábrica por acción de bioturbadores. En esta concentración fue notable la presencia de bioturbación. Así la presencia de moldes de Dosinia? biorturbados, sugiere el enterramiento permanente de estos bivalvos en 
condiciones que favorecieron los cambios en la saturación de aguas porales promovió su preservacion.

Los organismos seminfaunales y epifaunales mostraron una preservación de buena a moderada en $\mathrm{C} 1$ y $\mathrm{C} 3$, de moderada a mala en $\mathrm{C} 4$ y mala en $\mathrm{C} 2$. Si bien las diferencias preservacionales entre epifaunales e infaunales en $\mathrm{C} 1$ y $\mathrm{C} 3$ no son considerables, después de la muerte de los primeros, su inmediata exposición en la interfase agua-sedimento influyó en su alteración física por procesos físicos, químicos y biológicos. En particular, en el caso de los balanos y los briozoos de colonias fenestradas y ramificadas gruesas y finas, después de la muerte es común la desarticulación de los organismos y su posterior modificación tafonómica por procesos de resedimentación. En todas las concentraciones estudiadas se observó desarticulación, principalmente en balanos, y fragmentación de las colonias de briozoos en talles equivalentes entre arena media y grava (gránulo o guija).

El estudio de las características paleontológicas de cada una de las concentraciones de Cabeza de León mediante la obtención de muestras volumétricas de conchillas y sedimento, y su posterior procesamiento y análisis en laboratorio, permitió realizar una mejor aproximación al conocimiento de la riqueza taxonómica. En este sentido, el estudio de la malacofauna en laboratorio incrementó en más del $50 \%$ el número de taxones presentes en las concentraciones ya que gran parte del material quedó retenido en los tamices con mallas de 1,190 y $0,710 \mathrm{~mm}$, talle que en general no es tenido en cuenta en la caracterización taxonómica de las concentraciones en campo. Esto también permitió reconocer que la calidad de preservación de los bioclastos (macro y micro moluscos) en las concentraciones fósiles de la Formación Monte León estuvo influenciada por el talle de las conchillas y su vulnerabilidad a diferentes procesos de alteración, desgaste y depósito.

Con relación a la fragmentación y la alteración superficial la relación superficie-volumen fue determinante en la calidad de preservación, ya que en C1, C3 y C4, se observaron índices altos de fragmentación y alteración superficial en la malla de mayor apertura, 5,660 mm; mientras que en la de 1,190 mm la fragmentación y la alteración superficial fue de baja a moderada y en la malla $0,710 \mathrm{~mm}$ se observó un índice moderado de fragmentación y de moderado a alto de alteración superficial. Los bioclastos redondeados predominaron en todas las concentraciones y en todos los talles, de guisa que no se considera que exista una relación entre este atributo y el talle de las conchillas. Sin embargo, la proporción de redondeamiento fue mayor en conchillas completas e incompletas de la malla $5,660 \mathrm{~mm}$, esto puede estar relacionado con el hecho de que este atributo tafonómico tiende a estar estrechamente relacionado con la fragmentación y la alteración superficial; también se ha considerado su relación con la microbioerosión. En Cabeza de León esta no fue considerada en los alcances de este trabajo.

Al evaluar la relación de los otros índices tafonómicos con respecto a la fragmentación en los bioclastos retenidos en los diferentes tamaños de malla empleados (Tablas 3.7, 3.22, 3.33), se observó que ésta varía en proporción directa con la alteración superficial, al redondeamiento y a la modificación de bordes; haciéndolo en forma inversa con respecto a la bioerosión.

En el último caso, al considerar la superficie de las conchillas con trazas de bioerosión, se observó un bajo índice de bioerosión en todas las concentraciones. Sin embargo en la 
malla de 5,660 mm fue más evidente la presencia de trazas que en los bioclastos retenidos en mallas de menor apertura. El análisis icnológico, además de contemplar la superficie de las conchillas cubiertas, consideró la icnodiversidad, lo que permitió reconocer un total de 24 icnotaxones producidos por briozoos, poliquetos, esponjas, moluscos carnívoros y ramoneadores, y braquiópodos. Algunos de los icnotaxones corresponden a trazas en roseta incluidas en la icnofamilia Dendrinidae cuyos potenciales productores aún no se han reconocido de forma inequívoca. Al igual que ocurrió con el grado de bioerosión, las conchillas de más de 5,660 mm mostraron una icnodiversidad mayor; en C1, C2 y C4, se reconocieron entre 14 y 15 icnotaxones mientras que en $\mathrm{C} 3$ se reconocieron 10 icnotaxones. En la malla de 1,190 mm se reconocieron entre 6 y 7 icnotaxones en C2 y C3, mientras que en C1 y C4 la icnodiversidad fue similar a la de la malla de 5,660 mm (14 icnotaxones). Finalmente, en la malla de menor apertura $(0.710 \mathrm{~mm})$ únicamente se reconocieron 3 icnotaxones. El reconocimiento de las trazas de bioerosión en las muestras volumétricas, considerando tanto especímenes completos como fragmentos y teniendo en cuenta todas las tallas recuperadas, ha permitido no subestimar este atributo tafonómico en las concentraciones estudiadas, y reconocer la importancia de la retroalimentación tafonómica en su historia. Asimismo, a partir del trabajo icnotaxonómico ha sido posible reconocer los posibles productores, así como su paleobiología y su papel en el desarrollo de comunidades de sustratos duros.

A través de la cuantificación de las trazas de bioerosión en relación a la superficie colonizada (externa versus interna) por sus productores, fue posible reconocer que el desarrollo de comunidades de sustratos duros sobre conchillas de moluscos presentes en las concentraciones fósiles de la Formación Monte León estuvo relacionado con la colonización del sustrato en diferentes etapas de resedimentación y exhumación, previas al enterramiento final.

Las trazas identificadas correspondieron principalmente con las categorías etológicas Domichnia y Praedichnia. Las trazas producidas por briozoos fueron las más abundantes en la sección, destacando las del género Pennatichnus, las cuales se atribuyen a diferentes ctenostomados. Otro icnotaxón abundante en la sección es Finichnus, atribuido a las familias de cheilostomados Membraniporidae, Electridae, Cribrilinidae, Hippothoidae, Microporellidae y Romancheinidae. Considerando que la presencia y abundancia de briozoos es un buen indicador de factores tales como temperatura y la presencia de fitoplancton, es posible que los bioclastos de Cabeza de León, especialmente aquellos de $\mathrm{C} 1$ y $\mathrm{C} 4$ estuvieran expuestos en un ambiente de plataforma interna a submareal con baja a moderada tasa de sedimentación en donde el retrabajo por corrientes mareales y olas de tormenta favoreciera la presencia de nutrientes. Con relación a su preferencia por el sustrato, en la mayoría de los icnotaxones no se observó ningún patrón en las conchillas de gasterópodos ni de bivalvos ya que comúnmente se encuentran distribuidos a lo largo de toda la superficie disponible (ambas superficies), lo que sugiere que la tendencia a asentarse en un sector de la conchilla puede estar determinada principalmente por las condiciones ambientales a las que está expuesta la superficie de la conchilla colonizada. En los organismos epifaunales no es posible determinar cuáles trazas ocurrieron syn vivo y cuáles lo hicieron post mortem; mientras que, los organismos infaunales, principalmente en C2 y C3, habrían sido colonizados post mortem, después de la desarticulación y en algunos casos, después de la fragmentación. 
Las trazas producidas por poliquetos no fueron tan abundantes como las de briozoos, pero sí mostraron mayor icnodiversidad. La presencia de otros organismos con los mismos requerimientos ecológicos posiblemente limitó los recursos disponibles para estos anélidos. Con relación a la selectividad del sustrato en $\mathrm{C} 1$ se observó una tendencia significativa por colonizar la superficie externa; en $\mathrm{C} 1$ es posible que esta tendencia se deba a la abundancia de gasterópodos en los que el acceso a la superficie interna de la conchilla es limitado; en C2 las trazas cerca de los márgenes del borde ventral y lateral de la cara interna fueron realizadas después de la muerte del molusco. En C3 y C4 por otra parte, no se observó preferencia estadísticamente significativa por una superficie del sustrato, por lo que se sugiere que la colonización por estos organismos, en el caso de organismos epifaunales, pudo ocurrir tanto syn vivo como post motem.

Las trazas producidas por esponjas también fueron reconocidas, aunque en baja proporción, en las concentraciones estudiadas. Estos organismos, al igual que los briozoos, requieren condiciones ambientales particulares para desarrollarse, dependiendo de factores tales como la naturaleza, homogeneidad y disponibilidad de sustrato, la tasa de sedimentación, la luminosidad y energía del ambiente y la presencia de incrustantes y depredadores. La baja abundancia relativa de las esponjas en relación a los briozoos en los bioclastos de Cabeza de León posiblemente esté relacionada a que la abundancia de estos últimos limitó la colonización de esponjas. Por otra parte, las esponjas para asentarse y diversificarse en una comunidad requieren de largos periodos de tiempo ( $\geq 10$ años), por lo cual el tiempo de exposición en la interfase de los bioclastos, su movilidad y la interacción con otros competidores pudo influir en la baja abundancia de sus trazas.

El análisis icnológico también permitió el reconocimiento de diferentes trazas rosetadas incluidas en la Icnofamilia Dendrinidae. La diversidad en la morfología de las trazas permitió reconocer de manera especulativa algunos icnotaxones. Sin embargo, su determinación quedó a reserva; por otra parte, la identidad de los productores de este tipo de trazas aún es ampliamente debatida, por lo que la información paleontológica y paleambiental que éstas brindan aún es limitada.

Entre las trazas producidas por moluscos, en C2 se reconocieron las del icnogénero Radulichnus, las cuales corresponden a trazas de alimentación por ramoneo de gasterópodos herbívoros y poliplacóforos. La forma de las trazas guarda similitudes con aquellas producidas por gasterópodos con rádula ripidoglosa que, en la Formación Monte León, estarían representados por especímenes de las familias Calliostomatidae, Trochidae y algunos del orden Littorinimorpha. La presencia de estas trazas en la cara interna es evidencia del crecimiento post mortem de algas sobre las conchillas, sugiriendo su depositación en un ambiente de baja turbidez en la zona fótica y reflejan parte de la dinámica de las comunidades que habitan estos sustratos ya que la remoción de las algas favorece el reclutamiento de otros esclerobiontes. Por otra parte, las trazas del icnogénero Oichnus son producidas por gasterópodos durófagos. Sobre la base de las determinaciones taxonómicas realizadas, se consideran como posibles productores a gasterópodos de las familias Naticidae, Muricidae y Buccinidae. Estas trazas fueron abundantes en las conchillas retenidas en el tamiz de 1,190 mm, lo que sugiere que esta talla de conchillas era fácil de subyugar para los depredadores y posiblemente aseguraba un ataque exitoso. 
Finalmente, escasas trazas atribuidas a braquiópodos fueron identificadas en C4. Estos organismos pueden desarrollar hábitos gregarios en ambientes someros, sin embargo la baja abundancia de trazas sugiere que la presencia de otros incrustantes, posiblemente impidió el desarrollo de este tipo de poblaciones. La fototaxsis negativa que muestran las larvas de estos organismos, sugiere que las conchillas fueron expuestas en un ambiente fótico y el asentamiento de las larvas corresponde con sectores de las conchillas que estaban asociados a microhábitas crípticos.

El análisis de concentraciones fósiles es una vasta tarea que puede ser aplicada con diferentes enfoques y a diferentes escalas; si bien en cualquier caso se aporta información sobre los depósitos estudiados, un estudio detallado de cada uno de sus componentes es fundamental para realizar una aproximación adecuada. En esta tesis, la inclusión de un enfoque icnológico fue fundamental para reconocer las complejas historias tafonómicas que sufrieron algunos de los elementos que conformaban las concentraciones y resultó ser una herramienta útil para el reconocimiento de la promediación temporal y dentro del hábitat, que en conjunto con otras características tafonómicas, estratigráficas y sedimentológicas soportan que las concentraciones de Cabeza de León se formaron principalmente por eventos de tormenta mayormente desarrollados en un ambiente de plataforma interna. Adicionalmente, la información palebiológica que aportan las trazas permitió reconocer las condiciones ambientales bajo las cuales estuvieron expuestos los bioclastos antes del enterramiento final.

En esta tesis, las observaciones en campo se vieron enriquecidas con la recolección, procesamiento y análisis cuantitativo de las muestras procesadas en laboratorio, ya que fue posible reconocer la diversidad y potencial preservación de la malacofauna y de otros invertebrados como briozoos, balanos y equinodermos con relación a la talla. En este sentido, a pesar de que existen concentraciones fósiles en las que la preservación de los bioclastos y las características de los estratos que las contienen no permiten la extracción de muestras, en concentraciones fósiles con preservaciones similares a las de la Formación Monte León, el análisis de muestras volumétricas puede ser una herramienta fundamental para la caracterización de las mismas y para análisis semicuantitativos y cuantitativos detallados que además brindarían información paleoecológica y paleoambiental.

A pesar de que los métodos seguidos y los resultados obtenidos en este trabajo contribuyen al conocimiento paleontológico, tafonómico, icnológico y estratigráfico de la Formación Monte León, también mostraron ciertas limitaciones. La replicación de este método en otras secciones de la unidad como así también en sedimentitas de unidades litoestratigráficas equivalentes, permitiría mostrar un enfoque comparativo para conocer en una escala mayor como operaron los procesos tafonómicos transversal y lateralmente a lo largo de la costa de Patagonia durante el Mioceno temprano. Por otra parte, el análisis icnológico se limitó únicamente al estudio de trazas de bioerosión, mas la realización de análisis de biofábrica permitiría ampliar el conocimiento sobre las condiciones paleoambientales, la paleoecología de las comunidades marinas en el Cenozoico de la región y, en un contexto tafonómico, sería posible obtener una aproximación sobre el impacto de los bioturbadores en la fosildiagénesis de los bioclastos. En este sentido, la metodología de campo y laboratorio desarrollada y los resultados obtenidos en esta tesis alientan a desarrollar futuras líneas de investigación que, en este marco, contribuyan al 
conocimiento de la biota y las condiciones paleoambientales existentes en el sur de Sudamérica a comienzos del Neógeno. 


\section{Referencias bibliográficas}

Pues más allá de nuestro sueño las palabras, que no nos pertenecen, se asocian como nubes que un día el viento precipita sobre la tierra, para cambiar, no inútilmente, el mundo. -José Ángel Valente Inútilmente 
Abel, O., 1912, Grundzüge der Palaobiologie der Wirbeltiere E. Schweitzerbart'sche Verlagsbuchhandlung, Stuttgart, $708 \mathrm{p}$.

Abel, O., 1922, Lebensbilder aus der Tierwelt der Vorzeit, Verlag von Gustav Fischer, Jena, $643 \mathrm{p}$.

Abel, O., 1935, Vorzeitliche Lebensspuren, Verlag von Gustav Fischer, Jena, 644 p.

Ager, D.V., 1974, Storm deposits in the Jurassic of the Moroccan High Atlas: Palaeogeography, Palaeoclimatology, Palaeoecology, 15, 83-93.

Addicott, W.O., 1976, Molluscan paleontology of the lower Miocene Clallam Formation, northestern Washington: Geological Survey Professional Papper, 976, 44.

Aguirre, J., Martín, J.M., Braga, J.C., Betzler, C., Berning, B.; Buckeridge, J.S., 2008, Densely packed concentrations of sessile barnacles (Cirripedia: Sessilia) from the Early Pliocene of SE Spain: Facies, 54, 193-206.

Aigner, T., 1982, Calcareous tempestites: storm-dominated stratification in upper Muschelkalk limestones (Middle Trias, SW-Germany), in: Einsele, G., Seilacher, A. (eds.), Cyclic and Event Stratification: Berlin, Springer-Verlag, 180-198.

Aigner, T.,1985, Storm Depositional Systems, Lecture Notes in Earth Sciences 3: Berlín, Springer-Verlag, 174pp.

Alexander, R.R., 1981, Predation scars preserved in Chesterian brachiopods: probable culprits and evolutionary consequences for the articulates: Journal of Paleontology, 55, 192-203.

Alexandersson, E.T., 1978, Destructive diagenesis of carbonate sediments in the eastern Skagerrak, North Sea: Geology, 6, 324-327.

Almeida, M. J., Moura, C., Machado, J., Coimbra, J., Vilarinho, L., Ribeiro, C., 1996, Aminoacid and metal content of Crassostrea gigas shell infested by Polydora sp. in the prismatic layer insoluble matrix and blister membrane: Aquatic Living Resources, 9, 179186.

Allmon, W.D., 1988, Ecology of recent turritelline gastropods (Prosobranchia, Turritellidae): Current knowledge and paleontological implications: Palaios, 3, 259-284.

Allmon, W.D., 1992, Role of nutrients and temperature in extinction of turritelline gastropods in the northwestern Atlantic and northeastern Pacific: Palaeogeography, Palaeoclimatology, Palaeoecology, 92, 41-54.

Allmon, W.D., 2001, Nutrients, temperature, disturbance, and evolution: a model for the late Cenozoic marine record of the western Atlantic: Palaeogeography, Palaeoclimatology, Palaeoecology, 166, 9-26. 
Allmon, W.D., 2007, Cretaceous marine nutrients, greenhouse carbonates, and the abundance of turritelline gastropods: Journal of Geology, 115, 509-524.

Ameghino, C., 1890, Exploraciones geológicas de la Patagonia: Boletín Instituto Geográfico Argentino, 11(1), 3-46.

Ameghino, F., 1889, Contribución al conocimiento de los mamíferos fósiles de la República Argentina: Actas Academia Nacional de Ciencias en Córdoba, 6, 1-1028.

Ameghino, F., 1898. Sinopsis geológico-paleontológica: Segundo censo de la República Argentina, 1, 111-225.

Annoscia, E., Fierro, G. 1973, Bryozoan ecology in relation to sediment texture in the "Golfo dell' Asinara" (Sardinia, Italy), in: Larwood, G.P. (ed.), Living and Fossil Bryozoa Recent Advances in Research: London, Academic Press, 53-64.

Ankel, W.E., 1938, Erweb und Aufnahme der Nahrung bei den Gastropoda: Verhandlungen der Deutschen Zoologischen Gesellschaft, 40, 223.

Ansell, A.D., 1962, Observations on burrowing in the Veneridae (Eulamellibrnchia): Biological Bulletin, 123 (3), 521-530.

Assgard, U., Bromley, R.G., 1991, Colonization by micromorph brachiopods in the shallow subtotal of the eastern Mediterranean Sea, in: McKinnon, D.I.; Lee, D.E.; Campbell, J.D. (eds.), Brachiopods through time: Rotterdam, Balkema, 261-264.

Audouin, J.V., Edwards M.H., 1833, Classification des Annélides et description de celles qui habitent les côtes de la France: Annales des sciences naturelles, 28, 187-247.

Barreda, V., Palamarczuck, S., 2000a, Palinomorfos continentales y marinos de la Formación Monte León en su área tipo, provincia de Santa Cruz, Argentina: Ameghiniana , 37 (1), 3-12.

Barreda, V., Palamarczuck, S., 2000b, Estudio palinoestratigráfico del Oligoceno tardíoMioceno en secciones de la costa patagónica y plataforma continental argentina, en Aceñolaza, F.G., Herbst, R. (eds.), El Neógeno de Argentina, INSUGEO: Serie Correlación Geológica, 14, 103-138.

Bassi, D., Posenato, R., Nebelsick, J.H., Owada, M., Domenicali, E., Iryu Y., 2017, Bivalve borings in Lower Jurassic Lithiotis fauna from northeastern Italy and its paleoecological interpretation: Historical Biology, 29 (7), 937-946.

Baucon, A., 2010, Leonardo da Vinci, the founding father of ichnology: Palaios, 25, 361-367, doi: 10.2110/palo.2009.p09-049r

Baucon, A., Bordy, E., Brustur, T., Buatois, L.A., Cunningham, T.J., De, C., Duffin, C., Felletu, 
F., Gaillard, C., Hu, B., Hu, L., Jensen, S., Knaust, D., Lockiey, M., Lowe, P., Mayor, A., Mayoral, E., Mikuláš, R., Muttoni, G., Neto de Carvalho, C., Pemberton, S.G., Pollard, J., Rindsberg, A.K., Santos, A., Seike, K., Song, H., Turner, S., Uchman, A., Wang, Y., Yi-ming, G., Zhang, L., Zhang, W., 2012, History of Ideas in Ichnology, in Kanust, D., Bromley, R. (eds.), Trace fossils as indicators of sedimentary environments: Oxford, Developments in Sedimentology 64, Elsevier, 3-44.

Becker, D., 1964, Micropaleontología de Superpatagoniense de las localidades Las cuevas y Monte Entrance (provincia de Santa Cruz): Ameghiniana, 3 (10), 319-351.

Behrensmeyer, A.K., 1975, The taphonomy and palaeocology of Plio-Pleistocene vertebrate assemblages east of Lake Rudolf, Kenya: Bulletin of the Museum of Comparative Zoology, Harvard University, 146 (10), 473-578.

Behrensmeyer, A.K., 1976a, Fossil assemblages in relation to sedimentary environments in the East Ruldolf succession, in: Coppens, Y., Howell, F.C., Isaac, G.LI., Leackey, R.E.F., (eds.), Earliest man an environments in the Lake Rudolf Basin: Stratigraphy, Paleoecology and Evolution (Prehistoric Archaeology and Ecology): Chicago, University of Chicago Press, 383-401.

Behrensmeyer, A.K., 1976b, Taphonomy and paleoecology in the hominid fossil record: Yearbook of Physical Anthropology, 19, 36-50.

Behrensmeyer, A.K., Kidwell. S.M., 1985, Taphonomy's contributions to Paleobiology: Paleobiology, 11 (1), 105-119.

Bellosi, E.S., 1990, Formación Chenque: Registro de la transgresión patagoniana (Terciario medio) de la cuenca de San Jorge, Argentina: $11^{\circ}$ Congreso Geológico Argentino, Actas 2, 57-60.

Bertels, A., 1970, Sobre el Piso "Patagoniano" y la representación de la época del Oligoceno en Patagonia Austral (República Argentina): Revista de la Asociación Geológica Argentina, 25 (4), 495-501.

Bertels, A., 1977, Estratigrafía y micropaleontología de la Formación San Julián en su área tipo, provincia de Santa Cruz, República Argentina: Ameghiniana, 14, 233-293.

Bertels, A., 1980, Estratigrafía y foraminíferos (Protozoa) bentónicos de la Formación Monte León (Oligoceno) en su área tipo, provincia de Santa Cruz, República Argentina: Actas $2^{\circ}$ Congreso de Paleontología y Bioestratgrafía y 1er Congreso Latinoamericano de Paleontología, 2, 213-273.

Best, M.M.R., Kidwell, S.M., 2000a, Bivalve taphonomy in tropical mixed siliciclasticcarbonate settings. II. Effect of bivalve life habits and shell types: Paleobiology, 26 (1), 103-115. 
Best, M.M.R., Kidwell, S.M., 2000b, Bivalve taphonomy in tropical mixed siliciclasticcarbonate settings. I. Environmental variation in shell condition: Paleobiology, 26 (1), 80-102.

Beu, A.G., Maxwell, P.A., 1990, Cenozoic Mollusca of New Zealand: New Zealand Geological Survey Paleontological Bulletin, 58, 518 p.

Bianucci, G., Di Celma, C., Landino, W., Buckridge, J., 2006, Palaeoecology and taphonomy of an extraordinary whale barnacle accumulation from the Plio-Pleistocene of Ecuador: Palaeogeography, Palaeoclimatology, Palaeoecology, 242, 326-342.

Bingham, B.L., 1992, Life histories in an epifaunal community: coupling of adult and larval processes: Ecology, 73 (6), 2244-2259.

Boekschoten, G.J., 1970, On bryozoan borings from the Danian at the Fakse, Denmark: Geological Journal, Special Issue 3, 43-48.

Borg, F., 1940, On the genus Tubiporella and a new boring bryozoan: Zoologiska Bidrag från Uppsala, 18, 415-438.

Borowski, G.H., 1781, Gemeinnüzzige Naturgeschichte des Thierreichs, darin die merkwürdigsten und nüzlichsten: Thiere in systematischer Ordnung beschrieben, und alle Geschlechter in Abbildungen nach der Natur vorgestellet werden. Zweiter Band, Wallfische und Vögel. Mit 48 Kupfertafeln: Berlin, Stralsund, 1-196.

Bosc, L.A.G., 1802, Histoire naturelle des vers, contenant leur description et leurs moerus; avec figures dessinées d'après nature: Paris, L'Imprimerie de Guillemient, 324 p.

Botelho de Souza, J.R., Oliveira Bonifácio, P.H.,de Assis, J.E., 2017, Infestation of Crassostrea cf. brasiliana by boring-polychaetes polydorids in estuaries from Notheastern Brazil: Journal of Environmental Analysis and Progress, 2(1), 16-22.

Boucot, A. J.,1981, Principles of Benthic Marine Paleoecology: New York, Academic Press, $463 \mathrm{p}$.

Bown, T.M., Fleagle, J.G., 1993, Systematics, biostratigraphy, and dental evolution of the Palaeothentidae, later Oligocene to early-middle Miocene (Deseadan-Santacrucian) caenolestoid marsupials of South America: The Paleontological Society Memoir, 29, 1-76.

Breton, G., 2011, Le gault du perthois: terriers, phosphates et petites crottes: Bulletin de I'Association Geologique Auboise, 31, 3-66.

Brett, C.E.; Baird, G.C., 1986. Comparative Taphonomy: A key to Paleoenvironmental Interpretation based on fossil preservation: Palaios, 1(3), 207-227.

Brezina, S.S., Romero, M.V., Casadío, S., Bremec, C., 2014, Boring polychaetes associated with Pycnodonte (Phygraea) vesicularis (Lamarck) from the Upper Cretaceous of Patagonia. A case of commensalism?: Ameghiniana, 51(2), 129-140. 
Brocchi G.B., 1814, Conchiologia fossile subapennina con osservazioni geologiche sugli Apennini e sul suolo adiacente: Milano Stamperia reale, vol. 1, 1-240 p., vol. 2, 241-712 p.

Bromley, R.G., 1978, Bioerosion of Bermuda Reefs: Palaeogeography, Palaeoclimatology, Palaeoecology 23, 169-197.

Bromley, R.G., 1981, Concepts in ichnotaxonomy illustrated by small round holes in shells: Acta Geológica Hispánica, 16 (1-2), 55-64.

Bromley, R.G., 1993, Predation habits of octopus past and present and a new ichnospecies, Oichnus ovalis: Bulletin of the Geological Society of Denmark, 40, 167-173.

Bromley, R.G., 2004, A stratigraphy of marine bioerosión, in: Mcllroy, D. (ed.), The application of Ichnology to Palaeoenvironmental and Stratigraphic Analysis: Geological Society of London, Special Publications, 228, 455-479.

Bromley, R.G., Asgaard, U., 1993, Two bioerosion ichnofacies produced by early and late burial associated with sea-level change: Geologische Rundschau, 82, 276-280.

Bromley, R.G., D'Alessandro, A., 1983, Bioerosion in the Pleistocene of southern Italy. Ichnogenera Caulostrepsis and Maeandropolydora: Rivista Italiana di Paleontologia e Stratigrafia, 89 (2), 283-309.

Bromley, R.G., D'Alessandro, A., 1984, The Ichnogenus Entobia from the Miocene, Pliocene and Pleistocene of Southern Italy: Rivista Italiana di Paleontologia e Stratigrafia, 90 (2), 227-296.

Bromley, R.G., Ekdale, A.A., 1986, Composite ichnofabrics and tiering of burrows: Geological magazine, 123, 59-65.

Bromley, R.G., Surlyk, F., 1973, Borings produced by brachiopod pedicles, fossil and Recent: Lethaia, 6, 349-365.

Bromley R.G., Wisshak, M., Glaub, I., Botquelen, A., 2007, Ichnotaxonomic review of Dendriniform borings attributed to Foraminiferans: Semidendrina igen. nov., in: Miller III, W. (ed.), Trace Fossils: Concepts, Problems, Prospects: Amsterdam, Elsevier, 518-530 p.

Brongniart, M.A., 1823, Observations sur les fucoides, et sur quelques autres plantes marines fossiles: Mémoires de la Sociétè d'histoire naturelle de Paris, 1, 301-321.

Bronn, H.G., 1837-38, Lethaea geognostica 2: Stuttgart Das Kreide und Molassen-Gebirge, 545-1350.

Bruguière J. G., 1791, Tableau Encyclopédique et Méthodique des trois Règnes de la Nature : vers, coquilles, mollusques et polypes divers: París, Panckoucke, [Lingula p. 151 e, pl. 250, fig. 1a-c]. 
Buatois, L.A., Mángano, M.G., Olea, R.A., Wilson, M.A., 2016, Decoupled evolution of soft and hard substrate communities during the Cambrian Explosion and Great Ordovician Biodiversification Event: Proceedings of the National Academy of Sciences of the United States of America, 113 (25), 6945-6948.

Buatois, L.A., Wisshak, M., Wilson, M.A., Mángano, M.G., 2017, Categories of architectural designs in trace fossils: A measure of ichnodisparity: Earth-Science Reviews, 164, 102-181.

Buckeridge J.S., Lee D.E., Robinson J.H., 2014, A diverse shallow-water barnacle assemblage (Cirripedia: Sessilia) from the Oligocene of Southland, New Zealand: New Zealand Journal of Geology and Geophysics, 57 (2), 253-263, DOI: $10.1080 / 00288306.2013 .873472$

Canfield, D. C., Raiswell, R., 1991, Carbonate precipitation and dissolution; its relevance to fossil preservation, in Allison, P.A., Briggs D. E. G., (eds.), Taphonomy: Releasing the data locked in the fossil record: New York, Plenum Press, 412-455.

Caramés, A., Malumián, N., Náñez, C., 2004, Foraminíferos del Paleógeno del Pozo Península de Valdés (PV.es-1), Patagonia septentrional, Argentina: Ameghiniana, 41 (3), 461-474.

Carmona, N.B., Mángano, M.G., Buatois, L.A., Ponce, J.J., 2007, Bivalve trace fossils in an early Miocene discontinuity surface in Patagonia, Argentina: Burrowing behaviour and implications for ichnotaxonomy at the firmground-hardground divide: Palaeogeography, Palaeoclimatology, Palaeoecology, 255, 329-341.

Casadío, S., Parras, A., Griffin, M., Marenssi, S., 2007, Borers and encrusters as indicators of the presence of hermit crabs in Antarctic Eocene gastropods shells: Antartic Science, 19(3), 297-309.

Chave, K. E., 1964., Skeletal durability and preservation in Imbrie, J.; Newell, N.D. (eds.), Approaches to paleoecology: New-York, Wiley, 377-387.

Cherns, L., Wheeey, J.R., Wright, P.V., 2011, Taphonomic bias in shelly faunas through time: Early Aragonitic Dissolution and its implications for the fossil record, in Allison, P.A., Bottjer, D.J. (eds.), Taphonomy, Second Edition: Process and bias throuh time: Heildelberg, Topics in Gebiology, 32 Springer, 79-105.

Chiesa, J.O., Camacho, H.H., 1995, Litoestratigrafía del Terciario marino en el noroeste de la Provincia de Santa Cruz, Argentina: Monografías de la Academia Nacional de Ciencias Exactas, Físicas y Naturales, 11, 9-15.

Clarke, J.M., 1908, The beginnings of dependent life: New York State Museum Bulletin, 121, 146-196, pl. 13.

Clarke J.M., 1921, Organic dependence and disease, their origin and significance: New York State Museum Bulletin, 221-222: 1-113. 
Cortez-Lucero, G., 2013, Ecología, biología y pesquería de la almeja de sifón Panopea globosa en la región central del Golfo de California: Baja California, México, Centro de investigaciones biológicas del noroeste, Tesis doctoral, $119 \mathrm{p}$.

Cuitiño, J.I., Scasso, R.A., 2010, Sedimentología y paleoambientes del Patagoniano y su transición a la Formación Santa Cruz al sur del Lago Argentino, Patagonia austral: Revista de la Asociación Geológica Argentina, 66 (3): 406-417.

Cuitiño, J.I., Scasso, R.A., 2015, Sr Ages for the Chenque Formation in the Comodoro Rivadavia Region (Golfo San Jorge Basin, Argentina): Stratigraphic implications: Latin America Journal of Sedimentology and Basin Analysis, 22 (1), 3-12.

Cuitiño, J.I., Pimentel, M.M., Ventura Santos, R., Scasso, R.A., 2012, High resolution isotopic ages for the early Miocene "Patagoniense" transgression in Southwest Patagonia: Stratigraphic implications: Journal of South American Earth Sciences, 38, 110-122.

Cutler, A. H., 1987, Surface textures of shells as taphonomic indicators, in Flessa K.W., (ed.), Paleoecology and taphonomy of recent to Pleistocene intertidal deposits, Gulf of California: Paleontological Society Special Publication 2, 164-176.

Da Costa, M.E., 1778, Historia naturalis testaceorum Britanniæ, or, the British conchology; containing the descriptions and other particulars of natural history of the shells of Great Britain and Ireland: illustrated with figures. In English and French: London, Millan, White, Emsley \& Robson, 1-254, i-vii, pl. I-XVII.

Da Vinci, L., 1508-1510, Codex Leicester/Hammer/ Bill Gates Colección particular, 72 pp.

Dall, W.H.,1870, A revision of the Terebratulidae and Lingulidae, with remarks on and descriptions of some recent forms: American Journal of Conchology, 6 (2), 88-168, pl. 6-8.

Dall, W.H., 1898, Contributions to the Tertiary fauna of Florida: Transactions of the Wagner Free Institute of Science of Philadelphia, 3 (4), 571-947.

Darwin, C., 1846, Geological observations on South America en The third part of the geology of the voyage of the Beagle under the command of Captain Fitzroy, R.N, during the years 1832 to 1836: London, Smith Elder and Co.

Darwin, C.R., 1859, On the origin of species: New York, D. Appleton and company, 440 pp.

Davies, D.J., Powell, E.N., Stanton Jr., R.J., 1989, Taphonomic signature as function of environmental process: shells and shell beds in a hurricane-influenced inlet on the texas coast: Palaeogeography, Palaeoclimatology, Palaeoecology, 72, 317-356.

De La Beche, H.T., 1846, On the formation of the rocks of the South Wales and South Western England: Memoirs of the Geological Survey of Great Britain and of the Museum of Economic Geology in London, 1, 1-296. 
Del Río, C.J., 1997, Cenozoic biogegraphic history of the eurythermal genus Retrotpes, new genus (Subfamily Tapetinae) from Southern South America and Antartica: The Nautilus, 110 (3), 77-93.

Del Río, C.J., 2002, Moluscos del Terciario marino, en: Haller, M.J. (ed.) Geología y Recursos Naturales de Santa Cruz: Relatorio XV Congreso Geológico Argentino, II-9, 1-22.

Del Río, C.J., 2004, Tertiary marine Molluscan Assemblages of Eastern Patagonia (Argentina): a biostratigraphic analysis: Journal of Paleontology, 78 (6), 1097-1122.

Deshayes G.P., 1839, Nouvelles espèces de mollusques, provenant des côtes de la Californie, du Mexique, du Kamtschatka et de la Nouvelle-Zélande: Revue Zoologique par la Société Cuvierienne, 2 (12), 356-361.

Di Martino, E., Taylor, P.D., Kudryavtsev, A.B., Schopf, L.W., 2016, Calcitization of aragonitic bryozoans in Cenozoic tropical carbonates from East Kalimantan, Indonesia: Facies, 62, 11 DOI: 10.1007/s10347-016-0462-z.

Di Paola, E.C, Marchesse, H.G., 1973, Litoestratigrafía de la Formación Patagonia en el área tipo (Bajo de San Julián-desembocadura del Río Santa Cruz), Provincia de Santa Cruz, República Argentina: Actas 5to Congreso Geológico Argentino, 3, 207-222.

Dix, G., Parras, A., 2014, Integrated diagenetic and sequence stratigraphy of a late Oligocene-early Miocene, mixed-sediment platform (Austral Basin, southern Patagonia): Resolving base-level and paleoceanographic changes, and paleoaquifer characteristics: Sedimentary Geology, 307, 17-33.

Doherty, P.J., 1979, A demographic study of a subtotal population of the New Zealand articulate brachiopod Terebratella inconspicua: Marine Biology, 52, 331-342.

d'Orbigny, A., 1842, Voyage dans l'Amerique méridionale (le Brésil, la République Orientale de l'Uruguay, la République Argentine, la Patagonie, la République du Chili, la République de Bolivia, la République du Pérou, exécuté pendant les années 1826, 1827, 1829, 1830, 1831, 1832 et 1833: París, Libraire de la Société géologique de France, 270 pp.

d'Orbigny, A., 1847, Voyage dans l'Amérique Méridionale (le Brésil, la République Orientale de I'Uruguay, la République Argentine, la Patagonie, la République du Chili, la République du Bolivia, la République du Perou), exécuté pendant les années 1826,1827,1828,1829, 1830,1831, 1832 et 1833: P. Bertrand. Paris, V. Levrault, Strasbourg, vol 4.

Domènech, R., Gibert, J.M., Martinell, J., 2001, Ichnological features of a marine transgression: middle Miocene rocky shores of Tarragona, Spain: Geobios 34 (1), 99-107.

Donovan, S.K., 1988, Palaeoecology and taphonomy of barnacles from the Plio-Pleistocene Red Crag of East Anglia: Proceedings of the Geologists' Association, 99, 279-289.

Dornellas, A.P.S., Simone, L.R.L., 2015, New morphological data on Sollariella obscura (Trochoidea: Solariellidae) from New Jersey, USA: Zoologia, 32 (2), 162-170. 
Doyle P., Mather A.E., Bennett M.R., Bussell M.A., 1997, Miocene barnacle assemblages from southern Spain and their palaeoenvironmental significance: Lethaia, 29, 267-274.

Driscoll, E.G., 1967, Experimental field study of shell abrasion: Journal of Sedimentary Petrology, 37 (4), 1117-1123.

Driscoll, E.G., Weltin, T.P., 1973, Sedimentary parameters as factors in abrasive shell reduction: Palaeogeography, Palaeoclimatology, Palaeoecology, 13 (1), 275-288.

Duke, W.L., 1985, Hummocky cross-stratification, tropical hurricanes, and intense winter storms: Sedimentology, 32 (2), 167-94.

Dunham, R.J., 1962, Classification of carbonate rocks according to depositional texture: Mem American Association of Petroleum, 40, 898-905.

Dyson, I.A., 1995, A review of storm deposits in the geological record: PESA Journal, 23, 39-50.

Efremov, J.A., 1940, Taphonomy: New branch of Paleontology: Pan-American Geologist,74 (2), 81-93.

Elias M.K., 1957, Late Mississippian fauna from the Redoak Hollow Formation of southern Oklahoma, part I: Journal of Paleontology 31, 370-427.

Elias R.J., 1980, Borings in solitary rugose corals of the Selkirk Member, Red River Formation (late Middle or Upper Ordovician), southern Manitoba: Canadian Journal of Earth Sciences, 17, 272-277.

Emery, K. O., 1963, Organic transportation of marine sediments, in: Hill, M., Wiley, N. (eds.), The sea: New York, 776-793.

Färber, C., Titschack, J., Schönberg, C.H.L., Ehrig, K., Boos, K., Baum. D., Illerhaus, B., Asgaard, U., Bromley, R.G., Freiwald, A., Wisshak, M., 2016, Long-term macrobioerosion in the Mediterranean Sea assessed by micro-computed tomography: Biogeosciences, 13, 3461-3474.

Fagerstrom, J.A.; 1964, Fossil communities in paleoecology: their recognition and significance: Bulletin of the Geological Society of America, 75 (12), 1197-1216.

Fenton C.L., Fenton M.A., 1932, Boring sponges in the Devonian of lowa: American Midland Naturalist, 13, 42-54.

Fernández-López, S., 1988, La Tafonomía: un subsistema conceptual de la Paleontología: Coloquios de Paleontología, Universidad Complutense de Madrid, 41, 9-34. 
Fernández-López, S., 1990. El significado de la autoctonía/aloctonía tafonómica, en Fernández López, S. (Coord.), Comunicaciones de la Reunión de Tafonomía y Fosilización. Departamento de Paleontología, Universidad Complutense de Madrid, 115-124.

Fernández-López, S., 1991, Taphonomic concepts for a theoretical Biochronology: Revista Española de Paleontología, 6 (1), 37-49.

Fernández-López, S., 2000, Temas de Tafonomía: Departamento de Paleontología, Universidad Complutense de Madrid. 167 pp.

Férussac, A.E., d'Audebard de Baron de, 1822, Tableaux systématiques des animaux mollusques classés en familles naturelles, dans lesquels on a établi la concordance de tous les systèmes; suivis d'un prodrome général pour tous les mollusques terrestres ou fluviatiles, vivants ou fossils: París, A. Bertrand, $110 \mathrm{p}$.

Feruglio, E., 1949, Descripción Geológica de la Patagonia: Dirección General de Yacimientos Petrolíferos Fiscales. Ministerio de Industria y Comercio de la República Argentina, 1, 1-334.

Fischer, M.P., 1868, Recherches sur les éponges perforantes fossiles: Nouvelles Archives du Muséum d'Histoire Naturelle de Paris, 4, 117-173.

Fischer M.P., 1875, D’un type de sarcodaires: Journal de Zoologie, 4, 530-533.

Fleagle, J.G., Bown, T.M., Swisher, C., Buckley, G., 1995, Age of the Pinturas and Santa Cruz Formations: Actas $6^{\circ}$ Congreso Argentino de Paleontología y Bioestratigrafía, 129-135.

Flessa, K.W.; Brown, T.J., 1983, Selective solution of macro invertebrate calcareous hard parts: a laboratory study: Lethaia, 16 (2), 193-205.

Frey, R.W., 1973, Concepts in the study of biogenic sedimentary structures: Journal of Sedimentary Petrology, 43 (1), 6-19.

Fürsich, F.T., 1995, Shell concentrations: Eclogae Geologicae Helvetiae, 88 (3), 643-655.

Fürsich, F.T., Oschmann, W., 1993, Shell beds as tools in basin analysis: the Jurassic of Kachchh, western India: Journal of the Geological Society of London, 150, 169-185.

Ghiglione, M.C, Quinteros, J., Yagupsky, D., Bonillo-Martínez, P., Hlebszevitch, J., Ramos, V.A., Vergani, G., Figueroa, D., Quesada, S., Zapata, T., 2010, Structure and tectonic history of the foreland basins of southernmost South America: Journal of South American Earth Sciences, 29, 262-277.

Giacobbe, S., Mondello, G.P., 1994, Turritella thanatofacies in the terrigenous mud biocoenosis (VTC) in southern Tyrrhenian Sea, in: Matteuci, R.; Carboni, M.; Pignatti, J.S. (eds.), Studies on ecology and palaeoecology of benthic communities: Modène, Mucchi, 141-151. 
Gibert, J.M. de, Domènech, R., and Martinell, J., 2007, Bioerosion in shell beds from the Pliocene Roussillon Basin, France: Implications for the (macro)bioerosion ichnofacies model: Acta Palaeontologica Polonica, 52 (4), 783-798.

Goette A., 1916, Die Gattungen Podocoryne, Stylactis und Hydractinia: Zoologische Jahrbücher, 39, 443-510.

González-Ortiz, L., Hernández-Alcántara, P., Vázquez-Juárez, R., Quiróz-Guzmán, E., García-Garza, M.E., León-González, J.A., 2017, Variación espacial y temporal de la infestación de la concha por Polydora sp.(Spionidae: Polychaeta) sobre la almeja mano de león (Nodipecten subnodosus) en la laguna Ojo de Liebre, Baja California Sur: Revista Mexicana de Biodiversidad, 88, 845-852.

Goodwin, C.L., Pease, B.C., 1991, Geoduck, Panopea abrupta (Conrad, 1849), size, density and quality as related to various environmental parameters in Puget Sound, Washington: Journal of Shellfish Research, 10, 65-77.

Goldring, R., Bridges, P.,1973, Sub-littoral sheet sandstones: Journal of Sedimentary Petrology, 43 (3), 736-747.

Gómez-García, D.E., 2005, Estudio de sedimentos superficiales en el sistema lagunas del Guaymas, Sonora: México, Instituto Tecnológico del Mar, Tesis de Licenciatura, 84 p.

Gordillo, S., 2006, Pleistoncene Retrotapes Del Río, 1997 (Veneridae, Bivalvia) from Tierra del Fuego: Ameghiniana, 43 (4), 757-761.

Grant R.E., 1826, Observations on the Nature and importance of Geology: The Edinburgh new philosophical journal,14, 270-84.

Gribben, P.E., 2003, Demography and life history characteristics of the New Zealand geoduck, Panopea zelandica: Auckland, University of Auckland, PhD. thesis, $182 \mathrm{p}$.

Griffin, M., Nielsen, S.N., 2008, A revision of the type specimens of Tertiary molluscs from Chile and Argentina described by d'Orbigny (1842), Sowerby (1846) and Hupé (1854): Journal of Systematic Palaeontology, 6 (3), 251-316.

Griffin, M., Pastorino, G., 2012, Microbivalves from the Monte León Formation (Early Miocene), Patagonia, Argentina: Revue de Paléobiologie, Genève, volume spécial, 11, 447-455.

Gripp, K., 1967, Polydora biforans n. sp. in Belemniten-Rostren bohrender Wurm der Kreidezeit: Meyniana, 17, 8-10.

Hamblin, A.P., Walker, R.G., 1979, Storm dominated shallow marine deposits: the FernieKootenay (Jurassic) transition, southern Rocky Mountains: Canadian Journal of Earth Sciences, 16 (9),1673-1690. 
Hancock, A., 1849, On the excavating powers of certain sponges belonging to the genus Cliona with descriptions of several new species, and an allied generic form: Annals and Magazine of Natural History, Series 2 (3), 321-348.

Hanken, N.-M., Uchman, A., Jakobsen, S.L., 2012, Late Pleistocene-Early Holocene polychaete borings in NE Spitsbergen and their paleoecological and climatic implications: an example from the Basissletta area: Boreas, 41, 42-55.

Hatcher, J.B., 1897, On the Geology of Southern Patagonia: American Journal Science, 4 (23), 321-354.

Hatcher, J.B., 1900, Sedimentary rocks of Southern Patagonia: American Journal Science, 9 (50), 85-108.

Hayward, B.W., 1976, Macropaleontology and paleoecology of the Waitakere Group, (lower Miocene) Waitakere Hills, Auckland: Tane, 22, 177-206.

Hutchings, P.A., 1986, Biological destruction of coral reefs, a review: Coral Reefs, 4, 239-252.

Ihering, $\mathrm{H}$. von, 1897, Os molluscos dos terrenos terciarios da Patagonia: Revista do Museu Paulista, II, 217-382.

Ihering, H. von, 1907, Les mollusques fossiles du Tertiare et du Crétacé supérieur de l'Argentine: Anales del Museo Nacional de Buenos Aires, 14 (3), 1-611.

James, M.A., Ansell, A.D., Collins, M.J., Curry, G.B., Peck, L.S., Rhodes, M.C., 1992, Biology of living brachiopods: Advances in Marine Biology, 28, 175-387.

Johnson, R.G., 1960, Models and methods for analysis of the mode of formation of fossil assemblages: Geological Society of America Bulletin, 71, 1075-1086.

Johnson M.E., Baarli, B.G., Santos, A., Mayoral E., 2011, Ichnofacies and microbial buildups on Late Miocene rocky shores from Menorca (Balearic Islands), Spain: Facies, 57, 255-265.

Kelling, G.; Mulling, P.R., 1975, Graded limestones and limestone-quartzite couplets: possible storm-deposits from the Morrocan Carboniferous: Sedimentary Geology, 13, 161-190.

Kelley, P.H., 1988, Predation by Miocene gastropods of the Chesapeake Group stereotype and predictable: Palaios, 3, 436-448.

Kelley, P.H., Hansen, T.A., 1996, Naticid gastropod prey selectivity through time and the hypothesis of escalation: Geology, 437-445. 
Kennedy, J.J., 1995, The courtship, pseudocopulation behaviour and spermatophore of Turritella communis Risso, 1826 (Prosobranchia, Turritellidae): Journal of Molluscan Studies, $61,421-434$.

Khalifa, G.M., Weiner, S., Addadi, L., 2011, Mineral and matrix components of the operculum and shell of the Barnacle Balanus amphirite: Calcite crystal growth in a hydrogel: Crystal: Growth and Design, 11, 5122-5130.

Kidwell, S.M., 1985, Palaeobiological and sedimentological implications of fossil concentrations: Nature, 318, 457-460.

Kidwell, S.M., 1986, Models for Fossil Concentrations: Paleobiologic Implications: Paleobiology, 12 (1), 6-24.

Kidwell, S.M., 1991, The Stratigraphy of Shell concentrations, in: Allison, P.A., Briggs, D.E.G., Taphonomy: Releasing the data locked in the fossil record: New York, Topics in Geobiology, 9, 211-290.

Kidwell, S.M.; Jablonski, D., 1983, Taphonomic feedback: Ecological consequences of shell accumulation, in: Tevez, M.J.S., McCall, P.L. (eds.), Biotic interactions in the Recent and fossil benthic communities: New York, Topics in Geobiology 3, 195-248.

Kidwell, S.M., Fürsich, F.T., Aigner, T., 1986, Conceptual Framework for the Analysis and Classification of Fossil Concentrations: Palaios, 1 (3), 228-238.

Kidwell, S.M., Holland, S.M., 1991, Field description of coarse bioplastic fabrics: Palaios, 6 (4), 426-434.

Killian, C.E., Wilt, F.H., 2008, Molecular aspects of biomineralization of the echinoderm endoskeleton: Chemical Reviews, 108, 4463-4474.

Kitchell, J.A., Boggs, C.H., Kitchell, J.F., Rice, J.A., 1981, Prey selection by naticid gastropods: Experimental tests and application to the fossil record: Paleobiology, 7, 533-552.

Kondo, Y., 1987, Burrowing depth of infaunal bivalves-observation of living species and its relation to shell morphology: Transactions and Proceedings of the Palaeontological Society of Japan, 148, 306-323.

Kowalewski, M., 1999, Actuopaleontology: The strength of its limitations: Acta Palaeontologica Polonica, 44 (4), 452-454.

Kowalewski, M., 2002, The fossil record of predation: an overview of analytical methods: Paleontological Society Papers, 8, 3-42.

Kuenen, P. H., 1964, Experimental abrasion: 6. surf action: Sedimentology, 3, 29-43. 
Lamouroux, J.V.F.,1812, Sur la classification des Polypiers coralligènes non entièrement pierreux:Nouveau Bulletin des Sciences, 3, 181-188.

Lawrence, D.R., 1968, Taphonomy and information losses in fossil communities: Geological Society of America Bulletin, 79 (10),1315-1330.

Leckie, D.A., Krystinik, L.F., 1989, Is there evidence for geostrophic currents in the sedimentary record of inner to middle-shelf deposits?: Journal of Sedimentary Petrology, 59 (5), 862-870.

Lindström M., 1979, Probable sponge borings in Lower Ordovician limestone of Sweden: Geology 7, 152-155.

Linnaeus, C., 1758, Systema Naturae per regna tria naturae, secundum classes, ordines, genera, species, cum characteribus, differentiis, synonymis, locis. Editio decima, reformata: Holmiae, Laurentius Salvius, vol. 1, 824 p.

Linnaeus, C., 1767, Systema naturae per regna tria naturae: secundum classes, ordines, genera, species, cum characteribus, differentiis, synonymis, locis. Editio. 12. 1., Regnum Animale. 1 \& 2. Holmiae, Laurentii Salvii. Holmiae, Laurentii Salvius. pp. 1-532 [1766] pp. 533-1327 [1767].

Liow, L.H., Di Martino, E., Voje, K.L., Rust, S., Taylor, P.D., 2016, Interspecific interactions through 2 million years: are competitive outcomes predictable?: Proceedings of Royal Society B, 283 (1837), 20160981.

Luci, L., Lazo, D.G., 2015, Living on an island: characterization of the encrusting fauna of large pectinid bivalves from the Lower Cretaceous of the Neuquén Basin, west-central Argentina: Lethaia 48(2), 205-226.

Lyell, C., 1837, Principles of Geology being an inquiry how far the former changes of the earth's surface are referable to causes now in operation, vol. 2: London, John Murray, 442 p.

Mägdefrau K., 1937, Lebensspuren fossiler "Bohr"-Organismen: Beiträge zur naturkundlichen Forschung in Südwestdeutschland, 2, 54-67.

Malumián N., 2002, El Terciario Marino, sus relaciones con el eustatismo, in Haller M.J. (ed.) Geología y Recursos Naturales de Santa Cruz: Relatorio XV Congreso Geológico Argentino I-15, 237-244.

Malumián, N., Masiuk, V., Riggi, J.C., 1971, Micropaleontología y sedimentología de la perforación SC-1, provincia de Santa Cruz, República Argentina. Su importancia y correlaciones: Revista de la Asociación Geológica Argentina, 26 (2), 175-208.

Malumián, N., Nañez, C., 1989, Asociaciones de foraminíferos del Terciario medio de cuenca Austral: sus relaciones con eventos eustáticos globales: Revista de la Asociación Geológica Argentina, 43 (2), 257-264. 
Malumián, N., Náñez, C., 1998, El género Transversigerina y la edad de la Transgresión Patagonia: Actas $10^{\circ}$ Congreso Latinoamericano de Geología y $6^{\circ}$ Congreso Nacional de Geología Económica, Buenos Aires, 1-285-290.

Malumián, N., Náñez, C., 2002, Los foraminíferos de la Provincia de Santa Cruz: Su significado geológico y paleoambiental en Haller, M.J. (ed.), Geología y Recursos Naturales de Santa Cruz: Relatorio $15^{\circ}$ Congreso Geológico Argetino, El Calafate 2, 481-493.

Malumián, N.; Náñez, C., 2011, The Late Cretaceous-Cenozoic transgression in Patagonia and the Fueguian Andes: foraminifera, palaeoecology and paleogeography: Biological Journal of the Linnaean Society, 103, 269-288.

Mángano, M.G.; Buatois, L.A., 2016, The trace-fossil record of major evolutionary events. Volume 1: Precambrian and Palezoic: Berlin, Topics in Geobiology 39, Springer, 358 p.

Märkel, K., 1966, Über funktionelle Radulatypen bei Gastropoden, unter besonderer Berücksichtigung der Rhipidoglossa: Vie Milieu, 17, 1121.

Mayoral, E., 1987, Acción Bioerosiva de Mollusca (Gastropoda, Bivalvia) en el Plioceno Inferior de la Cuenca del Bajo Guadalquivir: Revista Española de Paleontología, 2, 49-58.

Mayoral, E., 1988. Pennatichnus nov. icnogen.; Pinaceocladichnus nov. icnogen. e Iramena. Huellas de Bioerosión debidas a bryozoa perforantes (Ctenostomata, Plioceno Inferior) en la cuenca del Bajo Guadalquivir: Revista Española de Paleontología 3, 13-22.

Mayoral, E., 1991, Caulostrepsis contorta Bromley \& D'Alessandro. Nuevas aportaciones al estudio de los fenómenos bioerosivos en el Plioceno del Bajo Guadalquivir: Revista Española de Paleontología, Número Extraordinario: El estudio de la Forma Orgánica y sus consecuencias en Paleontología Sistemática, Paleoecología y Paleontología Evolutiva, 53-60.

Mayoral, E., Reguant, S., 1995, Palaeoecology and taphonomy of bivalves, mainly Glycimeris insubrica (Brocchi), and bryozoans from the Huelva Sands Fm. (lower Pliocene, SW Spain): Revista Española de Paleontología, No. Homenaje al Dr. Guillermo Colom, 3147.

McKnight, D.G., 1969, Infaunal benthic communities of the New Zealand continental shelf: New Zealand Journal of Marine and Freshwater Research, 3 (3), 409-444.

McKinney, F.K., Jackson, J.B.C., 1989, Bryozoan Evolution: Boston, Unwin Hyman, 238 pp.

Mercerat, A., 1893a, Un viaje de exploración en la Patagonia Austral: Boletín Instituto Geográfico Argentino, 14, 267-291.

Mercerat, A., 1893b, Contribución a la Geología de la Patagonia: Anales Sociedad Geológica Argentina, 36, 65-103. 
Mercerat, A., 1896, Essai de classification des terrains sédimentaires du versant oriental de la Patagonie australe: Anales Museo Nacional de Buenos Aires, 2 (2), 105-130.

Merriam, C.W., 1941, Fossil turritellas from the Pacific coast region of North America: Bulletin of University of California publications in Geological Sciences, 26, 1-214.

Montfort Denys de, P., 1810, Conchyliologie systématique et classification méthodique des coquilles, T. 2: Paris F. Schoell, T.2, 676 p.

Mörch, O.A.L., 1853, Catalogus conchyliorum quæ reliquit D. Alphonso d'Aguirra \& Gadea Comes de Yoldi : regis daniæ cubiculariorum princeps, ordinis dannebrogici in prima classe \& ordinis caroli tertii eques. Fasciculus secundus, Acephala, Annulata Cirripedia, Echinodermata, fasc. 2: Hafniæ, Typ. L. Kleinii, 74 p.

Müller, A.H., 1979, Fossilization (Taphonomy), in Robinson, R.A.; Teichert, C. (eds.) Treatise on Invertebrate Paleontology, Part A, Fossilization (Taphonomy) Biogeography and Biostratigraphy: Geological Society of America and Kansas University Press, A2-A78.

Náñez, C., Quattrocchio, M.E., Ruiz, L., 2009, Palinología y micropaleotología de las Formaciones San Julián y Monte León (Oligoceno-Mioceno temprano) en el subsuelo de cabo Curioso, provincia de Santa Cruz: Ameghiniana, 46 (4), 669-693.

Nathorst, A.G., 1881, Om spår av nagra evertebrede djur och deras paleontologiska betydelse Kongl: Handlingar, Svenska Vetenskaps-Akademien, 18, 1-104.

Neumann, A.C., 1966, Observations on coastal erosion in Bermuda and measurements of the boring rate of the sponge Cliona lampa: Limnology and Oceanography 11, 92-108.

Nicastro, A.M., Bishop, M.J., Kelaher, P., Benedetti-Cecchi, L., 2009, Export of nonnative gastropods to a coastal lagoon: Alteration of habitat structure has a negligible effect on infauna: Journal of Experimental Marine Biology and Ecology, 374, 31-36

Nielsen J.K., Funder, S., 2003, Taphonomy of Eemian marine molluscs and acorn barnacles from eastern Arkhangelsk region, northern Russia: Palaeogeography, Palaeoclimatology, Palaeoecology, 191,139-168.

Nielsen, K.S.S., Nielsen, J.K., 2001, Bioerosion in Pliocene to late Holocene tests of benthic and planktonic foraminiferans, with a revision of the ichnogenera Oichnus and Tremichnus. Ichnos: An International Journal for Plant and Animal Traces, 8 (2), 99-116.

Niemeyer, H., Skármeta, J., Fuenzalida, R., Espinosa, W., 1984, Hojas Península de Taitao y Puerto Aysén: Servicio Nacional de Geología y Minería, Carta Geológica de Chile, Serie Geología Básica, 60-61, 80 p.

Oji, T., Ogaya, C., Sato, T., 2003, Increase of shell-crushing predation recorded in fossil shell fragmentation: Paleobiology, 29 (4), 520-526. 
Olivera, A.M., 1990, Aspectos paleoecológicos de asociaciones de moluscos fósiles de la Formación Monte León (Oligoceno), Puerto Santa Cruz (Santa Cruz): Actas I V Congreso Argetino de Paleontología y Biosestratigrafía, Tucumán, Serie Correlación Geológica, 7, 155-160.

Orensans, J.M., Hilborn, R., Parma, A.M., 2000, Harvesting Methuselah's clams is the geoduck fishery sustainable, or just apparently so?: Canadian Stock, Assessment Secretariat, Reseach document, 175, 68 p.

Ortmann, A. E., 1897, On some of the large oysters of Patagonia: American Journal of Science, 4, 355-356.

Osman, R.W., 1977, The establishment and development of a marine epifaunal community: Ecological Monographs, 47, 37-63.

Palmer T.J., Palmer C.D., 1977, Faunal distribution and colonization strategy in a Middle Ordovician hardground community: Lethaia 10, 179-199.

Panza, J.L., Irigoyen, M.V, Genini, A., 1995, Hoja Geológica 4969-IV, Puerto San Julián, provincia de Santa Cruz, República Argentina: Boletín de la Secretaría de Minería de la Nación, Dirección Nacional del Servicio Geológico, 211, 1-77.

Parras, A., Casadío, S., 2006, The oyster Crassostrea? hatcheri (Ortmann, 1897), a physical ecosystem engineer from the Upper Oligocene-Lower Miocene of Patagonia, Southern Argentina: Palaios 21 (2), 168-186.

Parras, A., Griffin, M., Feldmann, R., Casadío, S., Schweitzer, C., Marenssi, S., 2008, Correlation of marine beds based on Sr- and Ar-date determinations and faunal affinities across the Paleogene/Neogene Boundary in southern Patagonia, Argentina: Journal of South American Earth Sciences, 26, 2014-216.

Parras, A., Griffin, M., 2009, Darwin's Great Patagonian Tertiary Formation at the mouth of the Río Santa Cruz: A reappraisal: Revista de la Asociación Geológica Argentina, 64 (1), 70-82.

Parras, A., Dix, G.R., Griffin, M., 2012, Sr-isotope chronostratigraphy of PaleogeneNeogene marine deposits: Austral Basin, southern Patagonia (Argentina): Journal of South American Earth Sciences, 37, 122-135.

Parras, A., Cuitiño, J.I., 2018, The stratigraphic and paleoenvironmental significance of the regressive Monte Observación Member, Early Miocene of the Austral Basin, Patagonia. Latin American Journal of Sedimentology and Basin Analysis, 25 (2), 25-47.

Parsons, K.M., Brett, C.E., 1991, Taphonomic processes and biases, in: Donovan, S.K. (ed.), The process of fossilization: New York, Columbia University Press, 22-65. 
Patzkowsky, M.E., Holland, S.M., 2012, Stratigraphic Paleobiology: Understanding the distributions of fossil taxa in time and space: Chicago, The University of Chicago Press, 259 p.

Pérez, L.M, López-Gappa, J., Griffn, M., 2015, New and little-known bryozoans from Monte León Formation (early Miocene, Argentina) and their paleobiogeographic relationships: Journal of Paleontology, 89, 956-965

Pérez-Panera, J.P., 2012, Nanofósiles calcáreos y bioestratigrafía del Cretácico del sudeste de la Cuenca Austral, Patagonia, Argentina: Ameghiniana, 49 (2), 137-163.

Perkins, M.E., Fleagle, J.G., Heizler, M.T., Nash, B., Bown, T.M., Tauber, A.A., Dozo, M.T., 2012, Tephrochronology of the Miocene Santa Cruz and Pinturas Formations, Argentina, en: Vizcaíno, S.F., Kay, R.F., Bargo, M.S. (eds.), Early Miocene Paleobiology in Patagonia: highlatitude paleocommunities of the Santa Cruz Formation: Cambridge, Cambridge, UniversityPress, 23-40.

Peterson, C.H., 1976, Relative abundances of living and dead molluscs in two Californian lagoons: Lethaia, 9 (1), 137-148.

Pineda-Salgado, G., Quiroz-Barroso, S.A., Sour-Tovar, F., 2015, Analysis of bioerosion in clasts from a Miocene rocky-shore, Concepción Formation, Veracuz, México: Palaeogeography, Palaeoclimatology, Palaeoecology, 439, 50-62.

Pineda-Salgado, G., Parras, A., Griffin, M., 2018, Sclerobionts on biogenic substrates from the Monte León Formation (lower Miocene) in Santa Cruz Province, Argentina: Taphonomic and paleoenvironmental considerations: Palaeogeography, Palaeoclimatology, Palaeoecology, 511, 606-619.

Plewes C.R., 1996, Ichnotaxonomic Studies of Jurassic Endoliths: UK, University of Wales, Unpublished PhD Thesis.

Plewes C.R., Palmer T., Haynes J., 1993, A boring foraminiferan from the Upper Jurassic of England and Northern France: Journal of Micropalaeontology, 12, 83-89.

Pleydell, S.M.; and Jones, B., 1988, Boring of various faunal elements in the OligoceneMiocene Bluff Formation of Grand Cayman, British West Indies: Journal of Paleaontology, 62, 348- 367.

Pohowsky, R.A., 1978, The boring Ctenostomate Bryozoa taxonomy and paleobiology based on cavities in calcareous substrata: Bulletins of American Paleontology, 73, 1-192.

Portlock, J.E., 1843, Report on the geology of the county of Londonderry and parts of Tyrone and Fermanagh: Dublin and London Her Majesty's Stationery Office, 748 p., 37 pl.

Powell, A.W.B., 1950, Mollusca from the continental shelf, eastern Otago: Records of the Auckland Institute and Museum, 4, 73-81. 
Powell, E.N., Stanton Jr., R.J., Davies, D.J., Logan, A., 1986, Effect of a large larval settlement and catastrophic mortality on the ecologic record of the community in the death assemblage: Estuarine Coastal Shelf Science, 23, 513-525.

Quenstedt F.A., 1849, Petrefaktenkunde Deutschlands- Die Cephalopoden: Türbigen Ludwig Friedrich Fues.

Quoy, J.C.R., Gaimard, P., 1832-1835, Voyage de decouverts de I'Astrolabe, execute par ordre du Roi pendant les annees 1826-1827-1828-1829, sous le commandement de M.J. Dumont d'Urville. Mollusques: Zoologie, Tome 2, p. 1-320, 1832; p. 321-686, 1833; Tome 3, p. 1-366, 1834; p. 367-954, 1835].

Radwanski, A., 1977, Present-day types of traces in the Neogene sequence: their problems of nomenclature and preservation, in: Crimes, T.P.; Harper, J.C. (ed.), Trace fossils 2: London. Seel House Press, 227-164.

Richter, R., 1928, Aktuopaläontologie und Paläobiologie, eine Abgrenzung: Senckenbergiana, 10 (6), 285-292.

Riggi, J.C., 1978, La importancia de los sedimentos piroclásticos y de la sílice biogenética en la estratigrafía de la Formación Patagonia: Revista de la Asociación Geológica Argentina, 33 (2), 158-171.

Riggi, J.C. 1979, Nuevo esquema estratigráfico de la Formación Patagonia: Revista de la Asociación Geológica Argentina, 34 (1), 1-11.

Robinson, J.H., Lee, D.E., 2008, Brachiopod pedicle traces: recognition of three separate types of trace and redefinition of Podichnus centrifugalis Bromley \& Surlyk, 1973: Fossils and Strata 54, 219-225.

Rosselli, F.L., 1938, Apuntes de geología y paleontología uruguaya. Sobre insectos del Cretácico del Uruguay o descubrimiento de admirables instintos constructivos de esa época: Boletín de la Sociedad de Amigos de las Ciencias Naturales "Kraglievich-Fontana", 1, 72-102.

Rosso, A., 2008, Leptichnus tortus isp. nov., a new cheilostome etching and comments on other bryozoan-produced trace fossils. Studi Trentini di Scienze Naturali: Acta Geologica $83,75-85$.

Rovereto, G., 1899, Prime recherche sinonimiche sui generi dei gasteropodi: Atti della Società Linguistica di Scienze Naturali e Geografiche, 10,101-110.

Rovereto, G., 1921, Studi di Geomorfología Argentina: Bollettino della Società Geologica Italiana, 40 (1-2), 1-47.

Russo, A., Flores, M.A., 1972, Patagonia Austral Extra Andina, en Leanza, A.F. (ed.). Geología Regional Argetina: Academia Nacional de Ciencias en Córdoba, 70-725. 
Sacco, F.; 1889, II molluschi dei terreni terziarii del Piemonte e della Liguria, Stamperia Reale: Torino, pt. 27, 102 p.

Sacomani, L.E., Panza, J.L, 2011, Hojas Geológicas 5169-I y 5969-II Puerto Coig y Santa Cruz: Boletín del Instituto de Geología y Recursos Minerales, 393.

Saint-Seine, R., 1951, Un cirripède acrothoracique du Crétacé: Rogerella leconintrei nov. gen., nov. sp.: Comptes Rendus de l'Academie des Sciences, Paris, 233, 1051-1053.

Saller, A.H., 1992, Calcitization of aragonite in Pleistocene limestones in the Enewetal atoll, Bahamas and Yucatán-an alternative thin-film neomorphism: Carbonates and Evaporites, 7 (1), 56-73.

Santos, A., Mayoral, E., Muñíz, F., Boski, T., Cachão, M., 2003, Variaciones morfológicas en Maeandropolydora sulcans Voigt, 1965, del Neógeno Superior marino del extremo suroccidental de la península Ibérica, en: Buatois, L.A., Mángano, M.G. (eds.), Icnología: Hacia una convergencia entre Geología y Biología: Asociación Paleontológica Argentina, Publicación Especial 9, 177-184.

Santos, A.; Mayoral, E., 2008, Bioerosion versus colonization on Bivalvia: A case study from the Upper Miocene of Cacela (southeast Portugal): Geobios, 41, 43-59.

Santos A., Mayoral, E., Villas, E., Herrera, Z., Ortega, G., 2014, First record of Podichnus in orthide brachiopods from the Lower Ordovician (Tremadocian) of NW Argentina and its relation to the early use of an ethological strategy: Palaeogeography, Palaeoclimatology, Palaeoecology, 399, 67-77.

Sánchez, A., Aguiñiga, S., Lluch-Belda, D., Camalich-Carpizo, J., Del Monte-Luna, P., Ponce-Díaz, G., Arreguín-Sáncez, F., 2009, Geoquímica sedimentaria en áreas de pesca de arrastre y no arrastre de fondo en la costa de Sinaloa-Sonora, Golfo de California: Boletín de la Sociedad Geológica Mexicana, 61 (1), 25-30.

Sars, M., 1846, Fauna littoralis Norvegiae, oder Beschreibung und Abbildungen neuer oder wenig bekannten Seethiere: Bergen, Beyer, 1, 94 p.

Schäfer, W., 1972, Aktuo-Paläntologien ach Studien in der Nordsee, Verlag W. Kramer: Frankfurt am Main. $666 \mathrm{p}$.

Seilacher, A., 1967, Bathymetry of trace fossils: Marine Geology, 5, 413-428.

Seilacher, A., Westphal, F., 1971, Fossil-Lagerstätten, in: Sedimentology parts of Central Europe: : Heidelber, Guidebook 8th International Sedimentological Congress, 327-335.

Siggereud, E.I.H., Steel, R.J., Pollard, J.E., 2000, Bored pebbles and ravinement surface clusters in a transgressive system tract, Sant Llorenç del Munt fan-delta complex, SE Ebro Basin, Spain: Sedimentary Geology, 138, 161-177. 
Silén, L., 1946, On two groups of Bryozooa living in shell of molluscs: Arkiv för Zoologie, 338 (1), 1-7.

Silina, A.V., 2006, Tumor-like formations on the shells of Japanese scallops Patinopecten yessoensis (Jay): Marine Biology, 148, 833-840.

Smith, A.M., 1992, Aspects of the sedimentology of New Zealand bryozoans and mixed carbonate clastic deposits: A contribution to the temperate shelf carbonate model: New Zealand, University of Waikato, Hamilton, PhD. Thesis (Earth Sciences),122 p.

Smith, A.M., 1995, Palaeoenvironmental interpretations using bryozoans: a review, in: Bosence, D.W.J., Allison, P.A. (eds.), Marine Palaeoenvironmental Analysis from Fossils, Geological Society, Special Publication 83, 231-243.

Smith A.M., Key M.M.Jr., Gordon D.P., 2006, Skeletal mineralogy of bryozoans: taxonomic and temporal patterns: Earth-Science Reviews, 78, 287-306

Solle G., 1938, Die ersten Bohr-Spongien im europäischen Devon und einige andere Spuren Senckenbergiana: Lethaea, 20, 154-178.

Soulé, J.D., 1950, Penetrantiidae and Immergentidae from the Pacific (Bryozooa Ctenostomata): American Microscopy Society Transactions, 69, 359-367.

Sowerby, G. B., 1846, Descriptions of Tertiary fossil shells from South America, in Appendix to Darwin, C., Geological Observations on South America: London, Smith, Elder \& Co, 249264.

Steno, N., 1669, De solido intra solidvm natvraliter contento dissertationis prodromvs: Florencie, Ex Typographia sub signo Stellae, 79 p.

Straus, K.M., Crosson, L.M., Vadopalas, B., 2008, Effects on Geoduck aquaculture on the environment: A synthesis of current knowledge: Washington, Washington Sea Grant, Technical Report, WSG-TR 08-01, 66 p.

Swift, D.J.P., 1969, Inner shelf sedimentation- processes and products, in: Stanley, D.J. (ed.), The new concepts of continental-margin sedimentation: Washington, Short course lecture notes, A.G.I. DE-4-1-DS-4-46.

Tapanila, L., 2008, The medium is the message: imagining a complex micro boring (Pyrodendrina cupra n. igen. and isp.) from the early Paleozoic of Antocosti Island, Canada, en, Wisshak, M., Tapanila, L. (eds.), Current Developments in Bioerosion: Berlín, Erlangen Earth Conference Series, Springer, 123-146.

Taylor, P.D., 2016, Competition between encrusters on marine hard substrates and its fossils record: Palaeontology, 59 (4), 481-497.

Taylor, P.D., Wilson, M.A., 2002, A new terminology for marine organisms inhabiting hard substrates: Palaios, 17, 522-525. 
Taylor, P.D., Wilson, M.A., 2003, Palaeoecology and evolution of marine hard substrate communities: Earth-Science Reviews, 62, 1-103.

Taylor P.D., Wilson, M.A., Bromley, R.G., 1999, A new ichnogenus for etchings made by cheilostome Bryozoans into calcareous substrates: Palaeontology, 42 (4), 595-604.

Taylor, P.D., James, N.P., Bone, Y., Kuklinski, P., Kyser, T.K., 2009, Evolving mineralogy of cheilostome bryozoans: Palaios, 24, 440-452

Taylor, P.D., James, N.P., 2013, Secular changes in colony-forms and bryozoan carbonate sediments through geological history: Sedimentology, 60, 1184-1212.

Taylor, P.D., Wilson, M. A., Bromley, R.G., 2013, Finichnus, a new name for the ichnogenus Leptichnus Taylor, Wilson and Bromley, 1999, preoccupied by Leptichnus Simroth, 1896 (Mollusca, Gastropoda): Palaeontology, 56(2), 456.

Thayer, C.W.; 1977, Recruitment, growth and mortality of a living articulate brachiopod, with implications for the interpretation of survivorship curves: Paleobiology, 3, 98-109.

Thomas, R.D.K. (ed.), 1986, Taphonomy: ecology's loss in sedimentology's gain: Palaios, 1 (3), 206-338.

Tucker, M.E., 1991, The diagenesis of fossils, in: Donovan, S.K. (ed.) The process of fossilization: New York, Columbia University Press, 84-104.

Turner, S.J., Todd, C.D., 1993, The early development of epifaunal assemblages on artificial substrata at two intertidal sites on an exposed rocky shore in St. Andrews Bay, N.E. Scotland: Journal of Experimental Marine Biology and Ecology, 166, 251-272.

Urteaga, D., Griffin, M., Pastorino, G., 2011, Callochiton monteleonensis n. sp., first record of the Polyplacophora (Mollusca) from the Neogene of Argentina: Journal of Paleontology, 85 (6), 1181-1187.

Valencienes, A., 1839, Description de lànimal de la panopée australe, et recherches sur les autres espèces vivants ou fossiles de ce genre: Archives du Muséum d'Histoire Naturelle de Paris, Tome I: París, Gide, 464 pp.

Van Beneden, P.J., 1844, Recherches sur i'embryogénie de Tubulaires, et l'histoire naturelle des différents genres de cette famille qui qui habitent la côte d'Ostende: Nouveux Mémoires de l'Académie Royale des Sciences et des Belles-Lettres de Bruxelles, XVII, 72, pl. I-VI.

Varela, A.N., Poiré, D.G., Martin, T., Gerdes, A., Goin, F.J., Gelfo, J., Hoffmann, S., 2012, U$\mathrm{Pb}$ zircon constraints on the age of the Cretaceous Mata Amarilla Formation, Southern Patagonia, Argentina: its relationship with the evolution of the Austral Basin: Andean Geology, 39 (3), 359-379. 
Vénec-Peyré, M.T., 1996, Bioeroding foraminifera: a review: Marine Micropaleontology, 28, 19-30.

Vermeij, G.J., 1987, Evolution and escalation: an ecological history of life: : New Jersey, Princeton University Press, 544 p.

Vogel K., Golubic S., Brett C.E., 1987, Endolith associations and their relation to facies distribution in the Middle Devonian of New York State, USA: Lethaia, 20, 263-290.

Voigt, E., 1965, Über parasitiche Polychaeten in Kreide-Austern Sowie einige Andere in Muschelschalen bohrende Wurmer: Paläontologische Zeitschrift, 39, 193-211.

Voigt, E., 1971, Fremdskulpturen an Steinkernen von Polychaeten-Bohrgängen aus der Maastrichter Tuffkreide: Paläontologische Zeitschrift, 45 (3-4), 144-153.

Voigt, E., 1977, On grazing traces produced by the radula of fossil and recent gastropods and chitons, in: T.P. Crimes and J.C. Harper (eds.), Trace Fossils 2, 335-346: Liverpool, Geological Journal, Special Issues 9, Steel House Press, 335-346.

Walker, R.G., 1984, Shelf and shallow marine sands, in: Walker, R.G. (ed.), Facies Models: Geoscience Canada Reprint Series 1, 141-170.

Walker, R.G., 1985, Geological evidence for storm transportation and deposition on ancient shelves in: Tillman, R.W., Swift, D.J.P., Walker, R.G. (eds.), Shelf Sands and Sandstone Reservoirs: Society of Economic Palaeontologists and Mineralogists, short course notes, 13, 243-302.

Walker, R.G., Duke, W.L., Leckie, D.A., 1983, Hummocky stratification: significance of its variable bedding sequences: discussion: Geological Society of America Bulletin, 94 (10), $1245-1251$.

Walther, J., 1904, Die Fauna der Solnhofener Plattenkalke, Bionomisch, betrachtet,Verlag von Gustav Fischer: Jena, 135-214.

Wardlaw, N., Oldershaw, A., Stout, M., 1978, Transformation of aragonite to calcite in a marine gasteropod: Canadian Journal of Earth Sciencies, 15, 1861-1866.

Wargo, R.N., Ford, S.E., 1993, The effect of shell infestation by Polydora sp. and infection by Haplosporidium nelsoni (MSX) on the tissue condition oysters, Crassostea virginica: Estuaries, 16, 229-234.

Warme, J. E., 1975, Borings as trace fossils, and the process of marine bioerosion, in: Frey, R.W. (ed.), The study of trace fossils, Springer: New York, 181-227.

Weigelt, J., 1927, Rezente Wirbeltierleichen und ihre paläobiologische Bedeutung: Leipzig, Verlagvon M. Weg, $227 \mathrm{p}$. 
Wilkens, O., 1905, Die Meeresablagerungen der Kreide und Tertiärformation in Patagonien: Neues Jahrbuch für Mineralogie, Geologie und Paläntologie, 21, 98-195.

Wilson, M.A., 1985, Disturbance and ecologic succession in an Upper Ordovician cobbledwelling hardground fauna: Science, 228, 575-577.

Wilson, M.A., 1987, Ecological dynamics on pebbles, cobbles and boulders: Palaios, 2(6), 594-599.

Wilson, M.A., 1988, Ecological Succession on Cobble Substrates: A Reply: Journal of Paleontology, 62 (2), 313.

Wilson, M.A., 2007, Macroborings and the Evolution of Marine Bioerosión, in: Miller III, W. (Ed.), Trace Fossils: Concepts, Problems, Prospects, Elsevier: Amsterdam, 356-367.

Winston, J.E., Håkansson, E., 1986, The interstitial Bryozoan Fauna from Capron Shoal, Florida: American Museum Novitates, 2864, 1-50.

Wisshak M., 2006, High-Latitude Bioerosion: The Kosterfjord Experiment: Heidelberg, Lecture Notes in Earth Sciences 109. Springer.

Wisshak M., 2008, Two new Entobia ichnospecies in a diverse aphotic ichnocoenosis (Pleistocene / Rhodes, Greece), in: Wisshak M., Tapanila L. (eds), Current Developments in Bioerosion: Heidelberg, Springer, 213-233.

Wisshak, M., 2017, Taming an ichnotaxonomical Pandora's box: revision of dendritic and rosetted microborings (ichnofamily: Dendrinidae): European Journal of Taxonomy, 390, 2017390.

Wisshak, M., Kroh, A., Bertling, M., Knaust, D., Nielsen, J.K., Jagt, J.W.M., Neumann, C., Nielsen, K.S.S., 2015, In defense ofan iconic ichnogenus Oichnus Bromley, 1981: Annales Societatis Geologorum Poloniae, 85, 445-451.

Wisshak, M., Neumann, C., 2018, Large dendrinids meet giant clam: the bioerosion trace fossil Neodendrina carnelia igen. et isp. n. in a Tridacna shell from Pleistocene-Holocene coral reefs deposits, Red Sea, Egypt. Fossil Record 21, 1-9.

Zajac, R.N., 1991, Population ecology of Polydora lingo (Polichaeta:Spionidae). II. Seasonal demographic variation and its potential impact on life history evolution: Marine Ecology Progress Series, 77, 207-220.

Zambrano, J., Urien, C., 1970, Geological outline of the Basins in Southern Argentina and their continuation off the Atlantic shore: Journal of Gephysical Research, 75 (8), 1363-1396.

Zatón, M., Niedźwiedzki, G., Blom, H., Kear, B.P., 2016, Boreal earliest Triassic biotas elucidate globally depauperate hard substrate communities after the end-Permian mass extinction: Scientific Reports, 6, 36345. 
Zinsmeister, W.J., 1976, A new Genus and Species of the Gastropod Family Struhiolariidae, Antarctodarwinella ellioti from Seymour Island, Antartica: The Ohio Journal of Science, 76 (3), 111-114. 
Ya no puedo ver, ni oír, ni escribir y menos pintar, solo me queda la voluntad, pero de esa, tengo en abundancia -Francisco de Goya 
Apéndices 


\section{Apéndice I \\ Características tafonómicas y paleontológicas de las concentraciones de Cabeza de León}

\section{Concentración 1}

1

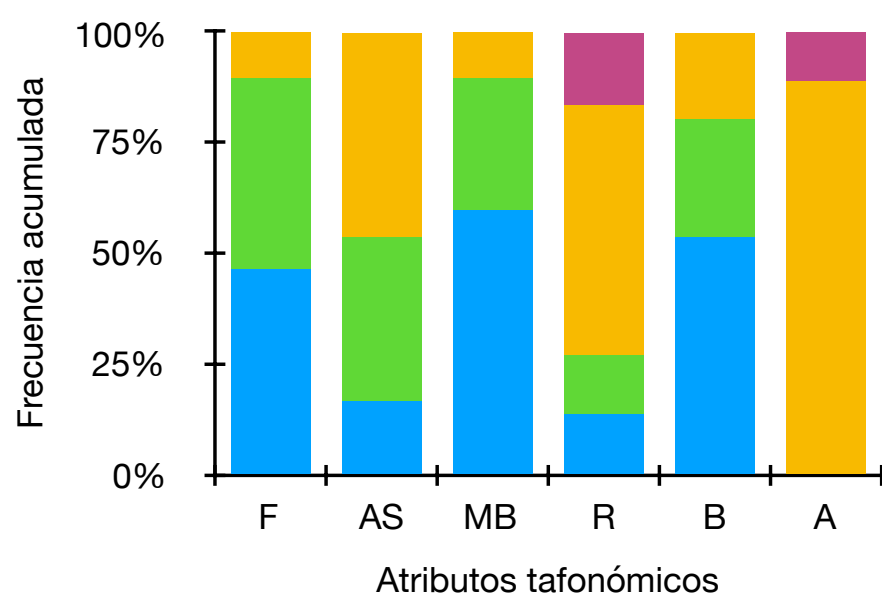

3

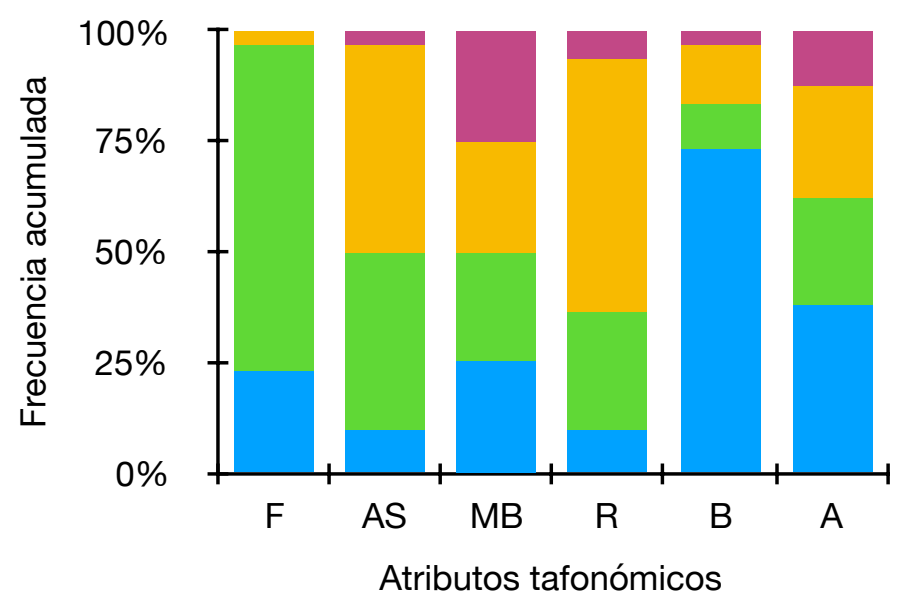

2

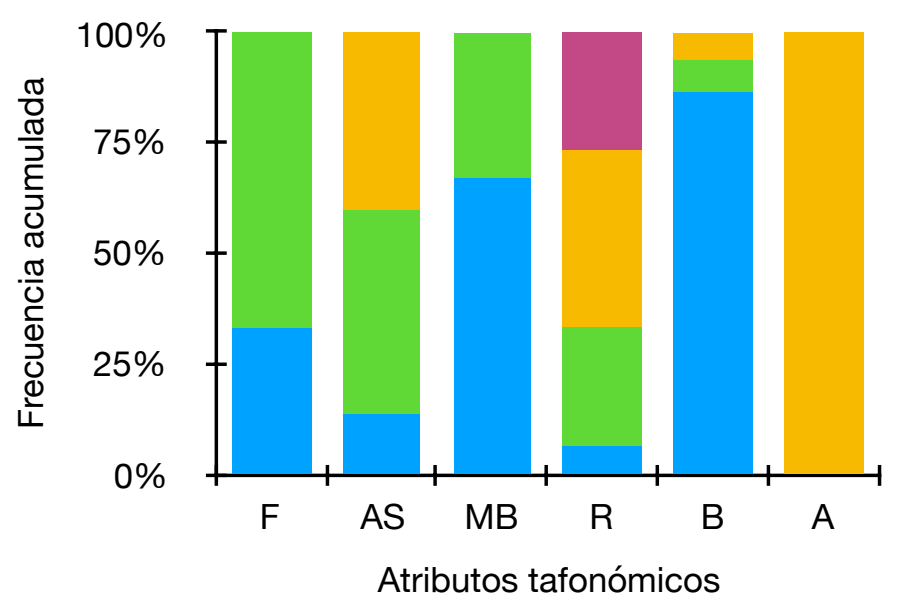

4

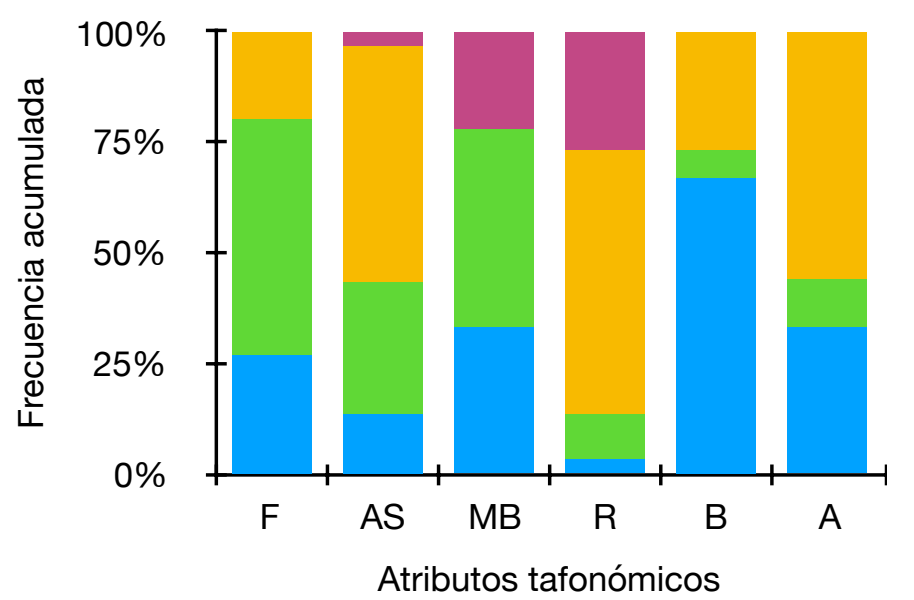

Figura 1. Frecuencia acumulada de los atributos tafonómicos observados en cada uno de los cuadros de C1. Fragmentación (F): (1) completo, (2) incompleto, (3) fragmento. Alteración superficial (AS): (1) baja, (2) moderada, (3) alta. Modificación de bordes (MB): (1) continuo, (2) discontinuo, (3) ausente. Redondeamiento (R): (1) ausente, (2) aguzado, (3) redondeado. Bioerosión (B): (1) baja, (2) moderada, (3) alta, Articulación (A) : (1) articulado, (2) separado, (3) desarticulado. 1, azul; 2, verde; 3 , amarillo; NV (no visible), violeta. Datos presentados en Capítulo 3, Tabla 3.2. 
5

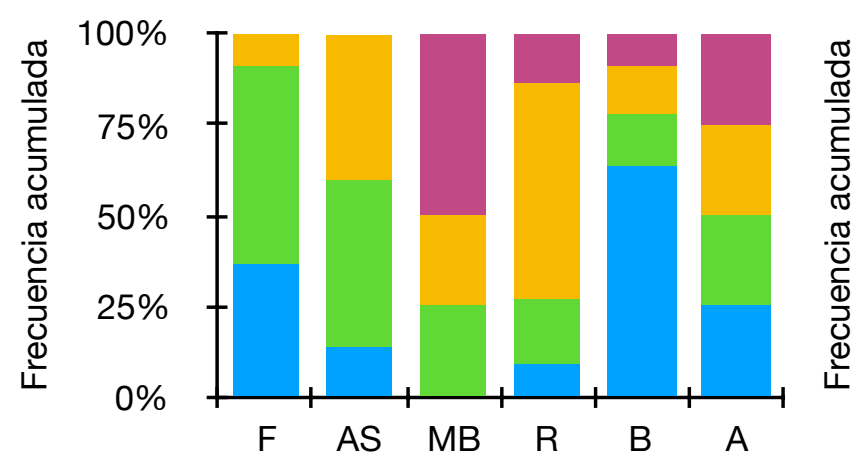

Atributos tafonómicos

7

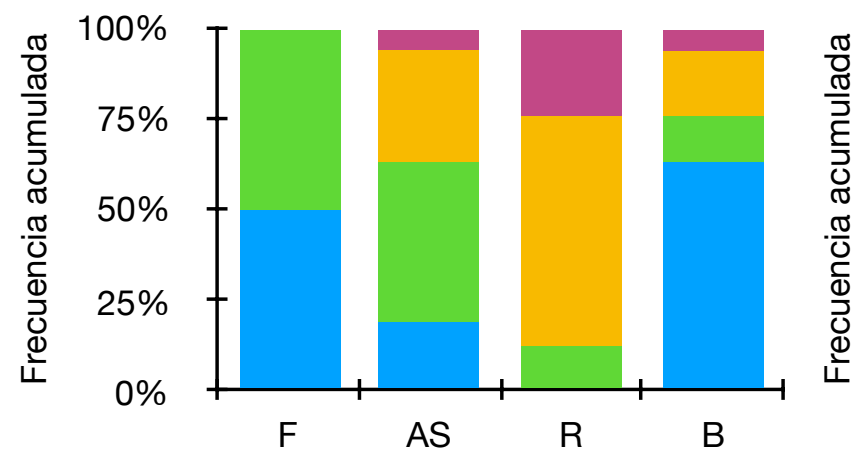

Atributos tafonómicos

Cuadros C1

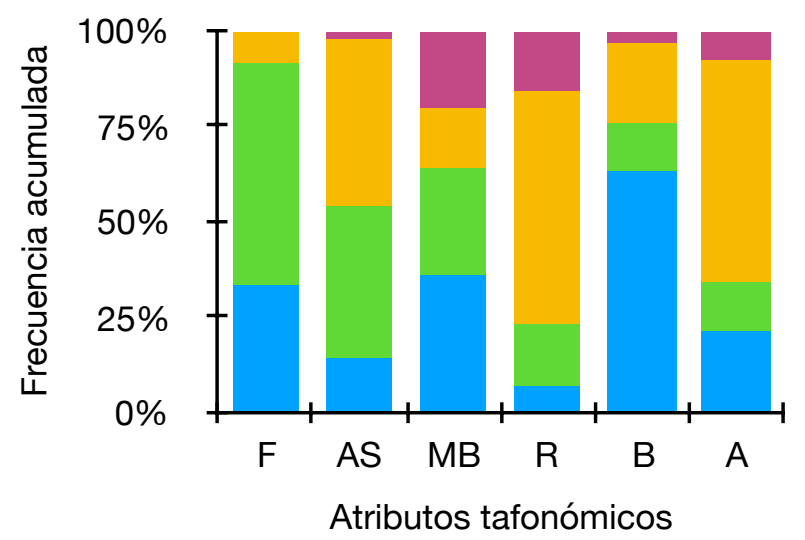

6

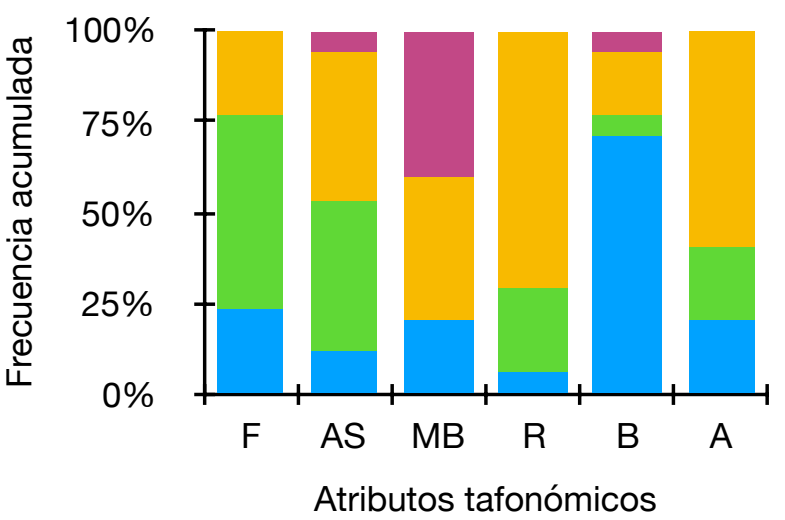

8

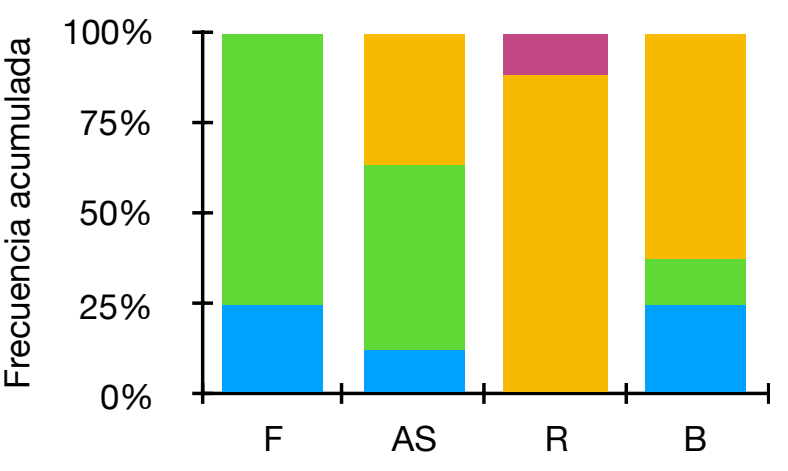

Atributos tafonómicos

Figura 1. (Continuación)Frecuencia acumulada de los atributos tafonómicos observados en cada uno de los cuadros de C1. Fragmentación (F): (1) completo, (2) incompleto, (3) fragmento. Alteración superficial (AS): (1) baja, (2) moderada, (3) alta. Modificación de bordes (MB): (1) continuo, (2) discontinuo, (3) ausente. Redondeamiento (R): (1) ausente, (2) aguzado, (3) redondeado. Bioerosión (B): (1) baja, (2) moderada, (3) alta, Articulación (A) : (1) articulado, (2) separado, (3) desarticulado. 1, azul; 2, verde; 3, amarillo; NV (no visible), violeta. Datos presentados en Capítulo 3, Tabla 3.2. 
$1 a$

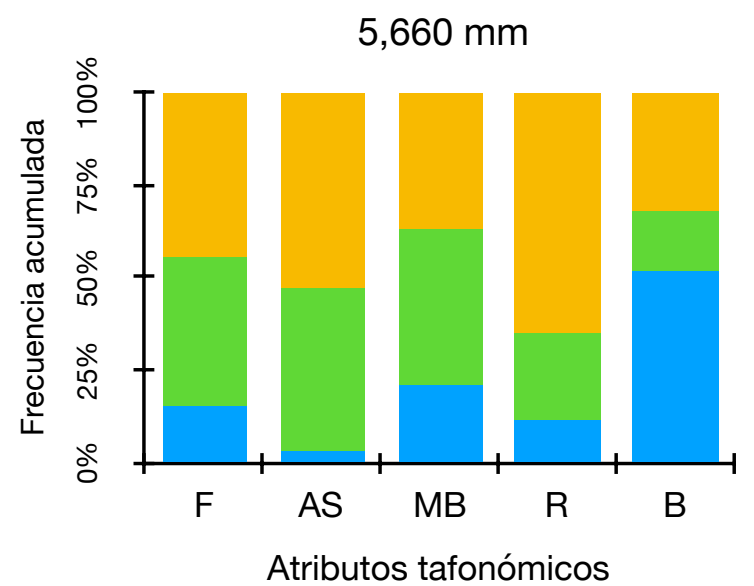

$1,190 \mathrm{~mm}$

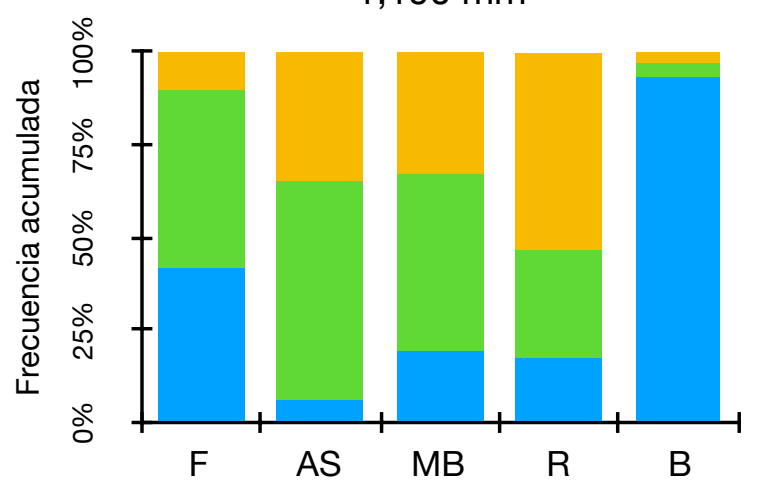

Atributos tafonómicos

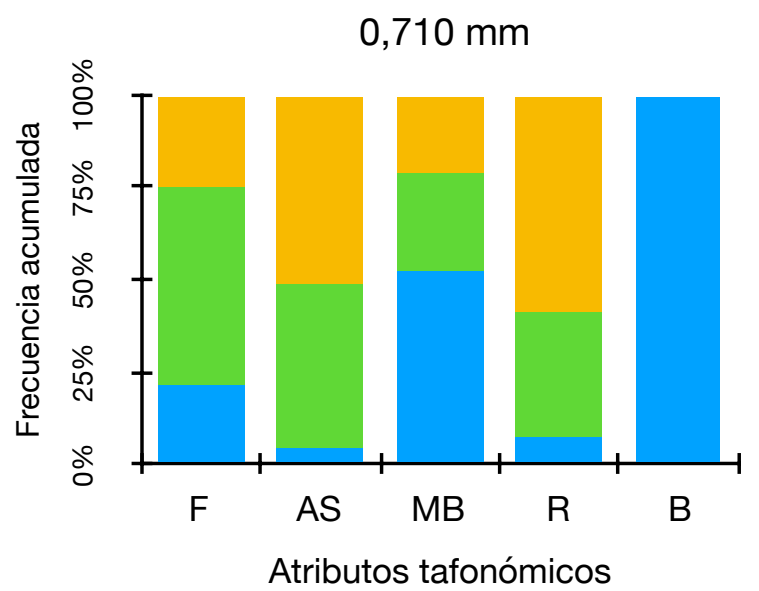

$1 b$
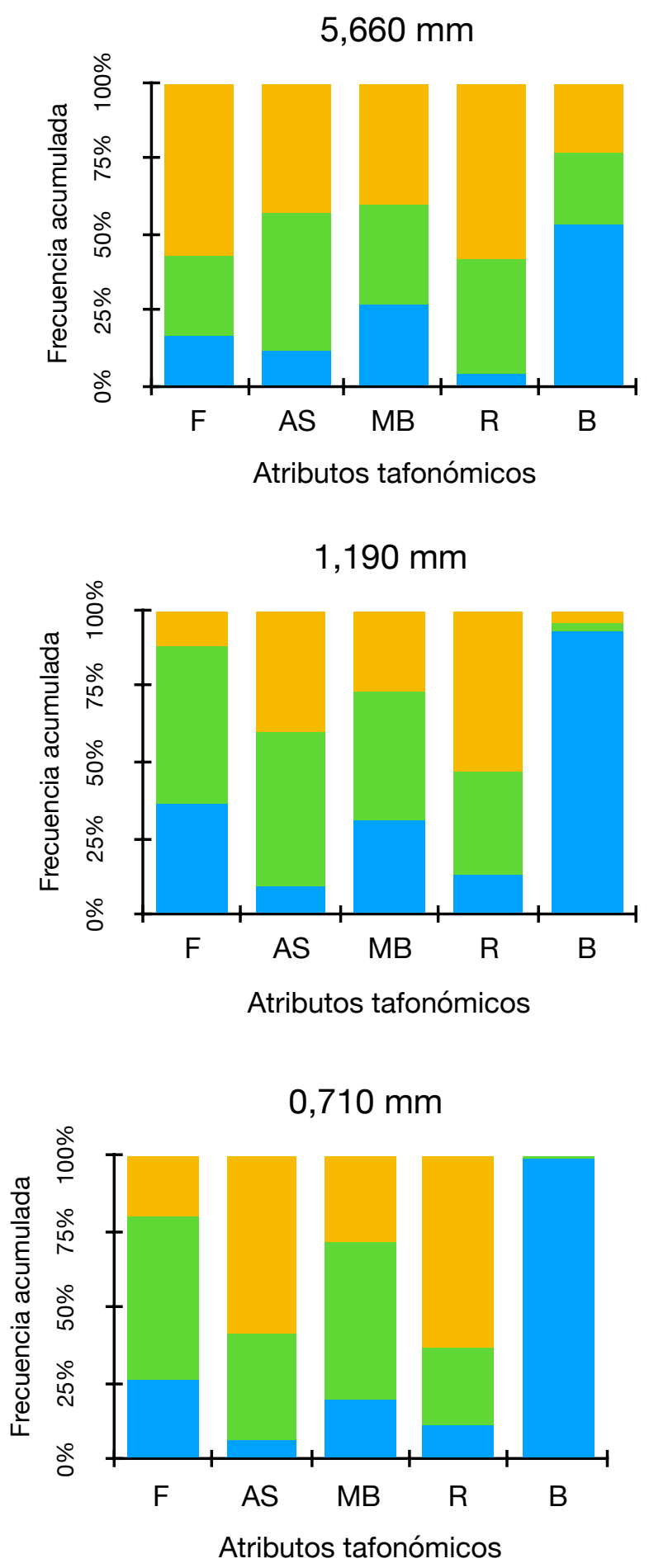

Figura 2. Frecuencia acumulada de los atributos tafonómicos observados en cada uno de los tamices en las submuestras procesadas de C1. Referencias igual que para la Figura 1. Datos presentados en Capítulo 3, Tabla 3.5. 

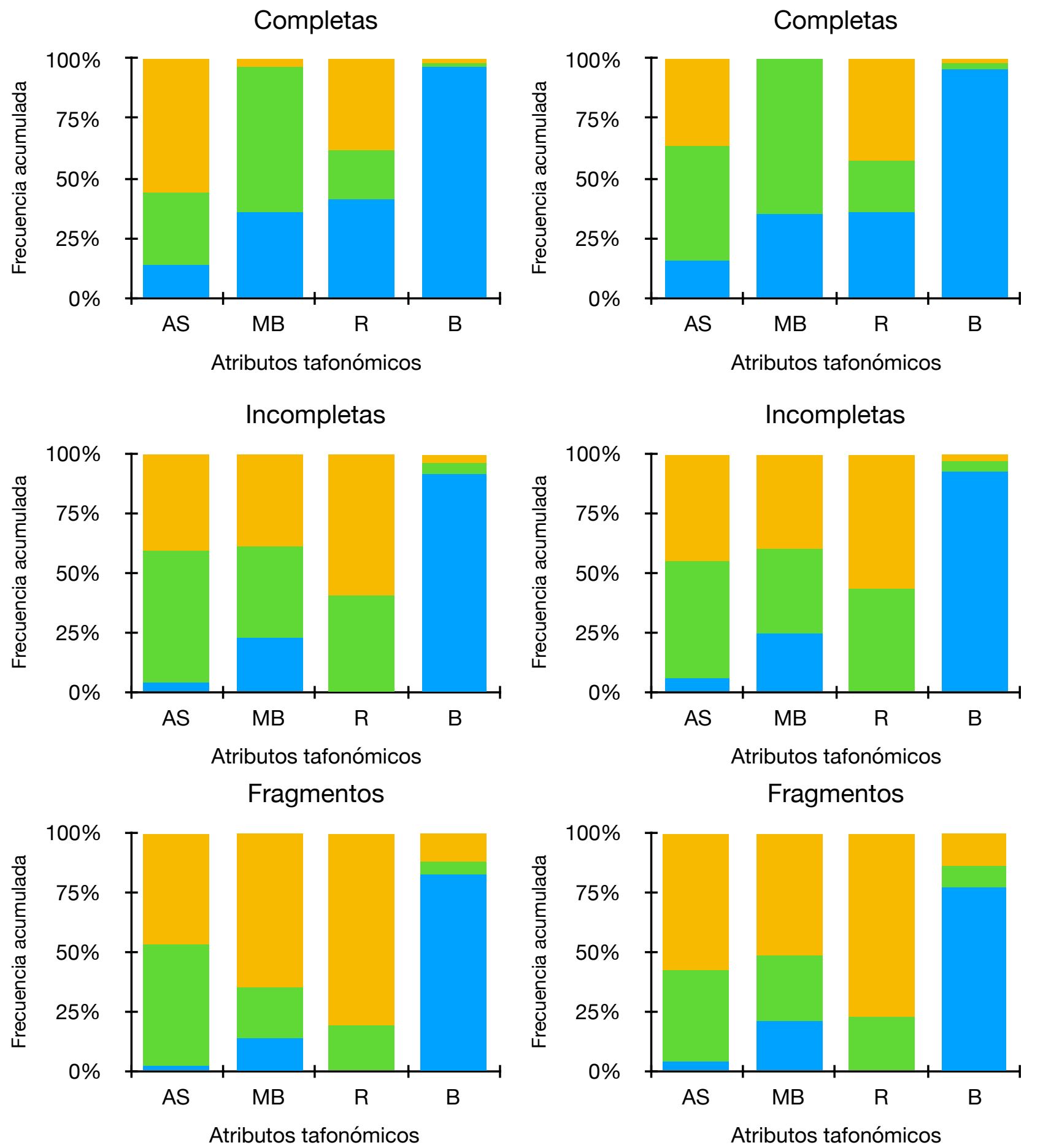

Figura 3. Frecuencia acumulada de los atributos tafonómicos observados en las conchillas completas, incompletas y fragmentos de las submuestras procesadas de $\mathrm{C} 1$. Referencias igual que para la Figura 1. Datos presentados en Capítulo 3, Tabla 3.6. 
Completas 5,660 mm

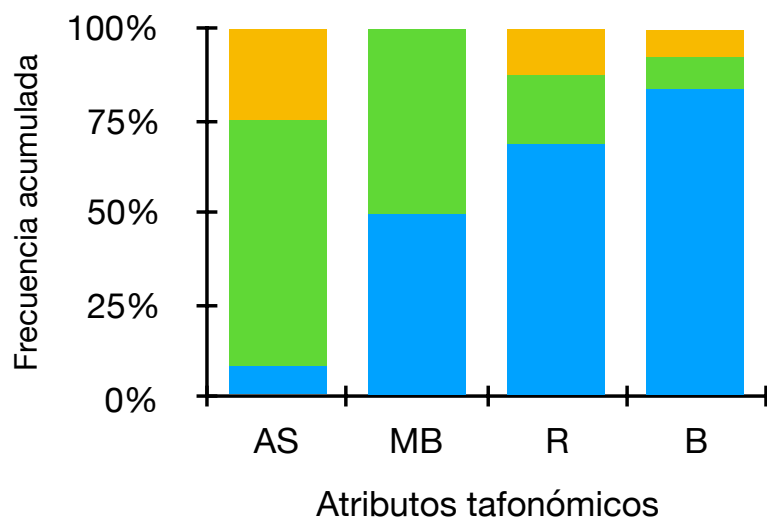

Completas 1, $190 \mathrm{~mm}$

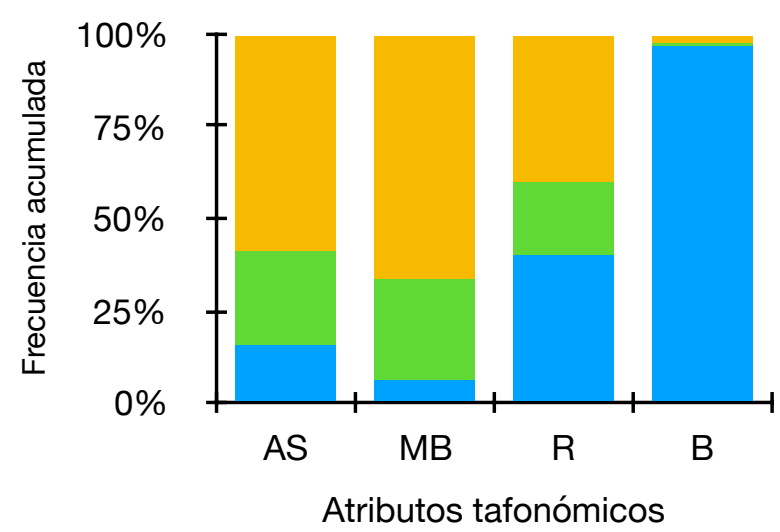

Completas 0, $710 \mathrm{~mm}$

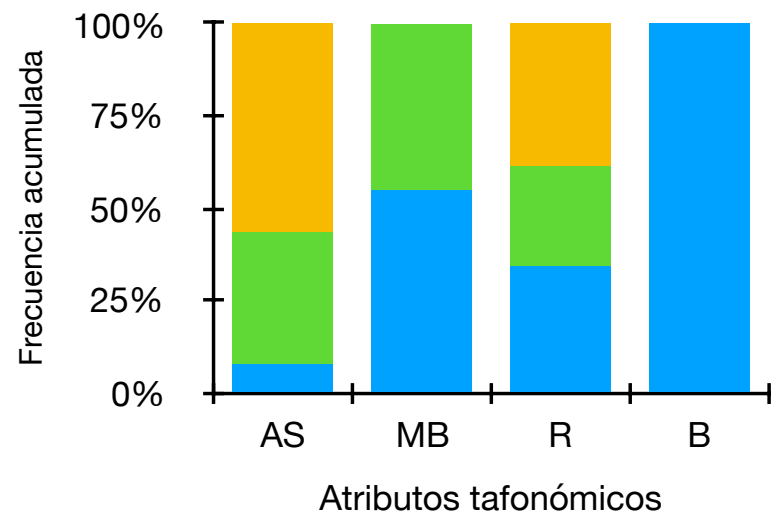

Completas 5,660 mm

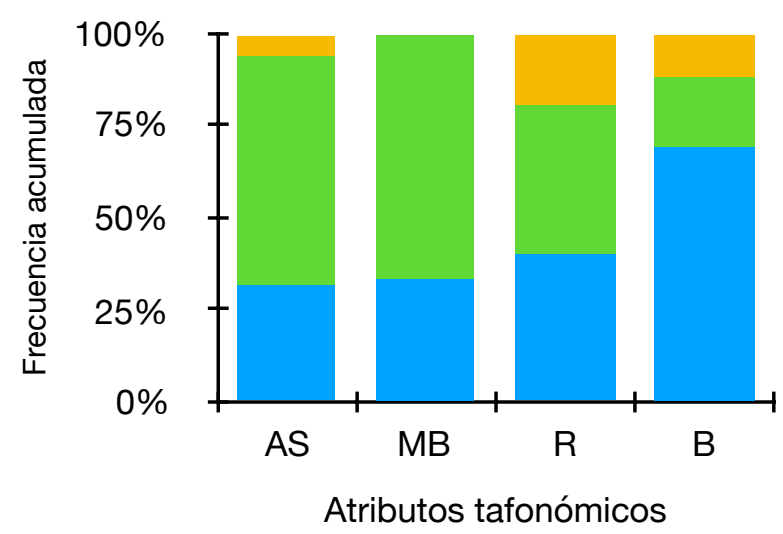

Completas 1,190 mm mm

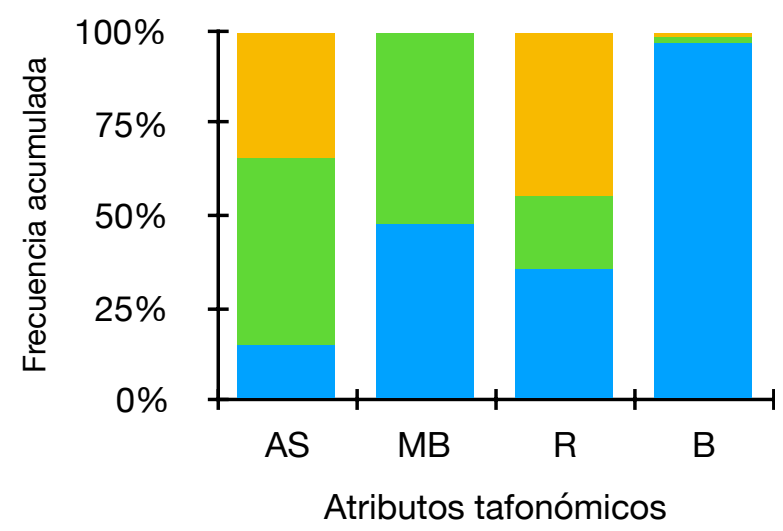

Completas 0,710 mm

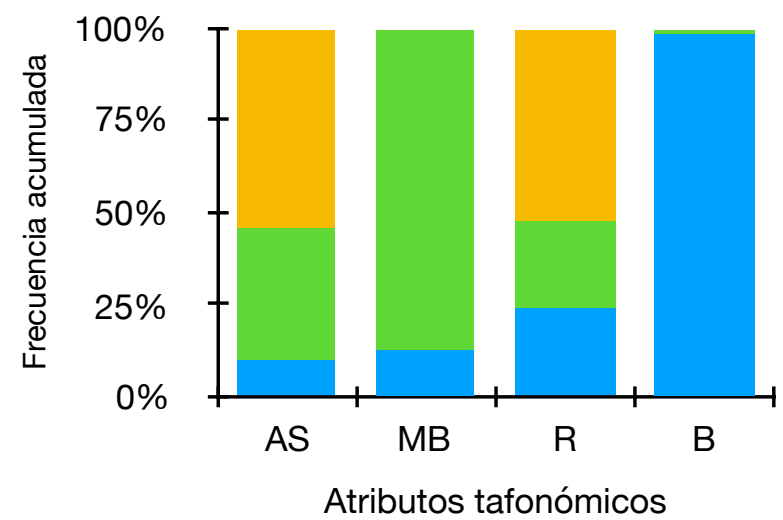

Figura 4. Frecuencia acumulada de los atributos tafonómicos observados en las conchillas completas, con relación al talle en las submuestras procesadas de $\mathrm{C} 1$. Referencias igual que para la Figura 1. Datos presentados en Capítulo 3, Tabla 3.7. 

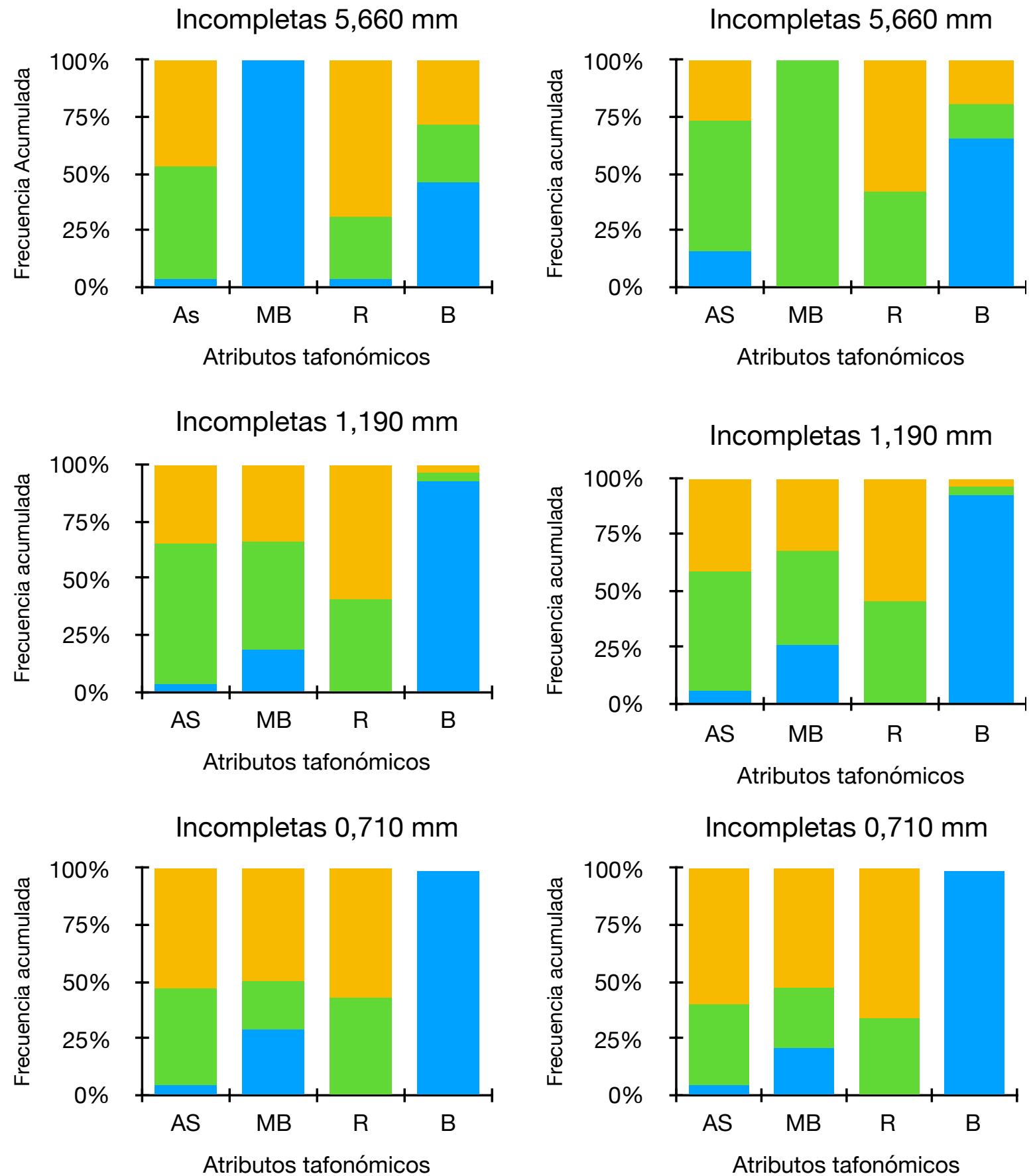

Figura 5. Frecuencia acumulada de los atributos tafonómicos observados en las conchillas incompletas, con relación al talle en las submuestras procesadas de C1. Referencias igual que para la Figura 1.Datos presentados en Capítulo 3, Tabla 3.7. 
Fragmentos 5, $660 \mathrm{~mm}$

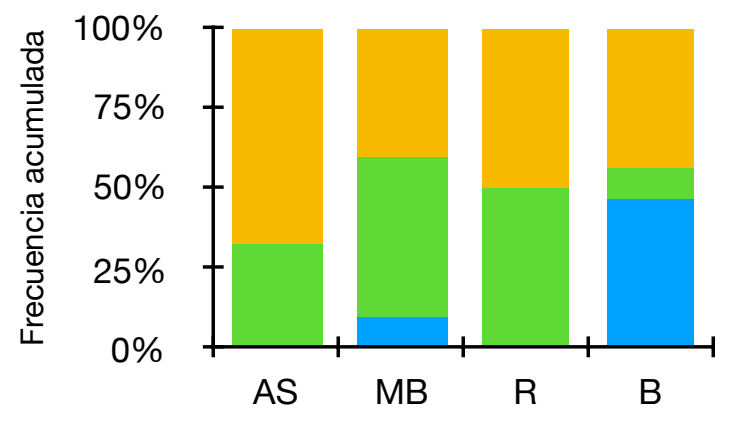

Atributos tafonómicos

Fragmentos 1,190 mm

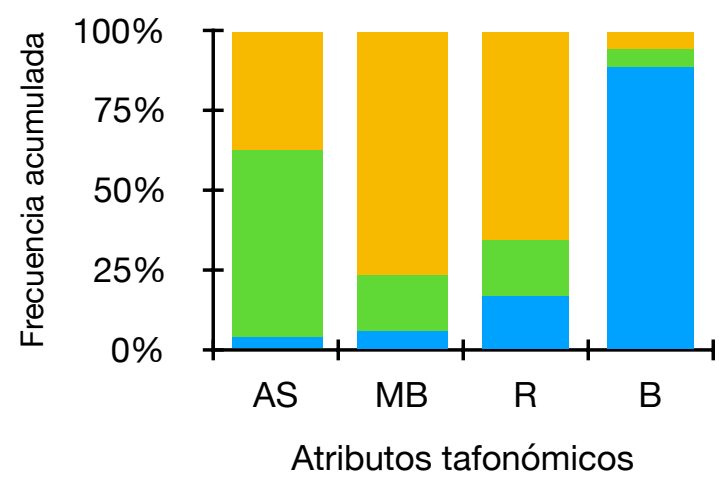

Fragmentos $0,710 \mathrm{~mm}$

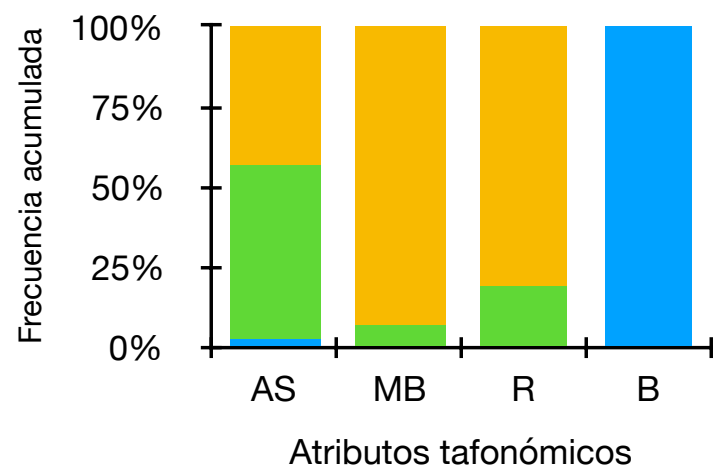

Fragmentos 5,660 mm

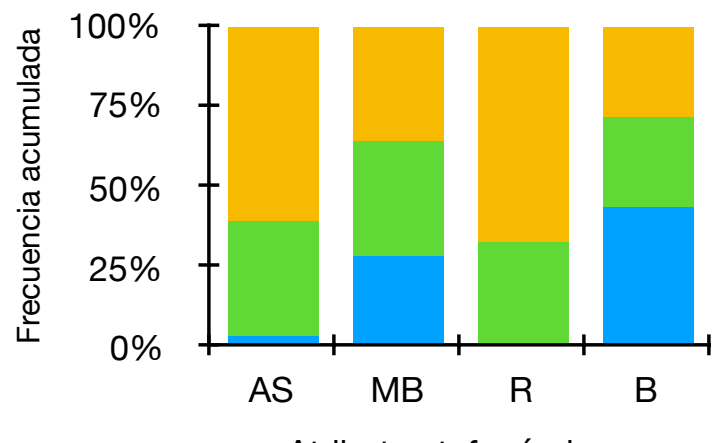

Atributos tafonómicos

Fragmentos 1,190 mm

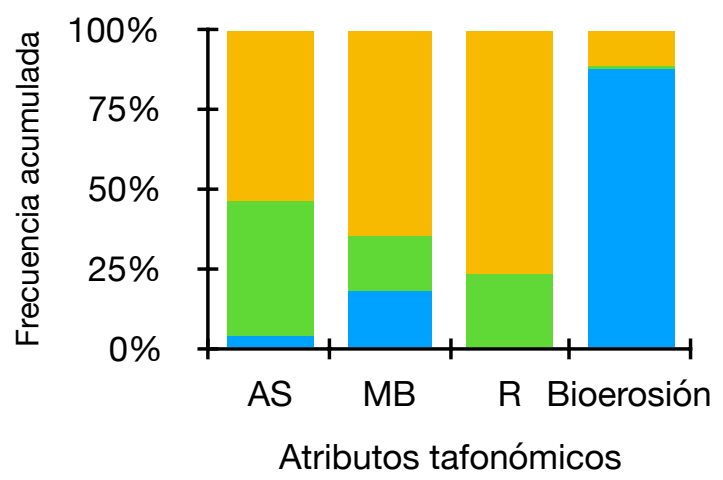

Fragmentos $0,710 \mathrm{~mm}$

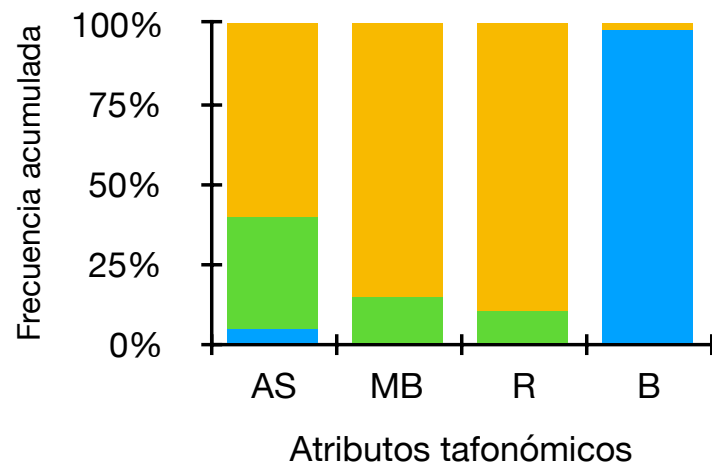

Figura 6. Frecuencia acumulada de los atributos tafonómicos observados en los fragmentos de conchillas, con relación al talle en las submuestras procesadas de C1. Referencias igual que para la Figura 1. Datos presentados en Capítulo 3, Tabla 3.7. 


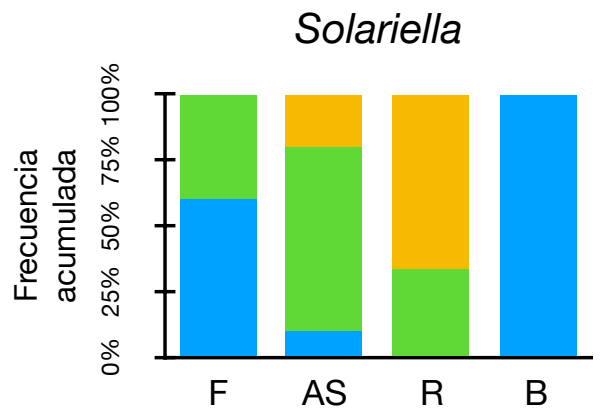

Atributos tafonómicos

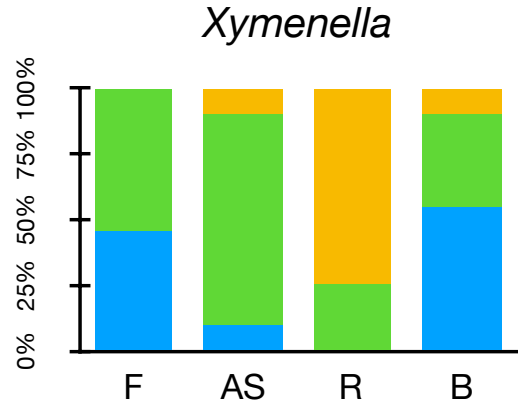

Atributos tafonómicos

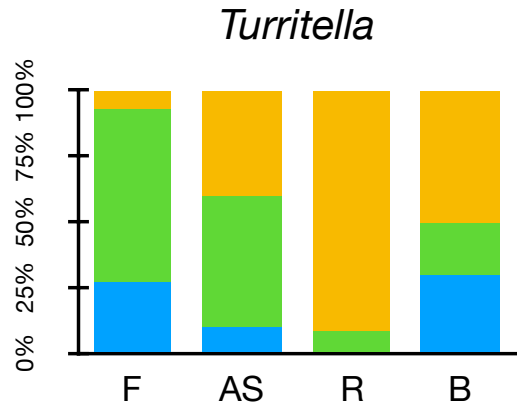

Atributos tafonómicos

Figura 7. Frecuencia acumulada de los atributos tafonómicos observados en los taxones más abundantes de los cuadros de $\mathrm{C} 1$, en campo. Referencias igual que para la Figura 1. Datos presentados en Capítulo 3, Tabla 3.8.

Cylichnania

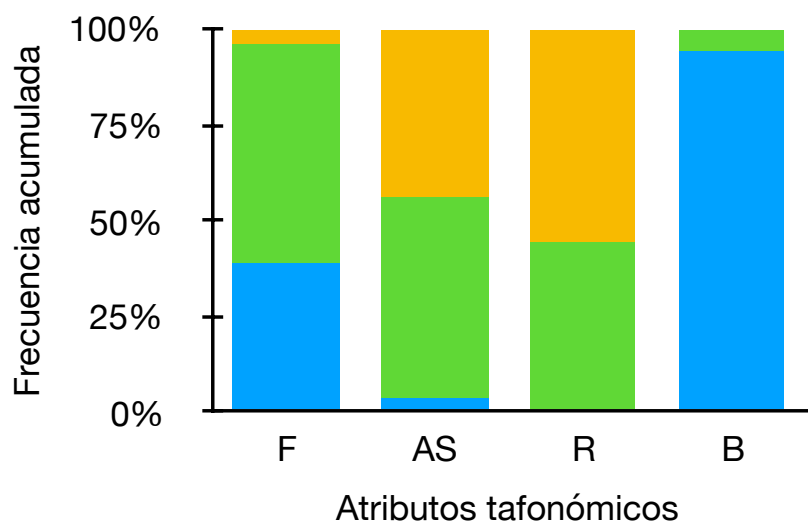

Solariella

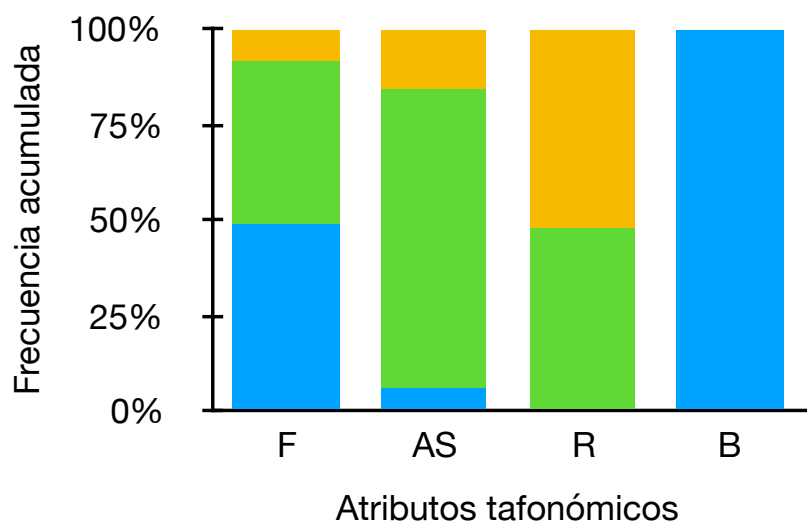

Kaitoa

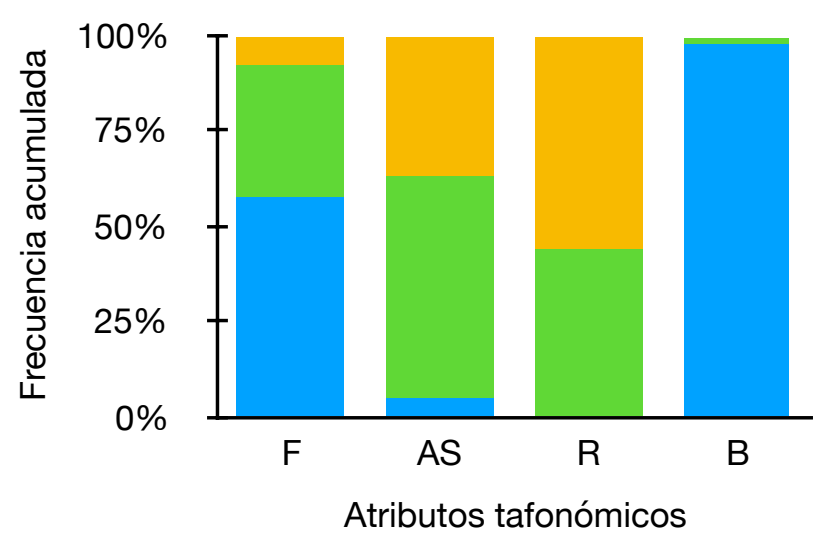

Turritella

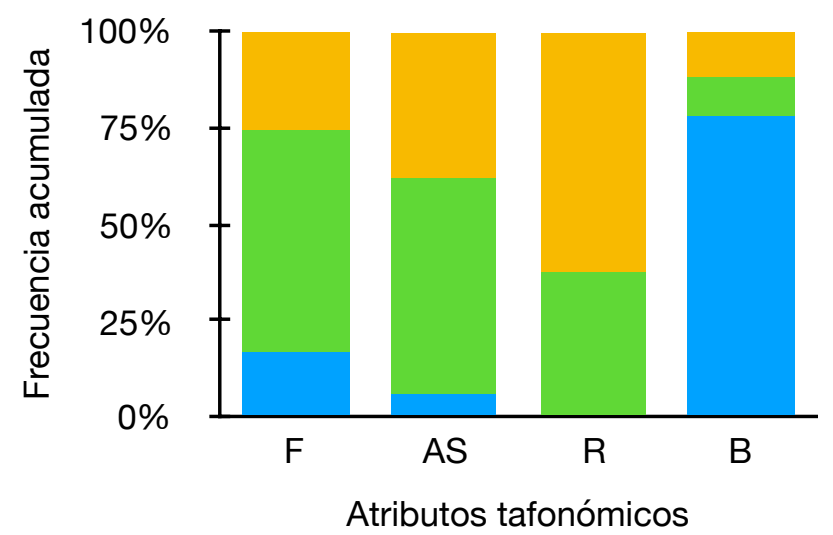

Figura 8. Frecuencia acumulada de los atributos tafonómicos observados en los taxones más abundantes de la submuestra 1a. Referencias igual que para la Figura 1. Datos presentados en Capítulo 3, Tabla 3.9. 
Carditidae

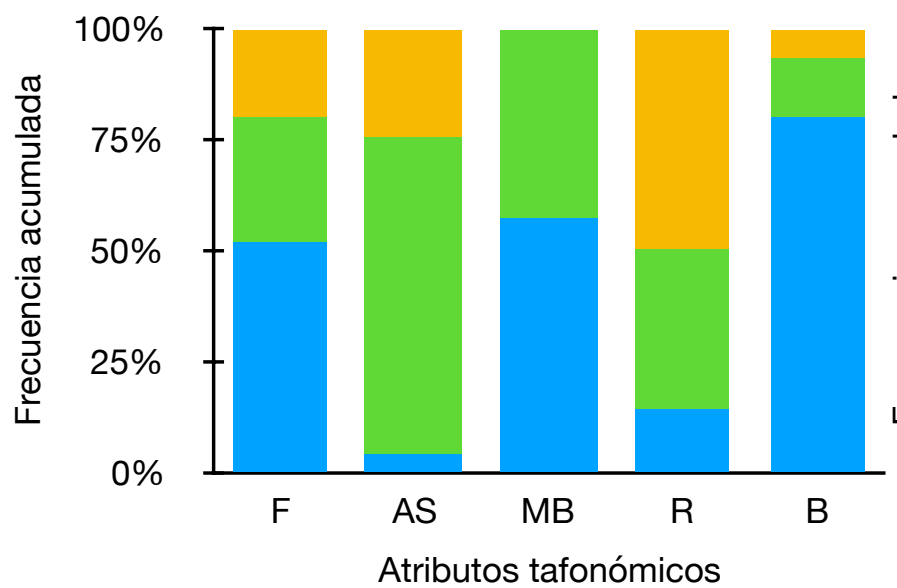

Muricidae

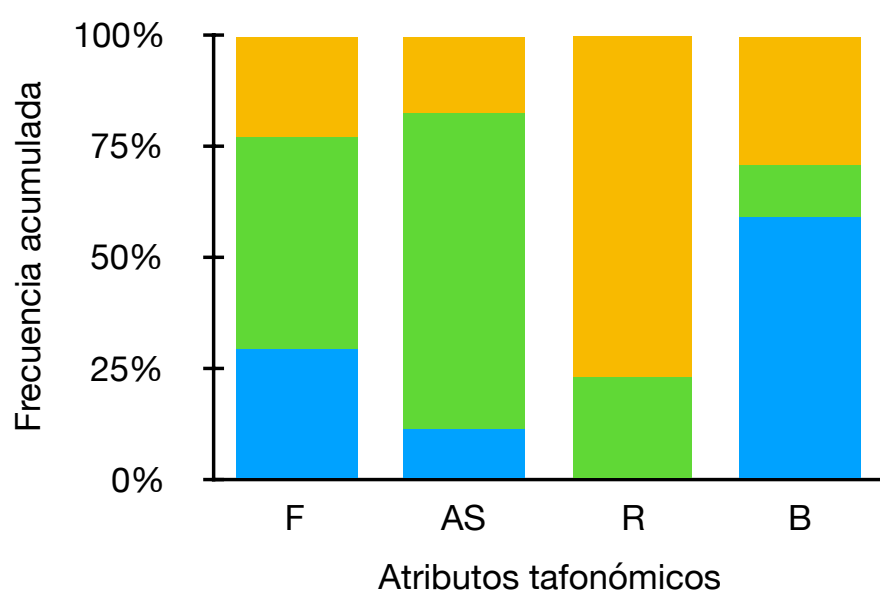

Mactridae

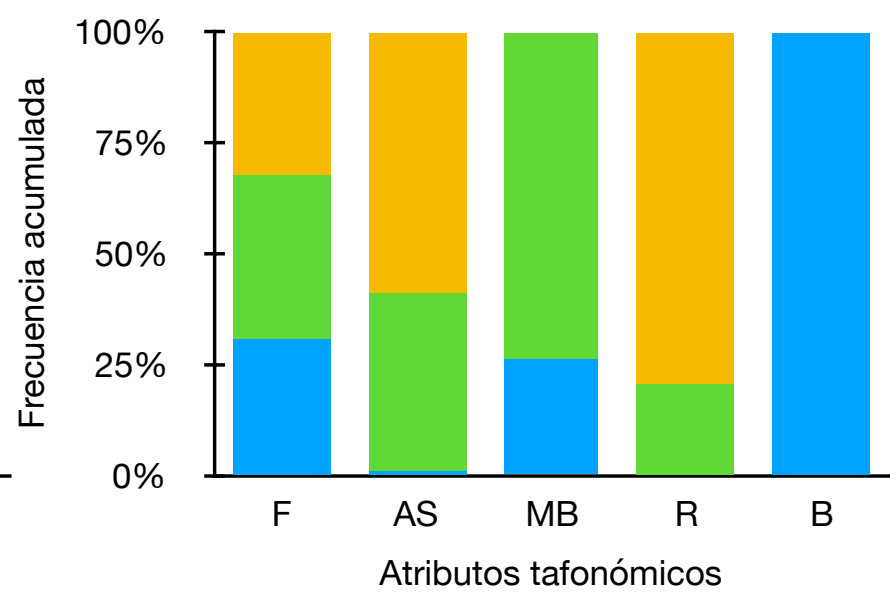

Naticidae

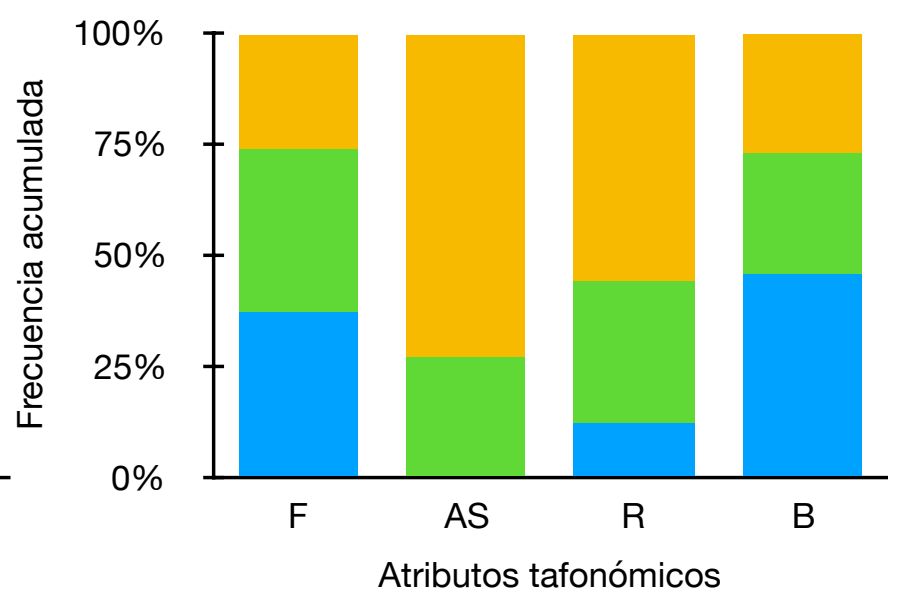

Figura 8. (Continuación) Frecuencia acumulada de los atributos tafonómicos observados en los taxones más abundantes de la submuestra 1a. Referencias igual que para la Figura 1. Datos presentados en Capítulo 3, Tabla 3.9. 
Cylichnania
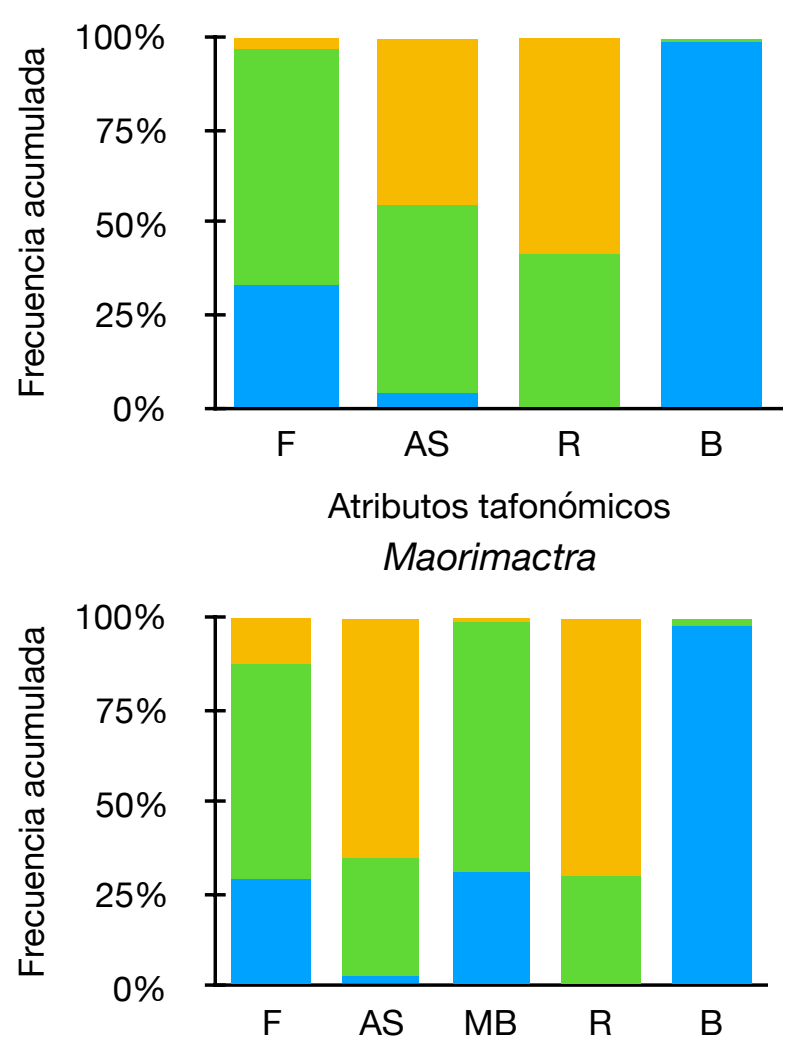

Atributos tafonómicos

Solariella

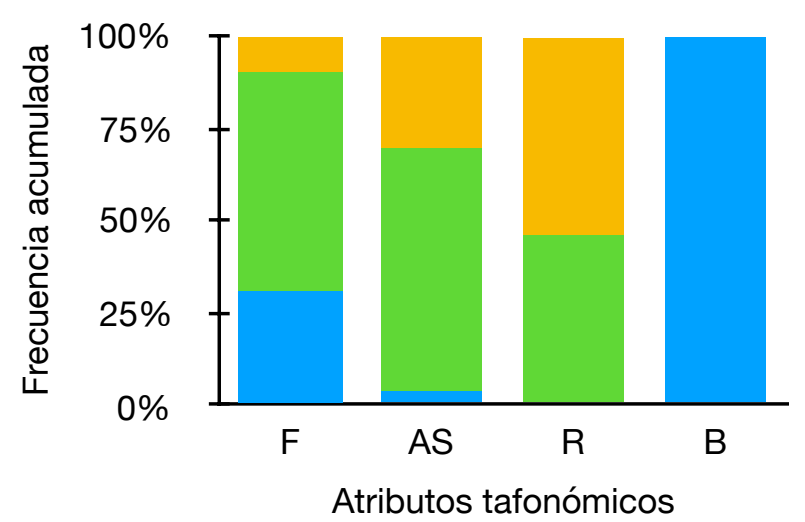

Kaitoa

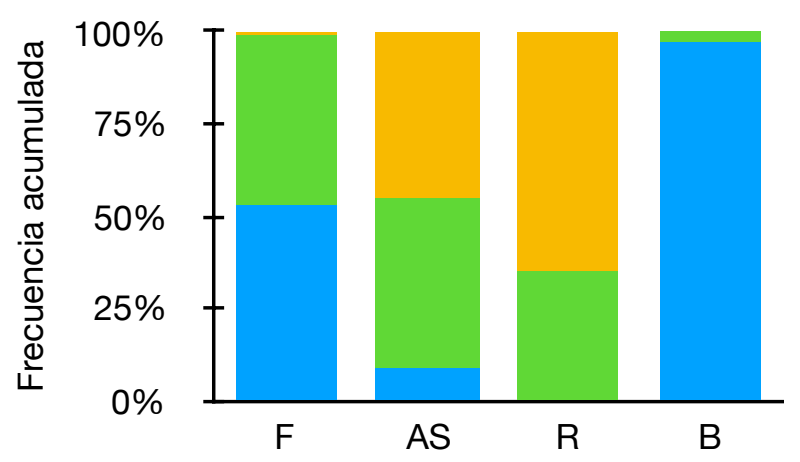

Atributos tafonómicos

Naticidae

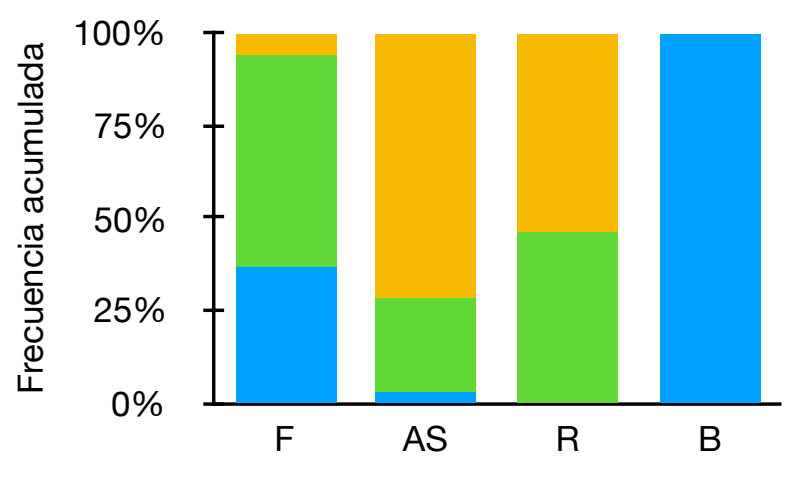

Atributos tafonómicos

Turritella

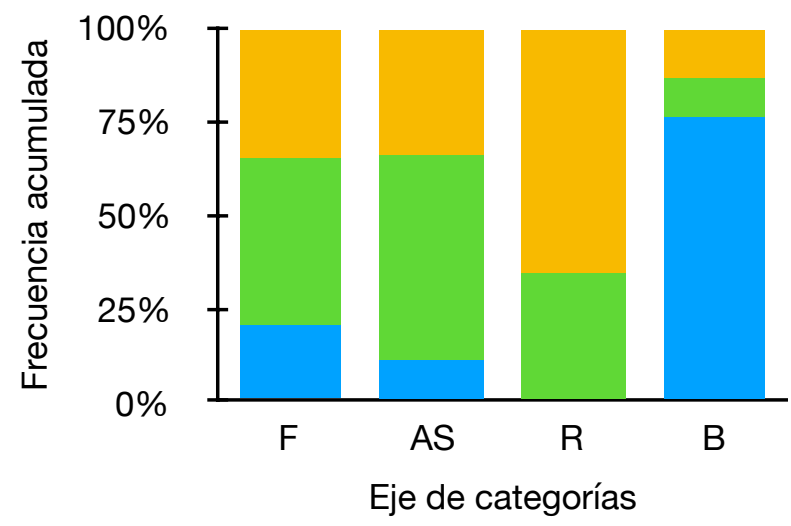

Figura 9. Frecuencia acumulada de los atributos tafonómicos observados en los taxones más abundantes de la submuestra $1 \mathrm{~b}$. Referencias igual que para la Figura 1. Datos presentados en Capítulo 3, Tabla 3.10. 


\section{Infaunales}

Cuadros

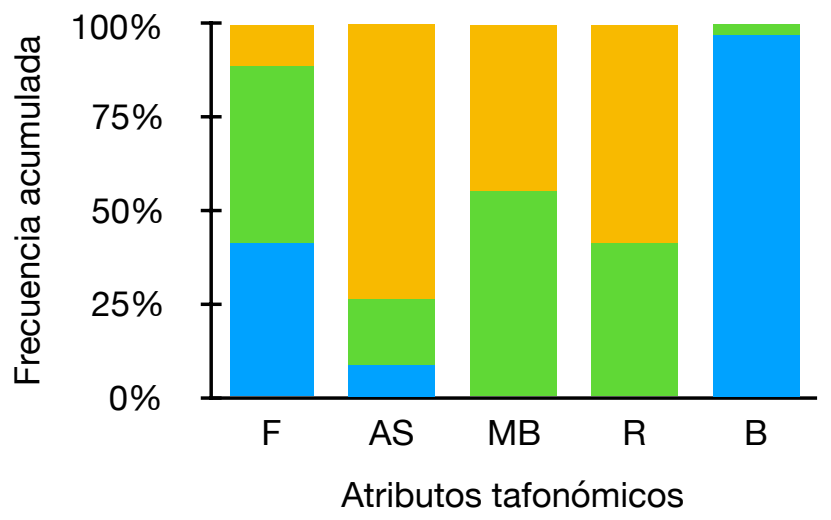

$1 \mathrm{a}$

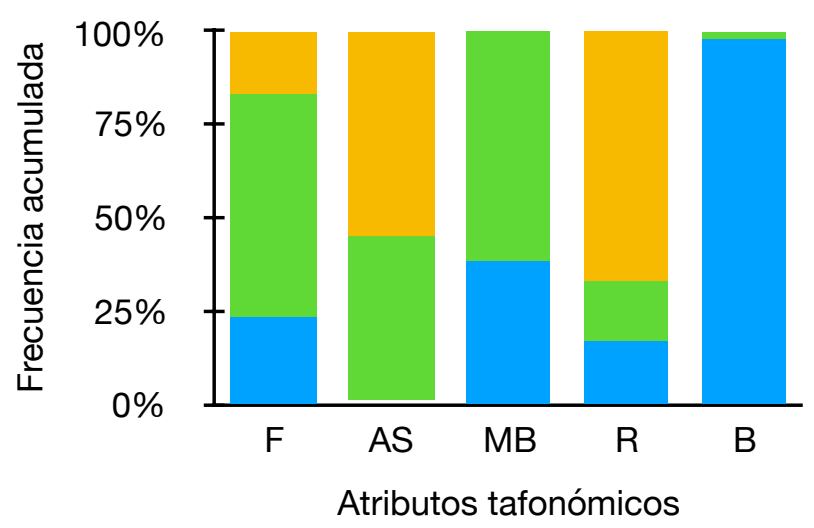

$1 b$

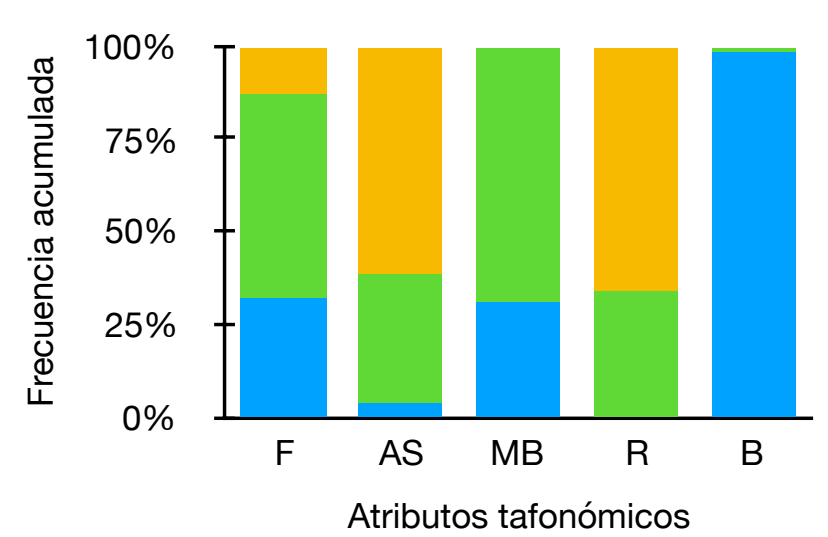

Epifaunales
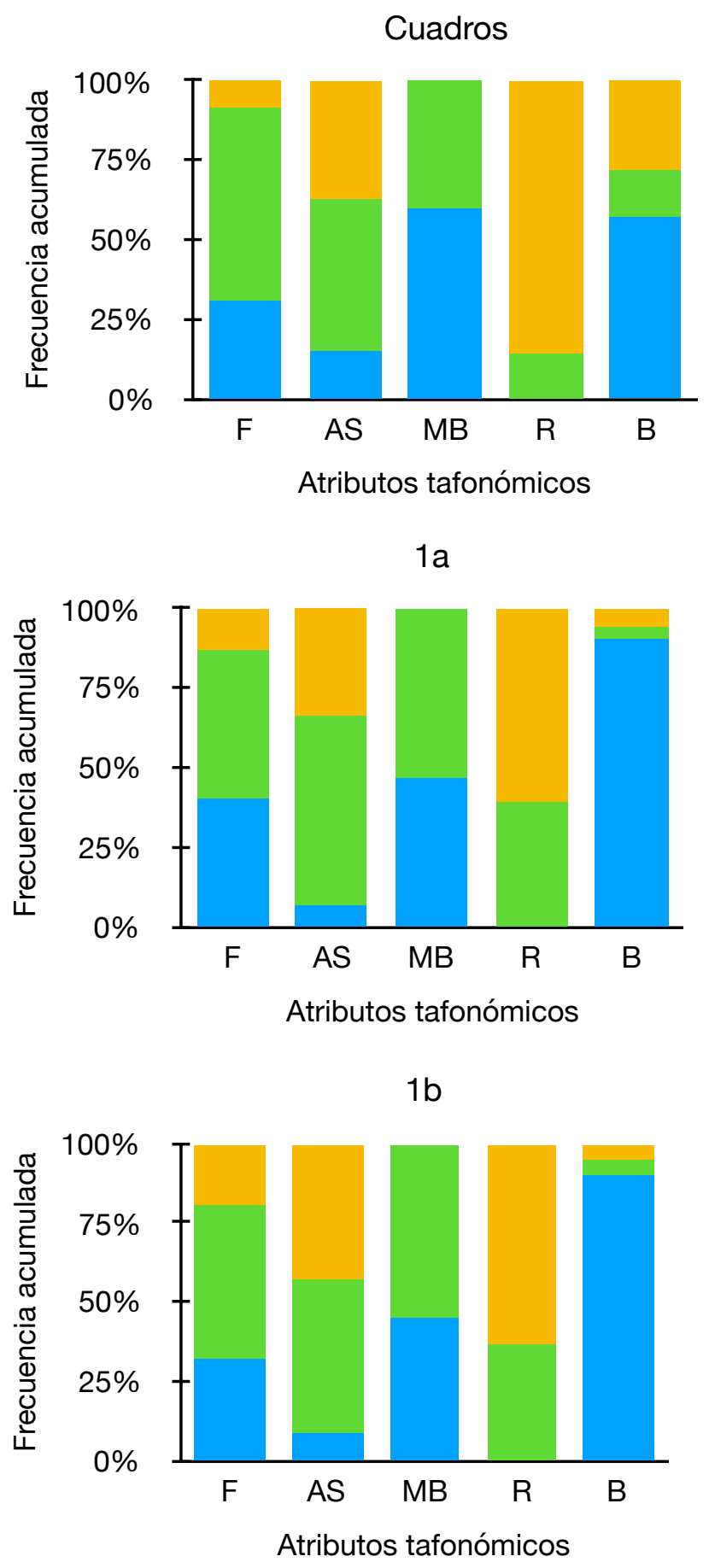

Figura 10. Frecuencia acumulada de los atributos tafonómicos observados en los bioclastos de los cuadros y las submuestras procesadas de $\mathrm{C} 1$ con relación a su hábito de vida. Referencias igual que para la Figura 1. Datos presentados en Capítulo 3, Tabla 3.11. 


\section{Concentración 2}

1

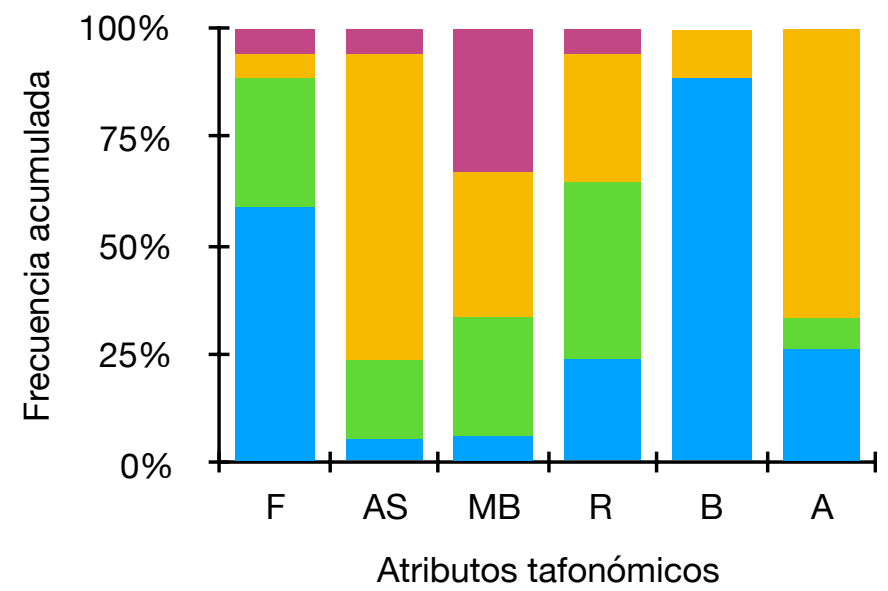

3

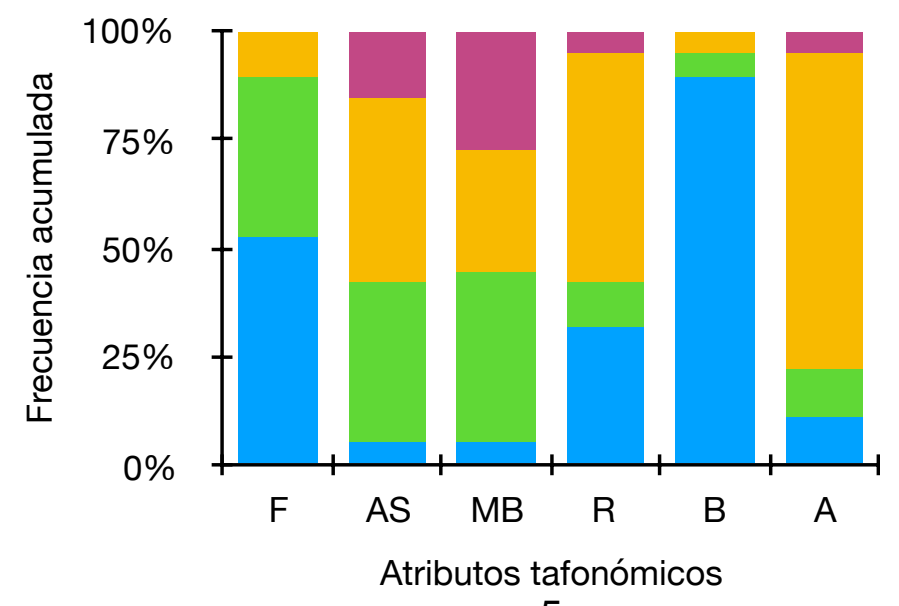

5

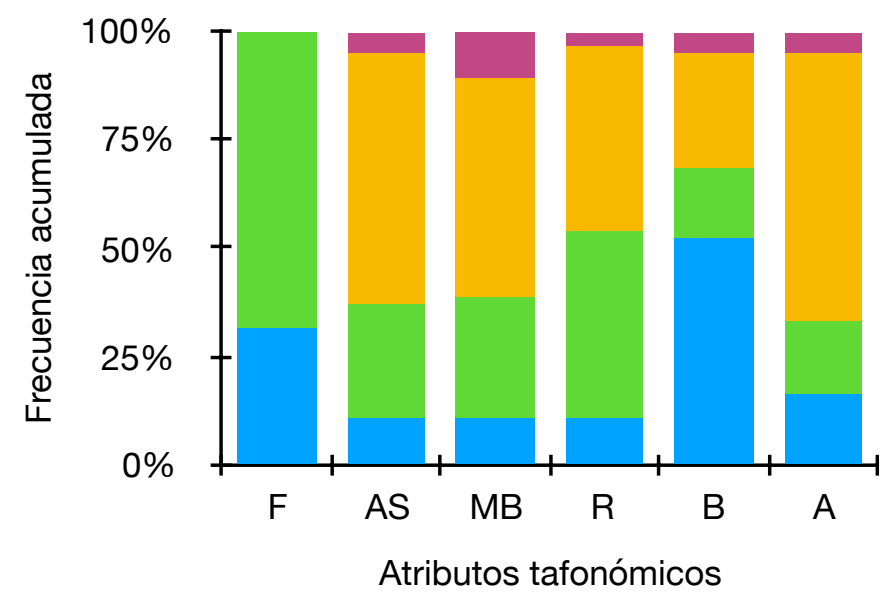

2

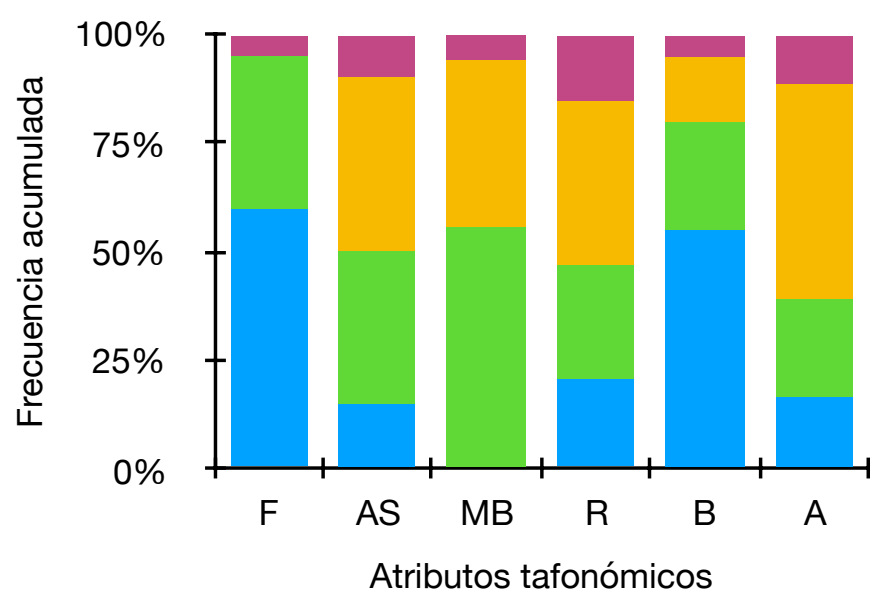

4

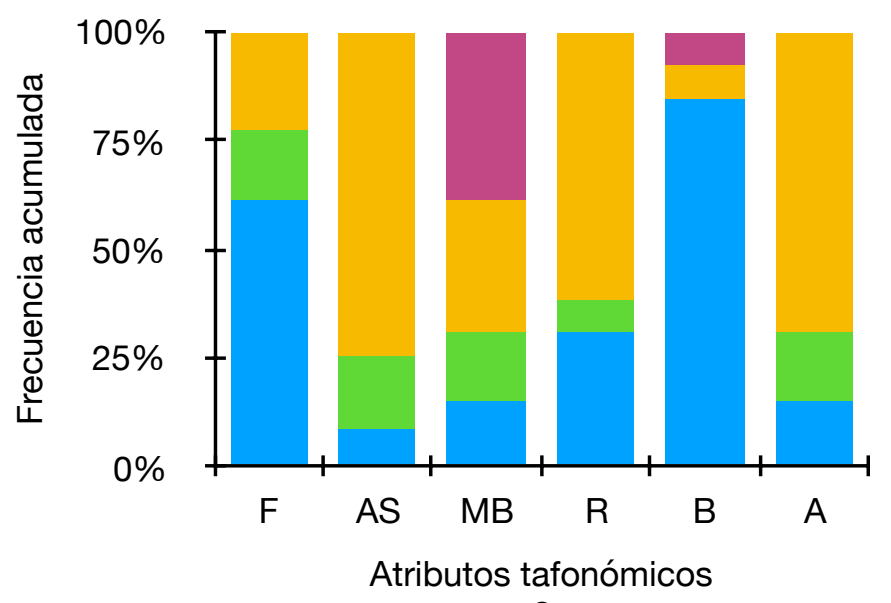

6

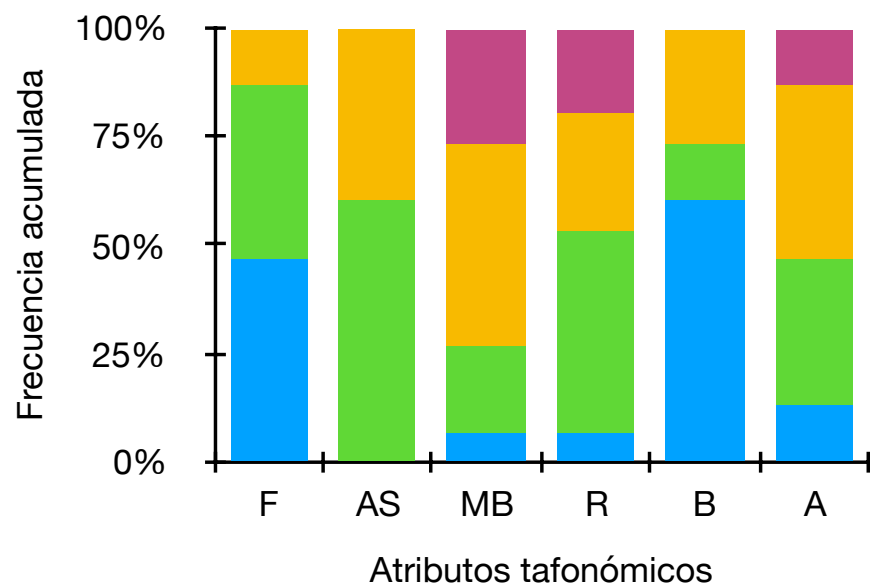

Figura 11. Frecuencia acumulada de los atributos tafonómicos observados en cada uno de los cuadros de C2. Fragmentación (F): (1) completo, (2) incompleto, (3) fragmento. Alteración superficial (AS): (1) baja, (2) moderada, (3) alta. Modificación de bordes (MB): (1) continuo, (2) discontinuo, (3) ausente. Redondeamiento (R): (1) ausente, (2) aguzado, (3) redondeado. Bioerosión (B): (1) baja, (2) moderada, (3) alta, Articulación (A) : (1) articulado, (2) separado, (3) desarticulado. 1, azul; 2, verde; 3 , amarillo; NV (no visible), violeta.. Datos presentados en Capítulo 3, Tabla 3.13 
7

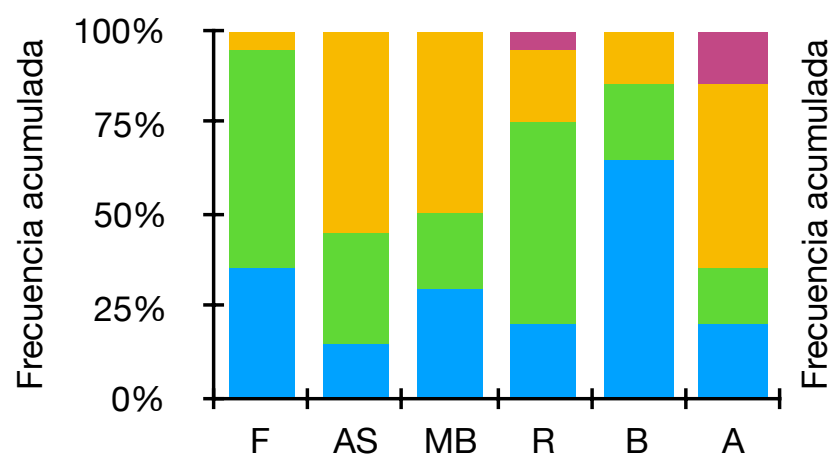

Atributos tafonómicos

9
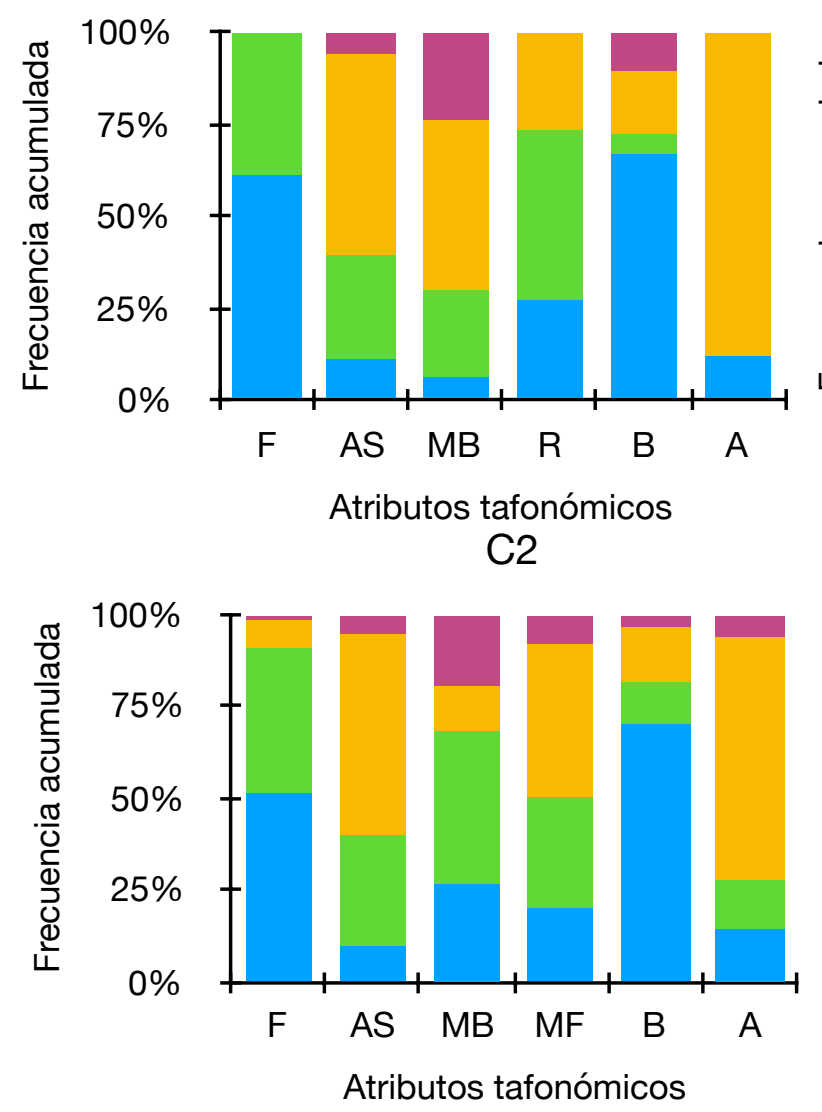

8

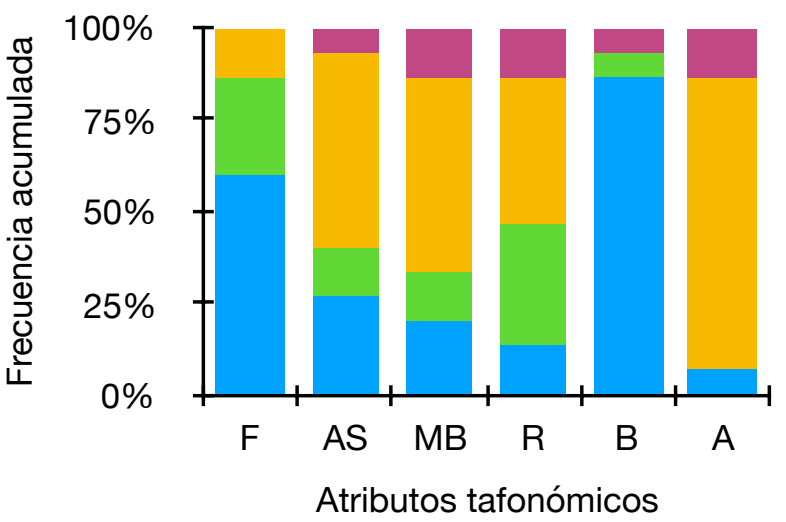

10

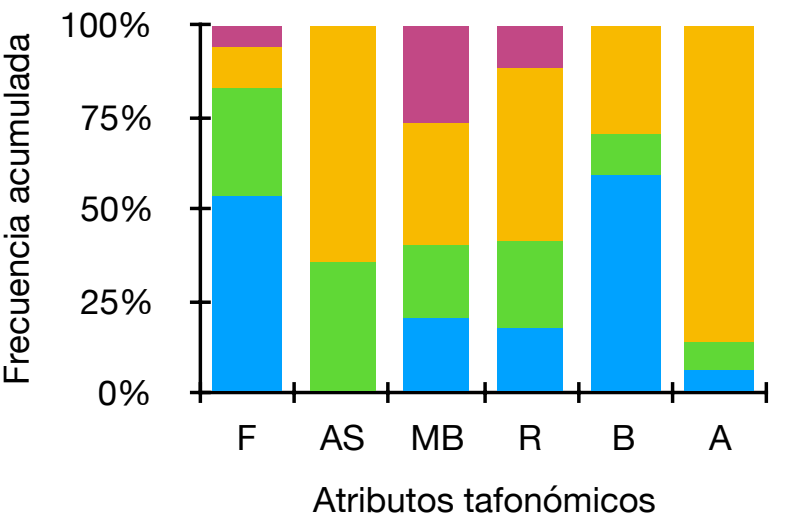

Figura 11. (Continuación) Frecuencia acumulada de los atributos tafonómicos observados en cada uno de los cuadros de C2. Fragmentación (F): (1) completo, (2) incompleto, (3) fragmento. Alteración superficial (AS): (1) baja, (2) moderada, (3) alta. Modificación de bordes (MB): (1) continuo, (2) discontinuo, (3) ausente. Redondeamiento (R): (1) ausente, (2) aguzado, (3) redondeado. Bioerosión (B): (1) baja, (2) moderada, (3) alta, Articulación (A) : (1) articulado, (2) separado, (3) desarticulado. 1, azul; 2, verde; 3, amarillo; NV (no visible), violeta. Datos presentados en Capítulo 3, Tabla 3.13 


\section{Concentración 3}

1
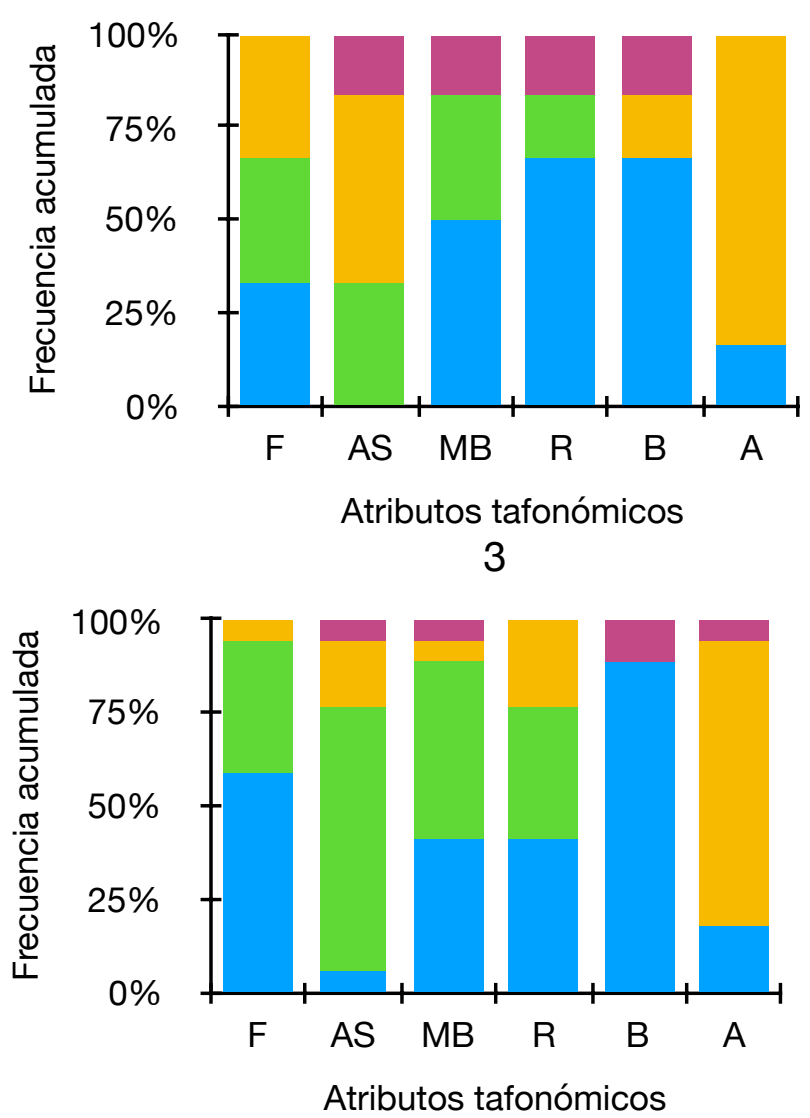

5

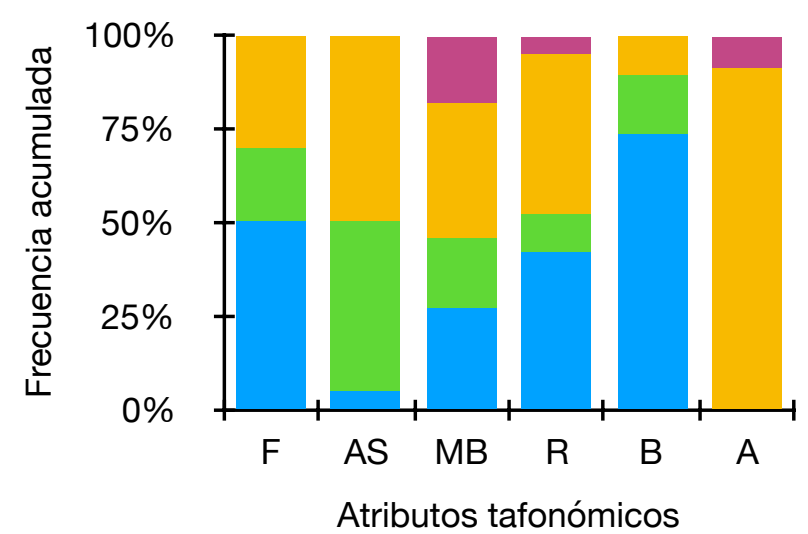

C3

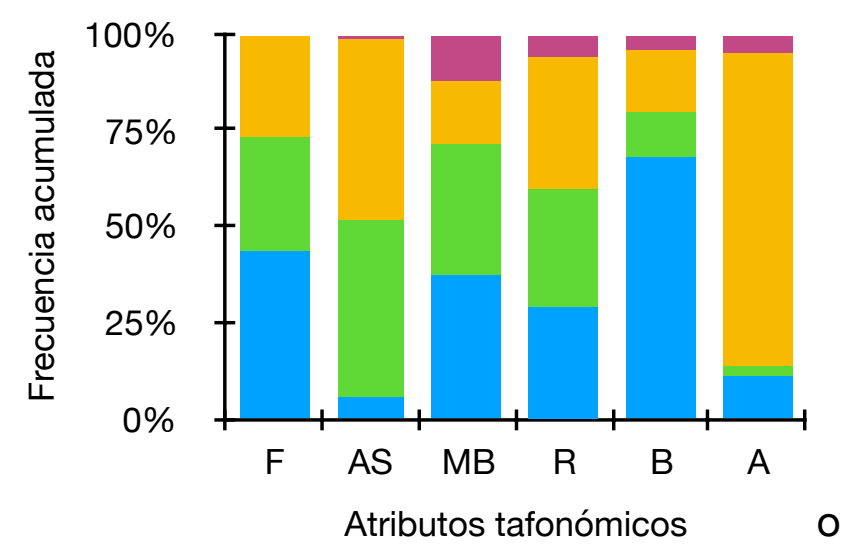

2
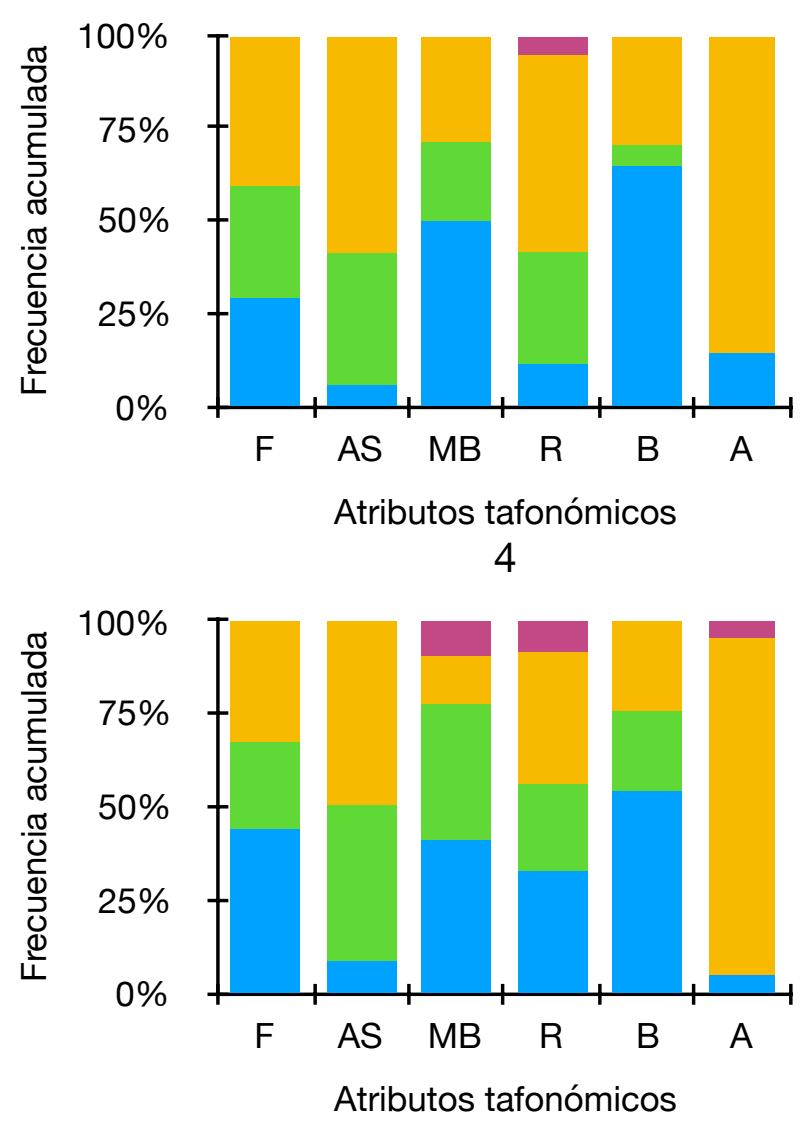

6

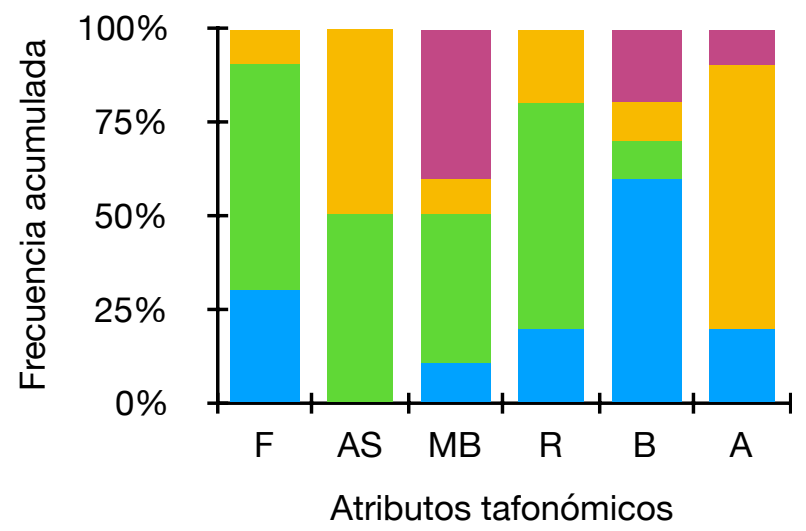


Figura 12. Frecuencia acumulada de los atributos tafonómicos observados en cada uno de los cuadros de C3. Fragmentación (F): (1) completo, (2) incompleto, (3) fragmento. Alteración superficial (AS): (1) baja, (2) moderada, (3) alta. Modificación de bordes (MB): (1) continuo, (2) discontinuo, (3) ausente. Redondeamiento (R): (1) ausente, (2) aguzado, (3) redondeado. Bioerosión (B): (1) baja, (2) moderada, (3) alta, Articulación (A) : (1) articulado, (2) separado, (3) desarticulado. 1, azul; 2, verde; 3 , amarillo; NV (no visible), violeta. Datos presentados en Capítulo 3, Tabla 3.17.

$3 a$
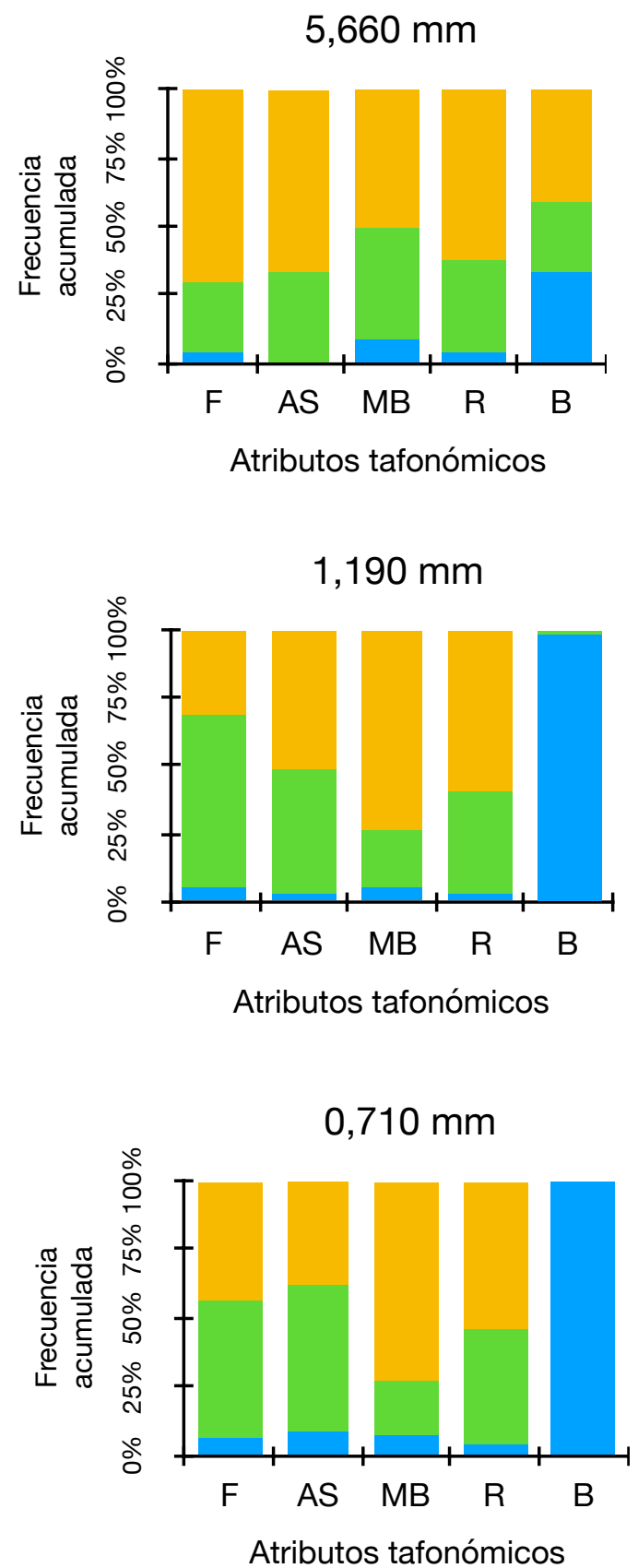

$3 b$
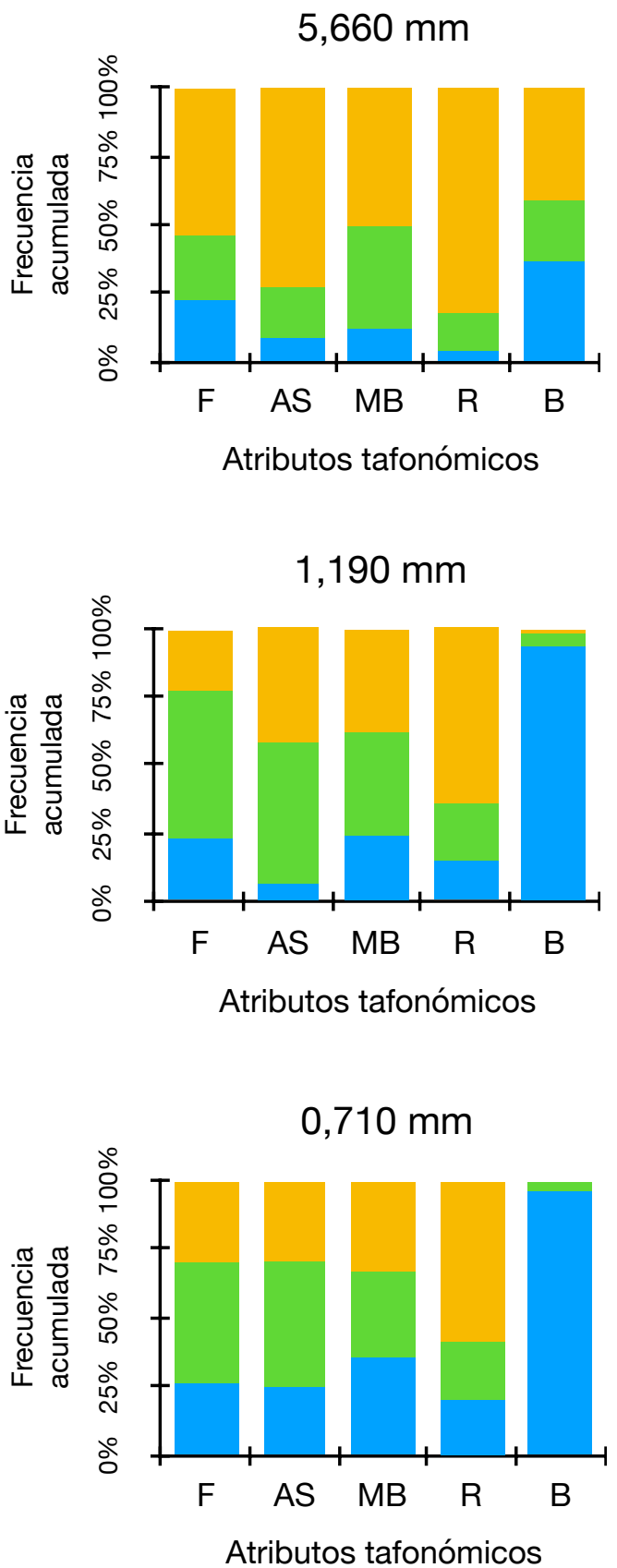

Figura 13. Frecuencia acumulada de los atributos tafonómicos observados en cada uno de los tamices en las submuestras procesadas de C3. Referencias igual que para la Figura 12. Datos presentados en Capítulo 3, Tabla 3.20. 
$3 a$
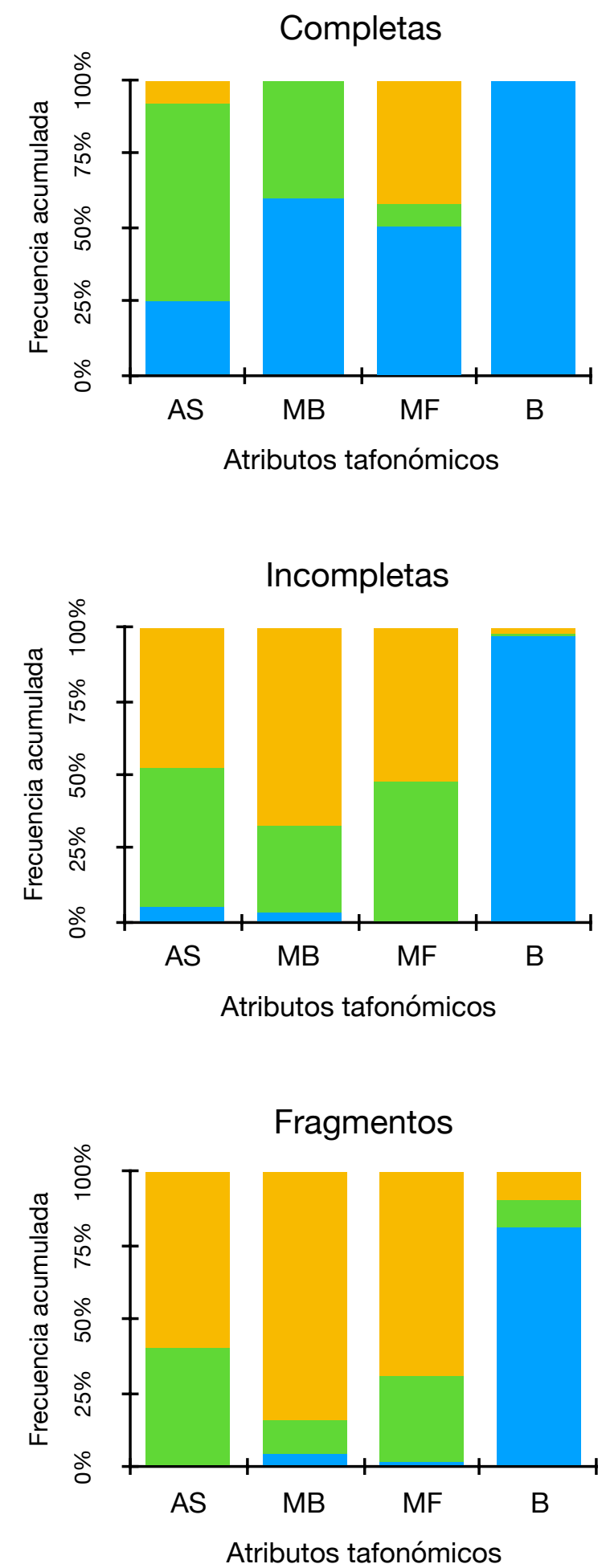
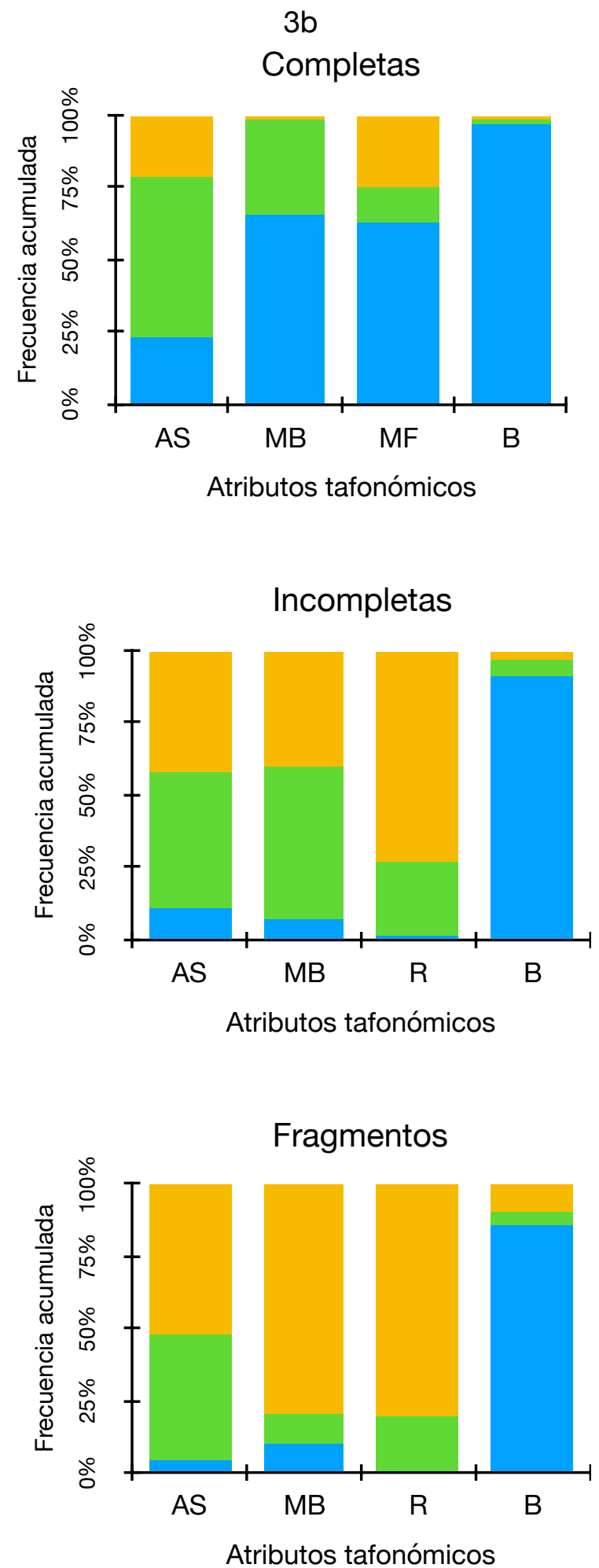

Figura 14. Frecuencia acumulada de los atributos tafonómicos observados en las conchillas completas, incompletas y fragmentos de las submuestras procesadas de C3. Referencias igual que para la Figura 12. Datos presentados en Capítulo 3, Tabla 3.21. 

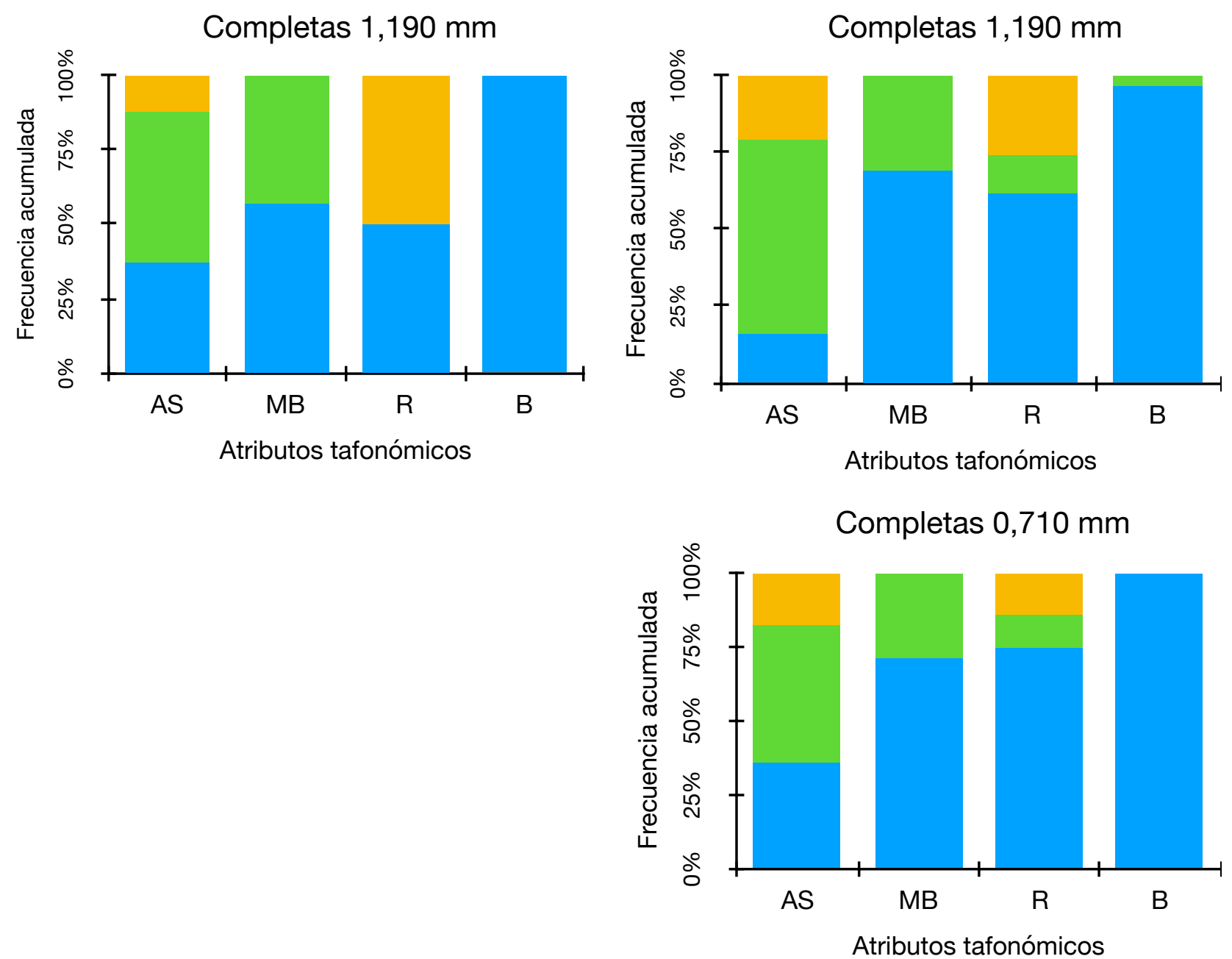

Figura 15. Frecuencia acumulada de los atributos tafonómicos observados en las conchillas completas, con relación al talle en las submuestras procesadas de C3. Referencias igual que para la Figura 12. Datos presentados en Capítulo 3, Tabla 3.22. 

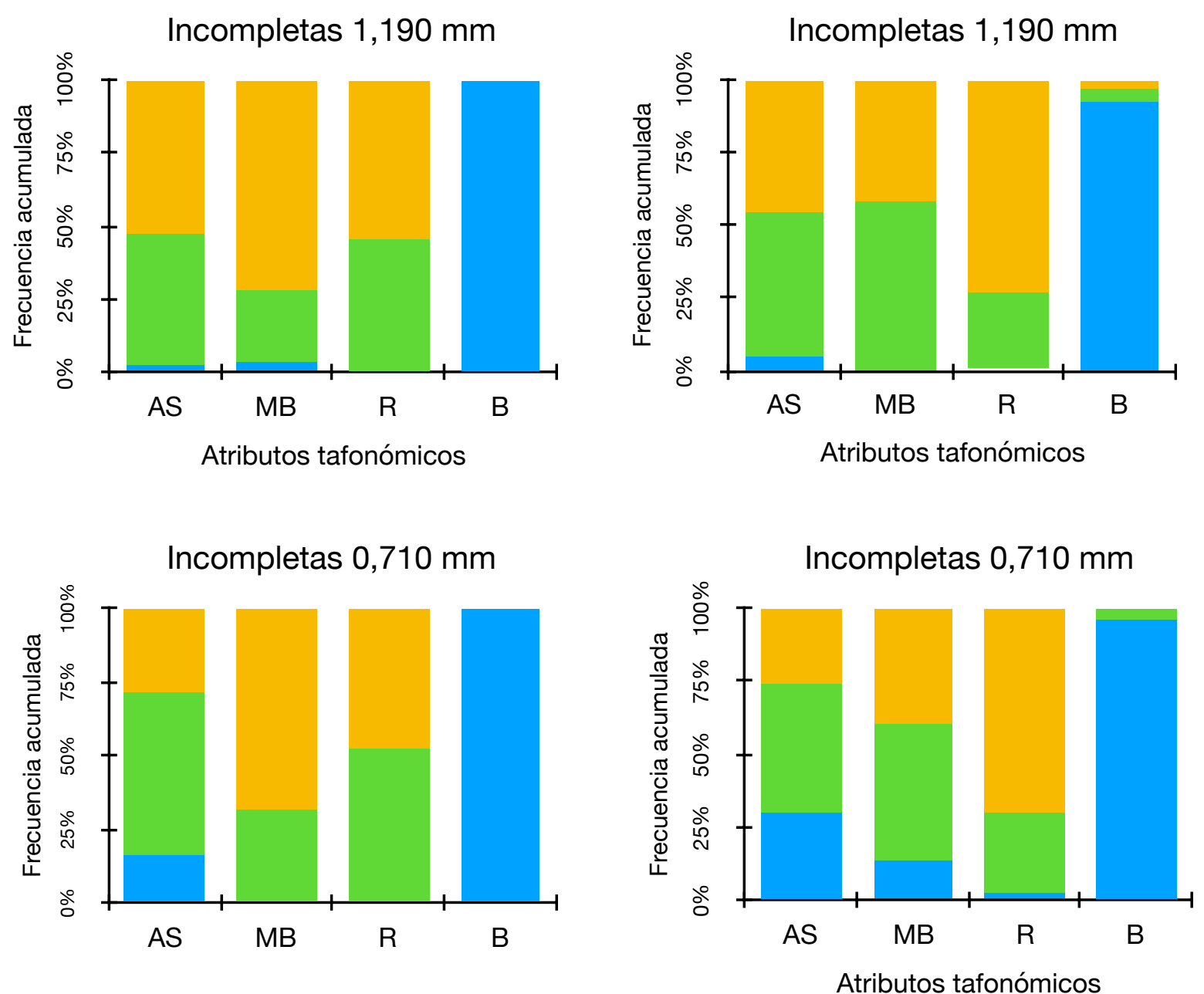

Figura 16. Frecuencia acumulada de los atributos tafonómicos observados en las conchillas incompletas, con relación al talle en las submuestras procesadas de C3. Referencias igual que para la figura 12. Datos presentados en Capítulo 3, Tabla 3.22 
Fragmentos 5,660 mm

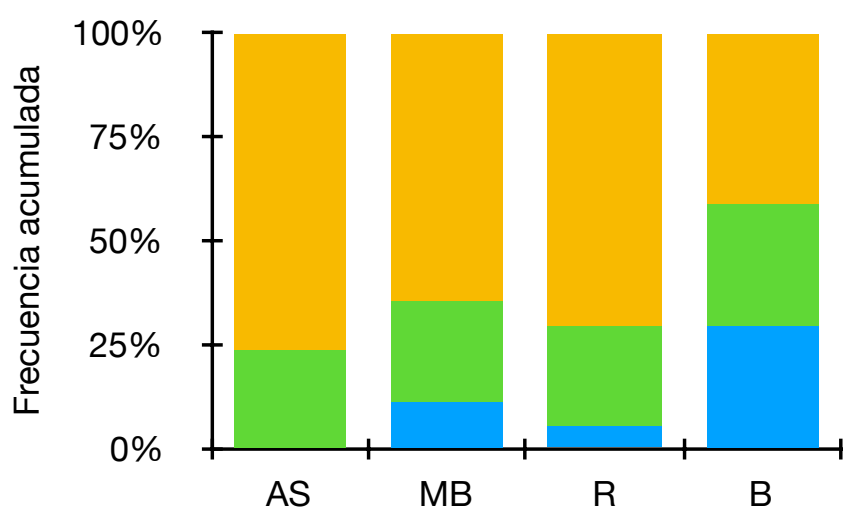

Fragmentos $1,190 \mathrm{~mm}$

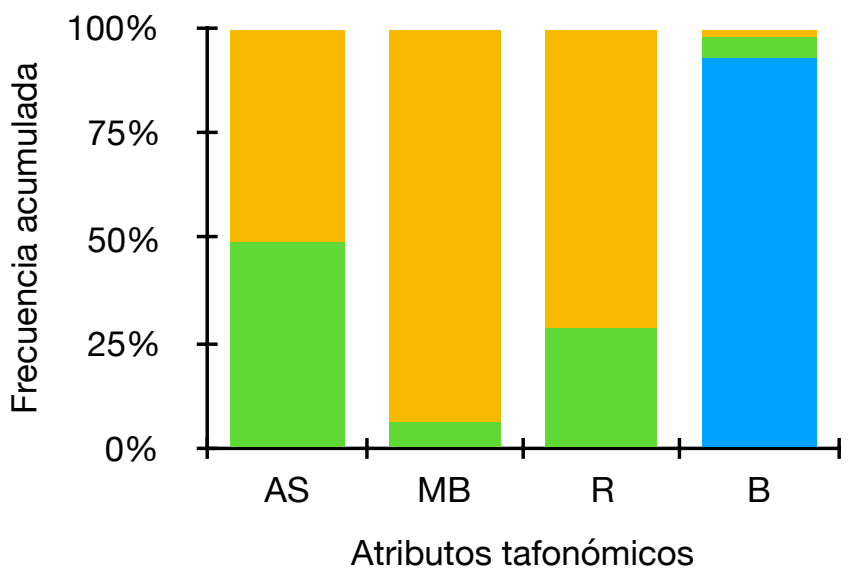

Fragmentos $0,710 \mathrm{~mm}$

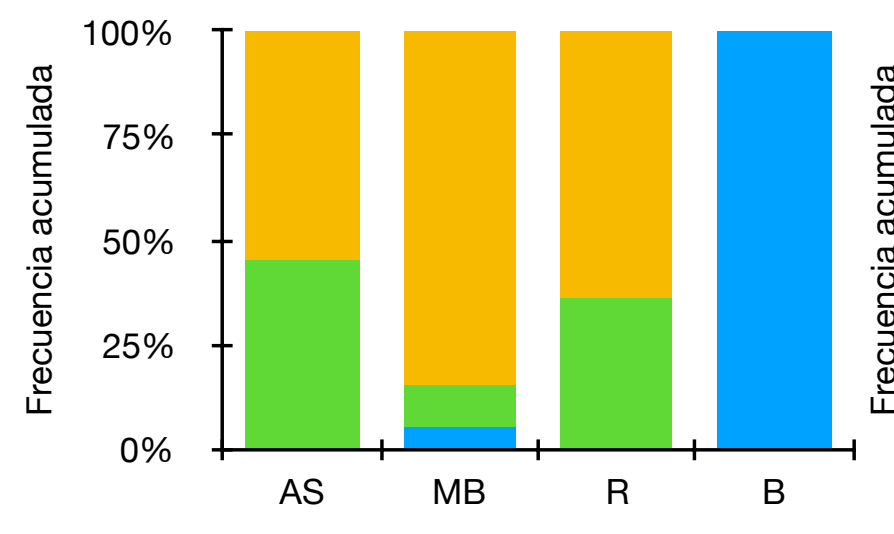

Atributos tafonómicos
Fragmentos $5,660 \mathrm{~mm}$

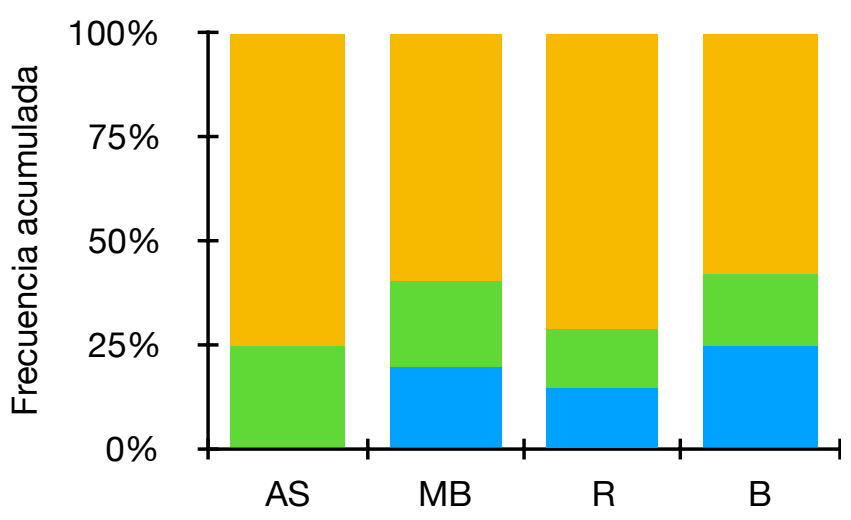

Fragmentos $1,190 \mathrm{~mm}$

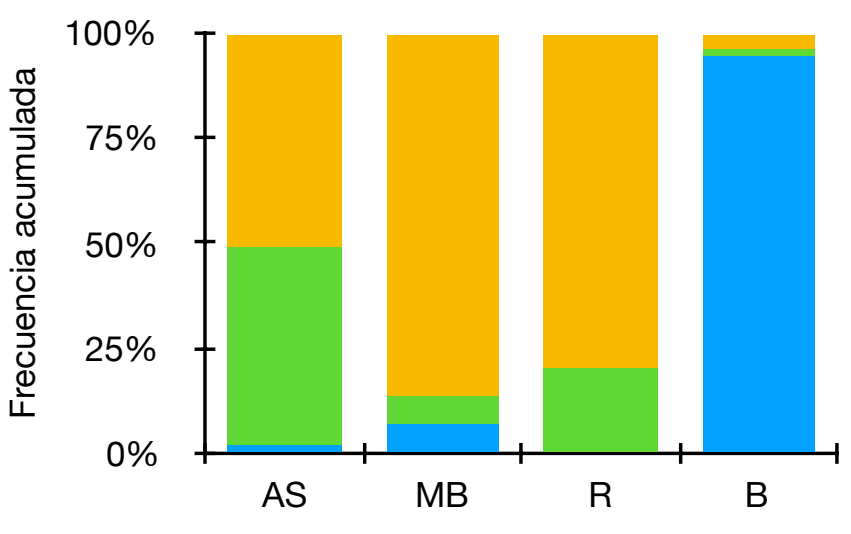

Atributos tafonómicos

Fragmentos $0,710 \mathrm{~mm}$

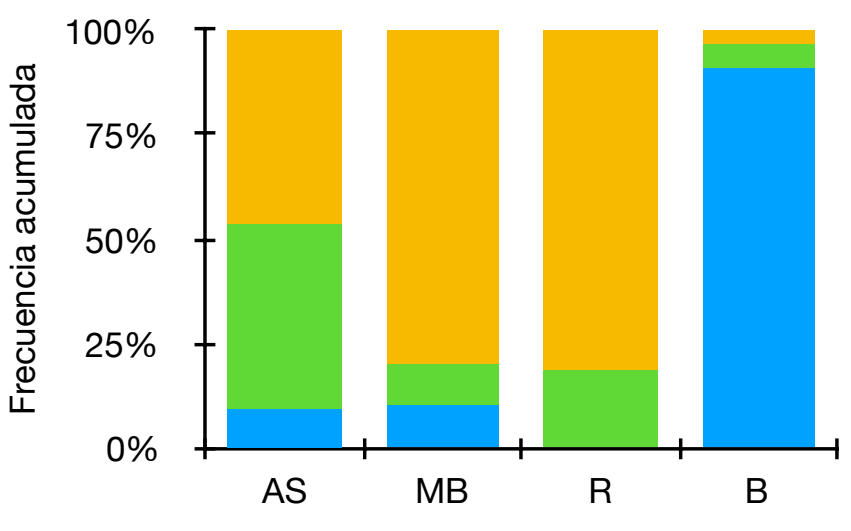

Atributos tafonómicos

Figura 17. Frecuencia acumulada de los atributos tafonómicos observados en los fragmentos de conchillas, con relación al talle en las submuestras procesadas de C3. Referencias igual que para la Figura 12. Datos presentados en Capítulo 3, Tabla 3.22. 
Pteromyrtea

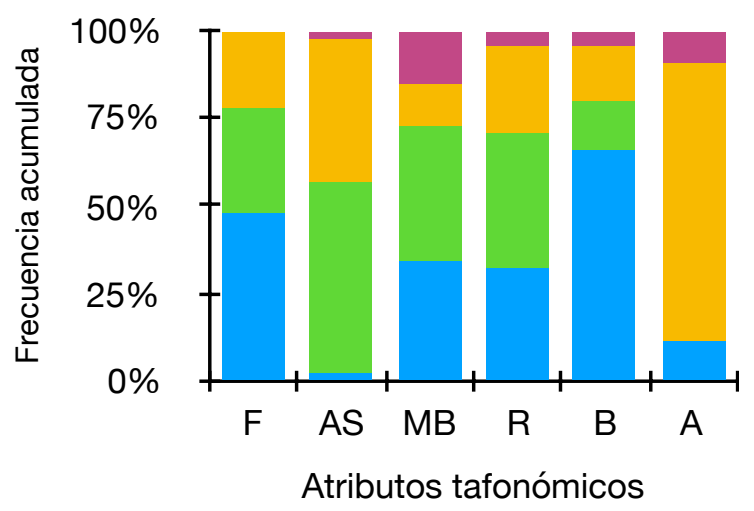

Turritella

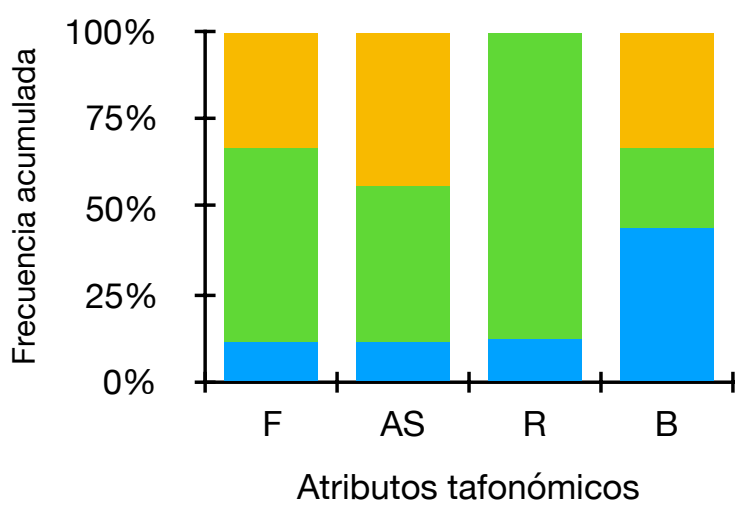

Figura 18. Frecuencia acumulada de los atributos tafonómicos observados en los taxones más abundantes de los cuadros de campo de C3. Referencias igual que para la Figura 12. Datos presentados en Capítulo 3, Tabla 3.23.

Pteromyrtea

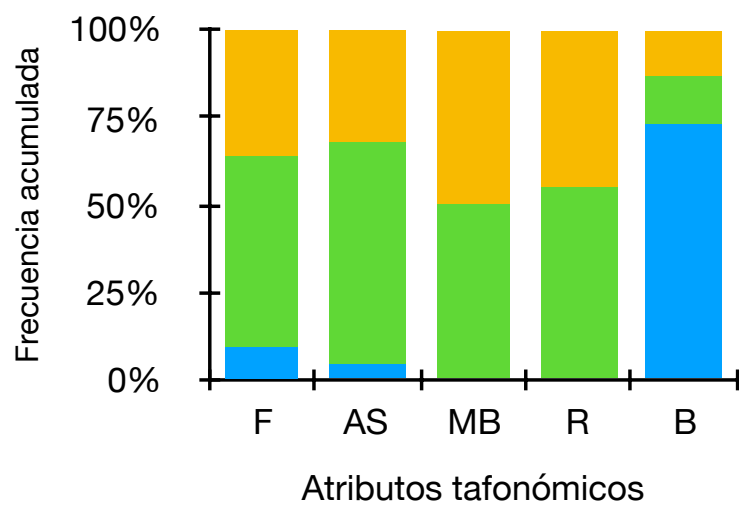

Retrotapes

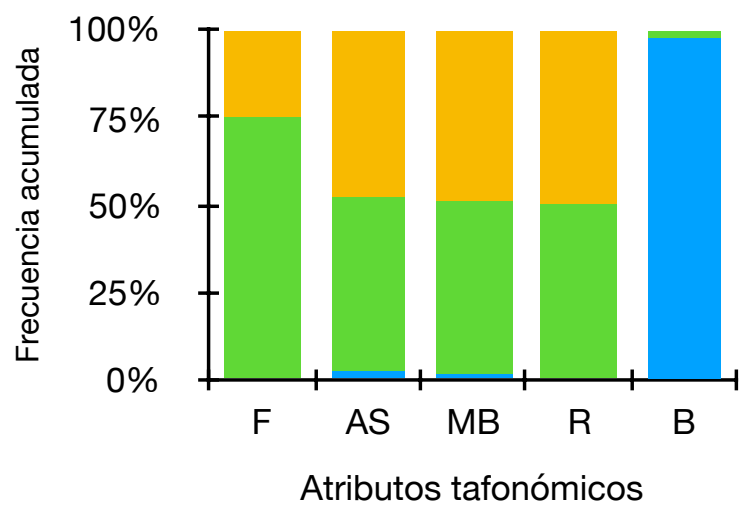

Figura 19. Frecuencia acumulada de los atributos tafonómicos observados en los taxones más abundantes de la submuestra 3a. Referencias igual que para la Figura 12. Datos presentados en Capítulo 3, Tabla 3.24.

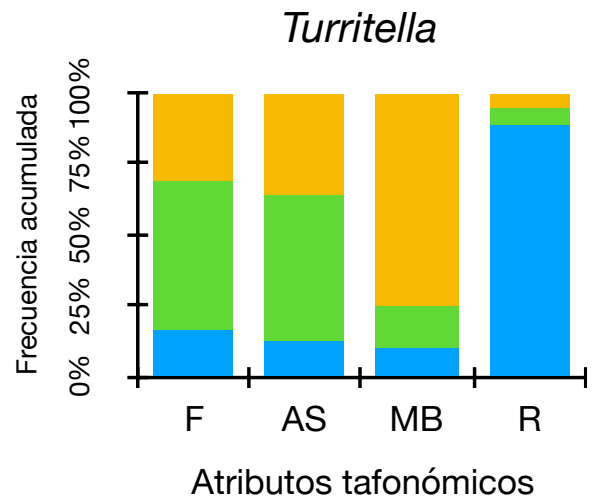

Atributos tafonómicos

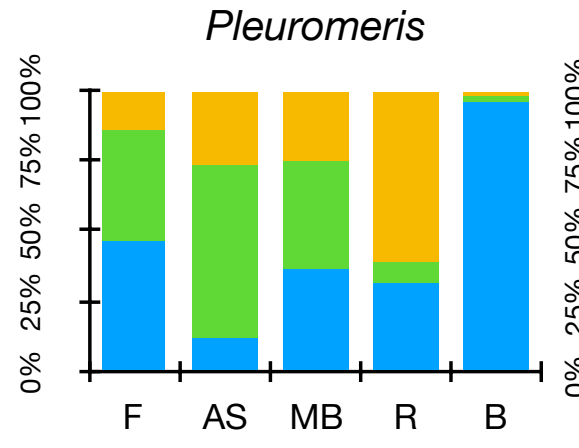

Atributos tafonómicos

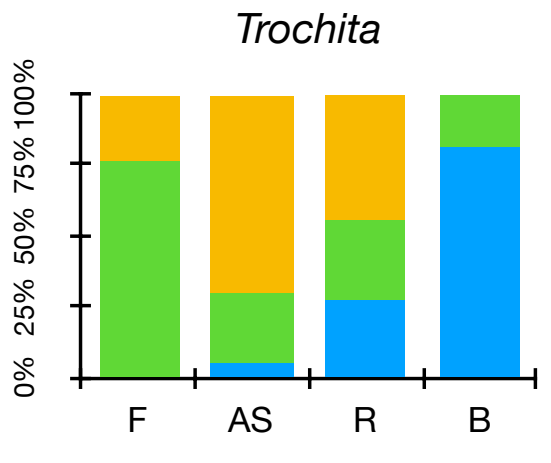

Atributos tafonómicos

Figura 20. Frecuencia acumulada de los atributos tafonómicos observados en los taxones más abundantes de la submuestra 3b. Referencias igual que para la Figura 12. Datos presentados en Capítulo 3, Tabla 3.25. 
Infaunales

Cuadros

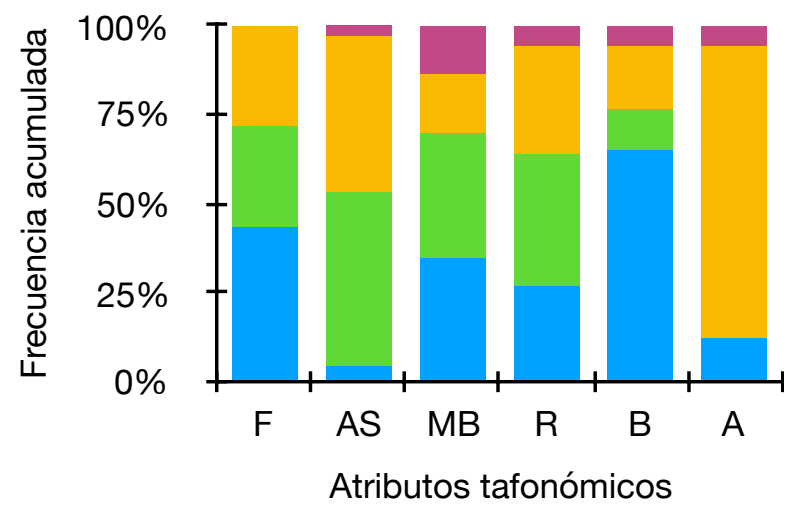

$3 a$

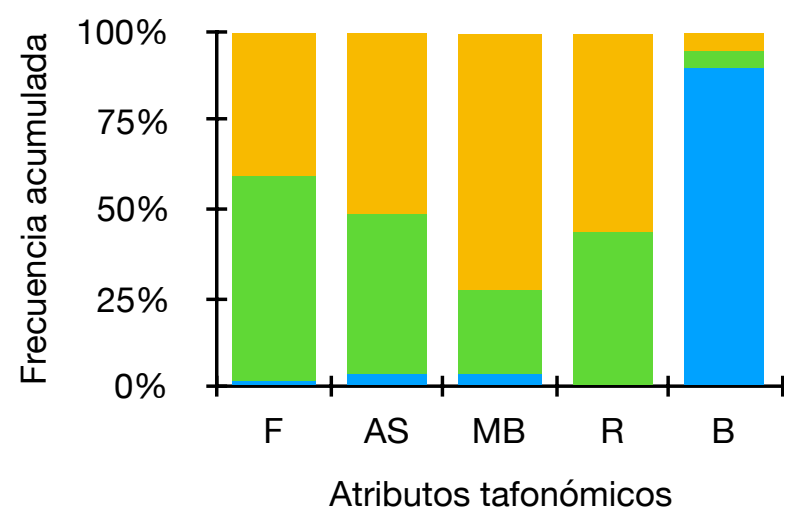

$3 a$

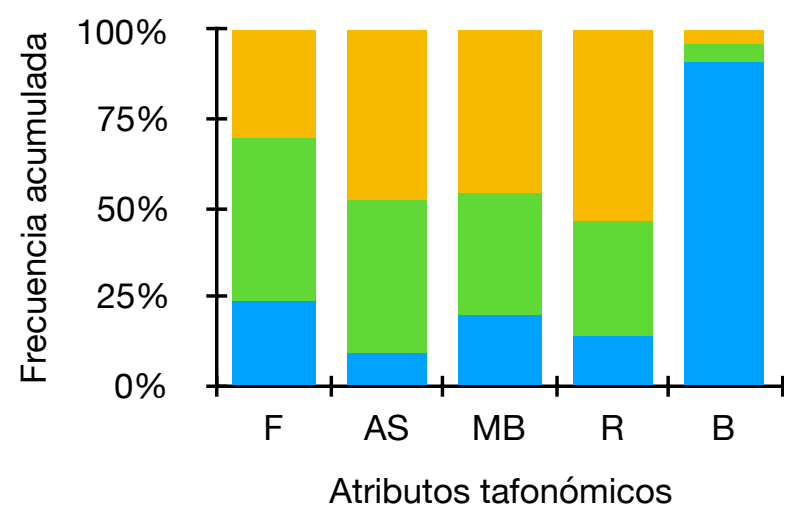

Epifaunales

Cuadros

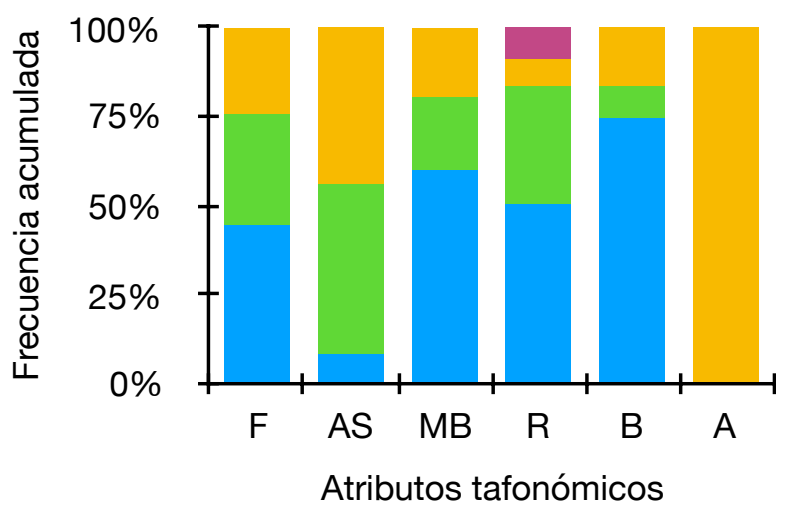

$3 b$

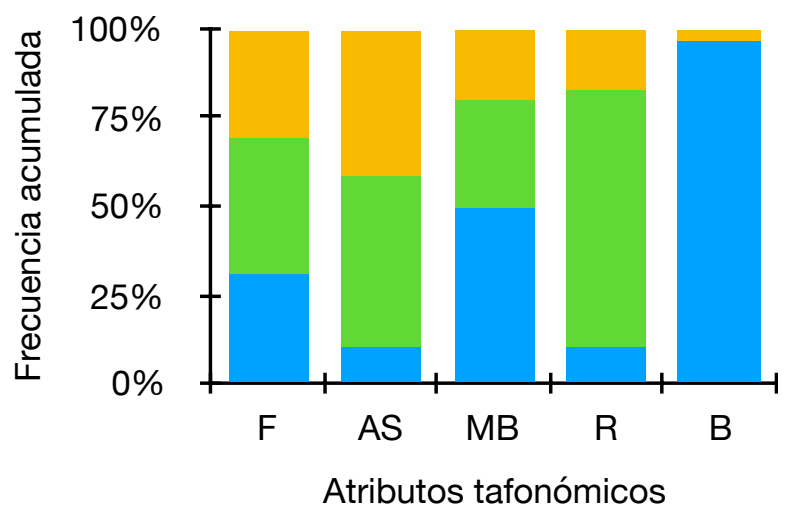

$3 b$

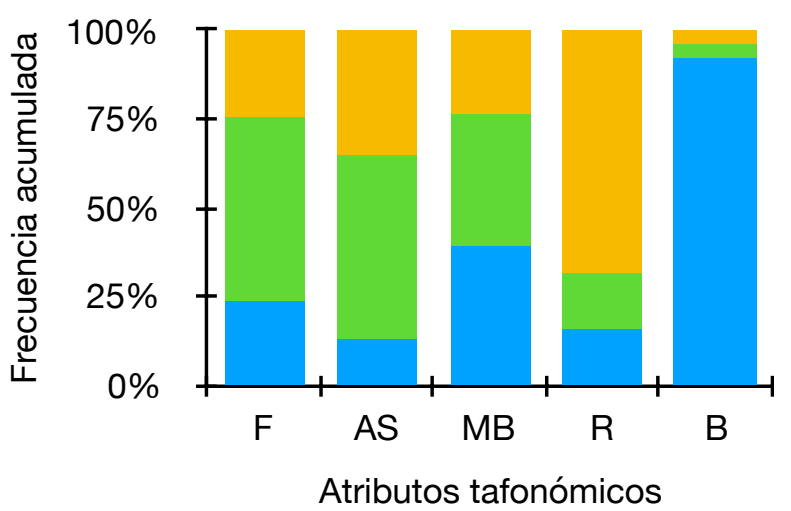

Figura 21. Frecuencia acumulada de los atributos tafonómicos observados en los bioclastos de los cuadros y las submuestras procesadas de C3 con relación a su hábito de vida. Referencias igual que para la figura 12. Datos presentados en Capítulo 3, Tabla 3.26. 


\section{Concentración 4}

1

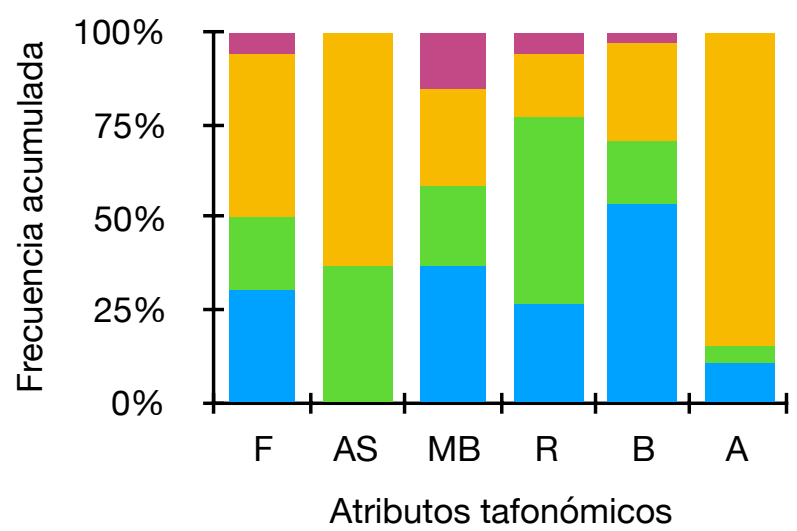

3

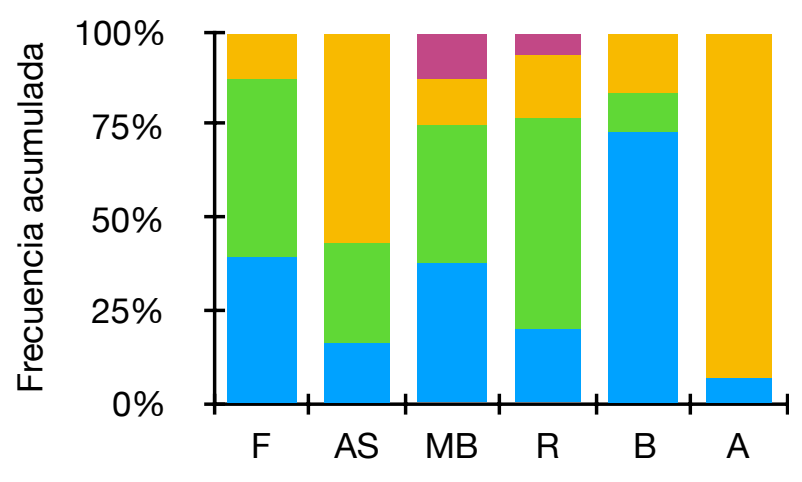

Atributos tafonómicos

5

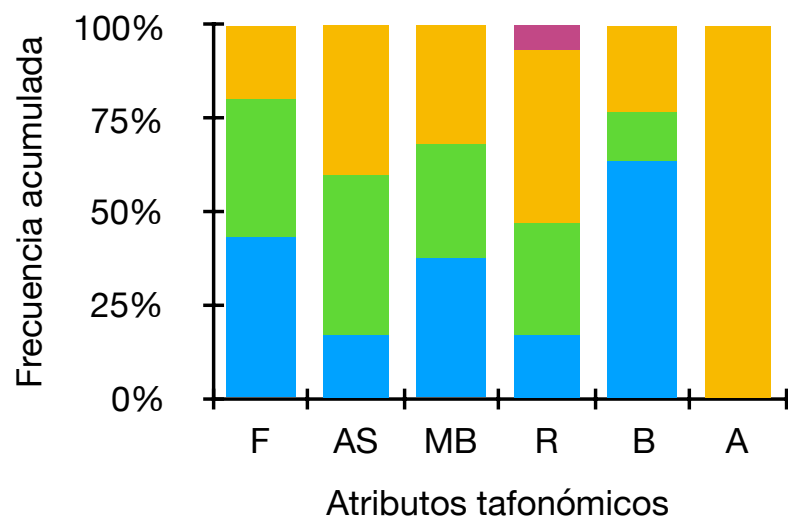

2
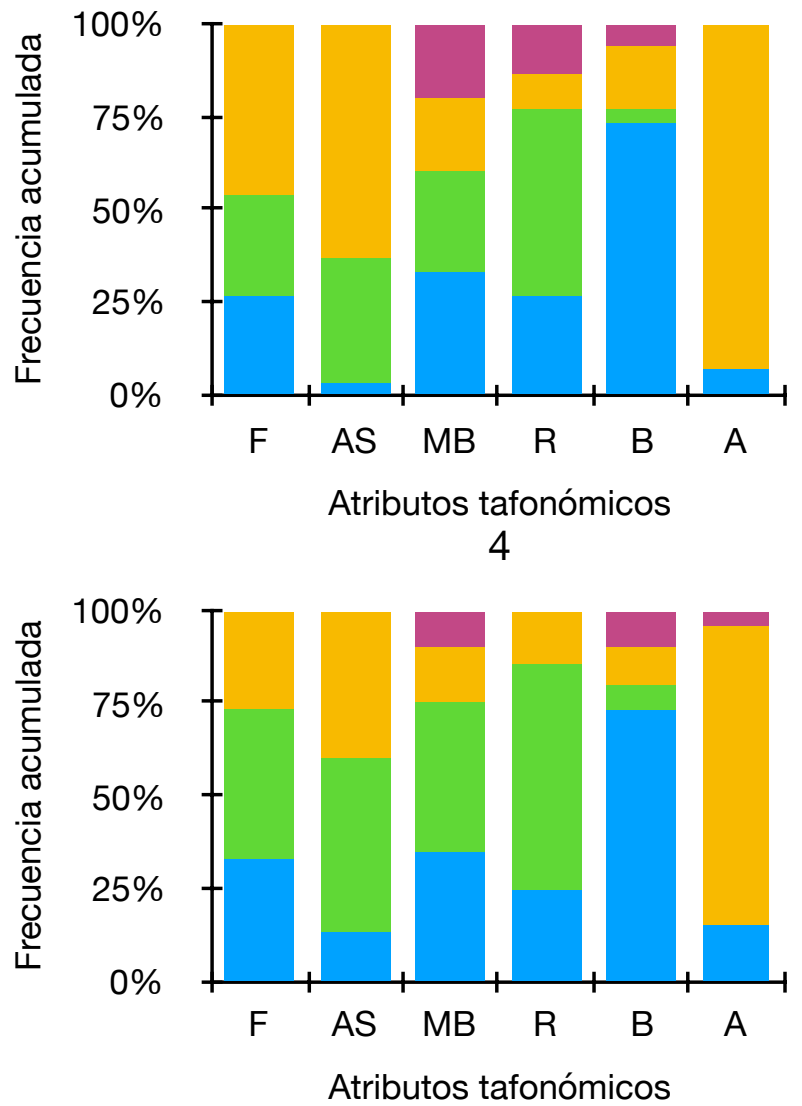

6

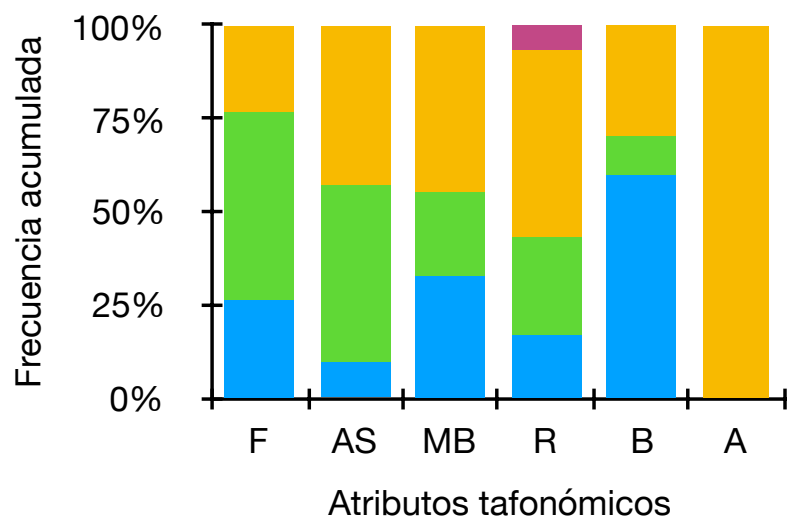

Figura 22. Frecuencia acumulada de los atributos tafonómicos observados en cada uno de los cuadros de C4. Fragmentación (F): (1) completo, (2) incompleto, (3) fragmento. Alteración superficial (AS): (1) baja, (2) moderada, (3) alta. Modificación de bordes (MB): (1) continuo, (2) discontinuo, (3) ausente. Redondeamiento (R): (1) ausente, (2) aguzado, (3) redondeado. Bioerosión (B): (1) baja, (2) moderada, (3) alta, Articulación (A) : (1) articulado, (2) separado, (3) desarticulado. 1, azul; 2, verde; 3 , amarillo; NV (no visible), violeta. Datos presentados en Capítulo 3, Tabla 3.28. 
7

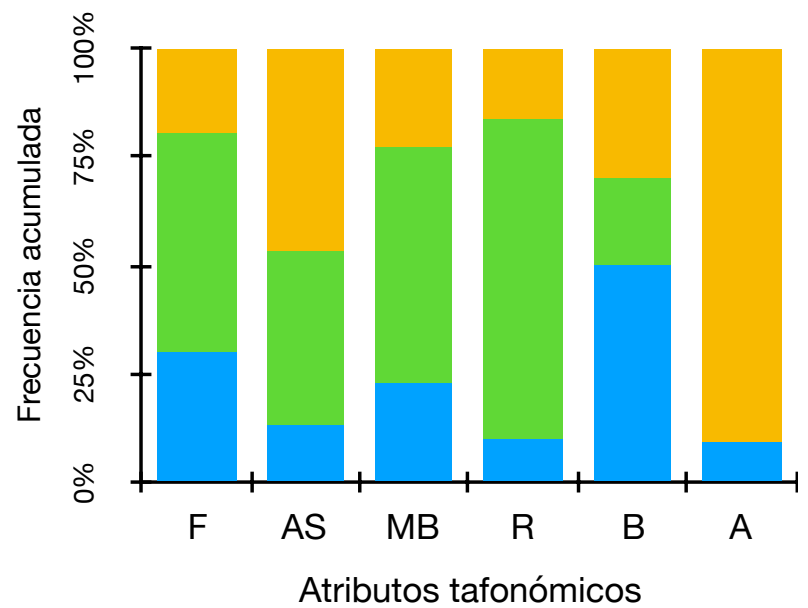

9

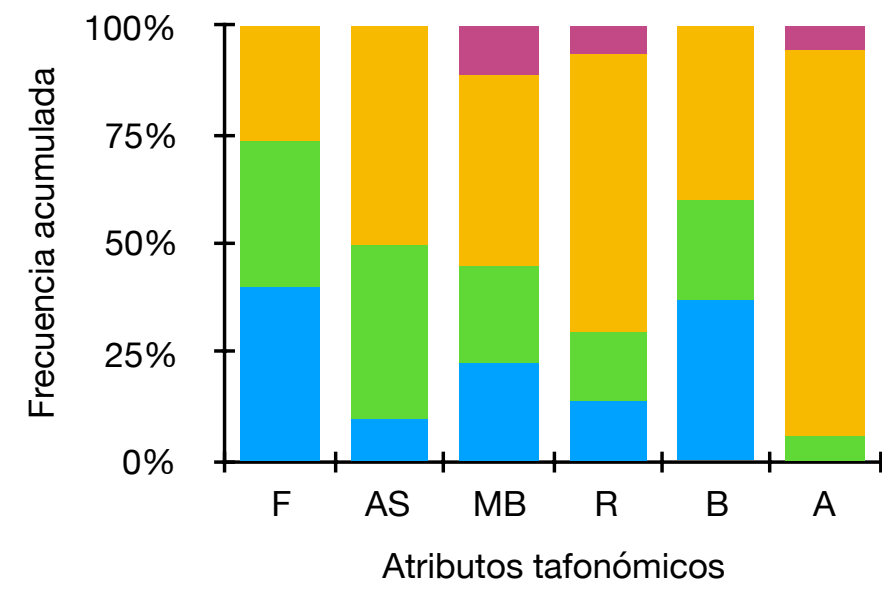

8

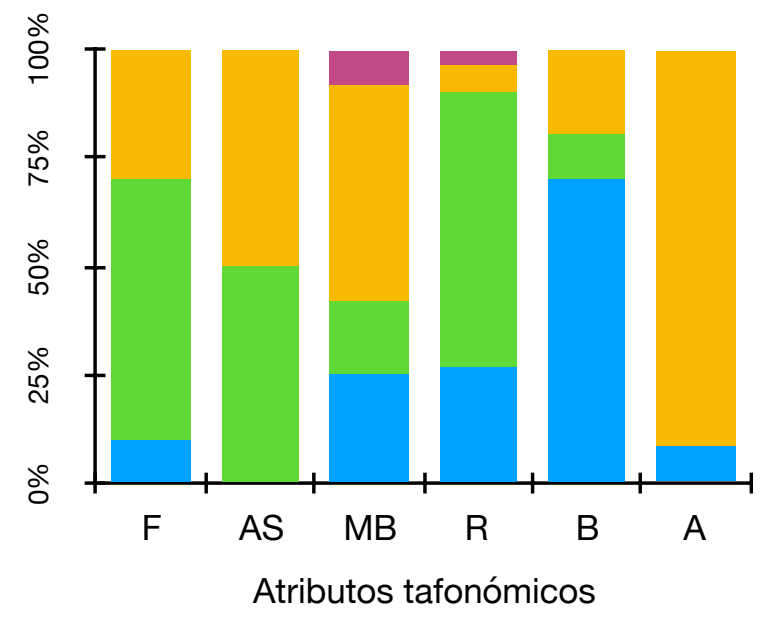

C4

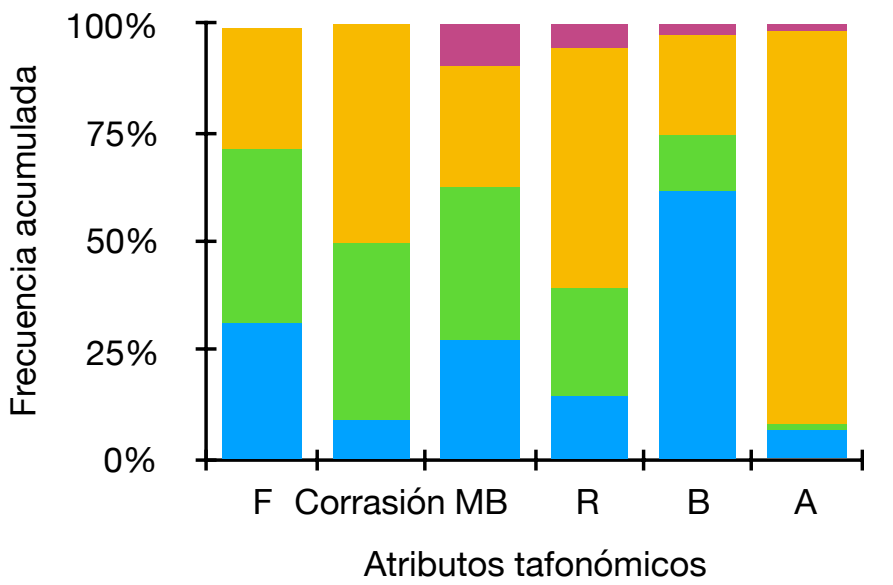

Figura 22. (Continuación) Frecuencia acumulada de los atributos tafonómicos observados en cada uno de los cuadros de C4. Fragmentación (F): (1) completo, (2) incompleto, (3) fragmento. Alteración superficial (AS): (1) baja, (2) moderada, (3) alta. Modificación de bordes (MB): (1) continuo, (2) discontinuo, (3) ausente. Redondeamiento (R): (1) ausente, (2) aguzado, (3) redondeado. Bioerosión (B): (1) baja, (2) moderada, (3) alta, Articulación (A) : (1) articulado, (2) separado, (3) desarticulado. 1, azul; 2, verde; 3, amarillo; NV (no visible), violeta. Datos presentados en Capítulo 3, Tabla 3.28. 
$4 a$
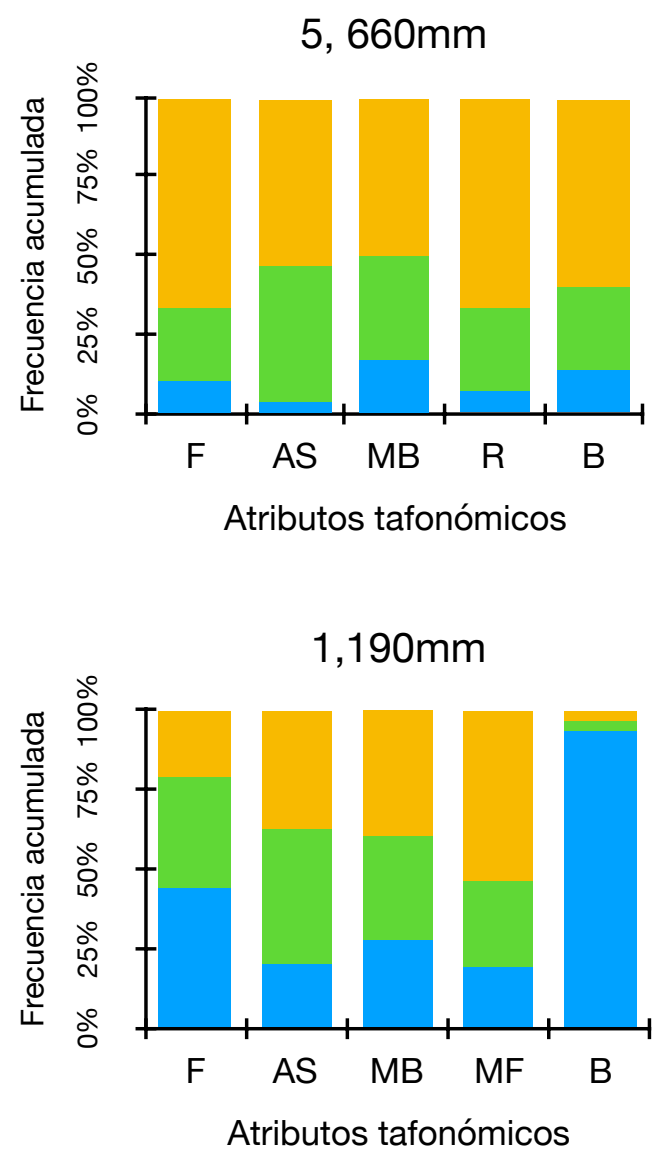

$0,710 \mathrm{~mm}$

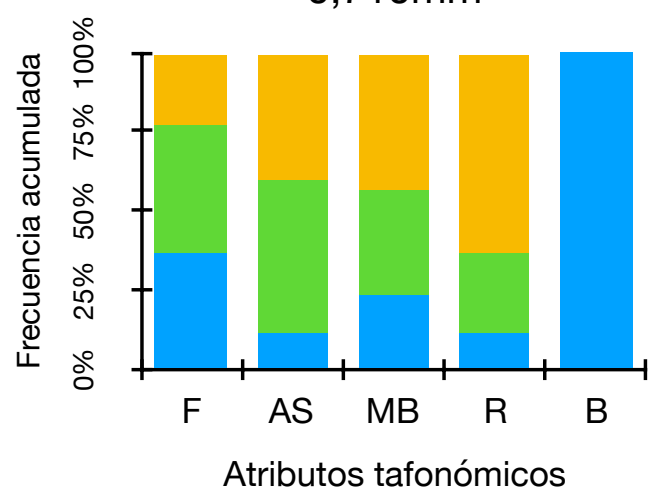

$4 b$
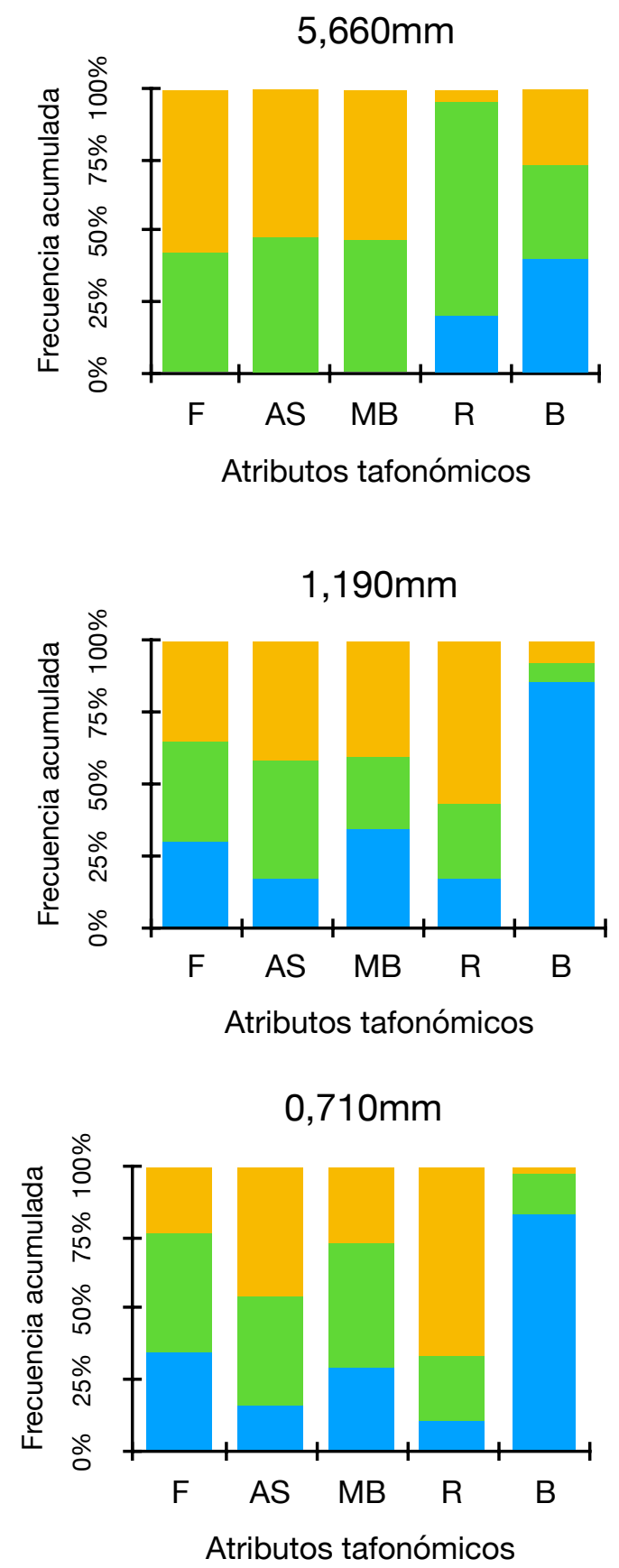

Figura 23. Frecuencia acumulada de los atributos tafonómicos observados en cada uno de los tamices en las submuestras procesadas de C4. Referencias igual que para la Figura 22. Datos presentados en Capítulo 3, Tabla 3.31. 

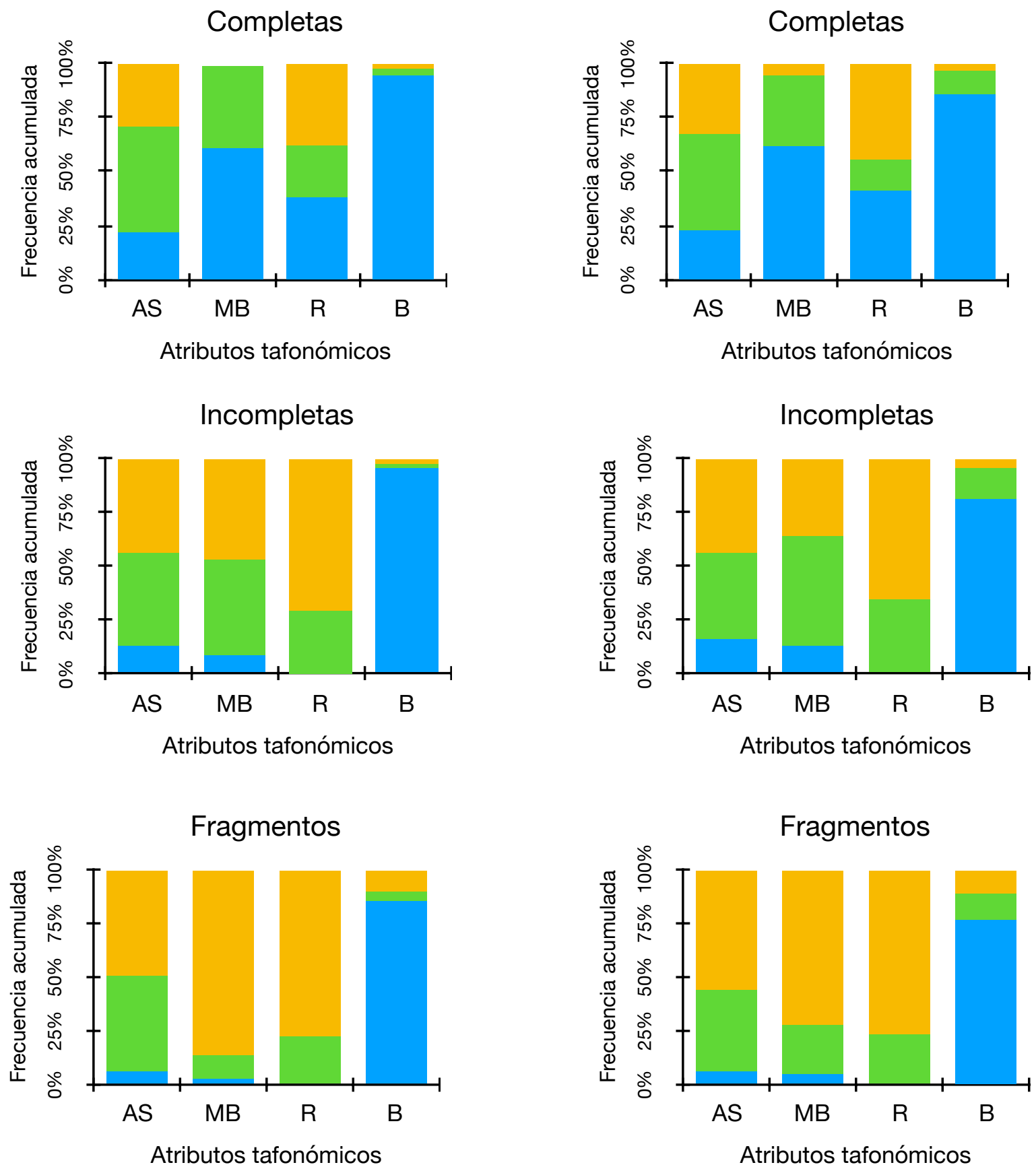

Figura 24. Frecuencia acumulada de los atributos tafonómicos con relación al grado de fragmentación observado en cada una submuestras procesadas de C4. Referencias igual que para la F igura 22. Datos presentados en Capítulo 3, Tabla 3.32. 
$4 \mathrm{a}$

Completas $1,190 \mathrm{~mm}$

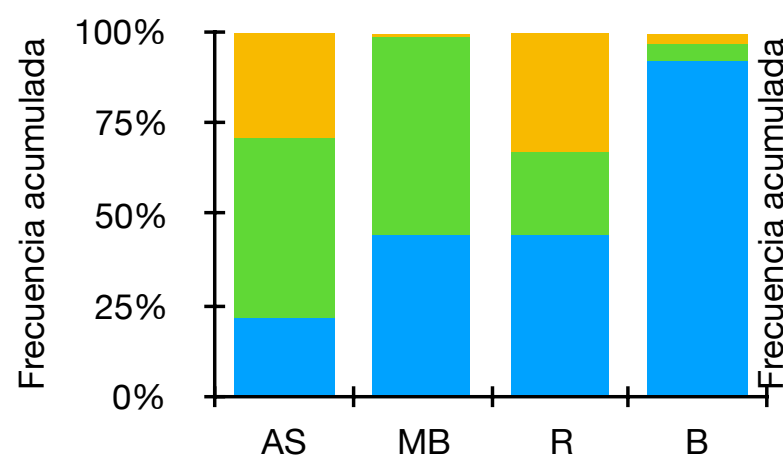

Atributos tafonómicos

Completas $0,710 \mathrm{~mm}$

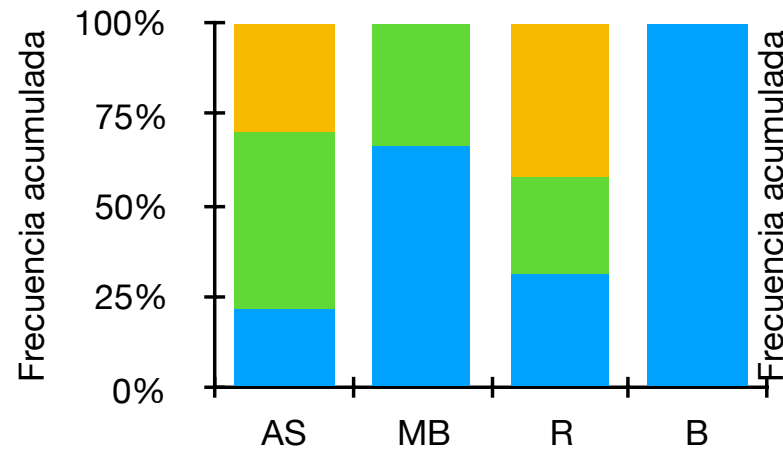

Atributos tafonómicos
$4 \mathrm{~b}$

Completas 1,190 mm
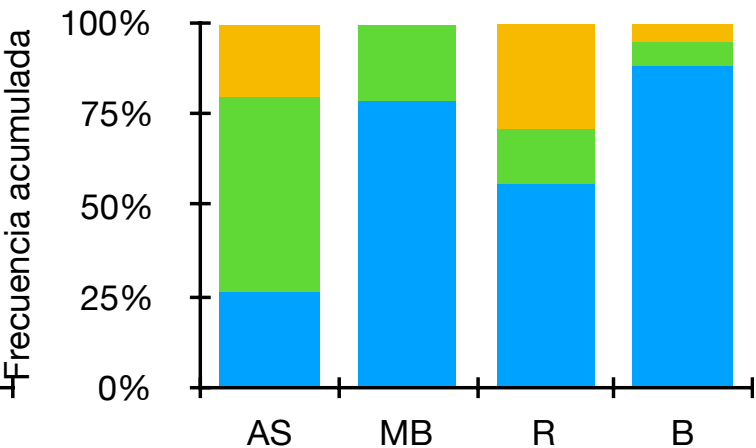

Atributos tafonómicos

Completas $0,710 \mathrm{~mm}$

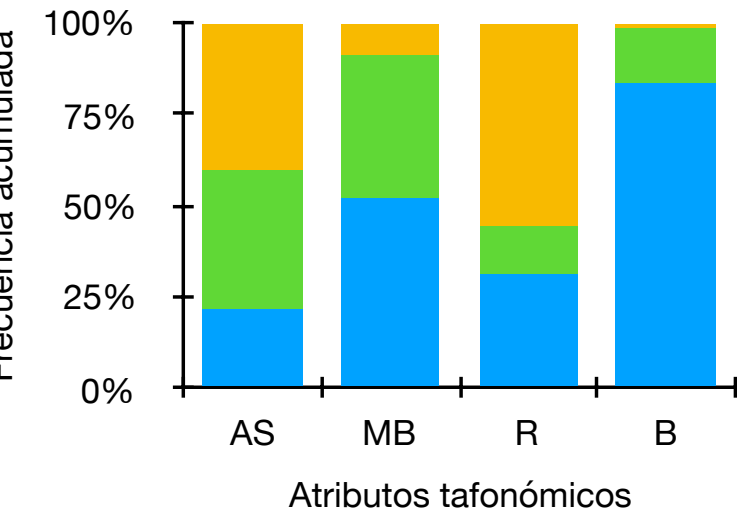

Figura 25. Frecuencia acumulada de los atributos tafonómicos observados en las conchillas completas, con relación al talle en las submuestras procesadas de C4. Referencias igual que para la Figura 22. Datos presentados en Capítulo 3, Tabla 3.33. 

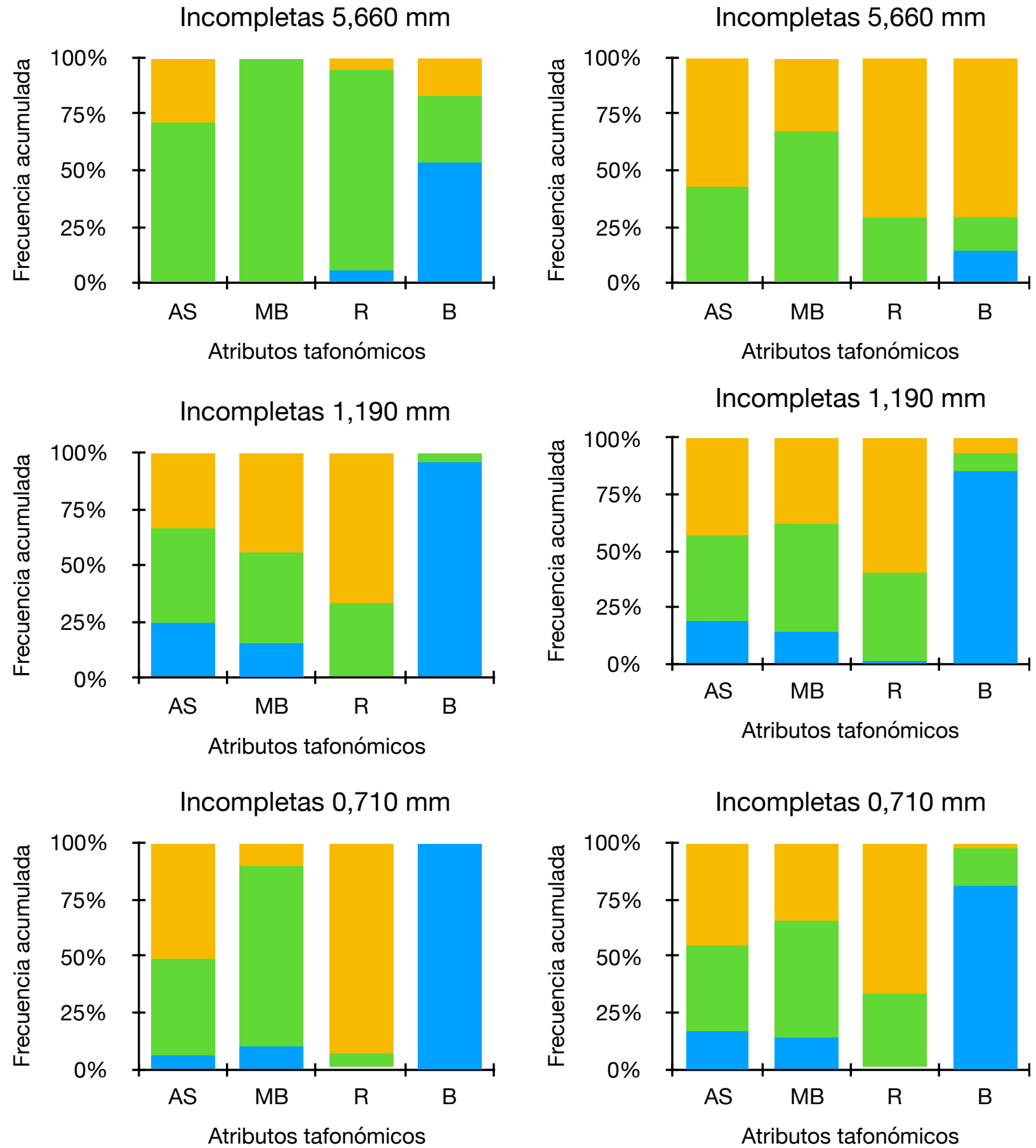

Figura 26.Frecuencia acumulada de los atributos tafonómicos observados en las conchillas incompletas, con relación al talle en las submuestras procesadas de C4. Referencias igual que para la Figura 22. Datos presentados en Capítulo 3, Tabla 3.33. 
Fragmentos 5,660 mm

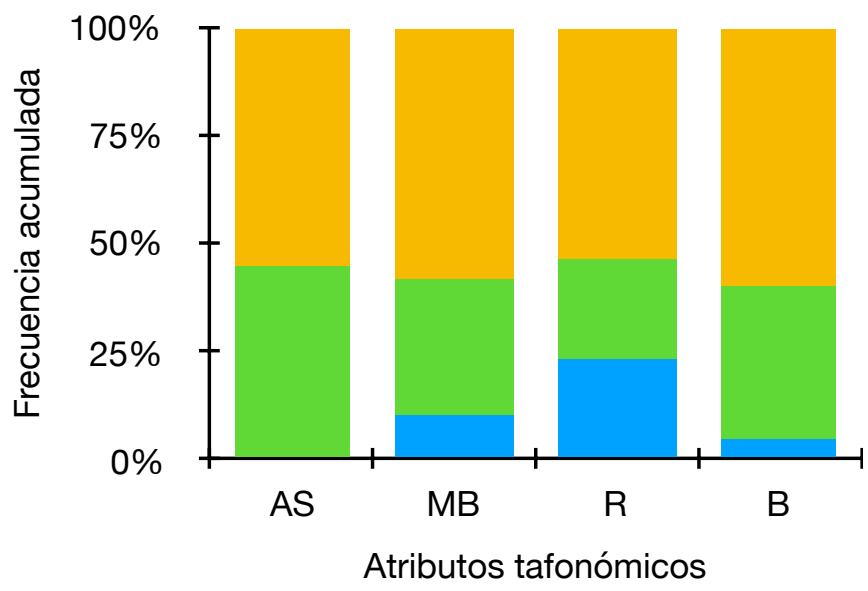

Fragmentos $1,190 \mathrm{~mm}$
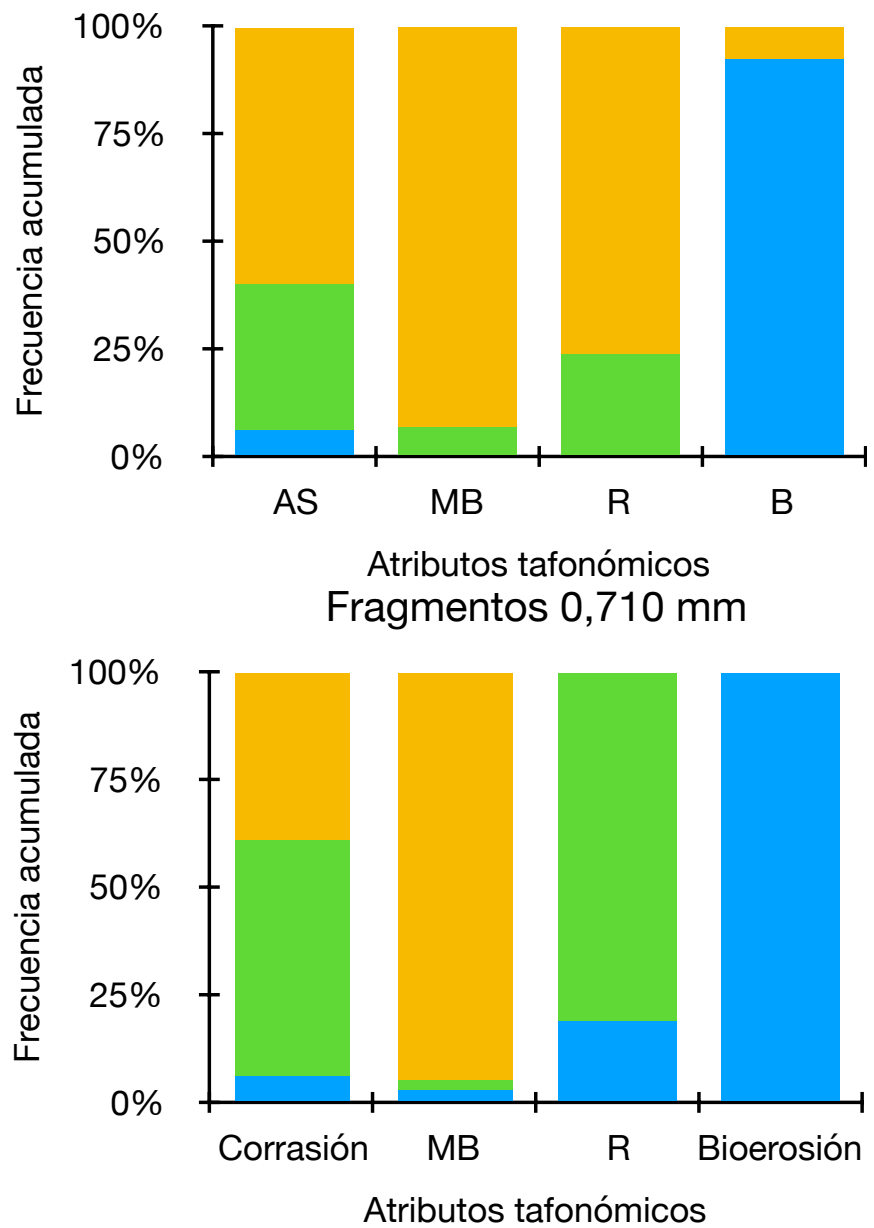

Fragmentos $5,660 \mathrm{~mm}$

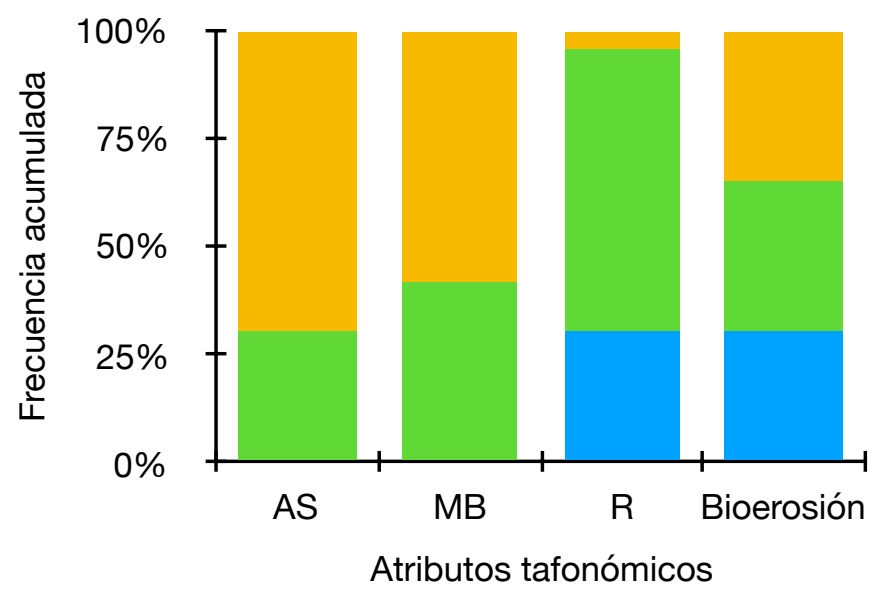

Fragmentos $1,190 \mathrm{~mm}$

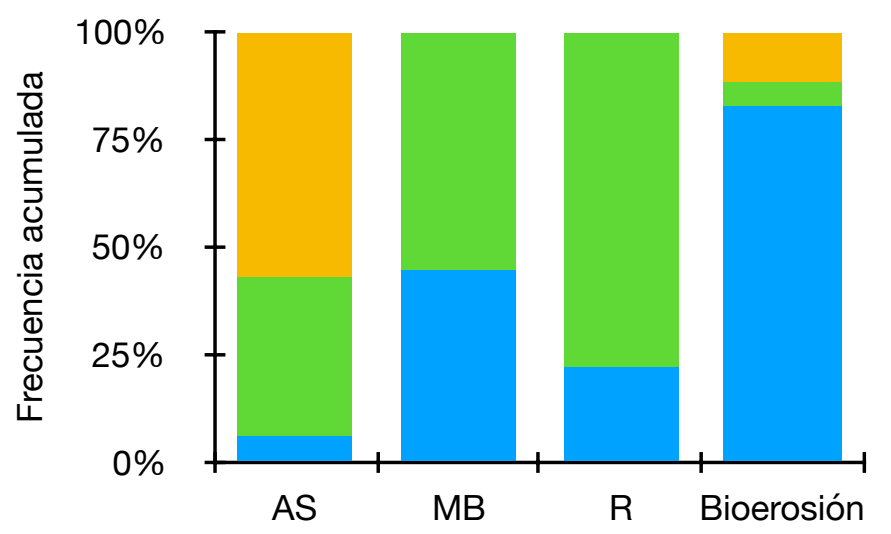

Atributos tafonómicos

Fragmentos $0,710 \mathrm{~mm}$

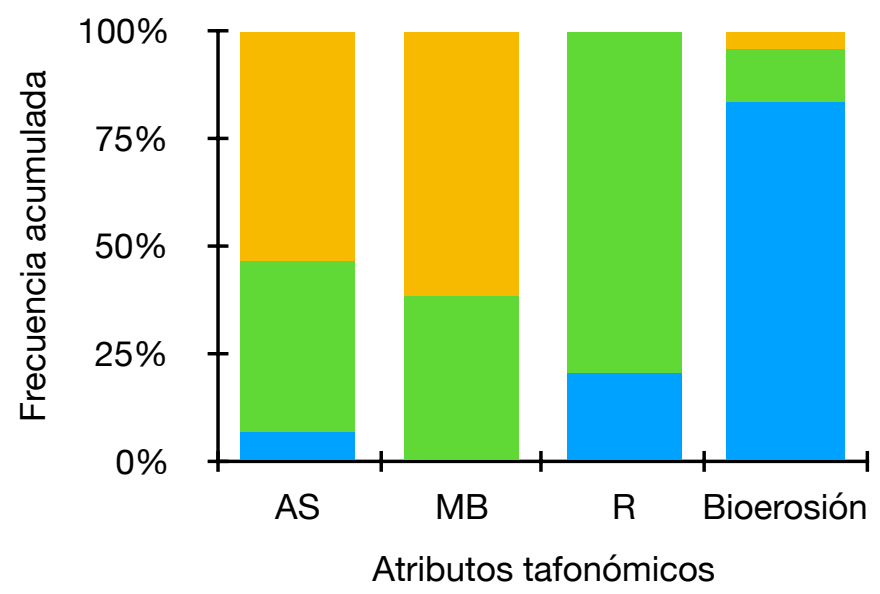

Figura 27. Frecuencia acumulada de los atributos tafonómicos observados en los fragmentos de conchillas, con relación al talle en las submuestras procesadas de C4. Referencias igual que para la Figura 22. Datos presentados en Capítulo 3, Tabla 3.33. 

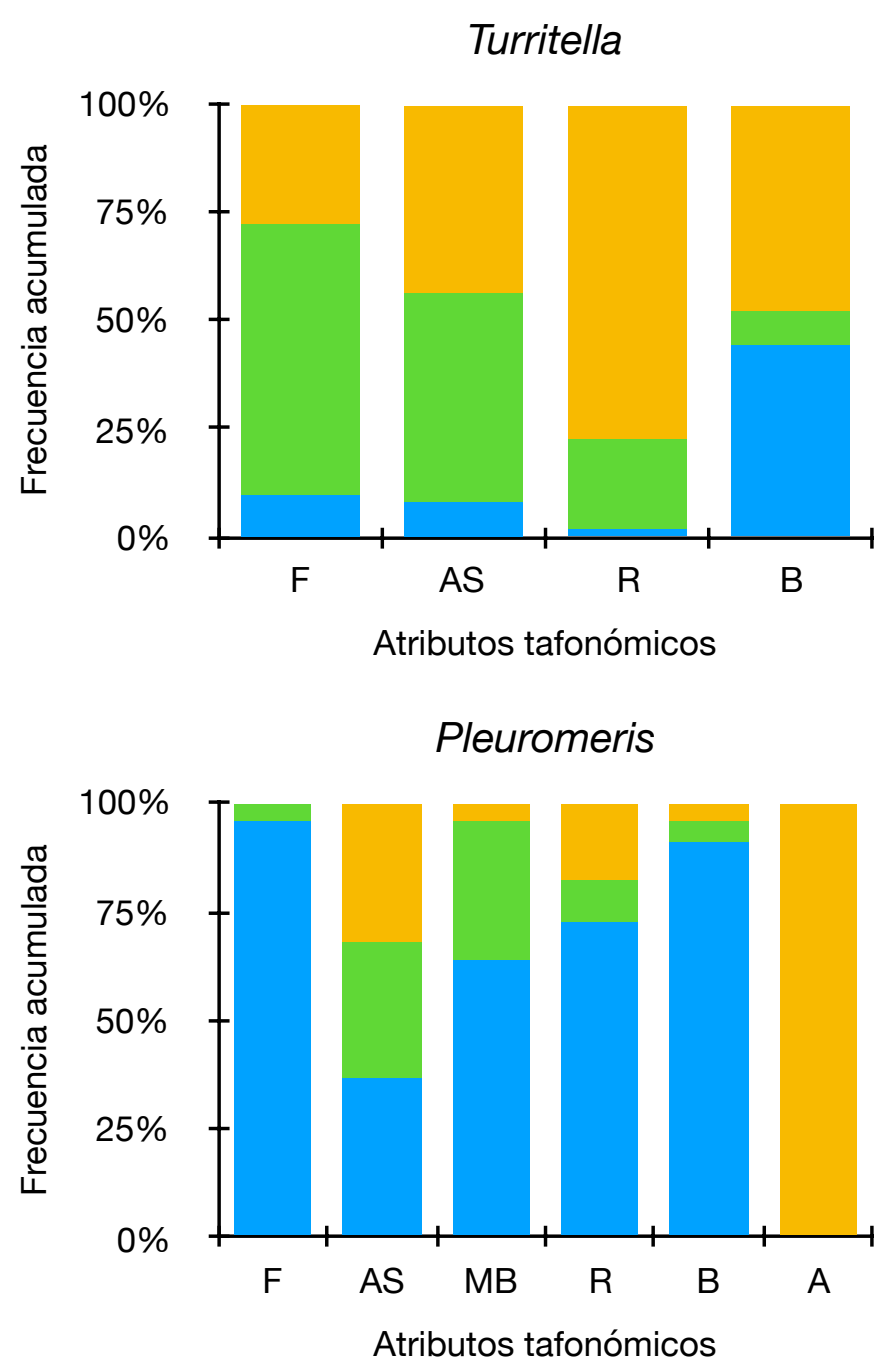
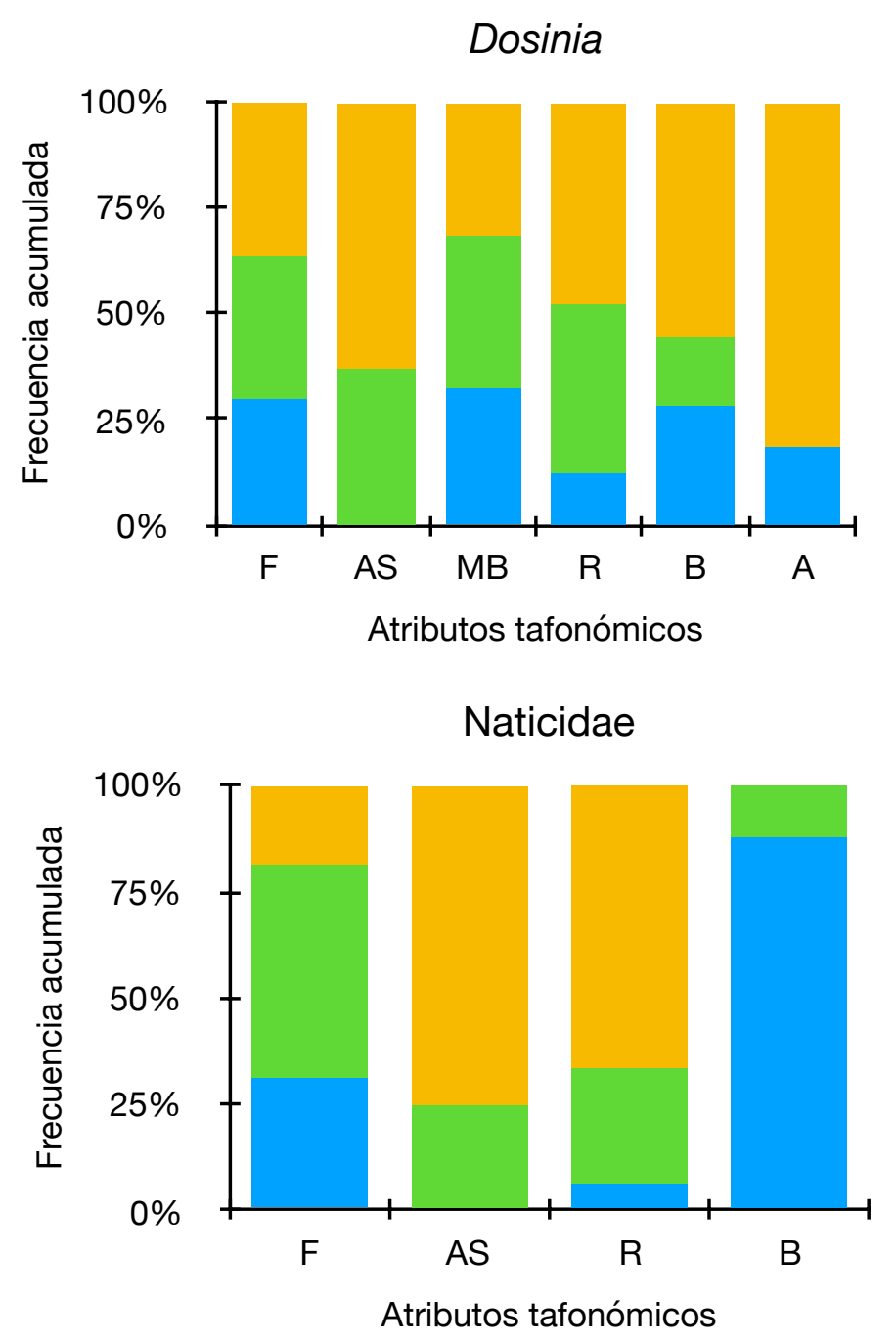

Figura 28. Frecuencia acumulada de los atributos tafonómicos observados en los taxones más abundantes de los cuadros de campo de C4. Referencias igual que para la Figura 22. Datos presentados en Capítulo 3, Tabla 3.34. 
Turritella

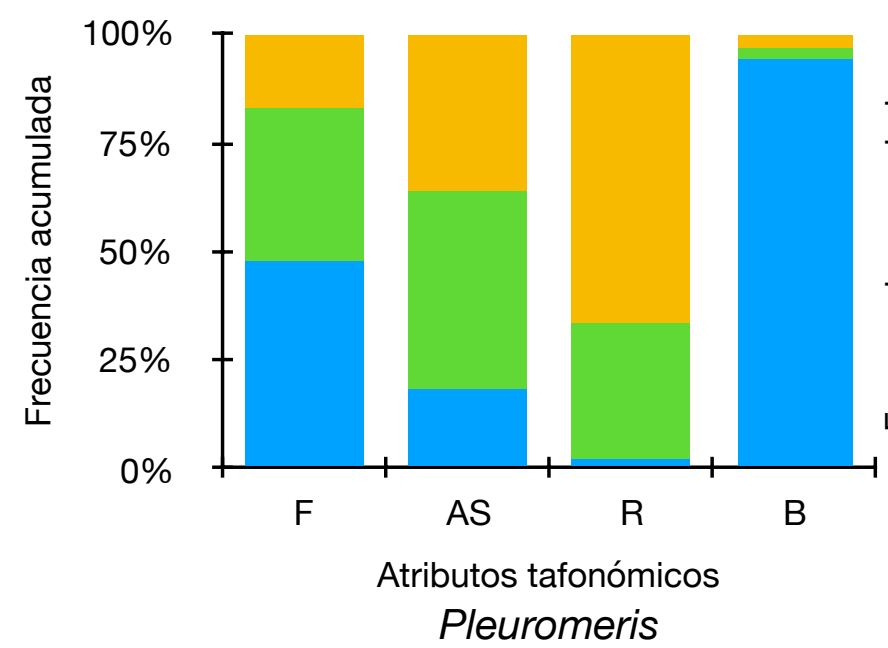

Cosa

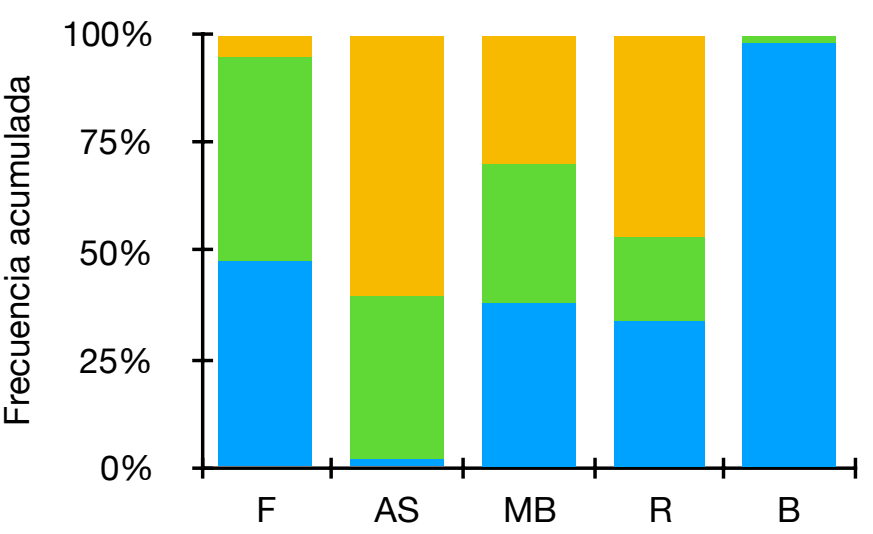

Atributos tafonómicos Nuculana

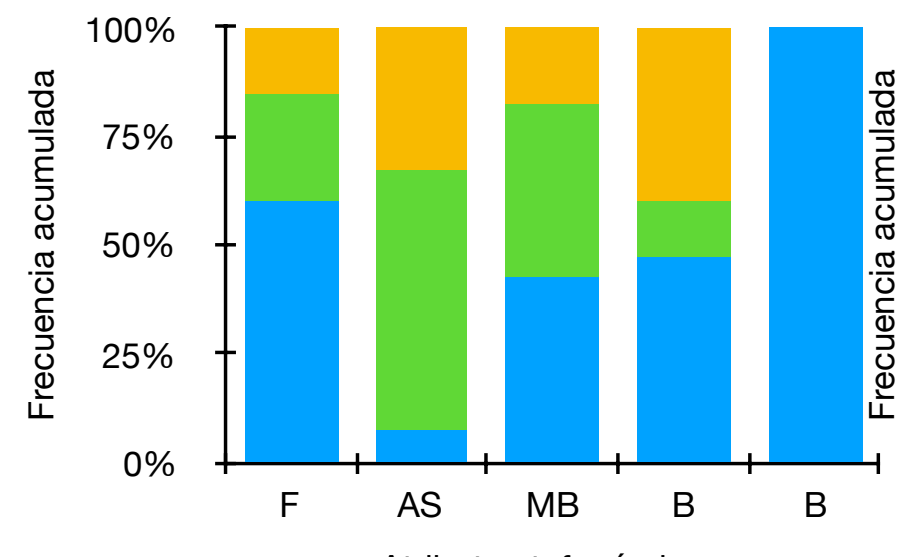

Atributos tafonómicos

\section{Maorimactra}

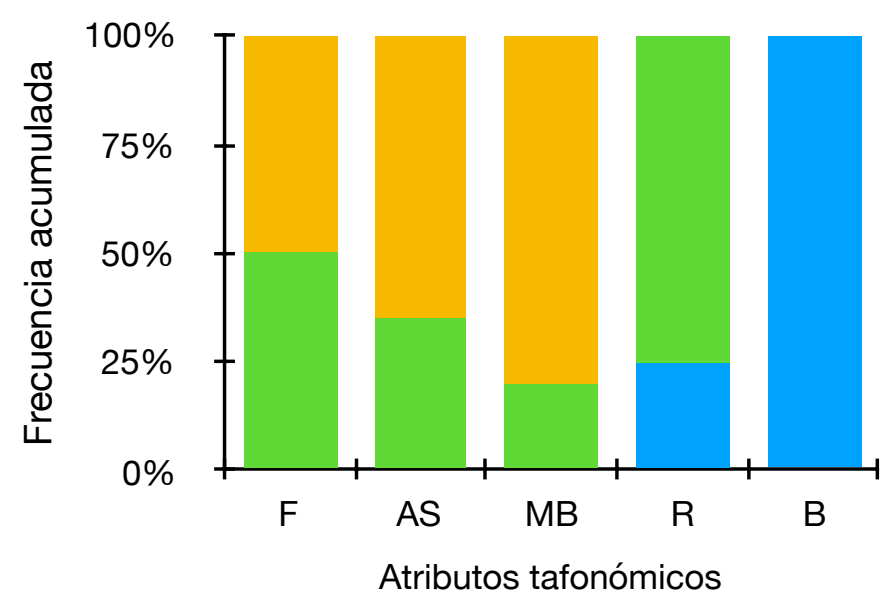

Figura 29. Frecuencia acumulada de los atributos tafonómicos observados en los taxones más abundantes la submuestra $4 a$. Referencias igual que para la Figura 22. Datos presentados en Capítulo 3, Tabla 3.35. 
Turritella

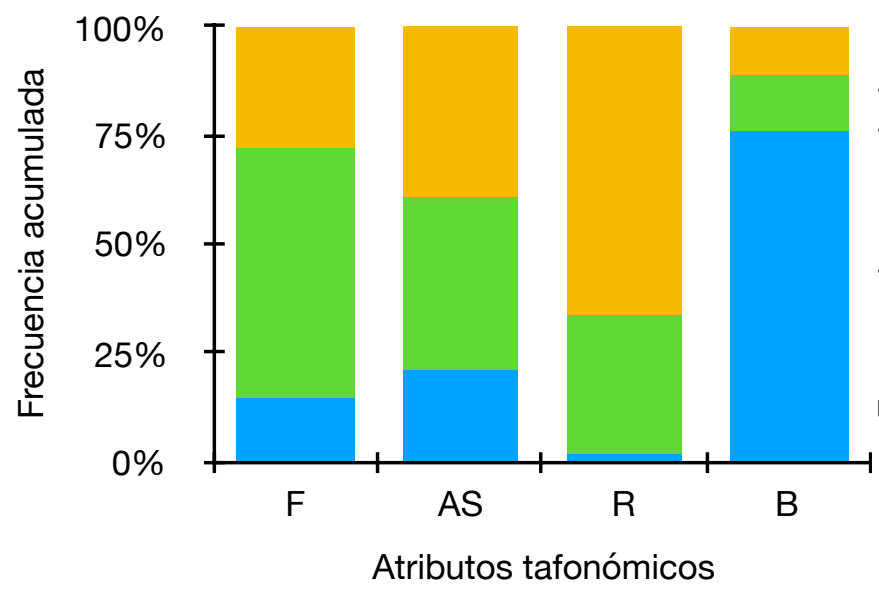

Pleuromeris

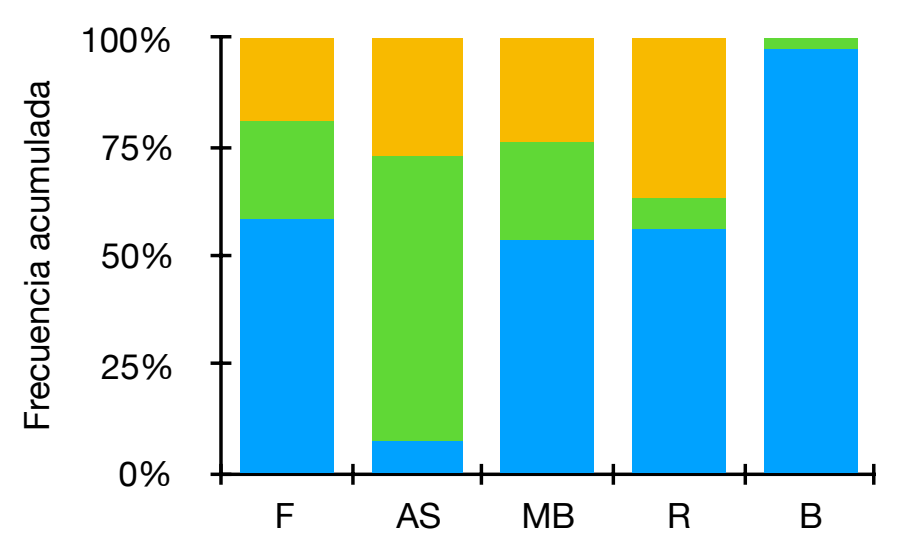

Atributos tafonómicos

Dosinia

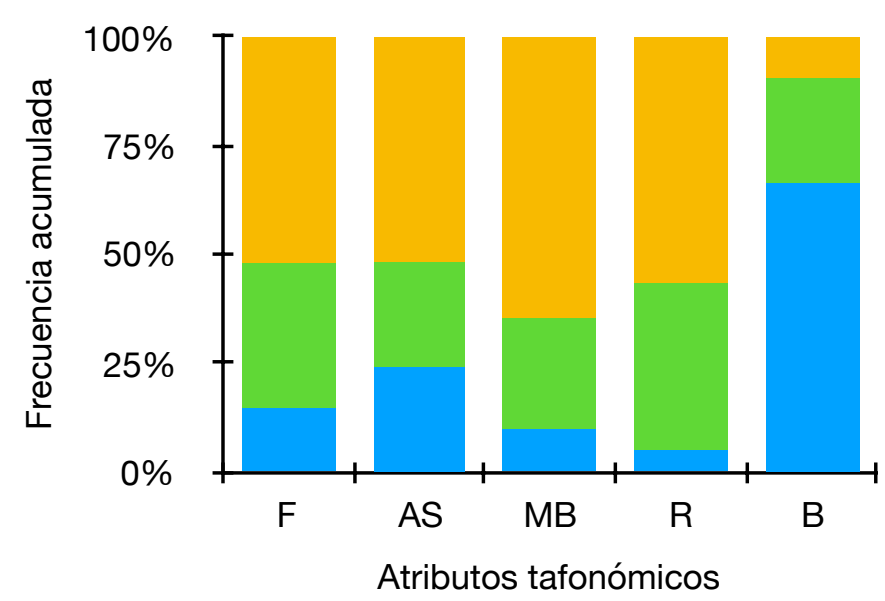

Maorimactra

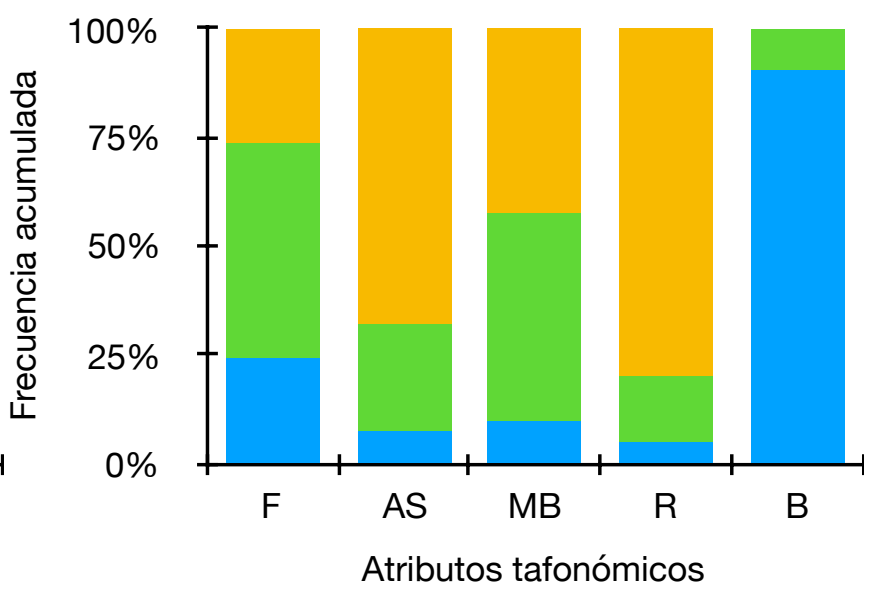

Cosa

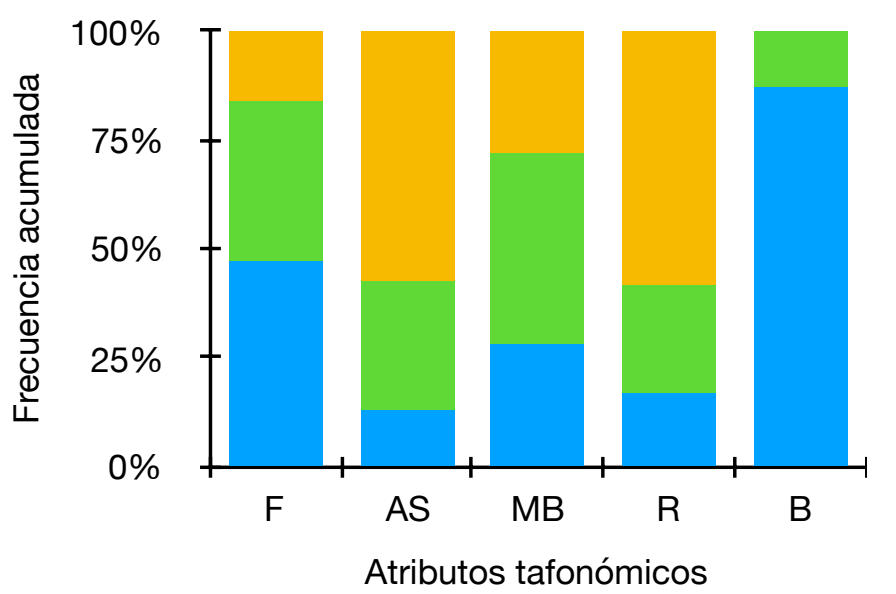

"Pleuromeris"

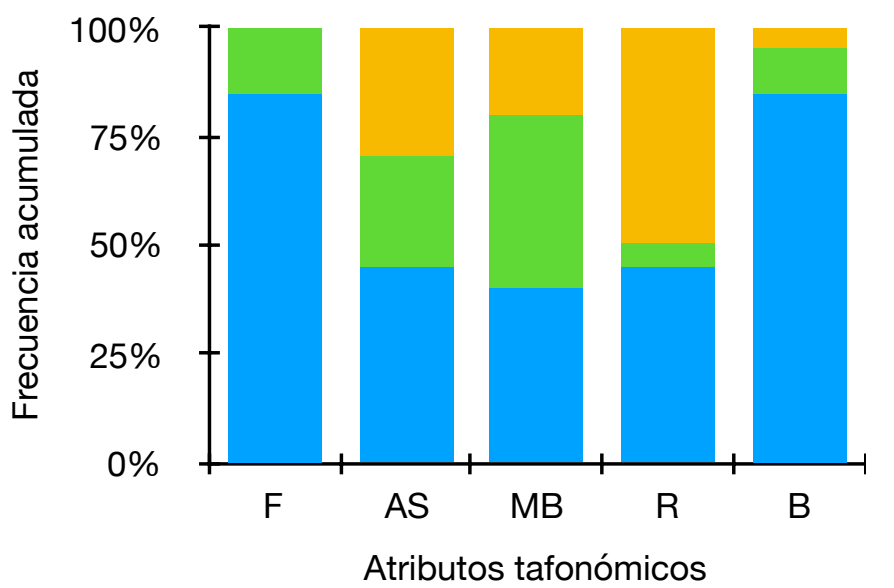

Figura 30. Frecuencia acumulada de los atributos tafonómicos observados en los taxones más abundantes la submuestra 4b. Referencias igual que para la Figura 22. Datos presentados en Capítulo 3, Tabla 3.36. 
Infaunales

Cuadros

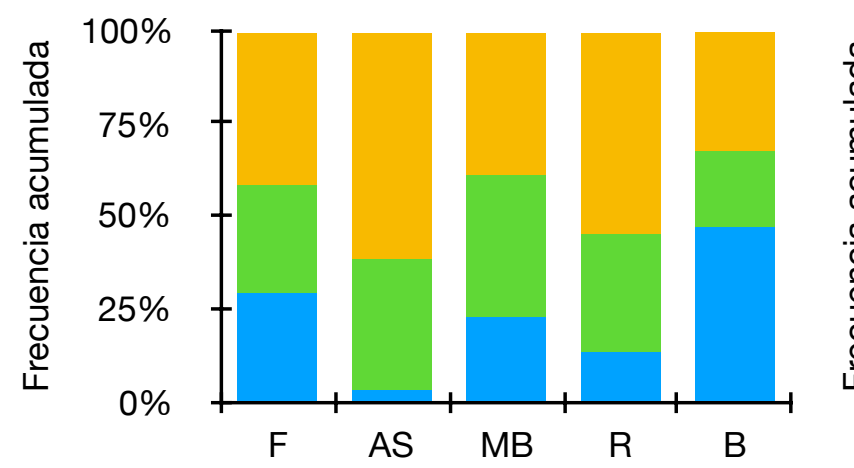

Atributos tafonómicos

$4 a$

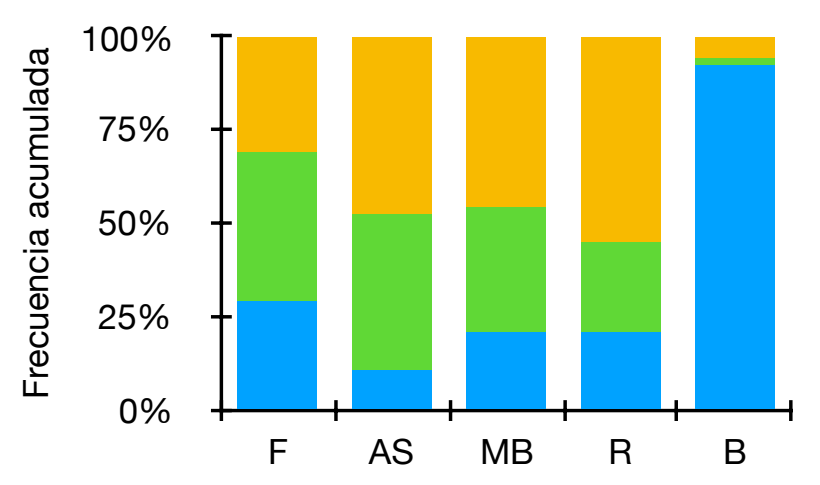

Atributos tafonómicos

$4 b$

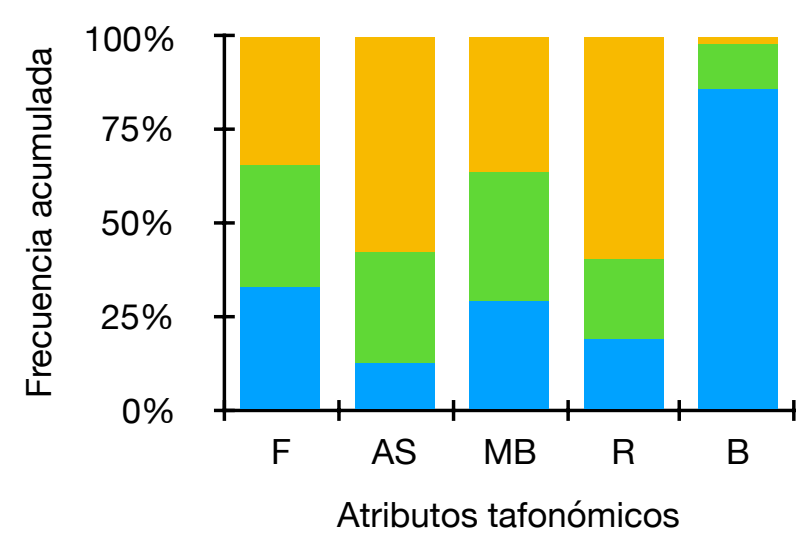

Epifaunales

Cuadros

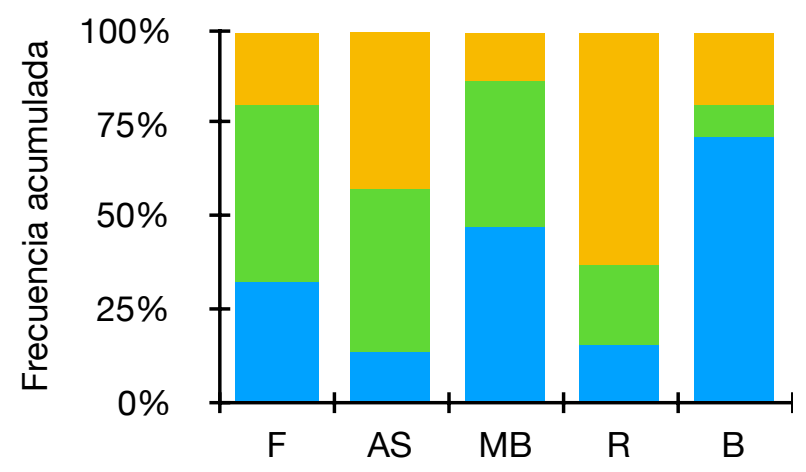

Atributos tafonómicos

$4 a$

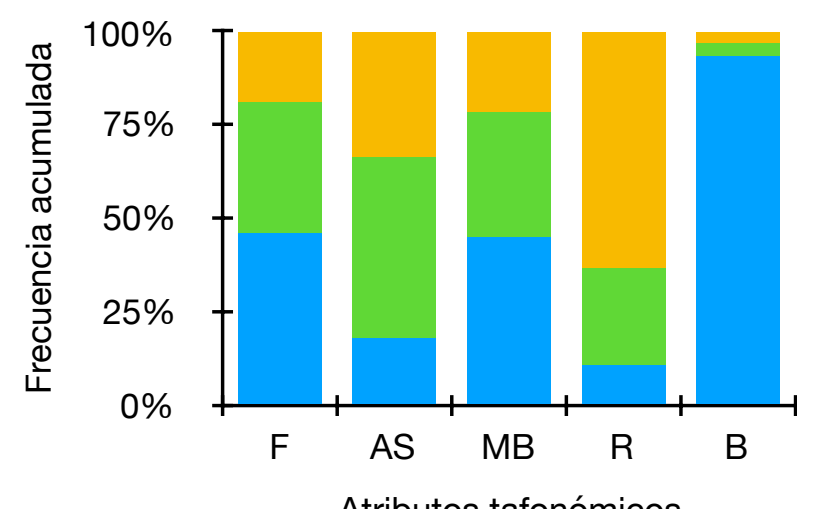

Atributos tafonómicos

$4 \mathrm{~b}$

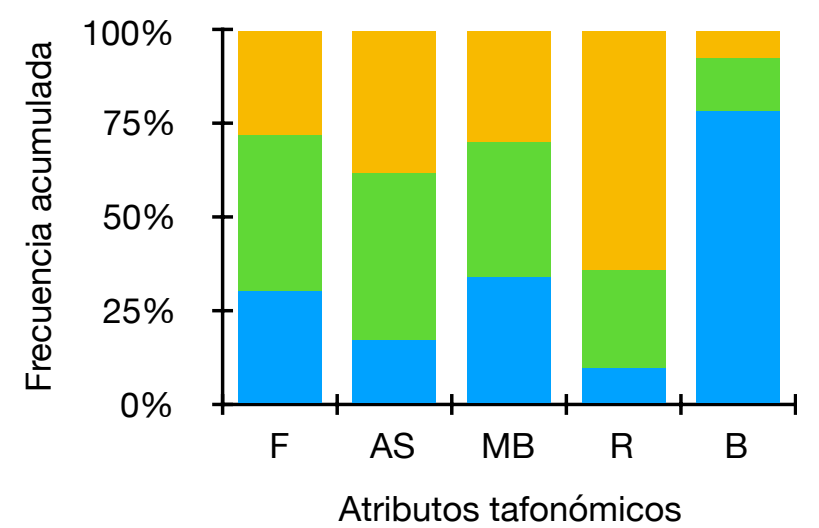

Figura 31. Frecuencia acumulada de los atributos tafonómicos observados en los bioclastos de los cuadros y las submuestras procesadas de C4 con relación a su hábito de vida. Referencias igual que para la Figura 22. Datos presentados en Capítulo 3, Tabla 3.37. 


\section{Apéndice II}

\section{Moluscos presentes en las concentraciones de Cabeza de León.}

\section{Clase Bivalvia}

1Mineralogía: Aragonítica (A); Calcítica (C)

2Hábito de vida: Epifaunal (EP); seminfaunal (SI); infaunal (IN), infaunal sifonado (IS); infaunal asifonado (IAS); anidados en sustratos duros (ASD); perforadores de sustratos duros (PSD); anidados en sustratos no consolidados (ASNC) Cavadores de sustratos arenosos (CSA), epibionte (EB), bisado (B), cementado (CE).

${ }^{3}$ Alimentación: Carnívoro depredador (CD); carnívoro ramoneador (CR); ramoneador $(\mathrm{R})$, herbívoro-omnivoro $(\mathrm{HO})$; herbívoro $(\mathrm{H})$; suspensívoro $(\mathrm{SU})$, detritívoros $(\mathrm{DE})$, depositívoro quimiosimbionte $(\mathrm{DQ})$ parásito $(\mathrm{PA})$ semi-parásito $(\mathrm{SP})$.

Subclase Protobranchia(=Paleotaxodonta)

\begin{tabular}{|c|c|c|c|c|c|c|c|c|c|}
\hline Orden & Familia & Género & Mineralogía 1 & $\begin{array}{l}\text { Habito de } \\
\text { vida }^{2}\end{array}$ & Alimentación ${ }^{3}$ & C1 & C2 & C3 & C4 \\
\hline Nuculida & Nuculidae & & A & IS & DE & & $x$ & & \\
\hline Nuculida & Nuculanidae & $\begin{array}{l}\text { Ennucula Iredale, } \\
1931\end{array}$ & A & IS & DE & $x$ & & $x$ & $x$ \\
\hline Nuculida & Nuculanidae & $\begin{array}{l}\text { Nucula Lamarck, } \\
1799\end{array}$ & A & IAS & $\mathrm{DE}$ & & & $x$ & $x$ \\
\hline Nuculida & Nuculanidae & $\begin{array}{l}\text { Nuculana Link, } \\
1807\end{array}$ & A & IS & DE & & & $x$ & $x$ \\
\hline Nuculida & Nuculanidae & $\begin{array}{l}\text { Scaeoleda Iredale, } \\
1929\end{array}$ & $A$ & IS & $\mathrm{DE}$ & & & & $x$ \\
\hline Nuculida & Nuculanidae & $\begin{array}{l}\text { Varinucula } \\
\text { Maxwell, } 1988\end{array}$ & $A$ & IS & DE & & & & $x$ \\
\hline Nuculida & Malletiidae & $\begin{array}{l}\text { Neilo Adams, } \\
1854\end{array}$ & A & IS & DE & & $x$ & $x$ & $x$ \\
\hline
\end{tabular}

Superorden Pteromorphia

\begin{tabular}{|c|c|c|c|c|c|c|c|c|c|}
\hline Orden & Familia & Género & Mineralogía1 & $\begin{array}{l}\text { Habito de } \\
\text { vida }^{2}\end{array}$ & Alimentación ${ }^{3}$ & C1 & C2 & C3 & C4 \\
\hline Arcida & Arcidae & & $A$ & $\mathrm{EP}$ & SU & & $x$ & & \\
\hline Arcida & Arcidae & $\begin{array}{l}\text { Arca Linnaeus, } \\
1758\end{array}$ & $A$ & EP & SU & & & $x$ & $x$ \\
\hline Arcida & Glycymeridae & $\begin{array}{l}\text { Glycymeris da } \\
\text { Costa, } 1778\end{array}$ & A & IAS & SU & & & $x$ & $x$ \\
\hline Arcida & Philobrydae & & A & $\mathrm{EB} / \mathrm{B}$ & SU & & & $x$ & $x$ \\
\hline Arcida & Philobrydae & Cosa Finlay, 1926 & A & $\mathrm{EB} / \mathrm{B}$ & SU & $x$ & $x$ & $x$ & $x$ \\
\hline Arcida & Philobrydae & $\begin{array}{l}\text { Lissarca Smith, } \\
1877\end{array}$ & A & & & & & & $x$ \\
\hline Arcida & Philobrydae & $\begin{array}{l}\text { Philobrya Cooper, } \\
1867\end{array}$ & A & $\mathrm{EB} / \mathrm{B}$ & SU & & & $x$ & $x$ \\
\hline
\end{tabular}




\begin{tabular}{|c|c|c|c|c|c|c|c|c|c|}
\hline Orden & Familia & Género & Mineralogía ${ }^{1}$ & $\begin{array}{l}\text { Habito de } \\
\text { vida }^{2}\end{array}$ & Alimentación ${ }^{3}$ & C1 & C2 & C3 & C4 \\
\hline Ostreida & Ostreidae & $\begin{array}{l}\text { Ostrea Linnaeus, } \\
1758\end{array}$ & $\mathrm{C}$ & $\mathrm{EP} / \mathrm{CE}$ & SU & & $x$ & $x$ & $x$ \\
\hline Pectinida & Anomiidae & $\begin{array}{l}\text { Pododesmus } \\
\text { Philippi, } 1837\end{array}$ & $\mathrm{C}$ & EP & SU & $x$ & & $x$ & $x$ \\
\hline Pectinida & Pectinidae & & $\mathrm{C}$ & $\mathrm{EP} / \mathrm{ER}$ & SU & & $x$ & $x$ & $x$ \\
\hline Pectinida & Pectinidae & $\begin{array}{l}\text { Zygochlamys } \\
\text { lhering, } 1907\end{array}$ & $\mathrm{C}$ & $\mathrm{EP}$ & SU & & & & $x$ \\
\hline Limida & Limidae & Limea Bronn, 1831 & $A$ & $\mathrm{EP}$ & SU & & & $x$ & $x$ \\
\hline Limida & Limidae & $\begin{array}{l}\text { Notolimea Iredale, } \\
1924\end{array}$ & $A$ & $\mathrm{EP}$ & SU & & & $x$ & $x$ \\
\hline
\end{tabular}

\section{Superorden Heteroconchia (Clado Heterodonta)}

\begin{tabular}{|c|c|c|c|c|c|c|c|c|c|}
\hline Orden & Familia & Género & Mineralogía1 & $\begin{array}{l}\text { Habito de } \\
\text { vida }^{2}\end{array}$ & Alimentación ${ }^{3}$ & C1 & C2 & C3 & C4 \\
\hline Lucinida & Lucinidae & & A & IS & $\mathrm{DQ}$ & $x$ & $x$ & $x$ & $x$ \\
\hline Lucinida & Lucinidae & $\begin{array}{l}\text { Pteromyrtea } \\
\text { Finleay, } 1926\end{array}$ & $A$ & IS & $\mathrm{DQ}$ & & $x$ & $x$ & $x$ \\
\hline Carditida & Crassatellidae & & $A$ & IS/IAS & SU & & & $x$ & $x$ \\
\hline Carditida & Carditidae & & A & SI/IAS & SU & & & & $x$ \\
\hline Carditida & Carditidae & $\begin{array}{l}\text { “Cardita” Brugiére, } \\
1792\end{array}$ & $A$ & SI/IAS & SU & $x$ & $x$ & $x$ & $x$ \\
\hline Carditida & Carditidae & $\begin{array}{l}\text { Cardites Link, } \\
1807\end{array}$ & $A$ & SI/IAS & SU & & & & $x$ \\
\hline Carditida & Cardiidae & $\begin{array}{l}\text { Cyclocardia } \\
\text { Conrad, } 1867\end{array}$ & $A$ & SI/IAS & SU & & & $x$ & $x$ \\
\hline Carditida & Carditidae & $\begin{array}{l}\text { Pleuromeris } \\
\text { Conrad, } 1867\end{array}$ & $A$ & SI/IAS & SU & $x$ & $x$ & $x$ & $x$ \\
\hline Carditida & Condylocardiinae & $\begin{array}{l}\text { Condylocuna } \\
\text { Laseron, } 1953\end{array}$ & $A$ & EP/IS & SU & & & & $x$ \\
\hline Venerida & Cardiidae & $\begin{array}{l}\text { Laubrieria } \\
\text { Septoski, } 2002\end{array}$ & $A$ & & SU & & & $x$ & $x$ \\
\hline Venerida & Cyamiidae & $\begin{array}{l}\text { Cyamiomactra } \\
\text { Bernard, } 1837\end{array}$ & $A$ & IS & SU & $x$ & & & $x$ \\
\hline Venerida & Cyamiidae & $\begin{array}{l}\text { Cyamium Philippi, } \\
1845\end{array}$ & $A$ & IS & SU & $x$ & & & \\
\hline Venerida & Galommatidae & & A & ASNC & SU & $x$ & & & \\
\hline Venerida & Galommatidae & Aligena Lea, 1843 & $A$ & ASNC & SU & $x$ & & & \\
\hline Venerida & Lasaeidae & & $A$ & ASNC & SU & $x$ & & & \\
\hline Venerida & Lasaeidae & Kellia Turton, 1822 & $A$ & ASNC & SU & $x$ & & & $x$ \\
\hline Venerida & Lasaeidae & Montacutinae (SF) & A & ASNC & SU & $x$ & & & $x$ \\
\hline Venerida & Lasaeidae & $\begin{array}{l}\text { Mysella Angas } \\
1877\end{array}$ & $A$ & ASNC & SU & $x$ & & & $x$ \\
\hline Venerida & Mactridae & & $A$ & IS & SU & $x$ & & & \\
\hline Venerida & Mactridae & $\begin{array}{l}\text { Mactra Linnaeus, } \\
1767\end{array}$ & $A$ & IS & SU & & & & $x$ \\
\hline
\end{tabular}




\begin{tabular}{|c|c|c|c|c|c|c|c|c|c|}
\hline Orden & Familia & Género & Mineralogía 1 & $\begin{array}{l}\text { Habito de } \\
\text { vida }^{2}\end{array}$ & Alimentación ${ }^{3}$ & C1 & C2 & C3 & C4 \\
\hline Venerida & Mactridae & $\begin{array}{l}\text { Maorimactra } \\
\text { Finlay, } 1928\end{array}$ & $A$ & IS & SU & $x$ & $x$ & $x$ & $x$ \\
\hline Venerida & Mactridae & $\begin{array}{l}\text { Scalpomactra } \\
\text { Finlay (en } \\
\text { Marwick), } 1928\end{array}$ & $A$ & IS & SU & $x$ & & & \\
\hline Venerida & Tellinidae & & $A$ & IS & SU & & & $x$ & \\
\hline Venerida & Tellinidae & $\begin{array}{l}\text { Tellina Linnaeus, } \\
1758\end{array}$ & $A$ & IS & SU & & $x$ & & \\
\hline Venerida & Tellinidae & $\begin{array}{l}\text { Eliptotellina } \\
\text { Cossmann, } 1886\end{array}$ & $A$ & IS & SU & & $x$ & $x$ & $x$ \\
\hline Venerida & Tellinidae & $\begin{array}{l}\text { Serratina Pallary, } \\
1920\end{array}$ & $A$ & IS & SU & $x$ & $x$ & $x$ & $x$ \\
\hline Venerida & Psammobiidae & $\begin{array}{l}\text { Asaphis Modeeer, } \\
1793\end{array}$ & $A$ & SI/IS & SU & & & & $x$ \\
\hline Venerida & Ungulinidae & $\begin{array}{l}\text { Diplodonta Bronn, } \\
1831\end{array}$ & A & IAS & SU & $x$ & & & $x$ \\
\hline Venerida & Veneridae & & A & IS & SU & $x$ & $x$ & & $x$ \\
\hline Venerida & Veneridae & $\begin{array}{l}\text { Dosinia Scopoli, } \\
1777\end{array}$ & $A$ & IS & SU & $x$ & $x$ & $x$ & $x$ \\
\hline Venerida & Veneridae & $\begin{array}{l}\text { Eurhomalea } \\
\text { Cossmann, } 1920\end{array}$ & $A$ & IS & SU & & & & $x$ \\
\hline Venerida & Veneridae & $\begin{array}{l}\text { Marcia Adams y } \\
\text { Adams, } 1857\end{array}$ & $A$ & IS & SU & & & $x$ & $x$ \\
\hline Venerida & Veneridae & Pitar Römer, 1857 & $A$ & IS & SU & & & & $x$ \\
\hline Venerida & Veneridae & $\begin{array}{l}\text { Retrotapes del } \\
\text { Río, } 1997\end{array}$ & $A$ & IS & SU & & $x$ & $x$ & $x$ \\
\hline Myida & Corbulidae & $\begin{array}{l}\text { Caryocorbula } \\
\text { Gardner, } 1926\end{array}$ & $A$ & IS & SU & $x$ & & & $x$ \\
\hline Myida & Corbulidae & $\begin{array}{l}\text { Corbula Bruguière, } \\
1797\end{array}$ & $A$ & IS & SU & & & & $x$ \\
\hline Myida & Pholadidae & & A & PSD & SU & & & & $x$ \\
\hline $\begin{array}{l}\text { No } \\
\text { asignado }\end{array}$ & Hiatellidae & $\begin{array}{l}\text { Panopea de la } \\
\text { Groye, } 1807\end{array}$ & $A$ & IS & SU & $x$ & $x$ & $x$ & $x$ \\
\hline $\begin{array}{l}\text { No } \\
\text { asignado }\end{array}$ & Hiatellidae & $\begin{array}{l}\text { Saxicava Fleuriau } \\
\text { de Bellevue, } 1802\end{array}$ & $A$ & IS & SU & & & & $x$ \\
\hline
\end{tabular}




\section{Clase Gastropoda}

${ }^{1}$ Mineralogía: Aragonítica (A); Calcítica (C)

2Hábito de vida: Epifaunal (EP); seminfaunal (SI); infaunal (IN), infaunal sifonado (IS); infaunal asifonado (IAS); anidados en sustratos duros (ASD); Cavadores de sustratos arenosos (CSA), epibionte (EB).

${ }^{3}$ Alimentación: Carnívoro depredador (CD); carnívoro ramoneador $(\mathrm{CR})$; ramoneador $(\mathrm{R})$, herbívoro-omnivoro $(\mathrm{HO})$; herbívoro $(\mathrm{H})$; suspensívoro $(\mathrm{SU})$, detritívoros $(\mathrm{DE})$, depositívoro quimiosimbionte $(\mathrm{DQ})$ parásito $(\mathrm{PA})$ semi-parásito $(\mathrm{SP})$.

\section{Subclase Vetigastropoda}

\begin{tabular}{|c|c|c|c|c|c|c|c|c|c|}
\hline Orden & Familia & Género & Mineralogía1 & $\begin{array}{l}\text { Habito de } \\
\text { vida }^{2}\end{array}$ & Alimentación ${ }^{3}$ & C1 & C2 & C3 & C4 \\
\hline Seguenziida & Eucyclidae & Cidarina Dall, 1909 & A & EP & $\mathrm{R}$ & & $\mathrm{x}$ & & \\
\hline Seguenziida & No asignada & $\begin{array}{l}\text { Brookula Iredale, } \\
1912\end{array}$ & $A$ & EP & $\mathrm{H}$ & & & & $x$ \\
\hline Trochida & Calliostomatidae & $\begin{array}{l}\text { Calliostoma } \\
\text { Swainson, } 1840\end{array}$ & $A$ & EP & $\mathrm{CR}$ & & $x$ & $x$ & $x$ \\
\hline Trochida & Colloniidae & $\begin{array}{l}\text { Homalopoma } \\
\text { Carpenter, } 1864\end{array}$ & $A$ & EP & $\mathrm{H}$ & & & $x$ & $x$ \\
\hline Trochida & Skeneidae & $\begin{array}{l}\text { Cirsonella Angas, } \\
1877\end{array}$ & $A$ & EP & $\mathrm{DE}$ & $x$ & & $x$ & $x$ \\
\hline Trochida & Trochidae & & $A$ & EP & $\mathrm{H}$ & $x$ & $x$ & $x$ & $x$ \\
\hline Trochida & Trochidae & $\begin{array}{l}\text { Phorcus Risso, } \\
1826\end{array}$ & A & EP & $\mathrm{H}$ & $x$ & & $x$ & $x$ \\
\hline Trochida & Solariellidae & $\begin{array}{l}\text { Solariella Wood, } \\
1842\end{array}$ & A & CSA & $\mathrm{H}$ & $x$ & $x$ & $x$ & $x$ \\
\hline Trochida & Turbinidae & & $A$ & EP & $\mathrm{H}$ & & & $x$ & \\
\hline
\end{tabular}

Subclase Caenogastropoda

\begin{tabular}{|c|c|c|c|c|c|c|c|c|c|}
\hline Orden & Familia & Género & Mineralogía1 & $\begin{array}{l}\text { Hábito de } \\
\text { vida }^{2}\end{array}$ & Alimentación ${ }^{3}$ & C1 & C2 & C3 & C4 \\
\hline $\begin{array}{l}\text { Sorbeoconcha } \\
\text { (Cohorte) }\end{array}$ & Cerithiidae & $\begin{array}{l}\text { Cerithium } \\
\text { Bruguière, } 1789\end{array}$ & $A$ & CSA & $\mathrm{H} / \mathrm{DE}$ & & & & $x$ \\
\hline No asignado & Turritellidae & $\begin{array}{l}\text { Turritella Lamarck, } \\
1799\end{array}$ & $A$ & IN & SU & $x$ & $x$ & $x$ & $x$ \\
\hline Littorinimorpha & Capulidae & $\begin{array}{l}\text { Capulus Montfort, } \\
1810\end{array}$ & $A$ & EB & SP & $x$ & & & $x$ \\
\hline Littorinimorpha & Capulidae & $\begin{array}{l}\text { Cerithioderma } \\
\text { Conrad, } 1860\end{array}$ & $A$ & EB & $\mathrm{PA}$ & $x$ & & $x$ & $x$ \\
\hline Littorinimorpha & Capulidae & $\begin{array}{l}\text { Trichotropis } \\
\text { Broderip y } \\
\text { Sowerby, } 1829\end{array}$ & A & EB & $\mathrm{PA}$ & $x$ & & & \\
\hline Littorinimorpha & Eatoniellidae & $\begin{array}{l}\text { Eatoniella Dall, } \\
1876\end{array}$ & $A$ & EP & $\mathrm{H}$ & & & & $x$ \\
\hline Littorinimorpha & Epitoniidae & $\begin{array}{l}\text { Epitonium Röding, } \\
1798\end{array}$ & $A$ & EP & $\mathrm{H}$ & $x$ & & & $x$ \\
\hline Littorinimorpha & Naticidae & & $A$ & EP & $C D$ & $x$ & $x$ & $x$ & $x$ \\
\hline Littorinimorpha & Naticidae & $\begin{array}{l}\text { Polinices Montfort, } \\
1810\end{array}$ & $A$ & $\mathrm{SI}$ & $\mathrm{CP}$ & $x$ & & & $x$ \\
\hline
\end{tabular}




\begin{tabular}{|c|c|c|c|c|c|c|c|c|c|}
\hline Orden & Familia & Género & Mineralogía1 & $\begin{array}{l}\text { Hábito de } \\
\text { vida }^{2}\end{array}$ & Alimentación ${ }^{3}$ & C1 & C2 & C3 & C4 \\
\hline Littorinimorpha & Vermetidae & $\begin{array}{l}\text { Dendropoma } \\
\text { Mörch, } 1861\end{array}$ & $A$ & EB & SU & & & $x$ & $x$ \\
\hline Littorinimorpha & Rissoinidae & & & EP & $\mathrm{H}$ & & & & $x$ \\
\hline Littorinimorpha & Tornidae & & & EP & $\mathrm{R}$ & & & & $x$ \\
\hline No asignado & Cerithiopsidae & $\begin{array}{l}\text { Cerithiopsis } \\
\text { Forbes \& Hanley, } \\
1850\end{array}$ & $A$ & EP & $\mathrm{R}$ & & & & $x$ \\
\hline No asignado & Cerithiopsidae & Seila Adams, 1861 & $A$ & EP & $\mathrm{R}$ & $x$ & & $x$ & $x$ \\
\hline No asignado & Newtoniellidae & & $A$ & EP & $\mathrm{CR}$ & & & & $x$ \\
\hline No asignado & Newtoniellidae & $\begin{array}{l}\text { Ataxocerithium } \\
\text { Tate, } 1894\end{array}$ & $A$ & EP & $\mathrm{CR}$ & & $x$ & $x$ & $x$ \\
\hline Littorinimorpha & Eulimidae & & $A$ & EP & $\mathrm{P}$ & $x$ & & $x$ & \\
\hline Littorinimorpha & Eulimidae & Eulima Risso, 1826 & $A$ & EP & $\mathrm{P}$ & & & $x$ & $x$ \\
\hline Littorinimorpha & Calyptraeidae & $\begin{array}{l}\text { Calyptraea } \\
\text { Lamarck, } 1799\end{array}$ & $A$ & EP & SU & $x$ & $x$ & $x$ & $x$ \\
\hline Littorinimorpha & Calyptraeidae & $\begin{array}{l}\text { Sigapatella } \\
\text { Lesson, } 1831\end{array}$ & $A$ & EP & SU & & & & $x$ \\
\hline Littorinimorpha & Calyptraeidae & $\begin{array}{l}\text { Trochita } \\
\text { Schumacher, } 1817\end{array}$ & $A$ & EP & SU & & & $x$ & $x$ \\
\hline Littorinimorpha & Calyptraeidae & $\begin{array}{l}\text { Spirogalerus Finlay } \\
\text { y Marwick, } 1937\end{array}$ & $A$ & EP & SU & & & $x$ & \\
\hline Littorinimorpha & Ficidae & $\begin{array}{l}\text { Ficus Röding, } \\
1798\end{array}$ & $A$ & EP & $C D$ & & & & $x$ \\
\hline Littorinimorpha & Struthiolariidae & $\begin{array}{l}\text { Perissodonta } \\
\text { Martens, } 1878\end{array}$ & $A$ & EP & SU & $x$ & $x$ & $x$ & $x$ \\
\hline Neogastropoda & Marginellidae & $\begin{array}{l}\text { Austroginella } \\
\text { Laseron, } 1957\end{array}$ & $A$ & EP & $C D$ & & & $x$ & $x$ \\
\hline Neogastropoda & Volutidae & $\begin{array}{l}\text { Miomelon Dall, } \\
1907\end{array}$ & $A$ & EP & $C D$ & & & & $x$ \\
\hline Neogastropoda & Cancellariidae & $\begin{array}{l}\text { Oamaruia Finlay, } \\
1924\end{array}$ & $A$ & EP & $\mathrm{CR}$ & $x$ & & & \\
\hline Neogastropoda & Cancellariidae & $\begin{array}{l}\text { Zeadmete Finlay, } \\
1926\end{array}$ & $A$ & EP & $\mathrm{CR}$ & & & $x$ & $x$ \\
\hline Neogastropoda & Buccinidae & & $A$ & EP & $C D$ & & & & $x$ \\
\hline Neogastropoda & Buccinidae & $\begin{array}{l}\text { Penion Fischer, } \\
1884\end{array}$ & $A$ & EP & $C D$ & & & & $x$ \\
\hline Neogastropoda & Columbellidae & & $A$ & EP & $C D$ & $x$ & & $x$ & \\
\hline Neogastropoda & Columbellidae & $\begin{array}{l}\text { Anachis Adams y } \\
\text { Adams, } 1853\end{array}$ & $A$ & EP & $\mathrm{DE}$ & $x$ & & & $x$ \\
\hline Neogastropoda & Columbellidae & $\begin{array}{l}\text { Retizafra Hedley, } \\
1913\end{array}$ & $A$ & EP & $C D$ & $x$ & & & $x$ \\
\hline Neogastropoda & Columbellidae & $\begin{array}{l}\text { Zemitrella Finlay, } \\
1926\end{array}$ & $A$ & EP & $C D$ & & $x$ & & \\
\hline Neogastropoda & Nassariidae & Hima Leach, 1847 & $A$ & EP & $C D$ & $x$ & & & \\
\hline Neogastropoda & Muricidae & & $A$ & EP & $C D$ & & $x$ & $x$ & $x$ \\
\hline Neogastropoda & Muricidae & $\begin{array}{l}\text { Fuegotrophon } \\
\text { Powell, } 1951\end{array}$ & $A$ & EP & $C D$ & & & & $x$ \\
\hline Neogastropoda & Muricidae & $\begin{array}{l}\text { Ocenebra Gray, } \\
847\end{array}$ & $A$ & EP & $C D$ & & & & $x$ \\
\hline Neogastropoda & Muricidae & $\begin{array}{l}\text { Trophon Montfort, } \\
1810\end{array}$ & A & EP & $C D$ & & & & $x$ \\
\hline
\end{tabular}




\begin{tabular}{|c|c|c|c|c|c|c|c|c|c|}
\hline Orden & Familia & Género & Mineralogía 1 & $\begin{array}{l}\text { Hábito de } \\
\text { vida }^{2}\end{array}$ & Alimentación ${ }^{3}$ & C1 & C2 & C3 & C4 \\
\hline Neogastropoda & Muricidae & $\begin{array}{l}\text { Urosalpinx } \\
\text { Stimpson, } 1865\end{array}$ & $A$ & EP & $C D$ & $x$ & $x$ & & $x$ \\
\hline Neogastropoda & Muricidae & $\begin{array}{l}\text { Xymenella Finlay, } \\
1926\end{array}$ & $A$ & EP & $C D$ & $x$ & $x$ & $x$ & $x$ \\
\hline Neogastropoda & Mitridae & $\begin{array}{l}\text { Austroimbricaria } \\
\text { Olivera y } \\
\text { Camacho, } 1990\end{array}$ & $A$ & EP & $C D$ & & & $x$ & \\
\hline Neogastropoda & Mangeliidae & $\begin{array}{l}\text { Neoguraleus } \\
\text { Powell, } 1939\end{array}$ & A & IN & $C D$ & $x$ & & $x$ & $x$ \\
\hline Neogastropoda & Terebridae & $\begin{array}{l}\text { Terebra Bruguière, } \\
1789\end{array}$ & $A$ & IN & $\mathrm{CD}$ & & & $x$ & \\
\hline
\end{tabular}

\section{Subclase Heterobranchia}

\begin{tabular}{|c|c|c|c|c|c|c|c|c|c|}
\hline Orden & Familia & Género & Mineralogía1 & $\begin{array}{l}\text { Hábito de } \\
\text { vida }^{2}\end{array}$ & Alimentación ${ }^{3}$ & C1 & C2 & C3 & C4 \\
\hline No asignado & Mathildidae & & A & $\mathrm{EP}$ & CR & & & & $x$ \\
\hline No asignado & Mathildidae & $\begin{array}{l}\text { Mathilda } \\
\text { Swainson, } 1840\end{array}$ & A & EP & $\mathrm{CR}$ & & & & $x$ \\
\hline No asignado & Acteonidae & & A & CSA/EP & CD & & & & $x$ \\
\hline No asignado & Acteonidae & $\begin{array}{l}\text { Acteon Montfort, } \\
1810\end{array}$ & A & CSA & CD & $x$ & & & $x$ \\
\hline No asignado & Acteonidae & $\begin{array}{l}\text { Fusiguraleus } \\
\text { Powell, } 1942\end{array}$ & A & $\mathrm{EP}$ & CD & $x$ & $x$ & $x$ & $x$ \\
\hline No asignado & Acteonidae & $\begin{array}{l}\text { Tornatellaea } \\
\text { Conrad, } 1860\end{array}$ & A & CSA & CD & $x$ & & & \\
\hline No asignado & Acteonidae & Triploca Tate, 1893 & A & CAS & $C D$ & $x$ & & & \\
\hline No asignado & Acteonidae & $\begin{array}{l}\text { Tenuiactaeon } \\
\text { Aldrich, } 1921\end{array}$ & A & $\mathrm{EP}$ & CD & $x$ & $x$ & & $x$ \\
\hline Cephalaspidea & Cylichnidae & $\begin{array}{l}\text { Cylichnania } \\
\text { Marwick, } 1931\end{array}$ & A & EP & $C D$ & $x$ & $x$ & $x$ & $x$ \\
\hline Cephalaspidea & Scaphandridae & $\begin{array}{l}\text { Kaitoa Marwick, } \\
1931\end{array}$ & A & $\mathrm{EP}$ & $\mathrm{CR}$ & $x$ & $x$ & $x$ & $x$ \\
\hline No asignado & Pyramidellidae & & A & EB & $\mathrm{PA}$ & & & & $x$ \\
\hline No asignado & Pyramidellidae & $\begin{array}{l}\text { Odostomia } \\
\text { Fleming, } 1813\end{array}$ & A & EB & PA & $x$ & $x$ & $x$ & $x$ \\
\hline No asignado & Pyramidellidae & $\begin{array}{l}\text { Pyramidella } \\
\text { Lamarck, } 1799\end{array}$ & A & EB & PA & $x$ & & & $x$ \\
\hline Ellobiida & Ellobiidae & & A & EP & $\mathrm{H}$ & $x$ & & & \\
\hline Ellobiida & Ellobiidae & Ellobia & A & $\mathrm{EP}$ & $\mathrm{H}$ & & $x$ & & $x$ \\
\hline Ellobiida & Ellobiidae & $\begin{array}{l}\text { Marinula King, } \\
1832\end{array}$ & $A$ & EP & $\mathrm{H}$ & $x$ & & & \\
\hline
\end{tabular}

